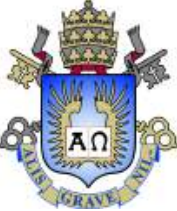

Lucas Buffon

Representatividade do modelo de fluido em modelos integrados de produção

Dissertação de Mestrado

Dissertação apresentada como requisito parcial para obtenção do grau de Mestre pelo Programa de Pós-graduação em Engenharia Mecânica, do Departamento de Engenharia Mecânica da PUCRio.

Orientador : Prof. Márcio da Silveira Carvalho Coorientador: Dr. Marcos Vitor Barbosa Machado 
Lucas Buffon

\title{
Representatividade do modelo de fluido em modelos integrados de produção
}

Dissertação apresentada como requisito parcial para obtenção do grau de Mestre pelo Programa de Pós-graduação em Engenharia Mecânica da PUC-Rio. Aprovada pela Comissão Examinadora abaixo:

\author{
Prof. Márcio da Silveira Carvalho \\ Orientador \\ Departamento de Engenharia Mecânica - PUC-Rio \\ Dr. Marcos Vitor Barbosa Machado \\ Petrobras
}

Prof. Brenno Romano Motta Filho

Departamento de Engenharia Mecânica - PUC-Rio

Dr. Ricardo Marques de Toledo Camargo

Petrobras

Rio de Janeiro, 13 de Maio de 2020 
Todos os direitos reservados. A reprodução, total ou parcial do trabalho, é proibida sem a autorização da universidade, do autor e do orientador.

\section{Lucas Buffon}

Graduou-se em Engenharia Elétrica pela Universidade Federal do Rio Grande do Sul em 2011. Em 2012, começou a trabalhar como Engenheiro de Petróleo na Petrobras, atuando em projetos de desenvolvimento da produção nas áreas de simulação de escoamento multifásico em meios porosos e em tubulações, elevação artificial e garantia de escoamento.

Ficha Catalográfica

Buffon, Lucas

Representatividade do modelo de fluido em modelos integrados de produção / Lucas Buffon; orientador: Márcio da Silveira Carvalho; coorientador: Marcos Vitor Barbosa Machado. - 2020.

313 f: il. color. ; $30 \mathrm{~cm}$

Dissertação (mestrado) - Pontifícia Universidade Católica do Rio de Janeiro, Departamento de Engenharia Mecânica, 2020.

Inclui bibliografia

1. Engenharia de Petróleo - Teses. 2. Engenharia Mecânica - Teses. 3. Engenharia Química - Teses. 4. Modelagem Integrada de Produção. 5. Modelagem de Fluido Composicional. 6. Modelagem de Fluido em Reservatório. 7. Modelagem de Fluido em Sistemas de Produção. 8. PVT. 9. Equation of State. I. Carvalho, Márcio da Silveira. II. Machado, Marcos Vitor Barbosa. III. Pontifícia Universidade Católica do Rio de Janeiro. Departamento de Engenharia Mecânica. IV. Título. 
Aos meus pais e irmãs, pelo apoio incondicional em toda a minha vida. 


\section{Agradecimentos}

Em primeiro lugar agradeço aos meus pais Jorge e Carmen pelo apoio em toda a minha vida. Não poderia deixar de agradecer às minhas irmãs Vanessa e Patricia pela eterna amizade, pelo incentivo ao estudo e por me ensinarem a nunca desistir.

À minha namorada Jenyfer, pelo carinho, otimismo e ajuda no atingimento deste objetivo.

Aos meus avôs, tios e primos, em especial ao meu primo e padrinho David, que, de forma inusitada, iniciou minha caminhada no mundo da engenharia.

Aos meus orientadores, Márcio e Marcos, pelo tempo cedido e estímulo para a conclusão deste trabalho.

Aos colegas da Petrobras, especialmente, Marcos Aurélio, Rogério Espósito, Rodrigo Carpio e Willer Planas, pela troca de ideias em relação aos assuntos discutidos nesta dissertação.

À Petrobras por ter me dado a oportunidade de me aperfeiçoar profissionalmente e ter cedido a infraestrutura necessária para a realização desta dissertação.

Aos professores e funcionários da PUC-RJ pelo conhecimento adquirido e suporte fornecido.

O presente trabalho foi realizado com apoio da Coordenação de Aperfeiçoamento de Pessoal de Nível Superior - Brasil (CAPES) - Código de Financiamento 001. 


\section{Resumo}

Buffon, Lucas; Carvalho, Márcio da Silveira; Machado, Marcos Vitor Barbosa. Representatividade do modelo de fluido em modelos integrados de produção. Rio de Janeiro, 2020. 313p. Dissertação de Mestrado - Departamento de Engenharia Mecânica, Pontifícia Universidade Católica do Rio de Janeiro.

O crescente uso de modelos integrados de produção (MIP) na indústria de petróleo como solução para representar o potencial de uma jazida se justifica pelos atuais cenários encontrados para o desenvolvimento de novos projetos, caracterizado por baixos preços de venda do petróleo e conceitos de produção de alta complexidade. Esta abordagem, em que diferentes partes de um sistema de produção são integradas, permite ao usuário um entendimento detalhado das interações entre reservatório, poços e rede de escoamento, e facilita a detecção de gargalos e consequentemente a otimização do plano de explotação.

Neste contexto, é fundamental obter uma modelagem satisfatória do fluido em todo o sistema de produção. O modelo deve honrar tanto o escoamento no meio poroso, isotérmico, quanto o escoamento nos poços e dutos, que precisa ser caracterizado em várias temperaturas. Além disso, o modelo deve ter tempo de simulação adequado.

Uma maneira criteriosa de modelar as propriedades de um fluido é através do ajuste de uma equação de estado (EOS). Uma EOS detalhada com 24 componentes determinada por cromatografia gasosa e EOS simplificadas com 14, 9, 7, 6, 5 e 4 pseudocomponentes foram geradas para avaliar este problema. As EOS foram usadas para representar as propriedades PVT em um MIP e ao final foram comparadas as respostas das EOS simplificadas e detalhadas, a fim de estabelecer resultados adequados com um tempo computacional adequado.

Os resultados obtidos mostram que o uso de EOS excessivamente simplificadas, apesar da melhoria no tempo computacional, podem gerar resultados insatisfatórios em modelos integrados de produção.

\section{Palavras-chave}

Modelagem Integrada de Produção; Modelagem de Fluido Composicional; Modelagem de Fluido em Reservatório; Modelagem de Fluido em Sistemas de Produção; PVT; Equation of State. 


\section{Abstract}

Buffon, Lucas; Carvalho, Márcio da Silveira (Advisor); Machado, Marcos Vitor Barbosa (Co-Advisor). Representativeness of the fluid model in integrated production models. Rio de Janeiro, 2020. 313p. Dissertação de Mestrado - Departamento de Engenharia Mecânica, Pontifícia Universidade Católica do Rio de Janeiro.

The growing use of integrated production models (IPM) in the oil industry as a solution to represent the potential of a field is justified by the current scenarios found for the development of new projects, characterized by low oil prices and high complexity production concepts. This approach, where different parts of a production system are integrated, allows the user to have a detailed understanding of the interactions between reservoir, wells and gathering system, and facilitates the detection of bottlenecks and consequently the optimization of the exploitation plan.

In this context, it is essential to obtain a satisfactory fluid model in the entire production system. The model must honor both the flow in the porous media, isothermal, and the flow in the wells and pipelines, which must be characterized at various temperatures. In addition, the model must have adequate simulation time.

A rigorous way to model the properties of a fluid is by adjusting an equation of state (EOS). A detailed EOS with 24 components determined by gas chromatography and simplified EOS with 14, 9, 7, 6, 5 and 4 pseudocomponents were generated to evaluate this problem. The EOS were used to represent the PVT properties in a IPM and the responses of the simplified and detailed EOS were compared, in order to establish an adequate results with an adequate computational time.

The results obtained show that the use of excessively simplified EOS, despite the improvement in computational time, can generate unsatisfactory results in integrated production models.

\section{Keywords}

Integrated Production Modeling; Compositional Fluid Modeling; Reservoir Fluid Modeling; Production Systems Fluid Modeling; PVT; Equation of Stat. 


\section{Sumário}

1 Introdução $\quad 31$

1.1 Apresentação 31

1.2 Motivação 33

1.3 Objetivos 33

1.4 Estrutura da dissertação 34

2 Fundamentação Teórica 35

2.1 Caracterização do comportamento de fases de uma mistura de hidrocarbonetos com equação de estado e análises PVT 35

2.1.1 Fluidos encontrados em reservatórios de petróleo 35

2.1.1.1 Composição dos fluidos encontrados em reservatórios de petróleo 35

2.1.1.2 Propriedades dos fluidos encontrados nos reservatórios e com$\begin{array}{ll}\text { portamento das fases } & 37\end{array}$

2.1.1.3 Classificação dos fluidos encontrados em reservatórios de petróleo 43

2.1.2 Análises PVT $\quad 50$

2.1.2.1 Mistura de gás natural $\quad 50$

2.1.2.2 Black-oils 51

$\begin{array}{lll}\text { 2.1.2.3 Mistura de gás condensado } & 56\end{array}$

2.1.2.4 Mistura de óleo volátil $\quad 56$

2.1.3 Equações de estado e cálculo de equilíbrio de fases 57

2.1.3.1 Equilíbrio de fases de um sistema multicomponente 58

2.1.3.2 Equações de estado 62

2.1.3.3 Caracterização das frações pesadas de hidrocarboneto $\quad 69$

$\begin{array}{lll}\text { 2.1.3.4 Propriedades físicas geradas pela EOS } & 70\end{array}$

$\begin{array}{lll}\text { 2.1.3.5 Propriedades de transporte reológicas } & 73\end{array}$

2.1.4 Ajuste de uma equação de estado cúbica através de uma regressão não-linear $\quad 81$

2.1.5 Técnicas de agrupamento/desagrupamento (Lumping/Delumping) 83

3 Modelagem Integrada de Produção $\quad 85$

$\begin{array}{lll}3.1 & \text { Introdução } & 85\end{array}$

$\begin{array}{ll}3.2 & \text { Modelo de reservatório }\end{array}$

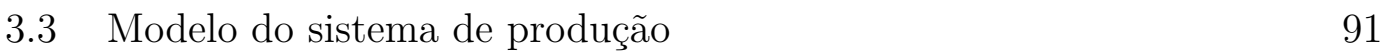

3.4 Acoplamento dos modelos 92

4 Metodologia $\quad 94$

4.1 Seleção do fluido e ajuste das EOS detalhada e pseudoizada para uso no MIP 94

4.1.1 Seleção do fluido e ensaios laboratoriais 94

$\begin{array}{lll}\text { 4.1.2 Ajuste da EOS detalhada } & 100\end{array}$

4.1.2.1 Escolha da equação de estado e do modelo de viscosidade 102

$\begin{array}{lll}\text { 4.1.2.2 Escolha dos componentes } & 104\end{array}$

$\begin{array}{lll}\text { 4.1.2.3 Escolha dos parâmetros de regressão } & 104\end{array}$

4.1.2.4 Resultado da regressão da EOS com 24 PC 108 
4.1.3 Metodologia de simplificação e regressão das EOS simplificadas 117

$\begin{array}{lll}4.2 & \text { Modelo integrado de produção } & 122\end{array}$

$\begin{array}{lll}\text { 4.2.1 Modelagem do fluxo no meio poroso } & 122\end{array}$

4.2.2 Modelagem do fluxo nos poços, dutos e chegada na UEP 124

$\begin{array}{lll}4.2 .2 .1 & \text { Poço produtor } & 125\end{array}$

$\begin{array}{lll}\text { 4.2.2.2 Duto submarino de produção } & 127\end{array}$

$\begin{array}{ll}\text { 4.2.2.3 Correlação de escoamento multifásico } & 129\end{array}$

$\begin{array}{lll}4.2 .2 .4 & \text { Elevação artificial do petróleo } & 130\end{array}$

$\begin{array}{ll}\text { 4.2.2.5 Poço e duto submarino de injeção } & 131\end{array}$

$\begin{array}{lll}\text { 4.2.2.6 Processamento primário de petróleo } & 131\end{array}$

4.2.3 Acoplamento dos modelos de reservatório e sistema de produção 132

4.3 Variáveis de interesse para validação dos resultados 134

$\begin{array}{lll}\text { 4.3.1 } & \text { Modelo de reservatório } & 134\end{array}$

$\begin{array}{lll}\text { 4.3.2 } & \text { Modelo de escoamento no poço e duto } & 137\end{array}$

$\begin{array}{lll}\text { 4.3.3 Tempo de simulação } & 143\end{array}$

5 Resultados $\quad 144$

$\begin{array}{lll}5.1 & \text { Modelo de reservatório } & 144\end{array}$

$\begin{array}{lll}\text { 5.2 Modelo do sistema de produção } & 145\end{array}$

$\begin{array}{lll}5.3 \text { Tempo de simulação } & 149\end{array}$

6 Considerações finais $\quad 151$

$\begin{array}{lll}6.1 \text { Conclusões } & 151\end{array}$

6.1.1 Modelo de reservatório 151

6.1.2 Modelo de escoamento em poços e dutos 152

$\begin{array}{ll}\text { 6.1.3 Tempo de simulação } & 153\end{array}$

$\begin{array}{lll}6.2 & \text { Sugestão para trabalhos futuros } & 153\end{array}$

$\begin{array}{ll}\text { Referências bibliográficas } & 155\end{array}$

A Resultados - Regressão das EOS simplificadas 158

A.1 Regressão da EOS 14 PC 158

A.1.1 Ensaio de liberação diferencial 158

A.1.2 Ensaios de expansão a composição constante $\mathrm{T}=122^{\circ} \mathrm{C}, 75^{\circ} \mathrm{C}$ e $30^{\circ} \mathrm{C} 162$

A.1.3 Ensaio de expansão a volume constante 166

A.2 Regressão da EOS com 9 PC 166

A.2.1 Ensaio de liberação diferencial 167

A.2.2 Ensaios de expansão a composição constante $\mathrm{T}=122^{\circ} \mathrm{C}, 75^{\circ} \mathrm{C}$ e $30^{\circ} \mathrm{C} 170$

$\begin{array}{lll}\text { A.2.3 Ensaio de expansão a volume constante } & 174\end{array}$

$\begin{array}{lll}\text { A.3 Regressão da EOS com } 7 \text { PC } & 174\end{array}$

A.3.1 Ensaio de liberação diferencial 175

A.3.2 Ensaios de expansão a composição constante $\mathrm{T}=122^{\circ} \mathrm{C}, 75^{\circ} \mathrm{C}$ e $30^{\circ} \mathrm{C} 178$

A.3.3 Ensaio de expansão a volume constante 182

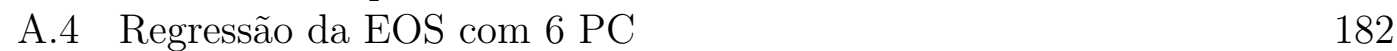

A.4.1 Ensaio de liberação diferencial 183

A.4.2 Ensaios de expansão a composição constante $\mathrm{T}=122^{\circ} \mathrm{C}, 75^{\circ} \mathrm{C}$ e $30^{\circ} \mathrm{C} 186$

$\begin{array}{lll}\text { A.4.3 Ensaio de expansão a volume constante } & 190\end{array}$

$\begin{array}{lll}\text { A.5 Regressão da EOS com 5 PC } & 190\end{array}$

$\begin{array}{lll}\text { A.5.1 Ensaio de liberação diferencial } & 191\end{array}$ 
A.5.2 Ensaios de expansão a composição constante $\mathrm{T}=122^{\circ} \mathrm{C}, 75^{\circ} \mathrm{C}$ e $30^{\circ} \mathrm{C} 194$

A.5.3 Ensaio de expansão a volume constante 198

A.6 Regressão da EOS com 4 PC 198

A.6.1 Ensaio de liberação diferencial 199

A.6.2 Ensaios de expansão a composição constante $\mathrm{T}=122^{\circ} \mathrm{C}, 75^{\circ} \mathrm{C}$ e $30^{\circ} \mathrm{C} 202$

A.6.3 Ensaio de expansão a volume constante 206

B Resultados - Escoamento no meio poroso 207

B.1 EOS 24 PC versus EOS 14 PC 207

B.2 EOS 24 PC versus EOS 9 PC 210

B.3 EOS $24 \mathrm{PC}$ versus EOS $7 \mathrm{PC} \quad 212$

B.4 EOS 24 PC versus EOS 6 PC 215

B.5 EOS 24 PC versus EOS 5 PC 217

B.6 EOS 24 PC versus EOS 4 PC 220

C Resultados - Escoamento nas tubulações 223

C.1 EOS $24 \mathrm{PC}$ versus EOS $14 \mathrm{PC}$

C.1.1 Cenário 1 - Período inicial logo após a abertura do poço 223

C.1.2 Cenário 2 - Período inicial antes do breaktrough de água 229

C.1.3 Cenário 3 - Corte de água intermediário 234

C.2 EOS 24 PC versus EOS 9 PC 239

C.2.1 Cenário 1 - Período inicial logo após a abertura do poço 239

C.2.2 Cenário 2 - Período inicial antes do breaktrough de água 244

C.2.3 Cenário 3 - Corte de água intermediário 249

C.3 EOS 24 PC versus EOS 7 PC 254

C.3.1 Cenário 1 - Período inicial logo após a abertura do poço 254

C.3.2 Cenário 2 - Período inicial antes do breaktrough de água 259

C.3.3 Cenário 3 - Corte de água intermediário 264

C.4 EOS 24 PC versus EOS 6 PC 269

C.4.1 Cenário 1 - Período inicial logo após a abertura do poço 269

C.4.2 Cenário 2 - Período inicial antes do breaktrough de água 274

C.4.3 Cenário 3 - Corte de água intermediário 279

C.5 EOS 24 PC versus EOS 5 PC 284

C.5.1 Cenário 1 - Período inicial logo após a abertura do poço 284

C.5.2 Cenário 2 - Período inicial antes do breaktrough de água 289

C.5.3 Cenário 3 - Corte de água intermediário 294

C.6 EOS 24 PC versus EOS 4 PC 299

C.6.1 Cenário 1 - Período inicial logo após a abertura do poço 299

C.6.2 Cenário 2 - Período inicial antes do breaktrough de água 304

C.6.3 Cenário 3 - Corte de água intermediário 309 


\section{Lista de figuras}

Figura 2.1 Estruturas moleculares de alguns componentes encontrados em reservatórios de petróleo - Adaptado de Pedersen et al. (2006)

Figura 2.2 Curva de pressão de vapor do metano e benzeno e envelope de fases da mistura de $25 \%$ de mols de metano e $75 \%$ mols de benzeno - Adaptado de Pedersen et al. (2006)

Figura 2.3 Variação do fator de compressibilidade do hidrogênio em função da pressão a temperatura constate. - Extraído de Moran et al. (2011)

Figura 2.4 Curva de pressão de um componente com o mesmo PC e fatores acêntricos 0,$0 ; 0,5$ e 1,0 — Adaptado de Pedersen et al. (2006)

Figura 2.5 Envelope de fase típico de fluidos encontrados em reservatórios de petróleo — Extraído de PUC-Rio (2019)

Figura 2.6 Envelope de fases de vários tipos de fluidos de reservatório - Extraído de Andreolli (2016)

Figura 2.7 Envelope de fases de um reservatório com contato óleogás - Adaptado de Danesh (1998)

Figura 2.8 Esquemático da variação do fator de volume de formação do gás com a pressão — Adaptado de Danesh (1998)

Figura 2.9 Comportamento das fases em um reservatório black-oil - Adaptado de Danesh (1998)

Figura 2.10 Fator volume de formação do óleo $\left(B_{o}\right)$ em função da pressão em um ensaio de liberação diferencial - Adaptado de Pedersen et al. (2006)

Figura 2.11 Razão de solubilidade $\left(R_{s}\right)$ em função da pressão em um ensaio de liberação diferencial - Adaptado de Pedersen et al. (2006)

Figura 2.12 Esquemático de um teste de separador com três estágios - Adaptado de Pedersen et al. (2006)

Figura 2.13 Volume de líquido depositado em uma expansão a volume constante - Adaptado de Danesh (1998)

Figura 2.14 Curva pressão-volume específico molar de um componente puro - Adaptado de Danesh (1998)

Figura 2.15 Iteração entre dois volumes elementares em um recipiente preenchido com gás — Adaptado de Danesh (1998)

Figura 2.16 Tensão externa aplicada a uma porção de um fluido. Os termos na figura são usados na definição de viscosidade - Adaptado de Pedersen et al. (2006)

Figura 2.17 Tensão externa aplicada a uma porção de um fluido. Os termos na figura são usados na definição de viscosidade - Adaptado de Pedersen et al. (2006)

Figura 2.18 Método de medição de tensão interfacial através do peso da gota — Adaptado de Danesh (1998) 
Figura 3.1 Arranjo de produção e injeção satélite. $\quad 86$

Figura 3.2 Arranjo de produção trunkline. $\quad 86$

Figura 3.3 Arranjo de produção manifold $\quad 87$

Figura 3.4 Arranjo de produção satélite e injeção trunkline operando com bombeamento multifásico.

Figura 3.5 Arranjo de produção satélite e injeção trunkline operando com SSGL.

Figura 3.6 Acoplamento explícito — Extraído de Cotrim (2012) 92

Figura 3.7 Acoplamento implícito — Extraído de Cotrim (2012) 93

Figura 4.1 Volume relativo de óleo da liberação diferencial acima da pressão de saturação.

Figura 4.2 Viscosidade do óleo da liberação diferencial acima da pressão de saturação.

Figura 4.3 Massa específica do óleo da liberação diferencial acima da pressão de saturação.

Figura 4.4 RGO da liberação diferencial abaixo da pressão de saturação.

Figura 4.5 $\quad B_{o}$ da liberação diferencial abaixo da pressão de saturação.110

Figura 4.6 $\quad B_{g}$ da liberação diferencial abaixo da pressão de saturação.110

Figura 4.7 Densidade do gás abaixo da pressão de saturação. 111

Figura 4.8 Densidade do óleo abaixo da pressão de saturação. 112

Figura 4.9 Viscosidade do óleo abaixo da pressão de saturação. 112

Figura 4.10 Viscosidade do gás abaixo da pressão de saturação. 112

Figura 4.11 Volume relativo de óleo, ECC a $122{ }^{\circ} \mathrm{C}$. 113

Figura 4.12 Volume de líquido, \% do volume da célula, ECC a $122{ }^{\circ} \mathrm{C} .113$

Figura 4.13 Massa específica de óleo, ECC a $122^{\circ} \mathrm{C}$. 114

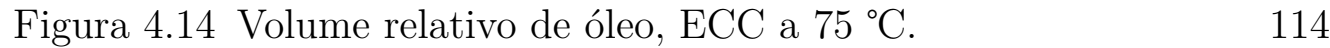

Figura 4.15 Volume de líquido, \% do volume da célula, ECC a $75{ }^{\circ} \mathrm{C} .114$

Figura 4.16 Massa específica de óleo, ECC a $75^{\circ} \mathrm{C}$. 115

Figura 4.17 Volume relativo de óleo, ECC a $30{ }^{\circ} \mathrm{C}$. 115

Figura 4.18 Volume de líquido, \% do volume da célula, ECC a $30{ }^{\circ} \mathrm{C} .115$

Figura 4.19 Massa específica de óleo, ECC a $30{ }^{\circ} \mathrm{C} . \quad 116$

Figura 4.20 Volume de líquido, \% do volume original, EVC a $122{ }^{\circ} \mathrm{C} .116$

Figura 4.21 Gás produzido, \% molar original, EVC a $122{ }^{\circ} \mathrm{C} . \quad 117$

$\begin{array}{ll}\text { Figura 4.22 Envelopes de fase das EOS. } & 121\end{array}$

Figura 4.23 Visão 3D do modelo simplificado de reservatório. 123

Figura 4.24 Curva de permeabilidade relativa água-óleo. 124

$\begin{array}{ll}\text { Figura 4.25 Fluxo fracionário de água. } & 124\end{array}$

$\begin{array}{ll}\text { Figura 4.26 Esquemático do poço produtor } & 126\end{array}$

$\begin{array}{ll}\text { Figura 4.27 Esquemático do poço produtor } & 127\end{array}$

Figura 4.28 Perfil de temperatura e velocidade de corrente da água do mar 129

Figura 4.29 Modelo de escoamento de produção 132

Figura 4.30 Modelo de escoamento de produção 133

Figura 4.31 Curva de produção de óleo instantânea e acumulada EOS $24 \mathrm{PC}$

Figura 4.32 Curva de produção de gás instantânea e acumulada EOS $24 \mathrm{PC}$ 
Figura 4.33 Curva de produção de água e watercut - EOS 24 PC 136

Figura 4.34 Pressão estática e nos canhoneados - EOS 24 PC 137

Figura 4.35 Padrões de escoamento em tubulação horizontal - Adaptado de Shoham (2006)

Figura 4.36 Padrões de escoamento em tubulação vertical - Adaptado de Shoham (2006)

Figura 4.37 Perfil de pressão e temperatura - EOS 24 PC - 01-AGO2020

Figura 4.38 Gradiente de pressão gravitacional e de fricção - EOS 24 PC - 01-AGO-2020

Figura 4.39 Hold-up e velocidades superficiais - EOS 24 PC - 01AGO-2020

Figura 4.40 Coeficiente global de troca de calor e Joule-Thomson EOS 24 PC - 01-AGO-2020

Figura A.1 Volume relativo de óleo da liberação diferencial acima da pressão de saturação.

Figura A.2 Viscosidade do óleo da liberação diferencial acima da pressão de saturação.

Figura A.3 Massa específica do óleo da liberação diferencial acima da pressão de saturação.

Figura A.4 RGO da liberação diferencial abaixo da pressão de saturação.

Figura A.5 $B_{o}$ da liberação diferencial abaixo da pressão de saturação.160

Figura A.6 $\quad B_{g}$ da liberação diferencial abaixo da pressão de saturação. 160

Figura A.7 Densidade do gás abaixo da pressão de saturação. $\quad 161$

$\begin{array}{lll}\text { Figura A.8 } & \text { Densidade do óleo abaixo da pressão de saturação. } & 161\end{array}$

Figura A.9 Viscosidade do óleo abaixo da pressão de saturação. 161

Figura A.10 Viscosidade do gás abaixo da pressão de saturação. 162

Figura A.11 Volume relativo de óleo, ECC a $122^{\circ} \mathrm{C}$. 162

Figura A.12 Volume de líquido, \% do volume da célula, ECC a $122{ }^{\circ} \mathrm{C} .163$

Figura A.13 Massa específica de óleo, ECC a $122{ }^{\circ} \mathrm{C} . \quad 163$

Figura A.14 Volume relativo de óleo, ECC a $75{ }^{\circ} \mathrm{C}$. 163

Figura A.15 Volume de líquido, \% do volume da célula, ECC a $75{ }^{\circ} \mathrm{C} .164$

Figura A.16 Massa específica de óleo, ECC a $75^{\circ} \mathrm{C}$. 164

Figura A.17 Volume relativo de óleo, ECC a $30{ }^{\circ} \mathrm{C}$.

Figura A.18 Volume de líquido, \% do volume da célula, ECC a $30{ }^{\circ} \mathrm{C} .165$

Figura A.19 Massa específica de óleo, ECC a $30{ }^{\circ} \mathrm{C} . \quad 165$

Figura A.20 Volume de líquido, \% do volume original, EVC a $122{ }^{\circ} \mathrm{C} .166$

Figura A.21 Gás produzido, \% molar original, EVC a $122{ }^{\circ} \mathrm{C} . \quad 166$

Figura A.22 Volume relativo de óleo da liberação diferencial acima da pressão de saturação.

Figura A.23 Viscosidade do óleo da liberação diferencial acima da pressão de saturação.

Figura A.24 Massa específica do óleo da liberação diferencial acima da pressão de saturação.

Figura A.25 RGO da liberação diferencial abaixo da pressão de saturação.

Figura A.26 $B_{o}$ da liberação diferencial abaixo da pressão de saturação.168 
Figura A.27 $B_{g}$ da liberação diferencial abaixo da pressão de saturação. 168 Figura A.28 Densidade do gás abaixo da pressão de saturação. $\quad 169$

Figura A.29 Densidade do óleo abaixo da pressão de saturação. $\quad 169$

Figura A.30 Viscosidade do óleo abaixo da pressão de saturação. $\quad 169$

Figura A.31 Viscosidade do gás abaixo da pressão de saturação. $\quad 170$

Figura A.32 Volume relativo de óleo, ECC a $122^{\circ} \mathrm{C}$. 170

Figura A.33 Volume de líquido, \% do volume da célula, ECC a $122{ }^{\circ} \mathrm{C} .171$

Figura A.34 Massa específica de óleo, ECC a $122{ }^{\circ} \mathrm{C}$. 171

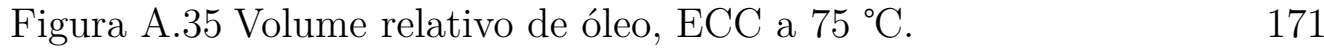

Figura A.36 Volume de líquido, \% do volume da célula, ECC a $75{ }^{\circ} \mathrm{C} .172$

Figura A.37 Massa específica de óleo, ECC a $75^{\circ} \mathrm{C} . \quad 172$

Figura A.38 Volume relativo de óleo, ECC a $30{ }^{\circ} \mathrm{C} . \quad 172$

Figura A.39 Volume de líquido, \% do volume da célula, ECC a $30{ }^{\circ} \mathrm{C} .173$

Figura A.40 Massa específica de óleo, ECC a $30{ }^{\circ} \mathrm{C} . \quad 173$

Figura A.41 Volume de líquido, \% do volume original, EVC a $122{ }^{\circ} \mathrm{C} .174$

Figura A.42 Gás produzido, \% molar original, EVC a $122{ }^{\circ} \mathrm{C} . \quad 174$

Figura A.43 Volume relativo de óleo da liberação diferencial acima da pressão de saturação.

Figura A.44 Viscosidade do óleo da liberação diferencial acima da pressão de saturação.

Figura A.45 Massa específica do óleo da liberação diferencial acima da pressão de saturação.

Figura A.46 RGO da liberação diferencial abaixo da pressão de saturação.

Figura A.47 $B_{o}$ da liberação diferencial abaixo da pressão de saturação. 176

Figura A.48 $B_{g}$ da liberação diferencial abaixo da pressão de saturação. 176

Figura A.49 Densidade do gás abaixo da pressão de saturação. $\quad 177$

Figura A.50 Densidade do óleo abaixo da pressão de saturação. $\quad 177$

$\begin{array}{ll}\text { Figura A.51 Viscosidade do óleo abaixo da pressão de saturação. } & 177\end{array}$

$\begin{array}{ll}\text { Figura A.52 Viscosidade do gás abaixo da pressão de saturação. } & 178\end{array}$

Figura A.53 Volume relativo de óleo, ECC a $122^{\circ} \mathrm{C}$. 178

Figura A.54 Volume de líquido, \% do volume da célula, ECC a $122{ }^{\circ} \mathrm{C} .179$

Figura A.55 Massa específica de óleo, ECC a $122^{\circ} \mathrm{C}$. 179

Figura A.56 Volume relativo de óleo, ECC a $75{ }^{\circ} \mathrm{C}$. 179

Figura A.57 Volume de líquido, \% do volume da célula, ECC a $75{ }^{\circ} \mathrm{C} .180$

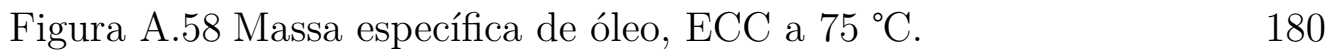

Figura A.59 Volume relativo de óleo, ECC a $30{ }^{\circ} \mathrm{C}$. 180

Figura A.60 Volume de líquido, \% do volume da célula, ECC a $30{ }^{\circ} \mathrm{C} .181$

Figura A.61 Massa específica de óleo, ECC a $30{ }^{\circ} \mathrm{C}$. 181

Figura A.62 Volume de líquido, \% do volume original, EVC a $122{ }^{\circ} \mathrm{C} .182$

Figura A.63 Gás produzido, \% molar original, EVC a $122{ }^{\circ} \mathrm{C} . \quad 182$

Figura A.64 Volume relativo de óleo da liberação diferencial acima da pressão de saturação. $\quad 183$

Figura A.65 Viscosidade do óleo da liberação diferencial acima da pressão de saturação.

183

Figura A.66 Massa específica do óleo da liberação diferencial acima da pressão de saturação. 
Figura A.67 RGO da liberação diferencial abaixo da pressão de saturação.

Figura A.68 $B_{o}$ da liberação diferencial abaixo da pressão de saturação.184

Figura A.69 $B_{g}$ da liberação diferencial abaixo da pressão de saturação.184

Figura A.70 Densidade do gás abaixo da pressão de saturação. $\quad 185$

Figura A.71 Densidade do óleo abaixo da pressão de saturação. $\quad 185$

Figura A.72 Viscosidade do óleo abaixo da pressão de saturação. $\quad 185$

Figura A.73 Viscosidade do gás abaixo da pressão de saturação. $\quad 186$

Figura A.74 Volume relativo de óleo, ECC a $122{ }^{\circ} \mathrm{C} . \quad 186$

Figura A.75 Volume de líquido, \% do volume da célula, ECC a $122{ }^{\circ} \mathrm{C} .187$

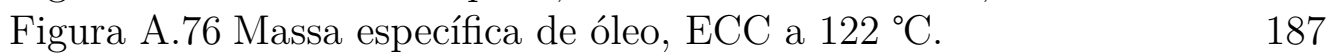

Figura A.77 Volume relativo de óleo, ECC a $75{ }^{\circ} \mathrm{C} . \quad 187$

Figura A.78 Volume de líquido, \% do volume da célula, ECC a $75{ }^{\circ} \mathrm{C} .188$

Figura A.79 Massa específica de óleo, ECC a $75^{\circ} \mathrm{C} . \quad 188$

Figura A.80 Volume relativo de óleo, ECC a $30{ }^{\circ} \mathrm{C}$. 188

Figura A.81 Volume de líquido, \% do volume da célula, ECC a $30{ }^{\circ} \mathrm{C} .189$

Figura A.82 Massa específica de óleo, ECC a $30{ }^{\circ} \mathrm{C} . \quad 189$

Figura A.83 Volume de líquido, \% do volume original, EVC a $122{ }^{\circ} \mathrm{C} .190$

Figura A.84 Gás produzido, \% molar original, EVC a $122{ }^{\circ} \mathrm{C} . \quad 190$

Figura A.85 Volume relativo de óleo da liberação diferencial acima da pressão de saturação.

Figura A.86 Viscosidade do óleo da liberação diferencial acima da pressão de saturação.

Figura A.87 Massa específica do óleo da liberação diferencial acima da pressão de saturação.

Figura A.88 RGO da liberação diferencial abaixo da pressão de saturação.

Figura A.89 $B_{o}$ da liberação diferencial abaixo da pressão de saturação. 192

Figura A.90 $B_{g}$ da liberação diferencial abaixo da pressão de saturação.192

Figura A.91 Densidade do gás abaixo da pressão de saturação. $\quad 193$

Figura A.92 Densidade do óleo abaixo da pressão de saturação. $\quad 193$

Figura A.93 Viscosidade do óleo abaixo da pressão de saturação. $\quad 193$

Figura A.94 Viscosidade do gás abaixo da pressão de saturação. 194

Figura A.95 Volume relativo de óleo, ECC a $122{ }^{\circ} \mathrm{C} . \quad 194$

Figura A.96 Volume de líquido, \% do volume da célula, ECC a $122{ }^{\circ} \mathrm{C} .195$

Figura A.97 Massa específica de óleo, ECC a $122^{\circ} \mathrm{C}$. 195

Figura A.98 Volume relativo de óleo, ECC a $75^{\circ} \mathrm{C}$. 195

Figura A.99 Volume de líquido, \% do volume da célula, ECC a $75{ }^{\circ} \mathrm{C} .196$

Figura A.100Massa específica de óleo, ECC a $75^{\circ} \mathrm{C}$. 196

Figura A.101Volume relativo de óleo, ECC a $30{ }^{\circ} \mathrm{C} . \quad 196$

Figura A.102Nolume de líquido, \% do volume da célula, ECC a $30{ }^{\circ} \mathrm{C} .197$

Figura A.103Massa específica de óleo, ECC a $30{ }^{\circ} \mathrm{C}$. 197

Figura A.104volume de líquido, \% do volume original, EVC a $122{ }^{\circ} \mathrm{C} .198$

Figura A.105Gás produzido, \% molar original, EVC a $122{ }^{\circ} \mathrm{C} . \quad 198$

Figura A.106Volume relativo de óleo da liberação diferencial acima da pressão de saturação.

199

Figura A.10సiscosidade do óleo da liberação diferencial acima da pressão de saturação. 
Figura A.108Massa específica do óleo da liberação diferencial acima da pressão de saturação.

Figura A.109RGO da liberação diferencial abaixo da pressão de saturação.

200

Figura A.110B $B_{o}$ da liberação diferencial abaixo da pressão de saturação. 200

Figura A. $111 B_{g}$ da liberação diferencial abaixo da pressão de saturação. 200

Figura A.112Densidade do gás abaixo da pressão de saturação. 201

Figura A.113ensidade do óleo abaixo da pressão de saturação. 201

Figura A.114Viscosidade do óleo abaixo da pressão de saturação. 201

Figura A.115Viscosidade do gás abaixo da pressão de saturação. 202

Figura A.116Volume relativo de óleo, ECC a $122{ }^{\circ} \mathrm{C}$. 202

Figura A.117olume de líquido, \% do volume da célula, ECC a $122{ }^{\circ} \mathrm{C} .203$

Figura A.118Massa específica de óleo, ECC a $122^{\circ} \mathrm{C}$. 203

Figura A.119Volume relativo de óleo, ECC a $75^{\circ} \mathrm{C}$. 203

Figura A.120Volume de líquido, \% do volume da célula, ECC a $75{ }^{\circ} \mathrm{C} .204$

Figura A.121Massa específica de óleo, ECC a $75^{\circ} \mathrm{C}$. 204

Figura A.122Nolume relativo de óleo, ECC a $30{ }^{\circ} \mathrm{C}$. 204

Figura A.123volume de líquido, \% do volume da célula, ECC a $30{ }^{\circ} \mathrm{C} .205$

Figura A.124Massa específica de óleo, ECC a $30{ }^{\circ} \mathrm{C}$. 205

Figura A.125Volume de líquido, \% do volume original, EVC a $122{ }^{\circ} \mathrm{C} .206$

Figura A.126Gás produzido, \% molar original, EVC a $122{ }^{\circ} \mathrm{C} . \quad 206$

Figura B.1 Vazão de óleo - EOS 24 PC versus EOS 14 PC. 207

Figura B.2 Vazão de líquido - EOS 24 PC versus EOS 14 PC. $\quad 208$

Figura B.3 watercut - EOS 24 PC versus EOS 14 PC. 208

Figura B.4 Pressão estática - EOS 24 PC versus EOS 14 PC. 209

Figura B.5 Pressão de fundo nos canhoneados - EOS $24 \mathrm{PC}$ versus

EOS 14 PC.

209

Figura B.6 Vazão de óleo - EOS 24 PC versus EOS 14 PC. 210

Figura B.7 Vazão de líquido - EOS 24 PC versus EOS 14 PC. 210

Figura B.8 watercut - EOS 24 PC versus EOS 14 PC. 211

Figura B.9 Pressão estática - EOS 24 PC versus EOS 14 PC. 211

Figura B.10 Pressão de fundo nos canhoneados - EOS 24 PC versus

EOS 14 PC.

212

Figura B.11 Vazão de óleo - EOS 24 PC versus EOS 14 PC. 212

Figura B.12 Vazão de líquido - EOS 24 PC versus EOS 14 PC. 213

Figura B.13 watercut - EOS 24 PC versus EOS 14 PC. 213

Figura B.14 Pressão estática - EOS 24 PC versus EOS 14 PC. 214

Figura B.15 Pressão de fundo nos canhoneados - EOS 24 PC versus EOS 14 PC.

Figura B.16 Vazão de óleo - EOS 24 PC versus EOS 14 PC. 215

Figura B.17 Vazão de líquido - EOS 24 PC versus EOS 14 PC. 215

Figura B.18 watercut - EOS 24 PC versus EOS 14 PC. 216

Figura B.19 Pressão estática - EOS 24 PC versus EOS 14 PC. 216

Figura B.20 Pressão de fundo nos canhoneados - EOS 24 PC versus

EOS 14 PC. 217

Figura B.21 Vazão de óleo - EOS 24 PC versus EOS 14 PC. 217

Figura B.22 Vazão de líquido - EOS 24 PC versus EOS 14 PC. 218

Figura B.23 watercut - EOS 24 PC versus EOS 14 PC. 218 
Figura B.24 Pressão estática - EOS 24 PC versus EOS 14 PC.

Figura B.25 Pressão de fundo nos canhoneados - EOS 24 PC versus EOS 14 PC.

Figura B.26 Vazão de óleo - EOS 24 PC versus EOS 14 PC. 220

Figura B.27 Vazão de líquido - EOS 24 PC versus EOS 14 PC. 220

Figura B.28 watercut - EOS 24 PC versus EOS 14 PC. 221

Figura B.29 Pressão estática - EOS 24 PC versus EOS 14 PC. 221

Figura B.30 Pressão de fundo nos canhoneados - EOS 24 PC versus EOS 14 PC.

Figura C.1 Perfil de pressão no poço e duto - Cenário 1 - EOS 24 $\mathrm{PC}$ versus EOS 14 PC.

Figura C.2 Perfil de temperatura no poço e duto - Cenário 1 - EOS $24 \mathrm{PC}$ versus EOS $14 \mathrm{PC}$.

Figura C.3 Holdup no poço e duto - Cenário 1 - EOS 24 PC versus EOS 14 PC.

Figura C.4 Velocidade superficial de líquido - Cenário 1 - EOS 24 $\mathrm{PC}$ versus EOS $14 \mathrm{PC}$.

Figura C.5 Velocidade superficial de gás - Cenário 1 - EOS 24 PC versus EOS $14 \mathrm{PC}$.

Figura C.6 Gradiente de pressão por fricção - Cenário 1 - EOS 24 $\mathrm{PC}$ versus EOS $14 \mathrm{PC}$.

Figura C.7 Gradiente de pressão gravitacional - Cenário 1 - EOS 24 $\mathrm{PC}$ versus EOS $14 \mathrm{PC}$.

Figura C.8 Gradiente de pressão total - Cenário 1 - EOS 24 PC versus EOS $14 \mathrm{PC}$.

Figura C.9 Coeficiente global de transferência de calor - Cenário 1 - EOS 24 PC versus EOS 14 PC.

Figura C.10 Coeficiente Joule-Thomson - Cenário 1 - EOS 24 PC versus EOS $14 \mathrm{PC}$.

Figura C.11 Perfil de pressão no poço e duto - Cenário 2 - EOS 24 $\mathrm{PC}$ versus EOS $14 \mathrm{PC}$.

Figura C.12 Perfil de temperatura no poço e duto - Cenário 2 - EOS $24 \mathrm{PC}$ versus EOS 14 PC.

Figura C.13 Holdup no poço e duto - Cenário 2 - EOS 24 PC versus EOS 14 PC.

Figura C.14 Velocidade superficial de líquido - Cenário 2 - EOS 24 $\mathrm{PC}$ versus EOS $14 \mathrm{PC}$.

Figura C.15 Velocidade superficial de gás - Cenário 2 - EOS 24 PC versus EOS 14 PC.

Figura C.16 Gradiente de pressão por fricção - Cenário 2 - EOS 24 $\mathrm{PC}$ versus EOS $14 \mathrm{PC}$.

Figura C.17 Gradiente de pressão gravitacional - Cenário 2 - EOS 24 $\mathrm{PC}$ versus EOS $14 \mathrm{PC}$.

Figura C.18 Gradiente de pressão total - Cenário 2 - EOS 24 PC versus EOS $14 \mathrm{PC}$.

Figura C.19 Coeficiente global de transferência de calor - Cenário 2 - EOS 24 PC versus EOS 14 PC. 
Figura C.20 Coeficiente Joule-Thomson - Cenário 2 - EOS 24 PC versus EOS $14 \mathrm{PC}$.

Figura C.21 Perfil de pressão no poço e duto - Cenário 3 - EOS 24 $\mathrm{PC}$ versus EOS $14 \mathrm{PC}$.

Figura C.22 Perfil de temperatura no poço e duto - Cenário 3 - EOS $24 \mathrm{PC}$ versus EOS 14 PC.

Figura C.23 Holdup no poço e duto - Cenário 3 - EOS 24 PC versus EOS 14 PC.

Figura C.24 Velocidade superficial de líquido - Cenário 3 - EOS 24 $\mathrm{PC}$ versus EOS $14 \mathrm{PC}$.

Figura C.25 Velocidade superficial de gás - Cenário 3 - EOS 24 PC versus EOS $14 \mathrm{PC}$.

Figura C.26 Gradiente de pressão por fricção - Cenário 3 - EOS 24 $\mathrm{PC}$ versus EOS $14 \mathrm{PC}$.

Figura C.27 Gradiente de pressão gravitacional - Cenário 3 - EOS 24 $\mathrm{PC}$ versus EOS $14 \mathrm{PC}$.

Figura C.28 Gradiente de pressão total - Cenário 3 - EOS 24 PC versus EOS $14 \mathrm{PC}$.

Figura C.29 Coeficiente global de transferência de calor - Cenário 3 - EOS 24 PC versus EOS 14 PC.

Figura C.30 Coeficiente Joule-Thomson - Cenário 3 - EOS 24 PC versus EOS $14 \mathrm{PC}$.

Figura C.31 Perfil de pressão no poço e duto - Cenário 1 - EOS 24 $\mathrm{PC}$ versus EOS $9 \mathrm{PC}$.

Figura C.32 Perfil de temperatura no poço e duto - Cenário 1 - EOS $24 \mathrm{PC}$ versus EOS 9 PC.

Figura C.33 Holdup no poço e duto - Cenário 1 - EOS 24 PC versus EOS 9 PC.

Figura C.34 Velocidade superficial de líquido - Cenário 1 - EOS 24 $\mathrm{PC}$ versus EOS 9 PC.

Figura C.35 Velocidade superficial de gás - Cenário 1 - EOS 24 PC versus EOS 9 PC.

Figura C.36 Gradiente de pressão por fricção - Cenário 1 - EOS 24 $\mathrm{PC}$ versus EOS 9 PC.

Figura C.37 Gradiente de pressão gravitacional - Cenário 1 - EOS 24 $\mathrm{PC}$ versus EOS 9PC.

Figura C.38 Gradiente de pressão total - Cenário 1 - EOS 24 PC versus EOS 9 PC.

Figura C.39 Coeficiente global de transferência de calor - Cenário 1 - EOS 24 PC versus EOS 9 PC.

Figura C.40 Coeficiente Joule-Thomson - Cenário 1 - EOS 24 PC versus EOS 9 PC.

Figura C.41 Perfil de pressão no poço e duto - Cenário 2 - EOS 24 $\mathrm{PC}$ versus EOS $9 \mathrm{PC}$.

Figura C.42 Perfil de temperatura no poço e duto - Cenário 2 - EOS $24 \mathrm{PC}$ versus EOS 9 PC.

Figura C.43 Holdup no poço e duto - Cenário 2 - EOS 24 PC versus EOS 9 PC. 
Figura C.44 Velocidade superficial de líquido - Cenário 2 - EOS 24 $\mathrm{PC}$ versus EOS $9 \mathrm{PC}$.

Figura C.45 Velocidade superficial de gás - Cenário 2 - EOS 24 PC versus EOS 9 PC.

Figura C.46 Gradiente de pressão por fricção - Cenário 2 - EOS 24 $\mathrm{PC}$ versus EOS 9 PC.

Figura C.47 Gradiente de pressão gravitacional - Cenário 2 - EOS 24 $\mathrm{PC}$ versus EOS $9 \mathrm{PC}$.

Figura C.48 Gradiente de pressão total - Cenário 2 - EOS 24 PC versus EOS 9 PC.

Figura C.49 Coeficiente global de transferência de calor - Cenário 2 - EOS 24 PC versus EOS 9 PC.

Figura C.50 Coeficiente Joule-Thomson - Cenário 2 - EOS 24 PC versus EOS 9 PC.

Figura C.51 Perfil de pressão no poço e duto - Cenário 3 - EOS 24 $\mathrm{PC}$ versus EOS $9 \mathrm{PC}$.

Figura C.52 Perfil de temperatura no poço e duto - Cenário 3 - EOS $24 \mathrm{PC}$ versus EOS 9 PC.

Figura C.53 Holdup no poço e duto - Cenário 3 - EOS 24 PC versus EOS 9 PC.

Figura C.54 Velocidade superficial de líquido - Cenário 3 - EOS 24 $\mathrm{PC}$ versus EOS $9 \mathrm{PC}$.

Figura C.55 Velocidade superficial de gás - Cenário 3 - EOS 24 PC versus EOS 9 PC.

Figura C.56 Gradiente de pressão por fricção - Cenário 3 - EOS 24 $\mathrm{PC}$ versus EOS 9 PC.

Figura C.57 Gradiente de pressão gravitacional - Cenário 3 - EOS 24 $\mathrm{PC}$ versus EOS $9 \mathrm{PC}$.

Figura C.58 Gradiente de pressão total - Cenário 3 - EOS 24 PC versus EOS 9 PC.

Figura C.59 Coeficiente global de transferência de calor - Cenário 3 - EOS 24 PC versus EOS 9 PC.

Figura C.60 Coeficiente Joule-Thomson - Cenário 3 - EOS 24 PC versus EOS 9 PC.

Figura C.61 Perfil de pressão no poço e duto - Cenário 1 - EOS 24 $\mathrm{PC}$ versus EOS $7 \mathrm{PC}$.

Figura C.62 Perfil de temperatura no poço e duto - Cenário 1 - EOS $24 \mathrm{PC}$ versus EOS 7 PC.

Figura C.63 Holdup no poço e duto - Cenário 1 - EOS 24 PC versus EOS 7 PC.

Figura C.64 Velocidade superficial de líquido - Cenário 1 - EOS 24 $\mathrm{PC}$ versus EOS $7 \mathrm{PC}$.

Figura C.65 Velocidade superficial de gás - Cenário 1 - EOS 24 PC versus EOS 7 PC.

Figura C.66 Gradiente de pressão por fricção - Cenário 1 - EOS 24 $\mathrm{PC}$ versus EOS 7 PC.

Figura C.67 Gradiente de pressão gravitacional - Cenário 1 - EOS 24 $\mathrm{PC}$ versus EOS 7 PC. 
Figura C.68 Gradiente de pressão total - Cenário 1 - EOS 24 PC versus EOS 7 PC.

Figura C.69 Coeficiente global de transferência de calor - Cenário 1 - EOS 24 PC versus EOS 7 PC.

Figura C.70 Coeficiente Joule-Thomson - Cenário 1 - EOS 24 PC versus EOS 7 PC.

Figura C.71 Perfil de pressão no poço e duto - Cenário 2 - EOS 24 $\mathrm{PC}$ versus EOS $7 \mathrm{PC}$.

Figura C.72 Perfil de temperatura no poço e duto - Cenário 2 - EOS $24 \mathrm{PC}$ versus EOS 7 PC.

Figura C.73 Holdup no poço e duto - Cenário 2 - EOS 24 PC versus EOS 7 PC.

Figura C.74 Velocidade superficial de líquido - Cenário 2 - EOS 24 $\mathrm{PC}$ versus EOS $7 \mathrm{PC}$.

Figura C.75 Velocidade superficial de gás - Cenário 2 - EOS 24 PC versus EOS 7 PC.

Figura C.76 Gradiente de pressão por fricção - Cenário 2 - EOS 24 $\mathrm{PC}$ versus EOS $7 \mathrm{PC}$.

Figura C.77 Gradiente de pressão gravitacional - Cenário 2 - EOS 24 $\mathrm{PC}$ versus EOS $7 \mathrm{PC}$.

Figura C.78 Gradiente de pressão total - Cenário 2 - EOS 24 PC versus EOS 7 PC.

Figura C.79 Coeficiente global de transferência de calor - Cenário 2 - EOS 24 PC versus EOS 7 PC.

Figura C.80 Coeficiente Joule-Thomson - Cenário 2 - EOS 24 PC versus EOS $7 \mathrm{PC}$.

Figura C.81 Perfil de pressão no poço e duto - Cenário 3 - EOS 24 $\mathrm{PC}$ versus EOS $7 \mathrm{PC}$.

Figura C.82 Perfil de temperatura no poço e duto - Cenário 3 - EOS $24 \mathrm{PC}$ versus EOS 7 PC.

Figura C.83 Holdup no poço e duto - Cenário 3 - EOS 24 PC versus EOS 7 PC.

Figura C.84 Velocidade superficial de líquido - Cenário 3 - EOS 24 $\mathrm{PC}$ versus EOS $7 \mathrm{PC}$.

Figura C.85 Velocidade superficial de gás - Cenário 3 - EOS 24 PC versus EOS 7 PC.

Figura C.86 Gradiente de pressão por fricção - Cenário 3 - EOS 24 $\mathrm{PC}$ versus EOS 7 PC.

Figura C.87 Gradiente de pressão gravitacional - Cenário 3 - EOS 24 $\mathrm{PC}$ versus EOS $7 \mathrm{PC}$.

Figura C.88 Gradiente de pressão total - Cenário 3 - EOS 24 PC versus EOS 7 PC.

Figura C.89 Coeficiente global de transferência de calor - Cenário 3 - EOS 24 PC versus EOS 7 PC.

Figura C.90 Coeficiente Joule-Thomson - Cenário 3 - EOS 24 PC versus EOS $7 \mathrm{PC}$.

Figura C.91 Perfil de pressão no poço e duto - Cenário 1 - EOS 24 $\mathrm{PC}$ versus EOS 6 PC. 
Figura C.92 Perfil de temperatura no poço e duto - Cenário 1 - EOS $24 \mathrm{PC}$ versus EOS 6 PC.

Figura C.93 Holdup no poço e duto - Cenário 1 - EOS 24 PC versus EOS 6 PC.

Figura C.94 Velocidade superficial de líquido - Cenário 1 - EOS 24 $\mathrm{PC}$ versus EOS $6 \mathrm{PC}$.

Figura C.95 Velocidade superficial de gás - Cenário 1 - EOS 24 PC versus EOS 6 PC.

Figura C.96 Gradiente de pressão por fricção - Cenário 1 - EOS 24 $\mathrm{PC}$ versus EOS $6 \mathrm{PC}$.

Figura C.97 Gradiente de pressão gravitacional - Cenário 1 - EOS 24 $\mathrm{PC}$ versus EOS $6 \mathrm{PC}$.

Figura C.98 Gradiente de pressão total - Cenário 1 - EOS 24 PC versus EOS 6 PC.

Figura C.99 Coeficiente global de transferência de calor - Cenário 1 - EOS 24 PC versus EOS 6 PC.

Figura C.100Coeficiente Joule-Thomson - Cenário 1 - EOS 24 PC versus EOS 6 PC.

Figura C.101Perfil de pressão no poço e duto - Cenário 2 - EOS 24 $\mathrm{PC}$ versus EOS 6 PC.

Figura C.102Perfil de temperatura no poço e duto - Cenário 2 - EOS $24 \mathrm{PC}$ versus EOS 6 PC.

Figura C.103Holdup no poço e duto - Cenário 2 - EOS 24 PC versus EOS 6 PC.

Figura C.104Velocidade superficial de líquido - Cenário 2 - EOS 24 $\mathrm{PC}$ versus EOS $6 \mathrm{PC}$.

Figura C.105Velocidade superficial de gás - Cenário 2 - EOS 24 PC versus EOS 6 PC.

Figura C.106Gradiente de pressão por fricção - Cenário 2 - EOS 24 $\mathrm{PC}$ versus EOS $6 \mathrm{PC}$.

Figura C.107Gradiente de pressão gravitacional - Cenário 2 - EOS 24 $\mathrm{PC}$ versus EOS $6 \mathrm{PC}$.

Figura C.108Gradiente de pressão total - Cenário 2 - EOS 24 PC versus EOS 6 PC.

Figura C.109Coeficiente global de transferência de calor - Cenário 2 - EOS 24 PC versus EOS 6 PC.

Figura C.110Coeficiente Joule-Thomson - Cenário 2 - EOS 24 PC versus EOS 6 PC.

Figura C.111Perfil de pressão no poço e duto - Cenário 3 - EOS 24 $\mathrm{PC}$ versus EOS $6 \mathrm{PC}$.

Figura C.112Perfil de temperatura no poço e duto - Cenário 3 - EOS $24 \mathrm{PC}$ versus EOS 6 PC.

Figura C.113Holdup no poço e duto - Cenário 3 - EOS 24 PC versus EOS 6 PC.

Figura C.114Velocidade superficial de líquido - Cenário 3 - EOS 24 $\mathrm{PC}$ versus EOS 6 PC.

Figura C.115Velocidade superficial de gás - Cenário 3 - EOS 24 PC versus EOS 6 PC. 
Figura C.116Gradiente de pressão por fricção - Cenário 3 - EOS 24 $\mathrm{PC}$ versus EOS 6 PC.

Figura C.117Gradiente de pressão gravitacional - Cenário 3 - EOS 24 $\mathrm{PC}$ versus EOS $6 \mathrm{PC}$.

Figura C.118Gradiente de pressão total - Cenário 3 - EOS 24 PC versus EOS 6 PC.

Figura C.119Coeficiente global de transferência de calor - Cenário 3 - EOS 24 PC versus EOS 6 PC.

Figura C.120Coeficiente Joule-Thomson - Cenário 3 - EOS 24 PC versus EOS 6 PC.

Figura C.121Perfil de pressão no poço e duto - Cenário 1 - EOS 24 $\mathrm{PC}$ versus EOS $5 \mathrm{PC}$.

Figura C.122Perfil de temperatura no poço e duto - Cenário 1 - EOS $24 \mathrm{PC}$ versus EOS 5 PC.

Figura C.123Holdup no poço e duto - Cenário 1 - EOS 24 PC versus EOS 5 PC.

Figura C.124Velocidade superficial de líquido - Cenário 1 - EOS 24 $\mathrm{PC}$ versus EOS 5 PC.

Figura C.125Velocidade superficial de gás - Cenário 1 - EOS 24 PC versus EOS 5 PC.

Figura C.126Gradiente de pressão por fricção - Cenário 1 - EOS 24 $\mathrm{PC}$ versus EOS $5 \mathrm{PC}$.

Figura C.127Gradiente de pressão gravitacional - Cenário 1 - EOS 24 $\mathrm{PC}$ versus EOS 5 PC.

Figura C.128Gradiente de pressão total - Cenário 1 - EOS 24 PC versus EOS 5 PC.

Figura C.129Coeficiente global de transferência de calor - Cenário 1 - EOS 24 PC versus EOS 5 PC.

Figura C.130Coeficiente Joule-Thomson - Cenário 1 - EOS 24 PC versus EOS 5 PC.

Figura C.131Perfil de pressão no poço e duto - Cenário 2 - EOS 24 $\mathrm{PC}$ versus EOS $5 \mathrm{PC}$.

Figura C.132Perfil de temperatura no poço e duto - Cenário 2 - EOS $24 \mathrm{PC}$ versus EOS 5 PC.

Figura C.133Holdup no poço e duto - Cenário 2 - EOS 24 PC versus EOS 5 PC.

Figura C.134Velocidade superficial de líquido - Cenário 2 - EOS 24 $\mathrm{PC}$ versus EOS 5 PC.

Figura C.135Velocidade superficial de gás - Cenário 2 - EOS 24 PC versus EOS 5 PC.

Figura C.136Gradiente de pressão por fricção - Cenário 2 - EOS 24 $\mathrm{PC}$ versus EOS 5 PC.

Figura C.137Gradiente de pressão gravitacional - Cenário 2 - EOS 24 $\mathrm{PC}$ versus EOS 5 PC.

Figura C.138Gradiente de pressão total - Cenário 2 - EOS 24 PC versus EOS 5 PC.

Figura C.139Coeficiente global de transferência de calor - Cenário 2 - EOS 24 PC versus EOS 5 PC. 
Figura C.140Coeficiente Joule-Thomson - Cenário 2 - EOS 24 PC versus EOS 5 PC.

Figura C.141Perfil de pressão no poço e duto - Cenário 3 - EOS 24 $\mathrm{PC}$ versus EOS $5 \mathrm{PC}$.

Figura C.142Perfil de temperatura no poço e duto - Cenário 3 - EOS $24 \mathrm{PC}$ versus EOS 5 PC.

Figura C.143Holdup no poço e duto - Cenário 3 - EOS 24 PC versus EOS 5 PC.

Figura C.144Velocidade superficial de líquido - Cenário 3 - EOS 24 $\mathrm{PC}$ versus EOS 5 PC.

Figura C.145Velocidade superficial de gás - Cenário 3 - EOS 24 PC versus EOS 5 PC.

Figura C.146Gradiente de pressão por fricção - Cenário 3 - EOS 24 $\mathrm{PC}$ versus EOS 5 PC.

Figura C.147Gradiente de pressão gravitacional - Cenário 3 - EOS 24 $\mathrm{PC}$ versus EOS 5 PC.

Figura C.148Gradiente de pressão total - Cenário 3 - EOS 24 PC versus EOS 5 PC.

Figura C.149Coeficiente global de transferência de calor - Cenário 3 - EOS 24 PC versus EOS 5 PC.

Figura C.150Coeficiente Joule-Thomson - Cenário 3 - EOS 24 PC versus EOS 5 PC.

Figura C.151Perfil de pressão no poço e duto - Cenário 1 - EOS 24 $\mathrm{PC}$ versus EOS $4 \mathrm{PC}$.

Figura C.152Perfil de temperatura no poço e duto - Cenário 1 - EOS $24 \mathrm{PC}$ versus EOS 4 PC.

Figura C.153Holdup no poço e duto - Cenário 1 - EOS 24 PC versus EOS 4 PC.

Figura C.154Velocidade superficial de líquido - Cenário 1 - EOS 24 $\mathrm{PC}$ versus EOS $4 \mathrm{PC}$.

Figura C.155Velocidade superficial de gás - Cenário 1 - EOS 24 PC versus EOS 4 PC.

Figura C.156Gradiente de pressão por fricção - Cenário 1 - EOS 24 $\mathrm{PC}$ versus EOS $4 \mathrm{PC}$.

Figura C.157Gradiente de pressão gravitacional - Cenário 1 - EOS 24 $\mathrm{PC}$ versus EOS 4 PC.

Figura C.158Gradiente de pressão total - Cenário 1 - EOS 24 PC versus EOS 4 PC.

Figura C.159Coeficiente global de transferência de calor - Cenário 1 - EOS 24 PC versus EOS 4 PC.

Figura C.160Coeficiente Joule-Thomson - Cenário 1 - EOS 24 PC versus EOS 4 PC.

Figura C.161Perfil de pressão no poço e duto - Cenário 2 - EOS 24 $\mathrm{PC}$ versus EOS $4 \mathrm{PC}$.

Figura C.162Perfil de temperatura no poço e duto - Cenário 2 - EOS $24 \mathrm{PC}$ versus EOS 4 PC.

Figura C.163Holdup no poço e duto - Cenário 2 - EOS 24 PC versus EOS 4 PC. 
Figura C.164Velocidade superficial de líquido - Cenário 2 - EOS 24 $\mathrm{PC}$ versus EOS $4 \mathrm{PC}$.

Figura C.165Velocidade superficial de gás - Cenário 2 - EOS 24 PC versus EOS 4 PC.

Figura C.166Gradiente de pressão por fricção - Cenário 2 - EOS 24 $\mathrm{PC}$ versus EOS $4 \mathrm{PC}$.

Figura C.167Gradiente de pressão gravitacional - Cenário 2 - EOS 24 $\mathrm{PC}$ versus EOS $4 \mathrm{PC}$.

Figura C.168Gradiente de pressão total - Cenário 2 - EOS 24 PC versus EOS 4 PC.

Figura C.169Coeficiente global de transferência de calor - Cenário 2 - EOS 24 PC versus EOS 4 PC.

Figura C.170Coeficiente Joule-Thomson - Cenário 2 - EOS 24 PC versus EOS 4 PC.

Figura C.171Perfil de pressão no poço e duto - Cenário 3 - EOS 24 $\mathrm{PC}$ versus EOS $4 \mathrm{PC}$.

Figura C.172Perfil de temperatura no poço e duto - Cenário 3 - EOS $24 \mathrm{PC}$ versus EOS 4 PC.

Figura C.173Holdup no poço e duto - Cenário 3 - EOS 24 PC versus EOS 4 PC.

Figura C.174Velocidade superficial de líquido - Cenário 3 - EOS 24 $\mathrm{PC}$ versus EOS $4 \mathrm{PC}$.

Figura C.175Velocidade superficial de gás - Cenário 3 - EOS 24 PC versus EOS 4 PC.

Figura C.176Gradiente de pressão por fricção - Cenário 3 - EOS 24 $\mathrm{PC}$ versus EOS $4 \mathrm{PC}$.

Figura C.177Gradiente de pressão gravitacional - Cenário 3 - EOS 24 $\mathrm{PC}$ versus EOS $4 \mathrm{PC}$.

Figura C.178Gradiente de pressão total - Cenário 3 - EOS 24 PC versus EOS 4 PC.

Figura C.179Coeficiente global de transferência de calor - Cenário 3 - EOS 24 PC versus EOS 4 PC.

Figura C.180Coeficiente Joule-Thomson - Cenário 3 - EOS 24 PC versus EOS 4 PC. 


\section{Lista de tabelas}

Tabela 2.1 Propriedades físicas de componentes comuns de reservatórios de petróleo - Adaptado de Pedersen et al. (2006)

Tabela 2.2 Composição da mistura de gás natural - Adaptado de Pedersen et al. (2006)

Tabela 2.3 Composição da mistura de gás condensado - Adaptado de Pedersen et al. (2006)

Tabela 2.4 Composição da mistura próxima ao ponto crítico - Adaptado de Pedersen et al. (2006)

Tabela 2.5 Composição da mistura black-oil - Adaptado de Pedersen et al. (2006)

Tabela 2.6 Relação pressão-volume de um ensaio de expansão a composição constante — Adaptado de Danesh (1998)

Tabela 2.7 Resultados de um ensaio de liberação diferencial - Adaptado de Pedersen et al. (2006)

Tabela 2.8 Parâmetros na correlação de viscosidade de óleo e gás de LBC - Adaptado de Pedersen et al. (2006)

Tabela 2.9 Valores de Parachor de componentes puros - Adaptado de Danesh (1998)

Tabela 4.1 Propriedades e composições molares da liberação flash experimental a $40,0{ }^{\circ} \mathrm{C}$.

Tabela 4.2 Propriedades da fase óleo na liberação diferencial experimental a $122,0{ }^{\circ} \mathrm{C}$.

Tabela 4.3 Propriedades da fase gás na liberação diferencial experimental a $122,0^{\circ} \mathrm{C}$.

Tabela 4.4 Teste de separador experimental.

Tabela 4.5 Ensaio de expansão a volume constante a $122,0{ }^{\circ} \mathrm{C}$

Tabela 4.6 Relação pressão-volume de um ensaio de expansão a composição constante a $30,0{ }^{\circ} \mathrm{C}$

Tabela 4.7 Relação pressão-volume de um ensaio de expansão a composição constante à $75,0{ }^{\circ} \mathrm{C}$

Tabela 4.8 Relação pressão-volume de um ensaio de expansão a composição constante à $122,0{ }^{\circ} \mathrm{C}$

Tabela 4.9 Viscosidades e massas específicas do óleo residual da liberação diferencial.

Tabela 4.10 Pesos globais usados na regressão das EOS.

Tabela 4.11 Coeficientes da correlação LBC após regressão das EOS. 107

Tabela $4.12 R_{s}$ e pressões de saturação após regressão das EOS 108

Tabela 4.13 EOS - 24 PC 111

$\begin{array}{ll}\text { Tabela } 4.14 \text { EOS - 14 PC } & 119\end{array}$

$\begin{array}{ll}\text { Tabela } 4.15 \text { EOS - 9 PC } & 119\end{array}$

Tabela 4.16 EOS - 7 PC 120

Tabela 4.17 EOS - 6 PC 120

$\begin{array}{lr}\text { Tabela } 4.18 \text { EOS - 5 PC } & 120\end{array}$

$\begin{array}{ll}\text { Tabela } 4.19 \text { EOS - } 4 \text { PC } & 121\end{array}$ 
Tabela 5.1 Produção de óleo acumulada EOS detalhada vs EOS pseudoizadas.

Tabela 5.2 Raiz do erro quadrático médio normalizado (\%) - Variáveis de reservatório

Tabela 5.3 Dados de produção - Cenário $1 \quad 146$

Tabela 5.4 Dados de produção - Cenário 2 147

Tabela 5.5 Dados de produção - Cenário $3 \quad 147$

Tabela 5.6 Raiz do erro quadrático médio normalizado (\%) - Variáveis de escoamento - Cenário 1

Tabela 5.7 Raiz do erro quadrático médio normalizado (\%) - Variáveis de escoamento - Cenário $2 \quad 148$

Tabela 5.8 Raiz do erro quadrático médio normalizado (\%) - Variáveis de escoamento - Cenário $3 \quad 149$

Tabela 5.9 Tempo de simulação. 150 


\section{Lista de Abreviaturas}

Siglas e abreviações

EUA - Estados Unidos da América

VPL - Valor presente líquido

MIP - Modelo integrado de produção

IPM - Integrated Production Model

UEP - Unidade estacionária de produção

PVT - Pressão Volume e Temperatura

EOS - Equação de estado (equation of state)

PC - Ponto crítico

RGO - Razão gás óleo

SARA - Saturados, aromáticos, resinas e asfaltenos

BMS - Bombeio multifásico submarino

SSGL - Separação submarina gás-líquido

IPR - Inflow production relationship

TPR - Tubing production relationship

PC - Pseudo-componentes

ANM - Árvode de natal molhada

PLET - Pipeline end termination

SDU - Subsea distribuition umbilical

UEH - Umbilical eletro hidráulico

STU - Steel tube umbilical

ESDV - Emergency shutdown valve

ILT - Inline termination

ECC - Expansão a composição constante

EVC - Expansão a volume constante

COP - Coluna de produção

CRF - Conexão riser-flow

TDP - Touchdown point

NRMSD - (Normalized root-mean-square deviation) 


\section{Letras Latinas}

$\boldsymbol{M}$ - Peso molecular

$\boldsymbol{T}$ - Temperatura

$\boldsymbol{p}$ - Pressão

$\boldsymbol{v}, \boldsymbol{V}$ - Volume específico, Volume

$\mathbf{v}$ - velocidade

$\boldsymbol{R}$ - Constante universal dos gases

$\boldsymbol{Z}$ - Fator de compressibilidade

$\mathbf{p}_{\mathbf{R}}$ - Pressão reduzida: $p / p_{c}$

$\mathbf{T}_{\mathbf{R}}$ - Temperatura reduzida: $T / T_{c}$

$\mathbf{B}_{\mathbf{g}}$ - Fator volume de formação do gás

$\mathbf{R}_{\mathbf{s}}$ - Razão de solubilidade do gás no óleo

$\mathbf{B}_{\mathbf{o}}$ - Fator volume de formação do óleo

$\boldsymbol{c}$ - Compressibilidade, Volume shift

$\boldsymbol{e}, \boldsymbol{E}$ - Energia por unidade de massa, Energia

$\boldsymbol{u}, \boldsymbol{U}$ - Energia interna por unidade de massa, Energia interna

$\boldsymbol{s}, \boldsymbol{S}$ - Entropia por unidade de massa, Entropia

$\boldsymbol{g}, \boldsymbol{G}$ - Energia livre de Gibbs por unidade de massa, Energia livre de Gibbs

$\boldsymbol{q}, \boldsymbol{Q}$ - Transferência de calor por unidade de área, transferência de calor

$\boldsymbol{W}$ - Trabalho

$\boldsymbol{f}$ - Fugacidade

$\boldsymbol{z}$ - Fração molar de um componente

$\boldsymbol{n}$ - Número de moles

$k_{i j}$ - Coeficiente de interação binária entre os componentes i e j

$c_{p}$ - Calor específico a pressão constante

$c_{v}$ - Calor específico a volume constante

$\boldsymbol{K}$ - Fator de caracterização de Watson

$\boldsymbol{d}$ - Densidade

$\boldsymbol{F}$ - Força

$\boldsymbol{g}$ - Aceleração da gravidade

$\mathbf{P}_{\sigma}$ - Parâmetro de Parachor

$\mathbf{k}_{\mathbf{r w}}$ - Permeabilidade relativa à água

$\mathbf{k}_{\mathbf{r o}}$ - Permeabilidade relativa ao óleo

$\mathbf{H}_{\mathbf{L}}-$ Holdup de líquido

$\mathbf{H}_{\mathbf{G}}-$ Fração de vazios

Letras Gregas

$\omega$ - Fator acêntrico

$\rho$ - Massa específica

$\delta$ - Variação total de uma propriedade

$\mu$ - Potencial químico

$\theta$ - Número total fases

$\eta$ - Viscosidade dinâmica, Cada fase de um sistema

$\phi$ - Coeficiente de fugacidade

$\mu_{\mathbf{j}}$ - Coeficiente Joule-Thomson

$\tau$ - Tensão de cisalhamento

$\lambda$ - Condutividade térmica

$\sigma-$ Tensão interfacial 


\section{Subscritos}

$\boldsymbol{e}$ - Ebulição

$\boldsymbol{c}$ - Propriedade no ponto crítico

$\boldsymbol{o}$ - fase óleo

$\boldsymbol{b}$ - propriedade no ponto de bolha da mistura

$\boldsymbol{t}$ - soma da propriedade na fase líquida e fase vapor na região de duas fases

$\boldsymbol{p}$ - Potencial

$\boldsymbol{k}$ - Cinética

$\boldsymbol{i}$ - Componente de mistura

$\boldsymbol{x}$ - Coordenada ou direção do eixo x

$\boldsymbol{y}$ - Coordenada ou direção do eixo y

$\boldsymbol{L}$ - Propriedade na fase líquida

$\boldsymbol{V}$ - Propriedade na fase gás

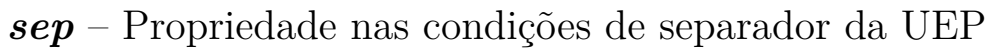

$\boldsymbol{t} \boldsymbol{q}$ - Propriedade nas condições de tanque da UEP

Sobrescritos

- - Barra sobre um símbolo denota uma propriedade em uma base molar 
Everything should be made as simple as possible, but not simpler

Albert Einstein, Albert Einstein quotes. 


\section{Introdução}

\section{1}

\section{Apresentação}

A recente queda nos preços de petróleo experenciada a partir de 2014, atingindo o ápice no início de 2016, quando o barril de petróleo chegou a ser comercializado abaixo de 30 dólares e posterior estabilização da cotação na faixa de 50 a 70 dólares, obrigou a indústria de petróleo a se reinventar e tornar-se mais eficiente, uma vez que o preço praticado de 2011 a 2014, na faixa de 120 dólares, não é mais realidade no setor do óleo e gás. Este movimento em grande parte se deve ao desenvolvimento da indústria de shale oil nos EUA, que expandiu a produção petrolífera dos EUA de 8 milhões de barris por dia (bpd) pra 13 milhões de bpd em apenas 6 anos.

Neste contexto, os novos projetos de desenvolvimento da produção precisaram buscar soluções não usuais para se adequar a nova realidade de preços e se mostrar atrativos economicamente. A constante busca pela melhor estratégia de desenvolvimento, isto é, maximizar o $\mathrm{VPL}^{1}$ sem perder de vista os riscos intrínsecos da indústria de petróleo, tornou-se questão crucial para que novos investimentos na área fossem concretizados.

Desta forma, soluções compartilhadas de sistemas de produção e injeção (visando a redução de custos), tais como manifolds, anéis de coleta, trunklines e soluções de elevação artifcial (visando o aumento de receitas), entre as quais destacam-se bombeio multifásico, separação submarina gás-líquido, gas-lift na base do riser e compressão submarina também estão sendo cada vez mais estudadas no intuito de extrair o máximo valor possível do projeto.

A simulação numérica computacional é o instrumento utilizado para avaliar a melhor maneira de explotar um campo de petróleo. O aumento da complexidade dos projetos citado acima, principalmente do sistema de produção, traz a necessidade de ferramentas computacionais capazes de representar fidedignamente o layout submarino arquitetado para o desenvolvimento do projeto.

\footnotetext{
${ }^{1}$ Um projeto de desenvolvimento da produção pode ter inúmeros direcionadores estratégicos econômicos, por exemplo, minimização da exposição financeira, retorno sobre o capital empregado, taxa interna de retorno, entre outras. O autor usou o VPL como principal direcionador apenas pelo fator do VPL ser a métrica de análise mais popular.
} 
O uso de modelos integrados de produção (MIP), isto é, que simulam não só o escoamento dos fluidos no meio poroso do reservatório, mas também o escoamento nas tubulações dos poços e dutos submarinos até chegar na UEP são cada vez mais comuns, pois através deles é possível ter uma representação mais fiel do escoamento no sistema de produção.

Dentro da ótica do modelos integrados de produção, um problema importante é a modelagem do fluido satisfatória em todo o sistema de produção, desde o reservatório até a UEP. Em modelos desacoplados de produção, as diferentes áreas de estudo fazem a modelagem de propriedades PVT a fim de representar o fluido para sua determinada condição de produção. Por exemplo, o engenheiro que trata do escoamento no meio poroso tem maior preocupação com as propriedades PVT na temperatura do reservatório, enquanto o engenheiro de escoamento nas tubulações deve se preocupar com as propriedades PVT em uma faixa maior de temperatura, já que o fluido sofre resfriamento ao longo do escoamento.

Em MIP, diferentemente dos modelos desacoplados, existe a necessidade de ajuste único para propriedades PVT que satisfaçam tanto o escoamento no meio poroso, isotérmico, e o escoamento nos dutos e tubulações. Além disso, o modelo deve ter tempo de simulação adequado para o desenvolvimento do projeto, ou seja, existe um ponto ótimo entre qualidade do ajuste das propriedades para cada fenômeno versus tempo de simulação.

Uma maneira criteriosa de modelar as propriedades de um fluido é através do ajuste de uma EOS que caracteriza o comportamento termodinâmico do fluido juntamente com os dados experimentais obtidos em laboratório. Uma série de ensaios são conduzidos e os dados obtidos, juntamente com a composição do fluido, são usados em simuladores que realizam a regressão dos dados, isto é, modificam variáveis da EOS que possuem elevada incerteza a fim de representar através da EOS ajustada o comportamento observado nos ensaios laboratoriais. Esta abordagem é conhecida na literatura como caracterização de fluido composicional para as propriedades PVT de uma mistura.

Para reduzir o tempo de simulações numéricas computacionais, um número mínimo de componentes devem ser usados para representar a EOS. Uma EOS detalhada contém cerca de 20 a 30 componentes, enquanto uma simplificada ${ }^{2}$ possui apenas de 4 a 10 . Neste trabalho, é realizado o ajuste de várias EOS para uma mistura de óleo volátil. Cada EOS é usada para prever as propriedades termodinâmicas e reológicas em um MIP onde serão comparadas

${ }^{2} \mathrm{O}$ termo EOS simplificada será usado ao longo do texto para denotar as EOS pseudoizadas, isto é, as EOS obtidas a partir de um processo de agrupamento de componentes. 
variáveis de interesse em relação ao MIP com EOS detalhada. A resposta obtida do campo de pressões e saturações no modelo de escoamento no meio poroso, assim como os perfis de pressão, temperatura, hold-up no sistema de produção, são os pontos-chave para definir até que ponto é válido simplificar a EOS em prol de eficiência computacional sem perder qualidade na simulação.

\section{2 \\ Motivação}

O aumento de complexidade nas soluções para viabilizar grandes projetos está demandando cada vez mais capacidade de processamento e memória computacional, especialmente quando se trata de MIP com simulação numérica composicional, que são geralmente usados para uma análise mais detalhada das interações entre reservatório e sistema de produção.

A simplificação da EOS é a solução usual para diminuir o esforço computacional nesse tipo de simulação. Inúmeros trabalhos podem ser encontrados na literatura abordando este tema, contudo, focados apenas na simplificação da EOS com o intuito de ajustar as propriedades relevantes para o fluxo no meio poroso, caracterizado por ser isotérmico.

Com a recente popularidade de MIP e a necessidade de abordagem composicional para a propriedade dos fluidos, surge a necessidade da EOS ser representativa também para as propriedades relevantes do escoamento nos poços e dutos, não isotérmico, com tempo de simulação viável para os engenheiros tomarem decisões rápidas no decorrer do desenvolvimento dos projetos.

A literatura é rica em estudos para definir a estratégia de simplificação para escoamento em meios porosos, contudo, são escassos os trabalhos na literatura abordando este tema para modelos integrados de produção. Desta forma, a motivação principal deste trabalho é estudar o efeito da simplificação de uma EOS para ser usado em MIP, avaliando não só a qualidade da EOS para uso em simulação de escoamento em meio poroso, mas também para o escoamento nas tubulações dos poços e dutos, com o menor tempo de simulação possível.

\section{3}

\section{Objetivos}

O objetivo deste trabalho é avaliar o número ideal de componentes para ajustar uma EOS capaz de representar o escoamento no meio poroso e nas tubulações dos poços e dutos em um MIP, com o menor tempo de simulação possível. A avaliação será feita para um fluido de reservatório categorizado 
na literatura como óleo volátil, adequado para modelagem composicional do fluido. As principais etapas do trabalho são:

(i) Ajuste da EOS detalhada da amostra de petróleo;

(ii) Elaborar metodologia de simplificação da EOS;

(iii) Construir MIP para simular a produção com cada EOS;

(iv) Comparar respostas para variáveis de interesse das EOS simplificadas com a EOS detalhada;

(v) Definir a EOS simplificada ótima.

\section{4}

\section{Estrutura da dissertação}

Este trabalho está estruturado em cinco capítulos. No Capítulo 1 apresenta-se o tema proposto, assim como as motivações e objetivos do trabalho.

No Capítulo 2 é apresentada a fundamentação teórica necessária para entendimento da dissertação. Serão abordados temas como: tipos de fluidos encontrados em reservatórios, análises laboratoriais comuns para determinação de propriedades de fluido e modelagem e regressão de EOS.

No Capítulo 3 é feita uma breve descrição de MIP com foco nas ferramentas de simulação numérica disponíveis, abordando o modelo de escoamento no meio poroso e nas tubulações dos poços e dutos, assim como as formas de acoplamento dos modelos. As referências encontradas sobre o tema foram acrescentadas neste capítulo.

O Capítulo 4 descreve a metodologia geral aplicada para a obtenção dos resultados da representatividade do modelo de fluido em todo o sistema de produção, desde o escoamento no meio poroso até a UEP. Também é feita uma descrição do MIP usado para a geração dos resultados. Destaca-se aqui a modelagem do escoamento no meio poroso, nas tubulações e o acoplamento entre os modelos. Além disso, descrevem-se as ferramentas de modelagem integrada de produção utilizadas no trabalho.

No Capítulo 5 são apresentados os resultados das simulações para o fluido estudado assim como sugestões para modelagem de EOS em MIP para óleos voláteis.

Finalmente no Capítulo 6 são destacadas as conclusões do autor a respeito do tema e são feitas algumas sugestões de trabalhos futuros. 


\section{2}

\section{Fundamentação Teórica}

\section{1}

Caracterização do comportamento de fases de uma mistura de hidrocarbonetos com equação de estado e análises PVT

\subsection{1}

\section{Fluidos encontrados em reservatórios de petróleo}

De acordo com Danesh (1998), fluidos encontrados em reservatórios de petróleo são constituídos principalmente de hidrocarbonetos. O comportamento das fases no reservatório e ao longo do sistema de produção é determinado por sua composição, pressão e temperatura, o qual tem relevada importância no desenvolvimento e gerenciamento de reservatórios, afetando todos os aspectos da exploração e produção de petróleo. Embora em um reservatório existam milhares de componentes, o comportamento da mistura pode ser explicado examinando-se a mistura de multicomponentes puros simples.

\subsubsection{1}

\section{Composição dos fluidos encontrados em reservatórios de petróleo}

Segundo Pedersen et al. (2006), metano $\left(\mathrm{CH}_{4}\right)$ é o mais simples hidrocarboneto existente e também o mais comum em um reservatório de petróleo. Como metano possui apenas um átomo de carbono, ele é frequentemente chamado de $\mathrm{C}_{1}$. Similarmente, o termo $\mathrm{C}_{2}$ é usado para o etano $\left(\mathrm{C}_{2} \mathrm{H}_{6}\right), \mathrm{C}_{3}$ para o propano $\left(\mathrm{C}_{3} \mathrm{H}_{8}\right)$ e assim por diante. $\mathrm{O}$ grupo de hidrocarbonetos com sete ou mais átomos de carbono são chamados de $\mathrm{C}_{7+}$. Da mesma forma, o grupo com vinte ou mais átomos de carbono é comumente chamado de $\mathrm{C}_{20+}$.

Reservatórios de petróleo também podem conter compostos inorgânicos, comumente chamados de impurezas, entre os mais comuns estão o nitrogênio $\left(\mathrm{N}_{2}\right)$, dióxido de carbono $\left(\mathrm{CO}_{2}\right)$ e ácido sulfídrico $\left(\mathrm{H}_{2} \mathrm{~S}\right)$. Além disso, água $\left(\mathrm{H}_{2} \mathrm{O}\right)$ também está presente no reservatório, contudo, devido a sua baixa miscibilidade com hidrocarbonetos, a maior parte da mesma é usualmente encontrada em uma zona separada localizada abaixo da região com óleo e gás. Ainda conforme Pedersen et al. (2006), os componentes mais pesados $\left(\mathrm{C}_{7+}\right)$ pertencem a uma das seguintes classes de componentes: 
(i) Saturados: São componentes compostos por segmentos de hidrocarbonetos do tipo $\mathrm{C}, \mathrm{CH}, \mathrm{CH}_{2}$ e $\mathrm{CH}_{3}$ conectados por ligações covalentes. São divididos em n-parafinas ou iso-parafinas. Nas n-parafinas, as cadeias não têm ramificações enquanto que nas iso-parafinas, existe pelo menos uma ramificação. Naftênicos também fazem parte deste grupo e são constituídos dos mesmos segmentos que as parafinas, entretanto eles diferem devido ao fato de possuir uma ou mais estruturas cíclicas. A Figura 2.1 mostra a estrutura de algumas parafinas (metano, etano e n-hexano) e naftênicos (ciclohexano e metil-ciclopentano).

(ii) Aromáticos: Similar aos naftênicos, também possuem estruturas cíclicas conhecidas como anéis aromáticos, contudo alternam-se ligações simples e duplas entre os carbonos. Benzeno, o aromático mais simples, é mostrado na Figura 2.1. Existem também estruturas com vários anéis aromáticos aglutinados. O Naftaleno é um exemplo deste tipo de componente encontrado em reservatórios de petróleo e sua estrutura pode ser vista na Figura 2.1.

(iii) Resinas e Asfaltenos: Em menor proporção, são encontrados também resinas e asfaltenos, compostos políciclicos, de alto peso molecular, compreendendo átomos de nitrogênio, enxofre e oxigênio.

O percentual de cada componente saturado $(\mathrm{S})$, aromático $(\mathrm{A})$, resinas (R) e asfaltenos (A) é determinado na indústria através da análise conhecida como SARA.

Conforme Pedersen et al. (2006), informações detalhadas de todos os componentes do fluido no reservatório não são normalmente encontradas na indústria do petróleo, uma vez que seria impossível identificar e medir as propriedades de todos os componentes. Para contornar esta dificuldade os hidrocarbonetos que pertencem a mesma classe estrutural são medidos e reportados em grupos. Normalmente os componentes são classificados em componentes definidos, frações individuais com o mesmo número de átomos de carbono e fração plus:

(i) Componentes definidos: tais como $\mathrm{CO}_{2}, \mathrm{~N}_{2}, \mathrm{H}_{2} \mathrm{~S}, \mathrm{C}_{1}, \mathrm{C}_{2}, \mathrm{C}_{3}, i \mathrm{C}_{4}, n \mathrm{C}_{4}$, $i C_{5}, n C_{5}$ e $C_{6}$. ( $C_{6}$ usualmente corresponde a soma de normal $C_{6}$ com os componentes cíclicos e ramificados com 6 átomos de carbono).

(ii) Frações individuais com 7 ou mais carbonos, por exemplo, $C_{9}, C_{14}$ e $C_{17}$, que possuem praticamente apenas componentes com, respectivamente, 9 , 14 e 17 átomos de carbono. Esas frações apresentarão um intervalo para 

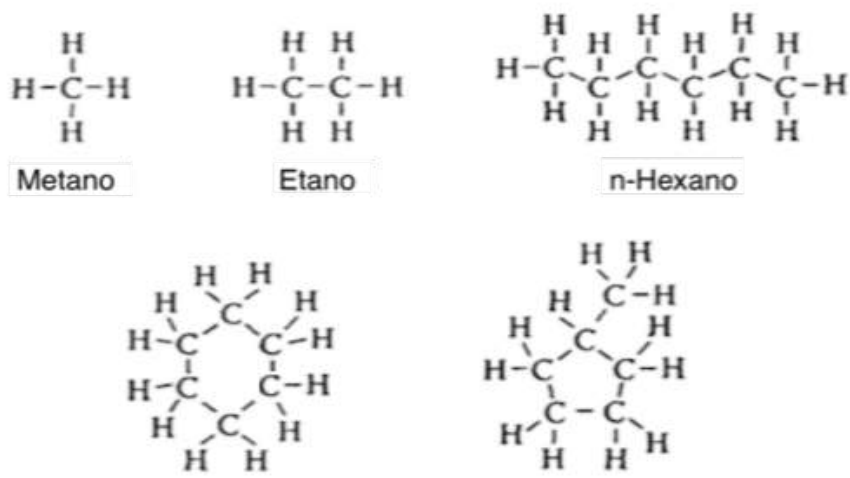

Ciclohexano

Metil-ciclopentano<smiles>c1ccccc1</smiles>

Benzeno

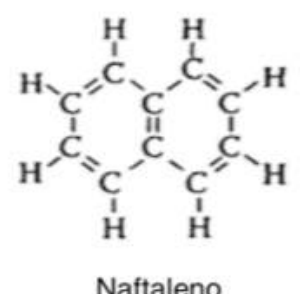

Figura 2.1: Estruturas moleculares de alguns componentes encontrados em reservatórios de petróleo - Adaptado de Pedersen et al. (2006)

as suas propriedades a depender de quais isômeros estão mais presentes na composição.

(iii) Fração plus, a qual constitui-se de componentes que são muito pesados para serem separados em frações individuais. Por exemplo, é comum em análises laboratoriais agrupar os componentes com 20 ou mais carbonos na fração plus $C_{20+}$.

Uma observação importante em relação ao agrupamento em classes estruturais é que a fração molar correspondente a cada grupo não está ligada diretamente ao número de carbonos de cada componente, e sim a temperatura de ebulição de cada composto. Portanto, pode existir, na fração $C_{9}$, componentes que não possuem 9 carbonos na sua cadeia mas que estão na mesma faixa de temperatura de ebulição desta fração.

\subsubsection{2}

\section{Propriedades dos fluidos encontrados nos reservatórios e comportamento das fases}

De acordo com Pedersen et al. (2006), os hidrocarbonetos encontrados nos reservatórios de petróleo possuem uma vasta variação nas propriedades dos seus constituintes. A Tabela 2.1 mostra propriedades físicas de alguns 
componentes puros encontrados naturalmente em misturas de óleo e gás. Podese ver, por exemplo, que a temperatura de ebulição do metano a pressão atmosférica é de $-161,6^{\circ} \mathrm{C}$, enquanto que, a mesma pressão, o benzeno evapora a temperatura de $80,1^{\circ} \mathrm{C}$. Componentes como n-decano e o naftaleno, ambos com 10 átomos de carbono, possuem propriedades químicas diferentes, como pode-se notar na Tabela 2.1. Da mesma forma, n-hexano, metil-ciclo-pentano e o benzeno, todos contendo 6 átomos de carbono, possuem massa específica nas condições de superfície diferentes.

Tabela 2.1: Propriedades físicas de componentes comuns de reservatórios de petróleo - Adaptado de Pedersen et al. (2006)

\begin{tabular}{cccccccc} 
Componente & Fórmula & $\begin{array}{c}M \\
(\mathrm{~g} / \mathbf{m o l})\end{array}$ & $\begin{array}{c}T_{e} \\
\left({ }^{\circ} \mathbf{C}\right)\end{array}$ & $\begin{array}{c}T_{c} \\
\left({ }^{\circ} \mathbf{C}\right)\end{array}$ & $\begin{array}{c}p_{c} \\
(\mathbf{b a r g})\end{array}$ & $\omega$ & $\begin{array}{c}\rho\left(\mathrm{g} / \mathrm{cm}^{3}\right) \\
\mathbf{1} \text { atm, 20 }\end{array}{ }^{\circ} \mathbf{C}$ \\
\hline Nitrogênio & $\mathrm{N}_{2}$ & 28,013 & $-195,8$ & -147 & $-33,9$ & 0,040 & - \\
\hline $\begin{array}{c}\text { Dióxido } \\
\text { de Carbono }\end{array}$ & $\mathrm{CO}_{2}$ & 44,010 & $-78,5$ & 31,1 & 73,8 & 0.225 & - \\
\hline $\begin{array}{c}\text { Sulfeto de } \\
\text { Hidrogênio }\end{array}$ & $\mathrm{H}_{2} \mathrm{~S}$ & 34,080 & $-59,7$ & 100,1 & 89,4 & 0.100 & - \\
\hline Metano & $\mathrm{CH}_{4}$ & 16,043 & $-161,6$ & $-82,6$ & $-46,0$ & 0.008 & - \\
\hline Etano & $\mathrm{C}_{2} \mathrm{H}_{6}$ & 30,070 & $-87,6$ & 32,3 & 48,8 & 0.098 & - \\
\hline Propano & $\mathrm{C}_{3} \mathrm{H}_{8}$ & 44,094 & $-42,1$ & 96,7 & 42,5 & 0,152 & - \\
\hline Iso-Butano & $\mathrm{C}_{4} \mathrm{H}_{10}$ & 58,124 & $-11,8$ & 135,0 & 36,5 & 0,176 & - \\
\hline N-Butano & $\mathrm{C}_{4} \mathrm{H}_{10}$ & 58,124 & $-0,5$ & 152,1 & 38,0 & 0,193 & - \\
\hline Iso-Pentano & $\mathrm{C}_{5} \mathrm{H}_{12}$ & 72,151 & 27,9 & 187,3 & 33,8 & 0,227 & 0,620 \\
\hline N-Pentano & $\mathrm{C}_{5} \mathrm{H}_{12}$ & 72,151 & 36,1 & 196,4 & 33,7 & 0,251 & 0,626 \\
\hline N-Hexano & $\mathrm{C}_{6} \mathrm{H}_{14}$ & 86,178 & 68,8 & 243,3 & 29,7 & 0,296 & 0,659 \\
\hline Iso-Octano & $\mathrm{C}_{8} \mathrm{H}_{18}$ & 114,232 & 117,7 & 286,5 & 24,8 & 0,378 & $0,702\left(16^{\circ} \mathrm{C}\right)$ \\
\hline N-Decano & $\mathrm{C}_{10} \mathrm{H}_{22}$ & 142,286 & 174,2 & 344,6 & 21,2 & 0,489 & 0,730 \\
\hline Ciclopentano & $\mathrm{C}_{5} \mathrm{H}_{10}$ & 70,135 & 49,3 & 238,6 & 45,1 & 0,196 & $0,745\left(16^{\circ} \mathrm{C}\right)$ \\
\hline $\begin{array}{c}\text { Metil- } \\
\text { Ciclopentano }\end{array}$ & $\mathrm{C}_{6} \mathrm{H}_{12}$ & 84,162 & 71,9 & 259,6 & 37,8 & 0,231 & $0,754\left(16^{\circ} \mathrm{C}\right)$ \\
\hline Ciclohexano & $\mathrm{C}_{6} \mathrm{H}_{12}$ & 84,162 & 80,7 & 280,4 & 40,7 & 0,212 & 0,779 \\
\hline Benzeno & $\mathrm{C}_{6} \mathrm{H}_{6}$ & 78,114 & 80,1 & 289,0 & 48,9 & 0,212 & $0,885\left(16^{\circ} \mathrm{C}\right)$ \\
\hline Tolueno & $\mathrm{C}_{7} \mathrm{H}_{8}$ & 92,141 & 110,7 & 318,7 & 41,0 & 0,263 & 0,867 \\
\hline Orto-Xileno & $\mathrm{C}_{8} \mathrm{H}_{10}$ & 106,168 & 144,5 & 357,2 & 37,3 & 0,310 & 0,880 \\
\hline Naftaleno & $\mathrm{C}_{10} \mathrm{H}_{8}$ & 128,174 & 218,0 & 475,3 & 40,5 & 0,302 & $0,971\left(90^{\circ} \mathrm{C}\right)$ \\
\hline & & & & & & & \\
\hline
\end{tabular}

Segundo Pedersen et al. (2006), as pressões de vapor e o ponto crítico dos componentes puros também são fundamentais para entender o comportamento das fases de misturas dos componentes encontrados em reservatórios 
de petróleo. A curva de pressão de vapor é determinada medindo-se os valores de temperatura e pressão nas quais uma substância passa do estado líquido para o gasoso. A curva de pressão de vapor termina no ponto crítico, acima do qual não é possível determinar uma transição entre estado líquido e gasoso. O fluido nesta região é chamado de super crítico. A Figura 2.2 mostra as curvas de pressão de vapor e os pontos críticos do metano e benzeno, assim como um diagrama de fases da mistura destes dois componentes, na proporção molar de $25 \%$ de metano e $75 \%$ de benzeno.

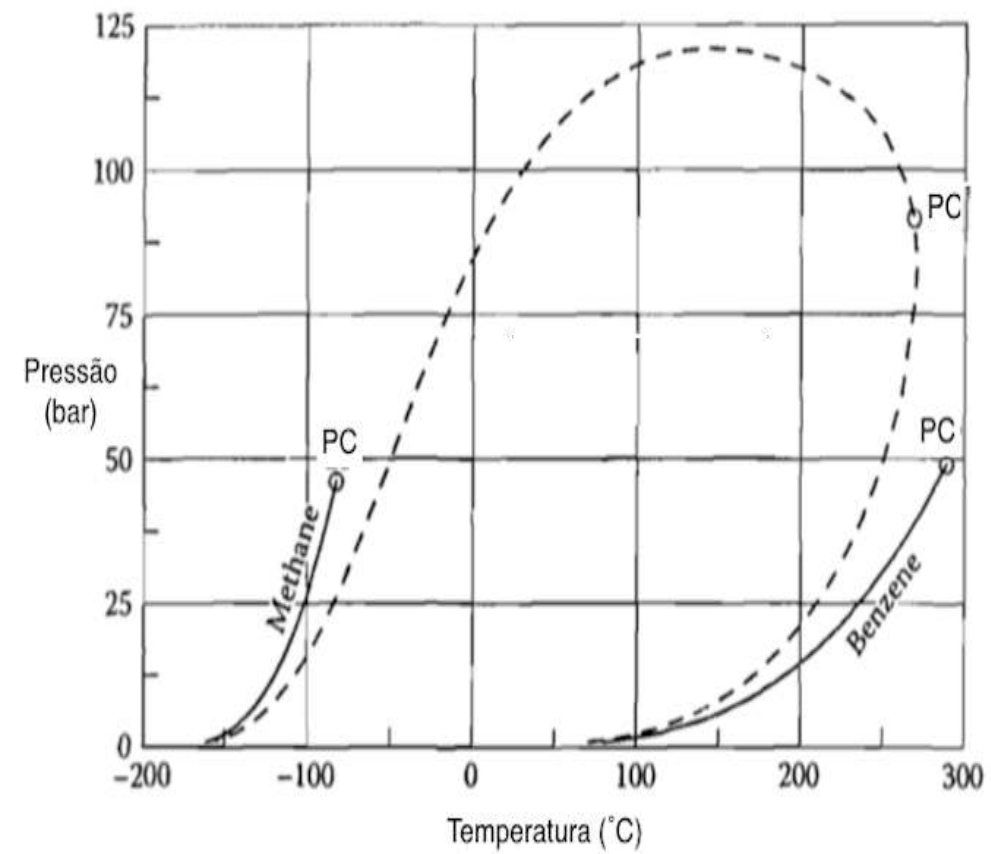

Figura 2.2: Curva de pressão de vapor do metano e benzeno e envelope de fases da mistura de $25 \%$ de mols de metano e $75 \%$ mols de benzeno - Adaptado de Pedersen et al. (2006)

De acordo com Danesh (1998), fluidos no estado gasoso também estão presentes em reservatórios de petróleo. Sabe-se que eles podem ser tratados como gases ideais apenas quando a pressão está proxima de zero. A relação pressão-volume para um gás ideal é,

$$
p \bar{v}=\bar{R} T
$$

onde $\bar{v}$ é o volume específico molar, $p$ é a pressão absoluta, $T$ é a temperatura absouta e $\bar{R}$ é a constante universal dos gases, que é assim chamada uma vez que todos os gases, quando levados à pressão atmosférica, a temperatura 
constante, tendem a apresentar o mesmo valor limite, isto é:

$$
\lim _{p \rightarrow 0} \frac{p \bar{v}}{T}=\bar{R}
$$

De acordo com Moran et al., devido às forças intermoleculares, gases não se comportam de forma ideal em pressões elevadas. Para quantificar a nãoidealidade dos gases é usado um fator de compressibilidade $(Z)$ na relação pressão-volume, logo,

$$
p \bar{v}=Z \bar{R} T
$$

Como $\bar{v}=M v$, onde $M$ é o peso molecular, o fator de compressibilidade pode ser expresso como:

$$
Z=\frac{p v}{R T}
$$

onde

$$
R=\frac{\bar{R}}{M}
$$

O fator de compressibilidade tende para a unidade quando a pressão tende para zero, a uma temperatura fixa. Este comportamento pode ser visto na Figura 2.3, a qual mostra o fator de compressibilidade do hidrogênio em função da pressão para alguns valores de temperatura. Pode-se notar também a não idealidade do hidrogênio para altas pressões.

Ainda de acordo com Moran et al., ao se avaliar o fator de compressibilidade em função da pressão e temperatura para outros gases, chega-se a conclusão que o comportamento é qualitativamente similar. Quando as coordenadas dos eixos são cuidadosamente modificadas, nota-se também que as curvas para vários diferentes gases coincidem, e inclusive similaridade quantitativa pode ser obitda. Isto é referenciado na literatura como princípio dos estados correspondentes. Nesta abordagem, o fator de compressibilidade $Z$ é plotado versus uma pressão reduzida $p_{R}$ e uma temperatura reduzida $T_{R}$, definidos como:

$$
\begin{gathered}
p_{R}=p / p_{c} \\
T_{R}=T / T_{c}
\end{gathered}
$$

onde $p_{c}$ e $T_{c}$ são a pressão e temperatura críticas, respectivamente.

Segundo Danesh (1998), o princípio dos estados correspondentes é um conceito muito importante, uma vez que ele estabelece que substâncias diferentes se comportam de forma similar quando estão relativamente a mesma distância de seus pontos críticos. Isto implica que todas as substâncias se comportam de forma parecida nos seus pontos críticos, logo, devem ter o mesmo 


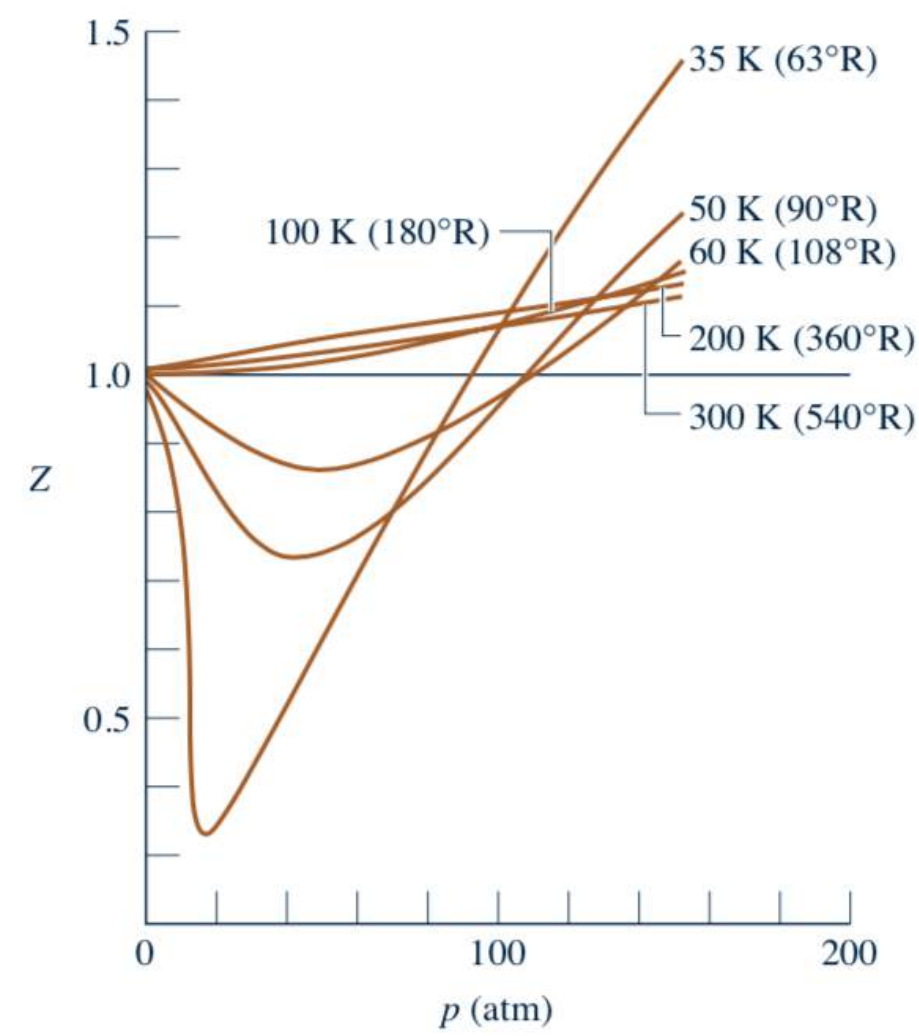

Figura 2.3: Variação do fator de compressibilidade do hidrogênio em função da pressão a temperatura constate. — Extraído de Moran et al. (2011)

fator de compressibilidade crítico, $Z_{c}$,

$$
Z_{c}=\frac{p_{c} v_{c}}{R T_{c}}
$$

Ainda conforme Danesh (1998), se o princípio dos estados correspondentes fosse exato, as curvas de pressão de vapor de todos os componentes, plotados na forma reduzida, teriam a mesma inclinação sobre a mesma linha. Na prática, isto não ocorre. O desvio se dá devido a diferenças nas estruturas moleculares dos vários componentes, resultando em diferentes forças intermoleculares. A inclusão de um terceiro parâmetro, adicional à pressão e temperatura reduzida, é o procedimento aceito para resolver o problema de equilíbrio de fases de componentes. Este parâmetro é conhecido como fator acêntrico, $\omega$.

Segundo Pedersen et al. (2006), outra forma de entender esta propriedade é pensar nela como uma medida da curvatura da curva de pressão de vapor de um componente puro. A Figura 2.4 mostra a curva de pressão de vapor de 3 substâncias, todas com o mesmo ponto crítico e com diferentes fatores acêntricos. Com o ponto crítico fixo, a curvatura das linhas de pressão de vapor são determinadas pelos fatores acêntricos. 


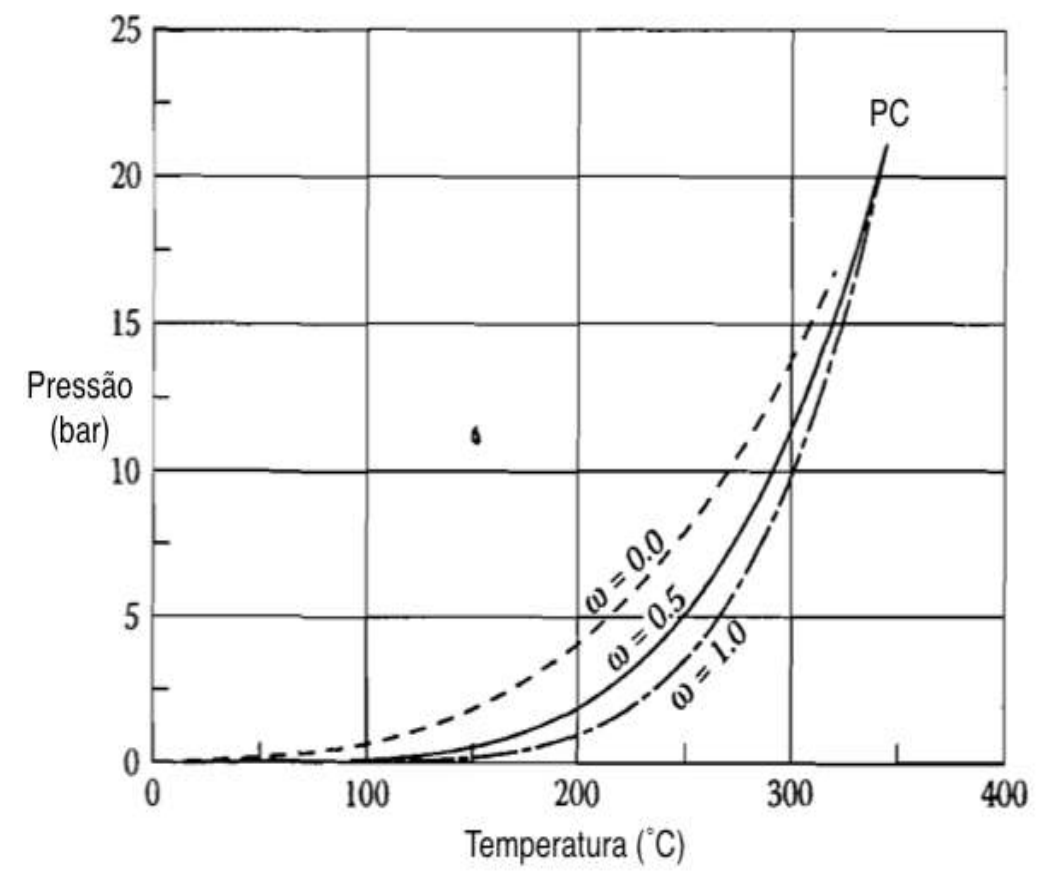

Figura 2.4: Curva de pressão de um componente com o mesmo PC e fatores acêntricos 0,0; 0,5 e 1,0 — Adaptado de Pedersen et al. (2006)

De acordo com Pedersen et al. (2006) e Ahmed (2007), fluidos de reservatórios de petróleo são misturas multicomponentes. Com dois ou mais componentes presentes, a região de duas fases não é mais restrita a uma linha no diagrama de pressão-temperatura. Na Figura 2.2 pode ser visto que a mistura de $25 \%$ molar de metano e $75 \%$ molar de benzeno forma uma área fechada com uma região de duas fases. A linha envolvendo esta área é chamada de envelope de fases.

Uma importante característica destes sistemas é a variação das propriedades termodinâmicas e físicas com a composição da mistura. Sendo assim, é necessário saber a composição da mistura em termos de frações molares ou frações mássicas de antemão para determinar suas propriedades.

A Figura 2.5 mostra um envelope de fase típico de uma mistura multicomponente encontrada em reservatórios de petróleo. Segundo Ahmed (2007), o envelope de fase consiste em uma curva dos ponto de orvalho e uma curva dos pontos de bolha se encontrando no ponto crítico da mistura.

Sobre a curva de ponto de orvalho a mistura é gasosa e está em equilíbrio com uma quantidade incipiente de líquido. Nessa condição o gás é dito saturado. Em temperaturas maiores, na mesma pressão, não há líquido presente. Neste ponto o gás é dito subsaturado.

$\mathrm{Na}$ curva de pontos de bolha a mistura é líquida em equilíbrio com uma 
quantidade incipiente de gás. Nessa condição o líquido é chamado saturado. Em temperaturas menores, sob a mesma pressão, o líquido é dito subsaturado.

Ainda segundo Ahmed (2007), no ponto crítico duas fases idênticas estão em equilíbrio, com a mesma composição. Em temperaturas próximas à temperatura crítica e pressões acima da pressão crítica há apenas uma fase presente, mas é difícil definir se a fase é líquida ou gasosa. O fluido nessa região é comumente chamado de supercrítico.

O interior do envelope é conhecido como a região de duas fases. Nessa região, encontram-se todas as combinações de temperatura e pressão onde a mistura de hidrocarbonetos pode permanecer com duas fases em equilíbrio. A maior pressão que duas fases ainda coexistem é chamada de crincondebárica e a maior temperatura com duas fases presentes é chamada de cricondotérmica.

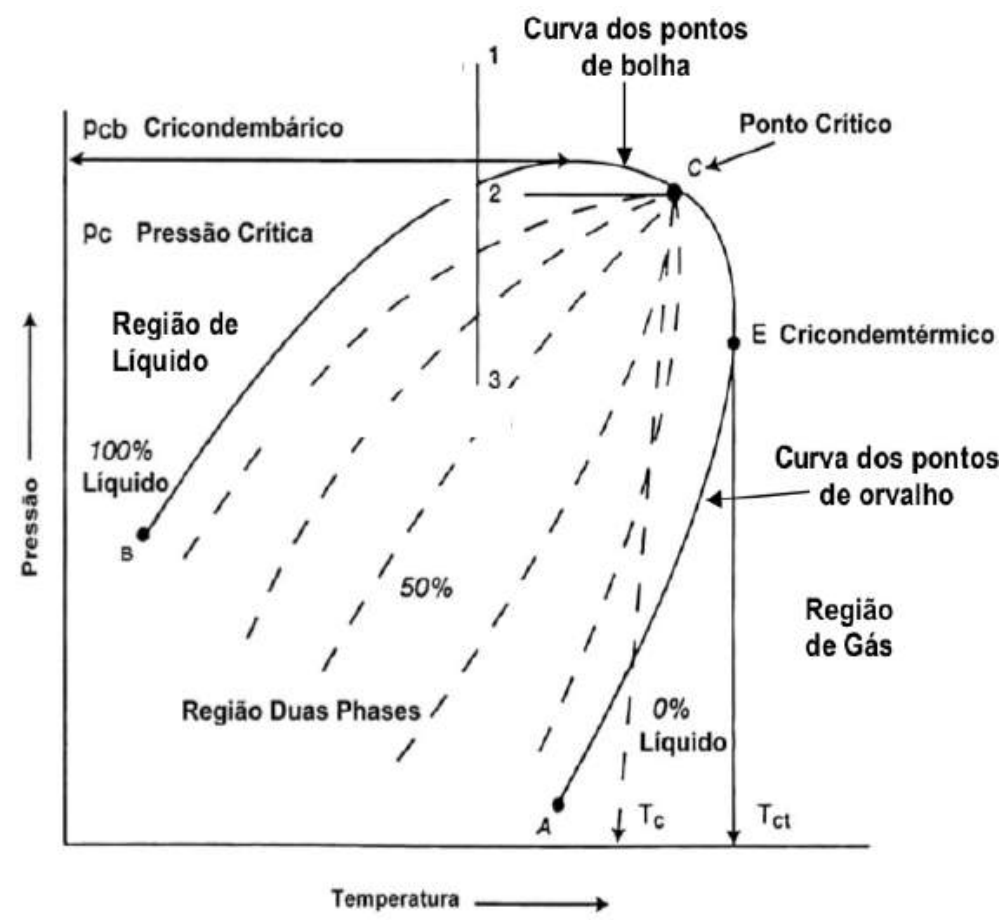

Figura 2.5: Envelope de fase típico de fluidos encontrados em reservatórios de petróleo - Extraído de PUC-Rio (2019)

\subsubsection{3}

\section{Classificação dos fluidos encontrados em reservatórios de petróleo}

Fluidos de reservatório de petróleo podem ser divididos em:

(i) Mistura de gás natural seco

(ii) Mistura de gás natural úmido

(iii) Mistura de gás condensado retrógrado 
(iv) Mistura de óleo volátil

(v) Mistura Black-oil

De acordo com Pedersen et al. (2006), as misturas podem ser identificados comparando-se a temperatura do reservatório com a $T_{c}$ da mistura. Isto é ilustrado na Figura 2.6. Durante a produção de um campo, a temperatura do reservatório permanece praticamente constante enquanto que a pressão decresce devido a retirada de massa do reservatório oriunda da produção. Conforme visto acima, os reservatórios de gás podem ser classificados em três tipos. Para um reservatório de gás natural seco, o decréscimo de pressão não afetará o número de fases, uma vez que o fluido permanecerá no estado gasoso em todas as pressões.

Além disso, segundo Andreolli (2016), durante o escoamento até o separador na UEP o fluido continua somente no estado gasoso. Este tipo de mistura é interessante do ponto de vista de amostragem de fluido, uma vez que a coleta no separador de superfície é representativa do reservatório, já que não há condensação durante o escoamento. Na Figura 2.6 está representado esta mistura pela condição $P_{3}$ e $T_{3}$ até atingir a condição $P_{S}$ e $T_{S}$ através da curva pontilhada $b$.

Quando a mistura de fluido gera condensado no escoamento até o separador de superfíicie a mistura é chamada de gás natural úmido. Neste caso a curva de pressão e temperatura adentra o envelope de fases antes de chegar a superfície. A Figura 2.6 ilustra o escoamento deste tipo de mistura, através da curva pontilhada a, saindo da condição $P_{3}$ e $T_{3}$ até a condição $P_{S}$ e $T_{S}$.

Reservatórios de gás condensado retrógrado possuem a condição inicial de temperatura e pressão localizada entre a $T_{c}$ e a cricondentérmica do envelope de fase. o decréscimo de pressão, em algum estágio, encontrará a curva de ponto de orvalho do envelope de fase e uma fase líquida estará em equilíbrio com o gás ainda no reservatório. Entretanto, essa fase se revaporiza quando a pressão continua a cair e ultrapassa determinado valor. O termo retrógrado é usado pois neste tipo de reservatório ocorre o comportamento inverso ao esperado de um gás, que é de condensar em um processo de pressurização, e não de despressurização. Na Figura 2.6 ilustra esta condição através do ponto $P_{2}$ e $T_{2}$.

Segundo Pedersen et al. (2006), reservatórios de óleo são caracterizados por apresentarem sua condição inicial de temperatura a esquerda da temperatura crítica do envelope de fases. Se o reservatório encontra-se na condição $P_{1}$ 
Tabela 2.2: Composição da mistura de gás natural — Adaptado de Pedersen et al. (2006)

\begin{tabular}{ll} 
Componente & Percentual Molar \\
\hline $\mathrm{N}_{2}$ & 0,340 \\
\hline $\mathrm{CO}_{2}$ & 0,840 \\
\hline $\mathrm{C}_{1}$ & 90,400 \\
\hline $\mathrm{C}_{2}$ & 5,199 \\
\hline $\mathrm{C}_{3}$ & 2,060 \\
\hline $\mathrm{iC}_{4}$ & 0,360 \\
\hline $\mathrm{nC}_{4}$ & 0,550 \\
\hline $\mathrm{iC}_{5}$ & 0,140 \\
\hline $\mathrm{nC}_{5}$ & 0,097 \\
\hline $\mathrm{C}_{6}$ & 0,014 \\
\hline
\end{tabular}

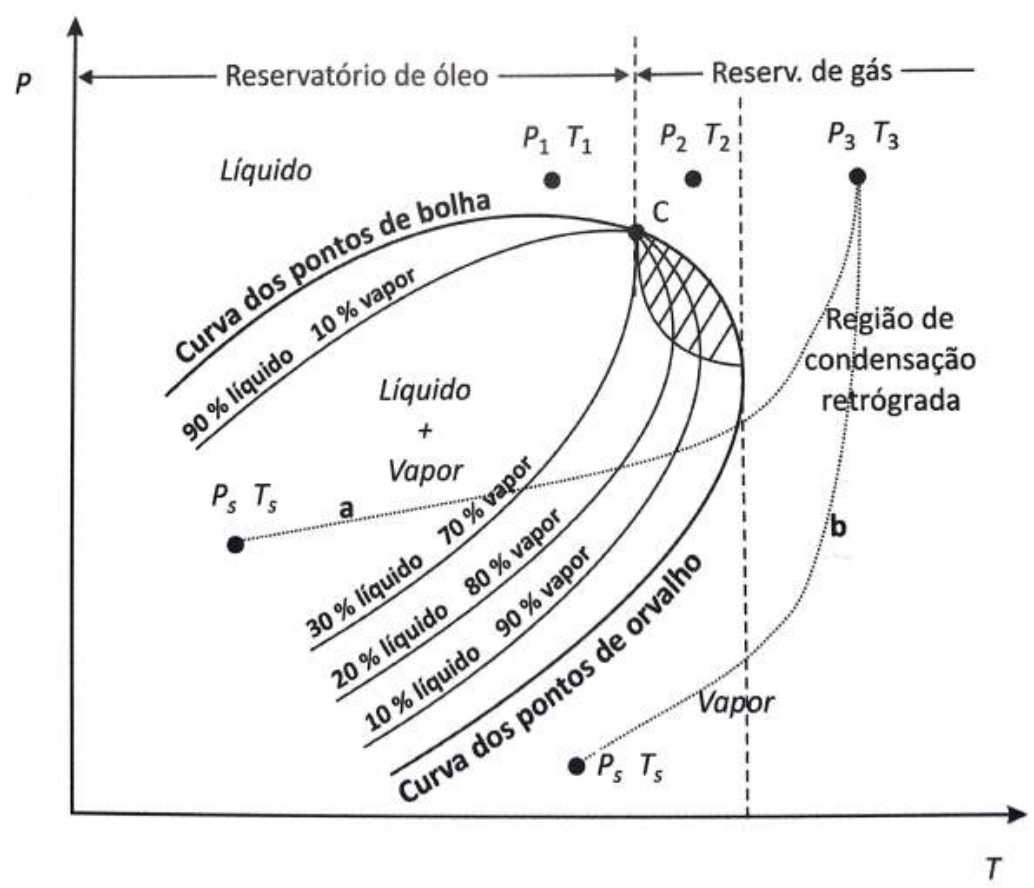

Figura 2.6: Envelope de fases de vários tipos de fluidos de reservatório - Extraído de Andreolli (2016)

e $T_{1}$, como na Figura 2.6, a segunda fase será gasosa, uma vez que ao encontrar o envelope de fase a curva de ponto de bolha é encontrada.

Se a condição $P_{1}$ e $T_{1}$ estiver relativamente próxima ao ponto crítico, o reservatório é de óleo volátil. Se a condição de reservatório for levemente maior, digamos $P_{2}$ e $T_{2}$, na Figura 2.6, a entrada no envelope de fases se dará 
Tabela 2.3: Composição da mistura de gás condensado — Adaptado de Pedersen et al. (2006)

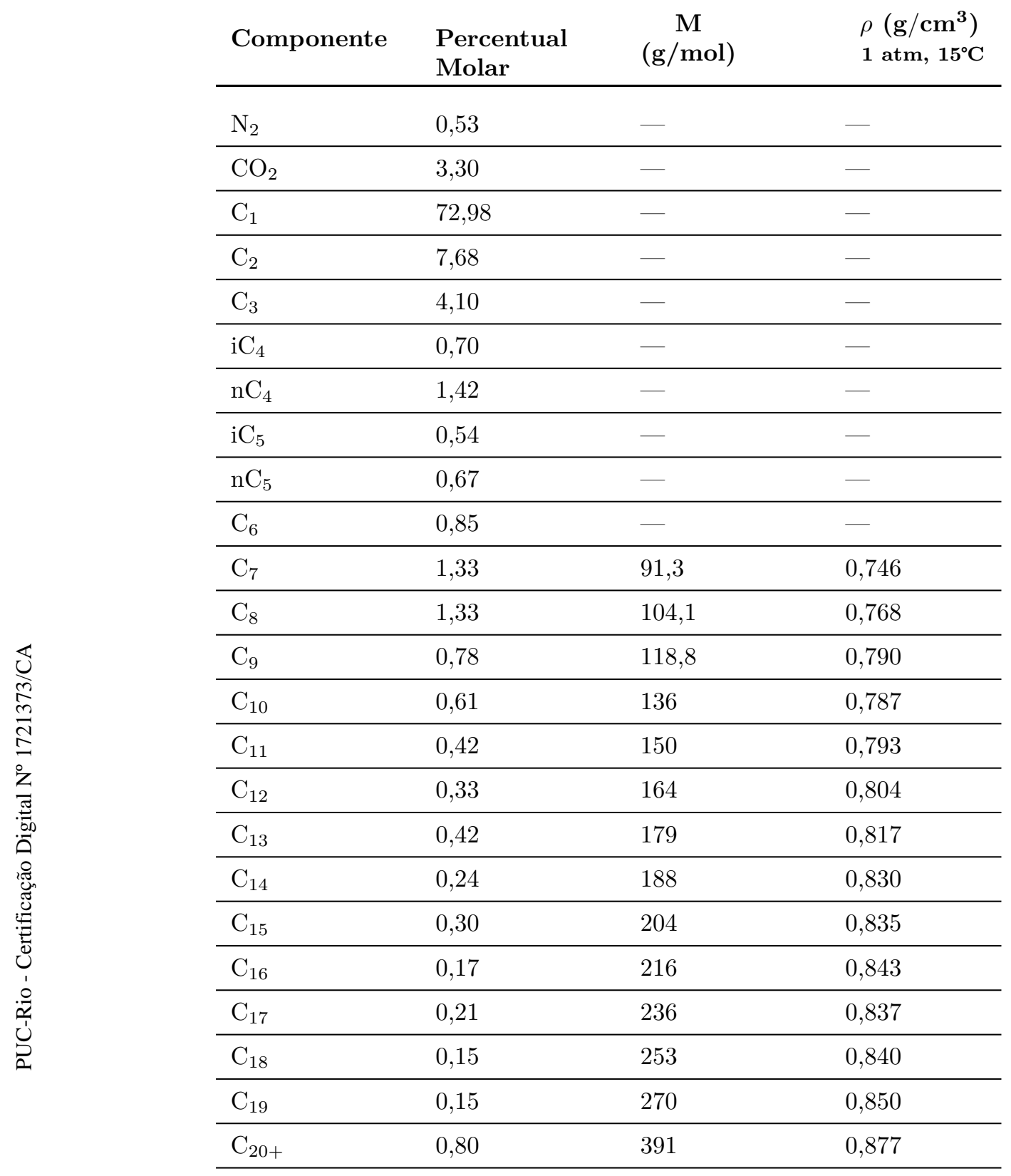

através da curva dos pontos de orvalho, e o reservatório será de gás condensado retrógrado. Apesar da diferente nomenclatura, misturas próximas ao ponto crítico possuem propriedades similares na região de duas fases do envelope.

Ainda de acordo com Pedersen et al. (2006), em misturas conhecidas como black-oils, a condição inicial do reservatório encontra-se afastada à esquerda da $T_{c}$, a entrada na região de duas fases também se dará através da curva de ponto de bolha, e a segunda fase formada é um gás. A Tabela 2.2 até a Tabela 2.5 mostram composições típicas destes 4 fluidos.

Os reservatórios de óleo ainda podem ser classificados em relação à 
Tabela 2.4: Composição da mistura próxima ao ponto crítico - Adaptado de Pedersen et al. (2006)

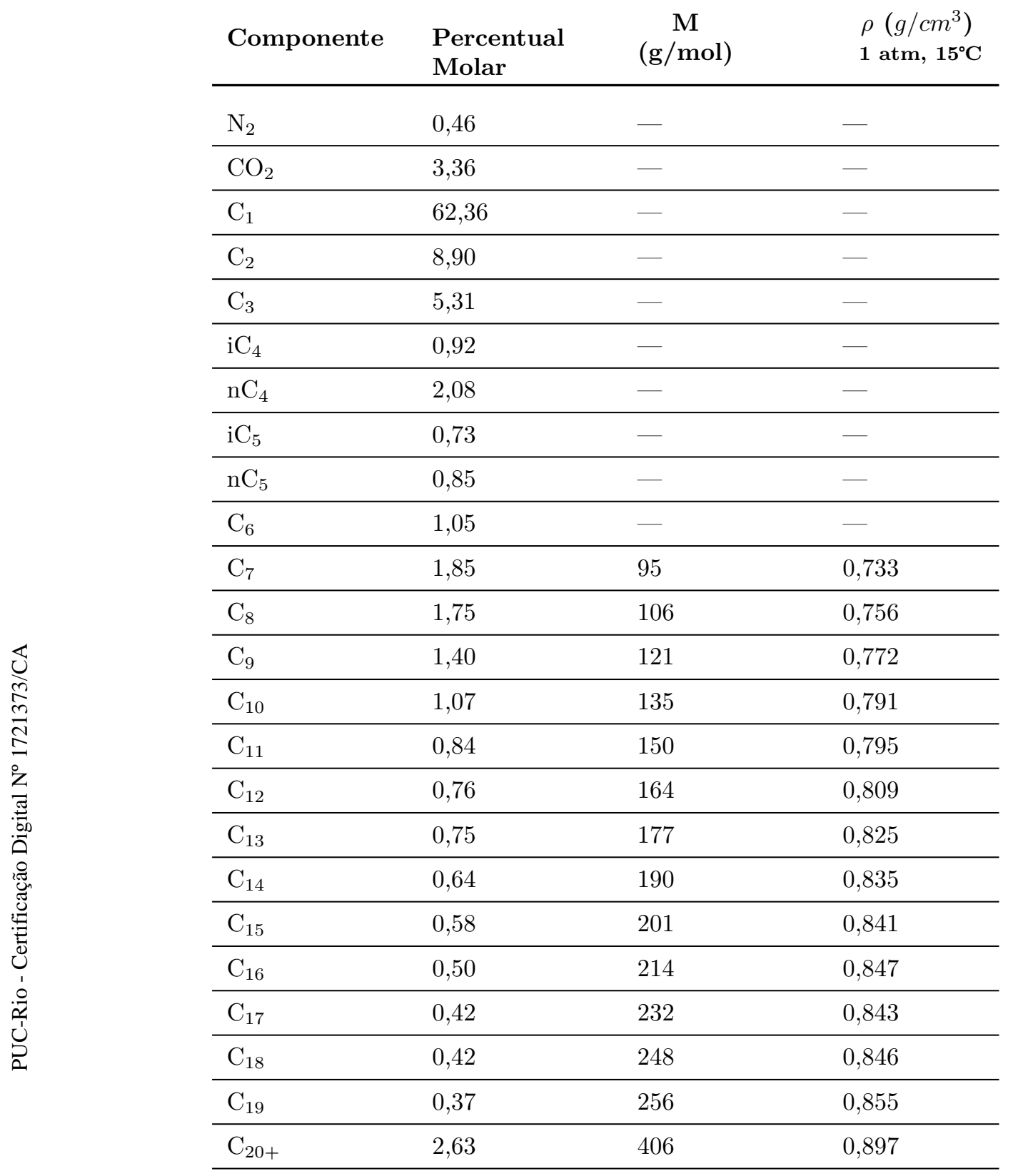

pressão inicial do reservatório em:

(i) Reservatório de óleo saturado

(ii) Reservatório de óleo subsaturado

(iii) Reservatórios de óleo com capa de gás

O reservatório é conhecido como saturado quando a pressão e temperatura iniciais estiverem sobre a curva de ponto de bolhas do envelope de 
fases. Isto é, qualquer decréscimo de pressão originará a segunda fase de gás.

Reservatórios de óleo subsaturado possuem pressão e temperatura iniciais acima da curva de ponto de bolha, de modo que um substancial decréscimo de pressão é necessário para iniciar a formação de uma segunda fase.

Ainda existem reservatórios que em sua condição inicial possuem uma capa de gás na parte superior do reservatório. Um diagrama de fases da capa de gás e da mistura de óleo podem ser visualizadas na Figura 2.7.

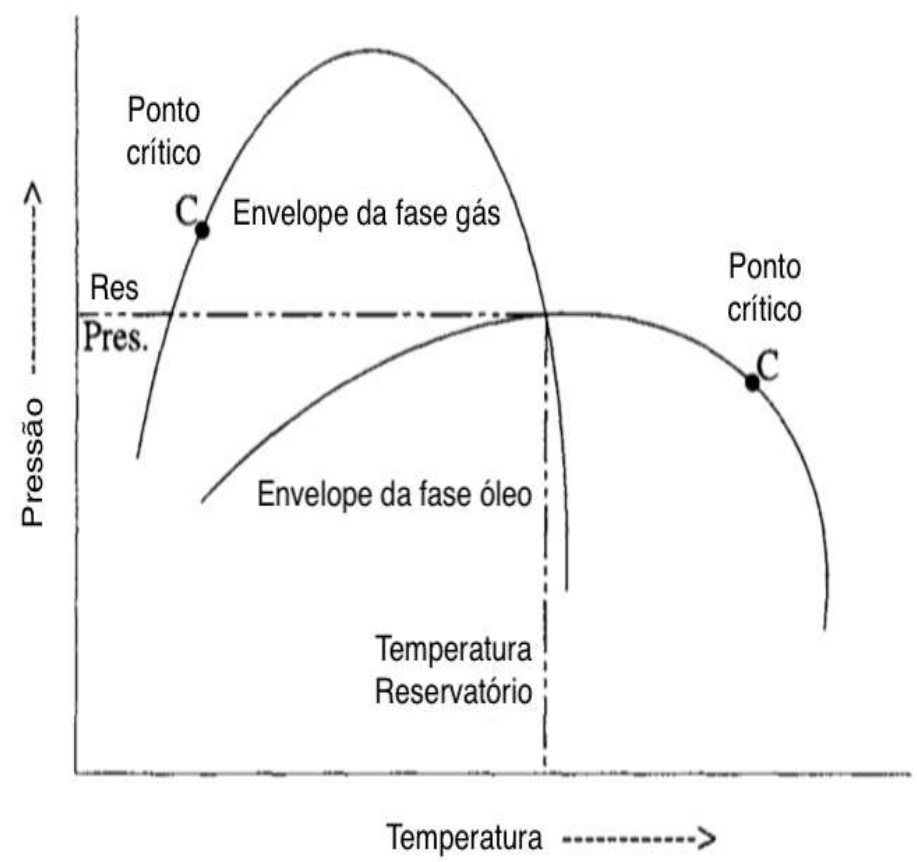

Figura 2.7: Envelope de fases de um reservatório com contato óleo-gás - Adaptado de Danesh (1998)

Do ponto de vista de simulação numérica, o engenheiro de escoamento em meio poroso e nas tubulações possuem duas abordagens a sua disposição. A metodologia black-oil se baseia na hipótese básica que, ao aumentar a pressão ou reduzir a temperatura, a volume constante, fará com que o equilíbrio seja deslocado de forma que mais gás estará dissovildo no óleo.

Pelo contrário, ao diminuir a pressão ou aumentar a temperatura, a volume constante, fará com que o equilíbrio se desloque de forma que o gás dissolvido no óleo saia de solução e vá para o estado gasoso. Isto não ocorre na região de condensação retrógrada, na qual existe conversão de gás em líquido com a redução de pressão. 
Tabela 2.5: Composição da mistura black-oil — Adaptado de Pedersen et al. (2006)

\begin{tabular}{llll} 
Componente & $\begin{array}{l}\text { Percentual } \\
\text { Molar }\end{array}$ & $\begin{array}{c}\mathbf{M} \\
(\mathrm{g} / \mathbf{m o l})\end{array}$ & $\begin{array}{c}\rho\left(\mathrm{g} / \mathrm{cm}^{3}\right) \\
\mathbf{~ a t m}, \mathbf{1 5}{ }^{\circ} \mathbf{C}\end{array}$ \\
\hline $\mathrm{N}_{2}$ & 0,04 & - & - \\
\hline $\mathrm{CO}_{2}$ & 0,69 & - & - \\
\hline $\mathrm{C}_{1}$ & 39,24 & - & - \\
\hline $\mathrm{C}_{2}$ & 1,59 & - & - \\
\hline $\mathrm{C}_{3}$ & 0,25 & - & - \\
\hline $\mathrm{iC}_{4}$ & 0,11 & - & - \\
\hline $\mathrm{nC}_{4}$ & 0,10 & - & - \\
\hline $\mathrm{iC}_{5}$ & 0,11 & - & - \\
\hline $\mathrm{nC}_{5}$ & 0,03 & - & - \\
\hline $\mathrm{C}_{6}$ & 0,20 & - & 0,769 \\
\hline $\mathrm{C}_{7}$ & 0,69 & 85,2 & 0,769 \\
\hline $\mathrm{C}_{8}$ & 1,31 & 104,8 & 0,765 \\
\hline $\mathrm{C}_{9}$ & 0,75 & 121,5 & 0,936 \\
\hline $\mathrm{C}_{10+}$ & 54,89 & 322,0 & \\
\hline & & & - \\
\hline
\end{tabular}

Misturas de petróleo do tipo black-oil são o caso típico de uso desta caracterização de fluido mais simples, tanto para o escoamento no meio poroso quanto para o escoamento nas tubulações.

Mistura de gás natural seco, onde não há condensação em nenhum ponto do sistema de produção, também podem fazer uso desta abordagem já que apenas uma relação entre pressão e volume do gás é suficiente para caracterizar as propriedades deste tipo de fluido.

As misturas de gás condensado retrógrado, conforme explicado, são conhecidas por apresentar o comportamento inverso do observado em misturas black-oil. Desta forma, a caracterização composicional é mandatória para este tipo de mistura.

Óleos voláteis também poderiam usar a abordagem black-oil para caracterizar as propriedades PVT, contudo, devido à elevada transferência de massa que ocorre durante a produção deste tipo de mistura, a opção pela caracterização composicional se mostra mais adequada, devido à representação mais rigorosa deste fenômeno através da EOS, tanto para predição do gradiente de pressão como o de temperatura. Além disso, o conhecimento da correta composição de mistura de óleos voláteis, que possui em sua composição poucos componentes pesados, facilita o uso de modelagem composicional. 
Nas misturas de gás úmido, mesmo sabendo-se que nas simulações de escoamento no meio poroso, o modelo black-oil já é suficiente, para o escoamento em tubulações, caracterizado por liberação de condensado, uma abordagem composicional, pelas mesmas razões apontadas para as misturas de gás condensado retrógrado, é mais adequada. Em MIPs, com modelo único para os fluidos, a abordagem composicional seria a melhor opção.

\subsection{2}

\section{Análises PVT}

Para otimizar a produção de óleo e gás de um campo, é essencial conhecer extensivamente o comportamento das fases e as propriedades volumétricas do fluido que escoa do reservatório até a UEP. Os poços e dutos que interligam o reservatório em projetos offshore até as plataformas de petróleo em alto mar podem ter tiebacks maiores que $10 \mathrm{~km}$.

A temperatura e pressão irão decrescer ao longo deste escoamento. As condições no próprio reservatório também mudam com o início da produção. O fluido que antes era monofásico pode se tornar bifásico após certo tempo de produção, com a retirada de massa do reservatório e consequente diminuição da pressão.

Uma série de análises laboratoriais são executadas de forma a representar as propriedades do fluido em toda faixa de pressão e temperatura do sistema de produção. É normal descrever os volumes de óleo e gás em uma condição dita de referência ${ }^{1}$.

Segundo Danesh (1998), independente da abordagem usada para a predição das propriedades PVT, black-oil ou composicional, os modelos usados em simulações computacionais precisam ser avaliados e ajustados com análises laboratoriais, que representam o caminho do fluido do reservatório até a UEP. A seguir serão descritos os experimentos mais comuns para cada tipo de fluido encontrado em reservatórios de petróleo.

\subsubsection{1}

\section{Mistura de gás natural}

Segundo Pedersen et al. (2006), uma vez que não há mudança de fase para uma mistura de gás natural seco, sua composição é constante durante a produção. O único teste necessário é uma relação pressão-volume na temperatura do reservatório. O experimento consiste em levar a amostra mantida em uma célula de laboratório das condições de reservatório para as

\footnotetext{
${ }^{1}$ Neste texto a condição de referência ou standard usada é $1 \mathrm{~atm}(1.01325 \mathrm{bar})$ e $15^{\circ} \mathrm{C}$.
} 
condições standard e medir o volume ocupado e a densidade em cada etapa de despressurização.

Com essas informações já é possível calcular o fator de compressibilidade e relação entre o volume que o gás ocupa numa condição de pressão e temperatura de interesse e o volume que ele ocupa nas condições de referência. Esta relação é conhecida como fator de volume de formação do gás, $B_{g}$, e na Figura 2.8 abaixo é ilustrado um esquemático típico desta propriedade.

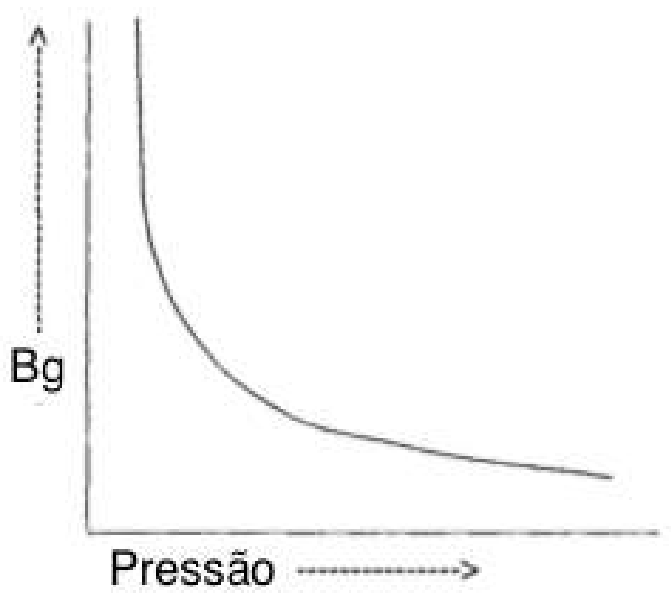

Figura 2.8: Esquemático da variação do fator de volume de formação do gás com a pressão - Adaptado de Danesh (1998)

Pedersen et al. (2006) também salienta que, os testes para amostras de misturas de gás natural úmidas são semelhantes. Adicionalmente, alguns testes de separador são necessários para determinar as propriedades do condensado formado em condições de superfíicie.

\subsubsection{2 \\ Black-oils}

Danesh (1998) advoga que um reservatório composto por uma mistura black-oil se comportará durante a produção de acordo com o que é ilustrado na Figura 2.9. Na área A do reservatório, onde a pressão ainda está acima do ponto de bolha, o óleo expande devido à redução da pressão com a produção, sem mudar de fase. Na área B do reservatório, a pressão está logo abaixo do ponto de bolha, iniciando a acumulação de uma segunda fase gás, que devido à baixa saturação no meio poroso, ainda é imóvel. Na zona $\mathrm{C}$, o gás já consegue se mover no reservatório e escoa em sentido ao poço. As forças gravitacionais e superficiais fazem com que o óleo e gás segreguem no reservatório. No poço e no duto até chegar na UEP, as duas fases escoam juntam devido ao efeito dominante da mistura das fases. 
Ainda segundo Danesh (1998), o processo explicado acima é simulado no laboratório através de múltiplas expansões a composição constante (ECC), (para alguma condição de referência, conhecidas como liberações flash, ou para as condições de separação da UEP, conhecidas como testes de separador) para as áreas A, B e para o fluxo multifásico no poço e dutos. Um ensaio de liberação diferencial é feito para a área C.

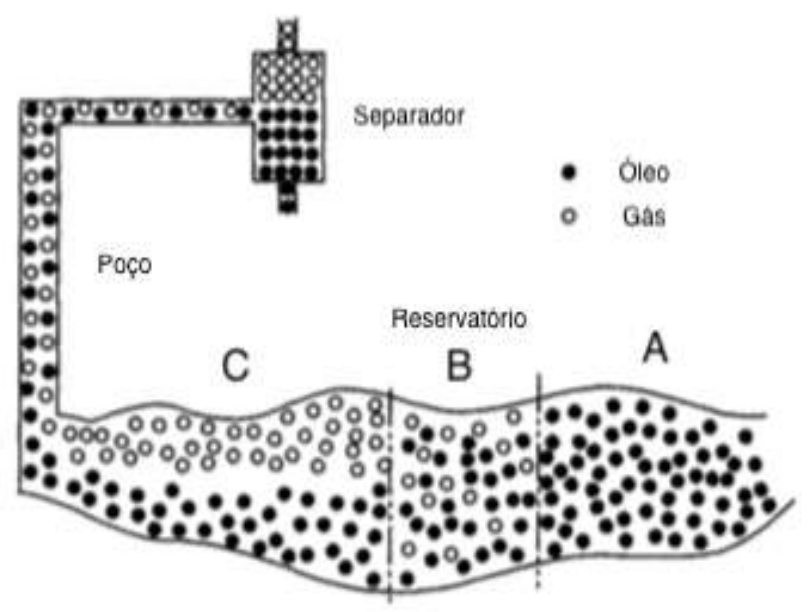

Figura 2.9: Comportamento das fases em um reservatório black-oil - Adaptado de Danesh (1998)

No ensaio de liberação flash a amostra de óleo é colocada na célula e a pressão é reduzida expandindo o volume ocupado pelo fluido, a temperatura contante. Os dados típicos reportados podem ser vistos na Tabela 2.6. As propriedades da fração plus $\left(C_{20+}\right)$ também são medidas e reportadas. Um outro importante resultado deste ensaio é a pressão de saturação na temperatura do teste, isto é, a pressão na qual a segunda fase começa a ser formada.

A compressibilidade isotérmica do óleo, $c_{o}$, acima do ponto de bolha é calculada com a seguinte relação:

$$
c_{o}=-\frac{1}{V} \frac{\partial V}{\partial p_{T}}
$$

O fator-Y, que nada mais é uma medida da razão entre as mudanças relativas entre pressão e volume na região das duas fases, também é calculado:

$$
Y=\frac{\frac{p_{b}-p}{p}}{\frac{V_{t}-V_{b}}{V_{b}}}
$$

Segundo Pedersen et al. (2006), o ensaio de liberação diferencial consiste em colocar a amostra em uma célula, a temperatura constante, a qual possui uma válvula no topo que permite que o gás seja removido durante o experi- 
Tabela 2.6: Relação pressão-volume de um ensaio de expansão a composição constante - Adaptado de Danesh (1998)

\begin{tabular}{llll} 
Pressão (bar) & $\begin{array}{l}\text { Volume } \\
\text { relativo }\end{array}$ & $\mathbf{Y}$ & $\begin{array}{l}\left.\rho\left(\mathrm{g} / \mathrm{cm}^{3}\right)\right) \\
\mathbf{~ a t m}, \mathbf{1 5}^{\mathbf{}} \mathbf{C}\end{array}$ \\
\hline 345,7 & 0,9639 & - & 0,6808 \\
\hline 311,3 & 0,9702 & - & 0,6763 \\
\hline 283,7 & 0,9756 & - & 0,6726 \\
\hline 276,8 & 0,9770 & - & 0,6716 \\
\hline 242,3 & 0,9845 & - & 0,6665 \\
\hline 207,8 & 0,9928 & - & 0,6609 \\
\hline 200,9 & 0,9946 & - & 0,6597 \\
\hline 194,1 & 0,9964 & - & 0,6585 \\
\hline 187,2 & 0,9984 & - & 0,6585 \\
\hline 181,6 & 1,0 & - & 0,6562 \\
\hline 156,3 & 1,0648 & 2,497 & - \\
\hline 145,1 & 1,1041 & 2,418 & - \\
\hline 131,8 & 1,1627 & 2,325 & - \\
\hline 118,1 & 1,2415 & 2,229 & - \\
\hline 102,8 & 1,3611 & 2,122 & - \\
\hline 90,1 & 1,5000 & 2,033 & - \\
\hline 72,7 & 1,7837 & 1,911 & - \\
\hline 58,2 & 2,1709 & 1,810 & - \\
\hline 33,5 & 3,6961 & 1,637 & - \\
\hline
\end{tabular}

mento. O ensaio começa em uma pressão acima do ponto de bolha e o volume do sistema é expandido a cada passo do experimento. O ponto de bolha é atingido quando uma quantidade ínfima de gás é vista. Em cada estágio de pressão abaixo da pressão do ponto de bolha, todo o gás que saiu de solução é removido.

A razão entre o volume de gás dissolvido no óleo e o volume de óleo, medidos na condição standard, conhecida como razão de solubilidade $\left(R_{s}\right)$, é medida neste ensaio. $\mathrm{O}$ fator volume de formação do óleo, $B_{o}$, definido como volume de óleo nas condições de pressão e temperatura de interesse em relação ao volume de óleo na condição standard, é outro resultado deste ensaio.

A Tabela 2.7 mostra os resultados típicos de uma liberação diferencial e as Figuras 2.10 e 2.11 mostram como o $B_{o}$ e $R_{s}$ variam com a pressão para uma mistura black-oil. Além destes, a massa específica do óleo em cada estágio de pressão também é um importante resultado do ensaio de liberação diferencial. 
Tabela 2.7: Resultados de um ensaio de liberação diferencial - Adaptado de Pedersen et al. (2006)

\begin{tabular}{|c|c|c|c|c|c|c|}
\hline $\begin{array}{c}\text { Pressão } \\
\text { (bar) }\end{array}$ & $\begin{array}{c}\mathbf{B}_{\mathbf{o}} \\
\left(m^{3} / S m^{3}\right)\end{array}$ & $\begin{array}{c}\mathbf{R}_{\mathbf{s}} \\
\left(m^{3} / S m^{3}\right) \\
\end{array}$ & $\begin{array}{c}\rho \\
\left(\mathrm{g} / \mathrm{cm}^{3}\right) \\
\end{array}$ & $\begin{array}{c}\mathbf{B}_{\mathbf{g}} \\
\left(m^{3} / S m^{3}\right) \\
\end{array}$ & $\mathbf{Z}$ & $\begin{array}{c}\mathbf{d}_{\mathbf{g}} \\
(a r=1)\end{array}$ \\
\hline 351,4 & 1,653 & 198,3 & 0,670 & - & - & - \\
\hline 323,2 & 1,662 & 198,3 & 0,667 & - & - & - \\
\hline 301,5 & 1,662 & 198,3 & 0,664 & - & - & - \\
\hline 275,9 & 1,679 & 198,3 & 0,660 & - & - & - \\
\hline 250,1 & 1,688 & 198,3 & 0,656 & - & - & - \\
\hline 226,1 & 1,699 & 198,3 & 0,652 & - & - & - \\
\hline 205,9 & 1,708 & 198,3 & 0,649 & - & - & - \\
\hline 200,0 (Psat) & 1,710 & 198,3 & 0,645 & - & - & - \\
\hline 179,1 & 1,648 & 176,2 & 0,656 & 0,00610 & 0,844 & 0,791 \\
\hline 154,6 & 1,588 & 154,3 & 0,668 & 0,00713 & 0,851 & 0,779 \\
\hline 132,1 & 1,534 & 134,5 & 0,679 & 0,00839 & 0,857 & 0,764 \\
\hline 109,0 & 1,483 & 115,5 & 0,691 & 0,01030 & 0,868 & 0,758 \\
\hline 78,6 & 1,413 & 91,7 & 0,706 & 0,01440 & 0,882 & 0,772 \\
\hline 53,6 & 1,367 & 72,8 & 0,719 & 0,02150 & 0,901 & 0,805 \\
\hline 22,0 & 1,288 & 46,1 & 0,739 & 0,05280 & 0,933 & 0,953 \\
\hline 1,0 & 1,077 & 0,0 & 0,778 & - & - & 2,022 \\
\hline 1,$01 ; 15^{\circ} \mathrm{C}$ & 1,0 & 0,0 & 0,838 & - & - & - \\
\hline
\end{tabular}

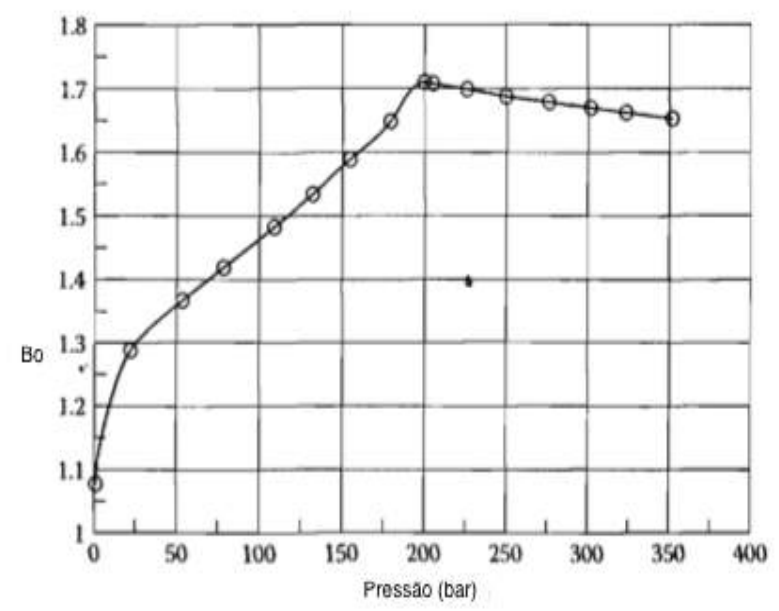

Figura 2.10: Fator volume de formação do óleo $\left(B_{o}\right)$ em função da pressão em um ensaio de liberação diferencial - Adaptado de Pedersen et al. (2006)

De acordo com Pedersen et al. (2006), outro importante ensaio laboratorial é o teste de separador, onde um volume conhecido da amostra é submetido 


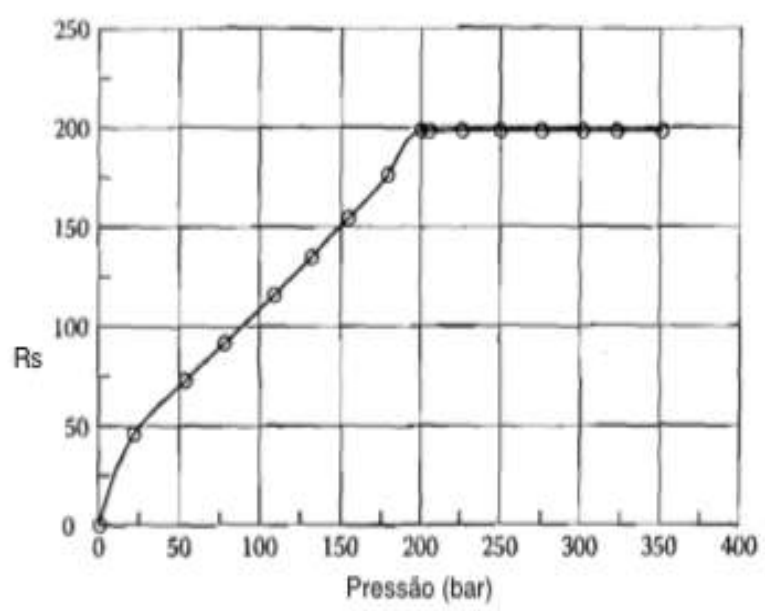

Figura 2.11: Razão de solubilidade $\left(R_{s}\right)$ em função da pressão em um ensaio de liberação diferencial - Adaptado de Pedersen et al. (2006)

a uma ou mais expansões e, normlamente, o último estágio representa a condição de referência. O teste tem por objetivo simular os estágios de separação que o fluido experimentará passando pelo processamento primário na UEP.

Um esquemático representando um teste de separador com três estágios é ilustrado na Figura 2.12. As composições do gás liberado em cada estágio são medidas e reportadas, assim como a RGO resultante do processo de separação.

A distribuição das fases gás e óleo, produzidas em condições de superfície, depende do número e condições de cada estágio de separação. Este teste, em conjunto com outras análises, é útil para determinar as condições ótimas de separação na UEP.

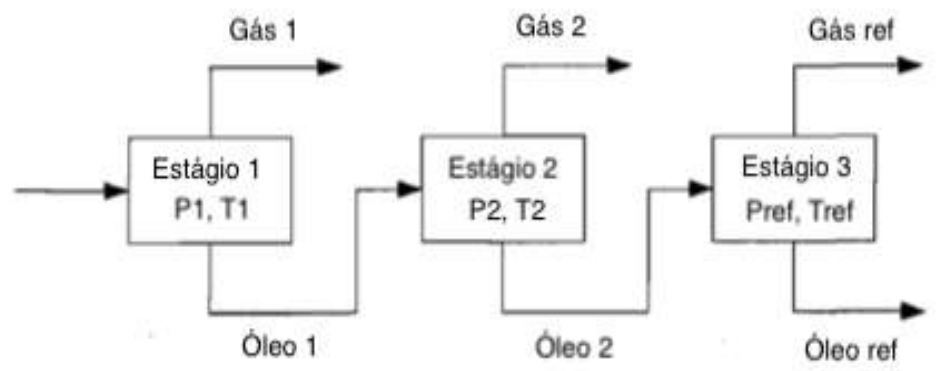

Figura 2.12: Esquemático de um teste de separador com três estágios - Adaptado de Pedersen et al. (2006)

A viscosidade dos fluidos também deve ser medida para representar adequadamente o comportamento reológico do fluido. O procedimento usual é medir com um viscosímetro o valor da viscosidade do óleo, em função da pressão e temperatura, para servir de insumo às simulações no meio 
poroso e nas tubulações. A viscosidade do gás normalmente não é medida em laboratório, são usadas apenas correlações para estimar os valores.

\subsubsection{3}

\section{Mistura de gás condensado}

De acordo com Pedersen et al. (2006), a análise composicional de misturas de gás condensado geralmente possui mais detalhes que uma mistura típica de óleo. A fração plus deste tipo de amostra é muito importante uma vez que os modelos de equilíbrio de fase são muito sensíveis a descrição correta desta fração.

Pedersen et al. (2006) comenta também que o ensaio de liberação diferencial não é realizado neste tipo de amostra, uma vez que este teste não representa adequadamente o comportamente das fases de um reservatório de gás condensado durante a produção. O ensaio mais comum que emula o que acontece em um reservatório de gás condensado é a expansão a volume constante (EVC).

Este teste é feito na temperatura de reservatório e consiste de diversas expansões seguidas pela retirada do excesso do gás, a pressão constante, de modo que o volume da célula permaneça constante ao final de cada estágio. $\mathrm{O}$ gás retirado em cada estágio de pressão é coletado, e sua composição, volume e fator de compressibilidade são medidos. O volume de condensado também é mensurado. A curva de condensado depositado típica encontrada neste tipo de ensaio está ilustrada na Figura 2.13.

Danesh (1998) salienta que este teste simula o que acontece normalmente na produção de gás condensado em um reservatório explotado por depleção. $\mathrm{O}$ reservatório é visto como uma fonte de volume e temperatura fixos. A pressão diminui durante a produção, uma vez que fluido é produzido, enquanto que o volume e temperatura permanecem constantes. Quando o reservatório atinge o ponto de orvalho, a fase óleo começa a se formar.

A mistura produzida terá uma composição parecida com a composição do gás removida em cada estágio do ensaio de EVC. O gás gradualmente fica mais pobre, uma vez que o condensado começa a se depositar no reservatório, assim como na célula, durante o teste.

\subsubsection{4}

\section{Mistura de óleo volátil}

Segundo Danesh (1998), ensaios laboratoriais para misturas de óleo voláteis não são bem definidas e documentadas. Testes similares aos feitos em misturas black-oil são comumente conduzidas nestas misturas. Como o gás 


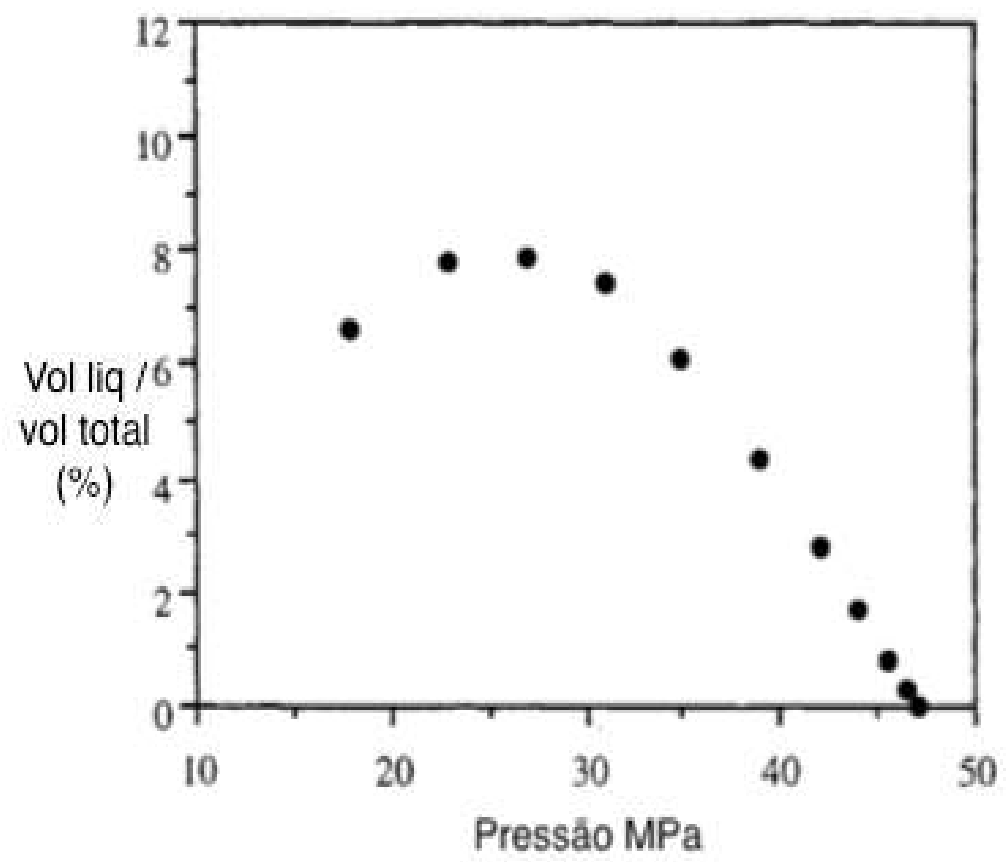

Figura 2.13: Volume de líquido depositado em uma expansão a volume constante - Adaptado de Danesh (1998)

que sai de solução abaixo do ponto de bolha quase que imediatamente começa a se mover no reservatório, o ensaio de liberação diferencial parece simular fielmente o processo. Contudo, o gás que é produzido junto com o óleo se comporta como um gás rico e contribui significativemente para o óleo residual em condições de superfície.

Ainda segundo Danesh (1998), a produção de óleos voláteis por depleção não é um método eficiente de recuperação pois quando a pressão cai abaixo do ponto de bolha, muito gás é produzido, podendo levar a mobilidade do gás ser maior do que a de óleo, resultando em grande produção de gás e deixando óleo imóvel no reservatório. Desta forma, um ensaio de depleção a volume constante, similar aos feitos em campos de gás condensado também é boa prática de ser conduzido neste tipo de mistura.

\subsection{3}

\section{Equações de estado e cálculo de equilíbrio de fases}

De acordo com Ahmed (2007), fase é a parte de um sistema que possui propriedades físicas e químicas uniformes, composição homogênea e, na existência de uma segunda fase, possui superfície de fronteira definida. A fase hidrocarboneto líquida e gasosa são as duas fases mais importantes que aparecem em um sistema de produção de petróleo. Água também pode estar 
presente na fase líquida. Estas fases coexistem em equilíbrio no reservatório enquanto não há mudanças de temperatura, pressão e composição.

Segundo Pedersen et al. (2006), as condições em que cada fase pode existir é de fundamental importância nos projetos de desenvolvimento da produção, assim é possível otimizar todo o sistema de produção, desde o escoamento no meio poroso até a UEP. Através dos conceitos de equilíbrio de fases, desenvolvimento de equações de estado e aumento da capacidade computacional, tornou-se possível a criação de modelos composicionais que, em segundos, calculam milhões de equilíbrios de fases e propriedades físicas de uma mistura multicomponente.

A evolução destas ferramentas permitiram calcular com mais rigor o potencial das jazidas de petróleo. A seguir é apresentado um breve resumo sobre a teoria de equilíbrio de fases e também a evolução na modelagem das equações de estado, assuntos fundamentais para os estudos desta dissertação.

\subsubsection{1}

\section{Equilíbrio de fases de um sistema multicomponente}

Segundo Danesh (1998), a produção de petróleo é acompanhada de variação na composição, pressão e temperatura dos fluidos. Isto implica não só mudanças nas propriedades, mas também na formação de novas fases ou até mesmo eliminação de fases existentes. Como as mudanças no reservatório e no sistema de produção são razoavelmente lentas, é razoável assumir que as fases estão em equilíbrio. Assim, o problema passa a ser a determinação das condições de equilíbrio em um sistema de fluido com multicomponentes. Este assunto já foi exaustivamente tratado em vários artigos e livros. A seguir só serão revisados os principais conceitos de equilíbrio de fases, fundamentais para o entendimento da dissertação.

Critério para equilíbrio Danesh (1998) comenta que, para um sistema fechado, sem trocar massa com os arredores, a variação da energia total do sistema $E$, composta pela energia interna $U$, potential $E_{p}$ e cinética $E_{k}$ é somente devido a troca de calor $Q$ e trabalho $W$, assim determinado pela primeira lei da termodinâmica,

$$
\Delta E=\Delta U+\Delta E_{p}+\Delta E_{k}=Q-W
$$

A troca de calor entregue ao sistema e o trabalho feito pelo sistema devem entrar com sinal positivo na equação acima. Quando este sistema passa por um processo irreversível, sem mudança na energia cinética e potencial, e ainda 
com pressão e temperatura uniforme, ao se combinar a primeira e segunda leis da termodinâmica, obtêm-se:

$$
d U<T d S-p d V
$$

Danesh (1998) também comenta que, uma vez que todos os processos são irreversíveis, a inequação acima estabelece que para um processo com entropia e volume constantes, a energia interna tende a diminuir quando aproxima-se do equilíbrio. Outras relações podem ser usadas para determinar o mesmo conceito. A energia livre de Gibbs pode ser usada para chegar na seguinte equação:

$$
d G \leq-S d T+V d p
$$

que determina que a pressão e temperaturas constantes, a energia livre de Gibbs tende a decrescer em processos reais, e permanece constante em processos reversíveis,

$$
(\partial G)_{p, T}=0
$$

Isto é, no estado de equilíbrio, a energia livre de Gibbs do sistema é mínima,

$$
(\partial G)_{p, T}=0
$$

e

$$
\left(\partial^{2} G\right)_{p, T}>0
$$

Potencial químico De acordo com Danesh (1998), um sistema fechado que consiste de um número de fases em contato, conhecido como um sistema heterogêneo fechado, pode ser tratado com um conjunto de sistemas abertos, onde cada fase é homogênea e pode trocar massa com outros sistemas abertos. Neste caso a energia livre de Gibbs possui um componente adicional, e energia parcial molar de Gibbs, conhecida como potencial químico, $\mu_{i}$, obtendo-se:

$$
d G=-S d T+V d p+\sum_{i} \mu_{i} d n_{i}
$$

Para um sistema fechado $\operatorname{com} \theta$ fases, a equação acima pode ser escrita para cada fase. Ou seja, a energia total de Gibbs de um sistema fechado é:

$$
d G=\sum_{\eta=1}^{\theta}(-S)_{\eta} d T+\sum_{\eta=1}^{\theta}(V)_{\eta} d p+\sum_{\eta=1}^{\theta}\left(\sum_{i} \mu_{i} d n_{i}\right)_{\eta}
$$

onde $\eta$ denota cada fase.

Ainda de acordo com Danesh (1998), em um sistema com pressão e 
temperatura constantes, o estado de equilíbrio determina que:

$$
(d G)_{p, T}=\sum_{\eta=1}^{\theta}\left(\sum_{i} \mu_{i} d n_{i}\right)_{\eta}=0
$$

Como o sistema é fechado e sem reações químicas, o número total de moles de cada componente permanece constante no sistema, logo:

$$
\sum_{\eta=1}^{\theta}\left(d n_{i}\right)_{\eta}=0 \quad i=1,2, \ldots . N
$$

Considerando as duas últimas equações, obtêm-se:

$$
\mu_{i}^{(1)}=\mu_{i}^{(2)}=\mu_{i}^{(3)}=\ldots . .=\mu_{i}^{(\theta)} \quad i=1,2, \ldots . N
$$

Danesh (1998) comenta que a constatação acima, que o potencial químico de cada componente, através de todas as fases coexistentes, durante o equilíbrio é igual, cria um ferramenta prática de engenharia se o potencial químico puder ser calculado através de quantidades mensuráveis. Isto foi possível expressandose o potencial químico em função de termos termodinâmicos auxiliares, tal como a fugacidade.

Fugacidade De acordo com Danesh (1998), como as relações entre propriedades de estado são independentes do caminho do processo, para um processo reversível a equação abaixo também pode ser usada para representar a variação na energia livre de Gibbs e, consequentemente, o potencial químico

$$
d G=-S d T+V d p
$$

Para uma substância pura, as propriedades molares são iguais às propriedade parciais molares e, consequentemente, a variação do potencial químico de uma substância pura i, é dada por:

$$
d \mu_{i}=d \bar{g}_{i}=-\bar{s}_{i} d T+\bar{v}_{i} d p
$$

onde $g, s$ e $v$ são respectivamente, energia livre de Gibbs molar, entropia molar e volume molar. Ainda de acordo com Danesh (1998), considerando a temperatura constante, a equação acima se reduz a

$$
\left(\partial \mu_{i} / \partial p\right)_{T}=\bar{v}_{i}
$$

o que nos leva a uma simples expressão para o potencial químico de um gás 
ideal, que usando uma equação de estado de gás ideal:

$$
p \bar{v}_{i}=\bar{R} T
$$

chega-se a:

$$
\left(\partial \mu_{i} / \partial p\right)_{T}=\bar{R} T / p
$$

onde $\bar{R}$ é a constante universal dos gases. Integrando a equação acima, a temperatura constante, obtêm-se:

$$
\mu_{i}-\mu_{i}^{0}=\bar{R} T \ln \left(p / p^{0}\right)
$$

A equação acima fornece uma relação simples para o potencial químico de um gás ideal puro quando a pressão varia de $p^{0}$ a $p$ isotermicamente. Segundo Danesh (1998, apud Lewis, 19-), a equação acima foi generalizada para a aplicação em sistemas reais, definindo uma "pressão ajustada", batizada de fugacidade:

$$
\mu_{i}-\mu_{i}^{0}=\bar{R} T \ln \left(f_{i} / f_{i}^{0}\right)
$$

onde $\mu_{i}^{0}$ e $f_{i}^{0}$ são o potencial químico e a fugacidade do componente i, respectivamente.

Danesh (1998) comenta que, para um gás ideal, a fugacidade é igual a sua pressão, e a fugacidade de cada componente é igual a sua pressão parcial. A razão entre a fugacidade e a pressão é conhecida como coeficiente de fugacidade, $\phi$. Para um sistema multicomponente,

$$
\phi_{i}=f_{i} /\left(p z_{i}\right)
$$

onde $z_{i}$ é a fração molar de cada componente i. Como todos os sistemas se comportam como gás ideal a pressões muito baixas,

$$
\phi_{i} \longrightarrow 1 \text { quando } p \longrightarrow 0
$$

Segundo Danesh (1998), reescrevendo a equação para o componente i, em cada fase de um sistema heterogêneo, com todos os estados na mesma temperatura, e sabendo que existe a igualdade do potencial químico no equilíbrio, chega-se a conclusão que:

$$
f_{i}^{(1)}=f_{i}^{(2)}=f_{i}^{(3)}=\ldots . .=f_{i}^{(\theta)} \quad i=1,2, \ldots . N
$$

isto é, a fugacidade de cada componente deve ser igual ao longo de todas as fases em um sistema heterogêneo em equilíbrio. 
Danesh salienta que, tanto a fugacidade quanto o potencial químico são propriedades termodinâmicas usadas para relacionar o equilíbrio de fases. A vantagem de usar a fugacidade é que ela é mais facilmente entendida e avaliada como uma "pressão ajustada". A fugacidade pode ser imaginada como a medida da tendência das moléculas escaparem de uma fase para outra adjacente.

Assim, em um sistema multicomponente, se a fugacidade de um componte em duas fases adjacentes é a mesma, estas duas fases estarão em equilíbrio sem transferência de moléculas de uma fase para a outra.

Segundo Danesh (1998), a fugacidade pode ser relacionada rigorosamente através de propriedades mensuráveis usando relações termodinâmicas,

$$
\ln \phi_{i}=\frac{1}{R T} \int_{v}^{\infty}\left[\left(\frac{\partial p}{\partial n_{i}}\right)_{T, v, n_{j \neq i}}-R T / v\right] d v-\ln Z \quad i=1,2, \ldots, N
$$

onde $\mathrm{V}$ é o volume total, $n_{i}$ é o número de moles de cada componente i e Z é o fator de compressibilidade da mistura, dado por

$$
Z=p v / n R T
$$

e n é o total de número de moles da mistura com $\mathrm{N}$ componentes,

$$
n=\sum_{i}^{N} n_{i}
$$

A equação da coeficiente de fugacidade pode ser integrada, com a acurácia aceitável para estudos de engenharia, usando uma equação de estado para eliminar uma das variáveis presentes na integral.

\subsubsection{2}

\section{Equações de estado}

O equilíbrio químico em um sistema multicomponente implica na igualdade da fugacidade de cada componente ao longo de todas as fases, conforme mostrado no item anterior. O coeficiente de fugacidade, definido como a razão entre a fugacidade e a pressão de cada componente em qualquer fase está relacionado a pressão, temperatura e volume atravês da seguinte equação:

$$
\ln \phi_{i}=\frac{1}{R T} \int_{v}^{\infty}\left[\left(\frac{\partial p}{\partial n_{i}}\right)_{T, v, n_{j \neq i}}-R T / v\right] d v-\ln Z \quad i=1,2, \ldots, N
$$

De acordo com Danesh (1998), o coeficiente de fugacidade pode, portanto, ser determinado pela equação acima com a ajuda de uma expressão relacionando, pressão, temperatura, volume e composição, isto é, uma equação 
de estado. Em geral, qualquer EOS que preveja dados volumétricos confiáveis em toda faixa de variação da integral pode ser usada para descrever o comportamento das fases do fluido. Várias EOS foram aplicadas para descrever o comportamento de fluidos encontrados em reservatórios de petróleo com sucesso. A seguir, as principais EOS serão detalhadas, com destaque para a equação de Peng-Robinson (PR), que será usada nas simulações desta dissertação.

Equação de van der Waals De acordo com Pedersen et al. (2006), a primeira equação cúbica de estado foi pensada por van der Waals partindo do comportamento das fases de um componente puro. A Figura 2.14 ilustra esquematicamente curvas de pressão $(p)$ vs volume molar $(\bar{v})$, em várias temperaturas para um componente puro. Para temperatura acima da temperatura crítica ( $T_{1}$ na Figura 2.14), a curva $p \bar{v}$ exibe um formato hiperbólico sugerindo que a pressão é inversamente proporcional ao volume molar. Este comportamento é conhecido e modelado para a equação de estado de um gás ideal:

$$
p=\frac{\bar{R} T}{\bar{v}}
$$

onde $\bar{R}$ é a constante universal dos gases e $T$ é a temperatura absoluta.

Ainda de acordo com Pedersen et al. (2006), o volume molar de um componente, comportando-se como um gás ideal, em altas pressões assintoticamente tenderia a zero. Como pode ser visto na Figura 2.14, o volume molar tende para um limite, o qual van der Waals chamou de $b$. Rearranjando a equação do gás ideal e adicionando o parâmetro $b$, chega-se a:

$$
\bar{v}=\frac{\bar{R} T}{p}+b
$$

Rearranjando os termos, a expressão para a pressão fica:

$$
p=\frac{\bar{R} T}{\bar{v}-b}
$$

Pedersen et al. (2006) comenta que em temperaturas abaixo da temperatura crítica ( $T_{3}$ na Figura 2.14), uma transição de fase vapor para líquido pode acontecer.

Considere um componente na temperatura $T_{3}$ inicialmente em baixas pressões, ou seja, na forma de vapor. Diminuindo o volume e mantendo a temperatura constante $T_{3}$, a pressão irá aumentar até um ponto que uma fase líquida começa a se formar, mostrando que o ponto de condensação deste componente foi atingido. Ao continuar a diminuir o volume, a pressão 


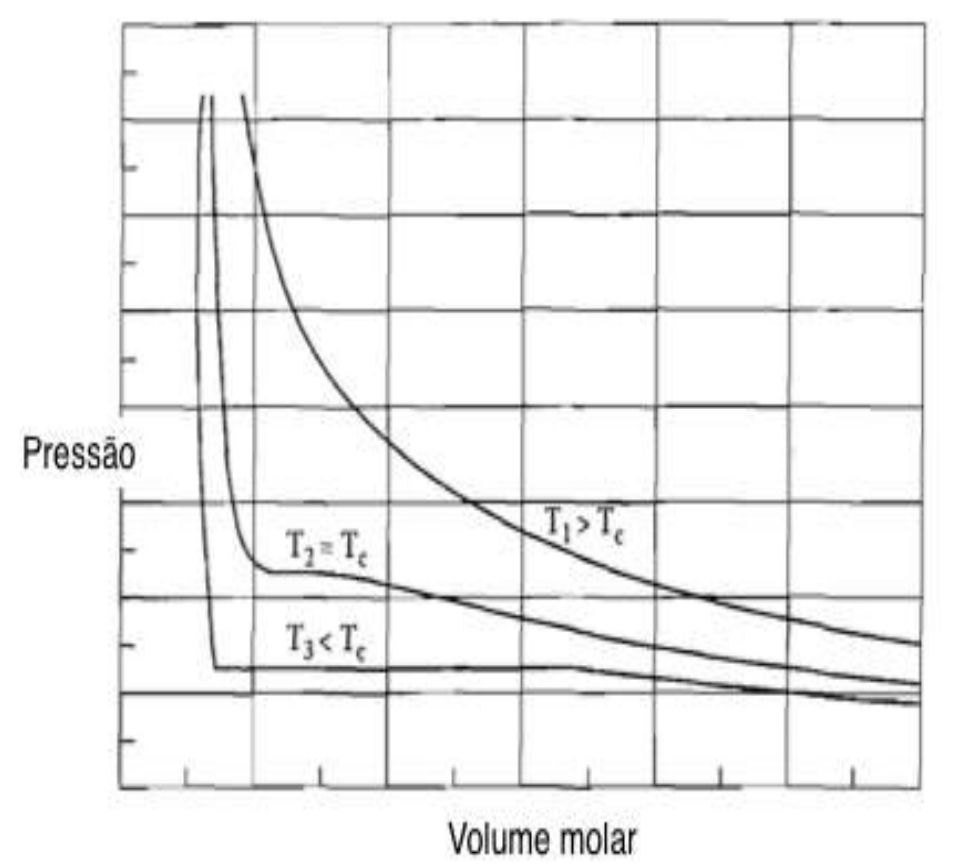

Figura 2.14: Curva pressão-volume específico molar de um componente puro - Adaptado de Danesh (1998)

permanecerá constante até todo vapor se transformar em líquido. Como o líquido é praticamente incompressível, uma nova redução no volume estará associada a um grande aumento da pressão, como ilustrado na Figura 2.14.

O fato de que a substância pode passar por uma transição de fase gasosa com moléculas bastante afastadas uma da outras para uma fase líquida onde as moléculas estão próximas mostra a existência de forças atrativas agindo entre as moléculas. Estas forças não estão contabilizadas na equação do gás ideal, logo ela não é capaz de descrever uma transição de fase da forma vapor para líquido.

A Figura 2.15 mostra um recipiente preenchido com gás. Pedersen et al. (2006) explica que os dois volumes elementares, $v_{1}$ e $v_{2}$, inicialmente contêm uma molécula apenas e a força entre os dois elementos seja $f$. Se outra molécula é adicionada em $v_{2}$ e mantendo uma molécula em $v_{1}$, a força agindo entre os dois volumes elementares será de $2 f$. Adicionando uma terceira molécula em $v_{2}$ aumentará para $3 f$, e assim por diante. A força de atração entre dois volumes elementares é, dessa forma, proporcional a $c_{2}$, a concentração de moléculas em $v_{2}$.

Se sucessivas moléculas são adicionadas a $v_{1}$, mantendo o número de moléculas constante em $v_{2}$, a força também irá aumentar na mesma proporção. A força é então, proporcional concentração de moléculas em $c_{1}$. Assim, a 
força agindo entre dois volumes elementares é proporcional ao produto entre $c_{1}$ e $c_{2}$. A concentração c é inversamente proporcional ao volume molar , implicando que as forças de atração são proporcionais a $1 / \bar{v}^{2}$. Baseado nessas considerações, van der Waals sugeriu que o termo atrativo deveria ser uma constante multiplicada pelo termo $1 / \bar{v}^{2}$, levando a:

$$
p=\frac{\bar{R} T}{\bar{v}-b}-\frac{a}{\bar{v}^{2}}
$$

que é a forma final da equação de estado cúbica da van der Waals.

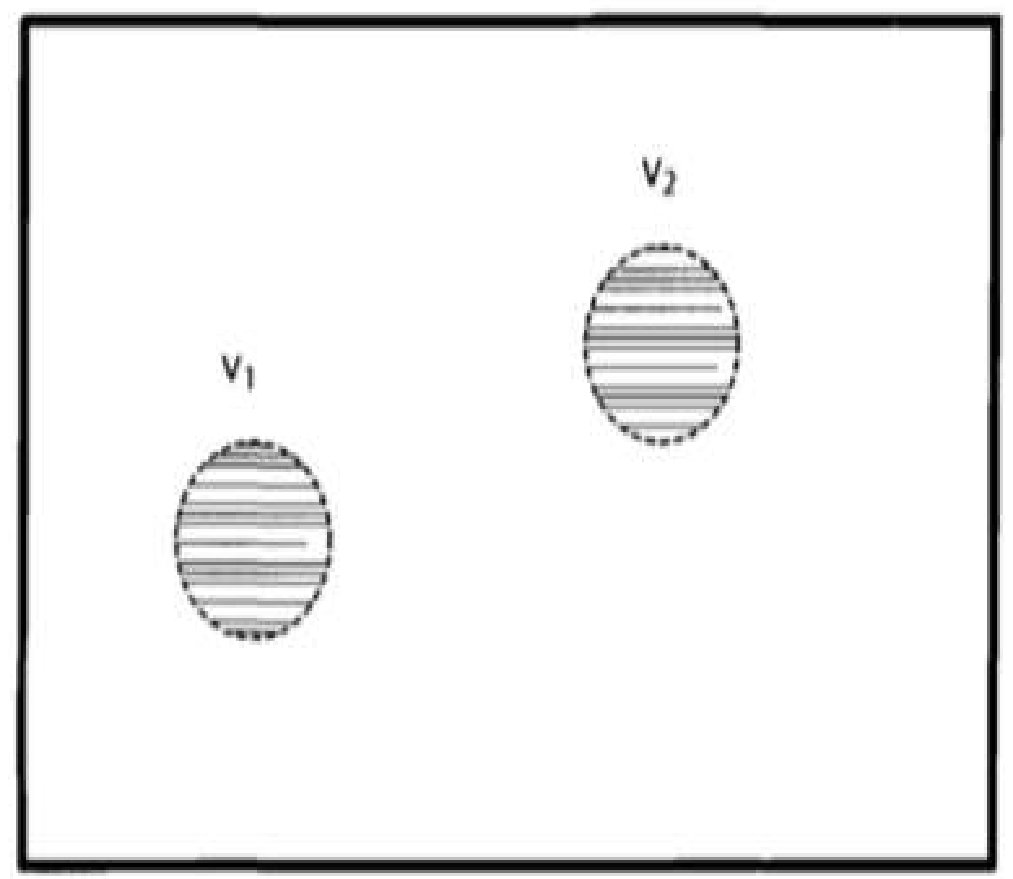

Figura 2.15: Iteração entre dois volumes elementares em um recipiente preenchido com gás - Adaptado de Danesh (1998)

As constantes $a$ e $b$ da equação são parâmetros da EOS determinados avaliando a curva $p \bar{v}$ para a temperatura crítica. A Figura 2.14 mostra que a curva tem um ponto de inflexão no ponto crítico, logo:

$$
\bar{v}\left(\frac{\partial p}{\partial \bar{v}}\right)_{T=T_{c}, p=p_{c}}=\left(\frac{\partial^{2} p}{\partial \bar{v}^{2}}\right)_{T=T_{c}, p=p_{c}}=0
$$

Existem 5 incógnitas, $T_{c}, p_{c}, \bar{v}_{c}, a$ e $b$ e 3 equações. Uma equação é usada para eliminar $\bar{v}_{c}$ e as duas equações restantes são expressões para $a$ e $b$ :

$$
a=\frac{27 \bar{R}^{2} T_{c}^{2}}{64 p_{c}}
$$




$$
b=\frac{\bar{R} T_{c}}{8 p_{c}}
$$

Conhecendo a pressão crítica e temperatura crítica de qualquer substância pura, e arrumando os termos da equação de van der Waals em função do volume molar chega-se a:

$$
\bar{v}^{3}-\left(b+\frac{\bar{R} T}{p}\right) \bar{v}^{2}+\frac{a}{p} \bar{v}-\frac{a b}{p}=0
$$

Segundo Pedersen et al. (2006), pode-se observar que a equação é cúbica em $\bar{v}$, o que explica porque as equações são conhecidas como equações cúbicas de estado. As EOS modernas melhoraram a previsão da curva pressão vapor através de adição de termos na equação de van der Waals. Além disso, muito esforço foi gasto na área para aprimorar o uso da aplicação em misturas de vários componentes, como por exemplo, na indústria do petróleo.

Equação de Redlich-Kwong (RK) De acordo com Pedersen et al. (2006), a equação de Redlich-Kwong (1949) é, considerada por muitos, a primeira EOS moderna, e sua forma é:

$$
p=\frac{\bar{R} T}{\bar{v}-b}-\frac{a}{\sqrt{T} \bar{v}(\bar{v}+b)}
$$

Ao comparar esta equação com a de van der Waals, pode-se notar que o termo de atração tem um termo com dependência da temperatura. Esta modificação tem o intuito de melhorar as predições da curva pressão-vapor. Os parâmetros $a$ e $b$ são determinados da mesma forma que van der Waals. As expressões ficam:

$$
\begin{gathered}
a=\frac{0.42748 \bar{R}^{2} T_{c}^{2,5}}{p_{c}} \\
b=\frac{0.08664 \bar{R} T_{c}}{p_{c}}
\end{gathered}
$$

Para uma mistura de $\mathrm{N}$ componentes, os parâmetros $a$ e $b$ acima são determinados usando as seguintes regras de mistura:

$$
\begin{gathered}
a=\sum_{i=1}^{N} \sum_{j=1}^{N} z_{i} z_{j} a_{i j} \\
b=\sum_{i=1}^{N} z_{i} b_{i}
\end{gathered}
$$

onde $z_{i}$ e $z_{j}$ são as frações molares dos componentes i e j, respectivamente. O 
termo $a_{i j}$ é determinado através da seguinte equação:

$$
a_{i j}=\frac{0.42748 \bar{R}^{2} T_{c i j}^{2.5}}{p_{c i j}}
$$

O termo $T_{c i j}$ está relacionado com as temperaturas críticas dos componentes puros da mistura, $T_{c i}$ e $T_{c j}$ :

$$
T_{c i j}=\sqrt{T_{c i} T_{c j}}\left(1-k_{i j}\right)
$$

Nesta expressão $k_{i j}$ é um coeficiente de interação binária entre os componentes i e j. Para dois componentes idênticos, $k_{i j}$ é zero por definição. Para dois componentes não polares, $k_{i j}$ é igual ou próximo de zero. Para um par de componentes com pelo menos um componente polar, valores diferentes de zero para $k_{i j}$ são apropriados. Finalizando, $p_{c i j}$ é determinado por:

$$
p_{c i j}=\frac{Z_{c i j} \bar{R}_{c i j}}{\bar{v}_{c i j}}
$$

onde

$$
Z_{c i j}=\frac{Z_{c i}+Z_{c j}}{2}
$$

e

$$
\bar{v}_{c i j}=\left(\frac{\bar{v}_{c i}^{1 / 3}+\bar{v}_{c j}^{1 / 3}}{2}\right)^{3}
$$

$Z_{c i}$ e $Z_{c j}$ são os fatores de compressibilidade dos componentes i e j dos componentes puros nos seus pontos críticos.

Equação de Soave-Redlich-Kwong (SRK) Segundo Pedersen et al. (2006), em 1972, Soave descobriu que as curvas pressão-vapor para componentes puros calculadas através da equação RK estavam de alguma forma imprecisas. Foi sugerido um novo termo de dependência da temperatura, $a(T)$, mais geral, deixando a equação com a seguinte forma:

$$
p=\frac{\bar{R} T}{\bar{v}-b}-\frac{a(T)}{\bar{v}(\bar{v}+b)}
$$

Esta equação é normalmente conhecida como Soave-Redlich-Kwong ou simplesmente equação SRK. Ele propôs o seguinte termo para expressar a dependência da temperatura no termo de atração:

$$
a(T)=a_{c} \alpha(T)
$$


onde

$$
\begin{gathered}
a_{c}=\frac{0.42747 \bar{R}^{2} T_{c}^{2}}{p_{c}} \\
b=\frac{0.08664 \bar{R} T_{c}}{p_{c}} \\
\alpha(T)=\left(1+m\left(1-\sqrt{\frac{T}{T_{c}}}\right)\right)^{2} \\
m=0.480+1.573 \omega-0.176 \omega^{2}
\end{gathered}
$$

Na equação acima, $\omega$ é o fator acêntrico, definido anteriormente.

Equação de Peng-Robinson (PR) As massas específicas previstas pela equação de SRK eram geralmente muito abaixo dos valores experimentais. Segundo Pedersen et al. (2006), em 1976, Peng e Robinson descobriram uma deficiência na equação de SRK no cálculo dos fatores de compressibilidade críticos para n-parafinas na faixa de $C_{1}$ a $C_{10}$. Foi sugerida a seguinte mudança na equação:

$$
p=\frac{\bar{R} T}{\bar{v}-b}-\frac{a(T)}{\bar{v}(\bar{v}+b)+b(\bar{v}-b)}
$$

onde

$$
\begin{gathered}
a(T)=a_{c} \alpha(T) \\
a_{c}=0.45724 \frac{\bar{R}^{2} T_{c}^{2}}{p_{c}} \\
\alpha(T)=\left(1+m\left(1-\sqrt{\frac{T}{T_{c}}}\right)\right)^{2} \\
m=0.37464+1.54226 \omega-0.26992 \omega^{2} \\
b=\frac{0.07780 \bar{R} T_{c}}{p_{c}}
\end{gathered}
$$

Foi sugerido então usar as regras de mistura apresentadas na equação de RK. Ainda segundo Pedersen et al. (2006), dois anos mais tarde, em 1978, Peng and Robinson apresentaram uma modificação no termo abaixo, para ser usado nos casos onde $\omega>0.49$ :

$$
m=0.379642+1.48502 \omega-0.164423 \omega^{2}+0.016666 \omega^{3}
$$

Fator de correção de volume de Peneloux De acordo com Pedersen et al. (2006), até 1982, a aplicação da EOS SRK foi limitada a cálculos de equilíbrio de fase e massa específica da fase gasosa uma vez que a previsão 
da massa específica da fase líquida não era muito acurada. Pedersen et al. (2006) comenta que em 1982 Peneloux apresentou uma modificação na EOS de SRK com um parâmetro de translação de volume. A EOS conhecida como SRK-Peneloux tem a forma:

$$
p=\frac{\bar{R} T}{\bar{v}-b}-\frac{a(T)}{(\bar{v}+c)(\bar{v}+b+2 c)}
$$

Segundo Pedersen et al. (2006), o parâmetro c é chamado de volume shift. Este parâmetro não tem influência no resultado do cálculo de equilíbrio de fases. A EOS SRK-Peneloux terá, por exemplo, as mesmas pressões de vapor e pontos de bolha que a EOS clássica de SRK. o parâmetro apenas influencia no volume molar e massa específicas. O conceito de translação de volume não é limitado a EOS de SRK, ele pode ser aplicado também na EOS de PR. Com a correção de volume, a EOS de PR-Peneloux torna-se:

$$
p=\frac{\bar{R} T}{\bar{v}-b}-\frac{a(T)}{(\bar{v}+c)(\bar{v}+2 c+b)+(b+c)(\bar{v}-b)}
$$

\subsubsection{3}

\section{Caracterização das frações pesadas de hidrocarboneto}

De acordo com Ahmed (2007), a fração plus dos componentes de petróleo agrupadas e identificadas como pseudocomponentes, por exemplo, fração $\mathrm{C}_{20+}$ e as frações com inúmeros isômeros, tais como $\mathrm{C}_{14}, \mathrm{C}_{15}$ precisam de uma descrição apropriada das propriedades termodinâmicas para se avaliar o comportamento das fases em modelos de fluido composicionais.

Para usar qualquer modelo de predição de propriedades termodinâmicas, por exemplo, equações de estado, é preciso saber o fator acêntrico, temperatura e pressão crítica para as frações da mistura. Além disso, por se tratar de uma mistura de componentes, coeficientes de interação binária $\left(k_{i j}\right)$ são necessários. Se uma EOS com translação de volume estiver sendo usada, o parâmetro $c$ também deverá ser definido para cada componente.

Normalmente as informações disponíveis para estas frações de petróleo podem ser divididas em 3 grupos:

1. Destilação fracionada: a fração indefinida é dividida em várias partes baseando-se na variação de ponto de ebulição de cada componente. Peso molecular, densidade e temperatura de ebulição de cada corte da destilação estarão disponíveis; 
2. Cromatografia: procedimento parecido com a destilação, que precisa de menor amostra e, portanto, é mais barato;

3. Nenhum dado de destilação é reportado, apenas a densidade e peso molecular da fração indefinida estão disponíveis.

Segundo Ahmed (2007), de acordo com os dados disponibilizados da amostra de petróleo, há 3 diferentes abordagens comumente usadas para gerar suas propriedades: correlações gerais, correlações baseadas na análise SARA das misturas e correlações gráficas.

Ahmed (2007) comenta que tratando-se das correlações gerais, pode-se citar o trabalho de Riazi and Daubert's (1980), que desenvolveram uma equação com dois parâmetros para estimar as propriedades físicas de componentes puros e misturas indefinidas de hidrocarbonetos. Carvett (1962) propôs correlações para estimar propriedades críticas das frações de hidrocarbonetos. As suas correlações são função da temperatura de ebulição e da massa específica de cada fração. Kesler and Lee (1976) também propuseram várias equações para estimar temperatura e pressão crítica, fator acêntrico e peso molecular das frações de petróleo. As equações usam a densidade e temperatura de ebulição como parâmetros. Sim e Daubert (1980), Watansiri, Owens e Starling (1985), Edmister (1958), Rowe (1978), Matthews, Roland e Katz (1942), Standing (1942), Willman e Teja (1987), Hall e Yarborough (1971), Magoulas e Tassios (1990) e Twu (1984) também foram importantes autores que trabalharam em correlações gerais para estimar propriedades das frações de petróleo.

Ahmed (2007) salienta que essas correlações são importantes no sentido de ser um ponto de partida em simuladores que realizam ajuste de equações de estado para representar as propriedades físicas de uma determinada mistura de petróleo. Como poderá ser visto adiante, o procedimento utilizado na indústria de petróleo é realizar ensaios laboratoriais da mistura de hidrocarbonetos e usar os resultados como função objetivo para prever de forma mais acurada a pressão crítica, temperatura crítica e fator acêntrico de cada componente pesado da mistura.

\subsubsection{4}

\section{Propriedades físicas geradas pela EOS}

De acordo com Pedersen et al. (2006), as EOS foram criadas primeiramente para realizar cálculo de quantidade e equilíbrio de fases, contudo, com o avanço computacional elas começaram a ser usadas para prever todas as propriedades importantes para as simulações que envolvem escoamento no meio poroso e escoamento nos poços e dutos. Propriedades como a massa específica, 
entalpia, entropia e calor específico são geradas a partir da EOS, garantindo uma consistente representação termodinâmica da mistura de fluido em questão.

Massa especfiíca Segundo Pedersen et al. (2006), as equações de estado cúbicas podem ser escritas como uma função polinomial de terceiro grau no volume molar $\bar{v}$ ou no fator de compressibilidade $Z$. Ao resolver a equação para o volume molar $\bar{v}$, para uma dada composição, se mais de uma raíz for encontrada, a solução com a menor energia livre de Gibbs é a correta (ou estável). Como o valor do peso molecular de cada componente é conhecido, a massa específica para cada componente pode ser encontrada através da seguinte relação:

$$
\rho=\frac{M}{\bar{v}}
$$

Entalpia De acordo com Pedersen et al. (2006), a entalpia H, para uma dada pressão e temperatura pode ser expressada como a soma de duas contribuições, a entalpia do gás ideal e residual

$$
H=\sum_{i=1}^{N} z_{i} h_{i}^{i d}+H^{r e s}
$$

onde $\mathrm{N}$ é o número de componentes, $z_{i}$ é a fração molar de cada componente $i$ na fase considerada e $h_{i}^{i d}$ é a entalpia por unidade de massa do gás ideal do componente $i$

$$
h_{i}^{i d}=\int_{T_{r e f}}^{T} c_{p_{i}}^{i d} d T
$$

onde $c_{p_{i}}^{i d}$ é o calor específico do componente $i$, nas condições ideias, que pode ser calculado a partir de um equação polinomial de terceiro grau na temperatura:

$$
c_{p_{i}}^{i d}=C_{1, i}+C_{2, i} T+C_{3, i} T^{2}+C_{4, i} T^{3}
$$

Os valores de $C_{1}$ a $C_{4}$ são tabelados para componentes definidos. Para os demais, os coeficientes são normalmente calculados a partir da correlação (apud Kesker \& Lee, 1976):

$$
\begin{gathered}
C_{1}=0,33886+0,02827 K-0,26105 C F+0,59332 \omega C F \\
C_{2}=\left(0,9291-1,1543 K+0,0368 K^{2}\right) \times 10^{4}+C F(4,56-9,48 \omega) \times 10^{4} \\
C_{3}=1,6658 \times 10^{7}+C F(0,536-0,6838 \omega) \times 10^{-7} \\
C_{4}=0
\end{gathered}
$$


onde $\omega$ é o fator acêntrico, $C F$ é definido como

$$
C F=\left(\frac{12,8-K}{10 w(10-K)}\right)^{2}
$$

e $K$ é o fator de caracterização de Watson:

$$
K=\frac{T_{e}^{\frac{1}{3}}}{d}
$$

$T_{e}$ é o ponto de ebulição e $d$ é a densidade.

Ainda de acordo com Pedersen et al. (2006), a entalpia residual pode ser derivada da equação de estado aplicando-se a seguinte relação termodinâmica:

$$
H^{r e s}=-R T^{2} \sum_{i=1}^{N} z_{i} \frac{\partial \ln \phi_{i}}{\partial T}
$$

onde $\phi_{i}$ é o coeficiente de fugacidade e $z_{i}$ é a fração molar do componente $i$. A entalpia é, ao contrário do equilíbrio de composição de fases, influenciado pelo fator volume de correção de Peneloux. A entalpia é então corrigida pela seguinte relação:

$$
H_{p e n}=H_{S R K / P R}-c \times p
$$

onde $p$ é a pressão e $c$ o fator volume de correção de Peneloux.

Energia interna A energia interna U está relacionada com a entalpia, $\mathrm{H}$, através da relação:

$$
u=h-p v
$$

onde $p$ é a pressão e $v$ o volume específico.

Entropia De acordo com Pedersen et al. (2006), a entropia pode ser calculada como a soma de duas contribuições, a entropia nas condições ideais e a entropia residual:

$$
S=\sum_{i=1}^{N} z_{i} s_{i}^{i d}+S^{r e s}
$$

A entropia do componente $i$ a temperatura $T$ pode ser calculado como:

$$
s_{i}^{i d}=\int_{T_{\text {ref }}}^{T} \frac{c_{p i}^{i d}}{T} d T-T \ln \frac{p}{p_{\text {ref }}}-R \ln z_{i}
$$


A $p_{\text {ref }}$ é a pressão de referência, normalmente 1 atm. A entropia residual é definida como:

$$
S^{r e s}=\frac{H^{r e s}}{T}-R \sum_{i=1}^{N} z_{i} \ln \phi_{i}
$$

A entropia não é influenciada pelo fator volume de correção de Peneloux.

Calor específico Segundo Pedersen et al. (2006), o calor específico a pressão constante é a derivada da entalpia em relação a temperatura mantida a pressão constante:

$$
c_{p}=\left(\frac{\partial h}{\partial T}\right)_{p}
$$

O calor específico a volume constante é relacionado ao calor específico a pressão constante através da seguinte formulação:

$$
c_{v}=c_{p}-T\left(\frac{\partial v}{\partial T}\right)_{p}\left(\frac{\partial p}{\partial T}\right)_{v}
$$

As derivadas acima são calculadas através da EOS. O calor específico não é influenciado por um possível fator volume de correção de Peneloux, que é contante em $T$.

Coeficiente Joule-Thomsom De acordo com Pedersen et al. (2006), o coeficiente de Joule-Thomson é definido como a derivada da temperatura em relação a pressão para entalpia constante e é relacionado ao $c_{p}$ através da seguinte relação:

$$
\mu_{j}=\left(\frac{\partial T}{\partial p}\right)_{h}=-\frac{1}{c_{p}}\left(\frac{\partial h}{\partial p}\right)_{T}
$$

\subsubsection{5}

\section{Propriedades de transporte reológicas}

Viscosidade Pedersen et al. (2006) comenta que, quando uma tensão externa é aplicada a um fluido, como ilustrado na Figura 2.16, é iniciado o movimento das moléculas da parte do fluido afetado na direção da tensão aplicada. O movimento das moléculas impactarão nas moléculas vizinhas que também iniciarão a se mover, contudo a velocidade será menor ao se comparar com as moléculas inicialmente expostas a tensão.

Pedersen et al. (2006) também fala que a viscosidade nada mais é que um fator de proporcionalidade para calibrar a transferência de quantidade de 
movimento entre moléculas que estão se movendo adjacentes uma as outras. A viscosidade dinâmica, $\eta$, é definida como:

$$
\eta=\frac{\tau_{x y}}{\frac{\partial v_{x}}{\partial y}}
$$

onde $\tau_{x y}$ é a tensão de cisalhamento aplicada ao fluido, $v_{x}$ é a velocidade do fluido na direção $x$ e $\frac{\partial v_{x}}{\partial y}$ é a taxa de cisalhamento. A unidade SI para a viscosidade é $N \mathrm{seg} / \mathrm{m}^{2}$, contudo na indústria de petróleo a unidade comumente utilizada é centipoise $(\mathrm{cP})$. Estas duas unidades estão relacionadas da seguinte forma: $1 \mathrm{Ns} / \mathrm{m}^{2}=1 \mathrm{Pas}=1000 \mathrm{cP}$.

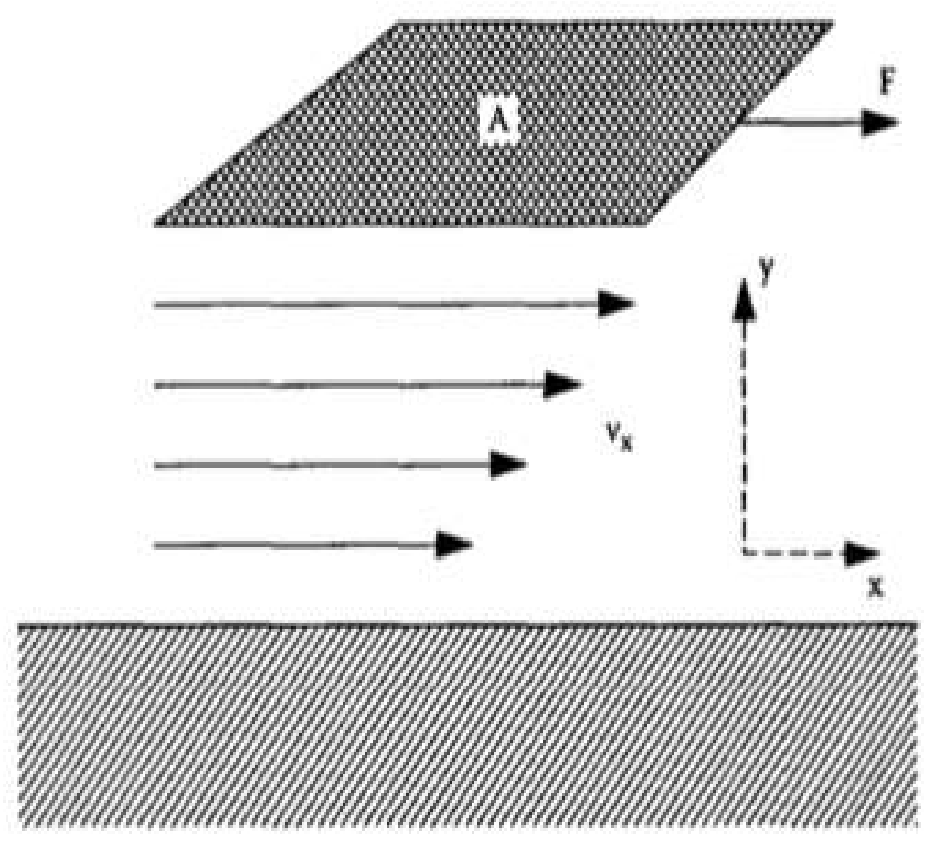

Figura 2.16: Tensão externa aplicada a uma porção de um fluido. Os termos na figura são usados na definição de viscosidade - Adaptado de Pedersen et al. (2006)

Pedersen et al. (2006) advoga que, se a viscosidade é independente da taxa de cisalhamento, o fluido é dito Newtoniano. A Figura 2.17 ilustra o comportamento de fluido Newtoniano e também três tipos de fluidos nãoNewtonianos. Fluidos pseudoplásticos e dilatantes são caracterizados por uma relação não linear entre a taxa de cisalhamento e a tensão de cisalhamento. A viscosidade de fluidos pseudoplásticos decresce com o aumento da taxa de cisalhamento enquanto que o contrário ocorre com fluidos dilatantes. O fluido conhecido como plástico de Bingham é similar ao fluido Newtoniano no sentido da relação linear entre taxa e tensão de cisalhamento, contudo ele exige uma 
tensão de cisalhamento inicial para começar o fluxo.

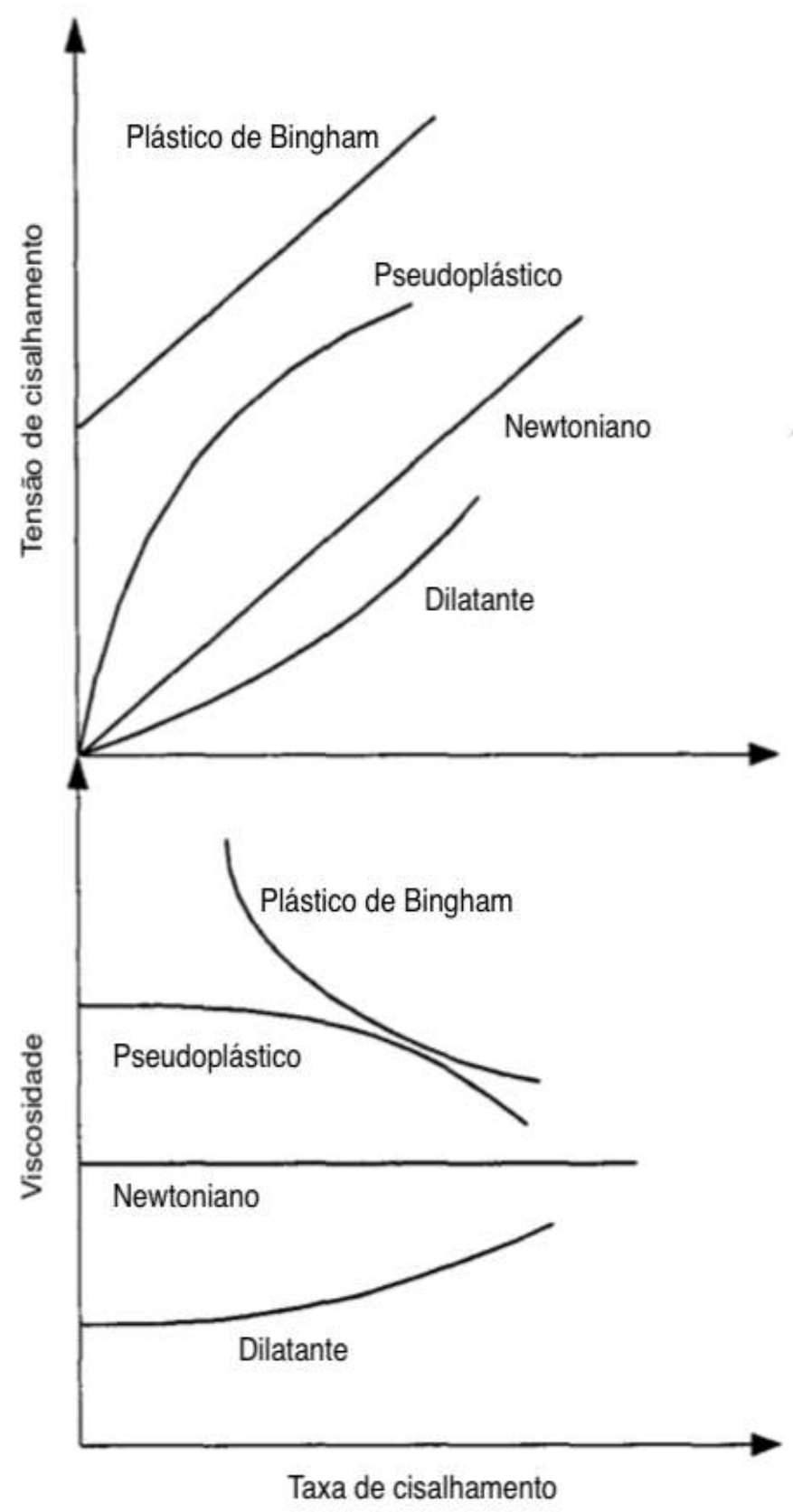

Figura 2.17: Tensão externa aplicada a uma porção de um fluido. Os termos na figura são usados na definição de viscosidade - Adaptado de Pedersen et al. (2006)

Segundo Pedersen et al. (2006) e Ahmed (2007), a viscosidade é uma propriedade chave para simulações de fluxo no meio poroso, projeto de poço e dutos e para as simulações de processamento primário de petróleo nas UEP. Em condições de reservatório ela varia na faixa de $0,1 \mathrm{cP}$ para misturas de óleo leve a $100 \mathrm{cP}$ para óleos pesados. No escoamento nos poços e dutos, com 
a diminuição da temperatura os valores de viscosidade podem chegar na faixa de milhares de $\mathrm{cP}$.

Ainda segundo Ahmed (2007), a viscosidade tem forte relação com a temperatura, pressão, massa especifíca do óleo e do gás, quantidade de gás dissolvido e composição do óleo. Sempre que possível, a viscosidade deve ser determinada em laboratório em condições de subsupperfície, isto é, nas condições de pressão e temperatura do reservatório, e também nas condições padrão em várias temperaturas. Dependendo da pressão, a viscosidade do óleo pode ser classificada em três categorias:

1. Viscosidade do óleo morto, $\eta_{o d}$. É a viscosidade da mistura de óleo sem gás em solução, em condições standard de pressão e a temperatura, T;

2. Viscosidade do óleo saturado, $\eta_{o b}$. É a viscosidade da mistura de óleo em qualquer pressão menor ou igual que a pressão do ponto de bolha da mistura e a temperatura, $T$;

3. Viscosidade do óleo subsaturado, $\eta_{o}$. É a viscosidade da nistura de óleo nas pressões acima do ponto de bolha da mistura, e na temperatura $T$.

A viscosidade do óleo morto é a máxima em uma mistura, uma vez que não há mais gás dissolvido no óleo. O valor mínimo de viscosidade é atingido na pressão de ponto de bolha da mistura, onde todo o gás está dissolvido no óleo. Com o aumento da pressão acima do ponto de bolha e consequente compressão do óleo, a viscosidade volta a aumentar.

Segundo Ahmed (2007), as correlações usadas em simulação numérica variam desde as mais simples que requerem apenas propriedades básicas como o ${ }^{\circ}$ API e temperatura, (apud Beggs \& Robinson, 19-) para a viscosidade do óleo e (apud Carr-Kobayashi-Burrows's, 19-) para a viscosidade do gás que depende apenas da temperatura, pressão e densidade do gás.

Ainda segundo Ahmed (2007), as correlações mais complexas usam a composição da mistura de fluido em questão. A correlação comumente usada na indústria vem do trabalho de Lohrenz, Bray e Clark que acabou sendo batizada pelas iniciais dos autores, LBC. Essas correlações são as usualmente adotadas quando modelos numéricos composicionais que utilizam equações de estado estão sendo usados, que é o caso deste trabalho.

Segundo Pedersen et al. (2006), a correlação LBC expressa as viscosidade de gás e óleo como um polinômio de quarta ordem em função da massa específica reduzida, $\rho_{r}$. Os autores propuseram a seguinte equação geral:

$$
\eta_{o b}=\eta_{o}+\frac{\left[a_{1}+a_{2} \rho_{r}++a_{3} \rho_{r}^{2}+a_{4} \rho_{r}^{3}+a_{5} \rho_{r}^{4}\right]^{4}-0,0001}{\xi_{m}}
$$


e as constante $a_{1}$ a $a_{5}$ podem ser vistas na Tabela 2.8.

Tabela 2.8: Parâmetros na correlação de viscosidade de óleo e gás de LBC - Adaptado de Pedersen et al. (2006)

\begin{tabular}{cl} 
Parâmetro LBC & Valor da constante \\
\hline$a_{1}$ & 0,10230 \\
\hline$a_{2}$ & 0,023364 \\
\hline$a_{3}$ & 0,058533 \\
\hline$a_{4}$ & $-0,040758$ \\
\hline$a_{5}$ & 0,0093324 \\
\hline
\end{tabular}

Mais detalhes a respeito da correlação LBC podem ser encontrados nas referências [2] e [3]. Uma vez que esta correlação é executada rapidamente nos computadores atuais, ela é usualmente a escolha preferida em estudos envolvendo modelos composicionais de propriedades PVT.

Condutividade térmica De acordo com Pedersen et al. (2006), a condutividade térmica é um fator de proporcionalidade, $\lambda$, entre o fluxo de calor por unidade de área, $q$, e o gradiente de temperatura na direção do fluxo de calor, $d T d x$ :

$$
q=-\lambda\left[\frac{d T}{d x}\right]
$$

A condutividade térmica do fluido é uma importante variável, principalmente nos estudos de escoamento nos poços e dutos, uma vez que ela influencia a troca de calor e, consequentemente, o perfil de temperatura no poço e dutos até chegar na UEP. A correta estimativa do perfil de temperatura é necessária para avaliar riscos de precipitação de sólidos ao longo do escoamento (parafinas, hidratos, incrustações).

As equações de estado podem ser usadas para prever a condutividade térmica usando a teoria de estados correspondentes, pois sabe-se que ela é função da pressão reduzida e temperatura reduzida:

$$
\lambda_{r}=f\left(p_{r}, T_{r}\right)
$$

Mais detalhes a respeito da formulação podem ser encontrados na referência [2].

Tensão interfacial gás/óleo Segundo Danesh (1998), o equilíbrio de fases é afetado por forças de superfície e, portanto, é importante avaliar essa 
propriedade através das equações de estado. Sempre existirá uma tensão na interface de duas fases de um fluido, devido ao balanceamento de forças moleculares de repulsão e atração. Pedersen et al. (2006) comenta que a tensão superficial pode ser interpretada como a resistência do líquido ao aumento da área de superfíicie em contato com outra fase, normalmente gás. A unidade SI para tensão superficial é $N / m$. Na indústria de petróleo normalmente é usada a unidade dina $/ \mathrm{cm}$. Estas duas unidades estão relacionadas da seguinte forma: $1 \mathrm{~N} / \mathrm{m}=10^{3}$ dina $/ \mathrm{cm}$.

Danesh (1998) comenta que o conhecimento da tensão superficial é necessário para simular corretamente o fluxo na escala do tamanho dos poros nos reservatórios. A pressão capilar é o conceito usado nos estudos de reservatório para considerar o efeitos de forças de superfície na distribuição de fluido no reservatório. A pressão capilar está relacionada à tensão interfacial e às características do meio poroso. Sabe-se também que a permeabilidade relativa, que descreve o fluxo multifásico nas rochas reservatórios depende fortemente da tensão interfacial. Além disso, a avaliação da tensão interfacial gás-líquido é de enorme interesse em processos de injeção de gás em reservatórios de óleo, já que as magnitudes relativas das forças de superfície, gravitacionais e viscosas afetam a recuperação do petróleo.

Danesh (1998) e Ahmed (2007) também salientam que a tensão interfacial também desempenha um papel importante no fluxo multifásico nos poços e dutos. Essa propriedade é usada para calcular o escorregamento entre as fases e para definir padrões de escoamento em simuladores de escoamento multifásico em dutos.

Danesh (1998) também comenta que a tensão interfacial em altas pressões é normalmente medida através do método do peso da gota. Um equilíbrio entre força de tensão superficial e a força peso da gota mantém juntas as duas partes de uma coluna líquida. Quando a força esta equilibrada pela massa da porção inferior, a gota desprende-se. A Figura 2.18 mostra esquematicamente o aparato. O tamanho da gota em condições estáticas, controlado pelo balanço das forças gravitacional e de superfície, é determinado e relacionado com a tensão interfacial gás-líquido através da seguinte relação:

$$
\sigma=\frac{g d_{e}^{2}}{l}\left(\rho_{L}-\rho_{V}\right)
$$

onde $g$ é a acelaração da gravidade, $\rho_{L}$ e $\rho_{V}$ são as massas específicas do líquido e do gás e $l$ é um fator de forma da gota que é função da geometria da gota dada pelas medidas $d_{s}$ e $d_{e}$. Este método de medição pode ser aplicado para avaliar a tensão interfacial de misturas de petróleo. 


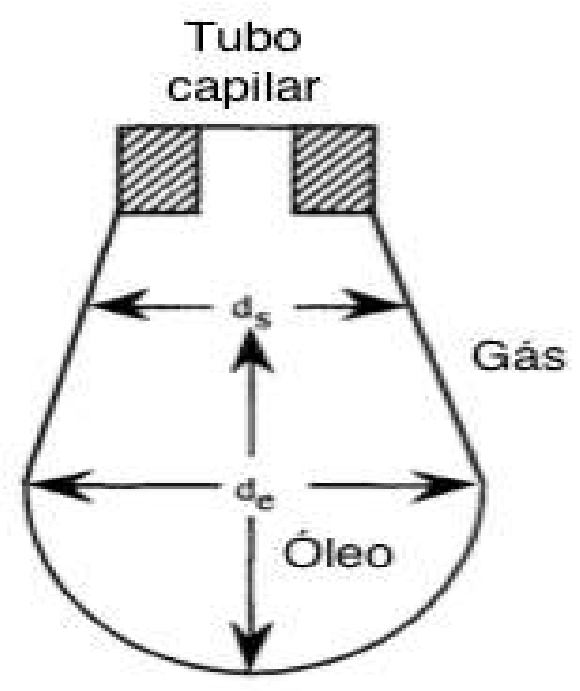

Figura 2.18: Método de medição de tensão interfacial através do peso da gota - Adaptado de Danesh (1998)

De acordo com Danesh (1998), a tensão interfacial entre fluidos de reservatório pode ser prevista por vários métodos. Embora alguns deles tenham fundamentos teóricos, requerem parâmetros determinados experimentalmente. A tensão interfacial de componentes puros pode ser relacionada por várias propriedades de fluidos, tais como massa específica, compressibilidade e calor latente de vaporização. A relação entre a tensão interfacial e a massa específica foi estendida para sistemas multicomponentes com sucesso, logo é largamente utilizada na indústria do óleo e gás.

Ainda de acordo com Danesh (1998), o método mais usado na indústria de petróleo para prever a tensão interfacial é através do fator Parachor (apud Macleod, 1923), onde a tensão interfacial de um componente puro está relacionado com a diferença de massa específica entre as duas fases, iesto é:

$$
\sigma^{\frac{1}{4}}=P_{\sigma}\left(\rho_{M}^{L}-\rho_{M}^{V}\right)
$$

onde $\rho_{M}^{L}$ e $\rho_{M}^{V}$ são a massa específica molar da fase líquida e gasosa, respectivamente, em gmolcm $^{3}$ e $\sigma$ em $m N m$.

Segundo Danesh (1998), a constante de proporcionalidade $P_{\sigma}$, conhecida como Parachor, é um parâmetro que representa o volume molecular de um componente sobre condições onde o efeito de temperatura está neutralizado. É considerado apenas um único valor para cada componente independente da pressão e temperatura. Os valores de Parachor para vários componentes puros são conhecidos graças as medições em laboratório de tensão interfacial usando a equação acima. 
Ainda segundo Danesh (1998), os valores de Parachor de hidrocarbonetos com o mesmo número de carbonos na cadeia mostram uma relação quase linear com o peso molecular. Uma correlação bastante usada para estimar esta relação é:

$$
P_{\sigma}=21,99+2,892 M
$$

Na Tabela 2.9 a seguir podem ser vistos os valores de Parachor experimentais até $n C 7$. A partir do componente $n C 8$ os valores foram estimados com a correlação acima.

Tabela 2.9: Valores de Parachor de componentes puros - Adaptado de Danesh (1998)

\begin{tabular}{cl} 
Componente & Parachor \\
\hline$C O 2$ & 78,0 \\
\hline$N 2^{\dagger}$ & 41,0 \\
\hline$C 1$ & 77,0 \\
\hline$C 2$ & 108,0 \\
\hline$C 3$ & 150,3 \\
\hline$i C 4$ & 181,5 \\
\hline$n C 4$ & 189,9 \\
\hline$i C 5$ & 225,0 \\
\hline$n C 5$ & 231,5 \\
\hline$n C 6$ & 271,0 \\
\hline$n C 7$ & 312,5 \\
\hline$n C 8$ & 351,5 \\
\hline$n C 9$ & 393,0 \\
\hline$n C 10$ & 433,5 \\
\hline$n C 11$ & 474,1 \\
\hline$n C 12$ & 514,7 \\
\hline$n C 13$ & 555,2 \\
\hline$n C 14$ & 595,8 \\
\hline$n C 15$ & 636,4 \\
\hline$n C 16$ & 676,9 \\
\hline
\end{tabular}

† O valor informado é para nitrogênio em misturas de hidrocarboneto. O valor para nitrogênio puro é 60,0

Danesh (1998), (apud Firoozabadi, (1988), comenta que a relação entre o número de Parachor e o peso molecular dos grupos de hidrocarbonetos separados por grupos de números de carbono desvia-se da linearidade. Isto é esperado uma vez que o peso da relação varia bastante entre hidrocarbonetos 
homólogos. A composição do petróleo, isto é, a quantidade de saturados, aromáticos, resinas e asfaltenos em cada grupo não é o mesmo, resultando em uma relação não-linear. A equação proposta foi a seguinte:

$$
P_{\sigma}=-11,4+3,23 M-0,0022 M^{2}
$$

\subsection{4}

\section{Ajuste de uma equação de estado cúbica através de uma regressão não- linear}

De acordo com Danesh (1998), uma importante consideração em aplicar um modelo para prever o comportamento de fases de um estudo de reservatórios é a ampla faixa de pressão e composição que deve ser modelada pela EOS. Em modelos integrados de produção, o comportamento de fases precisa prever corretamente as propriedades de diferentes reservatórios, e a mistura destes fluidos em poços, dutos e separadores em apenas uma simulação, tornando a tarefa ainda mais difícil fazendo com que o modelo normalmente não gere resultados satisfatórios.

Segundo Pedersen et al. (2006) e Ahmed (2007), além da complexidade do problema dos modelos integrados, as equações de estado podem prever comportamentos errados, particularmente para fluidos muito voláteis. Fluidos reais, encontrados em reservatórios de petróleo, são compostos por milhares de componentes e descritos por apenas um limitado número de substâncias puras e grupos de carbono. A análise composicional destes fluidos nem sempre é confiável ou então não são perfeitamente definidas. Correlações generalizadas são usadas para estimar propriedades críticas dos grupos de carbono. Finalmente, devido ao tempo de computação elevado em simulações composicionais, o agrupamento de componentes é mandatório. Todos estes fatores deterioram a predição de propriedades PVT de uma EOS para fluidos reais.

Conforme Danesh (1998), a abordagem comum para contornar as deficiências acima é calibrar o modelo contra dados experimentais em condições de produção. A seleção de dados e parâmetros da EOS para ajuste no processo e o uso de métodos relevantes consitituem um dos trabalhos mais importantes do engenheiro de reservatório e escoamento em dutos.

Ainda conforme Danesh (1998), embora a indústria não tenha um método padrão para o ajuste, a sistemática é similar: valores com incerteza nos dados de entrada nos modelos são ajustados para minimizar a diferença entre o que a EOS está prevendo e os dados encontrados nas análises laboratoriais. O exercício consiste basicamente em minimizar uma função objetivo, definida 
como a soma dos desvios quadrados ponderados.

$$
\delta=\sum_{j=1}^{N_{\text {dados }}}\left[w_{j}\left(\frac{\psi_{j}^{\text {prev }}\left(X_{i}\right)-\psi_{j}^{\text {exp }}}{\psi_{j}^{\exp }}\right)\right]^{2}
$$

onde cada elemento da função objetivo expressa a diferença ponderada entre os valores previstos e experimentais, $\psi^{\text {pred }}$ e $\psi^{\exp }$, respectivamente; $w$ é um fator para enfatizar ou diminuir o peso de uma variável na função objetivo e $N_{\text {data }}$ expressa o número de dados medidos a serem ajustados. $X_{i}$ designa as variáveis usadas na regressão. O problema passa a ser encontrar os ótimos valores das variáveis que são incertas para minimizar a função objetivo $\delta$.

Segundo Danesh (1998), os parâmetros normalmente usados para o ajuste são os coeficientes de interação binária, as propriedades dos componentes indefinidos da mistura (frações acima de $C 6$ ), principalmente as propriedades críticas, e também alguns parâmetros da EOS. Em regressão multi-variável, o ajuste dos parâmetros que possuem maiores valores para a derivada da função objetiva em relação a certo parâmetro é normalmente a solução mais elegante.

Danesh (1998) comenta que a seleção dos $k_{i j}$ como variável de regressão é principalmente devido ao fato de que estes coeficientes estão mais para um parâmetro de ajuste do que para uma propriedade física, logo, ajustar os coeficientes de interação binária entre os componentes mais leve da mistura, (presentes em maior concentração), e os componentes mais pesados é bastante comum. Além disso, conforme mencionado, é bastante efetivo em mudar a previsão dos resultados da EOS.

As propriedades críticas e o fator acêntrico dos componentes indefinidos são, provavelmente, o dado de entrada com a menor acurácia, e portanto, podem ser usados no ajuste. As propriedades críticas são, na maioria das vezes, estimadas a partir da densidade e do ponto de ebulição ou peso molecular das frações. Desvios na faixa de $\pm 6 \%$ para a temperatura crítica e fator acêntrico e $\pm 30 \%$ para a pressão crítica de hidrocarbonetos podem ser gerados a partir destas correlações. A concentração das frações plus $(C 20+)$ e suas propriedades provavelmente são os dados de entrada menos confiáveis e, sem dúvida, seu ajuste é bastante justificado. A fração plus afeta enormemente a predição das propriedades, especialmente em fluidos voláteis e fluidos do tipo gás retrógrado.

Danesh (1998) também salienta que, é sempre aconselhável diminuir o número de variáveis na regressão para evitar problemas numéricos e melhorar a busca pelo mínimo global da função objetivo. Embora o ajuste simultâneo de variáveis na regressão pode levar a resultados satisfatórios, a seleção dos parâmetros que mais influenciam acaba sendo mais apropriado. Por exemplo, ao usar as EOS com correção de volume de Peneloux, a massa específica 
pode ser inicialmente deixada de fora da regressão. Depois, o parâmetro volume shift dos componentes indefinidos podem ser ajustados para calibrar os dados medidos de massa específica em laboratório. Para as propriedades de trasnsporte, como a viscosidade, realizar a regressão em separado aos dados que influenciam no equilíbrio de fases também é uma boa prática, já que tratam-se de fenômenos físicos diferentes.

Finalmente, Danesh (1998), reitera que é importante também manter a consistência dos parâmetros após regressão quando mais de uma variável está sendo usada para o ajuste global da EOS. A temperatura crítica, fator acêntrico e temperatura de ebulição devem geralmente crescer com o peso molecular e os números de pseudo-componentes, pelo contrário, a pressão crítica segue o caminho inverso.

Pedersen et al. (2006) comenta que é sempre importante lembrar que a EOS após regressão, se usada para prever propriedades PVT em condições muito diferentes dos ensaios laboratoriais usados na regressão, poderá a levar a valores errados.

\subsection{5}

\section{Técnicas de agrupamento/desagrupamento (Lumping/Delumping)}

Equações de estado são frequentemente sobrecarregadas por um grande número de frações necessárias para descrever a mistura de hidrocarbonetos com acurácia suficiente para simulação numérica do comportamente de suas fases. Contudo, o custo computacional requerido aumenta consideravelmente com o número de componenentes usados para descrever o fluido.

Em um simulador, o reservatório ou tubulação são comumente dividido em células. Os fluidos em cada célula são considerados em equilíbrio na temperatura e pressão. As mudanças nas condições do reservatório e tubulações, ao longo do tempo e espaço, são investigadas determinando-se valores médios para as propriedades PVT para cada célula durante sucessivos pequenos passos de tempo.

A condição de equilíbrio dentro do passo de tempo é determinado através de cálculos de flash em cada célula. Uma vez que a solução é iterativa, para um sistema de produção de tamanho razoável, milhões de equilíbrios flash são realizados a cada passo de tempo.

Segundo Danesh (1998), é natural que a qualidade da descrição do fluido varie com a complexidade do processo que se deseja modelar. O comportamento de fases de um fluido de reservatório produzindo por depleção pode ser modelado por apenas dois componentes, enquanto que mais de dez podem ser necessários para representar estudos de miscibilidade na injeção de gás em 
um reservatório. Em modelos integrados de produção composicionais, o efeito da simplificação da EOS é pouco conhecido e é a principal motivação deste trabalho.

Danesh (1998) e Ahmed (2007) concluem que desta forma, sabendose que o número de cálculos de equilíbrio aumentam com o número de componentes, a redução de variáveis através de técnicas de agrupamento é prática comum na indústria de petróleo para acelerar as simulações.

Segundo Danesh (1998), os pontos chave em técnicas de agrupamento/desagrupamento são:

1. O número de grupos requeridos e a distribuição de componentes em cada grupo;

2. A estimativa das propriedades de cada grupo na modelagem de comportamento das fases;

3. O desagrupamento (delumping) da descrição do fluido na forma original quando necessário.

A técnica usada para simplificar a EOS detalhada neste trabalho é basicamente a proposta por vários autores [1] [2] [3] [6]. As técnicas mais comuns são: agrupamento de compostos com pesos moleculares semelhantes; evitar agrupar não-hidrocarbonetos, por exemplo $\mathrm{CO}_{2}$; e evitar o agrupamento da fração plus $(C 20+)$ com outros pseudocomponentes. Alavian et al. (2014) comenta que a quantidade de possíveis combinações de agrupamento para uma EOS simplificada pode ser astronômica. Por exemplo, uma EOS detalhada com 22 componentes pode ser agrupada em uma EOS simplificada de 9 pseudocomponentes de $1,8 \cdot 10^{11}$ formas diferentes. Vários destes agrupamentos são intuituivamente ilógicos, por exemplo, agrupar $C 1 \mathrm{com}$ a fração plus.

Outro ponto importante, objeto deste estudo, é que o agrupamento que pode ser ótimo para descrever o fenômeno de fluxo no meio poroso no reservatório pode não descrever o fenômeno de escoamento em poços, dutos e processamento na UEP, por exemplo, um agrupamento pode representar muito bem a pressão de saturação no meio poroso, contudo, o equilíbrio de fases nas temperaturas de interesse de escoamento não é bem representado. Desta forma, o agrupamento sempre deve ser validado em relação a EOS detalhada de forma a ser usado em modelos de engenharia. 


\section{3}

\section{Modelagem Integrada de Produção}

\section{1}

\section{Introdução}

De acordo com Cotrim (2012), os MIP são usados quando se necessita de uma análise mais detalhada da interação entre o modelo de subsuperfície (fluxo no meio poroso) e o modelo de escoamento nos poços e tubulações (fluxo em dutos). Normalmente a flexibilidade e precisão provenientes desta modelagem não justificam o grande esforço empregado na sua obtenção, contudo em algumas situações o uso desta abordagem traz ganhos valiosos e compensadores.

A MIP é interessante nos casos em que a complexidade nos sistemas de produção é tamanha que as ferramentas usuais de simulação não são capazes de representar com o rigor necessário para se tomar decisões de engenharia, que normalmente envolvem quantias substanciais de investimento. Por exemplo, quando os poços produtores e injetores estão interligados à UEP de forma direta, arranjo conhecido como satélite e ilustrado na Figura 3.1 abaixo, uma simples tabela com dados de pressão nos canhoneados para cada condição de fluxo gerada por um simulador de escoamento desacoplado do modelo de reservatório é suficiente para representar o fluxo no poço e no duto.

Quando o sistema de produção torna-se mais complexo, como em sistemas conhecidos como trunklines de produção e injeção e manifolds, ilustrados nas Figura 3.2 e Figura 3.3, no qual os poços não estão mais conectados diretamente à UEP mas sim a uma rede convergente que então é encaminhada para a plataforma, uma tabela com pressões não é mais suficiente para representar adequadamente o escoamento. Tradicionalmente pode-se gerar duas tabelas, uma a montante do ponto de encontro da rede e outra tabela a jusante do ponto de encontro. No caso de fluidos diferentes em cada poço a questão da representação do fluido já começa a se mostrar relevante.

Em modelos integrados de produção a representação destes sistemas é bastante simples e mais intuitiva, gerando menos problemas de interface entre engenheiros de elevação e escoamento e de reservatórios. O sistema conhecido como anel de coleta, que nada mais é que dois trunklines unidos e coletando a 


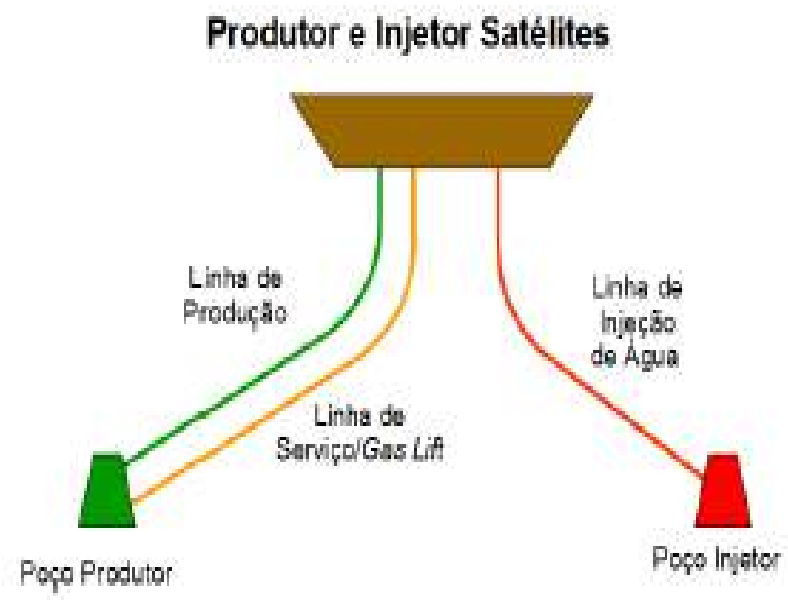

Figura 3.1: Arranjo de produção e injeção satélite.

produção de vários poços, também tem sua representação mais adequada em modelos integrados de produção.

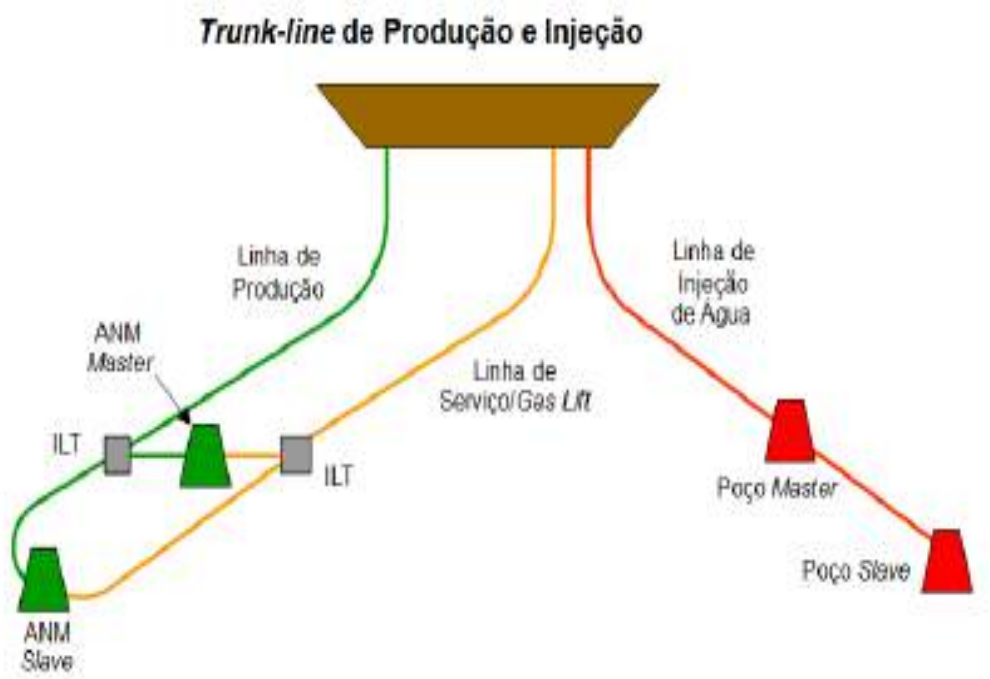

Figura 3.2: Arranjo de produção trunkline.

Sistemas de bombeamento, muito comuns em campos com longo tieback, também são melhores representados com MIP. A Figura 3.4 mostra um sistema de produção operando com uma bomba multifásica no leito marinho. Esse método de elevação artificial é conhecido como bombeio multifásico submarino (BMS). Em MIP, é possível obter um detalhamento maior da curva de diferencial de pressão em função da vazão entregue pela BMS do que é possível em simulações desacopladas.

Em modelos desacoplados de produção, o tratamento comumente dado 


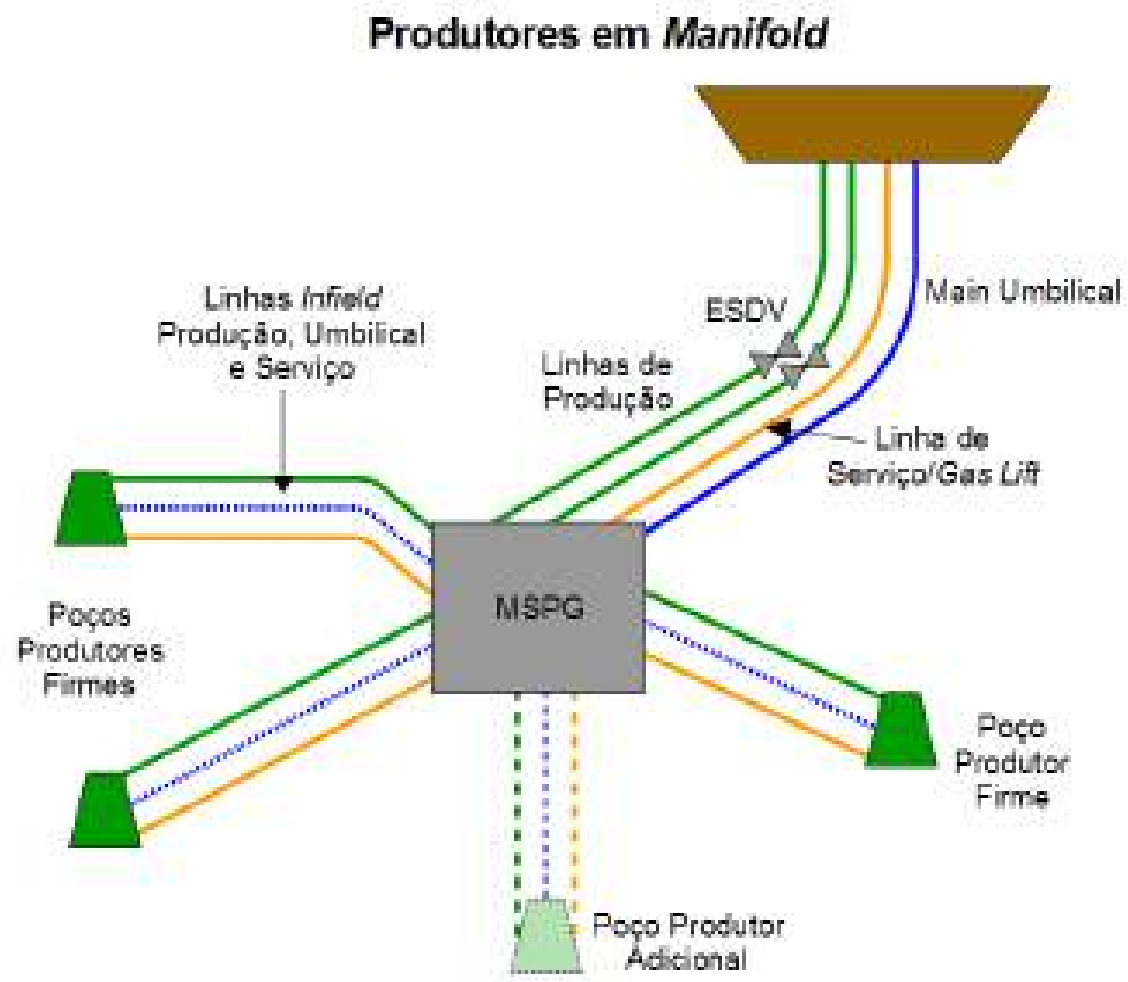

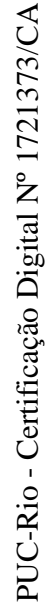

Figura 3.3: Arranjo de produção manifold

é segregar o escoamento até a entrada da bomba e considerar este ponto com pressão fixa. Esta abordagem não é rigorosa e as curvas de produção geradas a partir deste modelo podem não representar a realidade.

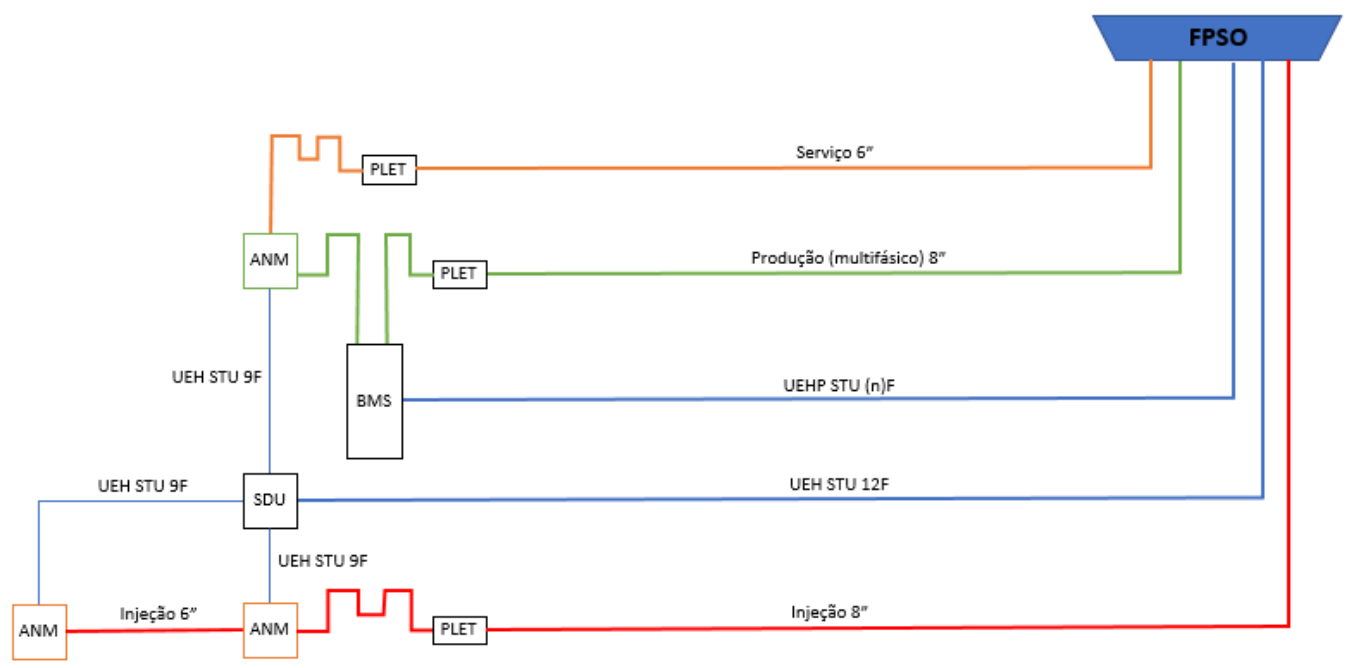

Figura 3.4: Arranjo de produção satélite e injeção trunkline operando com bombeamento multifásico. 
Outro típico sistema difícil de representar através de tabelas de pressão são os sistemas de processamento submarino. A complexidade demandada atualmente para a viabilização de projetos offshore pode trazer o processamento de fluidos para o leito marinho, e não mais na UEP. Em sistemas de produção em revitalização, com altas produções de água, pode ser útil, por exemplo, utilizar um sistema para separar a água do óleo ainda no leito marinho e efetuar a reinjeção no reservatório, sem passar na UEP.

Da mesma forma, sistemas com alto teor de $\mathrm{CO}_{2}$ podem ter essa fração separada ainda no leito marinho e já reinjetada sem passar por processamento na UEP, diminuindo o custo em dutos e na plataforma. Além disso, a separação gás-líquido com posterior bombeamento é um método que pode trazer aumento de VPL nos projetos, dada sua capacidade de antecipar a produção de óleo. A Figura 3.5 ilustra um sistema operando com separação submarina gás-líquido (SSGL).

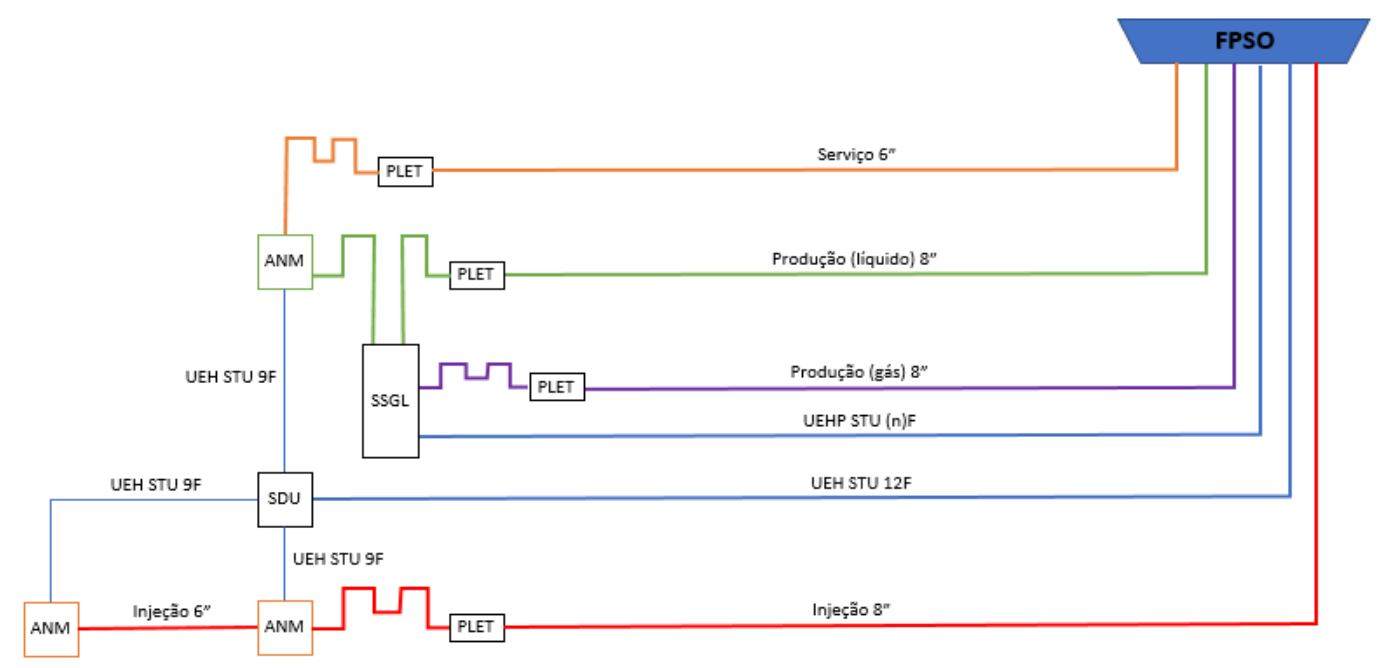

Figura 3.5: Arranjo de produção satélite e injeção trunkline operando com SSGL.

Como pode-se notar, o sistema é muito parecido com o BMS, exceto pelo sistema de separação gás-líquido. O fluido multifásico chega no vaso onde as fases são separadas e escoam separadamente até a UEP. O duto de produção de líquido possui uma bomba para ajudar no diferencial de pressão necessário para a fase líquida chegar na UEP. Este sistema só consegue ser tratado de forma rigorosa através de simulação integrada de produção.

Segundo Cotrim (2012) e Machado (2012), outra situação complexa que é contornada através de MIP é quando diversas unidades isoladas de reservatórios, cada qual sendo estudada separadamente e caracterizada por 
seu próprio modelo de simulação, têm como destinação da produção uma única UEP. Isto é comum em reservatórios marginais que não justificam um sistema de produção de forma isolada. Imagine a situação em que 3 reservatórios produzem para a mesma UEP e que também usufruam dela para receber fluidos de injeção. Como os reservatórios estão sujeitos às mesmas restrições da UEP que é única, o MIP traz uma garantia que as restrições internas (limite de vazão de escoamento, limite da planta de tratamento, limite da cota de injeção, etc) sejam respeitadas. Em simulações convencionais, cada reservatório consitui de um modelo com restrições independentes, Com o MIP, esses vários modelos podem ser acoplados de modo que as restrições globais sejam respeitadas.

Ainda segundo Machado (2012), a MIP também garante o tratamento adequado para a modelagem do fluido produzido. Em cenários de produção nos quais a composição varia com o tempo, por exemplo: (i): reservatórios de gás úmido e de condensação retrógrada ou (ii): reservatórios que são afetados pela reinjeção de fluidos, como $\mathrm{CO} 2$, fazendo com o que a fração molar deste componente no fluido produzido aumente com o passar do tempo, podem não ter o rigor necessário com tabelas, seja por que elas são geradas com modelos de fluidos simples ou então não são atualizadas com o passar do tempo e a mudança na composição.

Além das vantagens citadas acima, estudos envolvendo MIP citando outros casos de sucesso são recorrentes na literatura. Zade et al (2015) cita o desenvolvimento de MIP para capturar a interação entre 5 modelos de reservatório de gás condensado produzindo através da mesma infraestrutura de escoamento. O objetivo foi criar uma plataforma que poderia ser usada para otimização da produção, identificação de gargalos, desenvolvimento do campo e garantia de escoamento. O modelo busca prover uma solução que assegurasse: (i) Adequada representação do fluido de 5 diferentes reservatórios; (ii) Garantia do atendimento das restrições da rede de escoamento e filosofia de desenvolvimento do projeto; (iii) Projetar a malha de escoamento ótima e uso de otimização da produção e (iv) flexibilidade para adicionar malha de escoamento complexa.

Torrens et al (2015) mostra um MIP criado para integrar um reservatório carbonático onshore de gás condensado e um óleo volátil. Devido ao compartimentação dos reservatórios, o modelo constituía-se de 19 modelos separados. A produção se dava através de três redes de escoamento, com fluido variando significativamente de gás seco, condensado e óleo volátil. O modelo salientou várias diferenças com o modelo tradicional desacoplado. A correta determinação na pressão necessária nos canhoneados aumentou o platô de produção; o correto dimensionamento do número de poços para cada rede de escoamento e, 
finalmente, a informação composicional detalhada em todos os pontos da rede de escoamento foi importante para o projeto da infraestrutura de produção.

Galvan et al (2014) descreve o MIP para o campo de Perdido, operado pela Shell em parceria com a Chevron e BP, um dos campos offshore em lâmina d'água ultra-profunda mais complexos no mundo. Produz através de 12 poços de 4 diferentes reservatórios. Os fluidos variam desde óleo pesados até campos de gás condensado. Os fluidos são misturados no sistema submarino e bombeados por bombas submarinas localizadas na base dos risers de produção. Uma EOS especial para atender a ampla faixa de propriedades dos 4 reservatórios foi criada.

Marmier et al (2016) mostra um interessante caso em que um MIP de produção de um campo de gás foi feito para melhor avaliar uma questão de garantia de escoamento relacionada ao que é conhecido na literatura como liquid loading. O problema consiste de uma intermitência no poço devido à baixa velocidade do gás na coluna de produção e consequente acúmulo de condensado na região dos canhoneados, podendo até mesmo a matar o poço e também para avaliar a repartida de poços e planejar a estratégia de garantia de escoamento no curto e médio prazo, após as paradas.

Harley et al (2016) exemplifica o potencial que MIP tem de identificar na cadeia de processos oportunidade de redução de custos, desde todo o conceito de produção até mesmo mudanças individuais de equipamentos. Ele cita como o processo de tomada de decisão é muitas vezes prejudicado pela falta de definição, entendimento e comunicação. Quando um MIP é usado estes três problemas são resolvidos em uma única ferramenta, dada sua característica holística onde as disciplinas de reservatório, escoamento, processamento e garantia de escoamento devem trabalhar colaborativamente para remoção de incertezas. Ele cita também como a MIP permite viabilizar tecnicamente projetos marginais.

Musameh et al (2019) mostra um roadmap para destravar os benefícios da transformação digital na cadeia de geração de valor do petróleo. Um dos pontos chaves para isso é a utilização dos MIP, que facilitam a localização de gargalos e oportunidades de aumento de produção e geração de valor.

\section{2}

\section{Modelo de reservatório}

Um MIP sempre terá associado a ele um modelo de reservatório, seja ele o mais simples possível, como um modelo de balanço de massa até os complexos modelos numéricos, que descrevem as equações constitutivas do fluxo de fases ou componentes, em meio poroso. Para a criação de um modelo 
de reservatório vários profissionais são envolvidos. Cabe destacar-se o papel do geofísico, responsável por delimitar, a partir de seções sísmicas, os horizontes do reservatório, falhas, possíveis contatos entre fluidos, etc. Ao geólogo, na posse das informações de perfis de poço, dados da perfuração dos poços, testemunhos e amostras laterias. cabe preencher o arcabouço delimitado pelo geofísico com propriedades permo-porosas.

Com o modelo geológico definido, o engenheiro de reservatório é o responsável por terminar o modelo de simulação numérica completando as demais informações necessárias. Entre as principais pode-se destacar a modelagem de fluido, curvas de permeabilidade relativa, dados de compressibilidade da formação e condições iniciais do reservatório.

Os detalhes da formulação matemática empregada para a solução das equações diferenciais do problema de escoamento no meio poroso, que tem como objetivo calcular os valores de pressão e saturação no modelo ao longo do espaço e do tempo, podem ser encontradas nas referências [10] e [17].

\section{3}

\section{Modelo do sistema de produção}

O modelo do sistema de produção normalmente se inicia na interface poço-reservatório, na altura dos canhoneados, e na sequência temos o modelo de escoamento do poço, seguido pela modelagem dos dutos e a chegada na UEP. Em alguns casos, os MIPs contam também com a modelagem da planta de processo. Normalmente o engenheiro de elevação e escoamento é o responsável por integrar todas as informações necessárias para a modelagem do sistema.

O engenheiro de poço fornece as informações construtivas do poço, tais como o diâmetro das colunas de produção e revestimento de produção, informações dos fluidos que estão nos anulares de cada revestimento, importantes para o modelo de troca térmica no poço, posição de equipamentos importantes para elevação artificial, tais como válvula de gas-lift e bombas no poço.

O engenheiro submarino é responsável por informar as características construtivas dos dutos, flexíveis ou rígidos, a posição dos equipamentos, a configuração de riser utilizada (catenária livre ou lazy-wave).

O engenheiro de processamento fornece informações à respeito do processamento do óleo até chegar às condições standard. Em casos de elevada complexidade, o modelo de processamento pode ser acoplado diretamente no modelo integrado.

Os detalhes da formulação matemática do fenômeno de escoamento em dutos e como as equações diferenciais que controlam o problema são 
discretizadas em simuladores comerciais podem ser vistos em Machado (2012) e Chen et al. (2006).

\section{4}

\section{Acoplamento dos modelos}

Existem duas maneiras principais de realizar o acoplamento dos modelos de reservatório e do sistema de produção. O acoplamento explícito é quando os simuladores que tratam do escoamento em meio poroso e do sistema de produção têm suas formulações separadas e de alguma forma os simuladores trocam informação entre si.

O acoplamento explícito é designado fraco quando apenas uma tabela com pressões requeridas nos canhoneados representa todo o sistema de produção no modelo de reservatório. O simulador de reservatório usa os valores da tabela para achar a condição de equilíbrio e utilizar isto como condição de contorno na matriz jacobiana de solução do fluxo no meio poroso.

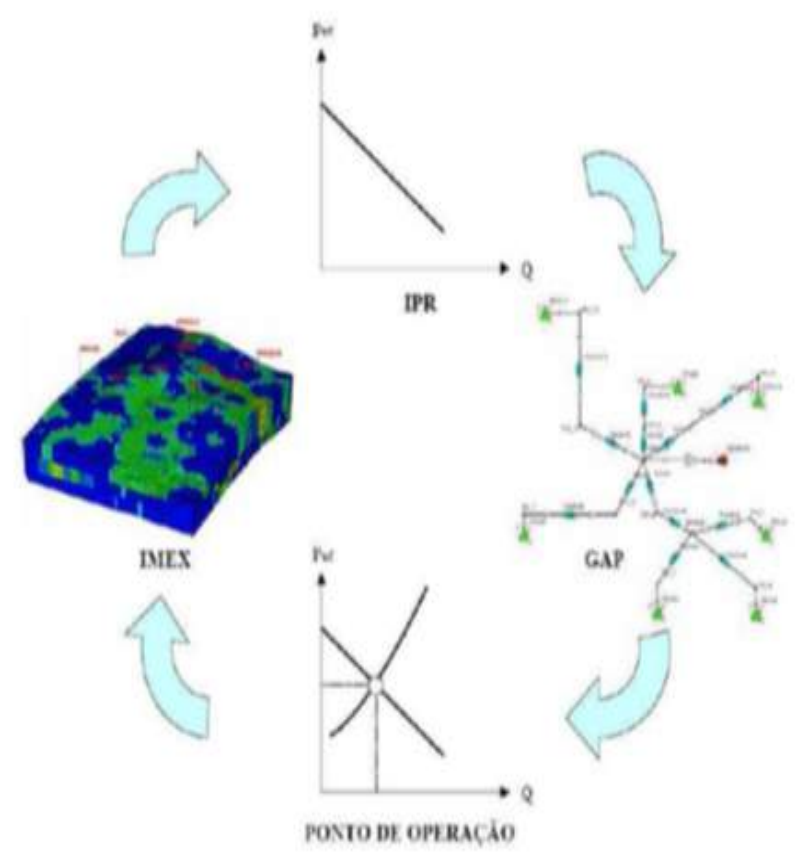

Figura 3.6: Acoplamento explícito — Extraído de Cotrim (2012)

Quando o acoplamento é denominado explícito forte, normalmente há um terceiro software responsável por orquestrar a passagem de informação entre os simuladores de reservatório e do sistema de produção. Normalmente o modelo de reservatório manda uma IPR (Inflow Performance Relationship) e o modelo do sistema de produção tem a informação da TPR (Tubing Performance Relationship). O cruzamento destas curvas determina a condição de operação 
que é então usada no modelo de reservatório como condição de contorno até o próximo acoplamento.

Esta metodologia confere mais robustez uma vez que a curva TPR é feita online e sistemas complexos podem ser modelados, ao contrário de metodologia explícita fraca, que possui apenas uma tabela com valores previamente calculados. A Figura 3.6 mostra resumidamente como o acoplamento explícito funciona.

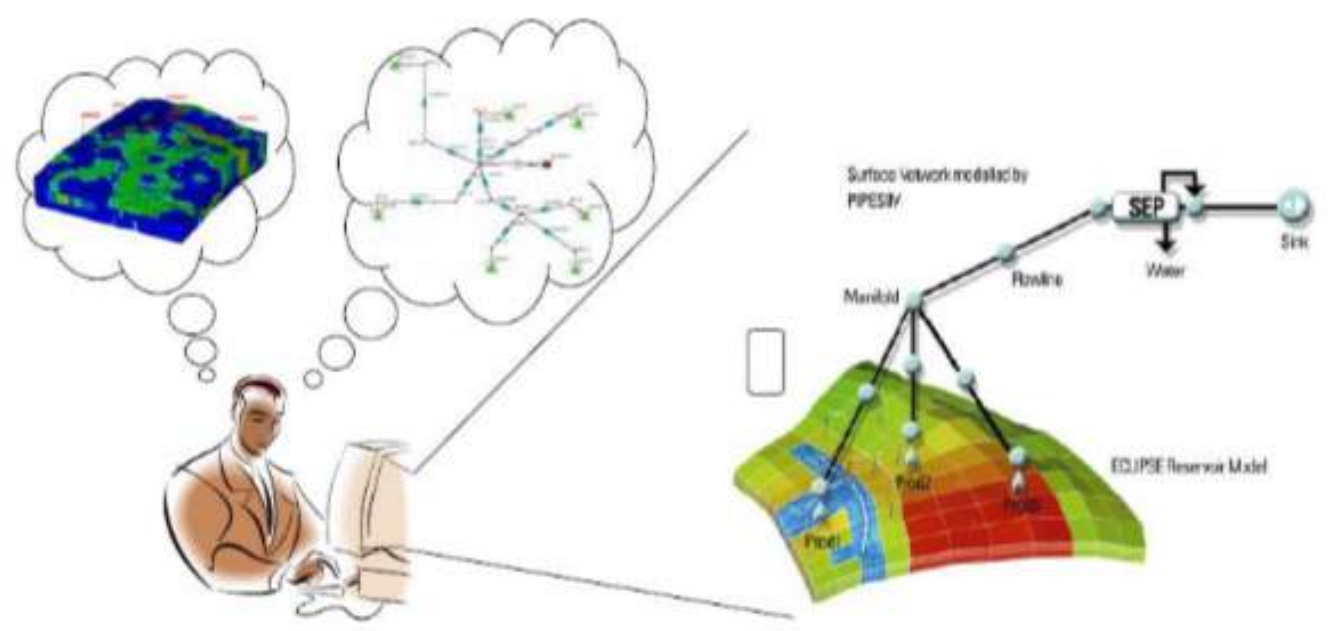

Figura 3.7: Acoplamento implícito — Extraído de Cotrim (2012)

O acoplamento implícito visa resolver simultanemanete e acopladamente as equacões diferenciais que regem o escoamento no meio poroso e no sistema de produção. É importante quando as condições do reservatório mudam tão rapidamente de forma que o acoplamento explícito não consegue mais representar fidedignamente as mudanças temporais no fluxo do reservatório. A Figura 3.7 ilustra o conceito. Para mais detalhes em relação ao acomplamento entre modelos de reservatório e do sistema de produção, os trabalhos de Filho et al. (2012), Cotrim (2012) e Carpio (2012) são um bom ponto de partida. 


\section{Metodologia}

A seguir será mostrada a metodologia usada para avaliar como a simplificação da EOS influencia no resultado das análises tanto para o escoamento no meio poroso como para o escoamento em poços e dutos até chegar à plataforma. Primeiramente será abordada como foi feita a seleção do fluido e as análises laboratoriais disponíveis para realizar a regressão dos fluidos para a EOS detalhada. A metodologia usada para simplificação, as EOS simplificadas e suas regressões também serão discutidas neste capítulo.

Na sequência será dada uma visão geral do modelo de simulação usado para realizar as simulações com as EOS modeladas. Uma visão geral do modelo de reservatório e de escoamento, assim como o acoplamento entre os dois, poderá ser visto a seguir.

Finalmente, serão detalhadas as principais variáveis de interesse dos engenheiros de reservatório e de elevação e escaomento quando um modelo está sendo elaborado com a finalidade de auxiliar nas decisões de engenharia. Estas variáveis serão importantes para definir, a partir dos resultados que serão detalhados no próximo capítulo, a melhor forma de modelar uma EOS para estudos composicionais em modelos integrados de produção.

\section{1}

Seleção do fluido e ajuste das EOS detalhada e pseudoizada para uso no MIP

\subsection{1}

\section{Seleção do fluido e ensaios laboratoriais}

A escolha do fluido para ser usado nas análises desta dissertação não pode ser aleatória. Em geral, as análises PVT apresentam a descrição das impurezas e das frações apenas até um determinado limite. No caso desta análise, até isômeros de 19 carbonos do fluido, concentrando todos os componentes restantes no componente plus $C_{20+}$. Óleos pesados possuem composição molar da fração $C_{20+}$ muito elevada. Usar um modelo composicional nesse tipo de óleo, sem cromatografia detalhada da fração $C_{20+}$, pode levar a resultados até piores do que com modelagens mais simples, baseadas em correlações, como por exemplo, a modelagem black-oil. 
Para fluidos mais leves, em geral com ${ }^{\circ}$ API acima de 30, a modelagem composicional, fruto de estudo desta dissertação, é mais adequada, justamente devido ao menor peso da fração $C_{20+}$ na composição do fluido. A faixa de ${ }^{\circ}$ API a qual começa a ser mandatória modelagem composicional são para óleos de ${ }^{\circ}$ API acima de 40, que já é a faixa dos condensados retrógrados. Entretanto estes intervalos não são claros na literatura e valores diferentes aos indicados aqui podem ser encontrados.

Desta forma, recomenda-se a modelagem black-oil para fluidos abaixo de $30^{\circ} \mathrm{API}$ e modelagem composicional para fluidos acima de $40^{\circ}$ API e entre estes valores deve-se ter mais cautela ao escolher a modelagem e analisar prós e contras de cada metodologia. Essa classificação de modelagem pode se alterar também em função do método de recuperação empregado no reservatório. Métodos baseados em injeção de gás requerem uma abordagem composicional devido à alta probabilidade de alteração composicional do fluido do reservatório quando o mesmo estabelece contato com o gás injetado.

Além da questão do tipo de fluido, outro ponto importante para a escolha do fluido foram as análises laboratoriais disponíveis. Como este trabalho tem o objetivo de definir o modelo composicional com EOS simplificada ótima não apenas para o fluxo no meio poroso, isotérmico, mas também para o fluxo ao longo dos poços e dutos até a plataforma, análises laboratoriais em temperaturas diferentes do reservatório precisam estar disponíveis, caso contrário a regressão pode não ter validade fora da faixa de temperatura próxima à temperatura do reservatório. Não é comum a coleta de fluido adicional para realizar análises laboratoriais na faixa de temperatura de interesse do escoamento em poços e dutos.

Para os estudos que serão apresentados foi escolhido um fluido que apresentou no ensaio de liberação flash da pressão de $561,0 \mathrm{~kg} f / \mathrm{cm}^{2}$ e temperatura de $122{ }^{\circ} \mathrm{C}$, que representam a condição inicial do reservatório, para a pressão atmosférica e $40{ }^{\circ} \mathrm{C}, 34,3^{\circ}$ API e RGO de $346,54 \mathrm{~m}^{3} s t d / \mathrm{m}^{3} s t d$. A fração plus de $C_{20+}$ deste fluido é, em percentual molar, de apenas 5,96\%. A Tabela 4.1 mostra a expansão a composição constante da condição de reservatório até a condição de pressão standard e temperatura de $40{ }^{\circ} \mathrm{C}$ (liberação flash) do fluido. Além disso, a composição do fluido de reservatório usada para a regressão das EOS advém deste ensaio.

Os resultados deste tipo de ensaio normalmente mostram a composição molar do fluido em condições de reservatório e a composição molar dos componentes nas fases óleo e gás após a expansão, obtida por cromatografia gasosa. Como era de se esperar os componentes leves acabam ficando no gás do flash e os pesados se concentram no óleo morto. A densidade do gás do flash 
Tabela 4.1: Propriedades e composições molares da liberação flash experimental a $40,0{ }^{\circ} \mathrm{C}$.

\begin{tabular}{|c|c|c|c|}
\hline Componentes & $\begin{array}{l}\text { Óleo } \\
\text { morto }\end{array}$ & $\begin{array}{c}\text { Gás } \\
\text { do flash }\end{array}$ & $\begin{array}{c}\text { Fluido } \\
\text { de reservatório }\end{array}$ \\
\hline $\mathrm{CO}_{2}$ & 0,00 & 1,66 & 1,31 \\
\hline$N_{2}$ & 0,00 & 0,47 & 0,37 \\
\hline$C_{1}$ & 0,00 & 74,43 & 59,11 \\
\hline$C_{2}$ & 0,00 & 9,59 & 7,62 \\
\hline$C_{3}$ & 0,40 & 6,50 & 5,25 \\
\hline$I C_{4}$ & 0,25 & 1,34 & 1,12 \\
\hline$N C_{4}$ & 0,78 & 2,82 & 2,40 \\
\hline$I C_{5}$ & 0,89 & 1,02 & 1,00 \\
\hline$N C_{5}$ & 1,13 & 0,97 & 1,00 \\
\hline$C_{6}$ & 3,24 & 0,71 & 1,23 \\
\hline$C_{7}$ & 7,42 & 0,36 & 1,81 \\
\hline$C_{8}$ & 10,15 & 0,13 & 2,19 \\
\hline$C_{9}$ & 8,29 & 0,01 & 1,71 \\
\hline$C_{10}$ & 6,69 & 0,00 & 1,38 \\
\hline$C_{11}$ & 5,21 & 0,00 & 1,07 \\
\hline$C_{12}$ & 4,37 & 0,00 & 0,90 \\
\hline$C_{13}$ & 4,68 & 0,00 & 0,96 \\
\hline$C_{14}$ & 3,83 & 0,00 & 0,79 \\
\hline$C_{15}$ & 3,53 & 0,00 & 0,73 \\
\hline$C_{16}$ & 2,75 & 0,00 & 0,57 \\
\hline$C_{17}$ & 2,52 & 0,00 & 0,52 \\
\hline$C_{18}$ & 2,55 & 0,00 & 0,52 \\
\hline$C_{19}$ & 2,32 & 0,00 & 0,48 \\
\hline$C_{20+}$ & 28,98 & 0,00 & 5,96 \\
\hline \multicolumn{2}{|l|}{ Densidade do gás } & 0,8116 & \\
\hline Massa molar total & 224,92 & 23,51 & 64,96 \\
\hline Massa molar $C_{20+}$ & & 417 & \\
\hline Densidade $C_{20+}$ & & 0,9149 & \\
\hline$B_{o}\left(P_{\text {sat }}\right.$ e $\left.T_{r e s}\right)$ & & 2,0705 & \\
\hline
\end{tabular}

medida foi de 0,8116 . Uma importante medição feita neste ensaio é a massa molar e densidade da fração plus $C_{20+}$ e a partir dela é calculada a massa molar total das misturas. O fator volume de formação, ou fator de encolhimento do óleo medido, em relação a pressão de saturação e temperatura do reservatório, 
foi de 2,0705.

Óleos leves como este apresentam esta característica de alta volatilidade, isto é, uma vez que eles possuem muito componentes leves que tendem a ficar na fase gás em baixas pressões, tendendo a um elevado encolhimento da fase óleo. Em reservatórios deste tipo a injeção de água é muito importante para manter a pressão do reservatório para evitar que a pressão de saturação seja atingida, pois uma pequena queda de pressão pode liberar muito gás no reservatório, prejudicando o fator de recuperação da jazida.

Outro ensaio fundamental para a calibragem das propriedades do fluxo no meio poroso é o ensaio de liberação diferencial. O resultado do ensaio para a fase óleo pode ser visto na Tabela 4.2. Este ensaio é normalmente conduzido apenas na temperatura de reservatório, que para este óleo é de $122{ }^{\circ} \mathrm{C}$. O ${ }^{\circ}$ API do óleo residual encontrado neste ensaio foi 32,71 e as condições padrão considerada foi de $1 \mathrm{~atm}$ e $15,6{ }^{\circ} \mathrm{C}$. Os dados de pressão são manométricos.

Tabela 4.2: Propriedades da fase óleo na liberação diferencial experimental a $122,0{ }^{\circ} \mathrm{C}$.

\begin{tabular}{ccccc}
$\mathbf{p}\left(\mathrm{kgf} / \mathrm{cm}^{2}\right)$ & $B_{o}\left(\mathrm{~m}^{3} / \mathrm{Sm}^{3}\right)$ & $R_{s}\left(\mathrm{Sm}^{3} / \mathrm{Sm}^{3}\right)$ & $\eta_{o}(\mathrm{cP})$ & $\rho_{o}\left(\mathrm{~g} / \mathrm{cm}^{3}\right)$ \\
\hline 650,0 & 2,2627 & 444,56 & 0,259 & 0,5907 \\
\hline 610,0 & 2,2800 & 444,56 & 0,249 & 0,5862 \\
\hline 570,0 & 2,3000 & 444,56 & 0,239 & 0,5812 \\
\hline 530,0 & 2,3218 & 444,56 & 0,229 & 0,5757 \\
\hline 490,0 & 2,3469 & 444,56 & 0,219 & 0,5695 \\
\hline 450,0 & 2,3744 & 444,56 & 0,209 & 0,5630 \\
\hline 440,0 & 2,3820 & 444,56 & 0,206 & 0,5612 \\
\hline 420,0 & 2,3985 & 444,56 & 0,201 & 0,5573 \\
\hline 400,0 & 2,4158 & 444,56 & 0,196 & 0,5533 \\
\hline $372,7\left(P_{\text {sat }}\right)$ & 2,4311 & 444,56 & 0,189 & 0,5498 \\
\hline 350,0 & 2,1631 & 336,18 & 0,220 & 0,5611 \\
\hline 300,0 & 1,9092 & 253,70 & 0,274 & 0,5906 \\
\hline 250,0 & 1,7371 & 196,89 & 0,337 & 0,6184 \\
\hline 200,0 & 1,6154 & 151,60 & 0,415 & 0,6388 \\
\hline 150,0 & 1,5103 & 112,46 & 0,521 & 0,6588 \\
\hline 100,0 & 1,4158 & 77,78 & 0,646 & 0,6797 \\
\hline 50,0 & 1,3219 & 44,98 & 0,778 & 0,7037 \\
\hline 0,0 & 1,0847 & 0,00 & 1,420 & 0,7863 \\
\hline
\end{tabular}

Este ensaio captura muitas variáveis importantes para o fluxo no meio poroso. A viscosidade, obtida por um experimento em um reômetro e, em 
geral, reportada junto às medidas da liberação diferencial é fundamental para os estudos no reservatório, ainda mais quando se trata de um fluido que em condições de reservatório possui valores muito similares à viscosidade da água. A quantidade de gás dissolvido, o fator de encolhimento do óleo e a massa específica para cada diferencial de pressão também são computados neste ensaio.

As propriedades do gás liberado em cada estágio de separação também são medidas e reportadas, podendo ser usadas como dados para regressão. A Tabela 4.3 resume os dados do ensaio, que também foi conduzido apenas na temperatura de reservatório. A pressão informada é manométrica. A densidade média do gases liberados em relação ao ar, em cada estágio de separação, ponderada pela RGO de cada estágio foi de 0,8757 .

A viscosidade do gás é estimada por correlação, a partir da composição do gás liberado.

Tabela 4.3: Propriedades da fase gás na liberação diferencial experimental a $122,0{ }^{\circ} \mathrm{C}$.

\begin{tabular}{ccccc}
$\mathbf{p}\left(\mathrm{kgf} / \mathrm{cm}^{2}\right)$ & $B_{g}\left(\mathrm{~m}^{3} / \mathrm{Sm}^{3}\right)$ & $d_{g}$ & $Z$ & $\eta_{g}(\mathrm{cP})$ \\
\hline 350,0 & 0,00400 & 0,9276 & 0,9930 & 0,0331 \\
\hline 300,0 & 0,00443 & 0,8554 & 0,9435 & 0,0281 \\
\hline 250,0 & 0,00511 & 0,7695 & 0,9066 & 0,0231 \\
\hline 200,0 & 0,00616 & 0,7632 & 0,8753 & 0,0202 \\
\hline 150,0 & 0,00812 & 0,7715 & 0,8667 & 0,0177 \\
\hline 100,0 & 0,01242 & 0,7717 & 0,8873 & 0,0156 \\
\hline 50,0 & 0,02581 & 0,8025 & 0,9312 & 0,0141 \\
\hline 0,0 & - & 1,2602 & - & 0,0119 \\
\hline
\end{tabular}

Três testes de separador foram executados para este fluido com o intuito de capturar diferentes pressões e temperaturas possíveis no primeiro estágio de separação da plataforma. Os testes executados consideraram apenas um estágio de separação, isto é, foi considerado um primeiro estágio de separação e em seguida o fluido foi expandido para a condição padrão de pressão e a temperatura de tanque indicada na Tabela 4.4.

A unidade da pressão de separação é $\mathrm{kgf} / \mathrm{cm}^{2}$. A temperatura está em ${ }^{\circ} \mathrm{C}$. A unidade da RGO é $m^{3} s t d / m^{3} s t d$. O subscrito "sep"se refere ao primeiro estágio de separação e "tq"se refere a condição de tanque, isto é, na pressão atmosférica e temperatura informada. Por exemplo, o valor de $R G O_{\text {sep }}$ na tabela se refere na quantidade de gás liberada no primeiro estágio de separação, 
Tabela 4.4: Teste de separador experimental.

\begin{tabular}{llllllll}
$p_{\text {sep }}$ & $T_{\text {sep }}$ & $T_{t q}$ & $R G O_{\text {sep }}$ & $R G O_{t q}$ & $R G O_{\text {total }}$ & $B_{o}$ & $A P I$ \\
\hline 7,03 & 85,0 & 20,3 & 302,57 & 8,29 & 310,86 & 2,106 & 36,11 \\
\hline 10,2 & 40,0 & 20,6 & 285,32 & 16,12 & 301,44 & 2,039 & 37,46 \\
\hline 14,76 & 30,0 & 22,5 & 274,58 & 22,11 & 296,69 & 2,000 & 37,98 \\
\hline
\end{tabular}

e a $R G O_{t q}$ se refere ao gás liberado depois do fluido passar do primeiro estágio de separação para a condição de tanque.

Este ensaio, em conjunto com outras análises, é importante para definição da pressão ótima de separação. A $R G O_{t q} \mathrm{e}^{\circ}$ API residual de óleos leves e gás retrógrados variam fortemente a depender da quantidade de estágios de separação são usados na plataforma. Pode-se observar pela Tabela 4.4 que ao aumentar a pressão do primeiro estágio acarretou em menor $R G O_{\text {total }}$, maior ${ }^{\circ}$ API residual e fator de encolhimento menor. Ou seja, mais gás ficou em solução no óleo morto ao se aumentar a pressão de estágio. Como o óleo possui valor agregado maior, definir a pressão ótima de separação é um trabalho importante dos engenheiros de instalações de superfície.

Mesmo não sendo comum a realização deste ensaio para óleos voláteis, um teste de EVC na temperatura do reservatório está disponível para o fluido. A Tabela 4.5 mostra as propriedades medidas neste ensaio. Além do fator de compressibilidade, fator volume de formação do gás e a massa específica em função da pressão dos gases liberados em cada estágio, estão plotadas a razão percentual entre o volume de líquido na pressão especificada e o volume de fluido na pressão de saturação (Vol Líq Sat) e também a produção molar acumulada de gás (Pcum) na pressão especificada.

Tabela 4.5: Ensaio de expansão a volume constante a $122,0{ }^{\circ} \mathrm{C}$

\begin{tabular}{cccccc}
$\begin{array}{c}\text { Pressão } \\
\left(\mathrm{kgf} / \mathrm{cm}^{2}\right)\end{array}$ & $\begin{array}{c}\text { Vol Líq } \\
(\%)\end{array}$ & $\mathbf{Z}$ & $\begin{array}{c}\text { Pcum } \\
(\mathbf{\%})\end{array}$ & $\begin{array}{c}\mathbf{B}_{\mathbf{g}} \\
\mathrm{m}^{3} / \mathrm{Sm}^{3}\end{array}$ & $\begin{array}{c}\rho_{g} \\
\left(\mathrm{~g} / \mathrm{cm}^{3}\right)\end{array}$ \\
\hline 373,7 & 100 & - & 0 & - & - \\
\hline 282,3 & 84,0 & 0,9639 & 9,19 & 0,00481 & 0,2629 \\
\hline 212,0 & 77,3 & 0,8507 & 21,46 & 0,00566 & 0,1821 \\
\hline 141,7 & 73,6 & 0,8634 & 37,15 & 0,00859 & 0,1120 \\
\hline 71,3 & 68,8 & 0,8732 & 55,5 & 0,01725 & 0,0567 \\
\hline
\end{tabular}

Além dos ensaios acima, o fluido selecionado possui três ensaios de expansão a composição constante, em três diferentes temperaturas, a de 
reservatório, $122^{\circ} \mathrm{C}$, e os outros dois ensaios em temperaturas características do escoamento, uma a $30^{\circ} \mathrm{Ce}$ a outra a $75^{\circ} \mathrm{C}$. O resultado dos ensaios laboratoriais podem ser vistos nas Tabelas 4.6, 4.7 e 4.8.

Estes ensaios são importantíssimos pois permitem calibrar o equilíbrio de fases em temperaturas diferentes do reservatório, logo é fundamental para os engenheiros que se preocupam com o escoamento em dutos e poços.

Os principais resultados deste ensaio são a pressão de saturação em temperaturas representativas de escoamento, o volume total relativo na pressão especificada em relação ao volume na pressão de saturação, a massa específica do óleo acima da pressão de saturação para temperaturas diferentes do reservatório e o fator-Y, que expressa uma relação entre pressão e volume na região de duas fases.

Outro importante ensaio para o escomento nas tubulações é o ensaio que mede a viscosidade e a massa específica da fase óleo na condição padrão de pressão, em várias temperaturas. Muitas vezes este é o único ensaio disponível em temperatura diferente do reservatório. Em óleos pesados a viscosidade influencia a perda de carga por atrito no escoamento nos dutos, fazendo com que este ensaio seja de fundamental importância para óleos pesados. A Tabela 4.9 mostra os resultados deste ensaio para o óleo selecionado.

A partir dos dados laboratoriais discutidos acima foi feita a regressão para o ajuste das EOS detalhada e simplificadas, onde as premissas e resultados são discutido na sequência.

\subsection{2}

\section{Ajuste da EOS detalhada}

Para realizar o ajuste das EOS foi usado o software comercial Winprop, da fabricante $C M G$, versão 2016. O Winprop é um simulador capaz de simular propriedades de fluidos e possui algoritmo de regressão para ajustar dados experimentais.

O software possui uma extensa base de dados com propriedades de fluidos. Ele é capaz de simular todos os experimentos citados ao longo da dissertação. Ele é muito usado na indústria de petróleo por engenheiros de reservatório. De forma sumarizada, o ajuste de uma equação de estado consiste nas seguintes etapas:

(i) Escolha da equação de estado e do modelo viscosidade. Para este trabalho a EOS de Peng-Robinson corrigida (1978) e o modelo de viscosidade LBC foram usados; 
Tabela 4.6: Relação pressão-volume de um ensaio de expansão a composição constante a $30,0^{\circ} \mathrm{C}$

\begin{tabular}{|c|c|c|c|}
\hline $\begin{array}{l}\text { Pressão } \\
\left(\mathrm{kgf} / \mathrm{cm}^{2}\right)\end{array}$ & $\begin{array}{l}\text { Volume } \\
\text { relativo }\end{array}$ & $\mathbf{Y}$ & $\begin{array}{c}\rho_{o} \\
\left(\mathrm{~g} / \mathrm{cm}^{3}\right) \\
\end{array}$ \\
\hline 704,3 & 0,9482 & - & 0,6873 \\
\hline 669,1 & 0,9524 & - & 0,6842 \\
\hline 633,9 & 0,9563 & - & 0,6815 \\
\hline 598,8 & 0,9601 & - & 0,6788 \\
\hline 563,6 & 0,9648 & - & 0,6755 \\
\hline 528,5 & 0,9699 & - & 0,6719 \\
\hline 493,3 & 0,9741 & - & 0,669 \\
\hline 479,2 & 0,9758 & - & 0,6678 \\
\hline 465,2 & 0,9771 & - & 0,667 \\
\hline 451,1 & 0,9792 & - & 0,6655 \\
\hline 437,0 & 0,9826 & - & 0,6632 \\
\hline 423,0 & 0,9839 & - & 0,6623 \\
\hline 408,9 & 0,9868 & - & 0,6604 \\
\hline 394,8 & 0,989 & - & 0,6589 \\
\hline 380,8 & 0,9911 & - & 0,6575 \\
\hline 366,7 & 0,9945 & - & 0,6553 \\
\hline 352,7 & 0,9968 & - & 0,6537 \\
\hline $345,6 P_{\text {sat }}$ & 1,0 & - & 0,6517 \\
\hline 331,6 & 1,0055 & 7,73 & - \\
\hline 324,5 & 1,0085 & 7,59 & - \\
\hline 317,5 & 1,0123 & 7,22 & - \\
\hline 310,5 & 1,0161 & 7,05 & - \\
\hline 268,3 & 1,0412 & 7,00 & - \\
\hline 240,1 & 1,0633 & 6,95 & - \\
\hline 212,0 & 1,1062 & 5,94 & - \\
\hline 176,8 & 1,1873 & 5,10 & - \\
\hline
\end{tabular}

(ii) Escolha dos componentes: Para a EOS detalhada foi utilizada a informação integral obtida na cromatografia gasosa e as simplificadas seguiram a metologia descrita em Danesh (1998, apud Whitson, 1983);

(iii) Escolha dos parâmetros de regressão: ensaios de laboratório em diversas pressões e temperatura foram usados para a regressão; propriedades reológicas e termodinâmicas foram ajustadas separadamente; fração $C_{20+}$ 
Tabela 4.7: Relação pressão-volume de um ensaio de expansão a composição constante à $75,0^{\circ} \mathrm{C}$

\begin{tabular}{|c|c|c|c|}
\hline $\begin{array}{l}\text { Pressão } \\
\left(\mathrm{kgf} / \mathrm{cm}^{2}\right)\end{array}$ & $\begin{array}{l}\text { Volume } \\
\text { relativo }\end{array}$ & $\mathbf{Y}$ & $\begin{array}{c}\rho_{o} \\
\left(\mathrm{~g} / \mathrm{cm}^{3}\right) \\
\end{array}$ \\
\hline 704,3 & 0,9307 & - & 0,6549 \\
\hline 669,1 & 0,9368 & - & 0,6507 \\
\hline 633,9 & 0,9435 & - & 0,6461 \\
\hline 598,8 & 0,9501 & - & 0,6416 \\
\hline 563,6 & 0,9567 & - & 0,6371 \\
\hline 528,5 & 0,9638 & - & 0,6324 \\
\hline 493,3 & 0,9705 & - & 0,6281 \\
\hline 458,1 & 0,9781 & - & 0,6232 \\
\hline 423,0 & 0,9857 & - & 0,6184 \\
\hline 408,9 & 0,9898 & - & 0,6158 \\
\hline 394,8 & 0,9934 & - & 0,6136 \\
\hline 387,8 & 0,9939 & - & 0,6133 \\
\hline 380,8 & 0,9959 & - & 0,6120 \\
\hline 373,7 & 0,9975 & - & 0,6111 \\
\hline $366,7 P_{\text {sat }}$ & 1,0 & - & 0,6095 \\
\hline 359,7 & 1,0036 & 5,42 & - \\
\hline 338,6 & 1,0163 & 5,08 & - \\
\hline 324,5 & 1,0265 & 4,90 & - \\
\hline 310,5 & 1,0387 & 4,67 & - \\
\hline 296,4 & 1,0515 & 4,61 & - \\
\hline 282,3 & 1,0667 & 4,48 & - \\
\hline 247,2 & 1,1162 & 4,17 & - \\
\hline 212,0 & 1,1936 & 3,77 & - \\
\hline 176,8 & 1,3169 & 3,39 & - \\
\hline 141,7 & 1,5273 & 3,01 & - \\
\hline
\end{tabular}

foi usada para calibrar as propriedades termodinâmicas;

Um maior detalhamento de cada item poderá ser visto na sequência.

\subsubsection{1}

\section{Escolha da equação de estado e do modelo de viscosidade}

A primeira escolha que deve ser feita é qual será a equação de estado usada para realizar a regressão. A equação de estado de Peng-Robinson corrigida (1978) foi escolhida uma vez que ela é resultado de diversas melhorias 
Tabela 4.8: Relação pressão-volume de um ensaio de expansão a composição constante à $122,0^{\circ} \mathrm{C}$

\begin{tabular}{llll}
$\begin{array}{c}\text { Pressão } \\
\left(\mathrm{kgf} / \mathrm{cm}^{2}\right)\end{array}$ & $\begin{array}{c}\text { Volume } \\
\text { relativo }\end{array}$ & $\mathbf{Y}$ & $\begin{array}{c}\rho_{o} \\
\left.\mathrm{~g} / \mathrm{cm}^{3}\right)\end{array}$ \\
\hline 704,3 & 0,9158 & - & 0,6239 \\
\hline 669,1 & 0,9239 & - & 0,6184 \\
\hline 633,9 & 0,9313 & - & 0,6135 \\
\hline 598,8 & 0,9378 & - & 0,6092 \\
\hline 563,6 & 0,9449 & - & 0,6046 \\
\hline 528,5 & 0,9534 & - & 0,5993 \\
\hline 493,3 & 0,9618 & - & 0,5941 \\
\hline 458,1 & 0,9709 & - & 0,5885 \\
\hline 423,0 & 0,9819 & - & 0,5819 \\
\hline 408,9 & 0,9864 & - & 0,5792 \\
\hline 394,8 & 0,9909 & - & 0,5766 \\
\hline 387,8 & 0,9935 & - & 0,5751 \\
\hline 380,8 & 0,9961 & - & 0,5736 \\
\hline $373,7 P_{\text {sat }}$ & 1,0 & - & 0,5714 \\
\hline 366,7 & 1,0045 & 4,15 & - \\
\hline 338,6 & 1,0291 & 3,55 & - \\
\hline 310,5 & 1,0602 & 3,39 & - \\
\hline 296,4 & 1,0790 & 3,30 & - \\
\hline 282,3 & 1,0997 & 3,25 & - \\
\hline 247,2 & 1,1684 & 3,04 & - \\
\hline 212,0 & 1,2714 & 2,81 & - \\
\hline 176,8 & 1,4242 & 2,63 & - \\
\hline 141,7 & 1,6742 & & - \\
\hline & & - & - \\
\hline
\end{tabular}

ao longo da evolução da modelagem de EOS. A equação de estado de SoaveRedlich-Kwong apresenta piores resultados para a previsão de massa específica. Naturalmente o fator de correção de volume de Peneloux foi utilizado para realizar a correção de volume e melhorar ainda mais a previsão da massa específica, especialmente na faixa de pressões baixas.

A correlação usada para prever a viscosidade foi a correlação de LBC, descrita anteriormente. Por se tratar de um óleo volátil com viscosidades muito baixas, a escolha da correlação de viscosidade não interfere muito no resultado, uma vez que os dados experimentais serão facilmente reproduzidos por qualquer correlação disponível. O principal motivo desta escolha é que esta 
Tabela 4.9: Viscosidades e massas específicas do óleo residual da liberação diferencial.

\begin{tabular}{ccc}
$\begin{array}{c}\mathbf{T} \\
{ }^{\circ} \mathrm{C}\end{array}$ & $\begin{array}{c}\eta_{o} \\
(\mathrm{cP})\end{array}$ & $\begin{array}{c}\rho_{o} \\
\left(\mathrm{~g} / \mathrm{cm}^{3}\right)\end{array}$ \\
\hline 30,0 & 9,08 & 0,8498 \\
\hline 40,0 & 6,62 & 0,8429 \\
\hline 50,0 & 5,03 & 0,8360 \\
\hline 60,0 & 3,95 & 0,8291 \\
\hline 70,0 & 3,19 & 0,8222 \\
\hline 80,0 & 2,64 & 0,8153 \\
\hline 90,0 & 2,22 & 0,8084 \\
\hline 100,0 & 1,90 & 0,8015 \\
\hline 110,0 & 1,66 & 0,7946 \\
\hline 120,0 & 1,46 & 0,7877 \\
\hline 122,0 & 1,42 & 0,7863 \\
\hline
\end{tabular}

correlação está disponível tanto no modelo de fluxo no meio poroso quanto no modelo de escoamento, e é extremamente importante que os modelos de fluido do escoamento no meio poroso e nos poços e dutos estejam iguais para a validade dos resultados das simulações.

\subsubsection{2}

\section{Escolha dos componentes}

O passo seguinte é selecionar a quantidade de componentes desejados para realizar a regressão. Para o ajuste da EOS detalhada foram utilizados todos os componentes descritos na liberação flash da Tabela 4.1. Esta EOS será considerada base para as comparações ao longo da dissertação uma vez que acredita-se que o maior detalhamento da composição do fluido traz mais confiabilidade para a previsão das propriedades. Logo a EOS detalhada possui 24 componentes e a fração molar de cada um deles também pode ser vista na Tabela 4.1. A escolha dos componentes das EOS simplificadas serão detalhadas a seguir.

\subsubsection{3}

\section{Escolha dos parâmetros de regressão}

Primeiramente é necessário carregar os dados de todos os ensaios laboratoriais descritos acima no simulador. Eles serão a base de comparação durante a regressão. A pressão de saturação nas temperaturas de $122^{\circ} \mathrm{C}, 75^{\circ} \mathrm{Ce} 30^{\circ} \mathrm{C}$, os 
ECCs nas mesmas temperaturas, os testes de separador, ensaio de liberação diferencial e o ensaio de EVC foram utilizados na regressão.

O próximo passo é selecionar as propriedades que o simulador poderá variar a fim de minimizar o erro global da regressão, utilizando como base os dados experimentais. É uma boa prática segregar a regressão das propriedades de cunho termodinâmico das propriedades reológicas, isto é, em um primeiro momento a EOS é ajustada para representar o equilíbrio de fases. Após o ajuste termodinâmico, o ajuste da viscosidade é feito sem modificar o equilíbrio de fases obtido na etapa anterior.

Como premissa para o ajuste da EOS busca-se, de maneira geral, modificar as propriedades do menor número de componentes possível e prioritariamente dos componentes com mais incerteza em relação às propriedades. Desta forma, foi permitido apenas variar as propriedades da fração plus $C_{20+}$, uma vez que a incerteza na sua composição e, consequentemente, na caracterização de suas propriedades é enorme. As propriedades que foram usadas para a regressão foram a pressão crítica, temperatura crítica, fator acêntrico, peso molecular e o fator de correção de volume, volume shift. Além destas propriedades, naturalmente os coeficientes de interação binária entre os componentes foram usados na regressão, já que estes coeficientes representam na EOS a incerteza entre as forças moleculares entre os diversos componentes da mistura.

Finalmente, antes do início da simulação, o usuário precisa definir, através de pesos, qual propriedade ele deseja ajustar de forma mais precisa, em detrimento de outras. Este procedimento é importante pois, a depender do fenômeno que se deseja modelar, pode ser enfatizada no ajuste uma propriedade que impacte mais fortemente tal fenômeno. Esta etapa é especialmente importante em modelos integrados de produção, pois a carcterização dos fluidos deve satisfazer o escoamento no meio poroso e nas tubulações, que muitas vezes dão prioridades a propriedades diferentes na modelagem de fluido.

Um exemplo comum é o ajuste da viscosidade do óleo para óleos pesados. É fundamental para o escoamento no meio poroso que a correlação usada represente os dados encontrados no laboratório para calcular a mobilidade da fase óleo no meio poroso. Pequenos erros na viscosidade podem levar a erros inaceitáveis nas previsões de produção. No escoamento em tubulações, a viscosidade do óleo é fundamental para o cálculo da perda de pressão por atrito, principalmente em óleos pesados. O problema reside na ampla faixa de temperatura que a correlação deve cobrir no modelo de escoamento em tubulações, enquanto que no meio poroso a propriedade é calculada somente em função da pressão, uma vez que o reservatório é considerado um 
meio isotérmico. Se a correlação usada não conseguir representar os dados encontrados no laboratório em toda a faixa de temperaturas e pressão o engenheiro deverá escolher qual fenômeno será privilegiado.

Outro exemplo, agora relacionado a uma propriedade termodinâmica, é o ajuste da massa específica do óleo. Para o escoamento em tubulações esta propriedade é de fundamental importância. No escoamento de petróleo em águas ultraprofundas, a perda de carga gravitacional é a grande responsável pela diminuição da pressão ao longo do sistema de produção. Logo, a EOS ajustada por um engenheiro de escoamento em tubulações terá um peso maior para esta propriedade em detrimento a outras, por exemplo, o $B_{o}$. O escoamento no meio poroso também carece de um bom ajuste para a massa específica, contudo, o engenheiro de reservatório normalmente opta por um ajuste mais preciso na $R_{s}$ e no $B_{o}$.

No caso desta dissertação, em primeiro lugar buscou-se um ajuste mais preciso da pressão de saturação nas três temperaturas. Além disso, por se tratar de um óleo com elevada razão de solubilidade, utilizou-se um peso maior para o valor inicial de $R_{s}$, uma vez que um erro grande nesta propriedade pode acarretar em erros inaceitáveis na predição de vazão de gás e de fração de líquido ao longo da coluna de produção e do duto. As outras propriedades se utilizaram do mesmo peso na regressão. A Tabela 4.10 ilustra os pesos usados para as principais variáveis de interesse em todas as EOS modeladas.

Após o ajuste satisfatório das propriedades termodinâmicas, os cinco coeficientes da correlação LBC e o volume crítico de cada componente são usados para realizar o ajuste da viscosidade do óleo e do gás. Como a viscosidade no resevatório tem um papel fundamental na mobilidade da fase óleo, foi dada a prioridade total no ajuste para a viscosidade na temperatura de reservatório e sobretudo o ensaio de viscosidade acima da pressão de saturação teve peso maior na regressão em relação ao ensaio de liberação diferencial em baixas pressões, dado que é uma premissa deste estudo escoamento monofásico no reservatório.

Por se tratar de um óleo leve com viscosidade muito baixa, o ajuste nas temperaturas características de escoamento em dutos foi deixado sem peso na regressão uma vez que mesmo elevados erros relativos em baixíssimas viscosidades não afetam a perda de carga por fricção de forma relevante a ponto de impactar os diferenciais de pressão ao longo do escoamento. A Tabela 4.11 ilustra o resultado encontrado para os 5 coeficientes da correlação LBC após o ajuste das viscosidades de óleo e gás.

O fluxo de processo descrito acima é executado diversas vezes variando-se os pesos e as propriedades passíveis de ajuste até o engenheiro ficar satisfeito 
Tabela 4.10: Pesos globais usados na regressão das EOS.

\begin{tabular}{|c|c|c|c|c|c|c|c|}
\hline $\begin{array}{l}\text { Propriedade } \\
\text { experimental }\end{array}$ & $\begin{array}{l}\text { Peso } \\
24 \text { PC }\end{array}$ & $\begin{array}{l}\text { Peso } \\
14 \text { PC }\end{array}$ & $\begin{array}{l}\text { Peso } \\
9 \text { PC } \\
\end{array}$ & $\begin{array}{l}\text { Peso } \\
7 \text { PC } \\
\end{array}$ & $\begin{array}{l}\text { Peso } \\
6 \text { PC } \\
\end{array}$ & $\begin{array}{l}\text { Peso } \\
5 \text { PC } \\
\end{array}$ & $\begin{array}{l}\text { Peso } \\
4 \text { PC }\end{array}$ \\
\hline Pressão Saturação $122{ }^{\circ} \mathrm{C}$ & 10 & 5 & 10 & 5 & 5 & 7 & 8 \\
\hline Pressão Saturação $75{ }^{\circ} \mathrm{C}$ & 1 & 3 & 3 & 3 & 3 & 3 & 6 \\
\hline Pressão Saturação $30{ }^{\circ} \mathrm{C}$ & 3 & 3 & 3 & 3 & 3 & 3 & 5 \\
\hline Volume Relativo & 1 & 1 & 1 & 1 & 1 & 1 & 1 \\
\hline Massa Específica Óleo & 1 & 1 & 1 & 1 & 1 & 1 & 1 \\
\hline$B_{o}$ & 1 & 1 & 1 & 1 & 1 & 1 & 1 \\
\hline RGO & 1 & 1 & 1 & 1 & 1 & 1 & 1 \\
\hline$R_{s i}$ & 5 & 5 & 5 & 5 & 5 & 5 & 4 \\
\hline Fator Z Gás & 1 & 1 & 1 & 1 & 1 & 1 & 1 \\
\hline Densidade do Gás & 1 & 1 & 1 & 1 & 1 & 1 & 1 \\
\hline Massa Específica Gás & 1 & 1 & 1 & 1 & 1 & 1 & 1 \\
\hline${ }^{\circ} \mathrm{API}$ & 1 & 1 & 1 & 1 & 1 & 1 & $\overline{1}$ \\
\hline Viscosidade do óleo & 0 & 0 & 0 & 0 & 0 & 0 & 0 \\
\hline Viscosidade do gás & 0 & 0 & 0 & 0 & 0 & 0 & 0 \\
\hline
\end{tabular}

Tabela 4.11: Coeficientes da correlação LBC após regressão das EOS.

\begin{tabular}{cccccc} 
EOS & $\mathbf{a 1}$ & $\mathbf{a} 2$ & $\mathbf{a} 3$ & $\mathbf{a} 4$ & $\mathbf{a 5}$ \\
\hline $24 \mathrm{PC}$ & 0,1020 & 0,0187 & 0,0702 & $-0,0376$ & 0,0075 \\
\hline $14 \mathrm{PC}$ & 0,1016 & 0,0187 & 0,0676 & $-0,0366$ & 0,0075 \\
\hline 9 PC & 0,1013 & 0,0187 & 0,0673 & $-0,0364$ & 0,0075 \\
\hline 7 PC & 0,1033 & 0,0187 & 0,0667 & $-0,0361$ & 0,0075 \\
\hline 6 PC & 0,0989 & 0,0234 & 0,0641 & $-0,0358$ & 0,0075 \\
\hline 5 PC & 0,1032 & 0,0187 & 0,0702 & $-0,0374$ & 0,0075 \\
\hline 4 PC & 0,1009 & 0,0187 & 0,0688 & $-0,0363$ & 0,0075 \\
\hline
\end{tabular}

com a resposta que a EOS está gerando. Apenas para ilustrar o ajuste de forma global, a Tabela 4.12 mostra o resultado encontrado para as principais propriedades de interesse encontradas deste modelo de fluido para as 7 EOS ajustadas e o valor encontrado nos ensaios experimentais.

De modo a ter um ajuste satisfatório das propriedades como um todo, tentou-se na medida do possível, manter o erro na $R_{s}$ em até $5 \%$ e o erro nas pressões de saturação abaixo de $2 \%$. A massa específica do óleo, importante para o escoamento em tubulações, teve um erro na faixa de $6 \%$. Além disso, 
foi premissa nas regressões que as 7 EOS gerassem propriedades semelhantes, de modo que o estudo no modelo integrado fosse comparável, já que vários ajustes satisfatórios são possíveis e se alguma propriedade apresentasse muito desvio nas diversas EOS o estudo perderia robustez.

Tabela 4.12: $R_{s}$ e pressões de saturação após regressão das EOS

\begin{tabular}{ccccc} 
EOS & $P_{\text {sat }}\left(\mathbf{1 2 2}{ }^{\circ} \mathbf{C}\right)$ & $P_{\text {sat }}\left(\mathbf{7 5}{ }^{\circ} \mathbf{C}\right)$ & $P_{\text {sat }}\left(\mathbf{3 0}{ }^{\circ} \mathbf{C}\right)$ & $R_{s}\left(\mathrm{~m}^{3} / \mathrm{m}^{3}\right)$ \\
\hline Experimental & 373,7 & 366,7 & 345,6 & 444,6 \\
\hline 24 PC & 372,2 & 362,5 & 350,7 & 422,1 \\
\hline 14 PC & 371,3 & 362,0 & 352,1 & 422,3 \\
\hline 9 PC & 372,0 & 363,0 & 352,4 & 423,1 \\
\hline 7 PC & 372,3 & 361,7 & 352,4 & 422,3 \\
\hline 6 PC & 372,0 & 361,6 & 352,6 & 421,7 \\
\hline 5 PC & 370,3 & 362,2 & 351,7 & 421,4 \\
\hline 4 PC & 372,5 & 360,5 & 345,9 & 416,6 \\
\hline
\end{tabular}

A EOS detalhada com 24 PC obtida após a regressão pode ser vista na Tabela 4.13. É importante observar após o ajuste final se a EOS não apresenta nenhuma inconsistência em suas propriedades. Por exemplo, espera-se que a pressão crítica decresça com o aumento do peso molecular dos componentes. Em contraste, espera-se que a temperatura crítica e o fator acêntrico aumentem com o aumento do peso molecular.

Muitas vezes, na busca de uma regressão com menor erro global acaba chegando-se a uma EOS com propriedades que não respeitam a teoria termodinâmica. Isso normalmente é evitado limitando a faixa de variação de cada propriedade dentro da regressão no software.

\subsubsection{4}

\section{Resultado da regressão da EOS com 24 PC}

A seguir poderão ser vistos os principais resultados gerados pela EOS detalhada. As Figuras 4.1, 4.2 e 4.3 ilustram os dados experimentais e os dados obtidos com a EOS de 24 PC no ensaio de liberação diferencial apresentado na Tabela 4.2, na faixa de pressões acima do ponto de bolha do fluido.

Na sequência, entre a Figura 4.4 e 4.10 estão ilustrados os resultados apresentados pela EOS detalhada para o ensaio de liberação diferencial apresentado na Tabela 4.2, na faixa de pressões abaixo do ponto do fluido. 


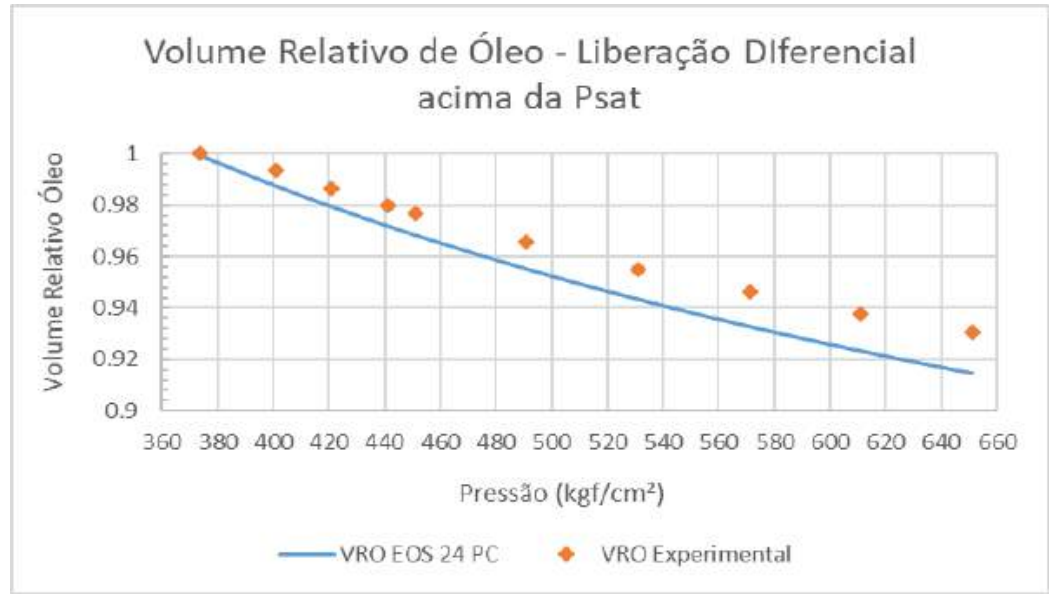

Figura 4.1: Volume relativo de óleo da liberação diferencial acima da pressão de saturação.

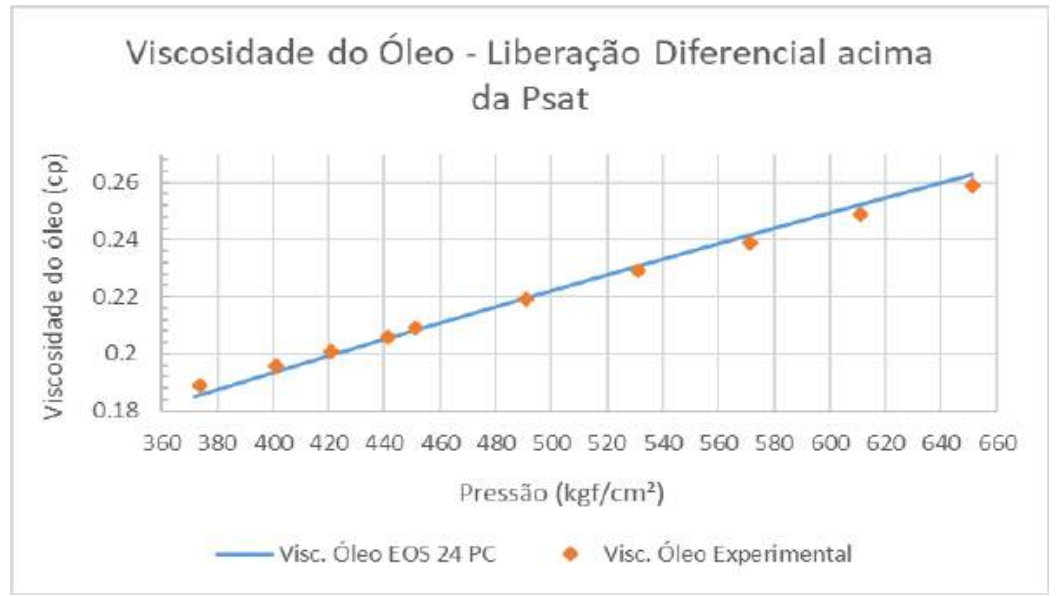

Figura 4.2: Viscosidade do óleo da liberação diferencial acima da pressão de saturação.

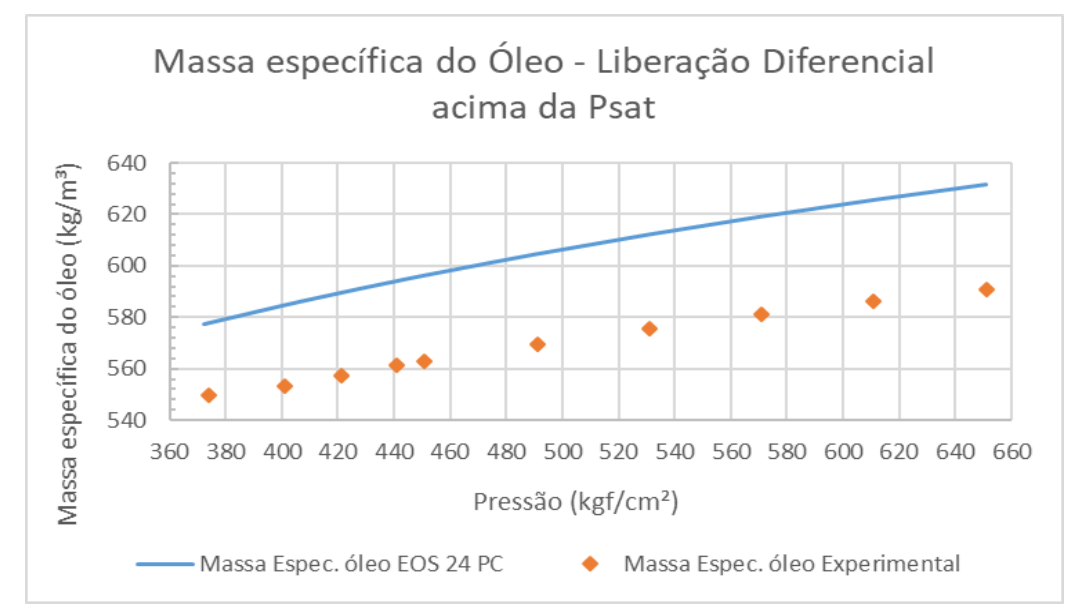

Figura 4.3: Massa específica do óleo da liberação diferencial acima da pressão de saturação. 


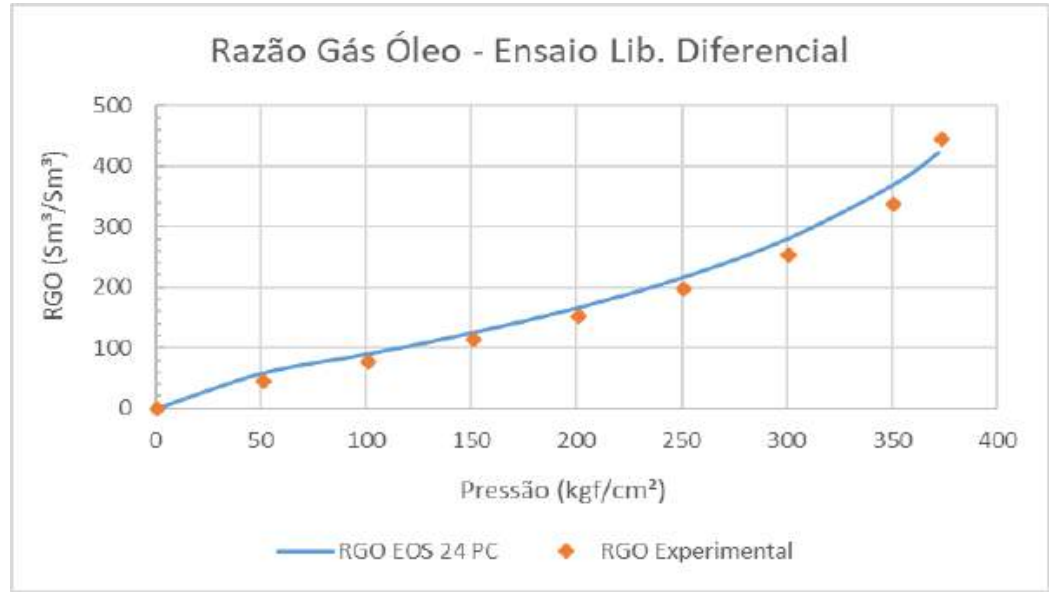

Figura 4.4: RGO da liberação diferencial abaixo da pressão de saturação.

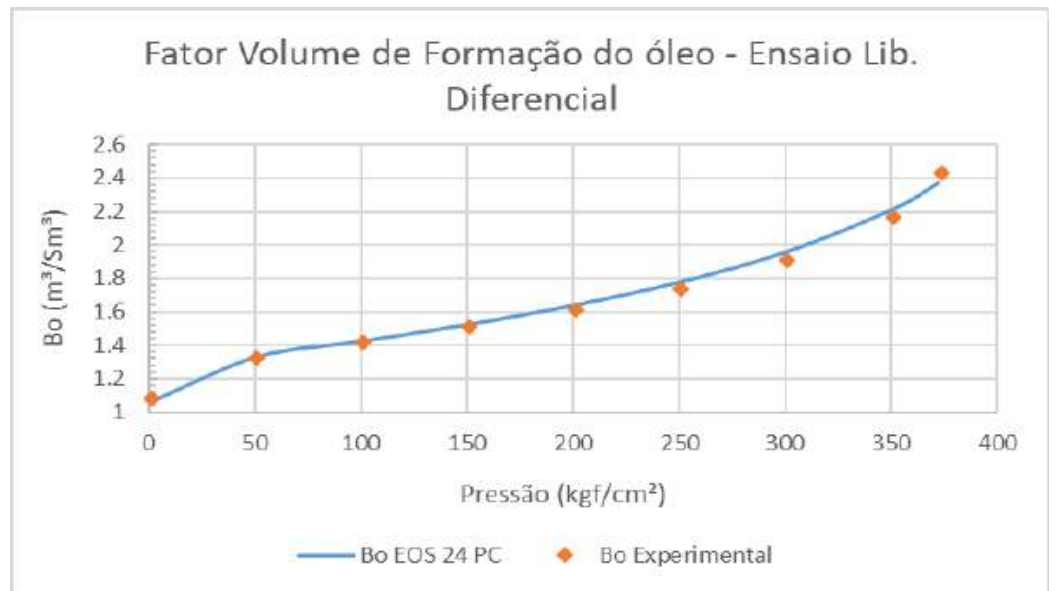

Figura 4.5: $B_{o}$ da liberação diferencial abaixo da pressão de saturação.

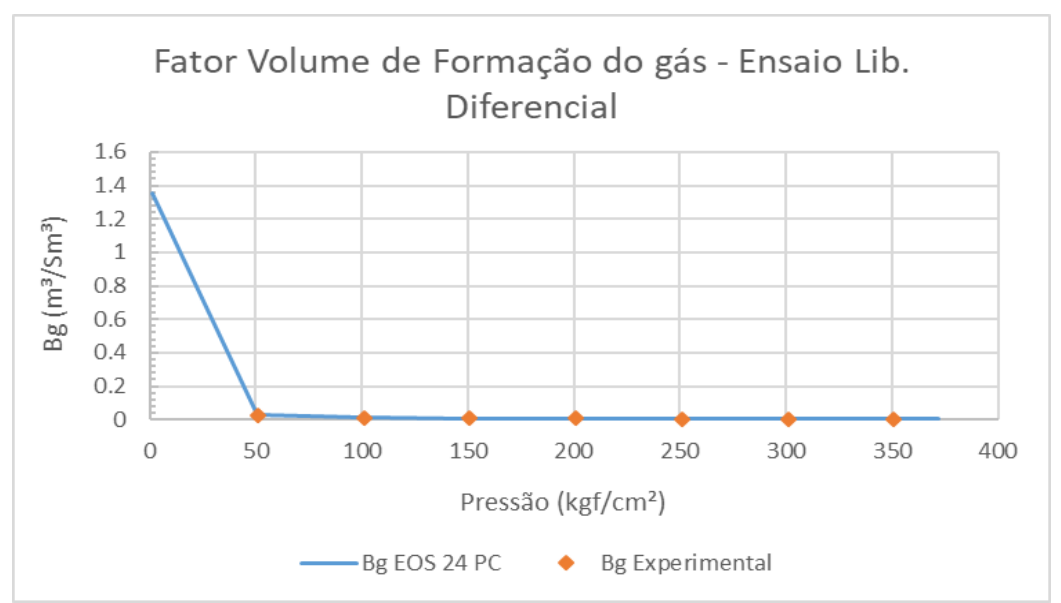

Figura 4.6: $B_{g}$ da liberação diferencial abaixo da pressão de saturação. 
Tabela 4.13: EOS - 24 PC

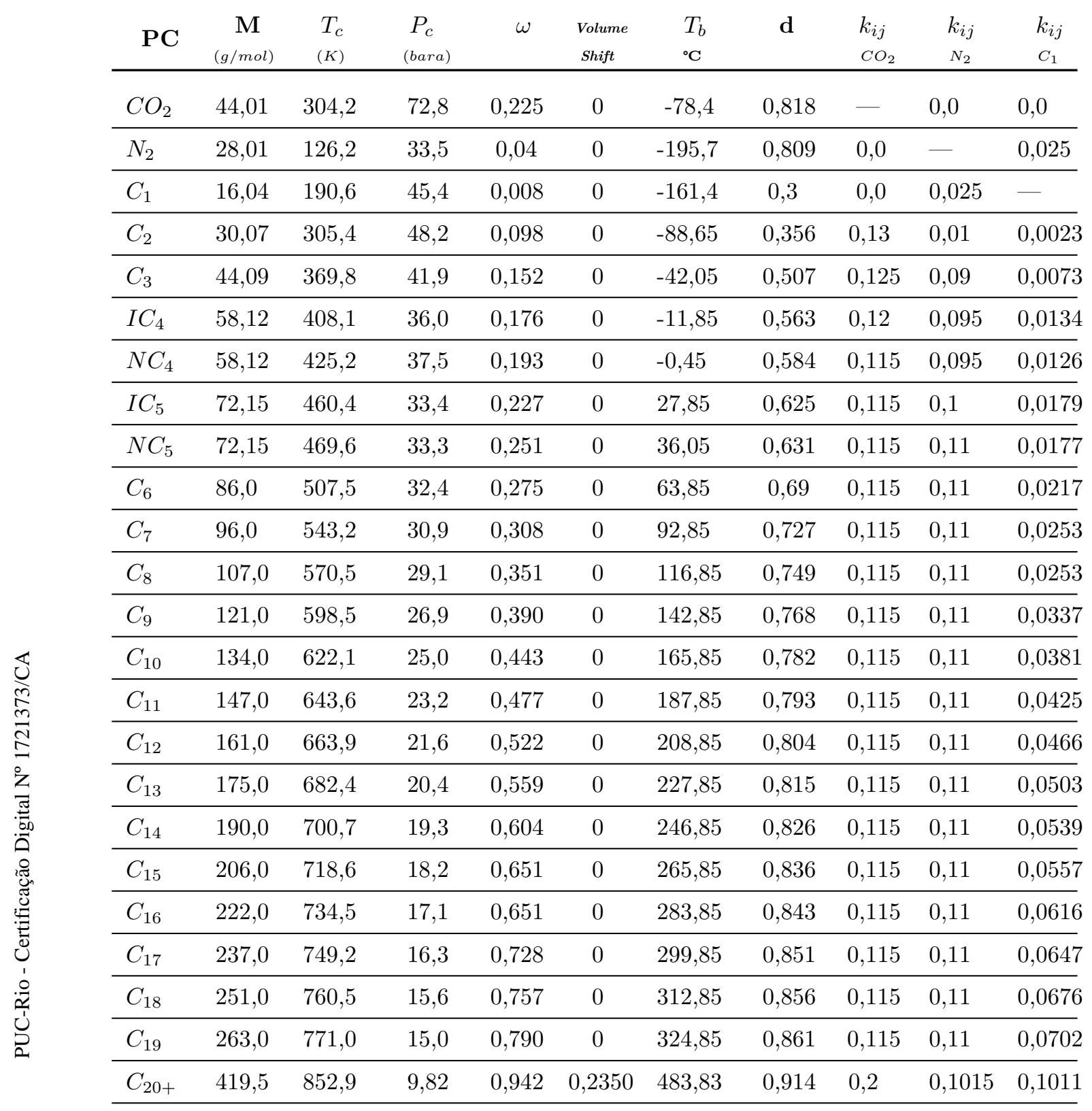

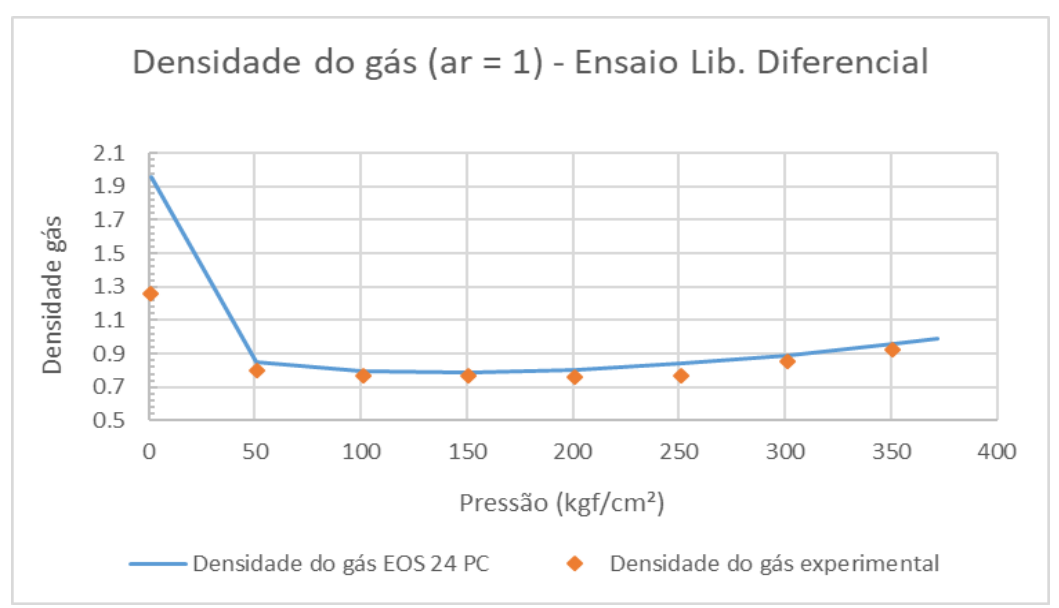

Figura 4.7: Densidade do gás abaixo da pressão de saturação. 


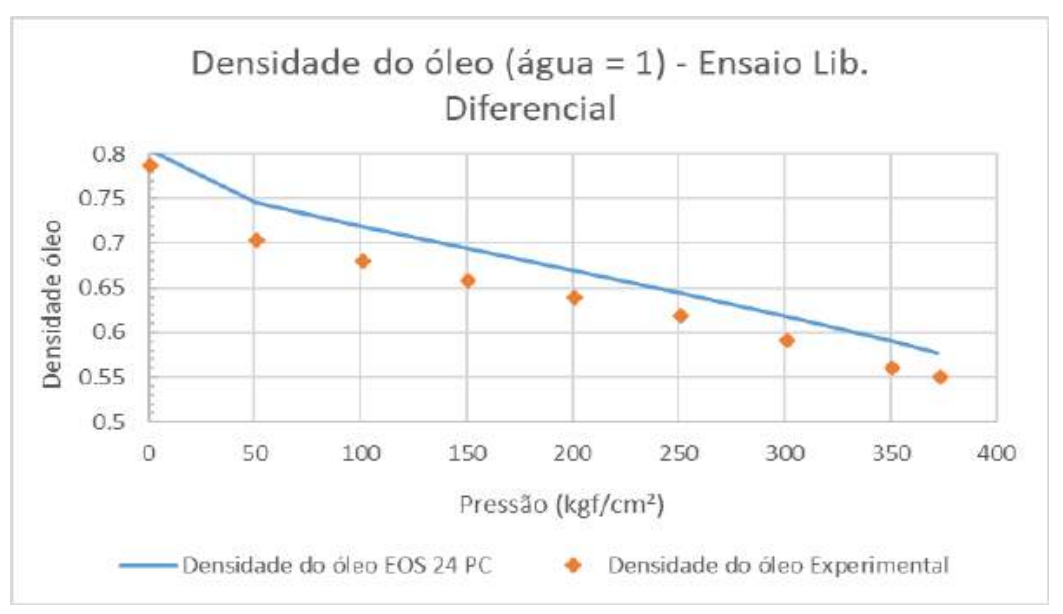

Figura 4.8: Densidade do óleo abaixo da pressão de saturação.

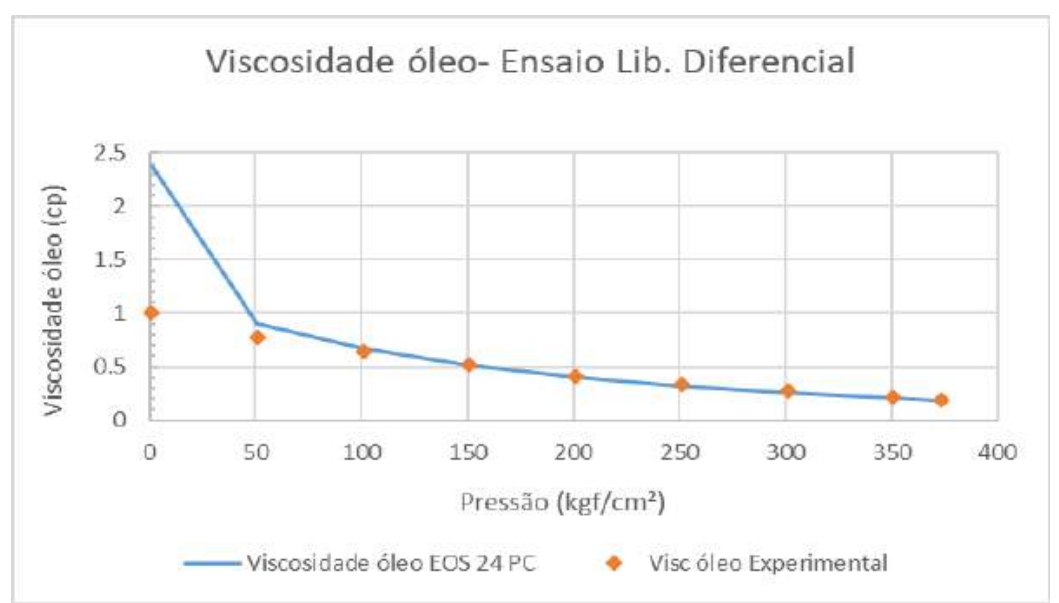

Figura 4.9: Viscosidade do óleo abaixo da pressão de saturação.

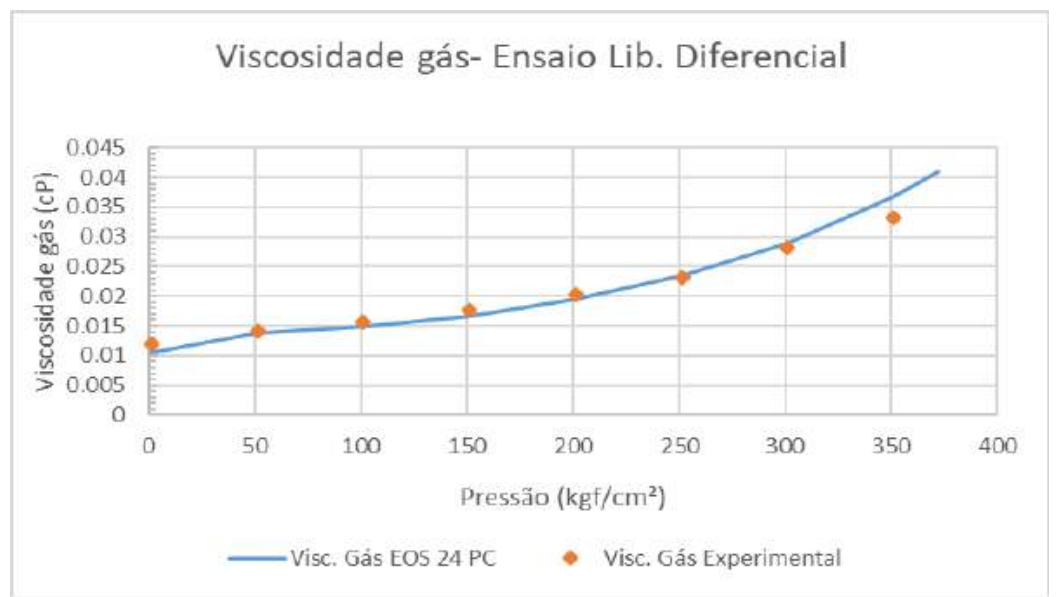

Figura 4.10: Viscosidade do gás abaixo da pressão de saturação. 
Os resultados das regressões dos ensaios de expansão a composição constante relatados nas Tabelas 4.6 a 4.8 estão ilustrados nas Figuras 4.11 a 4.13 para o ensaio na temperatura do reservatório de $122{ }^{\circ} \mathrm{C}$, nas Figuras 4.14 a 4.16 para a temperatura de $75^{\circ} \mathrm{Ce}$ nas Figuras 4.17 a 4.19 para a temperatura de $30^{\circ} \mathrm{C}$.

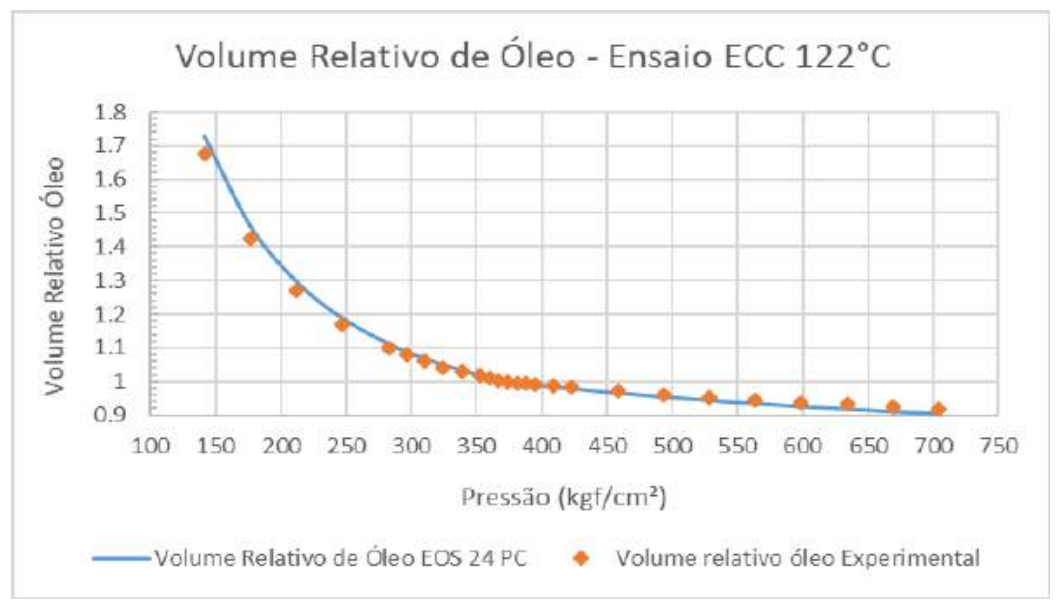

Figura 4.11: Volume relativo de óleo, ECC a $122{ }^{\circ} \mathrm{C}$.

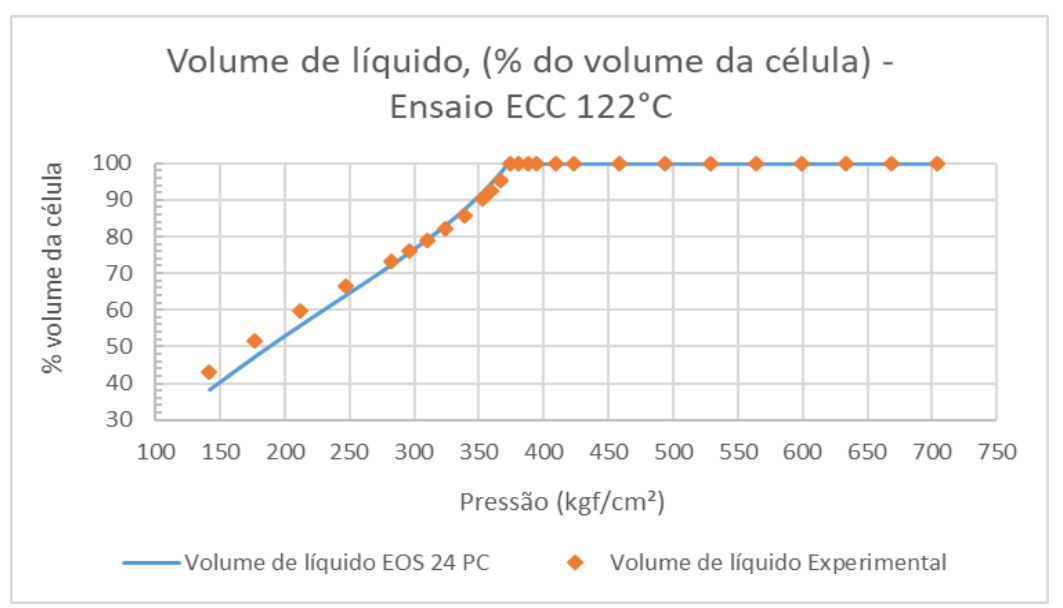

Figura 4.12: Volume de líquido, \% do volume da célula, ECC a $122{ }^{\circ} \mathrm{C}$. 


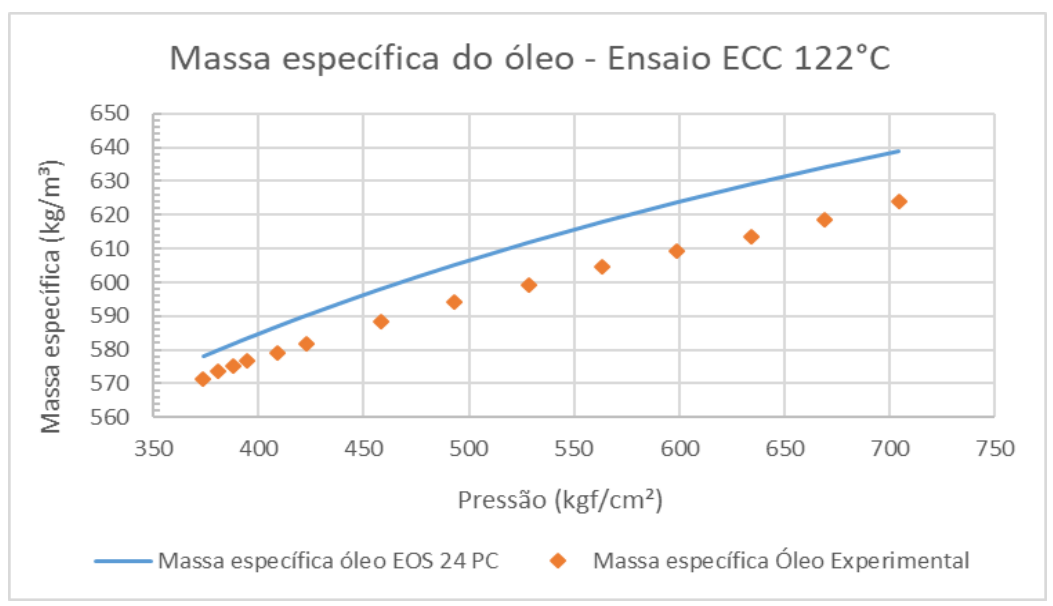

Figura 4.13: Massa específica de óleo, ECC a $122{ }^{\circ} \mathrm{C}$.

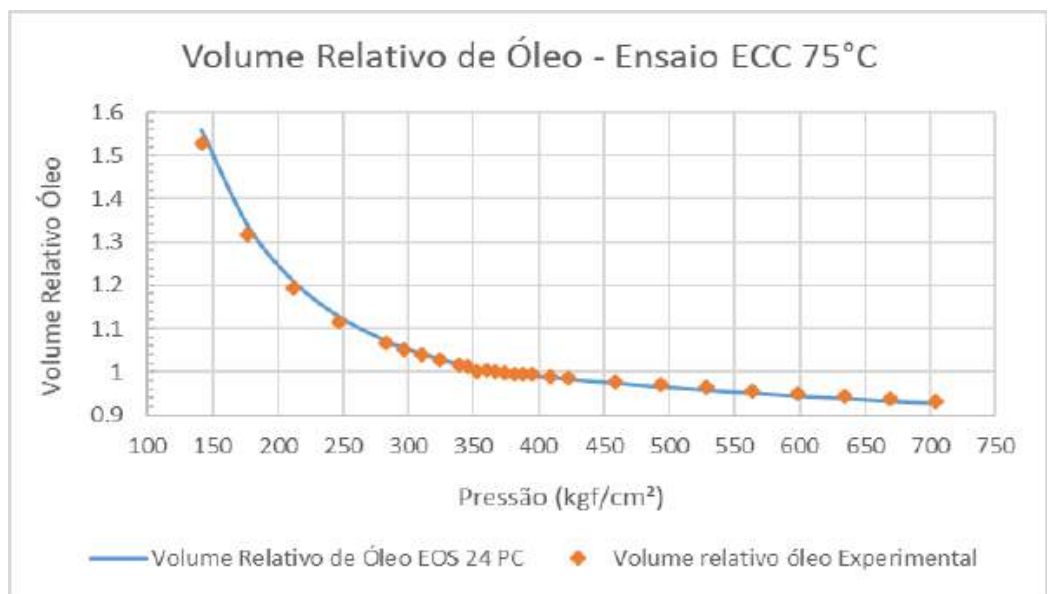

Figura 4.14: Volume relativo de óleo, ECC a $75{ }^{\circ} \mathrm{C}$.

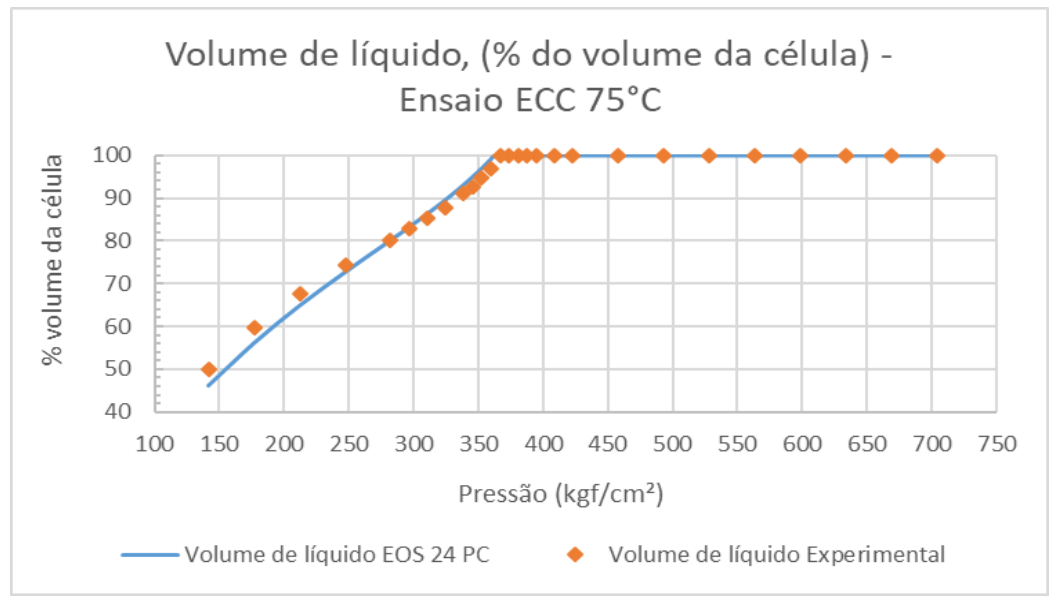

Figura 4.15: Volume de líquido, \% do volume da célula, ECC a $75{ }^{\circ} \mathrm{C}$. 


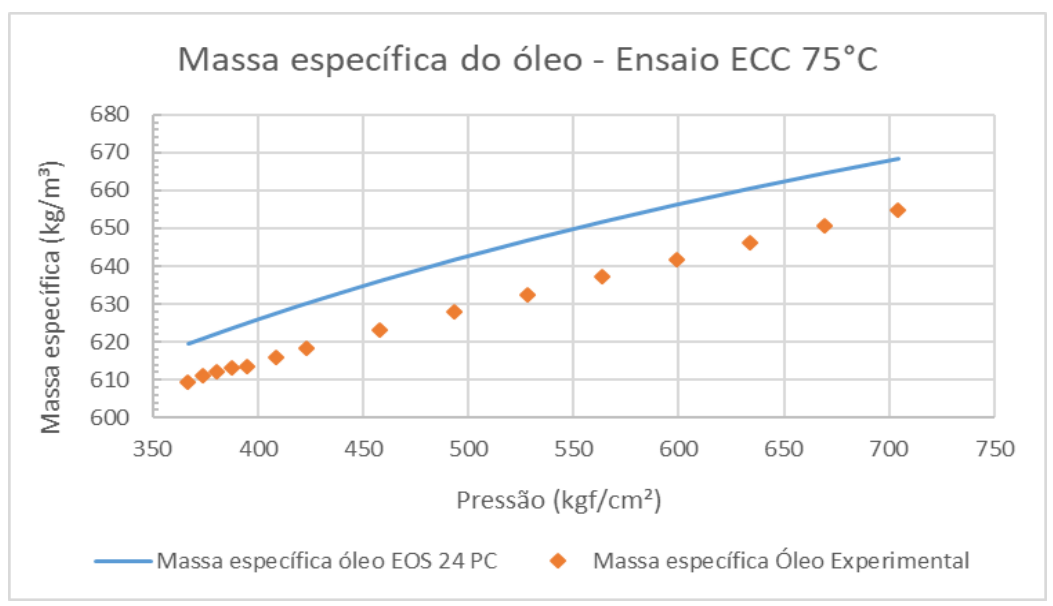

Figura 4.16: Massa específica de óleo, ECC a $75{ }^{\circ} \mathrm{C}$.

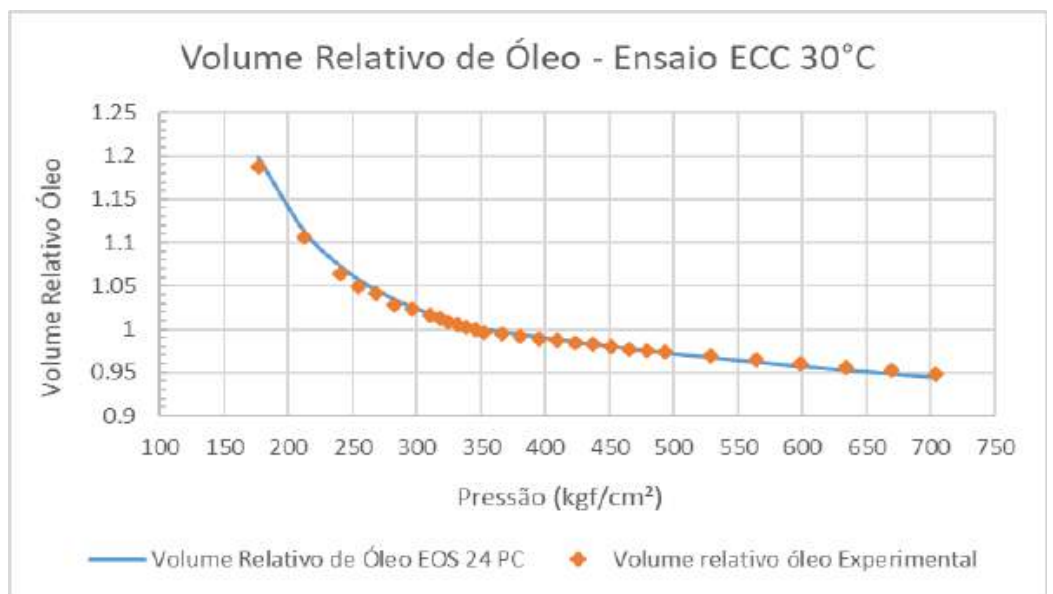

Figura 4.17: Volume relativo de óleo, ECC a $30{ }^{\circ} \mathrm{C}$.

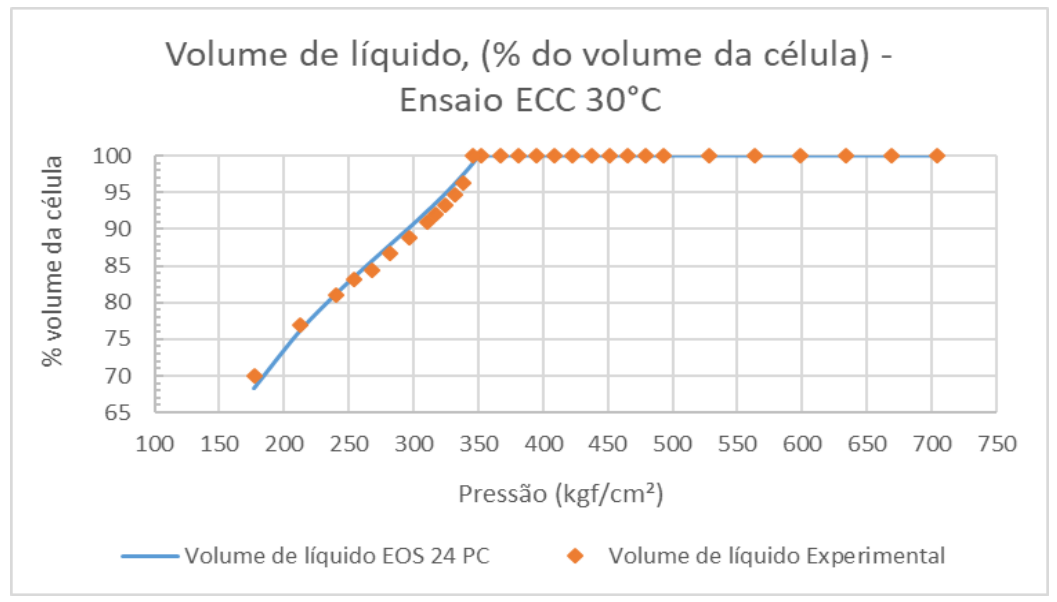

Figura 4.18: Volume de líquido, \% do volume da célula, ECC a $30{ }^{\circ} \mathrm{C}$. 


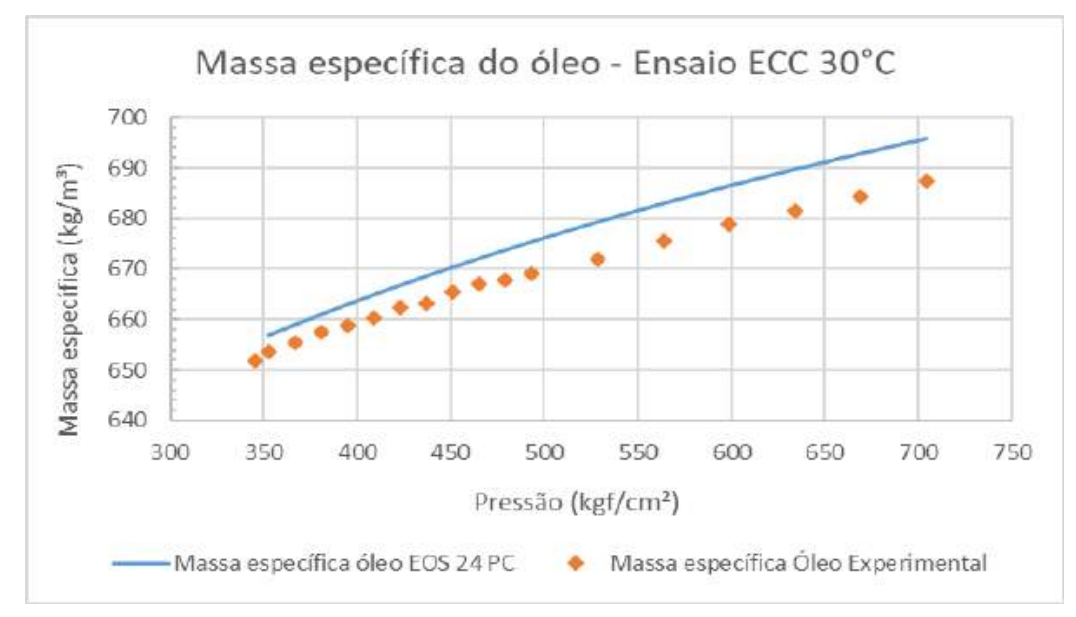

Figura 4.19: Massa específica de óleo, ECC a $30{ }^{\circ} \mathrm{C}$.

Nas Figuras 4.20 e 4.21 pode-se ver o resultado da predição da EOS detalhada para o ensaio de expansão a volume constante, cujos dados podem ser visto na Tabela 4.5 .

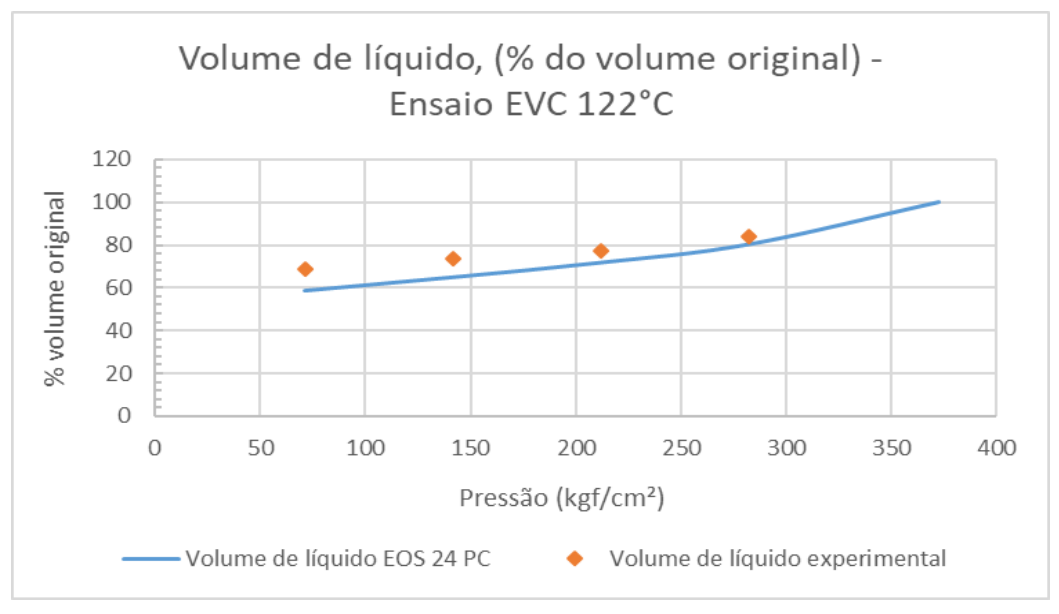

Figura 4.20: Volume de líquido, \% do volume original, EVC a $122{ }^{\circ} \mathrm{C}$.

Um importante ponto que deve ser mencionado em relação ao modelo de viscosidade é a formação de emulsões. Quando o escoamento possuir as condições básicas para a formação de emulsão: presença de dois líquidos imiscíveis; forte cisalhamento, a ponto das gotículas dos fluidos imiscíveis se misturarem; e agentes sustentadores da emulsão, normalmente os componentes mais pesados do óleo, como resinas e asfaltenos, a emulsão água-óleo estável pode se estabelecer no escoamento.

Nesta condição, o óleo e água se comportam como um novo fluido que possui características de reologia completamente diferentes dos fluidos não emulsionados. Especialmente no escoamento nas tubulações dos poços e dutos, 


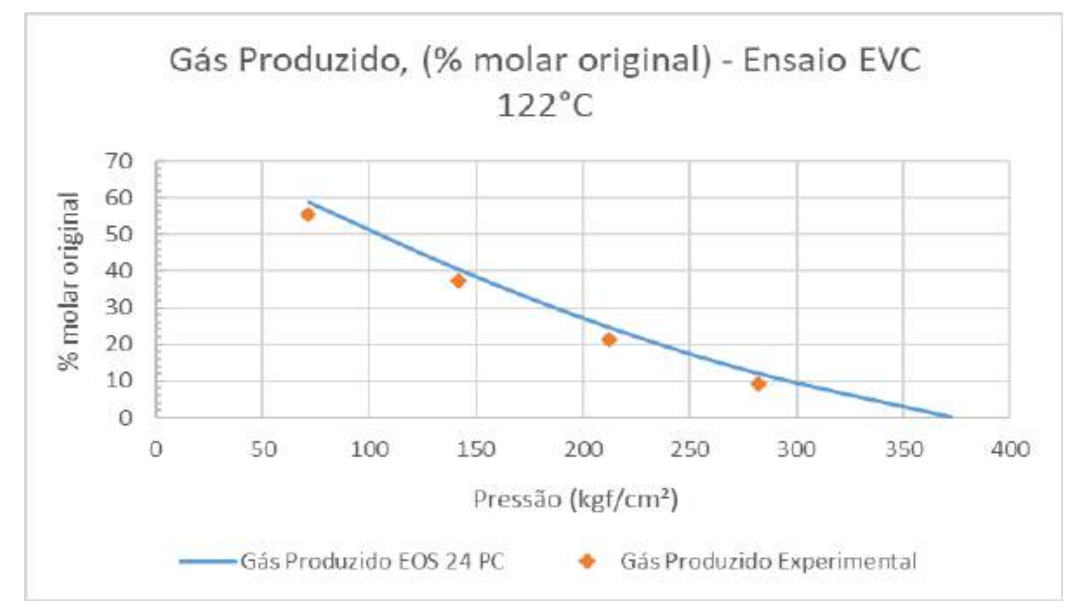

Figura 4.21: Gás produzido, \% molar original, EVC a $122{ }^{\circ} \mathrm{C}$.

este fenômeno é uma preocupação, pois há aumento da velocidade dos fluidos e escoamento por pontos tortuosos (válvulas, restrições na coluna de produção, etc.), aumentando a possibilidade de formação.

A viscosidade da emulsão é muitas vezes maior do que a viscosidade dos fluidos não emulsionados, e o problema se agrava enormemente com a diminuição de temperatura durante o escoamento. Contudo, como não é objetivo desta dissertação estudar o efeito da emulsão, e de modo a simplificar a modelagem da viscosidade, foi considerado que o fluido não forma emulsão água-óleo estável. Desta forma, nenhum multiplicador para a viscosidade do líquido foi usada para representar a formação de emulsão.

A seguir será discutido o método usado para a simplificação e também os resultados das regressões para cada EOS.

\subsection{3}

\section{Metodologia de simplificação e regressão das EOS simplificadas}

A simplificação de EOS é um assunto bastante debatido na indústria de petróleo, dado que modelos composicionais com vários componentes esbarram em limitação computacional, logo, várias técnicas podem ser encontradas na literatura.

Para os estudos desta dissertação o método de simplificação adotado foi baseado no trabalho de Whitson (1983), que propôs representar a fração $C_{7+}$ de uma mistura através de $N_{p}$ pseudocomponentes (PC) calculados a partir de:

$$
N_{p}=\text { Integer }[1+3,3 \log (N-7)]
$$

onde N é o número do último grupo de carbono. O limite entre grupos é baseado 
no peso molecular limítrofe, $M_{k}$, dado por:

$$
M_{k}=M_{20}\left[\exp \left[\left(\frac{1}{N_{p}}\right) \ln \left(\frac{M_{N}}{M_{20}}\right)\right]\right]^{k}
$$

para $k=1,2, \ldots, N_{p}$.

Como o último grupo de carbono são as moléculas com 20 ou mais átomos de carbono, a fórmula proposta por resulta em:

$$
N_{p}=\text { Integer }[1+3,3 \log (20-7)]=4
$$

Logo, já que precisamos de um número inteiro de $\mathrm{PC}$, a fração $C_{7+}$ da mistura será representada por 4 PC. A formulação proposta para o peso molecular limítrofe de cada grupo resulta nos seguintes pesos moleculares: $M_{1}=142,9 \mathrm{~g} / \mathrm{mol}, M_{2}=204,2 \mathrm{~g} / \mathrm{mol}, M_{3}=291,8 \mathrm{~g} / \mathrm{mol}$ e $M_{4}=417,0$ $\mathrm{g} / \mathrm{mol}$.

Decidiu-se então: (i) agrupar os $\mathrm{PC} C_{7}$ a $C_{10}$ no primeiro grupo $M_{1}$, uma vez que o peso molecular do PC $C_{10}$ é de $142 \mathrm{~g} / \mathrm{mol}$; (ii) agrupar os componentes $C_{11}$ a $C_{14}$ no grupo $M_{2}$, já que o peso molecular do PC $C_{14}$ é de $198 \mathrm{~g} / \mathrm{mol}$; (iii) agrupar os componentes $C_{15}$ a $C_{19}$ no grupo $M_{3}$, pois o peso molecular do PC $C_{19}$ é de $268 \mathrm{~g} / \mathrm{mol}$ e (iv) o PC $C_{20+}$ naturalmente ficará no grupo $M_{4}$.

Desta forma, o primeiro esquema de agrupamento proposto foi baseado nas fórmulas acima e resultou em uma equação de estado com 14 PC, contra os 24 PC da EOS original detalhada. A partir deste ponto, para diminuir ainda mais o número de $\mathrm{PC}$ regras básicas de agrupamento adotadas na indústria foram usadas para encontrarmos EOS ainda mais simplificadas. Uma EOS com 9 PC foi criada agrupando-se os componentes $C_{2}$ e $C_{3}$, formando um novo PC, e os componentes $I C_{4}, N C_{4}, I C_{5}, N C_{5}$ e $C_{6}$ formando outro PC.

Uma EOS com $7 \mathrm{PC}$ foi criada agrupando os componentes $N_{2}$ e $C_{1}$ em um mesmo PC, os componentes $C_{2}$ e $C_{2}$ em outro e os componentes $C_{3}, I C_{4}$, $N C_{4}, I C_{5}, N C_{5}$ e $C_{6}$ em um terceiro PC. Esse agrupamento dos mais leves é bastante usado quando os contaminantes $\mathrm{N}_{2}$ e $\mathrm{CO}_{2}$ são encontrados em baixo teor na composição da mistura de fluido, aproveitando-se da similaridade dos pesos moleculares destes componentes.

A partir da EOS com $7 \mathrm{PC}$, agrupou-se os grupos $M_{2}$ e $M_{3}$ no mesmo $\mathrm{PC}$, originando uma EOS com 6 PC. Ao adicionar a este novo PC o grupo $M_{1}$ originou-se uma EOS com $5 \mathrm{PC}$ e finalmente, em um esforço de testar ao máximo o agrupamento, a partir da EOS com $5 \mathrm{PC}$, Os componentes $\mathrm{CO}_{2}$, $C_{2}, C_{3}, I C_{4}, N C_{4}, I C_{5}, N C_{5}$ e $C_{6}$ foram agrupados em um único PC. 
Tabela 4.14: EOS - 14 PC

\begin{tabular}{ccccccccccc}
$\mathbf{P C}$ & $\begin{array}{c}\mathbf{M} \\
(\mathrm{g} / \mathrm{mol})\end{array}$ & $\begin{array}{c}T_{c} \\
(K)\end{array}$ & $\begin{array}{c}P_{c} \\
(\mathrm{bara})\end{array}$ & $\omega$ & $\begin{array}{c}\text { Volume } \\
\text { Shift }\end{array}$ & $\begin{array}{c}T_{b} \\
{ }^{\circ} \mathbf{C}\end{array}$ & $\mathbf{d}$ & $\begin{array}{c}k_{i j} \\
C_{2}\end{array}$ & $\begin{array}{c}k_{i j} \\
N_{2}\end{array}$ & $\begin{array}{c}k_{i j} \\
C_{1}\end{array}$ \\
\hline$C^{C} O_{2}$ & 44,01 & 304,2 & 72,8 & 0,225 & 0 & $-78,4$ & 0,818 & - & 0,0 & 0,0 \\
\hline$N_{2}$ & 28,01 & 126,2 & 33,5 & 0,04 & 0 & $-195,7$ & 0,809 & 0,0 & - & 0,020 \\
\hline$C_{1}$ & 16,04 & 190,6 & 45,4 & 0,008 & 0 & $-161,4$ & 0,3 & 0,0 & 0,020 & - \\
\hline$C_{2}$ & 30,07 & 305,4 & 48,2 & 0,098 & 0 & $-88,65$ & 0,356 & 0,0 & 0,010 & 0,0023 \\
\hline$C_{3}$ & 44,09 & 369,8 & 41,9 & 0,152 & 0 & $-42,05$ & 0,507 & 0,015 & 0,090 & 0,0074 \\
\hline$I C_{4}$ & 58,12 & 408,1 & 36,0 & 0,176 & 0 & $-11,85$ & 0,563 & 0,120 & 0,095 & 0,0137 \\
\hline$N C_{4}$ & 58,12 & 425,2 & 37,5 & 0,193 & 0 & $-0,45$ & 0,584 & 0,115 & 0,095 & 0,0128 \\
\hline$I C_{5}$ & 72,15 & 460,4 & 33,4 & 0,227 & 0 & 27,85 & 0,625 & 0,115 & 0,10 & 0,0182 \\
\hline$N C_{5}$ & 72,15 & 469,6 & 33,3 & 0,251 & 0 & 36,05 & 0,631 & 0,115 & 0,110 & 0,0180 \\
\hline$C_{6}$ & 86,0 & 507,5 & 32,4 & 0,275 & 0 & 63,85 & 0,69 & 0,115 & 0,110 & 0,0221 \\
\hline$C_{7}-C_{10}$ & 112,8 & 581,6 & 28,2 & 0,368 & 0 & 129,1 & 0,756 & 0,115 & 0,110 & 0,0315 \\
\hline$C_{11}-C_{14}$ & 166,7 & 671,4 & 21,2 & 0,537 & 0 & 217,2 & 0,809 & 0,115 & 0,110 & 0,0487 \\
\hline$C_{15}-C_{19}$ & 233,0 & 744,8 & 16,6 & 0,715 & 0 & 295,6 & 0,849 & 0,20 & 0,110 & 0,0647 \\
\hline$C_{20+}$ & 420,1 & 852,5 & 9,8 & 0,942 & 0,2347 & 483,8 & 0,915 & 0,20 & 0,0 & 0,1025 \\
\hline
\end{tabular}

Tabela 4.15: EOS - 9 PC

\begin{tabular}{lcccccccccc}
\multicolumn{1}{c}{$\mathbf{P C}$} & $\begin{array}{c}\mathbf{M} \\
(\mathrm{g} / \mathrm{mol})\end{array}$ & $\begin{array}{c}T_{c} \\
(K)\end{array}$ & $\begin{array}{c}P_{c} \\
(\text { bara })\end{array}$ & $\omega$ & $\begin{array}{c}\text { Volume } \\
\text { Shift }\end{array}$ & $\begin{array}{c}T_{b} \\
{ }^{\circ} \mathbf{C}\end{array}$ & $\mathbf{d}$ & $\begin{array}{c}k_{i j} \\
C O_{2}\end{array}$ & $\begin{array}{c}k_{i j} \\
N_{2}\end{array}$ & $\begin{array}{c}k_{i j} \\
C_{1}\end{array}$ \\
\hline$C_{2}$ & 44,01 & 304,2 & 72,8 & 0,225 & 0 & $-78,4$ & 0,818 & - & 0,0 & 0,105 \\
\hline$N_{2}$ & 28,01 & 126,2 & 33,5 & 0,04 & 0 & $-195,7$ & 0,809 & 0,0 & - & 0,025 \\
\hline$C_{1}$ & 16,04 & 190,6 & 45,4 & 0,008 & 0 & $-161,4$ & 0,3 & 0,105 & 0,025 & - \\
\hline$C_{2}-C_{3}$ & 35,8 & 333,4 & 45,6 & 0,120 & 0 & $-53,8$ & 0,419 & 0,128 & 0,043 & 0,004 \\
\hline$I_{4}-C_{6}$ & 67,4 & 450,4 & 35,1 & 0,219 & 0 & 25,7 & 0,616 & 0,116 & 0,101 & 0,017 \\
\hline$C_{7}-C_{10}$ & 112,8 & 581,6 & 28,2 & 0,368 & 0 & 129,1 & 0,756 & 0,115 & 0,110 & 0,033 \\
\hline$C_{11}-C_{14}$ & 166,7 & 671,4 & 21,2 & 0,537 & 0 & 217,2 & 0,809 & 0,115 & 0,110 & 0,050 \\
\hline$C_{15}-C_{19}$ & 233,0 & 744,8 & 16,6 & 0,715 & 0 & 295,6 & 0,849 & 0,115 & 0,110 & 0,067 \\
\hline$C_{20+}$ & 421,8 & 848,6 & 10,0 & 0,942 & 0,2043 & 483,8 & 0,915 & 0,0 & 0,0 & 0,106 \\
\hline
\end{tabular}

O processo de regressão das EOS pseudoizadas seguiu as mesmas premissas adotadas para a regressão da EOS detalhada, descrito no item anterior. As EOS modeladas podem ser vistas a seguir nas Tabelas 4.19 a 4.14. O resultado da predição de cada EOS e a comparação com os dados experimentais podem ser vistos no Apêndice A.

O principal critério para determinar se o agrupamento proposto é capaz 
Tabela 4.16: EOS - 7 PC

\begin{tabular}{ccccccccccc}
$\mathbf{P C}$ & $\begin{array}{c}\mathbf{M} \\
(\mathrm{g} / \mathrm{mol})\end{array}$ & $\begin{array}{c}T_{c} \\
(\mathrm{~K})\end{array}$ & $\begin{array}{c}P_{c} \\
(\text { bara })\end{array}$ & $\omega$ & $\begin{array}{c}\text { Volume } \\
\text { Shift }\end{array}$ & $\begin{array}{c}T_{b} \\
{ }^{\circ} \mathrm{C}\end{array}$ & $\mathbf{d}$ & $\begin{array}{c}k_{i j} \\
N_{2}-C_{1}\end{array}$ & $\begin{array}{c}k_{i j} \\
\mathrm{CO}_{2}-C_{2}\end{array}$ & $\begin{array}{c}k_{i j} \\
C_{3}-C_{6}\end{array}$ \\
\hline$N_{2}-C_{1}$ & 16,1 & 190,2 & 45,3 & 0,008 & 0 & $-160,6$ & 0,302 & - & 0,002 & 0,012 \\
\hline $\mathrm{CO}_{2}-C_{2}$ & 32,1 & 305,3 & 50,8 & 0,117 & 0 & $-68,0$ & 0,402 & 0,002 & - & 0,005 \\
\hline$C_{3}-C_{6}$ & 57,2 & 417,6 & 38,0 & 0,190 & 0 & 7,7 & 0,575 & 0,012 & 0,005 & - \\
\hline$C_{7}-C_{10}$ & 112,8 & 581,6 & 28,2 & 0,368 & 0 & 129,1 & 0,756 & 0,032 & 0,019 & 0,005 \\
\hline$C_{11}-C_{14}$ & 166,7 & 671,4 & 21,2 & 0,537 & 0 & 217,2 & 0,809 & 0,049 & 0,033 & 0,013 \\
\hline$C_{15}-C_{19}$ & 233,0 & 744,8 & 16,6 & 0,715 & 0 & 295,6 & 0,849 & 0,065 & 0,047 & 0,022 \\
\hline$C_{20+}$ & 428,1 & 863,1 & 9,7 & 0,942 & 0,2306 & 483,8 & 0,915 & 0,103 & 0,081 & 0,048 \\
\hline
\end{tabular}

Tabela 4.17: EOS - 6 PC

Tabela 4.18: EOS - 5 PC

\begin{tabular}{ccccccccccc}
$\mathbf{P C}$ & $\begin{array}{c}\mathbf{M} \\
(\mathrm{g} / \mathrm{mol})\end{array}$ & $\begin{array}{c}T_{c} \\
(K)\end{array}$ & $\begin{array}{c}P_{c} \\
(\text { bara })\end{array}$ & $\omega$ & $\begin{array}{c}\text { Volume } \\
\text { Shift }\end{array}$ & $\begin{array}{c}T_{b} \\
{ }^{\circ} \mathrm{C}\end{array}$ & $\mathbf{d}$ & $\begin{array}{c}k_{i j} \\
\mathrm{~N}_{2}-C_{1}\end{array}$ & $\begin{array}{c}k_{i j} \\
\mathrm{CO}_{2}-\mathrm{C}_{2}\end{array}$ & $\begin{array}{c}k_{i j} \\
C_{3}-C_{6}\end{array}$ \\
\hline$N_{2}-C_{1}$ & 16,1 & 190,2 & 45,3 & 0,008 & 0 & $-160,6$ & 0,302 & - & 0,002 & 0,014 \\
\hline $\mathrm{CO}_{2}-C_{2}$ & 32,1 & 305,3 & 50,8 & 0,117 & 0 & $-68,0$ & 0,402 & 0,002 & - & 0,005 \\
\hline$C_{3}-C_{6}$ & 57,2 & 417,6 & 38,0 & 0,190 & 0 & 7,7 & 0,575 & 0,014 & 0,005 & - \\
\hline$C_{7}-C_{19}$ & 152,4 & 647,4 & 23,2 & 0,486 & 0 & 201,4 & 0,799 & 0,048 & 0,032 & 0,011 \\
\hline$C_{20+}$ & 375,2 & 861,0 & 10,8 & 0,848 & 0,2556 & 483,8 & 0,915 & 0,114 & 0,089 & 0,053 \\
\hline
\end{tabular}

de manter o sentido físico termodinâmico e não apenas uma representação matemática é avaliar o diagrama de fases de pressão e temperatura gerado pela EOS.

O agrupamento naturalmente retira graus de liberdade para a equação de estado ajustar os equilíbrios físico-químicos da cada PC. Por exemplo, quando agrupamos as moléculas de $C O_{2}, C_{2}, C_{3}, I C_{4}, N C_{4}, I C_{5}, N C_{5}$ e $C_{6}$ em um 
Tabela 4.19: EOS - 4 PC

\begin{tabular}{ccccccccccc}
$\mathbf{P C}$ & $\begin{array}{c}\mathbf{M} \\
(\mathrm{g} / \mathrm{mol})\end{array}$ & $\begin{array}{c}T_{c} \\
(K)\end{array}$ & $\begin{array}{c}P_{c} \\
(\text { bara })\end{array}$ & $\omega$ & $\begin{array}{c}\text { Volume } \\
\text { Shift }\end{array}$ & $\begin{array}{c}T_{b} \\
{ }^{\circ} \mathbf{C}\end{array}$ & $\mathbf{d}$ & $\begin{array}{c}k_{i j} \\
N_{2}-C_{1}\end{array}$ & $\begin{array}{c}k_{i j} \\
C_{2}-C_{6}\end{array}$ & $\begin{array}{c}k_{i j} \\
C_{7}-C_{19}\end{array}$ \\
\hline$N_{2}-C_{1}$ & 16,1 & 190,2 & 45,3 & 0,008 & 0 & $-160,6$ & 0,302 & - & 0,008 & 0,046 \\
\hline $\mathrm{CO}_{2}-C_{6}$ & 46,5 & 375,3 & 43,0 & 0,158 & 0 & 4,8 & 0,510 & 0,008 & - & 0,017 \\
\hline$C_{7}-C_{19}$ & 152,4 & 647,4 & 23,2 & 0,486 & 0 & 201,4 & 0,799 & 0,046 & 0,017 & - \\
\hline$C_{20+}$ & 388,7 & 885,1 & 10,7 & 0,848 & 0,2464 & 483,8 & 0,915 & 0,109 & 0,064 & 0,016 \\
\hline
\end{tabular}

único PC, ao decrescer a pressão e a temperatura do sistema haverá uma tendência aos componentes mais leves passarem do estado líquido para o estado gasoso.

Esta passagem naturalmente aconteceria com moléculas de metano, etano, dióxido de carbono e propano em um primeiro momento e moléculas mais pesadas em um segundo momento. Quando estamos em uma equação simplificada, temos apenas um PC representando todas estas moléculas modificando de fase. É de se esperar que o equilíbrio de fases fique impossibilitado de ser representado com a diminuição extrema de componentes em troca de ganho computacional e respostas mais rápidas.

A Figura 4.22 mostra os diagramas de fase encontrados para cada EOS fruto do estudo desta dissertação.

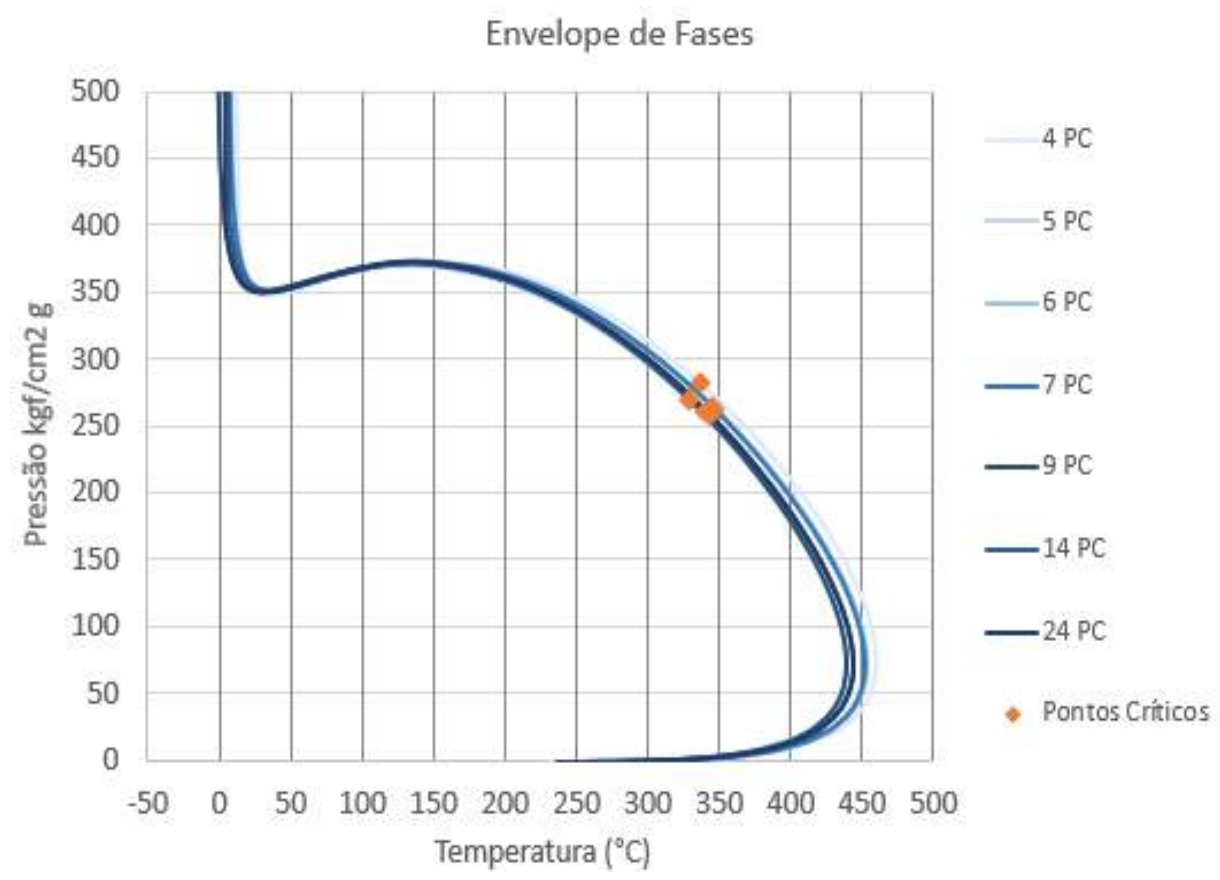

Figura 4.22: Envelopes de fase das EOS.

Pode-se observar que os envelopes de fase são similares, principalmente 
na região de pressão e temperatura dos ensaios laboratoriais. Na região de altas temperaturas há uma certa discrepância entre os envelopes das diferentes EOS, contudo não é necessário ter acurácia na previsão de propriedades em temperaturas acima da do reservatório.

\section{2}

\section{Modelo integrado de produção}

O MIP utilizado para validação dos resultados foi elaborado a partir da ferramenta comercial da Petroleum Experts (PETEX), denominada IPM Suite 11.0. Trata-se de um conjunto de aplicativos que são usados para acoplar o modelo de fluxo do meio poroso e o modelo de escoamento nos poços e dutos.

O software GEM, versão 2016, foi usado como simulador de reservatório. Para o escoamento em poços e dutos foram utilizadas as ferramentas da PETEX, Prosper e GAP. Finalmente, o Resolve é o simulador responsável pelo acoplamento entre os simuladores de reservatório e escoamento.

\subsection{1}

\section{Modelagem do fluxo no meio poroso}

O caso proposto se caracteriza por um modelo simplificado composto por um poço produtor e um poço injetor com um plano de drenagem do tipo quarto de five-spot. O modelo é composto por 30603 células, com um grid de 101x101 e 3 camadas verticais.

As células possuem 25 metros nas direções $x$ e $y$ e 10 metros na direção z. A porosidade das células é de $30 \%$. A permeabilidade absoluta nas direções $x$ e $y$ é de $250 \mathrm{mD}$ e na direção $z$ é de $25 \mathrm{mD}$.

A Figura 4.23 ilustra o modelo descrito acima.

O modelo geológico de simulação foi criado da forma mais simples possível para garantir que a análise da mudança do modelo de fluido não fosse impactada por fenômenos intrínsecos de fluxo do meio poroso. Além disso, respeitou-se as condições iniciais encontradas durante a amostragem de fluido que originaram os testes laboratoriais apresentados acima. Desta forma a pressão inicial do reservatório é de 550 bar e a temperatura inicial é de 122 ${ }^{\circ} \mathrm{C}$. A profundidade do modelo de reservatório é de 5141,7 metros. Não foi considerado contato óleo-água no modelo.

Segundo Machado (2012), originalmente, a lei de Darcy (1856) foi deduzida apenas para fluxo de uma única fase onde a permeabilidade do meio poroso ao fluido é a permeabilidade absoluta do meio. Em se tratando de escoamento em meio poroso multifásico, a lei de Darcy pode ser modificada para calcular a vazão de cada fase. As modificações necessárias incluem o uso da 


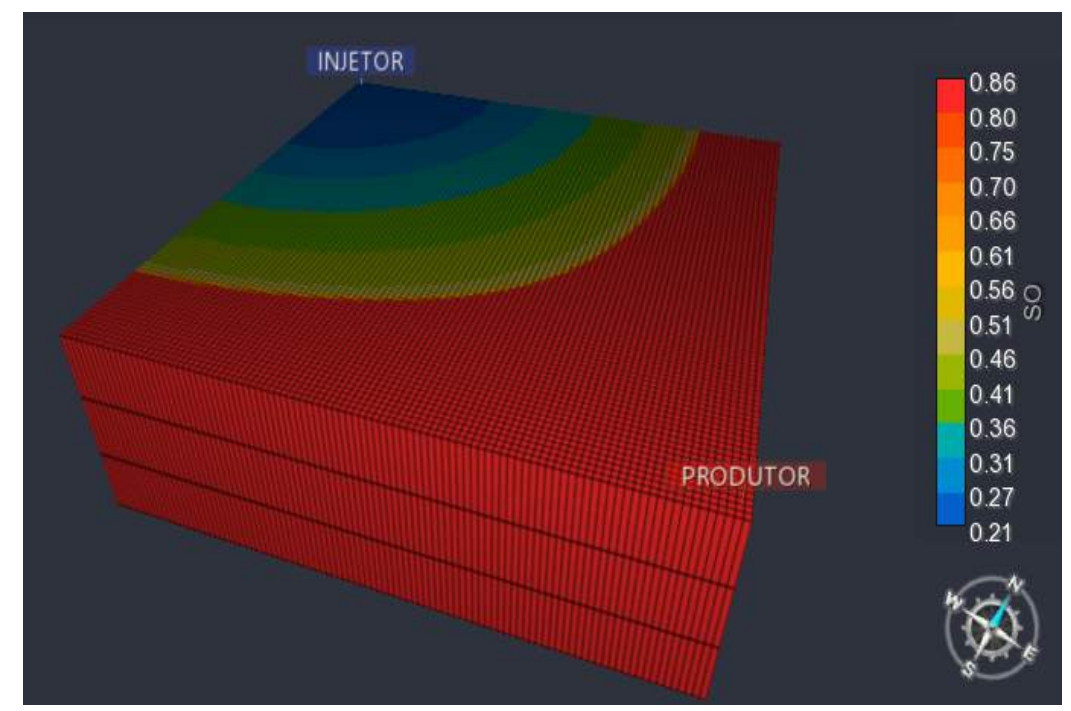

Figura 4.23: Visão 3D do modelo simplificado de reservatório.

permeabilidade efetiva da fase (ao invés da permeabilidade absoluta). Em aplicações de engenharia, a permeabilidade relativa é frequentemente representada como função da saturação de água.

A curva de permeabilidade relativa água-óleo usada no MIP pode ser vista na Figura 4.24. Devido à característica do fluido de ter mobilidade da água e óleo similares, o escoamento no meio poroso é praticamente tipo pistão, isto é, a frente de água oriunda do poço injetor chega ao poço produtor com uma alta saturação de água.

Para amenizar este fenômeno que pode trazer instabilidade numérica no MIP foi feito um ajuste da curva de permeabilidade de modo a minimizar a saturação de água da frente de saturação. A Figura 4.25 mostra a curva de fluxo fracionário de água, que nada mais é que a razão entre a vazão de água e a vazão total dos fluidos que escoam no meio poroso, medida em condições de reservatório em função da saturação da frente de água.

O período de produção estipulado foi de 30 anos, com início em 2020, compatível com um projeto típico de desenvolvimento da produção. O poço produtor foi aberto sem qualquer restrição ao escoamento. O poço injetor teve sua cota de injeção ajustada em $5000 \mathrm{Sm}^{3} / d$ até o final de 2035 e diminuída para $3000 \mathrm{Sm}^{3} / d$ até o final de 2050.

A estratégia de produção consiste em manter o escoamento no meio poroso monofásico, isto é, a pressão do reservatório nunca ficará abaixo da pressão de saturação. Desta forma, o aparecimento de gás no escoamento só se dará no poço e no duto. 


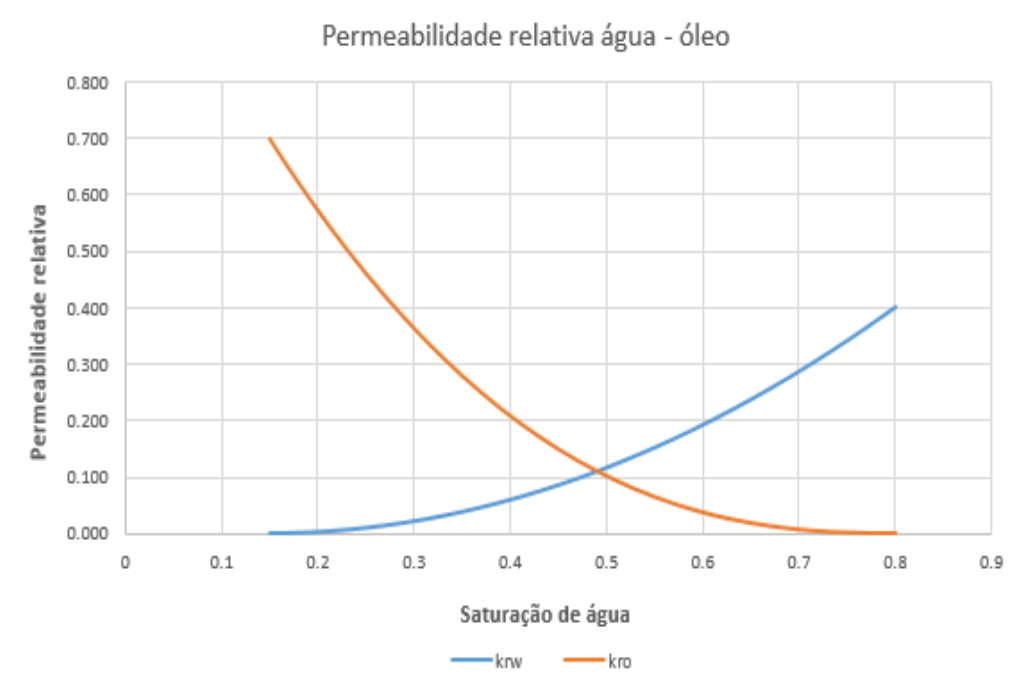

Figura 4.24: Curva de permeabilidade relativa água-óleo.

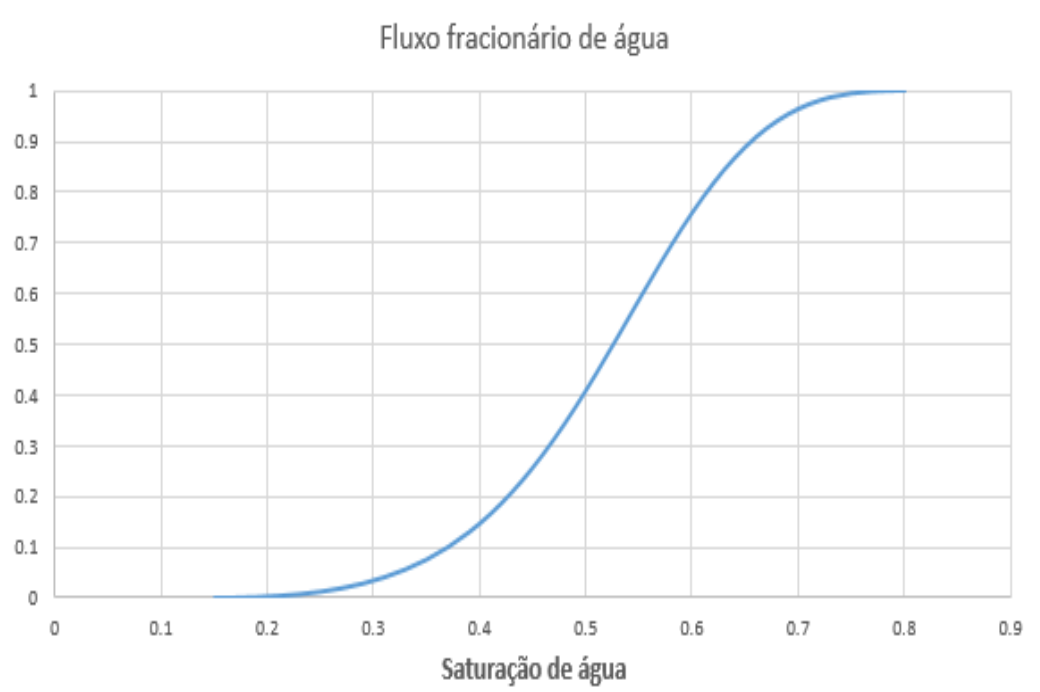

Figura 4.25: Fluxo fracionário de água.

\subsection{2}

\section{Modelagem do fluxo nos poços, dutos e chegada na UEP}

O sistema de produção usado no MIP para a análise corresponde a um caso comum de produção em águas ultra-profundas brasileiras. Seguindo o fluxo do petróleo, o sistema consiste de um poço vertical que tem como ponto inicial a interface poço-reservatório e um ponto final na ANM, equipamento instalado no leito marinho responsável por abrir e fechar o poço.

O escoamento continua através de um duto flexível que está conectado diretamente a ANM e à plataforma de produção. Na plataforma de produção ocorre o processamento primário do petróleo, as fases óleo e gás são separadas 
até atingir as condições de referência.

O gás normalmente é comprimido e exportado via gasodutos para terra e o óleo é armazenado em tanques na UEP que eventualmente é transferido aos navios aliviadores que transportam o óleo para as refinarias processarem os produtos finais para a venda, como diesel, gasolina, querosene, etc. A seguir mais detalhes a respeito da modelagem de cada item.

\subsubsection{1}

\section{Poço produtor}

A interface reservatório-poço, a depender da competência e tipo da rocha, pode consistir desde de um simples poço aberto até um complexo poço revestido, canhoneado e completado em diversas zonas diferentes de produção.

Como não é objetivo do estudo avaliar este ponto específico, considerou-se apenas que a interface poço-reservatório é tal que o índice de produtividade do modelo de reservatório é transferido parcialmente para o modelo de escoamento em dutos, isto é, considerou-se um dano nesta interface que resultou na perda de $50 \%$ do índice de produtividade do poço, por simplificação. Além disso, foi considerado que o poço produtor está canhoneado em toda extensão vertical do reservatório, ou seja, os 30 metros.

O poço produtor é considerado completamente vertical da profundidade do reservatório (5141,7 m) até o leito submarino $(2555 \mathrm{~m})$ por simplificação. Sabe-se que pequenas inclinações são possíveis mas o efeito na simulação pode ser considerado desprezível. O diâmetro da coluna de produção (COP) foi considerado constante com diâmetro nominal de 5,5 polegadas e com diâmetro interno, disponível para o fluido escoar, de 4,67 polegadas.

Ao longo da COP existem diversos equipamentos que geram perdas localizadas devido a restrições no escoamento, entre elas: dispositivo para permitir operações de manutenção e verificação de integridade; dispositivo para medir pressão e temperatura do poço; equipamentos para injeção de gaslift como método de elevação artificial; dispositivo de segurança de poço para evitar produção descontrolada, etc.

No modelo de escoamento usado, que é unidimensional, estas perdas de carga são consideradas desprezíveis frente as perdas de carga por fricção e gravitacional e, portanto, não são calculadas pelo software. A rugosidade da coluna de produção usada nas simulações foi $0,183 \mathrm{~mm}$, valor usual para uma coluna de produção que consiste de uma liga de carbono com $13 \%$ de cromo.

De forma a modelar a transferência de calor radial do fluido para a formação é preciso entrar com dados termofísicos dos materiais e da formação assim como dados da construção do poço. Os dados de perfuração considerados foram 
simplificados e desta maneira apenas a perfuração relativa ao assentamento do revestimento de produção em aço carbono foi considerado. Os revestimentos intermediários e condutores não foram considerados. Ainda assim, foi considerada a perfuração em duas fases do revestimento de produção, a primeira até 4470 metros de profundidade com diâmetro de broca de 14,75 polegadas e de 12,25 polegadas até a profundidade final de 5141,7 metros.

O revestimento de produção considerado tem diâmetro externo de 10,75 polegadas até a profundidade de 4470 metros e 9,625 polegadas até a profundidade final. Todo o revestimento foi cimentado. $\mathrm{O}$ anular entre coluna de produção e diâmetro interno do revestimento de produção foi todo preenchido com fluido de completação base água. A profundidade do packer de produção é de 5000 metros. Para finalizar, foi considerado que a formação é composta de folhelho do leito marinho até a profundidade do reservatório.

Foram usadas propriedades termofísicas padrão encontradas na literatura para os materiais, rochas e fluido usados na modelagem termofísica. $\mathrm{O}$ gradiente de temperatura da formação em repouso foi considerado linear, isto é, varia linearmente da temperatura de reservatório de $122{ }^{\circ}$ Caté a temperatura do leito marinho na profundidade de 2555 metros de $4{ }^{\circ} \mathrm{C}$. A Figura 4.26 mostra um esquemático de construção do poço produtor.

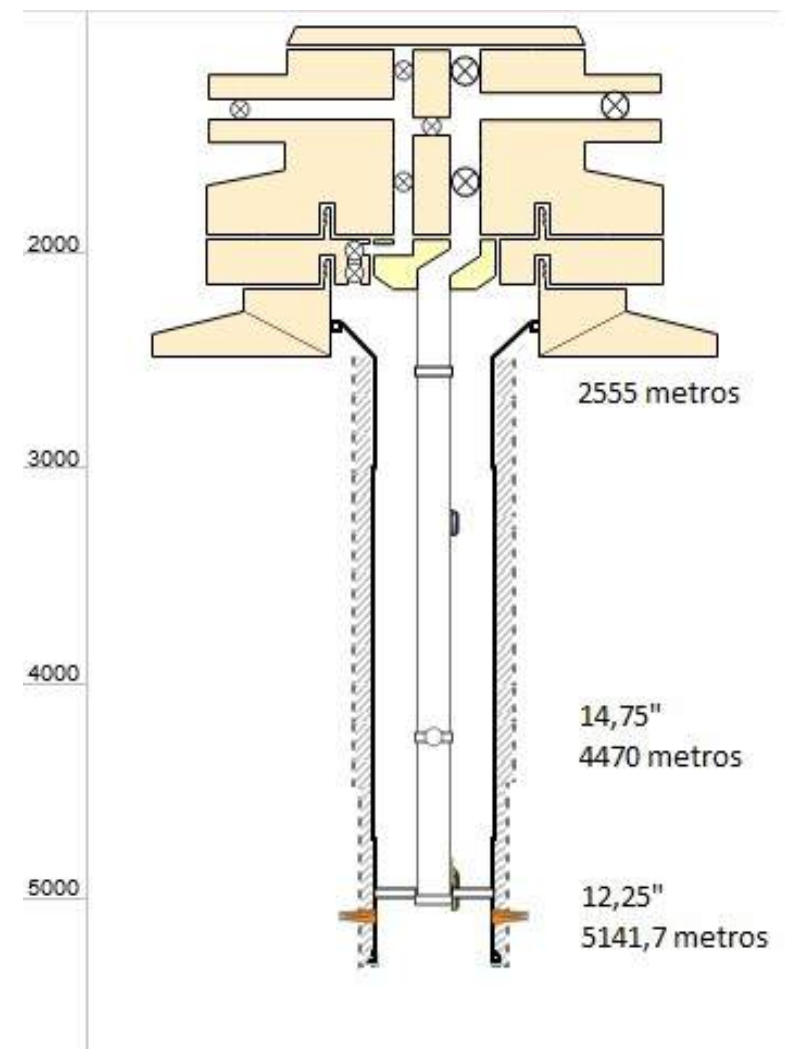

Figura 4.26: Esquemático do poço produtor 


\subsubsection{2}

\section{Duto submarino de produção}

O modelo do duto de produção se inicia na ANM e termina na UEP. O duto é conectado fisicamente em um suporte no costado da UEP. A conexão do duto com a planta de processo é feita com uma peça conhecida como spool de fechamento, e logo a jusante do mesmo encontra-se a válvula que controla a vazão do poço, o choke de produção.

O duto é constituído de duas estruturas principais, a flowline, que é instalada diretamente sobre o solo marinho e o riser, que é a estrutura que ascende verticalmente até a UEP. O ponto de encontro destas duas estruturas é conhecido como conexão riser-flow (CRF) e o ponto em que o riser deixa de estar em contato com o solo marinho é conhecido como touchdown point (TDP).

A flowline é praticamente horizontal até o TDP e o riser, dado que o modelo considera o escoamento em lâmina de água ultra profunda, possui configuração conhecida como lazy-wave, a qual consiste de elementos na estrutura do duto que atuam no sentido de diminuir o peso próprio do duto e, consequentemente, a carga de tração na plataforma, acabando por conferir a configuração que pode ser observada na Figura 4.27.

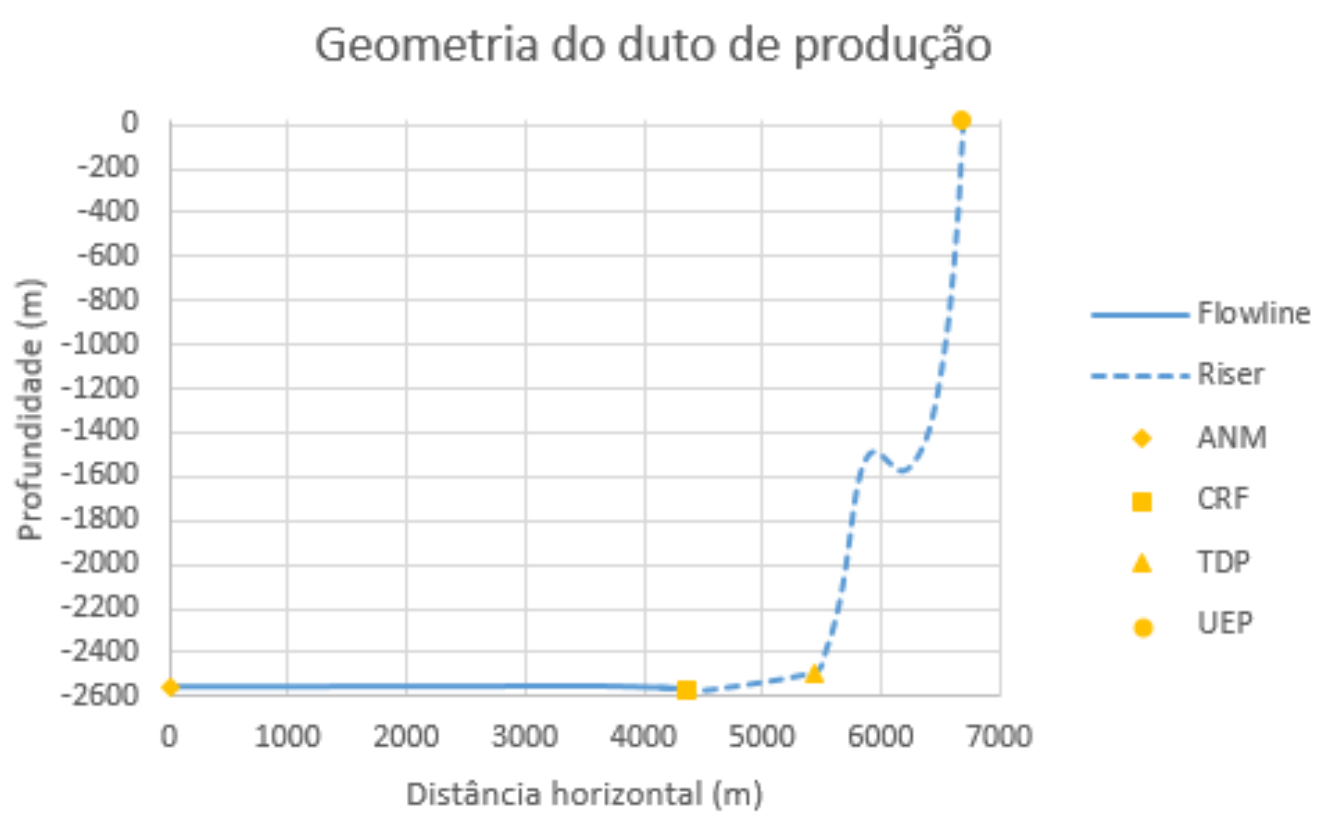

Figura 4.27: Esquemático do poço produtor

Tanto a flowline quanto o riser considerados para o modelo são do tipo flexível, com diâmetro interno de 6 polegadas, adequado para as vazões de 
líquido que o modelo de reservatório está produzindo. Este tipo de duto é composto por várias camadas, cada qual com determinada função estrutural para o duto.

A primeira camada é responsável por manter o duto íntegro em caso de baixas pressões no interior do mesmo, previnindo o rompimento devido ao colapso. Esta camada é a que está em contato direto com o fluido produzido, portanto a rugosidade desta estrutura é importante para a determinação da perda de carga por fricção ao longo do escoamento. Como esta estrutura é bem irregular devido ao modo que o duto é construído, costuma-se usar o valor conservador indicado pela American Petroleum Institute que corresponde ao diâmetro interno dividido por 250, que neste caso gera o valor de 0,61 milímetros de rugosidade.

As demais camadas do flexível são responsáveis por resistir a pressão interna do duto e carga de tração do duto. Algumas camadas intemediárias são colocadas para evitar a abrasão entre uma camada e outra do flexível.

Finalmente, uma importante camada requisitada pelos engenheiros de garantia de escoamento é a que tem a função de isolamento térmico do duto. Estas camadas são colocadas para diminuir o fluxo de calor com o ambiente marinho, tipicamente na temperatura de $4{ }^{\circ} \mathrm{C}$ em profundidades maiores que $800 \mathrm{~m}$, e manter o fluido no interior do duto o mais quente possível. Esta preocupação advém principalmente por conta da formação de hidratos, que podem bloquear o escoamento e interromper a produção de óleo e também a deposição de parafinas na parede interna no duto, que podem diminuir e até mesmo bloquear a área aberta ao fluxo, gerando perdas de produção e prejuízos.

Para os estudos desta dissertação um duto com baixa capacidade de isolamento foi modelado, com coeficiente de troca térmica de $10 \mathrm{~W} / \mathrm{m} / \mathrm{K}$. Esta decisão foi tomada justamente porque o intuito do trabalho é verificar o comportamento do escoamento para as várias equações de estado modeladas para representar o escoamento em temperaturas diferentes do reservatório. Todas as camadas do duto juntas acabam por conferir um diámetro externo de 9,43 polegadas a flowline e ao riser.

Para finalizar o modelo de escoamento nos dutos ainda é necessário calcular o coeficiente de película externo ao duto para satisfazer o cálculo de transferência de calor radial na flowline e riser. Para isso informações a respeito do enterramento do duto, temperatura da água do mar e velocidade da corrente marítima precisam ser informadas. A consideração assumida neste trabalho é que o duto não está enterrado, isto é, apenas a geratriz inferior do duto está em contato com o leito marinho. 
Na Figura 4.28 pode-se observar a temperatura e velocidade de corrente da água do mar assumidas para área, que são valores típicos encontrados em bacias offshore do litoral brasileiro.

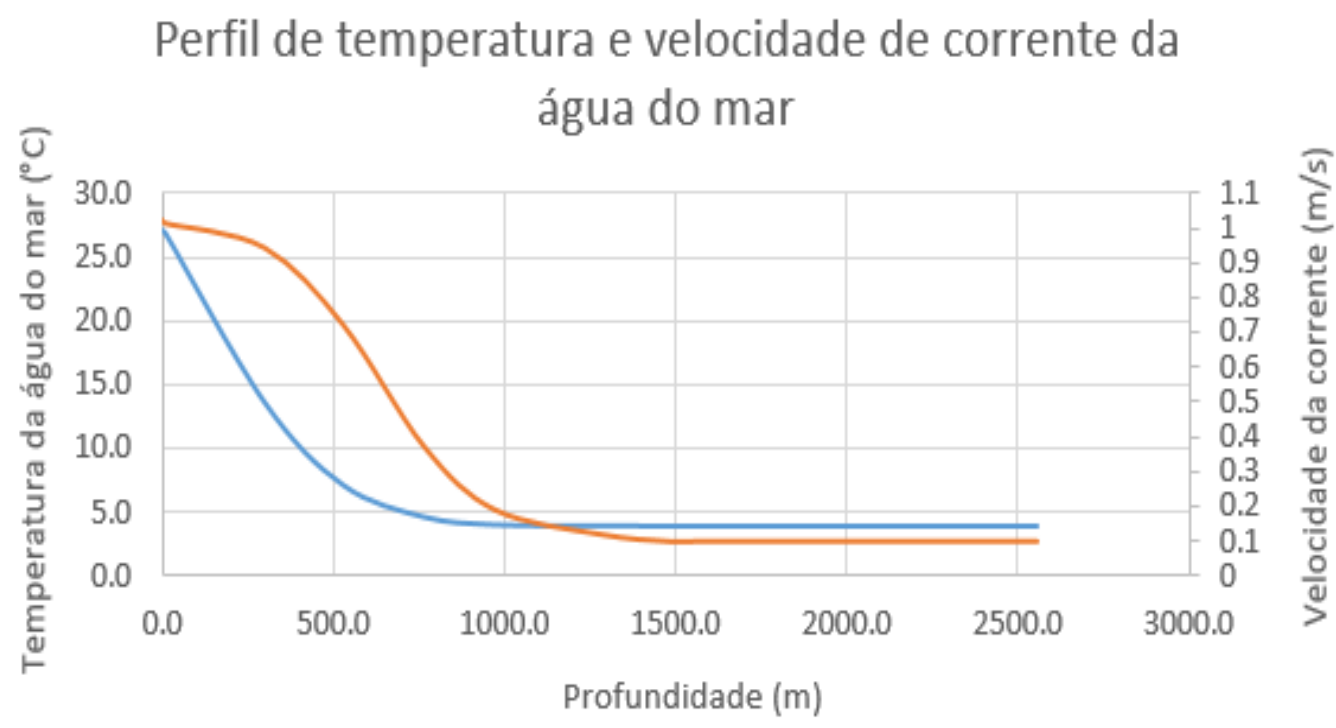

—Temperatura da água do mar $\left({ }^{\circ} \mathrm{C}\right) \quad$ Velocidade da água do mar $(\mathrm{m} / \mathrm{s})$

Figura 4.28: Perfil de temperatura e velocidade de corrente da água do mar

\subsubsection{3}

\section{Correlação de escoamento multifásico}

Para determinar a perda de carga no escoamento multifásico em tubulações, duas abordagens podem ser usadas. Existem as correlações empíricas, que se utilizam de observações do fenômeno de escoamento em laboratório para gerar formulações matemáticas, que representam a perda de pressão ao longo do escoamento, e existem as correlações mecanicistas, com forte embasamento matemático mas que ainda assim possuem certo grau de empirismo para algumas equações de fechamento do modelo.

$\mathrm{Na}$ indústria, em especial quando não há dados de campo para calibrar as correlações empíricas, costuma-se dar preferência ao uso das correlações mecanicistas. Para os estudos apresentados nesta dissertação foi usada a correlação denominada Petroleum Experts 5, desenvolvida pela fabricante da solução de integração usada neste trabalho. 


\subsubsection{4}

\section{Elevação artificial do petróleo}

Quando o poço produz apenas através de sua energia em forma de pressão estática confinada nos poros do reservatório, diz-se que o poço é surgente naturalmente. Parte da energia é gasta no fluxo no meio poroso e outra parte é gasta para levar o fluido até a plataforma de produção.

Com o início da produção, a pressão estática começa a diminuir e se a injeção de água não for suficiente para manter a pressão, a energia natural do reservatório diminuirá. Além disso, com o passar do tempo, água começa a ser produzida e há maior perda de energia ao longo do escoamento para movimentar a mistura de fluido até a plataforma. Estas condições podem levar a diminuição de produtividade e até mesmo perda da surgência do poço.

Os engenheiros de elevação e escoamento tem a função de maximizar a produção de óleo através métodos de elevação artificial, isto é, adicionar energia ao escoamento ou então diminuir a perda de energia ao longo do mesmo. A análise de qual método é mais adequado passa por uma série de fatores, tais como: razão gás-óleo do fluido, vazões de produção surgente, disponibilidade de energia na plataforma, entre outros.

A elevação artificial pode ser dividida, de forma simplificada, em dois grandes grupos, os métodos pneumáticos, com destaque para o gas-lift contínuo, e os métodos bombeamento, com destaque para as bombas centrífugas que podem ser instaladas no poço ou no leito marinho.

O gas-lift contínuo aumenta a produção pois ele diminui a perda de carga gravitacional no poço devido a injeção de gás no interior da coluna, contudo ele aumenta a perda de carga por atrito, ou seja, existe um ponto ótimo de operação. As bombas centrífugas aumentam a produção devido à energia transferida ao fluido. Ambos métodos permitem a diminuição da pressão de fundo do poço o que por consequência, o aumento de vazão.

Para os estudos desta dissertação, dois motivos levaram a não usar qualquer método de elevação artificial: primeiramente não é objeto de estudo deste trabalho o efeito da elevação artificial no escoamento, portanto, com o viés de simplificar o estudo e não mascarar os efeitos da simplificação das EOS, o poço produziu de forma surgente por toda a vida.

Além disso, o fluido em questão que foi selecionado não apresenta grande potencial de aumento de produção, uma vez que a razão gás-óleo deste fluido é muito alta. Nestes casos, os métodos de bombeamento não são recomendados e o gas-lift contínuo também não é eficaz já que as perdas devido ao gradiente de fricção são superiores ao ganho no gradiente de pressão gravitacional. 


\subsubsection{5}

\section{Poço e duto submarino de injeção}

Como o objetivo da dissertação é avaliar os resultados encontrados no escoamento no meio poroso e nos dutos em diferentes modelos de propriedade de fluidos, a modelagem do sistema de injeção de água no reservatório, importante para a manutenção de pressão no campo, não carece de detalhamento.

Buscou-se apenas garantir que a cota de injeção de água necessária para o balanço no reservatório fosse respeitada e que esta cota seja idêntica em todos os modelos de fluidos estudados.

\subsubsection{6}

\section{Processamento primário de petróleo}

O processamento primário de petróleo corresponde ao tratamento que o óleo e gás recebem ao chegar na unidade estacionário de produção até a estabilização do óleo e gás nas condições de referência. Normalmente o petróleo passa por trocadores de calor, separadores, tratadores eletrostáticos até atingir a condição de estabilização.

Em modelos de simulação todo este processamento primário é representado de forma bem sucinta por estágios de separação que representam todo o caminho do óleo até sua estabilização. Outro artíficio usado nas simulações é considerar como condição de contorno para o cálculo de vazão nos poços a pressão na chegada da plataforma, a montante do choke, no topo do riser. Para as simulações apresentadas nesta dissertação foi considerada a pressão de 30 $\mathrm{kgf} / \mathrm{cm}^{2}$.

A jusante deste ponto inicia todo o modelo de processamento primário, que para os estudos que serão apresentados considerou-se uma perda de carga de $20 \mathrm{kgf} / \mathrm{cm}^{2}$ nas tubulações e curvas da plataforma até a chegada no separador primário e além disso considerou-se um aquecimento do fluido da temperatura de chegada do topo do riser que é variável até a temperatura de $60{ }^{\circ} \mathrm{C}$. Desta forma, o separador primário opera a $10 \mathrm{kgf} / \mathrm{cm}^{2}$ e $60{ }^{\circ} \mathrm{C}$.

Neste separador a água, óleo e gás são separados e são levados diretamente a condição de referência, isto é $1,0133 \mathrm{kgf} / \mathrm{cm}^{2}$ e $15,6{ }^{\circ} \mathrm{C}$. O modelo foi simplificado pois o estudo proposto não tem a intenção de representar fielmente as condições de separação do processamento primário em uma plataforma, e sim avaliar como a simplificação do modelo de fluido impacta os resultados em um MIP. 


\subsection{3}

\section{Acoplamento dos modelos de reservatório e sistema de produção}

A última etapa de modelagem de um sistema integrado de produção é o acoplamento entre os modelos de fluxo no meio poroso e o modelo de escoamento em poços e dutos, descritos acima. Os estudos desta dissertação foram realizados com o software Resolve da Petroleum Experts, que apresenta a solução de acomplamento explícito forte para solucionar o problema de integração entre os modelos. Além do Resolve, o software chamado GAP, do mesmo fabricante, é usado para modelar todo o sistema de escoamento que compreende a interface poço-reservatório, o poço, flowline, riser e representar o processamento primário da UEP. A Figura 4.29 mostra o modelo de GAP.

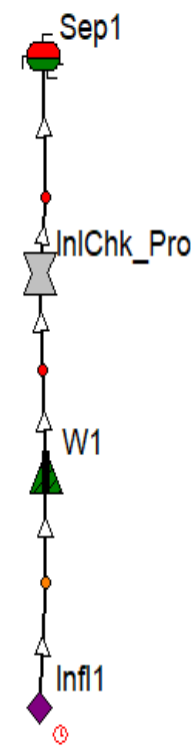

Figura 4.29: Modelo de escoamento de produção

O ícone "Infl1" corresponde a interface poço-reservatório, e é neste ponto onde o simulador de reservatório e escoamento trocam informações ao longo da simulação. O ícone "W1" se refere ao modelo de poço e duto modelado no software Prosper, também da Petroleum Experts. O ícone "InlChk _Pro" corresponde a válvula de controle de fluxo localizada no topo do riser, que simboliza o final do modelo de escoamento no duto e finalmente, o ícone "Sep1" representa todo o modelo de processamento primário da plataforma.

Na Figura 4.30 é ilustrado o modelo do Resolve, responsável por acoplar os modelos. Pode-se observar o modelo de reservatório feito no GEM e o poço produtor e injetor acoplados aos seus respectivos modelos de escoamento no $G A P$ de produção e injeção. 


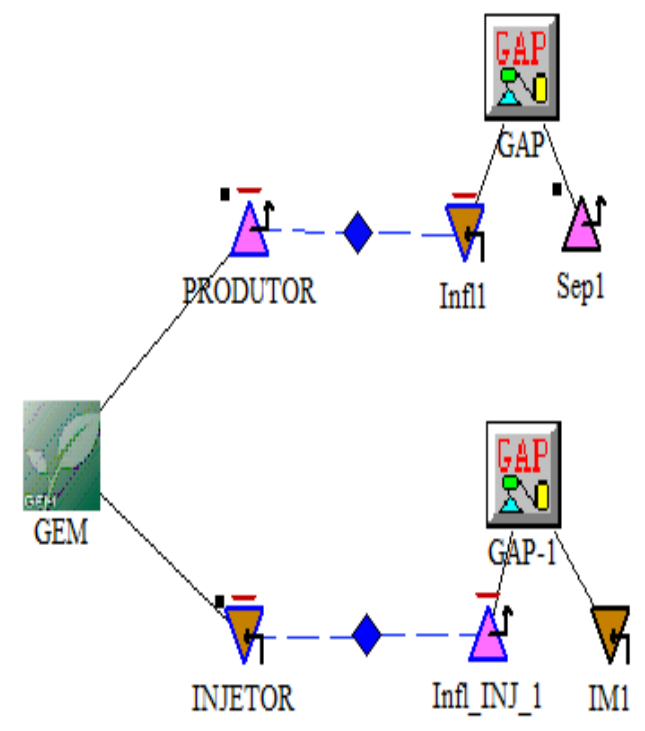

Figura 4.30: Modelo de escoamento de produção

O Resolve também é responsável por orquestrar a simulação, isto é, ele que coordena quando os modelos de escoamento no fluxo poroso e escoamento em dutos trocam informações. A cada passo de tempo de integração, o GEM fornece informações para o GAP calcular a vazão potencial do poço e este valor é usado como condição de contorno de vazão na solução da matriz jacobiana que resolverá as equações constitutivas do campo de pressões e velocidades do fluxo no meio poroso.

Desta forma é fundamental definir um passo de tempo adequado para o acoplamento dos modelos. Um passo de tempo muito curto poderá levar a um tempo de simulação inviável sem aumento de qualidade na resposta. Passos de tempo muito longos podem levar a respostas inadequadas ao fenômeno, uma vez que o potencial do poço pode variar muito de um passo de tempo para o outro, fazendo com que o modelo de reservatório faça os cálculos com a condição de contorno irreal.

Para os estudos desta dissertação foi adotado que o acoplamento dos modelos fosse realizado a cada 3 meses, exceto nos anos de 2036 e 2037, onde o passo de tempo foi reduzido para um mês. Nestes dois anos a fração de água produzida passa de zero para valores na ordem de $60 \%$, assim, decidiu-se representar bem a chegada de água neste período. Desta forma, no período de produção de 30 anos, os modelos foram acoplados 137 vezes. 


\section{3}

\section{Variáveis de interesse para validação dos resultados}

O objetivo final de representar os fenômenos de fluxo em meio poroso e fluxo em poços e dutos, através de simulação numérica computacional, é ter uma representação adequada das receitas oriundas da explotação de um campo de petróleo e também na definição e orçamentação de todo o sistema de produção, isto é, dos poços, equipamentos e dutos submarino e a plataforma de produção.

Os modelos usados em engenharia normalmente são uma representação aproximada dos fenômenos físicos e é trabalho dos engenheiros envolvidos com simulação definir o erro considerado aceitável para cada análise. Existem variáveis chaves que devem ser monitoradas quando uma sensibilidade na forma de modelar é avaliada. Na sequência serão discutidos os principais parâmetros de interesse em cada modelo que foram monitorados de forma a avaliar como a simplificação das EOS usadas no trabalho influencia no resultado final das simulações.

\subsection{1 \\ Modelo de reservatório}

Os engenheiros de reservatório, em conjunto com os engenheiros de elevação e escoamento, são os responsáveis por simular a expectativa da receita de um projeto de desenvolvimento de produção. Mesmo em campos desenvolvidos, onde há histórico de produção, as incertezas associadas a parâmetros de entrada do modelo podem levar a resultados inesperados de produção, e consequentemente de receitas.

Tal fato afeta muito a análise econômica dos projetos, uma vez que o valor presente líquido projetado de um determinado investimento pode não se concretizar. Nos casos de campos não-desenvolvidos, sem histórico de produção, o problema se torna ainda mais complexo de modo que o número de simulações necessárias para prever todo o espectro de curvas é proibitivo do ponto de vista de engenharia. Desta forma existem análises e simplificações para considerar apenas as incertezas mais relevantes nos estudos.

Discutidas todas as variáveis de incerteza relevante da modelagem geofísica, geológica e de engenharia, começa-se o trabalho de otimização do plano de explotação, a fim de definir um compromisso entre o custo de capital necessário para explotar o campo. A quantidade de poços, tipo de sistema submarino, diâmetros dos dutos e as capacidades de processamento de óleo e gás da plataforma são as variáveis que mais impactam na receita e custos de um projeto, e são o alvo de otimização dos engenheiros de reservatório. 
Desta forma, as curvas de produção de óleo e gás esperadas para o campo são um resultado importante pois ela representa ao longo do tempo a receita total oriunda do projeto. As Figuras 4.31 e 4.32 ilustram as vazões instantâneas de óleo e gás assim como as vazões acumuladas para o MIP com a EOS detalhada de 24 componentes. Como pode-se notar, ao analisar ambos os gráficos, é possível constatar que a razão gás-óleo é constante ao longo da produção. Logo a pressão do reservatório se manteve sempre acima da pressão de saturação, o que era uma premissa do estudo.

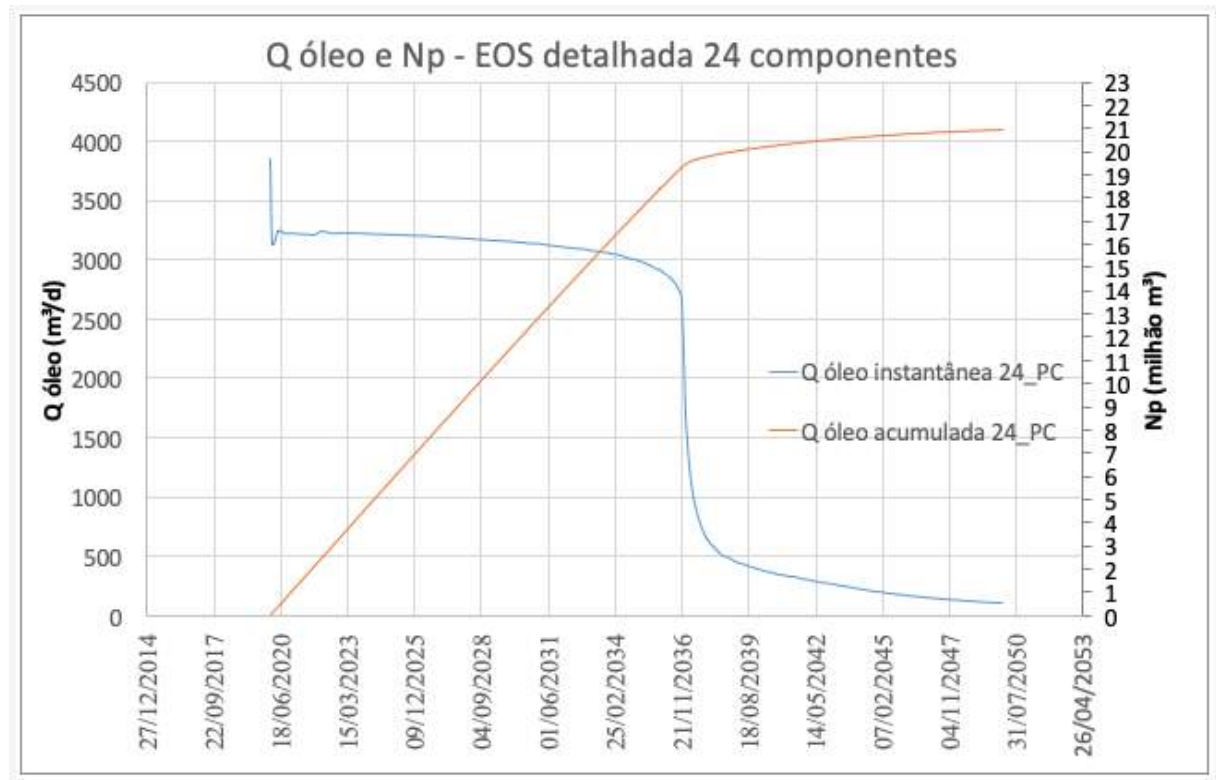

Figura 4.31: Curva de produção de óleo instantânea e acumulada - EOS 24 PC

Outra importante resposta a ser analisada no modelo de reservatório é como a chegada da frente de água oriunda do poço injetor chega no poço produtor. Uma otimização importante do sistema de explotação é garantir um gerenciamento da chegada prematura de água, para evitar perdas de receita e perda de produção dos poços. Para avaliar como a simplificação influenciou essa característica, pode-se visualizar a vazão de líquido e a razão da vazão de água e vazão de líquido, popularmente chamada de watercut na indústria de petróleo. A Figura 4.33 ilustra o resultado encontrado com o MIP com a EOS detalhada.

Um importante aspecto de interesse da engenharia de reservatórios é a recuperação secundária de petróleo, isto é, a injeção de água no reservatório para manutenção de pressão. A retirada de massa do reservatório reduz a pressão estática e, como consequência, a produção diminui. Se a pressão cair a ponto de atingir o ponto de bolha do envelope de fases, liberação de gás no reservatório irá ocorrer e a produtividade cairá a patamares ainda menores 


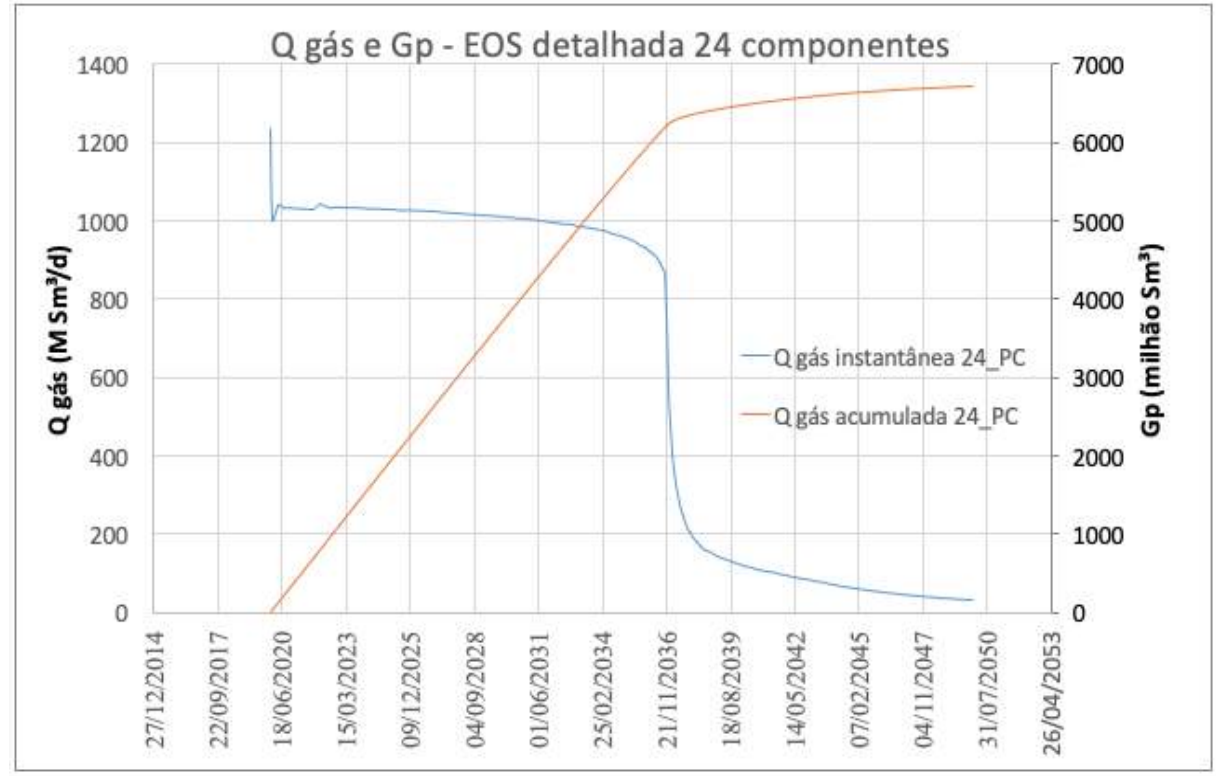

Figura 4.32: Curva de produção de gás instantânea e acumulada - EOS 24 PC

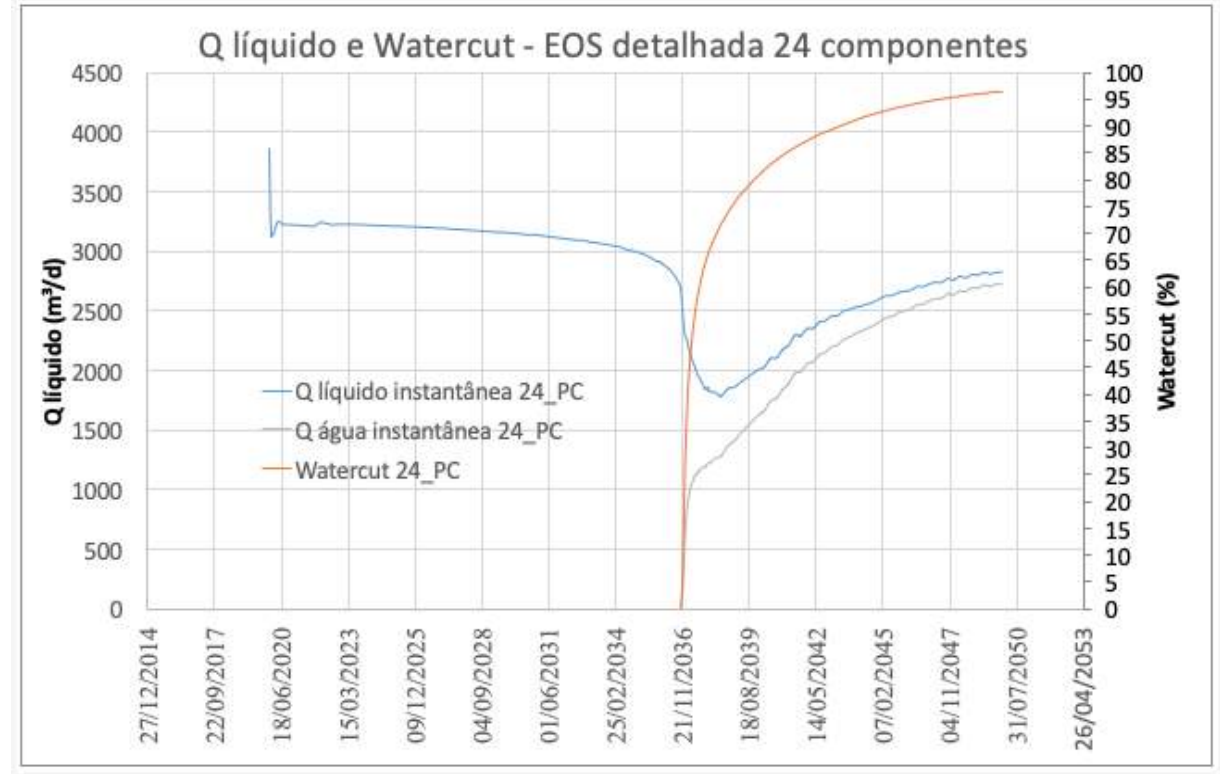

Figura 4.33: Curva de produção de água e watercut - EOS 24 PC

devido a diminuição de permeabilidade relativa ao líquido no meio poroso. Desta forma, a pressão estática do reservatório e a pressão de fundo na interface poço-reservatório também foram comparadas para as diversas EOS estudadas nesta dissetação. O resultado para a EOS detalhada pode ser visto na Figura 4.34. 


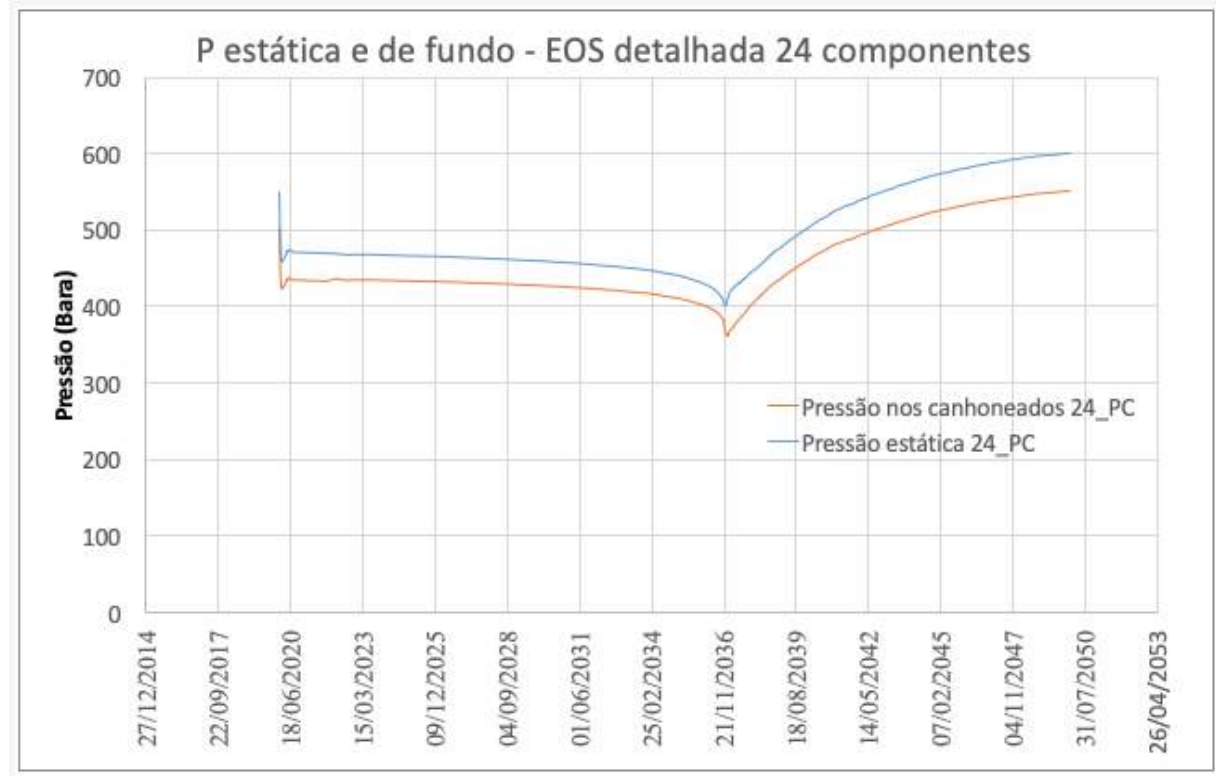

Figura 4.34: Pressão estática e nos canhoneados - EOS 24 PC

\subsection{2}

\section{Modelo de escoamento no poço e duto}

Os engenheiros de elevação e escoamento são os responsáveis por representar o fenômeno de escoamento nos poços e dutos e, sem dúvida, são também responsáveis pelas receitas oriundas da produção. Conforme explanado anteriormente, conjuntamente com os engenheiros de reservatório, são responsáveis por definir o número de poços ótimo para explotar uma jazida, definir o diâmetro das tubulações que escoam a produção do reservatório até a plataforma, definir a configuração do sistema submarino, definir o método de elevação artificial, definir a capacidade de processamento na plataforma de produção, entre outras análises.

De forma a equacionar corretamente a perda de carga e responder adequadamente todas as análises descritas acima, todo o referencial teórico sobre escoamento multifásico em tubulações é requerido. Em escoamento multifásico de petróleo, a diminuição de pressão e temperatura ao longo do escoamento acarreta na liberação de gás e assim está caracterizado o escoamento bifásico dentro dos dutos. Quando a produção de água inicia, temos escoamento trifásico. Até mesmo o escoamento de sendimentos sólidos (cristais de parafina, incrustação, areia, hidratos) podem ser considerados para determinadas análises, caracterizando uma quarta fase no escoamento. Não é intuito desta dissertação detalhar o ferramental teórico para entendimento do escoamento multifásico em dutos, entretanto, caso necessário, o leitor poderá encontrar mais detalhes no trabalho de Shoham (2006). 
O escoamento multifásico é particularmente mais complexo uma vez que para determinação de propriedades importantes do escoamento, como massa específica, viscosidade e entalpia é necessária a determinação do hold-up, $\left(H_{L}\right)$, e da fração de vazios, $\left(H_{G}\right)$, que representam, respectivamente, a fração de área ocupada pela fase líquida e pela fase gasosa em relação a área total da tubulação. Além disso, a fase gasosa escoa a velocidades maiores que a fase líquida, originando uma velocidade relativa entre as fases conhecida como velocidade de escorregamento. Da mesma forma, as tensões com a parede são diferentes se o contato com a mesma é feito com a fase líquida ou a fase gasosa. Como pode-se notar, o escoamento de mais de uma fase coloca elementos que aumentam a incerteza na determinação do gradiente de pressão gravitacional e de fricção.

As correlações do tipo mecanicista, usadas neste trabalho, dependem de como as fases se arranjam dentro da tubulação para então calcular o gradiente de pressão de forma correta. No escoamento horizontal, quatro padrões de escoamento são facimente detectados. O padrão estratificado que se caracteriza pela separação gravitacional do líquido e do gás, como líquido escoando na geratriz inferior do duto e gás na parte superior. Esse padrão é típico de velocidades baixas de gás e de líquido na tubulação.

O padrão intermitente é caracterizado pela alternância da vazão de gás e líquido. O pistão de líquido ora ocupa toda a área da tubulação contudo as bolhas de gás escoando no topo do duto se alternam com a camada de líquido. Há sempre uma camada de líquido na geratriz inferior do duto que escoa em alta velocidade.

O padrão anular é característico de altas vazões de gás, sendo que o mesmo escoa pelo centro do duto. Gotas de líquido são carreadas pelo gás em alta velocidade e um pequeno filme de líquido fica no entorno de toda a tubulação.

O padrão de bolhas dispersas é caracterizado pela alta vazão de líquido. A fase contínua é o líquido e o gás aparece na forma de pequenas bolhas dispersas na fase líquida. Este tipo de escoamento as fases escoam a mesma velocidade, ou seja, sem escorregamento. A Figura 4.35 ilustra os principais padrões de escoamento encontrados no escoamento multifásico horizontal. Nota-se que ainda é possível notar subdivisões dentro das principais categorias.

O escoamento vertical, também apresenta vários padrões a depender das características do escoamento. Os padrões identificados podem ser divididos em cinco principais categorias: bolhas, golfada, caótico, anular, e bolhas dispersas. No padrão de bolhas, a fase gás está dispersa no líquido em pequenas bolhas que se distribuem de forma homogênea. Esse padrão ocorre para baixas vazões 

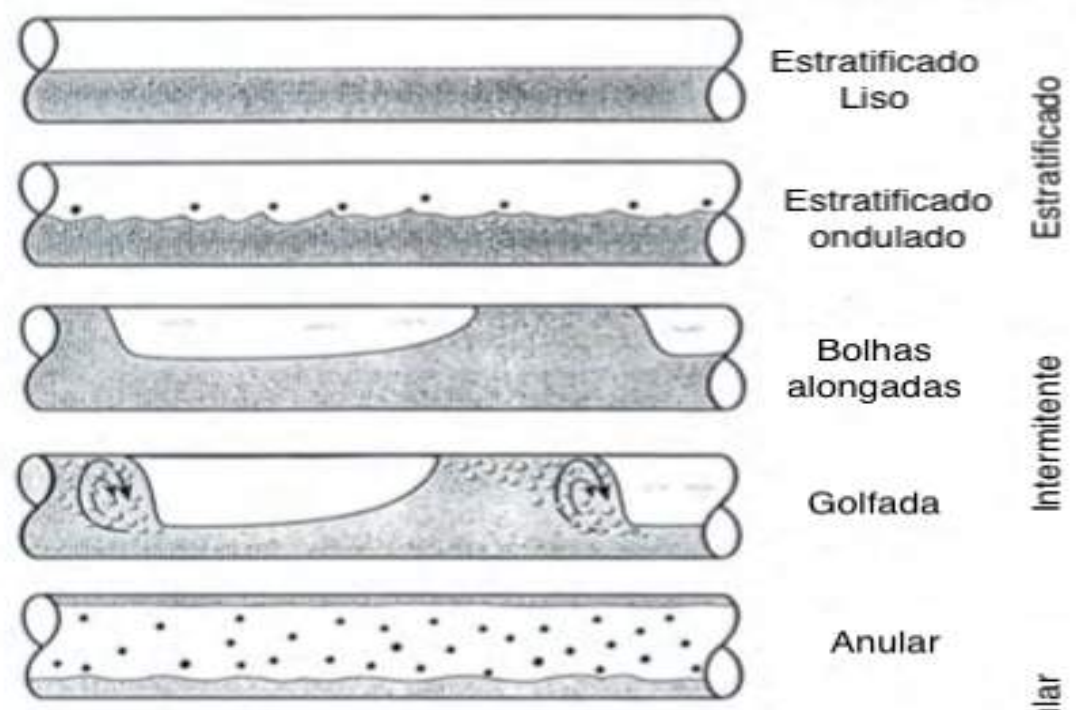

Anular

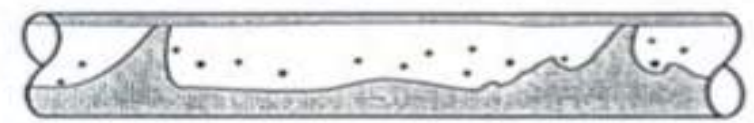

Anular ondulado

$$
\frac{\text { क्षे }}{\frac{3}{4}}
$$

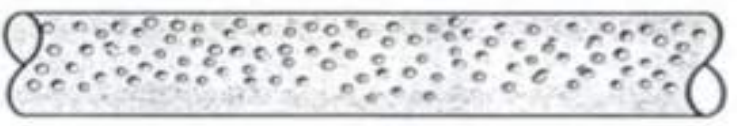

Bolhas

dispersas

Direçāo do fluxo

Figura 4.35: Padrões de escoamento em tubulação horizontal - Adaptado de Shoham (2006)

de líquido em que o nível de turbulência é baixo e há escorregamento entre as fases.

O padrão de golfadas ocorre quando há a formação das famosas bolhas de Taylor, que ocupam praticamente toda a tubulação, mas ainda há um pequeno filme de líquido ao redor das bolhas. As bolhas escoam em velocidade muito superior do filme.

O padrão caótico é semelhante ao padrão golfada exceto pelo fato de ser mais caótica, sem a formação de uma bolha de Taylor.

O padrão anular vertical é muito semelhante ao horizontal, onde é caracterizado pelas altíssimas vazões de gás.

O padrão de bolhas dispersas vertical também se assemelha muito ao horizontal, onde a desconsideração do escorregamentos entre as fases também é válida. A Figura 4.36 ilustra estes padrões.

Segundo Andreolli (2016), a formação destes padrões de escoamento dependem de diversos fatores, tais como: razão gás-líquido e velocidades das fases; parâmetros geométricos: inclinação da tubulação, diâmetros, rugosidade, singularidades; propriedades dos fluidos: viscosidades, densidades e tensão 


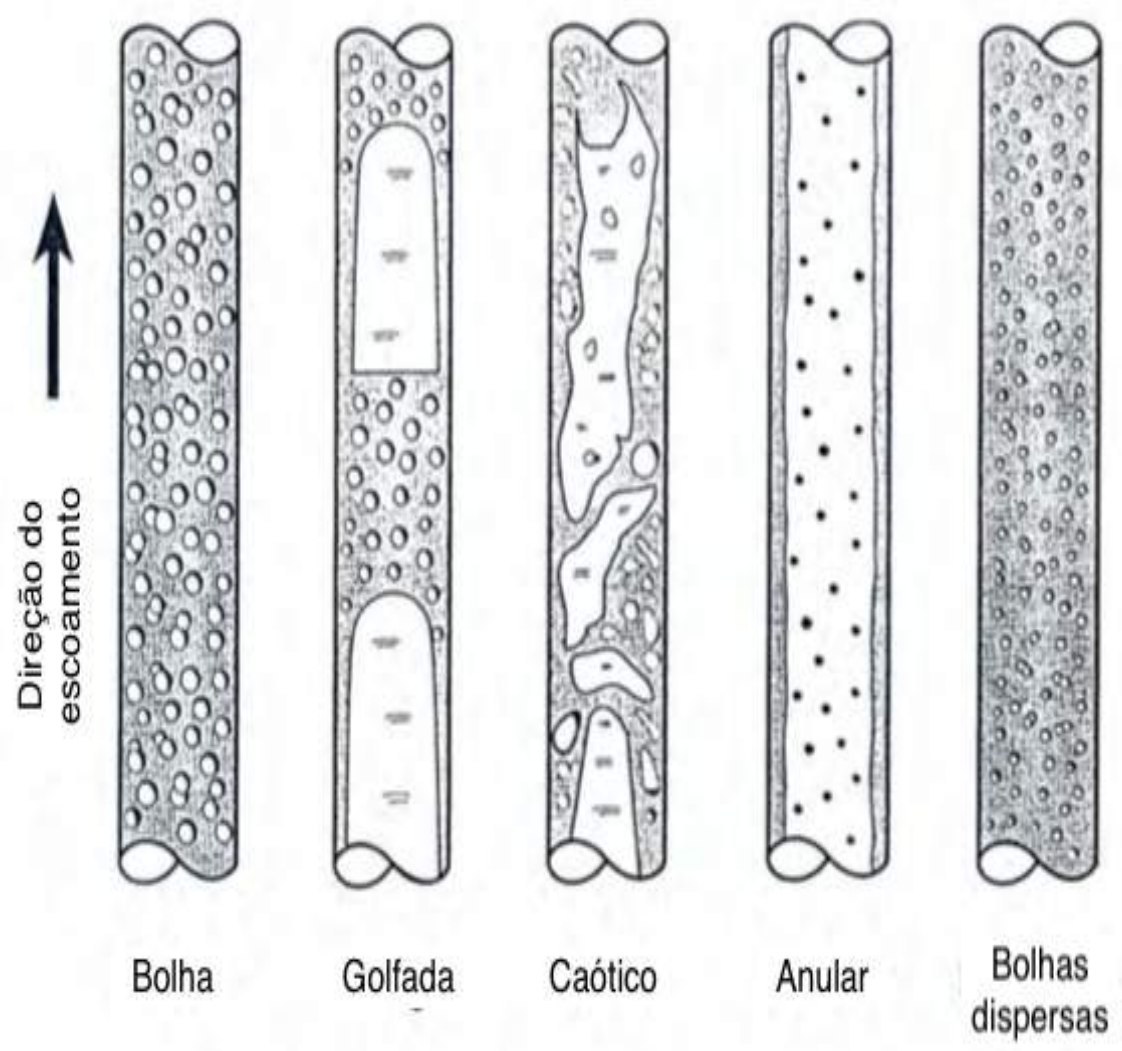

Figura 4.36: Padrões de escoamento em tubulação vertical - Adaptado de Shoham (2006)

interfacial e pressão e temperatura do escoamento. Em simuladores comerciais, mapas de padrão de escoamento são usados para estimar os padrões e calcular o gradiente de pressão total do escoamento com base no padrão correto.

A perda de pressão e temperatura total ao longo do escoamento pode ser dividida em cinco parcelas, (i) meio poroso, (ii) perda na coluna de produção do poço, (iii) perda da ANM até o TDP, (iv) do TDP até a chegada da plataforma e (v) as perdas de pressão no processamento primário até a estabilização do óleo e gás. A perda do meio poroso corresponde ao diferencial entre a pressão estática (Pe) e de fundo de poço (Pwf) necessário para escoar a produção até os canhoneados. A temperatura no reservatório geralmente é considerada constante.

A parcela (ii) corresponde a perda de pressão do fundo do poço até a ANM em um escoamento vertical. Neste trecho há grande perda de pressão devido a parcela gravitacional. A depender do diâmetro da coluna de produção e das vazões envolvidas, a parcela de fricção também pode ser relevante. Neste trecho também haverá fluxo de calor no sentido radial, com o petróleo perdendo calor e esquentando os arredores do poço. As propriedades dos fluidos 
variam bastante neste trecho de tubulação, e normalmente é neste trecho que o escoamento que o fluido atinge a região de duas fases.

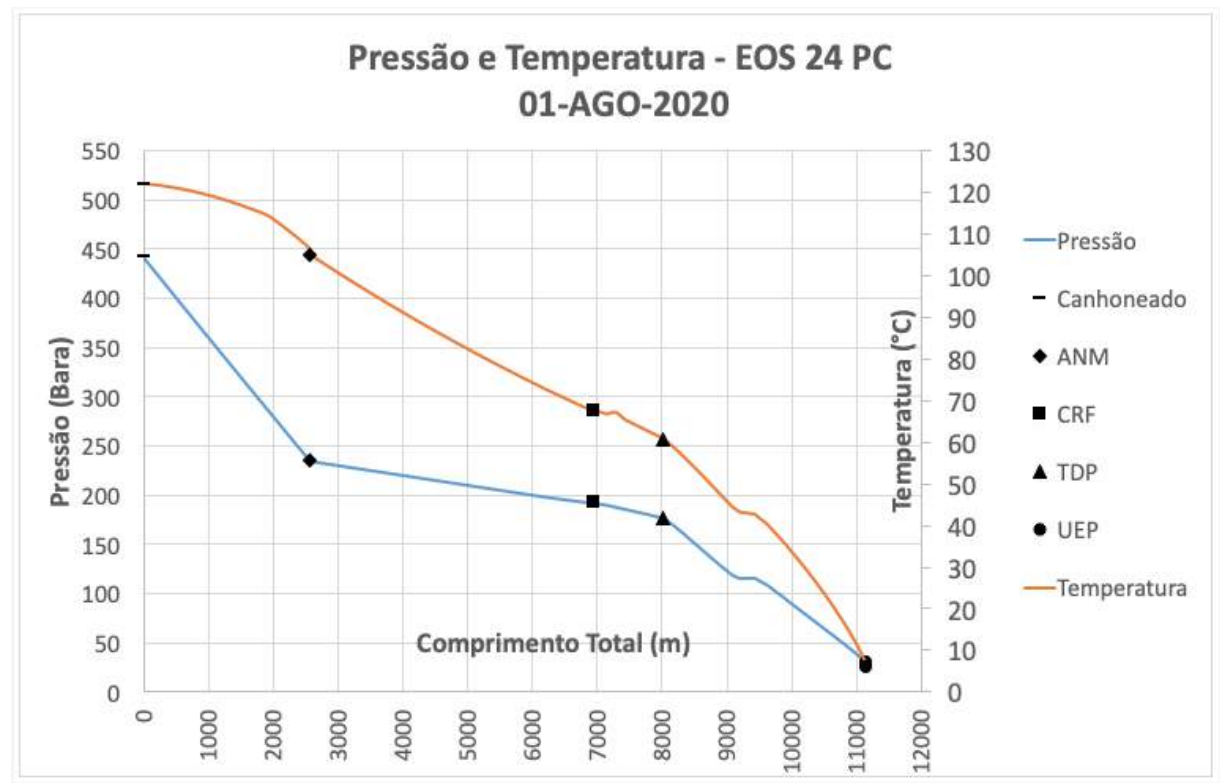

Figura 4.37: Perfil de pressão e temperatura - EOS 24 PC - 01-AGO-2020

A parcela (iii) corresponde a perda de pressão da ANM até o ponto de ancoramento do duto no solo (TDP) antes de iniciar a subida para a plataforma. O escoamento nesta região é praticamente horizontal. A perda de pressão devido a parcela gravitacional não é relevante e até mesmo pode ajudar se existir trechos levemente descendentes. Pelo contrário, a perda de carga por fricção é a responsável por quase todo o gradiente de pressão, ja que o gás começa a atingir velocidades maiores neste trecho. A perda de temperatura para o meio externo neste trecho é crítica, uma vez que a temperatura do mar em lâminas de água ultra-profundas é em torno de $4{ }^{\circ} \mathrm{C}$. Deposição de parafinas e formação de hidratos começam a preocupar neste trecho, que normalmente é isolado para manter a temperatura dos fluidos fora dos envelopes de deposição.

A parcela (iv) corresponde a perda de pressão do TDP até a plataforma. A geometria dos risers em lâminas de água ultra-profundas pode ser considerada praticamente vertical. Nas corcovas o escoamento volta a ser horizontal mas o trecho é curto. Neste trecho a parcela gravitacional é relevante mas menor que no poço, uma vez que a massa específica da mistura é menor do que no poço, por conta do gás liberado. A parcela de fricção é relevante já que o gás atinge as velocidades máximas neste trecho. A perda de temperatura neste trecho também é intensa e é agravada pelo efeito Joule-Thomson, isto é, queda na temperatura do fluido devido á expansão do gás na despressurização. 


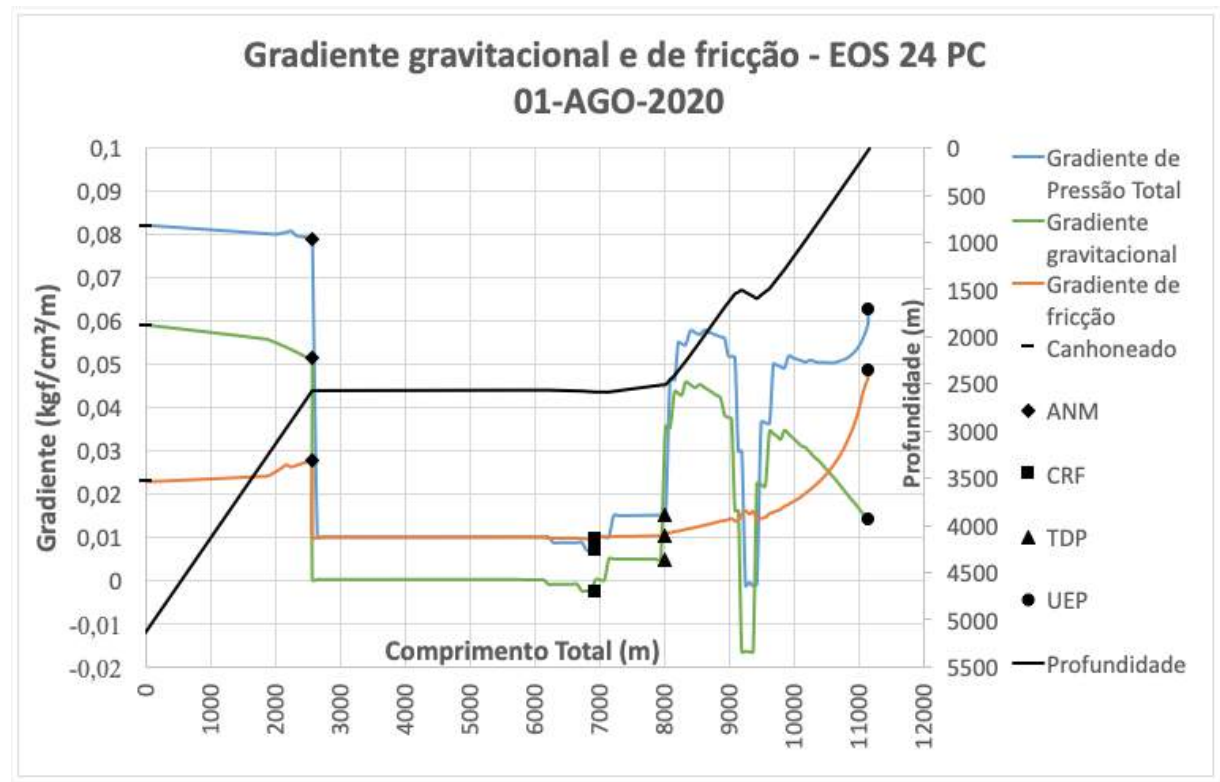

Figura 4.38: Gradiente de pressão gravitacional e de fricção - EOS 24 PC 01-AGO-2020

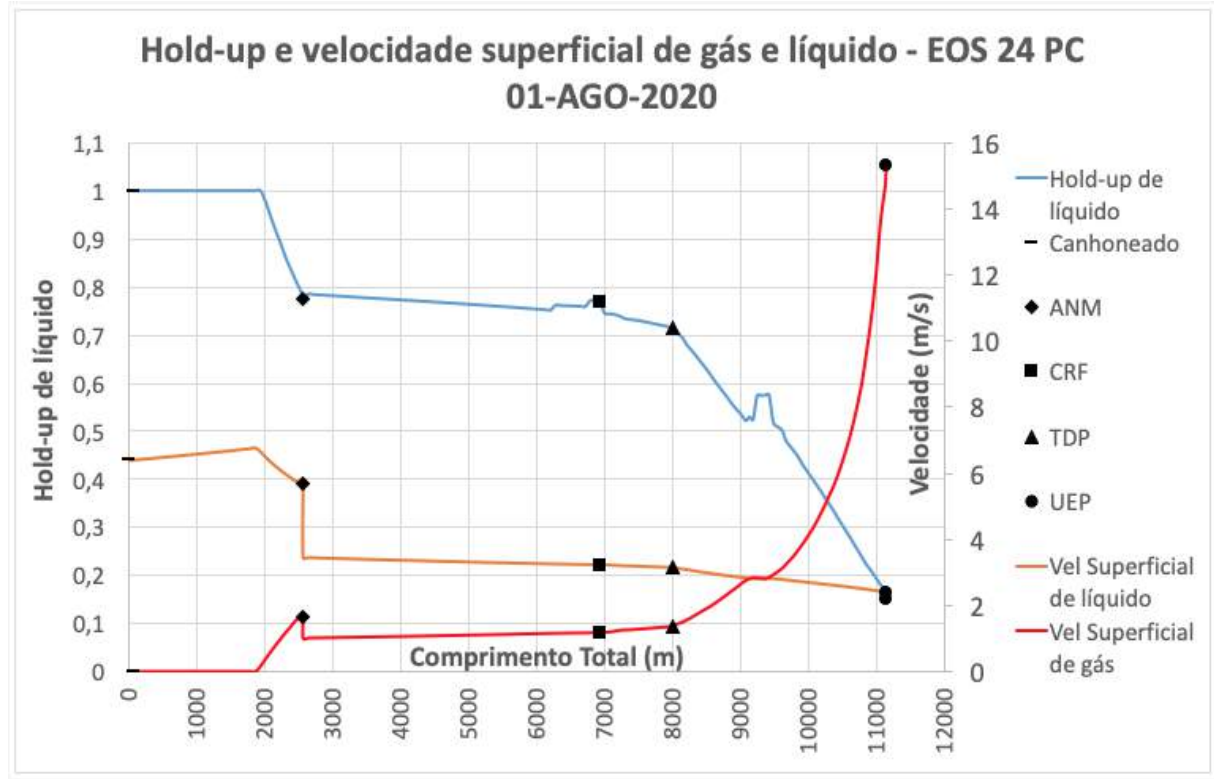

Figura 4.39: Hold-up e velocidades superficiais - EOS 24 PC - 01-AGO-2020

Nas Figuras 4.37, 4.39, 4.40 e 4.38 pode-se visualizar as principais grandezas avaliadas pelos engenheiros de escoamento em tubulações: perfis de pressão e temperatura ao longo do comprimento total desde o fundo do poço até a plataforma; holdup e velocidades superficiais de líquido e fração de vazios ao longo do comprimento total do duto; coeficiente global de transferência de calor e Joule-Thomson ao longo do comprimento totall e gradiente total de pressão e suas parcelas gravitacional e de friç̧ão ao longo do comprimento. 


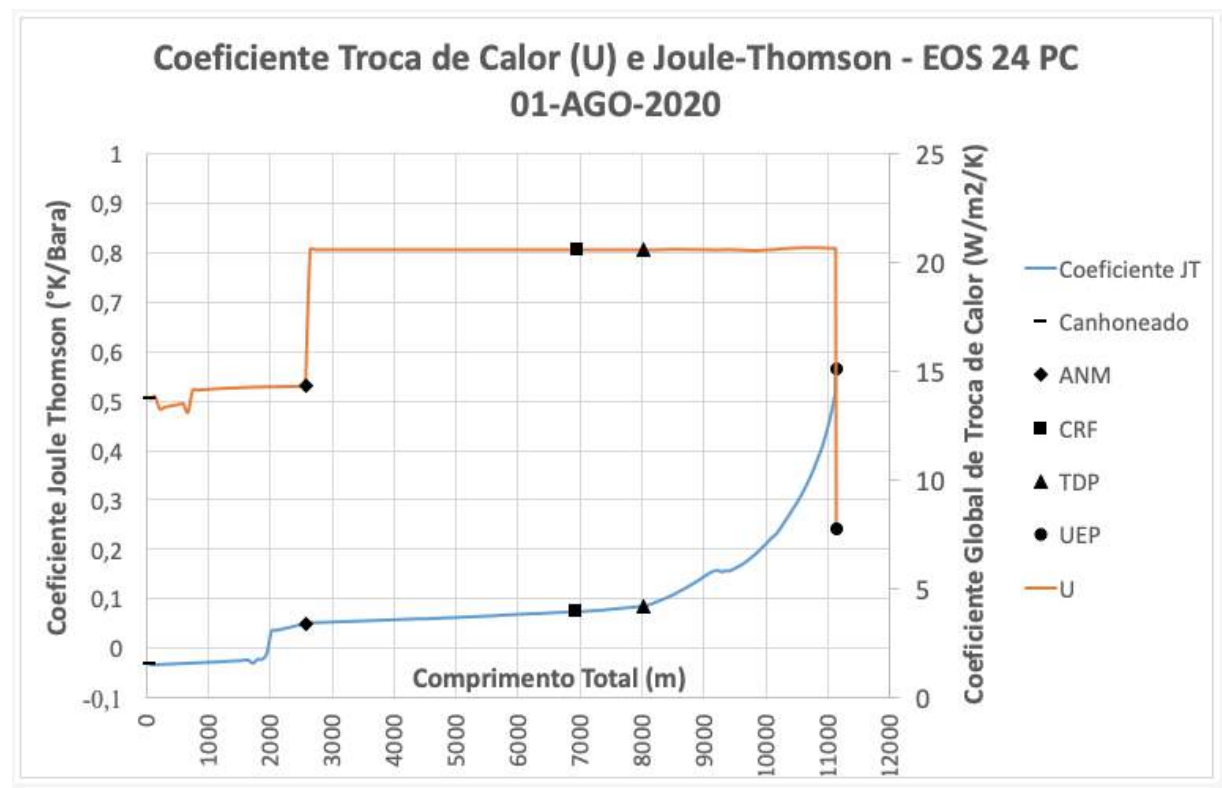

Figura 4.40: Coeficiente global de troca de calor e Joule-Thomson - EOS 24 PC - 01-AGO-2020

O gradiente de aceleração foi considerado desprezível nas análises. Os dados mostrados se referem a um período inicial de produção, logo após a abertura do poço.

\subsection{3}

\section{Tempo de simulação}

O tempo de simulação sem dúvida é uma das variáveis mais importantes para analisar o efeito da pseudoização das equações de estado. O número de componentes de uma EOS está correlacionado a quantidade de equações que precisam ser resolvidas para a marcha do simulador até a convergência dentro de um time-step. Em MIPs o tempo de simulação se torna ainda mais crítico, pois não só o simulador precisa resolver a equação cúbica de estado no espaço e ao longo do tempo no reservatório, mas também ao longo do espaço e no tempo do escoamento nos dutos.

As simulações de GEM e GAP foram paralelizadas na medida do possível. A partir de um estudo inicial variando o número de processadores a serem utilizados em paralelo, chegou-se a conclusão de usar 18 processadores. O modelo de processador usado nas simulações foi um $\operatorname{Intel}(\mathrm{R}) \mathrm{Xeon}(\mathrm{R})$ Gold 6244 CPU@3,60GHz. 


\section{5 \\ Resultados}

Neste capítulo serão apresentados os resultados encontrados para as diversas EOS estudadas nesta dissertação. As simulações seguiram as premissas e metodologia destacadas no capítulo anterior. Foram segregados os resultados da análise de escoamento no meio poroso e nas tubulações, dado que as variáveis de interesse, conforme explicitado anteriormente, diferem. Ao final, mostra-se o tempo total de simulação de cada caso.

\section{1}

\section{Modelo de reservatório}

Para analisar em detalhes o efeito da simplificação, os resultados foram segregados de forma a comparar os resultados de cada EOS simplificada em relação à EOS detalhada com maior rigor. Os gráficos da curva de produção de óleo instantânea, produção de líquido e watercut, e pressões estáticas e de fundo de poço podem ser visualizados no apêndice B, diretamente com uma comparação a EOS detalhada com 24 componentes e a evolução do erro com o tempo. Os gráficos relativos a vazão de gás não foram mostrados uma vez que a RGO é constante ao longo de toda a produção. O valor da RGO para cada ajuste pode ser visualizado na Tabela 4.12. A diferença encontrada na produção de óleo acumulada para as diversas EOS pode ser vista na Tabela 5.1 a seguir.

A Tabela 5.2 traz a raiz do erro quadrático médio normalizado para cada variável de interesse, definida como:

$$
R M S D=\sqrt{\frac{\sum_{t=1}^{T}\left(\hat{y}_{t}-y_{t}\right)^{2}}{T}}
$$

onde $\hat{y}_{t}$ é o resultado de variável de interesse na EOS simplificada e $y_{t}$ é o resultado da variável na EOS detalhada. O subscrito T é tempo no caso das variáveis de reservatório e comprimento nas variáveis de escoamento.

Quanto menor este valor, maior a acurácia do valor observado nas EOS simplificadas em relação ao valor teórico experimental da EOS detalhada. Os valores normalizados foram obtidos através da diferença entre os valores máximos e mínimos observados para cada variável da EOS detalhada, conforme 
equação abaixo:

$$
N R M S D=\frac{R M S D}{y_{\max }-y_{\min }}
$$

Tabela 5.1: Produção de óleo acumulada EOS detalhada vs EOS pseudoizadas.

\begin{tabular}{cll} 
Número de PC & $\mathbf{N p}\left(1000 \mathrm{~m}^{3}\right)$ & Erro (\%) \\
\hline 24 PC & 20,979 & - \\
\hline 14 PC & 20,79 & $-0,90$ \\
\hline 9 PC & 20,733 & $-1,17$ \\
\hline 7 PC & 20,551 & $-2,04$ \\
\hline 6 PC & 20,697 & $-1,34$ \\
\hline 5 PC & 20,132 & $-4,04$ \\
\hline 4 PC & 19,782 & $-5,71$ \\
\hline
\end{tabular}

Tabela 5.2: Raiz do erro quadrático médio normalizado (\%) - Variáveis de reservatório

\begin{tabular}{lllllll} 
Variável & EOS & EOS & EOS & EOS & EOS & EOS \\
& $\mathbf{1 4}$ PC & $\mathbf{9}$ PC & $\mathbf{7}$ PC & $\mathbf{6}$ PC & $\mathbf{5}$ PC & $\mathbf{4}$ PC \\
\hline NMRSD - Q óleo & 1,72 & 1,72 & 2,25 & 0,85 & 2,78 & 4,15 \\
\hline NMRSD - Q líquido & 2,41 & 2,55 & 3,61 & 1,87 & 5,21 & 7,29 \\
\hline NMRSD - Watercut & 2,16 & 2,08 & 2,47 & 0,24 & 1,67 & 2,78 \\
\hline NMRSD - P estática & 2,58 & 2,51 & 2,87 & 4,18 & 2,55 & 2,79 \\
\hline NMRSD - P fundo & 2,64 & 2,49 & 2,80 & 0,68 & 3,20 & 2,65 \\
\hline
\end{tabular}

\section{2}

\section{Modelo do sistema de produção}

Os resultados do modelo do sistema de produção também foram segregados para comparar os resultados de cada EOS simplificada em relação à EOS detalhada. Para a análise foram escolhidos três períodos pontuais da vida produtiva do campo para analisar os resultados das propriedades de interesse dos engenheiros de elevação e escoamento, ao longo do comprimento total dos poços e dutos. 
Foram escolhidos dois cenários de produção sem produção de água, dado que é neste cenário onde as propriedades PVT do óleo previstas pela EOS mais impactam nos resultados. Com a chegada da água, que possui propriedades bem conhecidas, cada vez mais o resultado ficará menos dependente das propriedades geradas pelas EOS modeladas.

O cenário escolhido para representar o efeito da chegada da frente de água foi o ponto da vida produtiva em que o corte de água é de $70 \%$. O primeiro cenário de produção sem água é em um período inicial de produção, onde as pressões de escoamento são máximas. O segundo cenário de produção sem água é em um período que antecede a chegada de água no poço produtor, onde as pressões no sistema sem produção de água são mínimas.

Os pontos escolhidos para a análise foram sumarizados nas Tabelas 5.3, 5.4 e 5.5 a seguir.

Tabela 5.3: Dados de produção - Cenário 1

\begin{tabular}{|c|c|c|c|c|c|c|c|c|c|}
\hline EOS & $\begin{array}{l}\text { Pressão } \\
\text { Estática }\end{array}$ & $\begin{array}{l}\text { Pressão } \\
\text { Fundo }\end{array}$ & $\begin{array}{l}\text { Pressão } \\
\text { UEP }\end{array}$ & $\begin{array}{l}\text { Vazão } \\
\text { Óleo }\end{array}$ & $\begin{array}{l}\text { Vazão } \\
\text { Água }\end{array}$ & $\begin{array}{l}\text { Vazão } \\
\text { Gás }\end{array}$ & $\begin{array}{l}\text { Vazão } \\
\text { Líquido }\end{array}$ & RGO & $\begin{array}{l}\text { Fração } \\
\text { Água }\end{array}$ \\
\hline & (bara) & ( bara) & (bara) & $\left(\mathrm{Sm}^{3} / d\right)$ & $\left(\mathrm{Sm}^{3} / d\right)$ & $\left(\mathrm{mSm}^{3} / \mathrm{d}\right)$ & $\left(\mathrm{Sm}^{3} / \mathrm{d}\right)$ & $\left(\mathrm{Sm}^{3} / \mathrm{Sm}^{3}\right)$ & $(\%)$ \\
\hline $24 \mathrm{PC}$ & 471,1 & 434,7 & 30,0 & 3227,6 & 0,0 & 1032,5 & 3227,6 & 319,9 & 0,0 \\
\hline $14 \mathrm{PC}$ & 471,2 & 435,0 & 30,0 & 3228,2 & 0,0 & 1027,6 & 3228,2 & 318,3 & 0,0 \\
\hline $9 \mathrm{PC}$ & 471,2 & 434,9 & 30,0 & 3215,2 & 0,0 & 1030,3 & 3215,2 & 320,5 & 0,0 \\
\hline $7 \mathrm{PC}$ & 470,4 & 434,3 & 30,0 & 3195,3 & 0,0 & 1029,6 & 3195,3 & 322,2 & 0,0 \\
\hline $6 \mathrm{PC}$ & 471,0 & 434,8 & 30,0 & 3195,7 & 0,0 & 1036,1 & 3195,7 & 324,2 & 0,0 \\
\hline $5 \mathrm{PC}$ & 470,7 & 434,3 & 30,0 & 3137,4 & 0,0 & 1074,3 & 3137,4 & 342,4 & 0,0 \\
\hline $4 \mathrm{PC}$ & 471,7 & 435,6 & 30,0 & 3072,2 & 0,0 & 1067,3 & 3072,2 & 347,4 & 0,0 \\
\hline
\end{tabular}


Tabela 5.4: Dados de produção - Cenário 2

\begin{tabular}{|c|c|c|c|c|c|c|c|c|c|}
\hline EOS & $\begin{array}{l}\text { Pressão } \\
\text { Estática } \\
\text { ( bara) }\end{array}$ & $\begin{array}{l}\text { Pressão } \\
\text { Fundo } \\
\text { ( bara) }\end{array}$ & $\begin{array}{l}\text { Pressão } \\
\text { UEP } \\
\text { (bara) }\end{array}$ & $\begin{array}{l}\text { Vazão } \\
\text { Óleo } \\
\left(S m^{3} / d\right)\end{array}$ & $\begin{array}{l}\text { Vazão } \\
\text { Água } \\
\left(S^{3} / d\right)\end{array}$ & $\begin{array}{l}\text { Vazão } \\
\text { Gás } \\
\left(m S m^{3} / d\right)\end{array}$ & $\begin{array}{c}\text { Vazão } \\
\text { Líquido } \\
\left(S m^{3} / d\right)\end{array}$ & $\begin{array}{c}\text { RGO } \\
\left(\mathrm{Sm}^{3} / \mathrm{Sm}^{3}\right)\end{array}$ & $\begin{array}{l}\text { Fração } \\
\text { Água } \\
(\%)\end{array}$ \\
\hline $24 \mathrm{PC}$ & 441,2 & 411,3 & 30,0 & 2995,0 & 0,0 & 958,1 & 2995,0 & 319,9 & 0,0 \\
\hline $14 \mathrm{PC}$ & 444,9 & 412,1 & 30,0 & 3003,0 & 0,0 & 955,9 & 3003,0 & 318,3 & 0,0 \\
\hline $9 \mathrm{PC}$ & 446,2 & 413,3 & 30,0 & 3000,6 & 0,0 & 961,9 & 3000,6 & 320,5 & 0,0 \\
\hline $7 \mathrm{PC}$ & 447,7 & 414,5 & 30,0 & 3001,3 & 0,0 & 967,1 & 3001,3 & 322,2 & 0,0 \\
\hline $6 \mathrm{PC}$ & 449,5 & 416,0 & 30,0 & 3006,4 & 0,0 & 975,8 & 3006,4 & 324,2 & 0,0 \\
\hline $5 \mathrm{PC}$ & 454,1 & 419,7 & 30,0 & 3000,5 & 0,0 & 1027,4 & 3000,5 & 342,4 & 0,0 \\
\hline $4 \mathrm{PC}$ & 463,0 & 428,1 & 30,0 & 3002,1 & 0,0 & 1042,9 & 3002,1 & 347,4 & 0,0 \\
\hline
\end{tabular}

Tabela 5.5: Dados de produção - Cenário 3

\begin{tabular}{|c|c|c|c|c|c|c|c|c|c|}
\hline EOS & $\begin{array}{l}\text { Pressão } \\
\text { Estática } \\
\text { ( bara) }\end{array}$ & $\begin{array}{l}\text { Pressão } \\
\text { Fundo } \\
\text { ( bara) }\end{array}$ & $\begin{array}{l}\text { Pressão } \\
\text { UEP } \\
\text { (bara) }\end{array}$ & $\begin{array}{l}\text { Vazão } \\
\text { Óleo } \\
\left(S^{3} / d\right)\end{array}$ & $\begin{array}{l}\text { Vazão } \\
\text { Água } \\
\left(\mathrm{Sm}^{3} / d\right)\end{array}$ & $\begin{array}{l}\text { Vazão } \\
\text { Gás } \\
\left(m S m^{3} / d\right)\end{array}$ & $\begin{array}{c}\text { Vazão } \\
\text { Líquido } \\
\left(\mathrm{Sm}^{3} / d\right)\end{array}$ & $\begin{array}{c}\text { RGO } \\
\left(\mathrm{Sm}^{3} / \mathrm{Sm}^{3}\right)\end{array}$ & $\begin{array}{l}\text { Fração } \\
\text { Água } \\
(\%)\end{array}$ \\
\hline $24 \mathrm{PC}$ & 455,2 & 413,9 & 30,0 & 554,2 & 1266,0 & 177,3 & 1820,2 & 319,9 & 69,6 \\
\hline $14 \mathrm{PC}$ & 463,0 & 416,7 & 30,0 & 515,7 & 1234,9 & 164,2 & 1750,6 & 318,3 & 70,5 \\
\hline $9 \mathrm{PC}$ & 462,4 & 416,4 & 30,0 & 510,2 & 1228,1 & 163,5 & 1738,3 & 320,5 & 70,6 \\
\hline $7 \mathrm{PC}$ & 460,4 & 415,6 & 30,0 & 496,5 & 1192,6 & 160,0 & 1689,1 & 322,2 & 70,6 \\
\hline $6 \mathrm{PC}$ & 461,1 & 412,1 & 30,0 & 536,3 & 1218,1 & 173,9 & 1754,4 & 324,2 & 69,4 \\
\hline $5 \mathrm{PC}$ & 458,9 & 412,9 & 30,0 & 494,8 & 1232,9 & 169,4 & 1727,7 & 342,4 & 71,4 \\
\hline $4 \mathrm{PC}$ & 461,9 & 416,0 & 30,0 & 496,8 & 1216,0 & 172,6 & 1712,8 & 347,4 & 71,0 \\
\hline
\end{tabular}

No Apêndice C são ilustrados os gráficos de pressão, temperatura e holdup ao longo do escoamento nos poços e dutos para os cenários de produção e EOS modeladas. As demais grandezas, como as velocidades superficiais de gás e líquido, os gradientes de pressão por fricção, gravitacional e total e o coeficiente global de transferência de calor e o coeficiente Joule-Thomson também podem ser vistos no Apêndice C. A evolução do erro ao longo do comprimento pode ser visualizada nestes gráficos. Nas Tabelas 5.6, 5.7 e 5.8 pode-se ver a raiz do erro quadrático médio normalizado, com as mesmas premissas para a elaboração adotadas nos resultados do modelo de reservatório. 
Tabela 5.6: Raiz do erro quadrático médio normalizado (\%) - Variáveis de escoamento - Cenário 1

\begin{tabular}{lllllll} 
Variável & EOS & EOS & EOS & EOS & EOS & EOS \\
& $\mathbf{1 4} \mathbf{P C}$ & $\mathbf{9} \mathbf{P C}$ & $\mathbf{7} \mathbf{P C}$ & $\mathbf{6} \mathbf{P C}$ & $\mathbf{5} \mathbf{P C}$ & $\mathbf{4} \mathbf{~ P C}$ \\
\hline NMRSD - Pressão & 0,09 & 0,07 & 0,08 & 0,02 & 0,06 & 0,07 \\
\hline NMRSD - Temperatura & 5,54 & 5,15 & 0,44 & 2,18 & 1,72 & 5,18 \\
\hline NMRSD - Holdup & 1,35 & 1,37 & 0,51 & 0,42 & 1,28 & 1,13 \\
\hline NMRSD - VSL & 0,45 & 0,60 & 0,28 & 0,26 & 0,65 & 0,81 \\
\hline NMRSD - VSG & 2,82 & 2,67 & 0,33 & 1,21 & 1,79 & 2,09 \\
\hline NMRSD - Grad Friç̧ão & 2,94 & 2,79 & 0,51 & 1,29 & 1,87 & 2,33 \\
\hline NMRSD - Grad Gravitacional & 0,86 & 0,77 & 0,24 & 0,32 & 0,75 & 0,53 \\
\hline NMRSD - Grad Total & 1,04 & 0,99 & 0,22 & 0,44 & 0,71 & 0,83 \\
\hline NMRSD - Coef Troca Calor U & 0,03 & 0,03 & 0,01 & 0,02 & 0,11 & 0,13 \\
\hline NMRSD - Coef Joule Thomson & 14,90 & 14,23 & 1,47 & 5,93 & 5,34 & 12,53 \\
\hline
\end{tabular}

Tabela 5.7: Raiz do erro quadrático médio normalizado (\%) - Variáveis de escoamento - Cenário 2

\begin{tabular}{lllllll} 
Variável & EOS & EOS & EOS & EOS & EOS & EOS \\
& $\mathbf{1 4} \mathbf{P C}$ & $\mathbf{9} \mathbf{P C}$ & $\mathbf{7} \mathbf{P C}$ & $\mathbf{6} \mathbf{P C}$ & $\mathbf{5} \mathbf{P C}$ & $\mathbf{4} \mathbf{~ P C}$ \\
\hline NMRSD - Pressão & 0,14 & 0,30 & 0,41 & 0,66 & 1,20 & 0,30 \\
\hline NMRSD - Temperatura & 5,93 & 5,66 & 1,26 & 3,14 & 2,99 & 7,04 \\
\hline NMRSD - Holdup & 1,66 & 1,49 & 0,66 & 0,95 & 1,52 & 3,27 \\
\hline NMRSD - VSL & 0,46 & 0,39 & 1,20 & 1,85 & 3,81 & 6,59 \\
\hline NMRSD - VSG & 3,15 & 2,86 & 0,49 & 1,39 & 3,02 & 3,97 \\
\hline NMRSD - Grad Frição & 3,44 & 3,29 & 1,07 & 2,27 & 5,05 & 7,18 \\
\hline NMRSD - Grad Gravitacional & 1,01 & 0,86 & 0,20 & 0,36 & 0,71 & 0,86 \\
\hline NMRSD - Grad Total & 1,05 & 1,00 & 0,52 & 0,82 & 1,65 & 2,91 \\
\hline NMRSD - Coef Troca Calor U & 0,05 & 0,04 & 0,01 & 0,03 & 0,10 & 0,12 \\
\hline NMRSD - Coef Joule Thomson & 15,34 & 14,71 & 1,95 & 6,64 & 5,97 & 13,58 \\
\hline
\end{tabular}


Tabela 5.8: Raiz do erro quadrático médio normalizado (\%) - Variáveis de escoamento - Cenário 3

\begin{tabular}{lllllll} 
Variável & EOS & EOS & EOS & EOS & EOS & EOS \\
& $\mathbf{1 4} \mathbf{P C}$ & $\mathbf{9} \mathbf{P C}$ & $\mathbf{7} \mathbf{P C}$ & $\mathbf{6} \mathbf{P C}$ & $\mathbf{5} \mathbf{P C}$ & $\mathbf{4} \mathbf{~ P C}$ \\
\hline NMRSD - Pressão & 0,61 & 0,57 & 0,56 & 0,18 & 0,11 & 0,57 \\
\hline NMRSD - Temperatura & 0,81 & 0,77 & 2,07 & 0,74 & 0,81 & 0,74 \\
\hline NMRSD - Holdup & 1,52 & 1,46 & 2,06 & 0,58 & 0,52 & 2,08 \\
\hline NMRSD - VSL & 5,25 & 6,13 & 9,10 & 3,84 & 6,06 & 5,54 \\
\hline NMRSD - VSG & 2,35 & 2,43 & 3,48 & 1,00 & 1,39 & 2,35 \\
\hline NMRSD - Grad Friç̧ão & 5,43 & 5,84 & 8,56 & 3,46 & 4,89 & 5,88 \\
\hline NMRSD - Grad Gravitacional & 0,77 & 0,80 & 1,03 & 0,11 & 0,26 & 0,82 \\
\hline NMRSD - Grad Total & 0,51 & 0,53 & 0,67 & 0,29 & 0,21 & 0,57 \\
\hline NMRSD - Coef Troca Calor U & 0,01 & 0,01 & 0,01 & 0,01 & 0,02 & 0,02 \\
\hline NMRSD - Coef Joule Thomson & 20,31 & 19,77 & 9,72 & 11,52 & 12,99 & 17,76 \\
\hline
\end{tabular}

\section{3}

\section{Tempo de simulação}

O resultado no tempo das simulações pode ser visualizadas na Tabela 5.9. O tempo total da simulação de reservatório $(G E M)$ e da rede de escoamento $(G A P)$ aparecem segregados. Há certo paralelismo entre as simulações de modo que o tempo total não é diretamente a soma do tempo de simulação de ambos softwares. O percentual de redução de tempo em relação ao tempo de simulação da EOS detalhada e também em relação a cada simplificação da EOS foi mostrada. 
Tabela 5.9: Tempo de simulação.

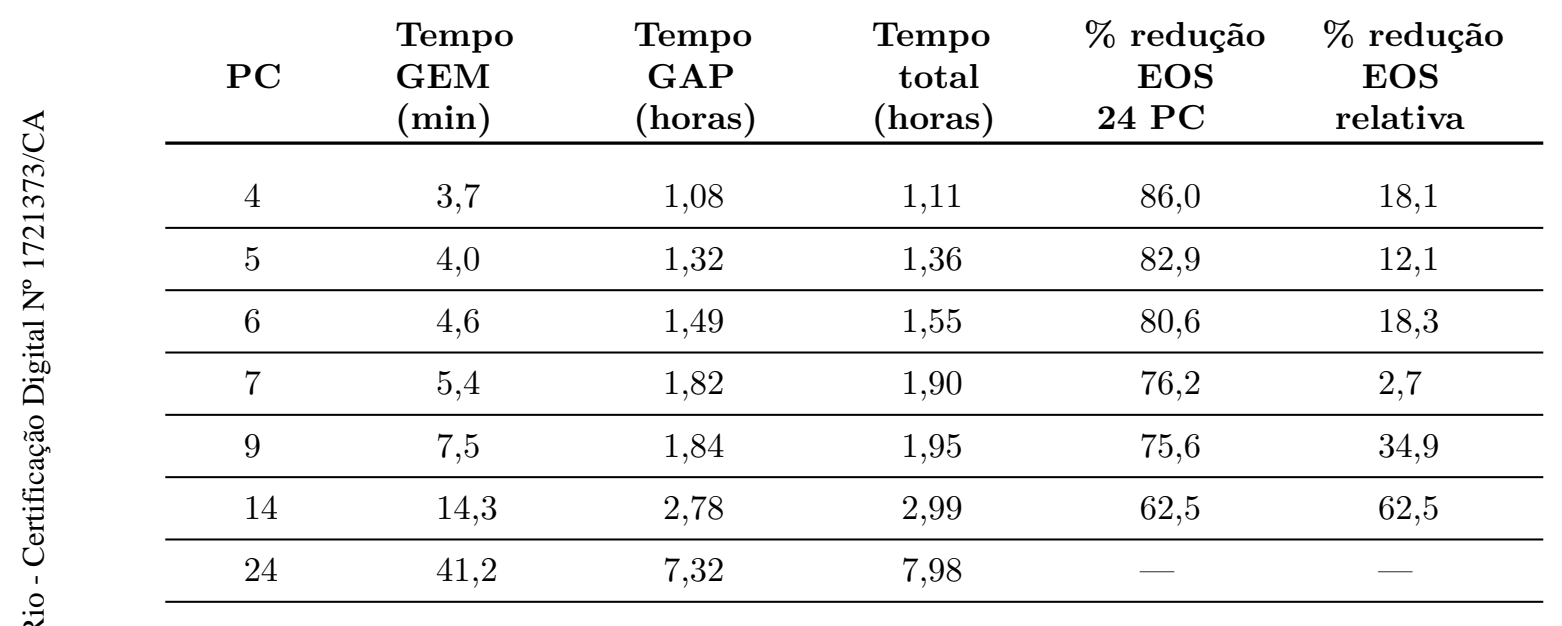




\section{Considerações finais}

\section{1}

\section{Conclusões}

Este trabalho preenche uma lacuna na literatura em relação à simplificação de EOS, que até então tratavam quase que exclusivamente dos efeitos no escoamento em meio poroso. O trabalho estabelece um ponto de partida para engenheiros envolvidos com MIPs com abordagem composicional para o fluido.

O trabalho mostra que é possível reduzir o tempo computacional no cenário proposto sem perder a qualidade na resposta tanto do escoamento no meio poroso quanto do escoamento em tubulações nos poços e dutos. Na sequência pode-se ver uma análise crítica dos resultados encontrados e alguns pontos de atenção.

\subsection{1}

\section{Modelo de reservatório}

Os resultados encontrados no modelo de reservatório seguiram a tendência demonstrada em outros trabalhos similares encontrados na literatura. A vazão de óleo instantânea e, consequentemente, a acumulada apresentaram valores de NMRSD dentro da faixa de $2 \%$ exceto para as EOS de 4 e 5 pseudocomponentes, que apresentaram erros significativamente maiores. Outro ponto a ressaltar das duas equações com maior simplificação é que a regressão da RGO ficou aquém do desejado, justamente devido ao efeito da elevada simplificação para um fluido de alta RGO. Em campos com este tipo de fluido o ajuste desta variável é muito importante, uma vez que ela tem muito efeito na determinação da capacidade de gás da plataforma de produção.

A chegada da frente de água apresentou erros elevados em relacão a EOS detalhada nos passos de tempo logo após o breaktrough, contudo, logo após um tempo o erro cai drasticamente e pode-se dizer que todas as EOS representam o fenômeno de forma semelhante. O comportamente da pressão estática e de fundo compartilham das mesmas considerações da frente de chegada de água. 
Do ponto de vista puramente do escoamento em meio poroso, pode-se chegar a conclusão que a EOS de 6 pseudocomponentes representa adequadamente os resultados apresentados na EOS detalhada. As EOS com nível maior de simplificação levariam a erros elevados na receita do campo e na quantidade de gás produzido, não justificando a melhoria no tempo computacional.

\section{1 .2}

\section{Modelo de escoamento em poços e dutos}

Em relação ao perfil de pressão do fundo do poço até a plataforma, mesmo com erros considerados elevados para algumas variáveis como holdup, velocidades superficiais de gás e gradientes de pressão em determinados pontos, os erros das EOS simplificadas em relação à EOS detalhada ficaram na faixa de $\pm 2 \%$. Este nível de erro compete com a incerteza nos modelos de fluxo multifásico usados na indústria e, portanto, é perfeitamente aceitável. Nota-se que o erro aumenta no trecho riser, onde as velocidades de gás aumentam consideravelmente.

O perfil de temperatura do cenário 3, onde a produção de água é elevada, apresentou erros muitos baixos ao se comparar as EOS simplificadas com a EOS detalhada. Este resultado já era esperado uma vez que neste cenário as propriedades térmicas da água, bem conhecidas, tem forte relevância no resultado. Para os cenários 1 e 2 , entretanto, houve desvios na temperatura que poderiam levar a um raciocínio equivocado em relação a problemas relacionados a garantia de escoamento no duto, muito dependentes da temperatura de escoamento.

Ao se analisar as variáveis que compõem o gradiente de temperatura do duto, pode-se observar que o coeficiente global de transferência de calor do duto obtido nas diversas EOS simplificadas é muito próximo da EOS detalhada, nos levando à conclusão que o coeficiente de filme interno do duto foi pouco impactado pela simplificação da EOS.

A diferença nos perfis de temperatura é então explicada pela determinação do coeficiente Joule Thomson. Pode-se observar que os cenários da EOS com 7 pseudocompentes, que obtiveram melhores resultados, foram os cenários onde o valor deste coeficiente se aproximou mais dos cenários da EOS detalhada, contudo não se pode afirmar que é a simplificação da EOS que prejudicou o resultado, uma vez que foi a EOS com número de componentes intermediário gerou o melhor resultado.

O perfil de holdup completa a análise das principais variáveis de escoamento e o comportamento observado sugere que a simplificação dos fluidos não interferiu na determinação das frações ocupadas pelo líquido e gás ao longo 
do comprimento total de duto. Desta forma, as propriedades de mistura que dependem desta propriedade, e que influenciam os perfis de pressão e temperatura foram geradas com o rigor necesário.

Do ponto de vista puramente do escoamento em poços e dutos, pode-se chegar a conclusão de que para este tipo de fluido, o perfil de pressão e consequentemente as vazões de produção são bem representadas até mesmo com EOS altamente simplificadas. Para avaliar questões relacionadas a garantia de escoamento, sugere-se um olhar criterioso para os resultados obtidos para o coeficiente Joule Thomson com a EOS utilizada para os estudos.

\section{1 .3}

\section{Tempo de simulação}

O tempo de simulação total do modelo integrado é dominado pelo tempo total de simulação no GAP, que resolve o problema de escoamento nos poços e dutos. Pode-se observar que mais de $90 \%$ do total do tempo é gasto neste simulador. Desta forma a redução de componentes na EOS torna-se mandatória de forma a otimizar o tempo total da simulação.

Olhando para as restrições impostas em cada modelo de fluxo, a EOS com 6 pseudocomponentes, que atende plenamente os fenômenos de fluxo no meio poroso e os perfis de pressão no duto, ou seja, pode ser usada para estimar as receitas de um projeto de desenvolvimento, obteve uma redução no tempo total de simulação em relação à EOS detalhada de 80,6\%.

Se o modelo estiver sendo usado para analisar questões de caráter de garantia de escoamento, a EOS com 7 pseudocomponentes apresentou o melhor resultado, e desta forma a redução do tempo de simulação foi de $76,2 \%$.

\section{2}

\section{Sugestão para trabalhos futuros}

A linha de estudo deste trabalho foi observar o comportamento da resposta de um modelo integrado de produção em relação a diferentes modelos de fluido, e avaliar as respostas do modelo de fluxo no meio poroso e no fluxo nas tubulações frente ao ganho de tempo de simulação com as EOS simplificadas.

O fluido escolhido para a análise foi um óleo volátil, e as conclusões obitdas não podem ser estendidas para outras classes de fluidos. Assim sendo, recomenda-se realizar o mesmo estudo para outras amostras de fluido que necessitem caracterização composicional. A modelagem ótima para representar um MIP com uma amostra do tipo gás retrógrado pode ser diferente do encontrado no resultado desta dissertação, dado que a natureza do escoamento 
multifásico neste tipo de fluido é diferente (baixo hold-up e altas velocidades de gás).

Recomenda-se avaliar também o modelo de fluido ótimo para óleos pesados. Mesmo que neste tipo de mistura normalmente não se faz uso da caracterização de fluido composicional, sabe-se que o efeito da temperatura na viscosidade neste tipo de óleo costuma ser muito relevante na perda de carga por fricção nas tubulações. Portanto, qualquer melhora na predição destas propriedades em um modelo integrado de produção pode significar muito para as previsões de receitas de um projeto.

Uma reflexão mais profunda à respeito do que teria causado um erro tão pronunciando no coeficiente Joule-Thomson, principalmente para as EOS simplificadas de 14 e 9 componentes, é também de interesse da indústria de petróleo. Os resultados mostram que os erros nesta propriedade não parecem estar ligados a simplificação, outro ponto interessante a ser esclarecido.

Outra linha de estudo importante é comparar a resposta obitda nos simuladores comerciais utilizados nesta dissertação com as respostas obtidas por simuladorers de tubulação em escoamento comerciais utilizados na indústria, como o Pipesim e Olga da fabricante Schulumberger. Estes simuladores são usados para prever a perda de carga e temperatura quando modelos com acoplamento explícito fraco são usados nas análises de produção. 


\section{Referências bibliográficas}

[1] DANESH, A.. PVT and phase behavior of petroleum reservoir fluids. Elsevier, Amsterdam, 1st edition, 1998.

[2] PEDERSEN, K. S.; CHRISTENSEN, P. L.. Phase behavior of petroleum reservoir fluids. CRC Press, Boca Raton, 1st edition, 2006.

[3] AHMED, T. H., P. L.. Equations of State and PVT Analysis. Gulf Publishing Company Houston, Houston, 1st edition, 2007.

[4] PUC-RIO. Comportamento Termodinâmico de Fluidos no Reservatório. PUC-Rio. PUC-Rio, 2019. Acesso em: Abril de 2019.

[5] DIÁRIO DO PRÉ-SAL. O que é o pré-sal. Diário do Pré-Sal. Diário do pré-sal, 2019. Acesso em: Maio de 2019.

[6] ALAVIAN, S. A.; WHITSON, C. A.; MARTINSEN, S. O.. Global Componente Lumping for EOS Calculations. SPE Annual Techical Conference and Exhibition, 2014.

[7] FILHO, J.C. H.; SCHIOZER, D. J.. Evaluation on Explixit Coupling between Reservoir Simulators and Production System. Unicamp, 2011.

[8] COTRIM, H. A.. Simulação de Múltiplos Reservatórios em Cenário com Restrição de Superfície Utilizando Modelagem Integrada de Produção. Tese de doutorado em engenharia de petróleo, Unicamp, São Paulo, 2012.

[9] CARPIO, R. S.. Representação de mistura de petróleos com abordagem composicional. Tese de mestrado em engenharia de petróleo, Unicamp, São Paulo, 2012.

[10] MACHADO, M. V. B.. Modelagem e Simulação Numérica de Reservatórios de Petróleo - Principais aspectos envolvidos. In: RH/UP/ECTEP 1-249, Rio de Janeiro, 2012. 
[11] ZADEH, S. G.; BARZANJI, D; BROCK, N.; ATEEQ, B. O. S.; BLOCH, G.; ABU-SNAINEH, A.. Development of Tightly-Coupled Integraded Asset Model For Use in Production Optimization, DeBottlenecking and Flow Assurance of Multiple Gas Reservoirs. SPE Annual Techical Conference and Exhibition, 2015.

[12] TORRENS, R; DAOUD, A.; AMARI, M.; SHARIFZADEH, A.; PRAKASH, R.; AL-ENZI, B; DASHTI, Q.. Modeling from Reservoir to Export: A Compositional Approach for Integrade Asset Model of Different Gas Fields in North Kuwait Jurassic Carbonate Reservoirs. SPE Annual Techical Conference and Exhibition, 2015.

[13] Galvan, D.; MCVInNIE, G; DINDORUK, B.. Perdido Development: Unified Fluid Model (UFM) for Integrated Production System Modeling (IPSM). SPE Annual Techical Conference and Exhibition, 2014.

[14] MARMIER, R.; BRANCHFLOWER, M. FOUCAULT, H.. Integrated asset Modeling - Coupling to a Dynamic Well and Network Flow Simulator for IMproved Flow Assrance in Field Development Planning and Production Forecasting. IPTC, 2016.

[15] HARLEY, J.; ABEL, C.; WATSON, M.. Generating Cost Reduction in the Supply Chain by Coupling Surface Facilities with Reservoir Data in Integrated Asset Modeling. SPE Annual Techical Conference and Exhibition, 2016.

[16] MUSAMEH, F. K.; ALJADI, I.. Production Excellence is the Platform to Support Digital Oil Field. SPE Annual Techical Conference and Exhibition, 2019.

[17] CHEN, Z.; HUAN, G.; MA, Y.. Computational Methods for Multiphase Flows in Porous Media. Society for Industrial Applied Mathematics, Philadelphia, 1st edition, 2006.

[18] LEVEQUE, R. J.. Finite Volume Methods for Hyperbolic Problems. Cambridge University Press, Cambridge, 1st edition, 2002.

[19] ANDREOLLI, I.. Introdução à Elevação e Escoamento Monofásico e Multifásico de Petróleo. Editora Interferência, Rio de Janeiro, 1 edição, 2016.

[20] WHITSON, C.H.. Characterising Hydrocarbon Plus Fractions. SPE Annual Techical Conference and Exhibition, 1983. 
[21] SHOHAM, O.. Mechanistic Modeling of Gas-Liquid Two-Phase FLow in Pipes. SPE, Richardson, 1st edition, 2006.

[22] MORAN, M. J.; SHAPIRO, H. N.; BOETTNER, D. D.; BAILEY, M. B.. Fundamentals of engineering thermodynamics. John Wiley Sons Inc., Hoboken, 7th edition, 2011. 
A

\section{Resultados - Regressão das EOS simplificadas}

A.1

Regressão da EOS 14 PC

\section{A.1.1}

Ensaio de liberação diferencial

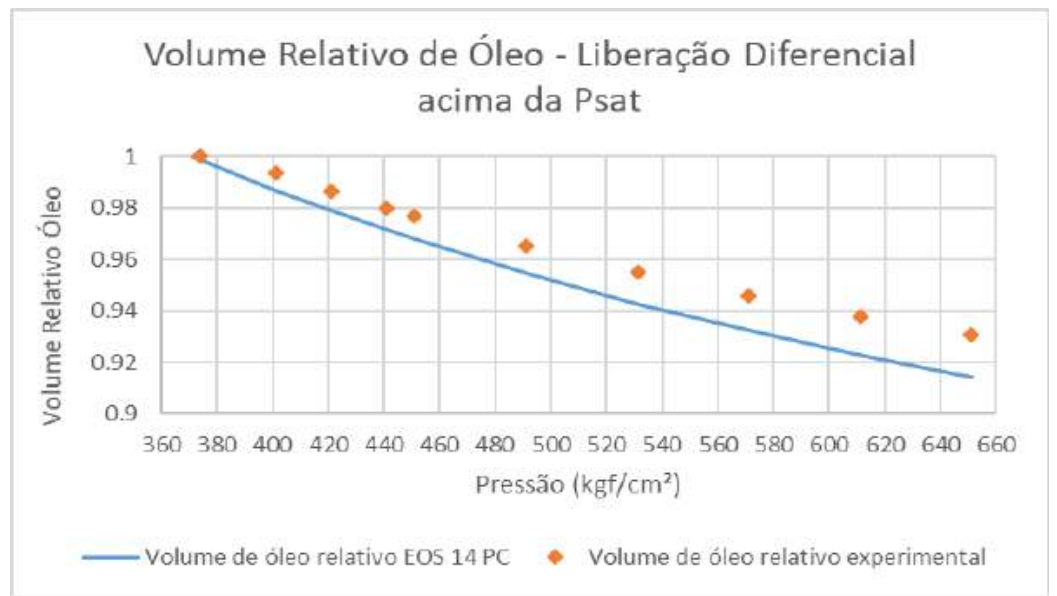

Figura A.1: Volume relativo de óleo da liberação diferencial acima da pressão de saturação. 


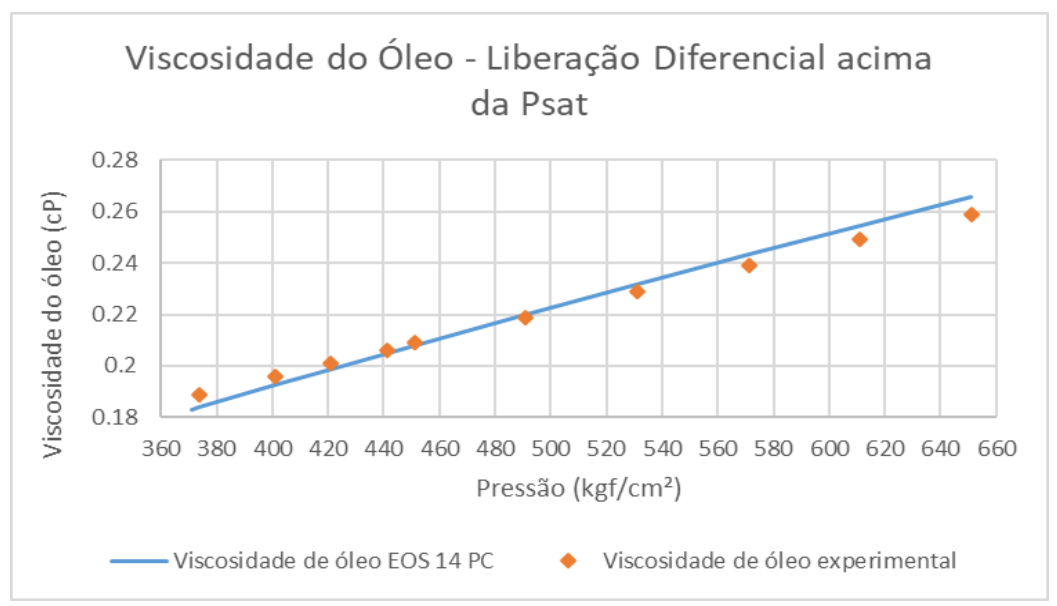

Figura A.2: Viscosidade do óleo da liberação diferencial acima da pressão de saturação.

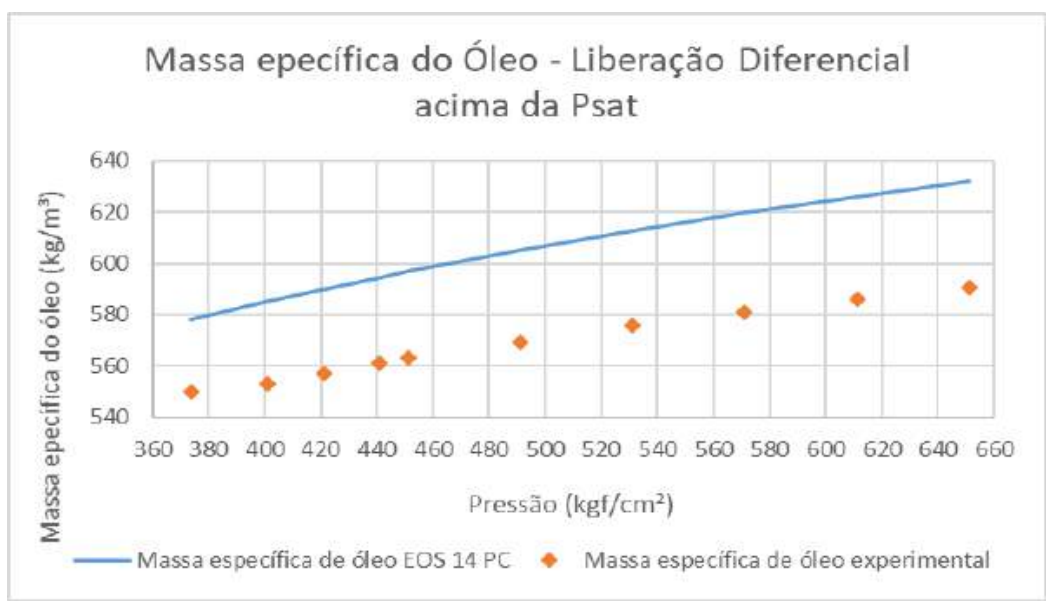

Figura A.3: Massa específica do óleo da liberação diferencial acima da pressão de saturação. 


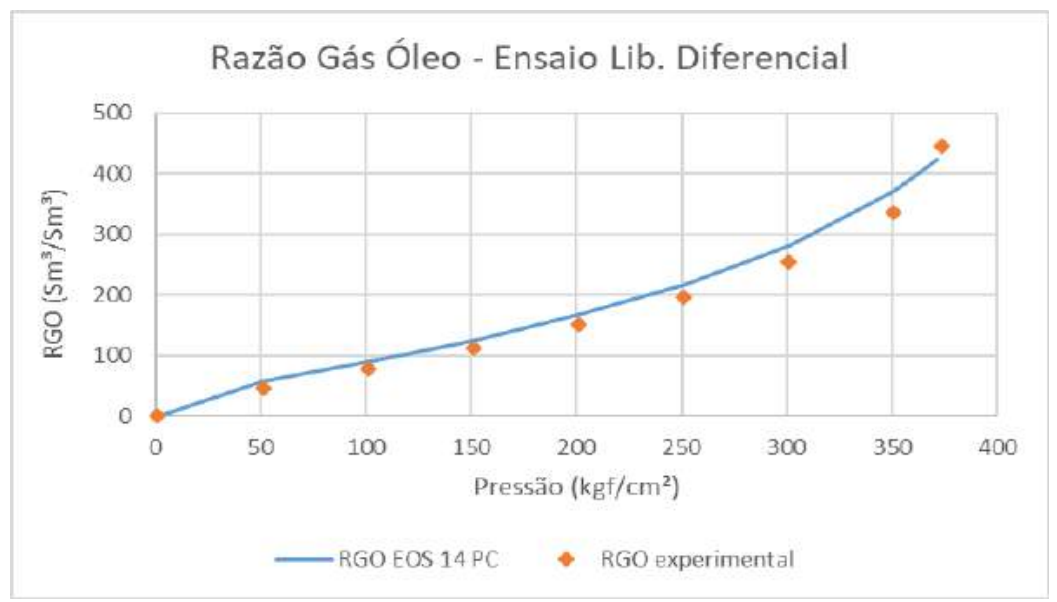

Figura A.4: RGO da liberação diferencial abaixo da pressão de saturação.

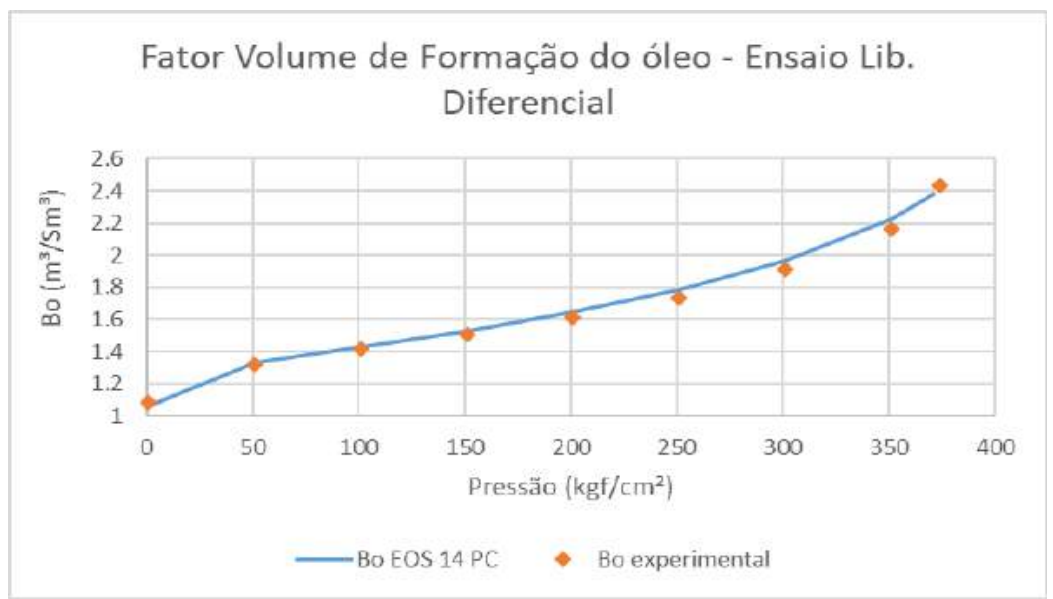

Figura A.5: $B_{o}$ da liberação diferencial abaixo da pressão de saturação.

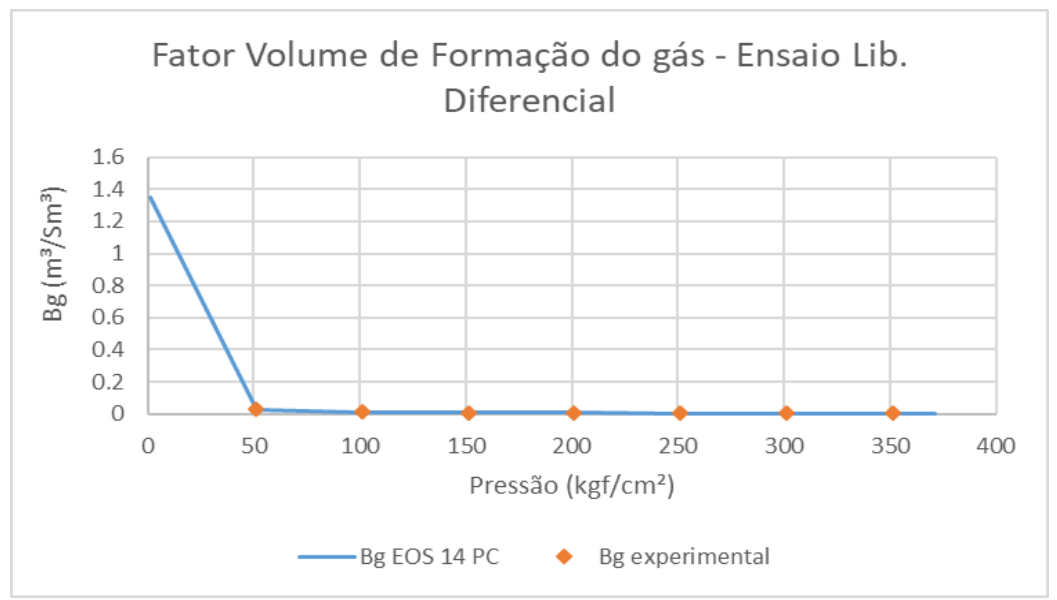

Figura A.6: $B_{g}$ da liberação diferencial abaixo da pressão de saturação. 


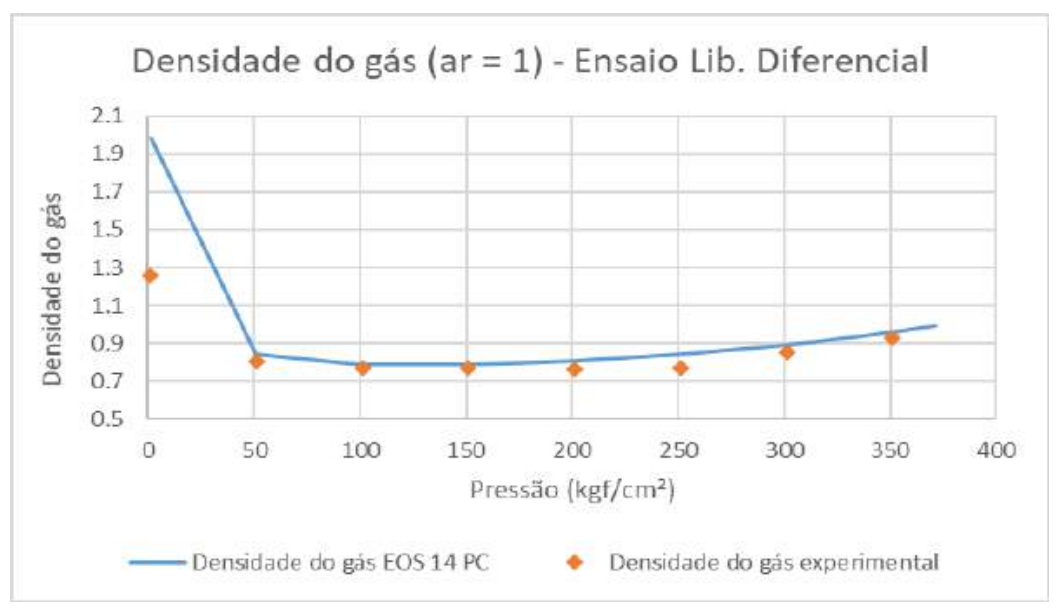

Figura A.7: Densidade do gás abaixo da pressão de saturação.

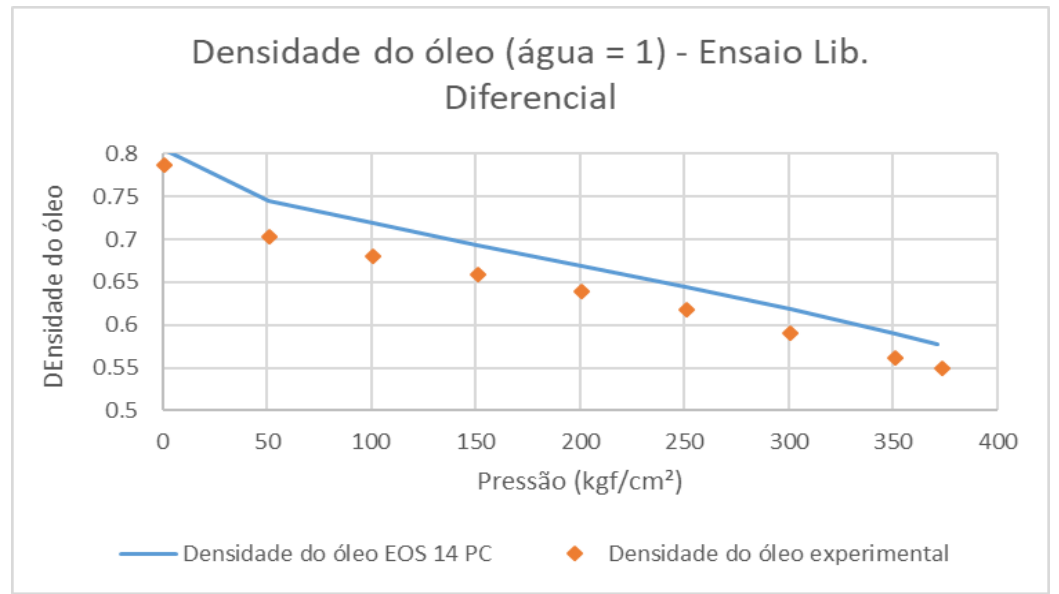

Figura A.8: Densidade do óleo abaixo da pressão de saturação.

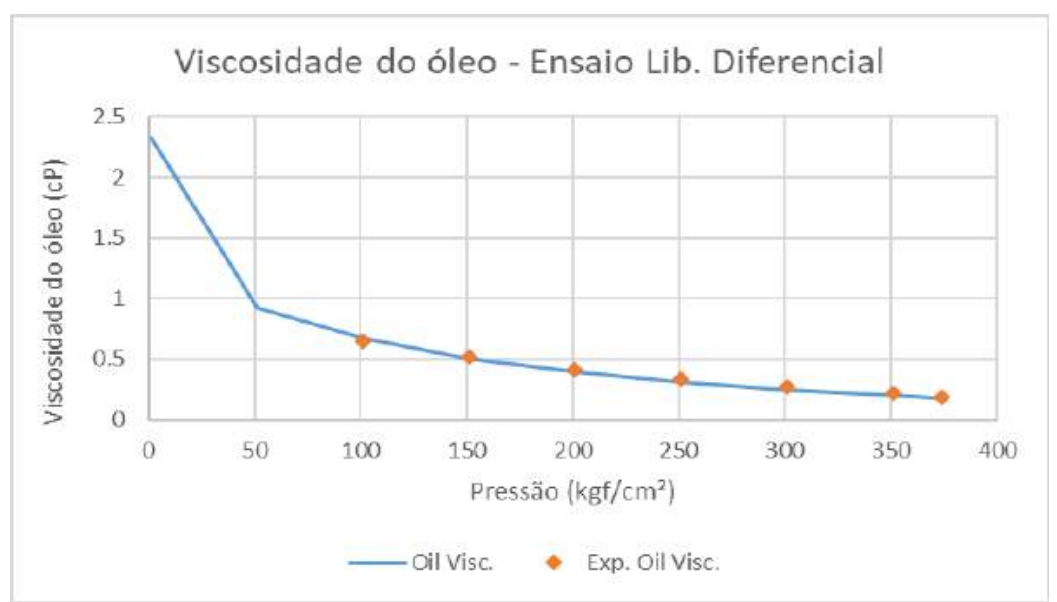

Figura A.9: Viscosidade do óleo abaixo da pressão de saturação. 


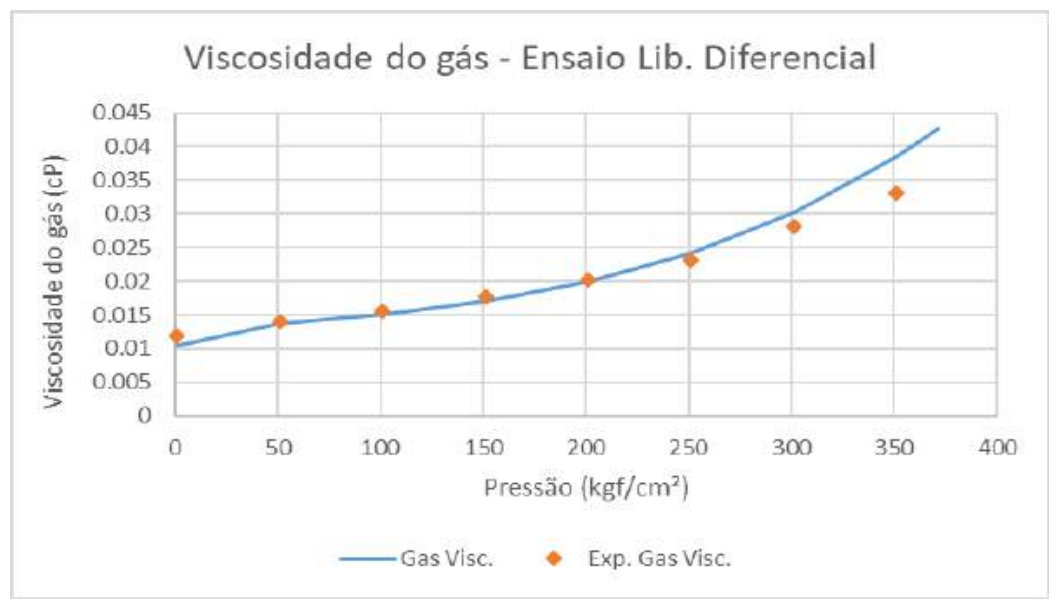

Figura A.10: Viscosidade do gás abaixo da pressão de saturação.

\section{A.1.2}

Ensaios de expansão a composição constante $\mathrm{T}=122^{\circ} \mathrm{C}, 75^{\circ} \mathrm{C}$ e $30^{\circ} \mathrm{C}$

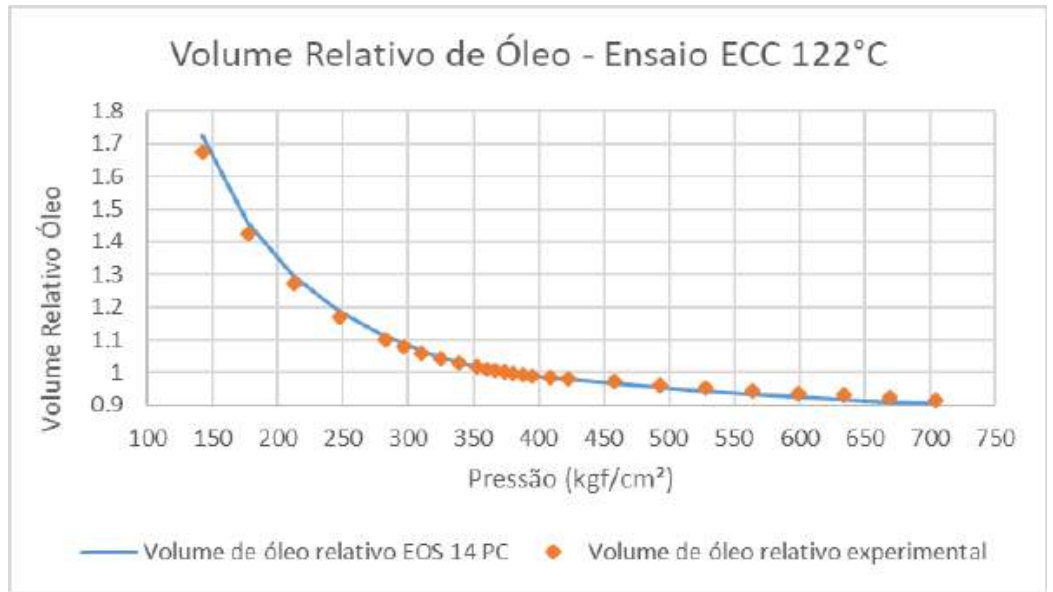

Figura A.11: Volume relativo de óleo, ECC a $122{ }^{\circ} \mathrm{C}$. 


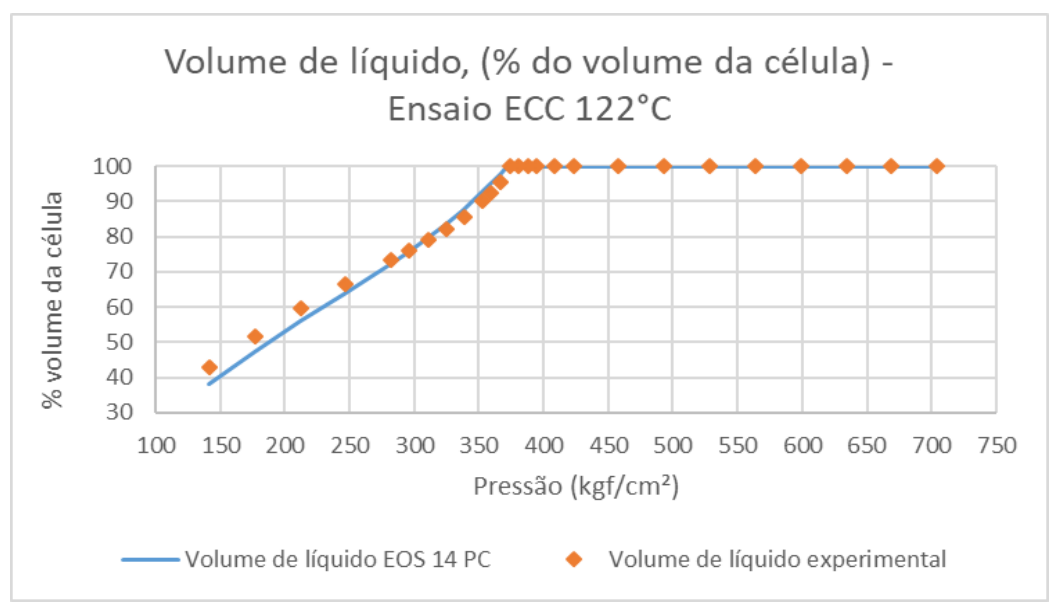

Figura A.12: Volume de líquido, $\%$ do volume da célula, ECC a $122{ }^{\circ} \mathrm{C}$.

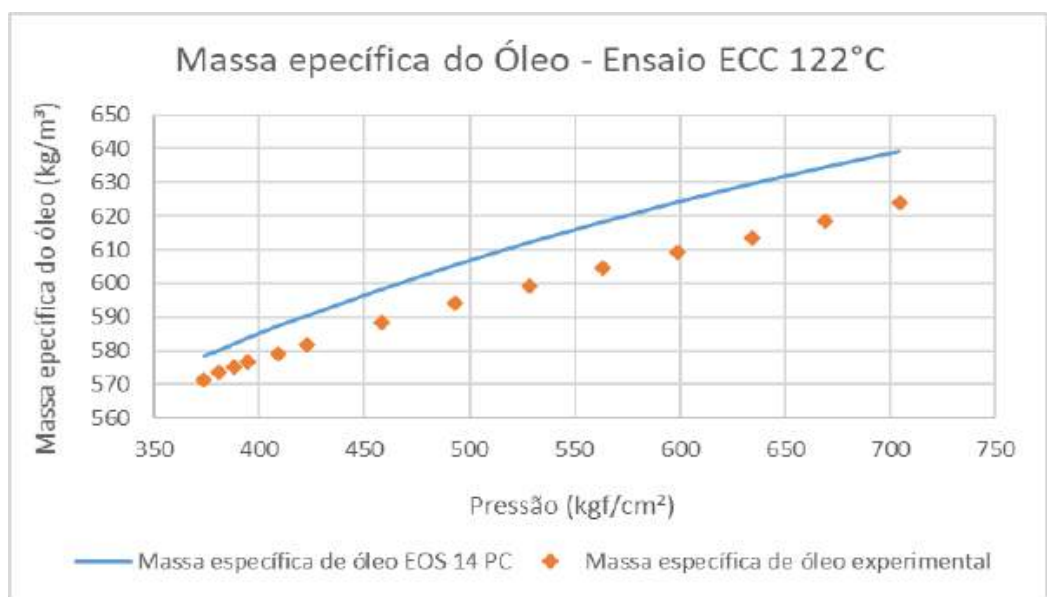

Figura A.13: Massa específica de óleo, ECC a $122{ }^{\circ} \mathrm{C}$.

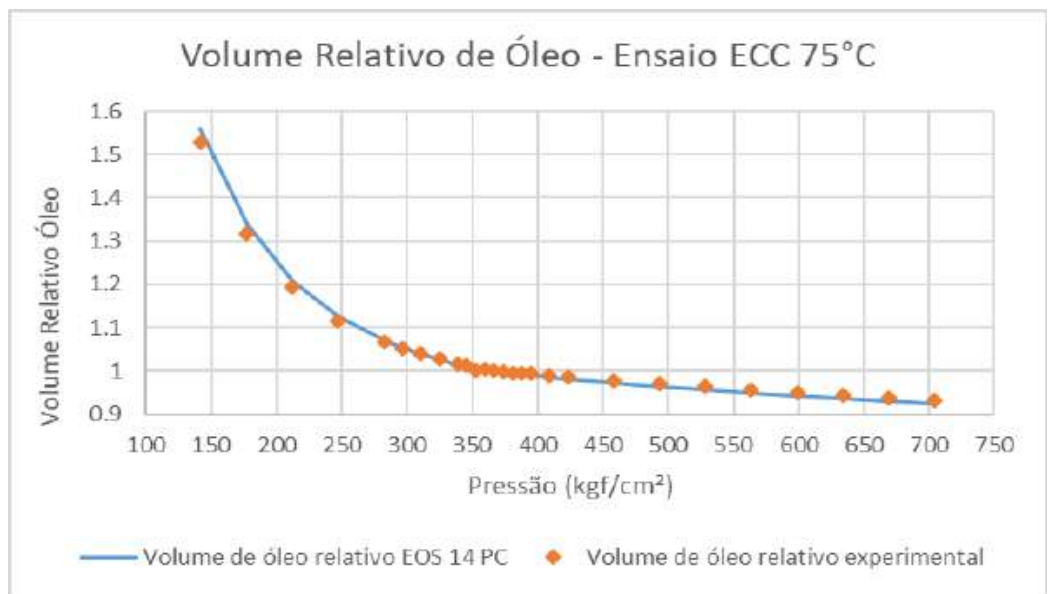

Figura A.14: Volume relativo de óleo, ECC a $75{ }^{\circ} \mathrm{C}$. 


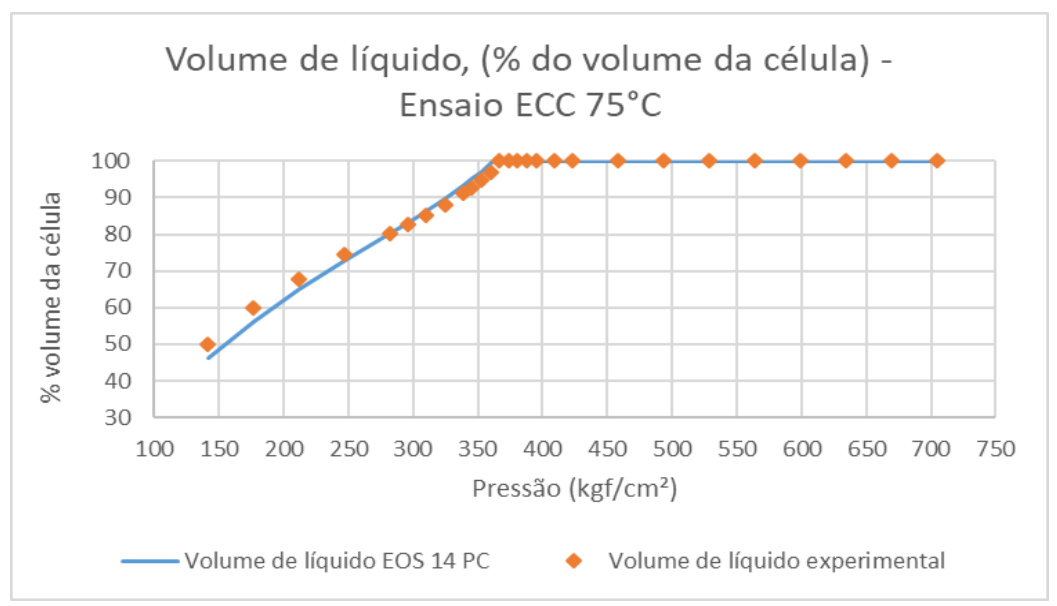

Figura A.15: Volume de líquido, \% do volume da célula, ECC a $75{ }^{\circ} \mathrm{C}$.

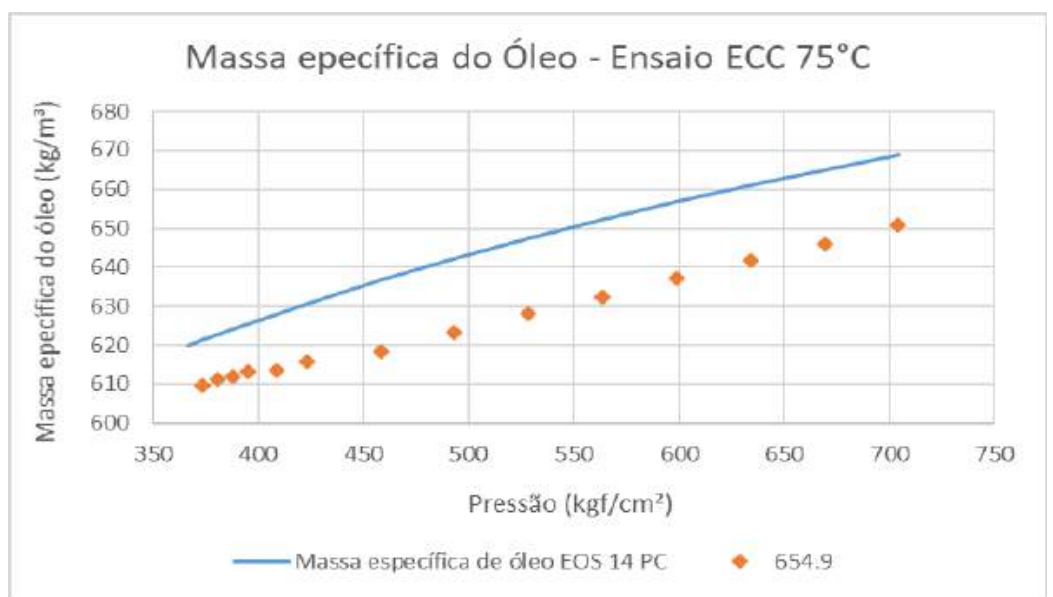

Figura A.16: Massa específica de óleo, ECC a $75{ }^{\circ} \mathrm{C}$.

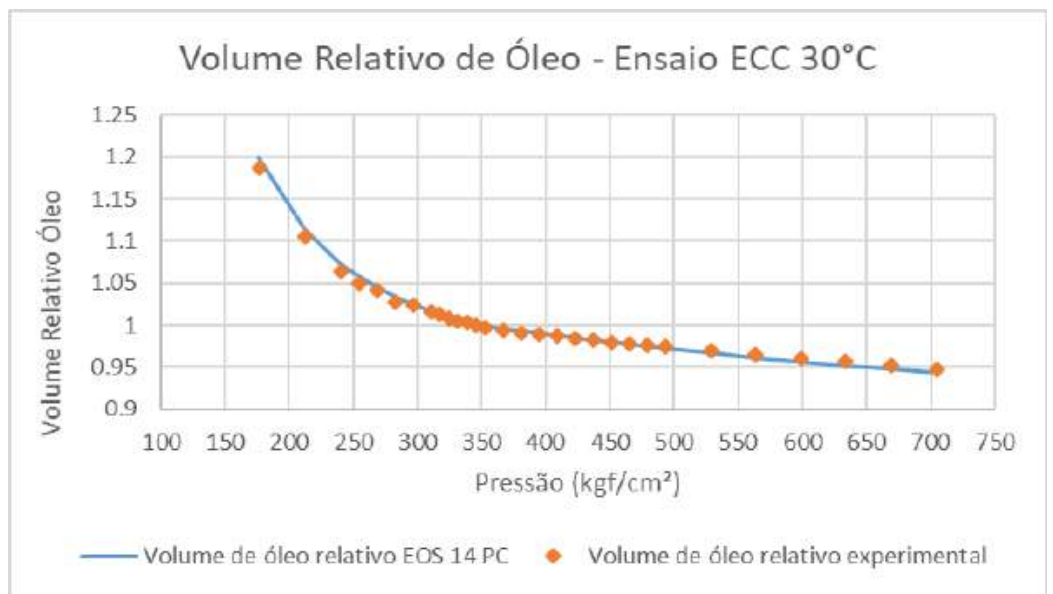

Figura A.17: Volume relativo de óleo, ECC a $30{ }^{\circ} \mathrm{C}$. 


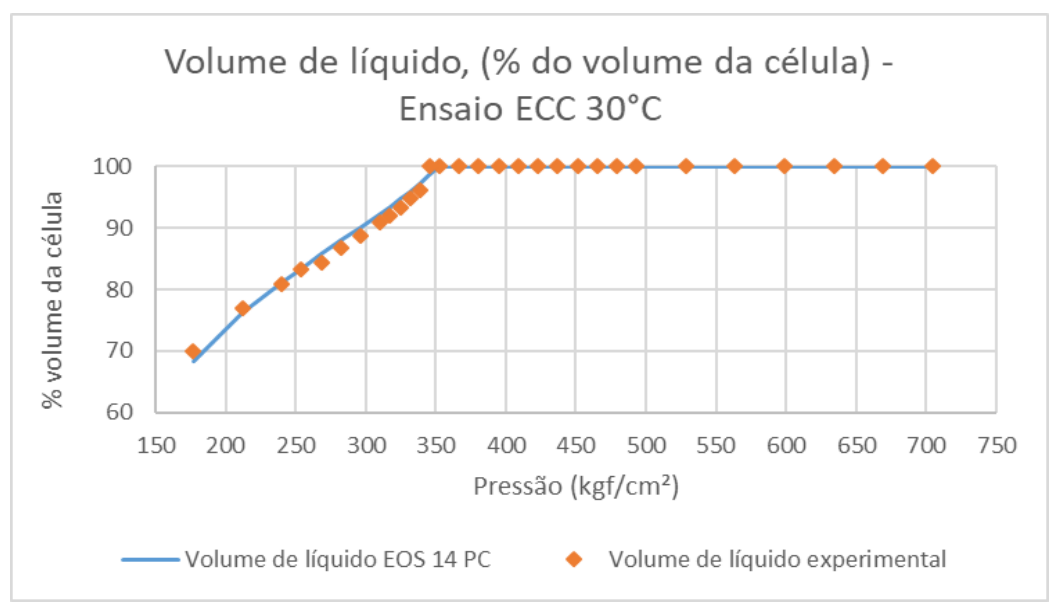

Figura A.18: Volume de líquido, $\%$ do volume da célula, ECC a $30{ }^{\circ} \mathrm{C}$.

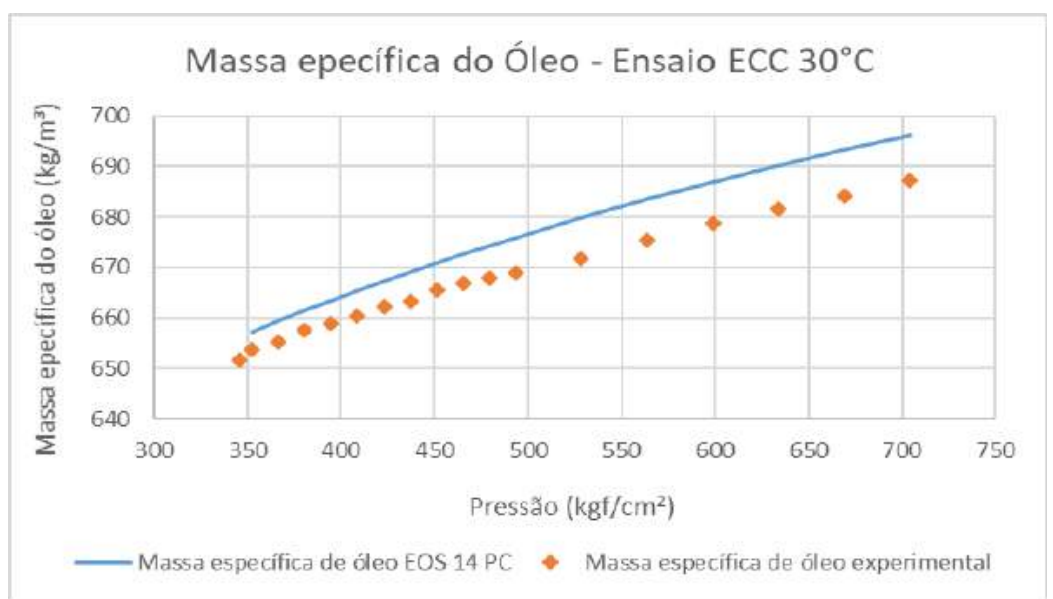

Figura A.19: Massa específica de óleo, ECC a $30{ }^{\circ} \mathrm{C}$. 


\section{A.1.3}

\section{Ensaio de expansão a volume constante}

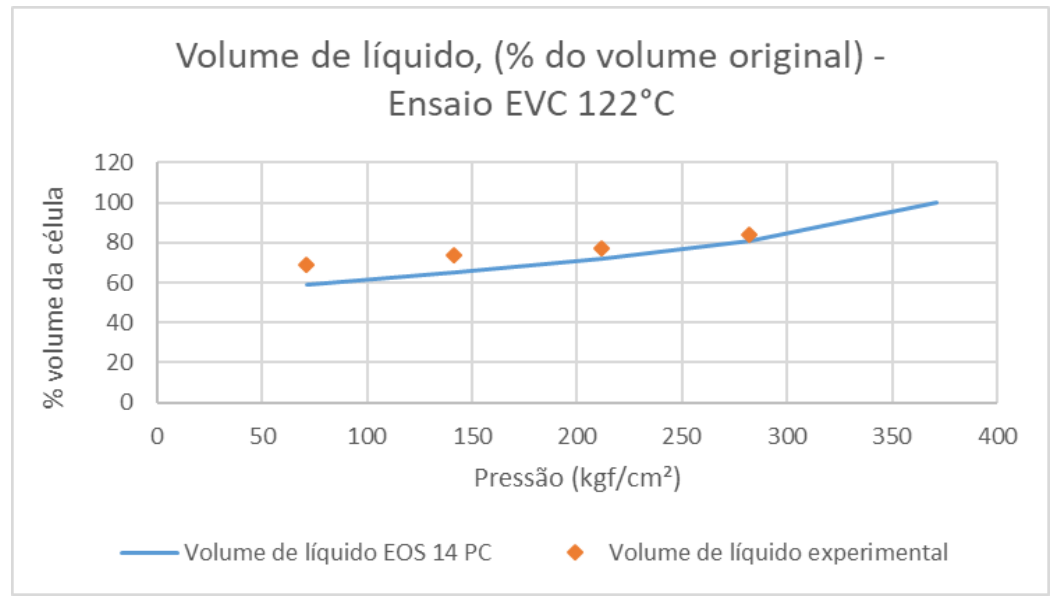

Figura A.20: Volume de líquido, \% do volume original, EVC a $122{ }^{\circ} \mathrm{C}$.

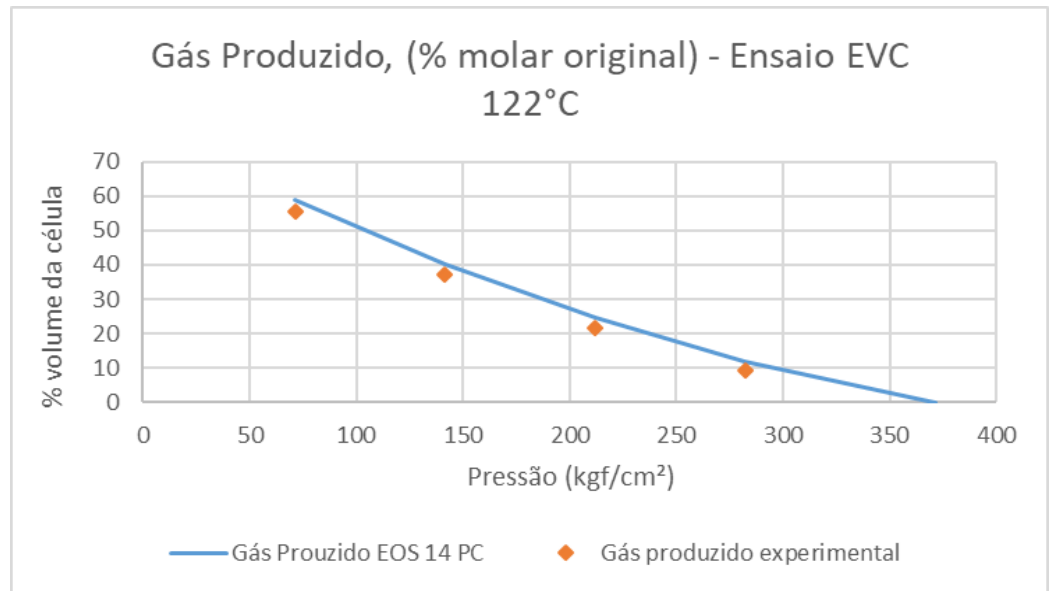

Figura A.21: Gás produzido, \% molar original, EVC a $122{ }^{\circ} \mathrm{C}$.

\section{A. 2}

Regressão da EOS com 9 PC 


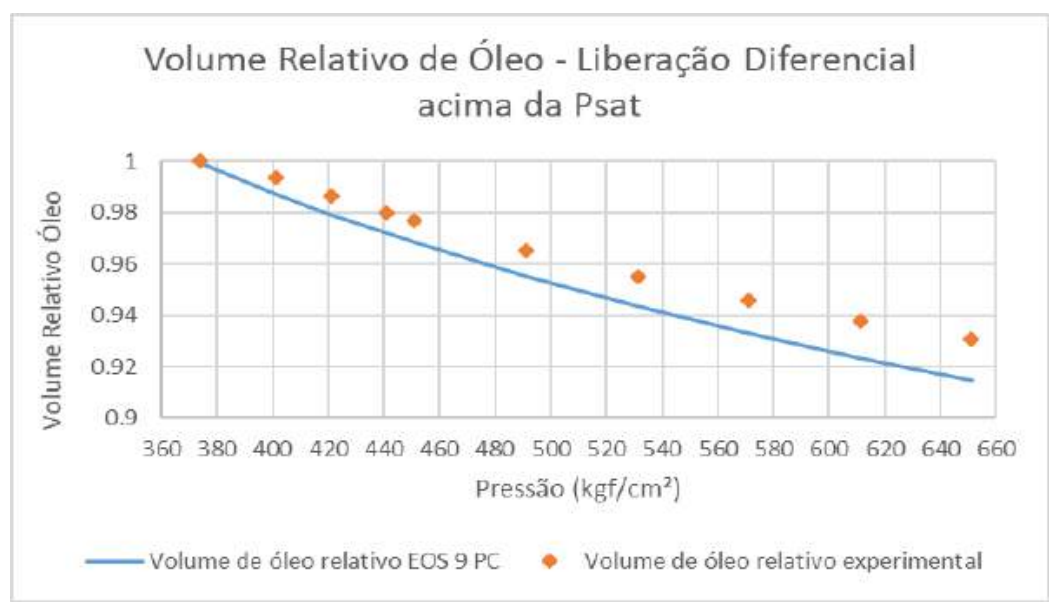

Figura A.22: Volume relativo de óleo da liberação diferencial acima da pressão de saturação.

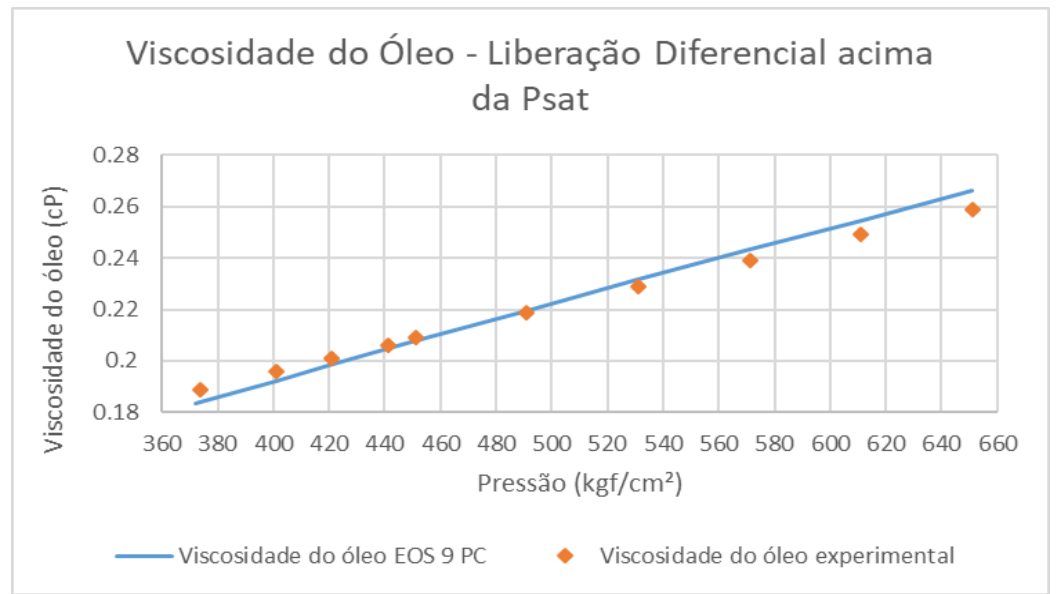

Figura A.23: Viscosidade do óleo da liberação diferencial acima da pressão de saturação.

\section{A.2.1}

\section{Ensaio de liberação diferencial}

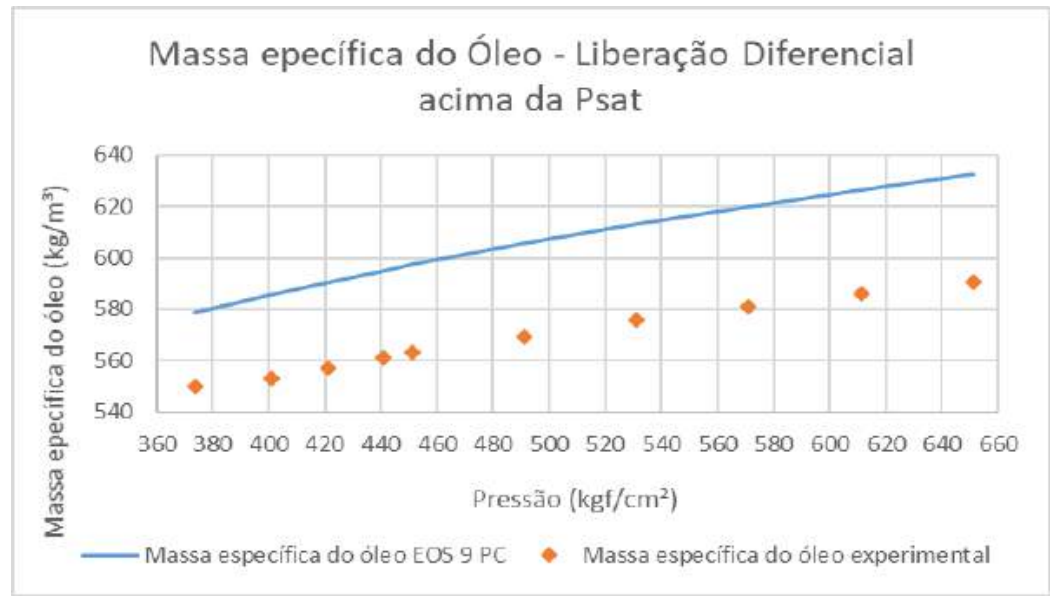

Figura A.24: Massa específica do óleo da liberação diferencial acima da pressão de saturação. 


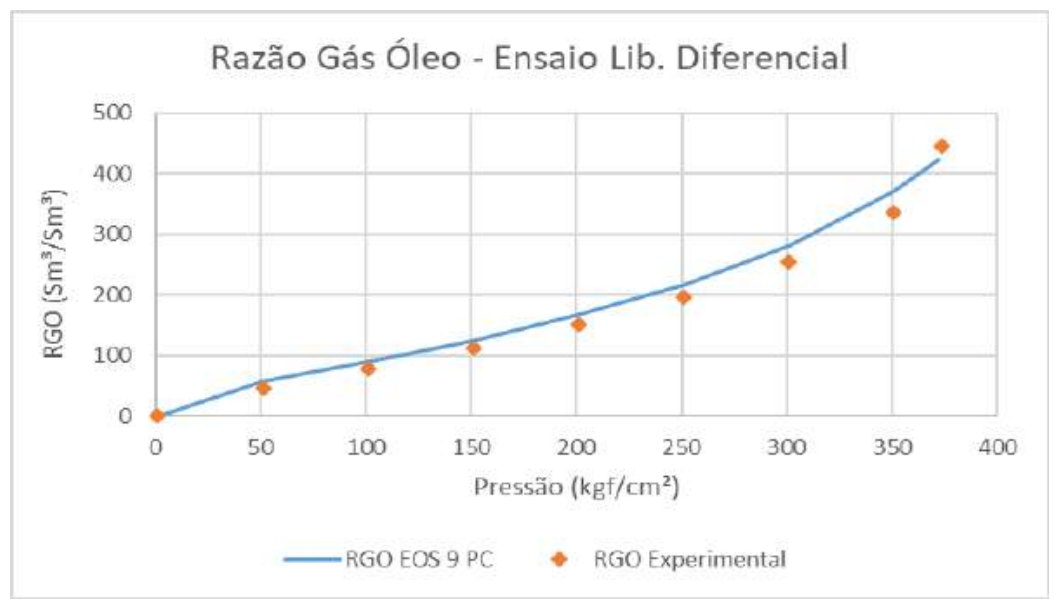

Figura A.25: RGO da liberação diferencial abaixo da pressão de saturação.

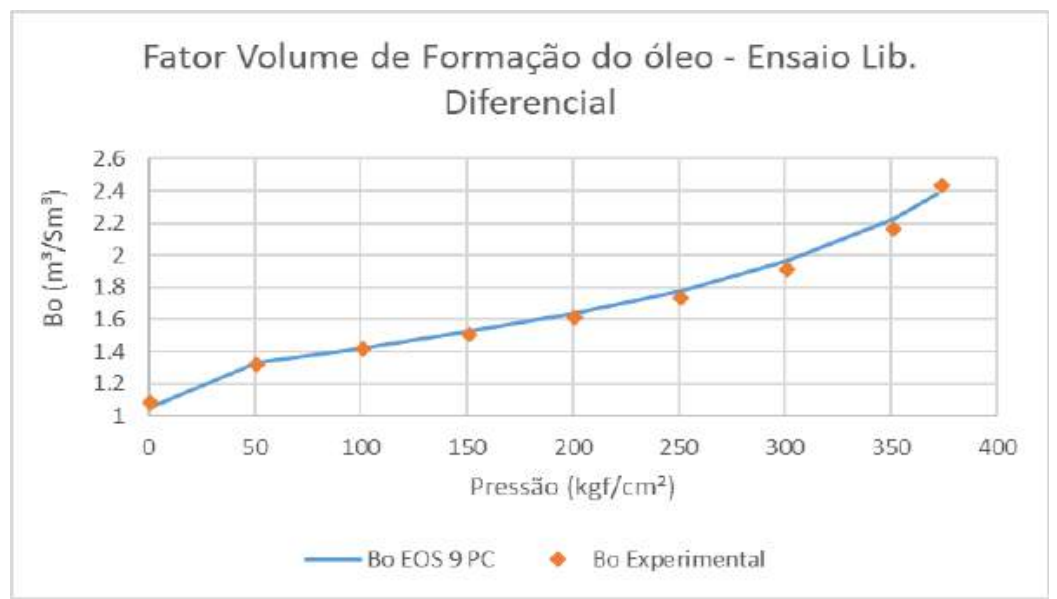

Figura A.26: $B_{o}$ da liberação diferencial abaixo da pressão de saturação.

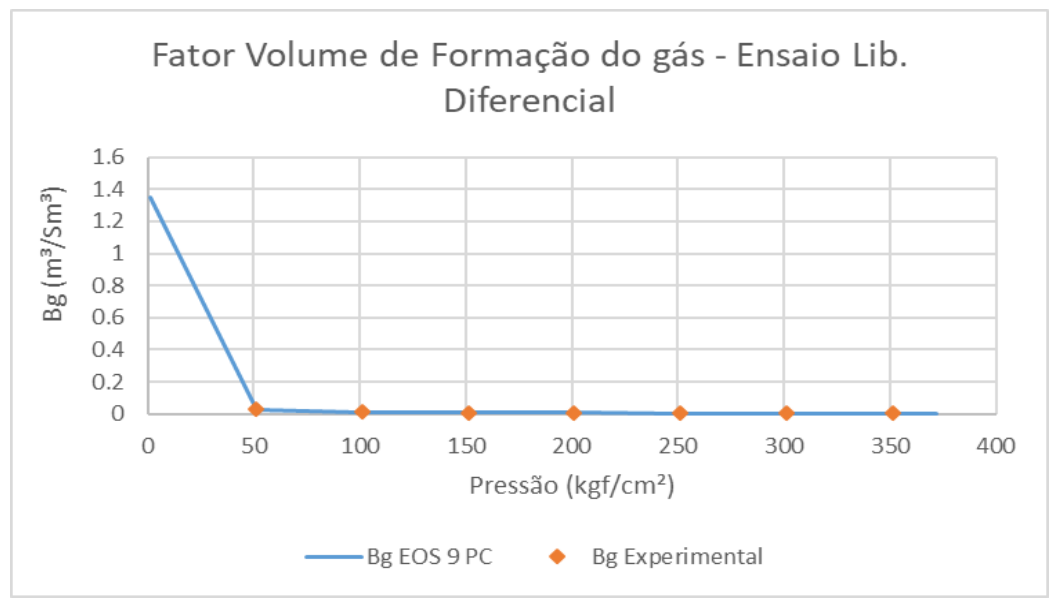

Figura A.27: $B_{g}$ da liberação diferencial abaixo da pressão de saturação. 


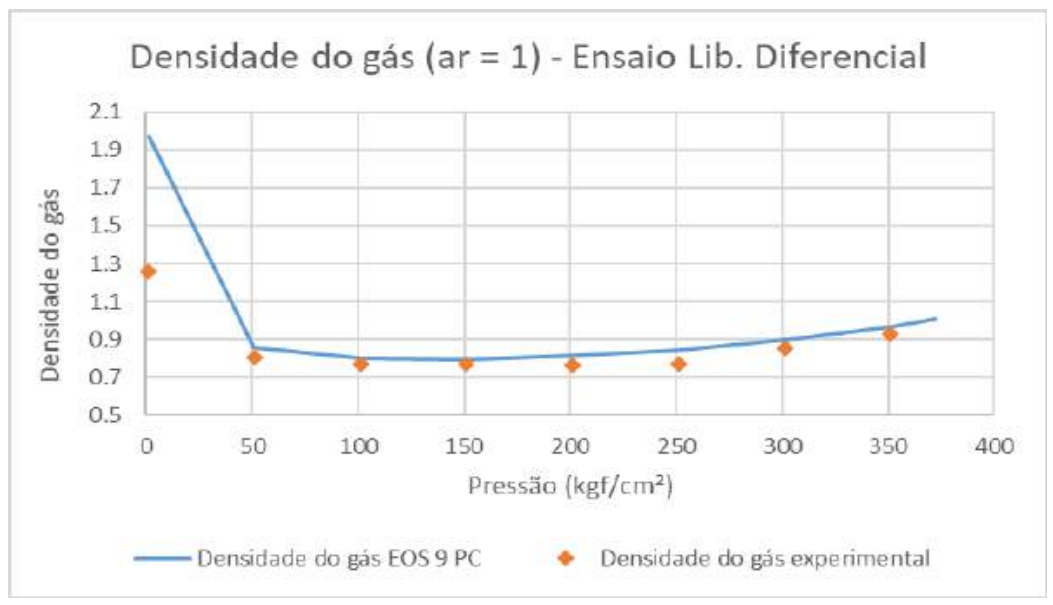

Figura A.28: Densidade do gás abaixo da pressão de saturação.

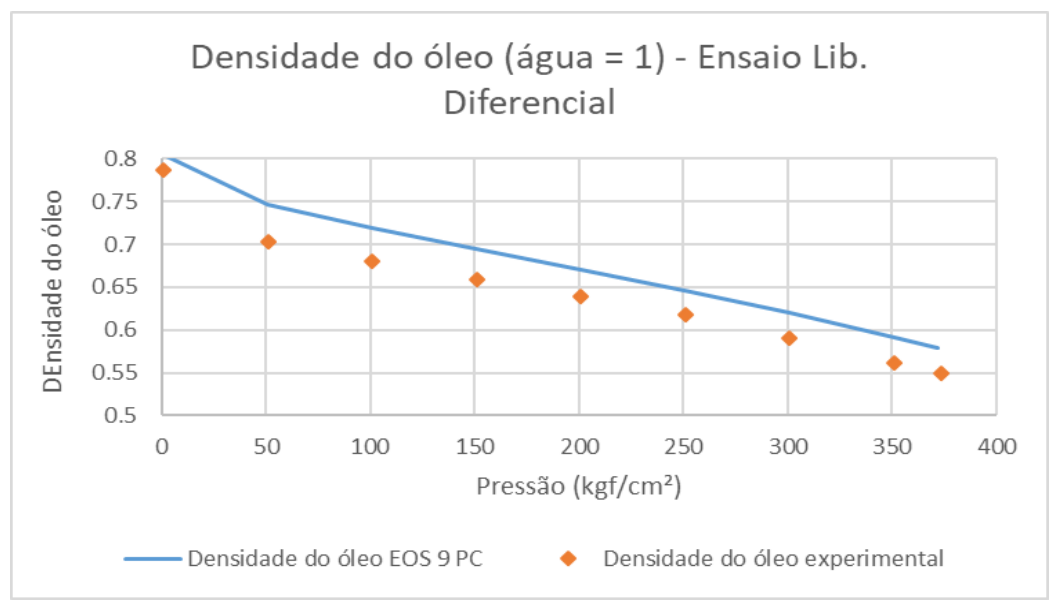

Figura A.29: Densidade do óleo abaixo da pressão de saturação.

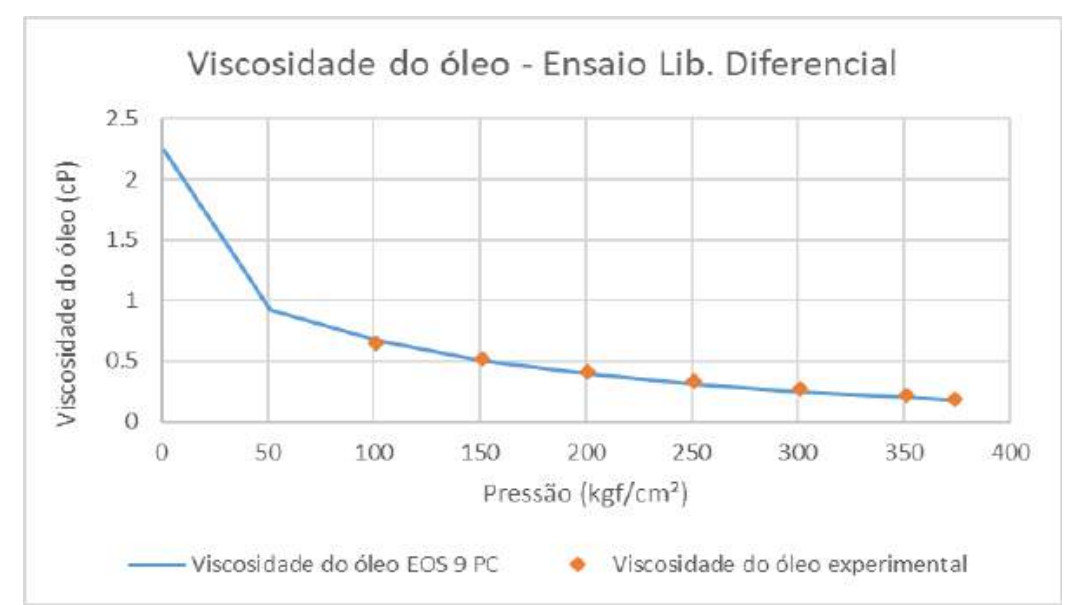

Figura A.30: Viscosidade do óleo abaixo da pressão de saturação. 


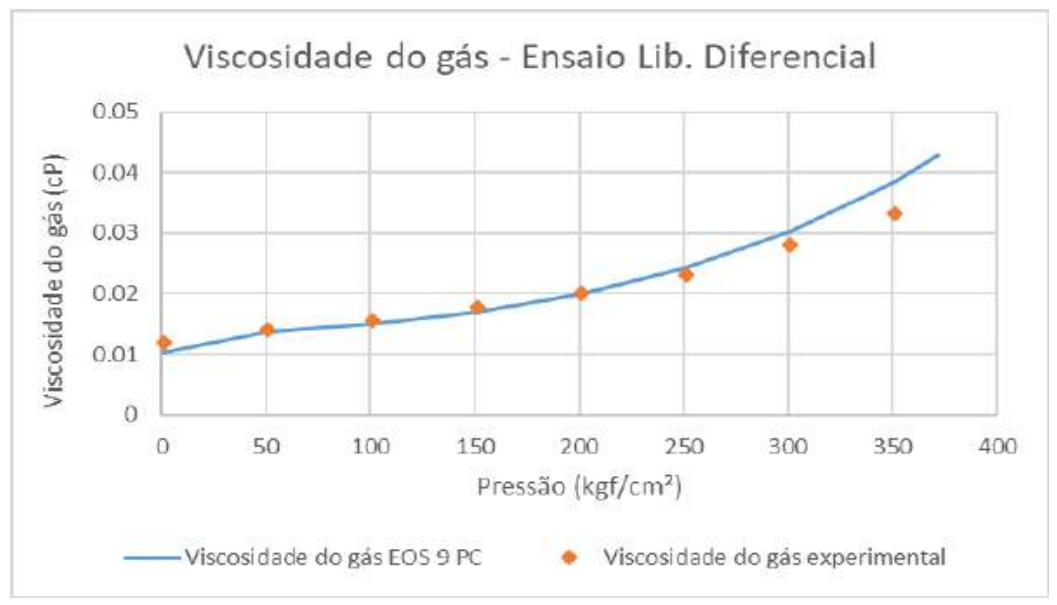

Figura A.31: Viscosidade do gás abaixo da pressão de saturação.

\section{A.2.2}

Ensaios de expansão a composição constante $\mathrm{T}=122^{\circ} \mathrm{C}, 75^{\circ} \mathrm{C}$ e $30^{\circ} \mathrm{C}$

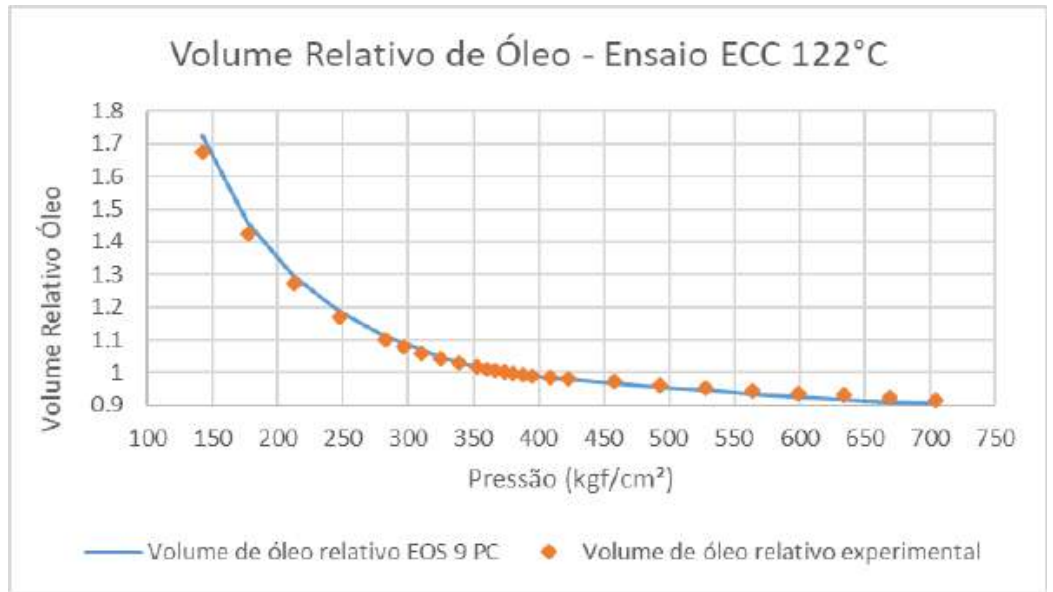

Figura A.32: Volume relativo de óleo, ECC a $122{ }^{\circ} \mathrm{C}$. 


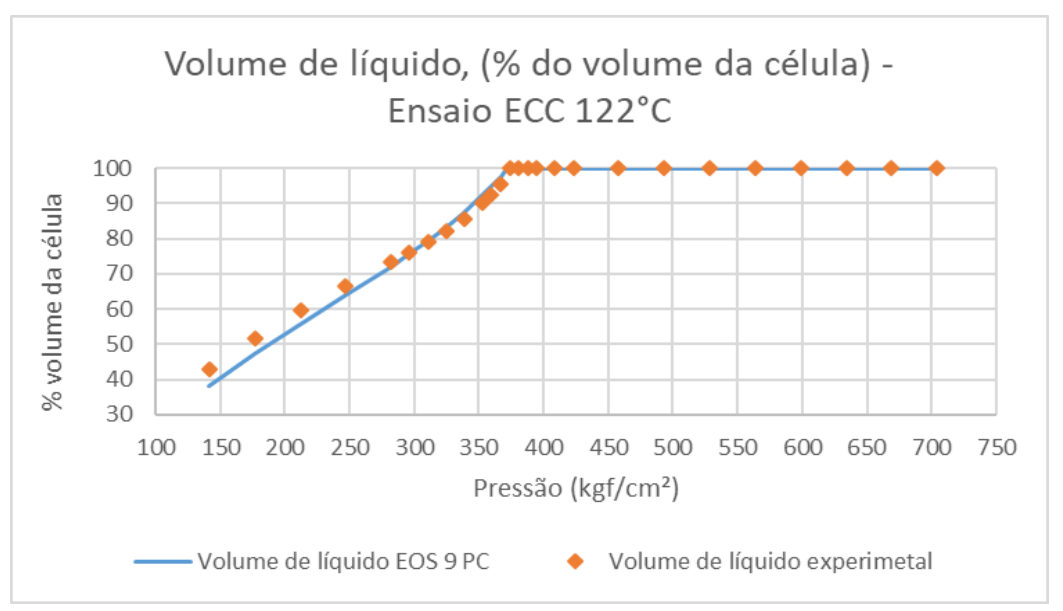

Figura A.33: Volume de líquido, $\%$ do volume da célula, ECC a $122{ }^{\circ} \mathrm{C}$.

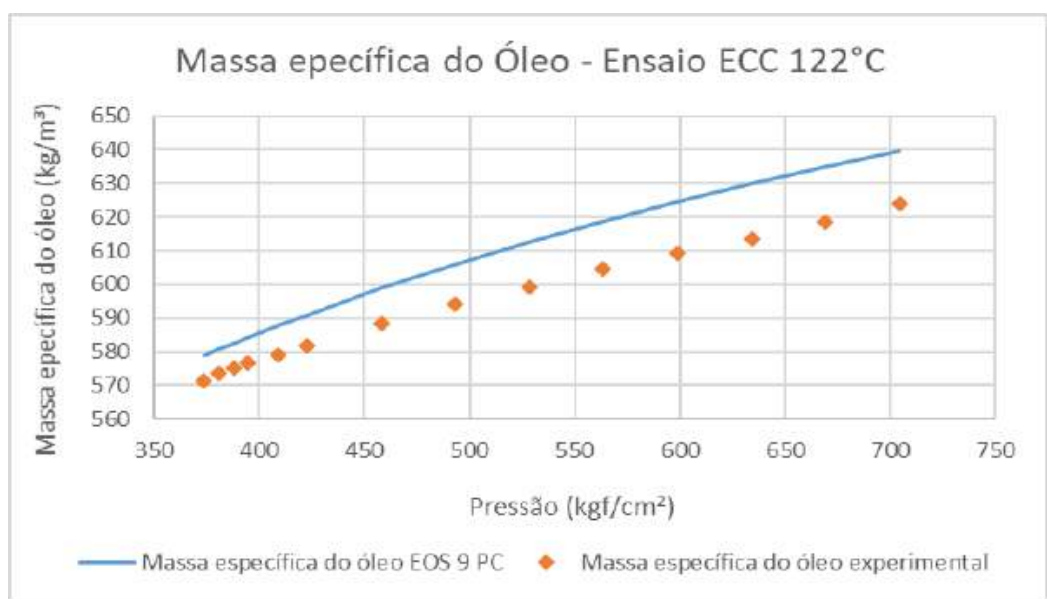

Figura A.34: Massa específica de óleo, ECC a $122{ }^{\circ} \mathrm{C}$.

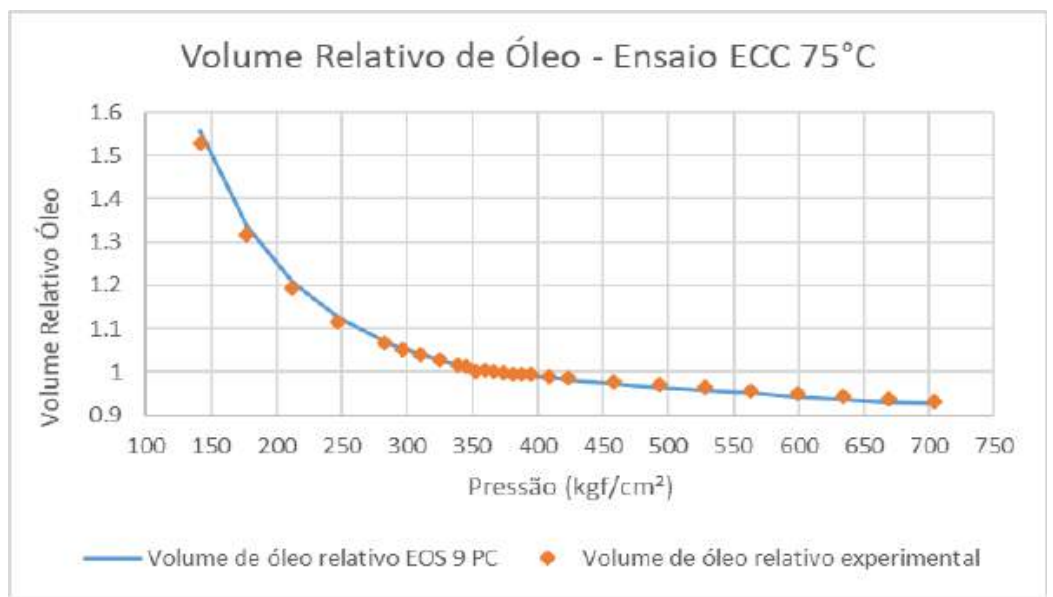

Figura A.35: Volume relativo de óleo, ECC a $75^{\circ} \mathrm{C}$. 


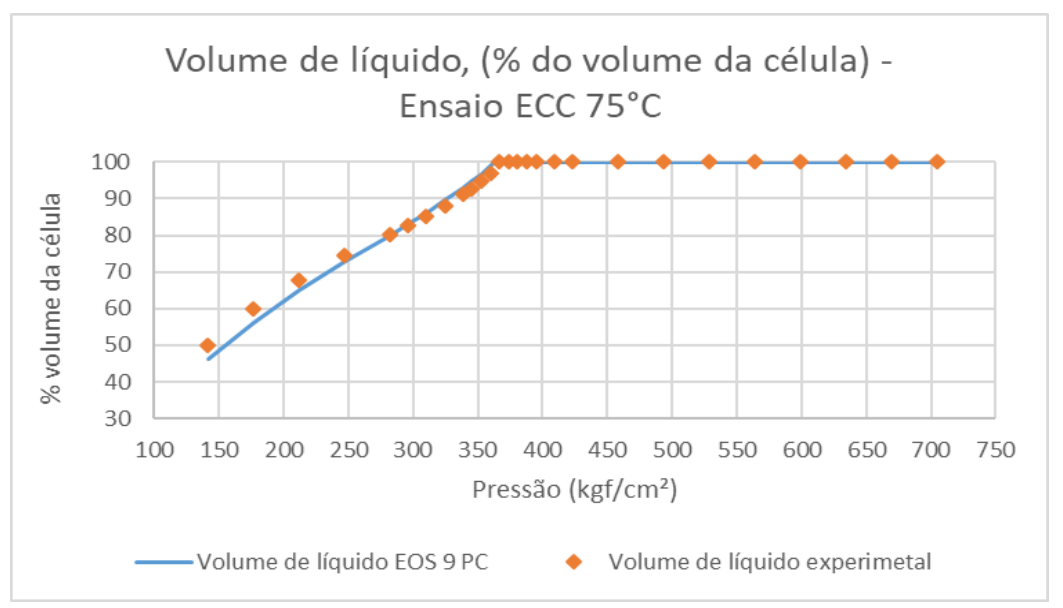

Figura A.36: Volume de líquido, \% do volume da célula, ECC a $75{ }^{\circ} \mathrm{C}$.

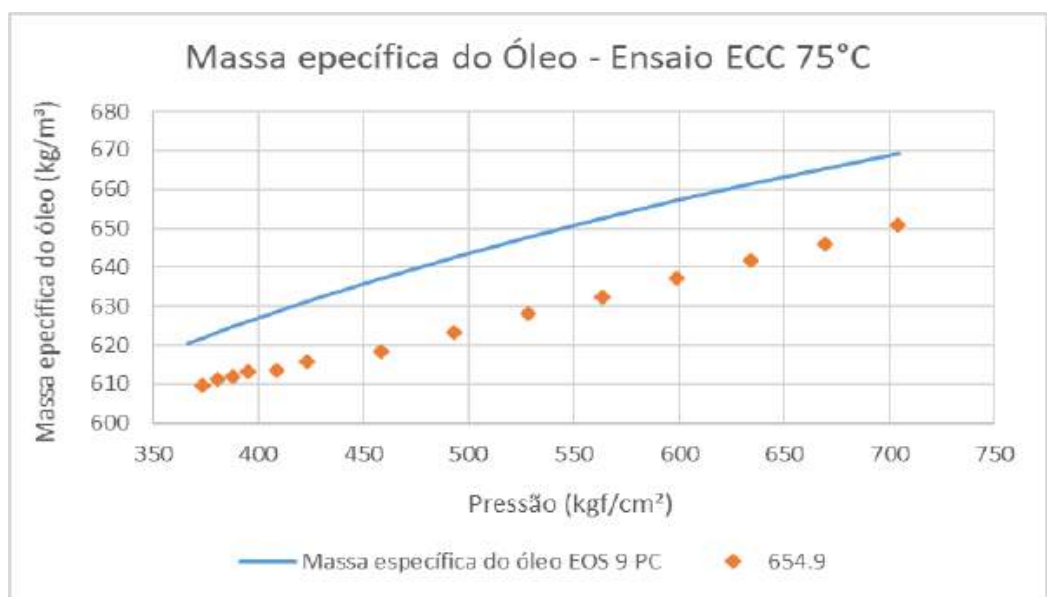

Figura A.37: Massa específica de óleo, ECC a $75^{\circ} \mathrm{C}$.

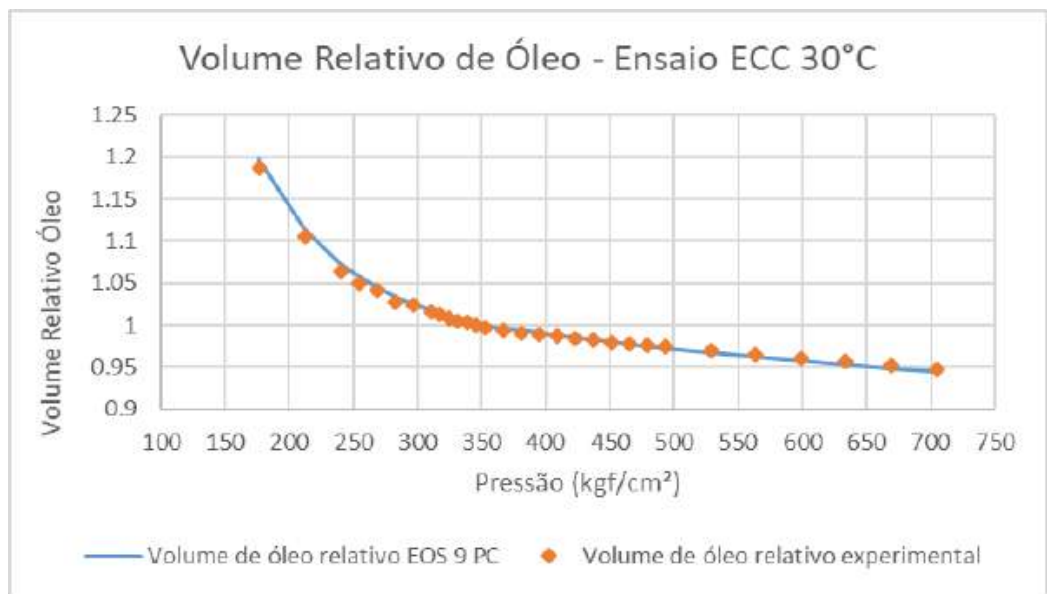

Figura A.38: Volume relativo de óleo, ECC a $30{ }^{\circ} \mathrm{C}$. 


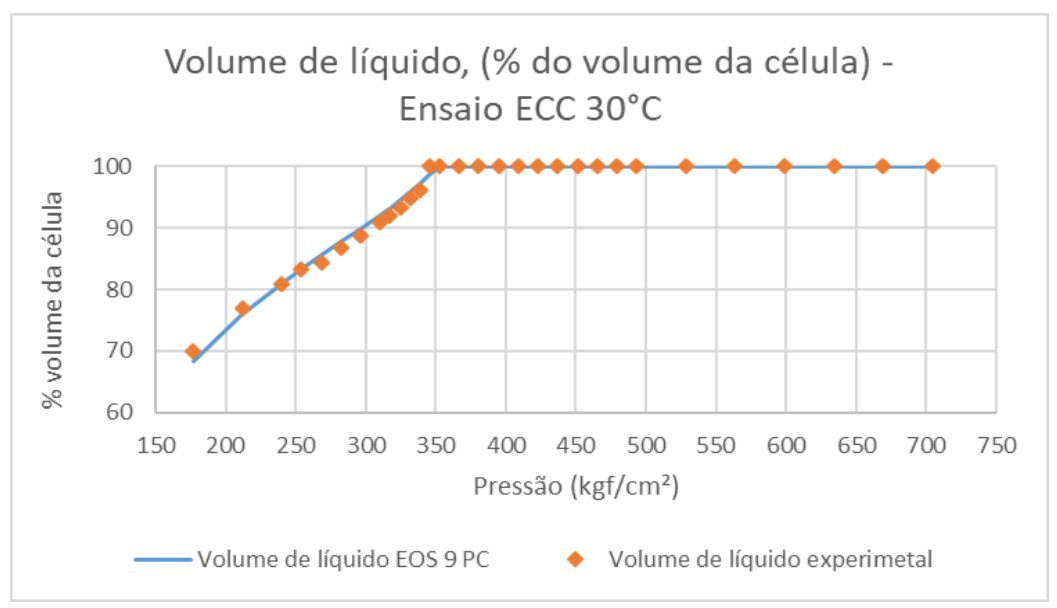

Figura A.39: Volume de líquido, $\%$ do volume da célula, ECC a $30{ }^{\circ} \mathrm{C}$.

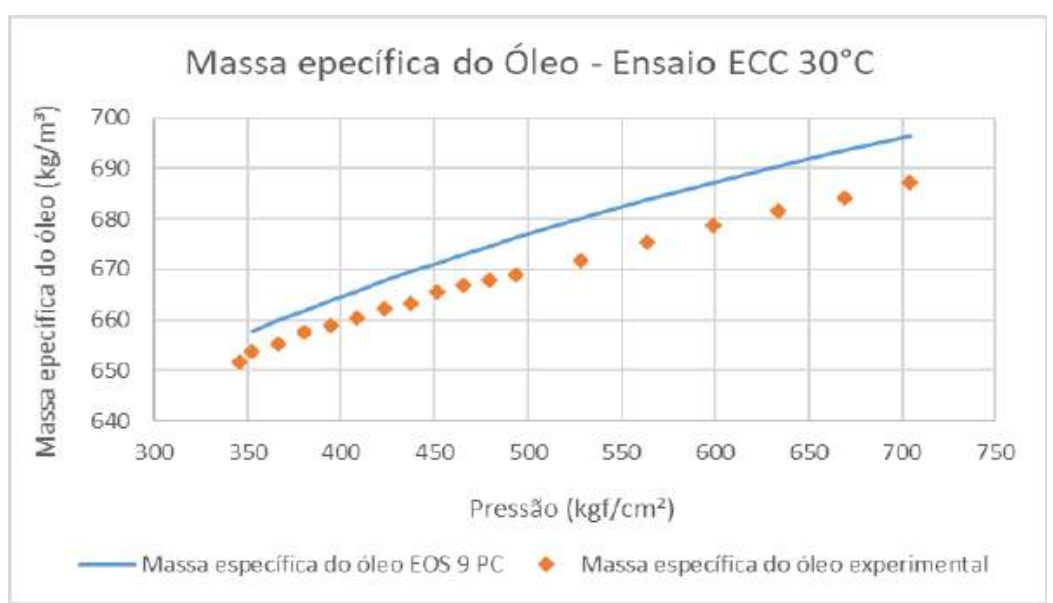

Figura A.40: Massa específica de óleo, ECC a $30{ }^{\circ} \mathrm{C}$. 


\section{A.2.3}

\section{Ensaio de expansão a volume constante}

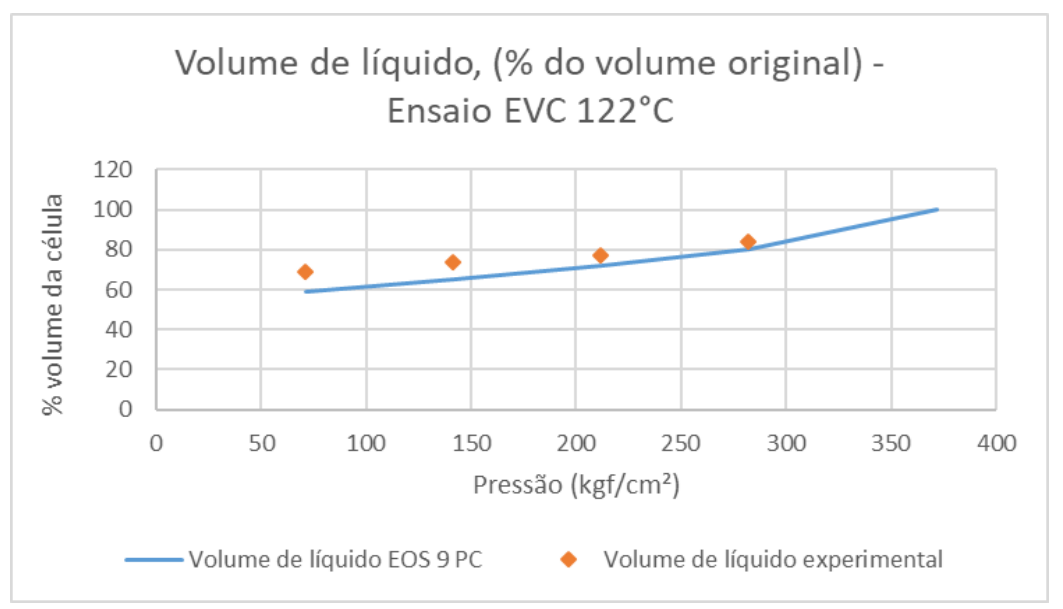

Figura A.41: Volume de líquido, \% do volume original, EVC a $122{ }^{\circ} \mathrm{C}$.

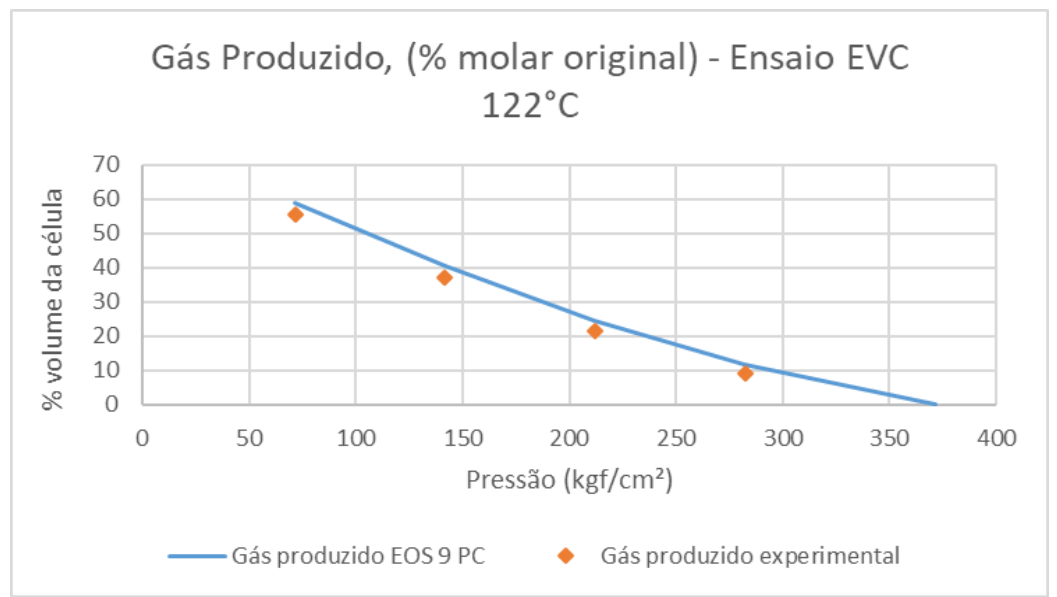

Figura A.42: Gás produzido, \% molar original, EVC a $122{ }^{\circ} \mathrm{C}$.

\section{A.3}

Regressão da EOS com 7 PC 


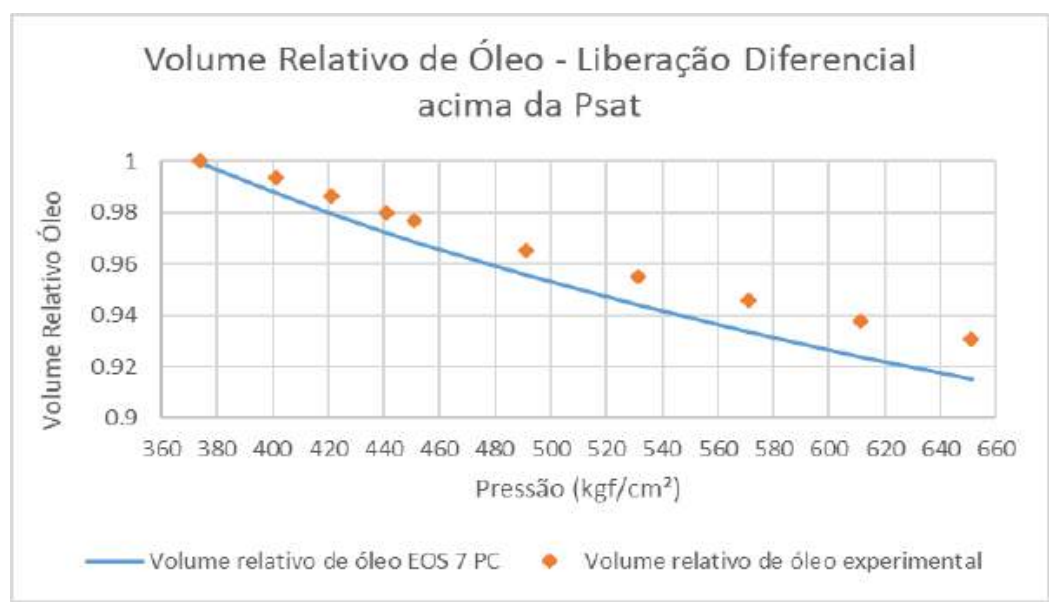

Figura A.43: Volume relativo de óleo da liberação diferencial acima da pressão de saturação.

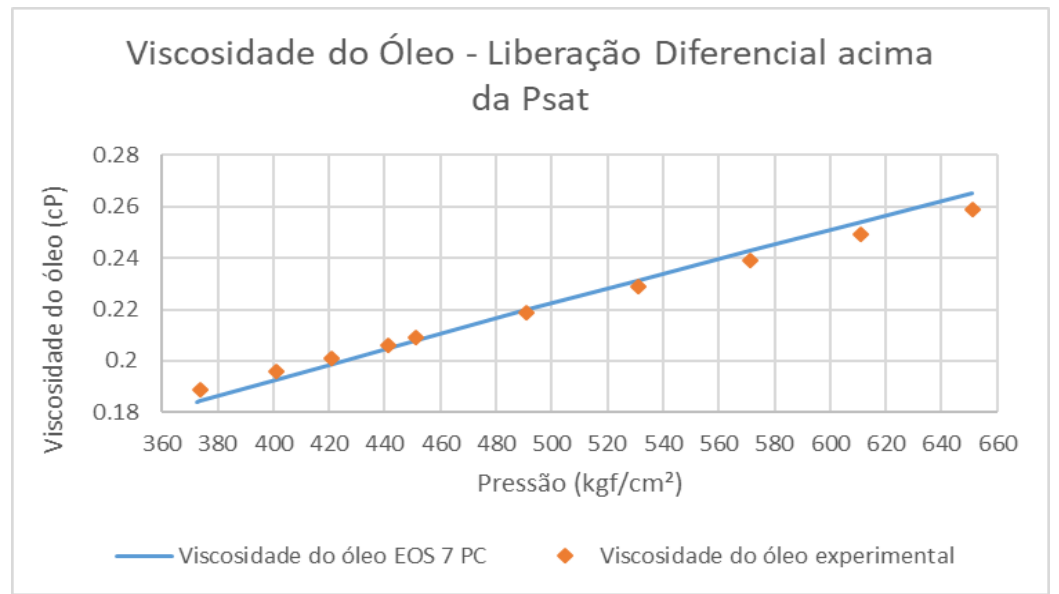

Figura A.44: Viscosidade do óleo da liberação diferencial acima da pressão de saturação.

\section{A.3.1}

\section{Ensaio de liberação diferencial}

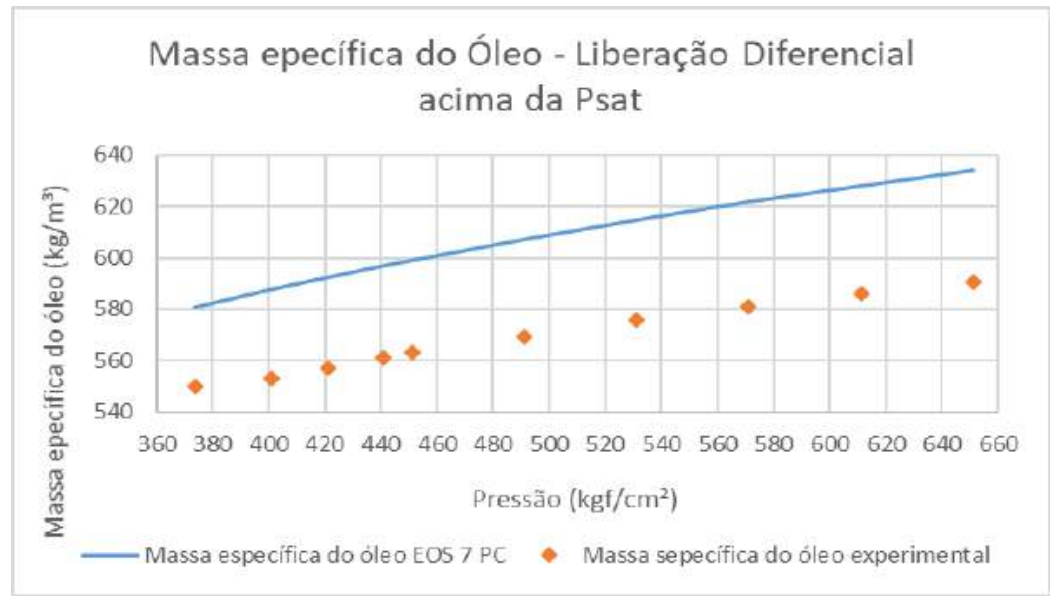

Figura A.45: Massa específica do óleo da liberação diferencial acima da pressão de saturação. 


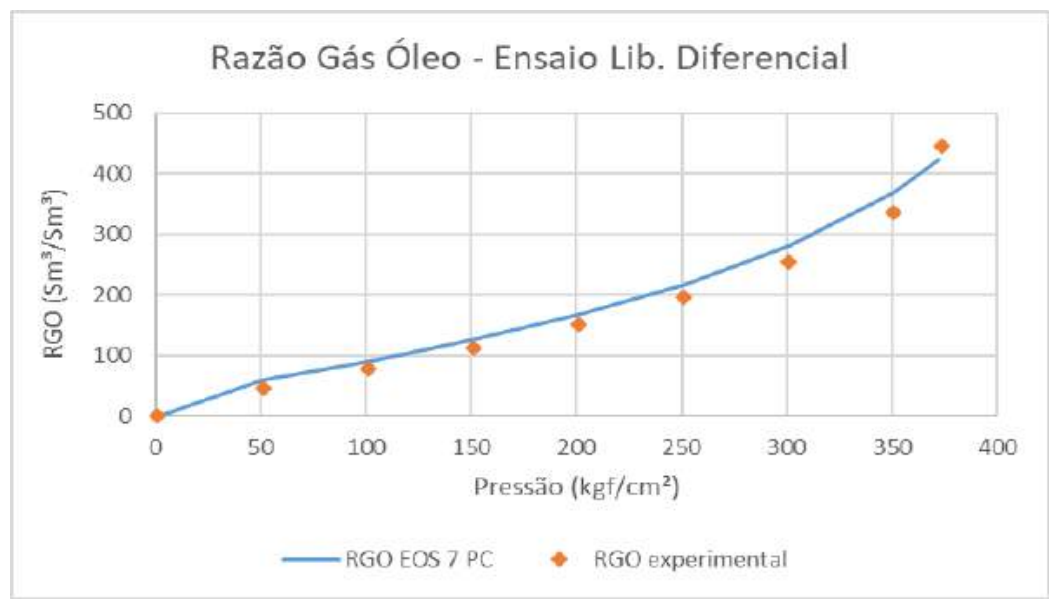

Figura A.46: RGO da liberação diferencial abaixo da pressão de saturação.

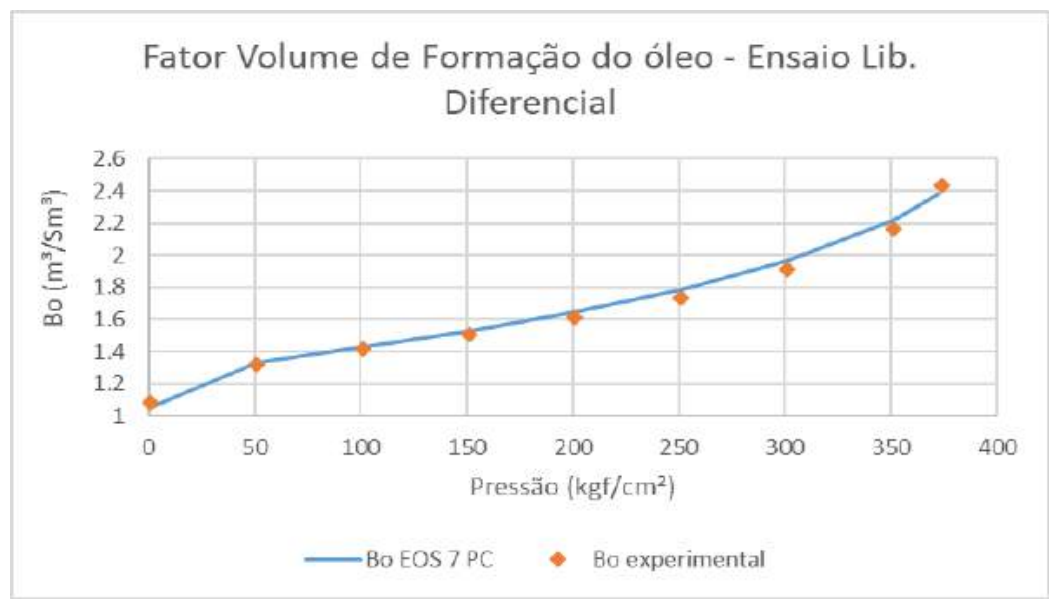

Figura A.47: $B_{o}$ da liberação diferencial abaixo da pressão de saturação.

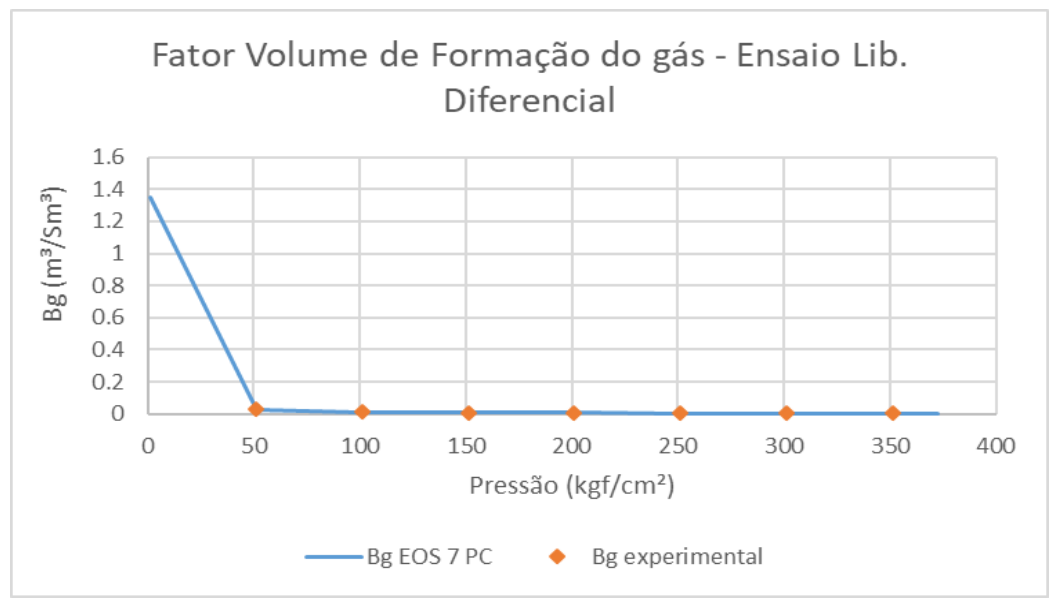

Figura A.48: $B_{g}$ da liberação diferencial abaixo da pressão de saturação. 


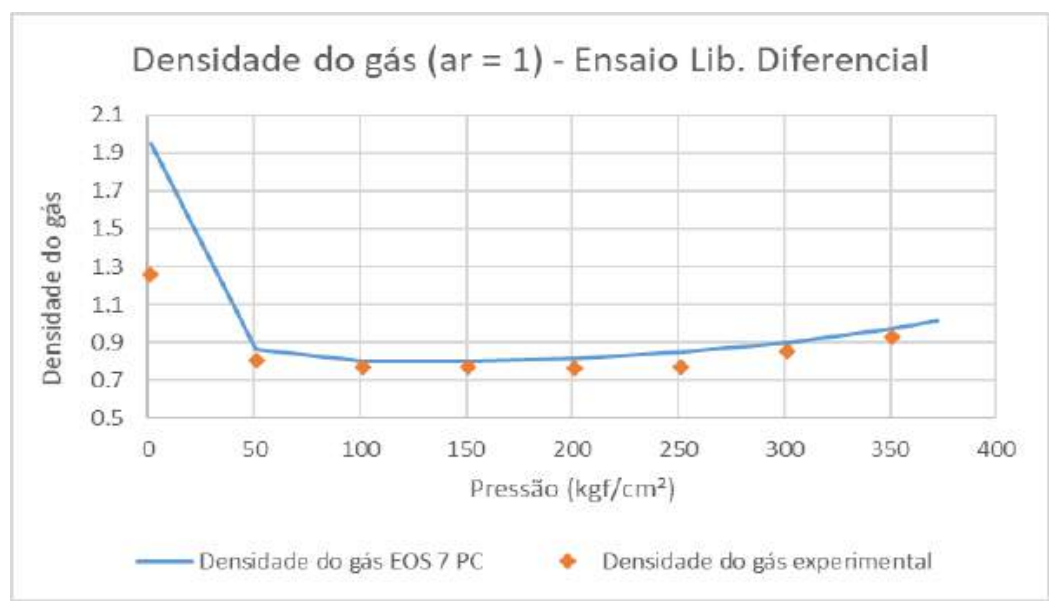

Figura A.49: Densidade do gás abaixo da pressão de saturação.

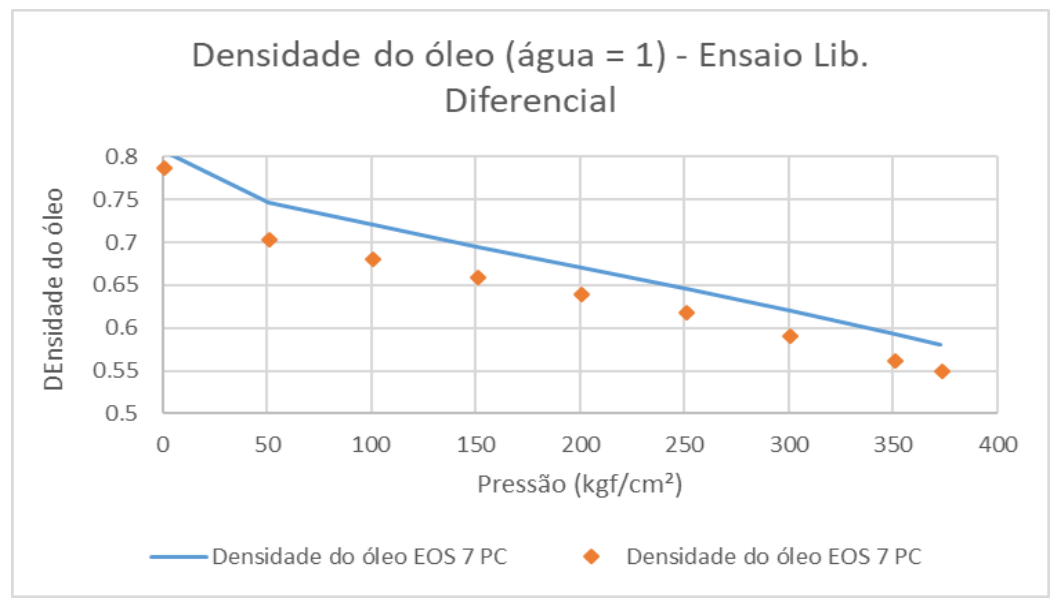

Figura A.50: Densidade do óleo abaixo da pressão de saturação.

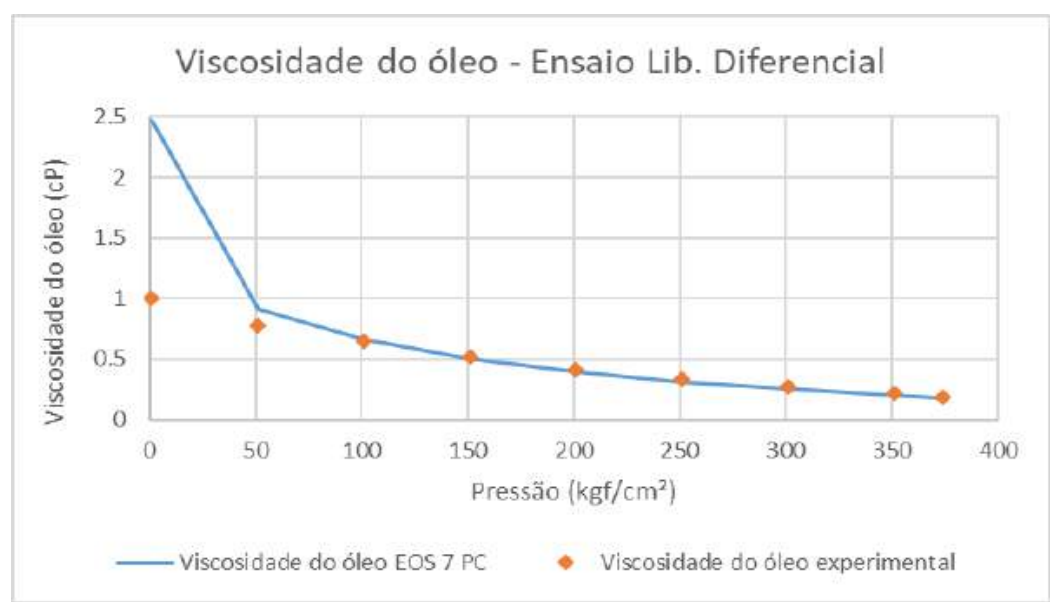

Figura A.51: Viscosidade do óleo abaixo da pressão de saturação. 


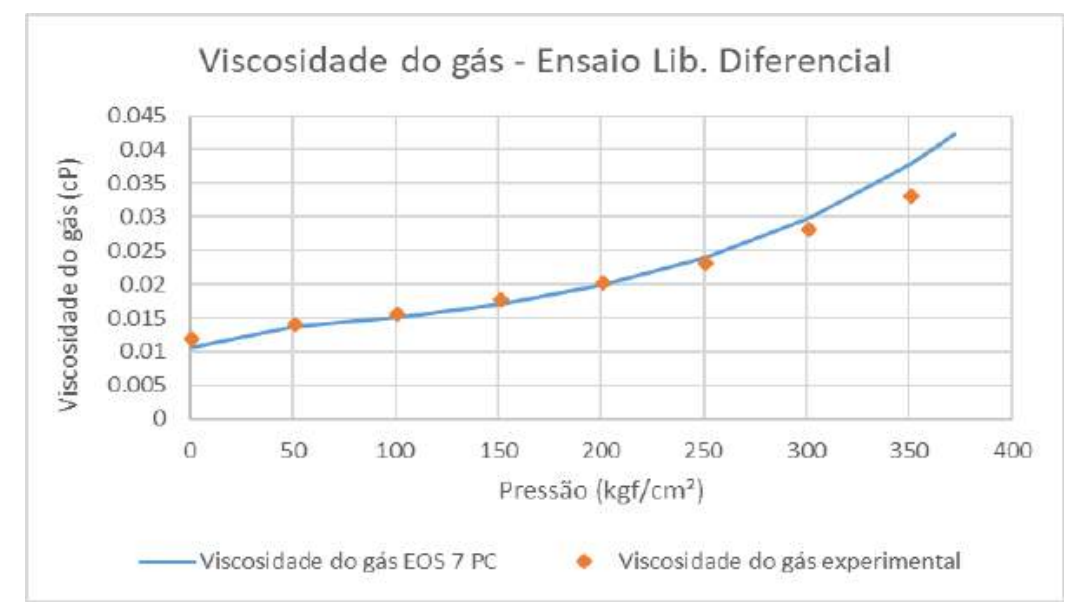

Figura A.52: Viscosidade do gás abaixo da pressão de saturação.

\section{A.3.2}

Ensaios de expansão a composição constante $\mathrm{T}=122^{\circ} \mathrm{C}, 75^{\circ} \mathrm{C}$ e $30^{\circ} \mathrm{C}$

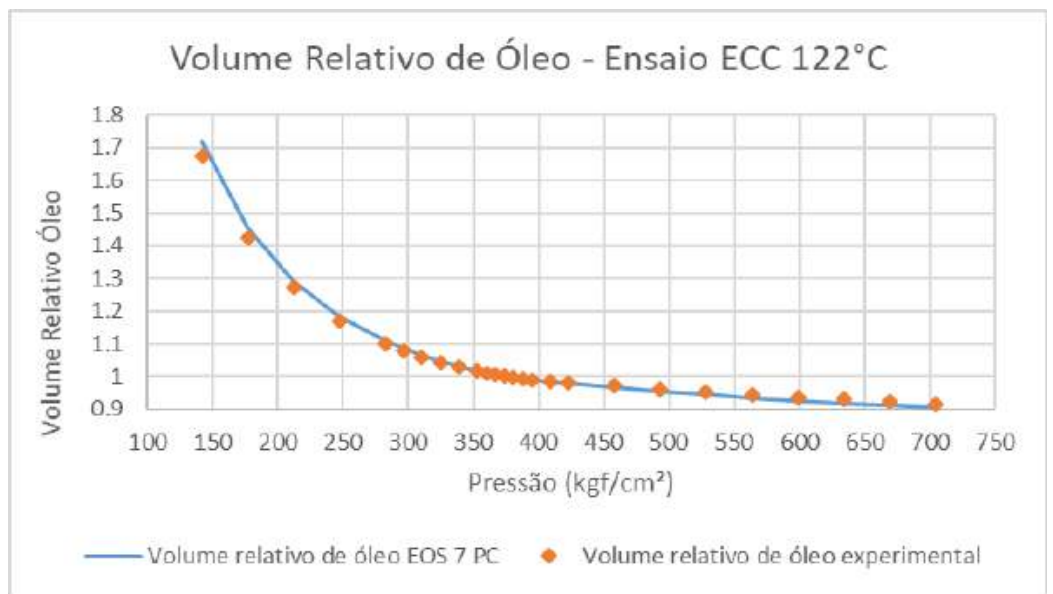

Figura A.53: Volume relativo de óleo, ECC a $122{ }^{\circ} \mathrm{C}$. 


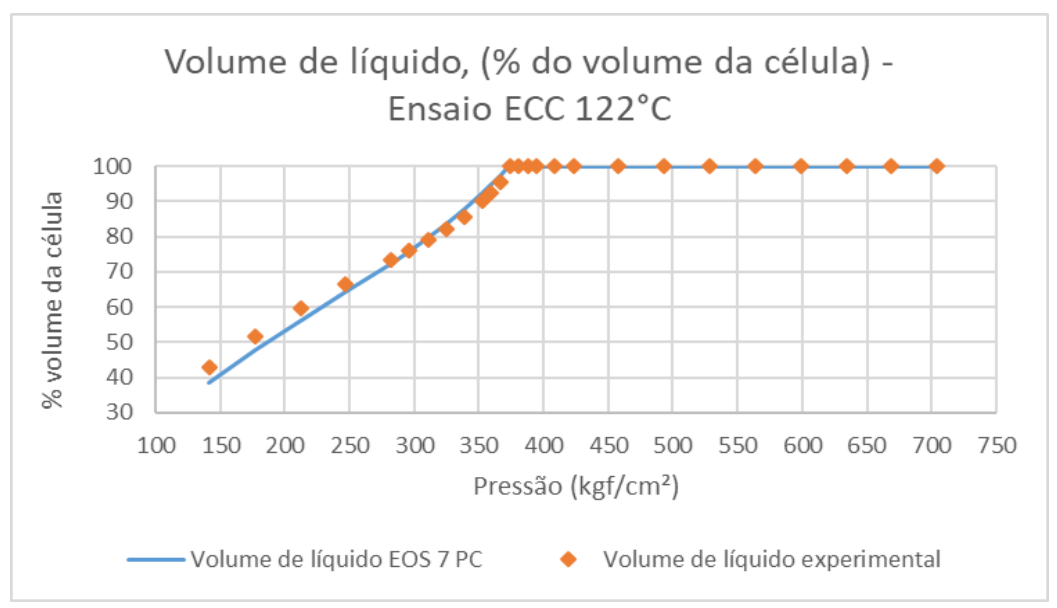

Figura A.54: Volume de líquido, $\%$ do volume da célula, ECC a $122{ }^{\circ} \mathrm{C}$.

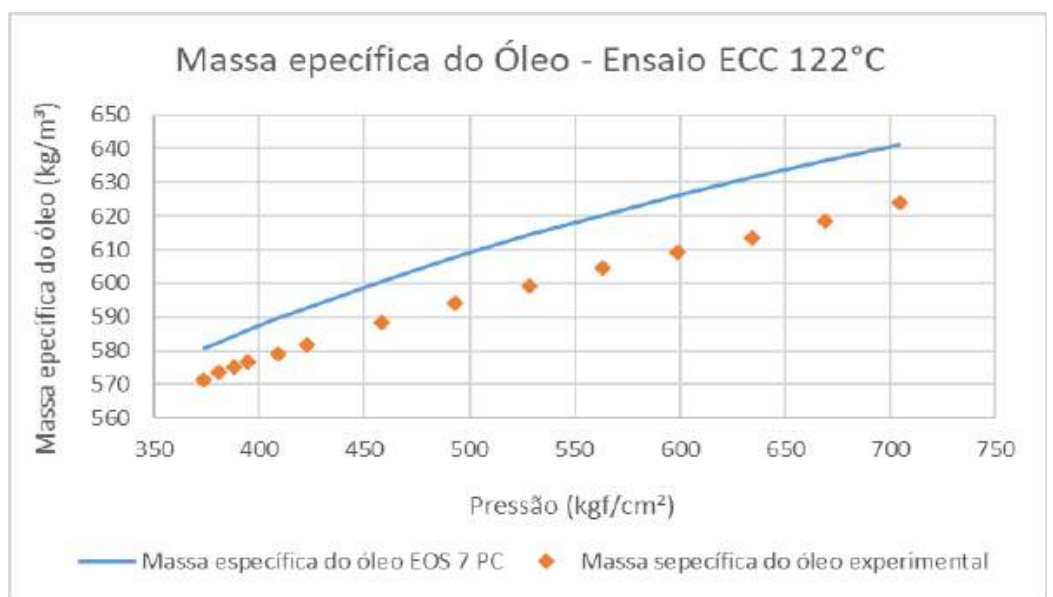

Figura A.55: Massa específica de óleo, ECC a $122{ }^{\circ} \mathrm{C}$.

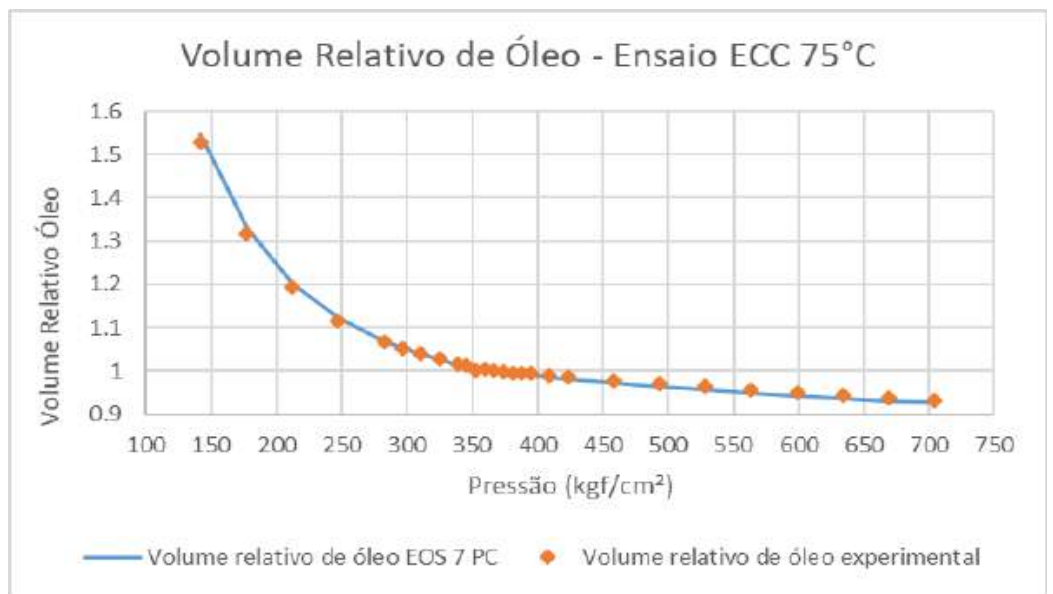

Figura A.56: Volume relativo de óleo, ECC a $75{ }^{\circ} \mathrm{C}$. 


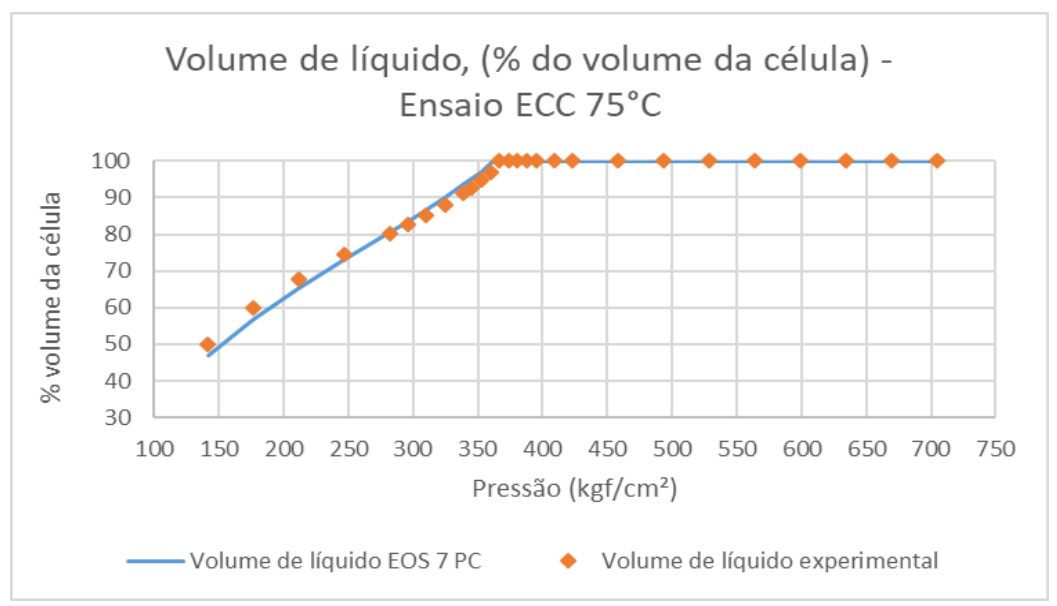

Figura A.57: Volume de líquido, $\%$ do volume da célula, ECC a $75{ }^{\circ} \mathrm{C}$.

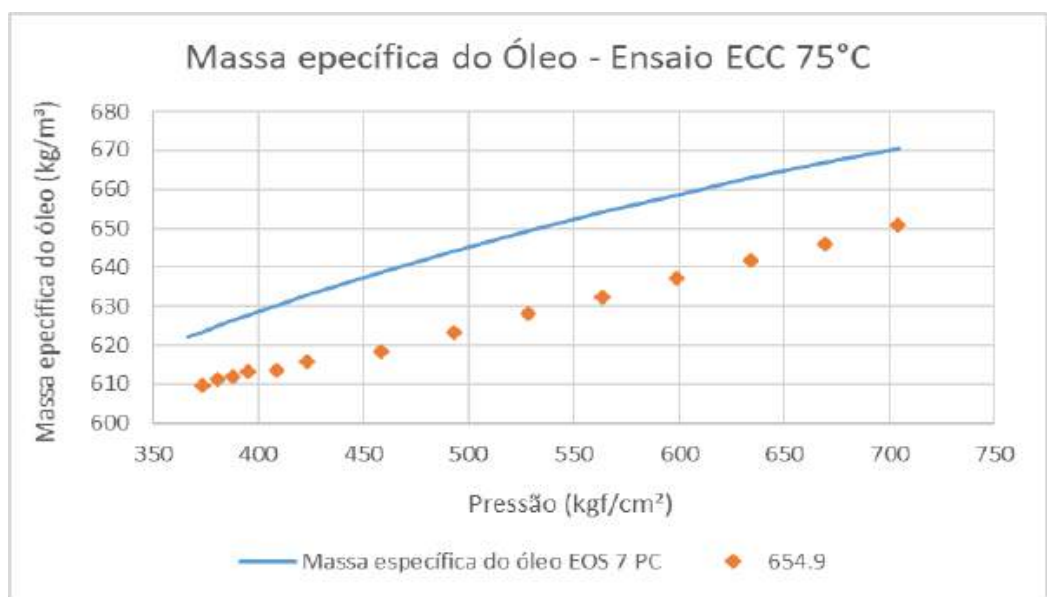

Figura A.58: Massa específica de óleo, ECC a $75^{\circ} \mathrm{C}$.

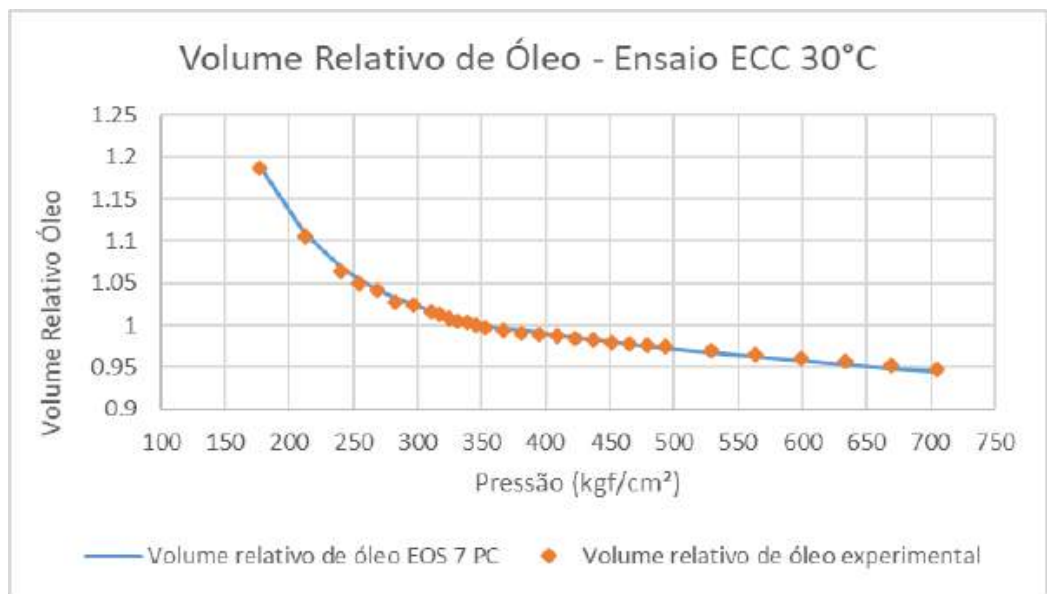

Figura A.59: Volume relativo de óleo, ECC a $30{ }^{\circ} \mathrm{C}$. 


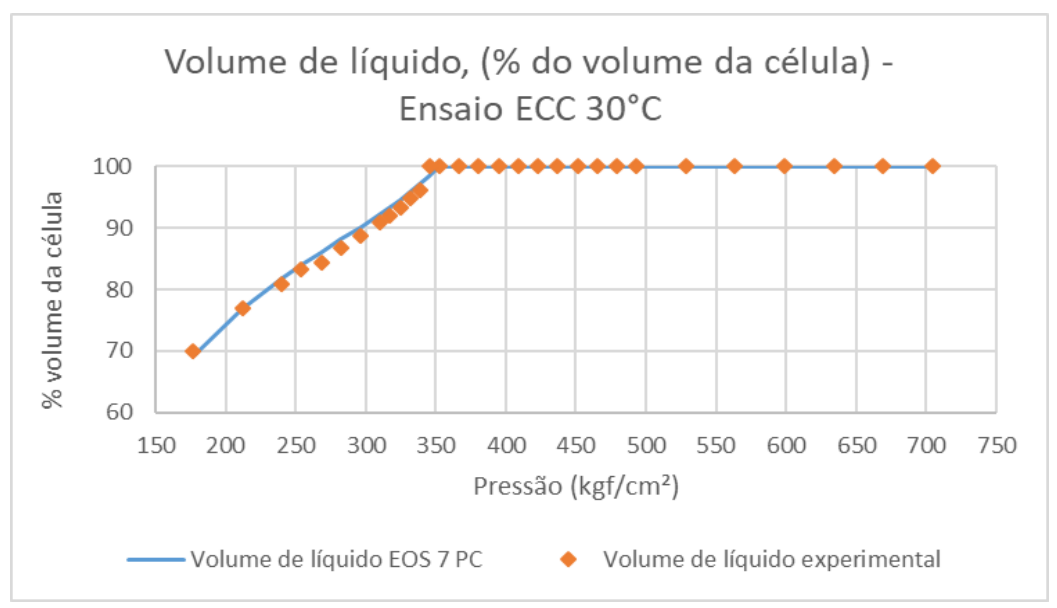

Figura A.60: Volume de líquido, $\%$ do volume da célula, ECC a $30{ }^{\circ} \mathrm{C}$.

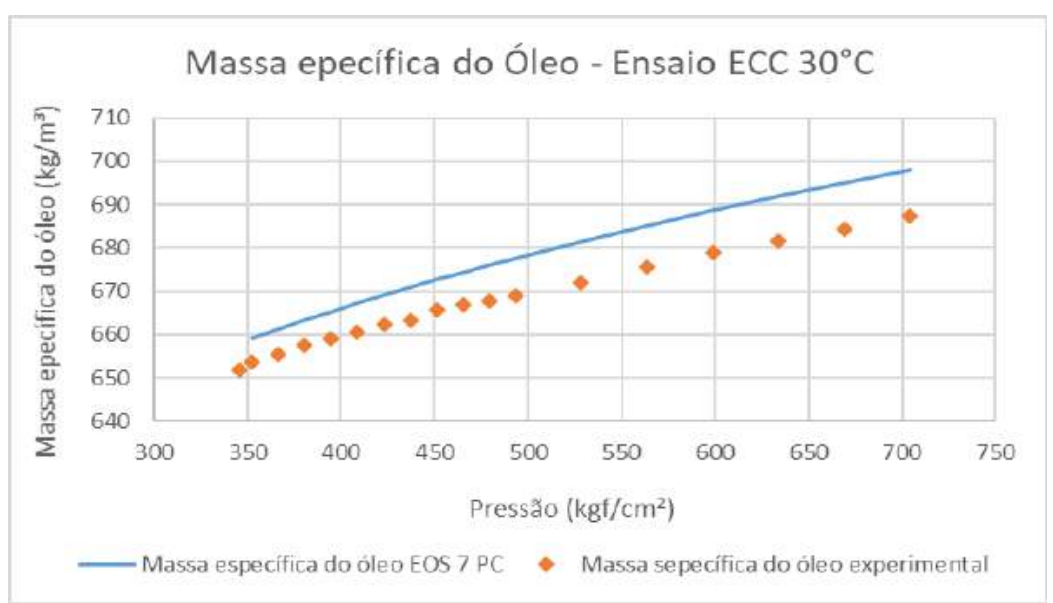

Figura A.61: Massa específica de óleo, ECC a $30{ }^{\circ} \mathrm{C}$. 


\section{A.3.3}

\section{Ensaio de expansão a volume constante}

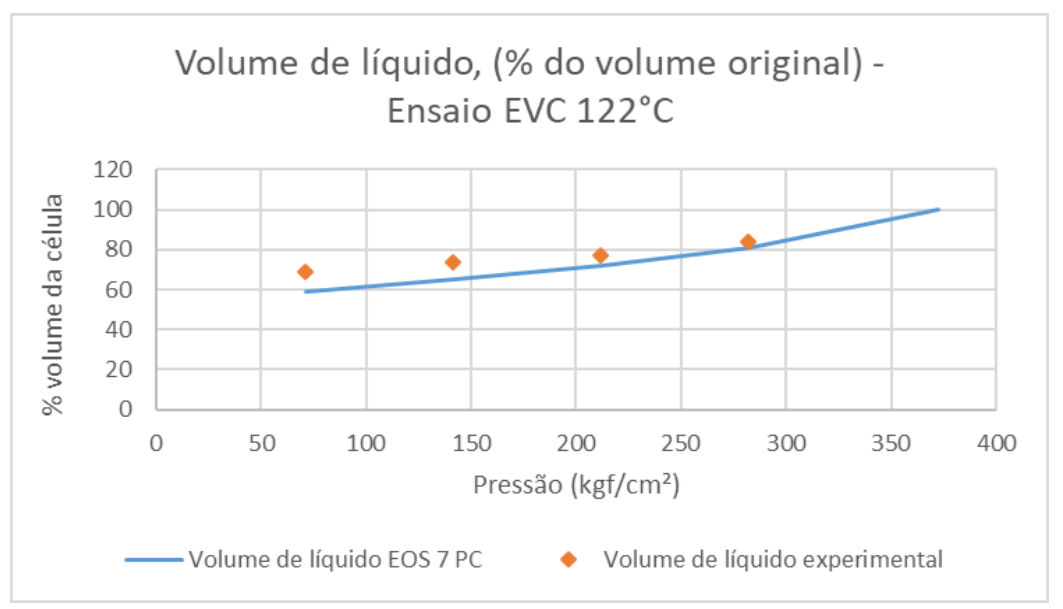

Figura A.62: Volume de líquido, \% do volume original, EVC a $122{ }^{\circ} \mathrm{C}$.

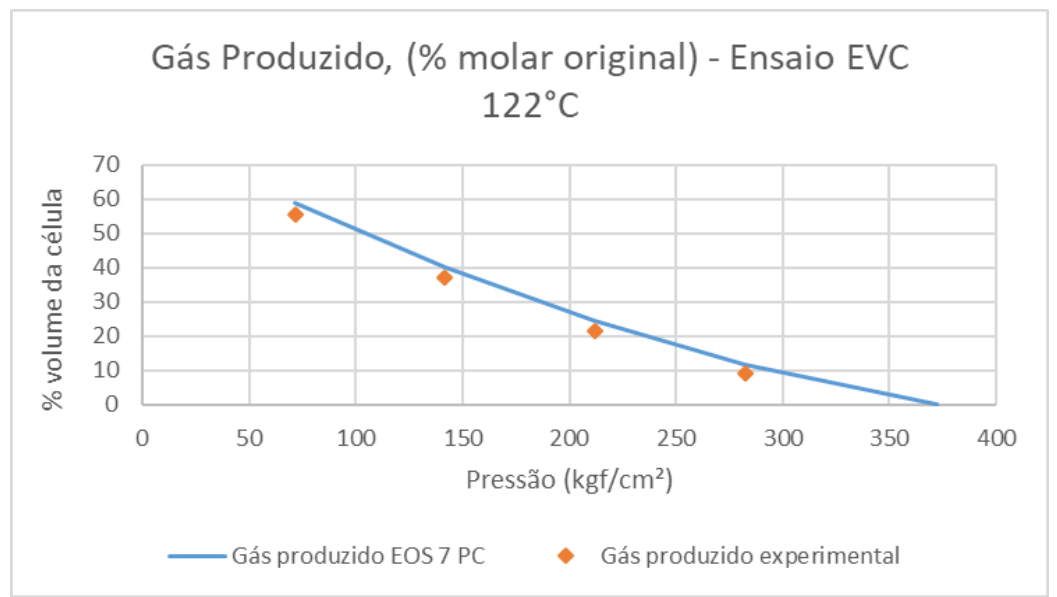

Figura A.63: Gás produzido, \% molar original, EVC a $122{ }^{\circ} \mathrm{C}$.

\section{A.4}

\section{Regressão da EOS com 6 PC}




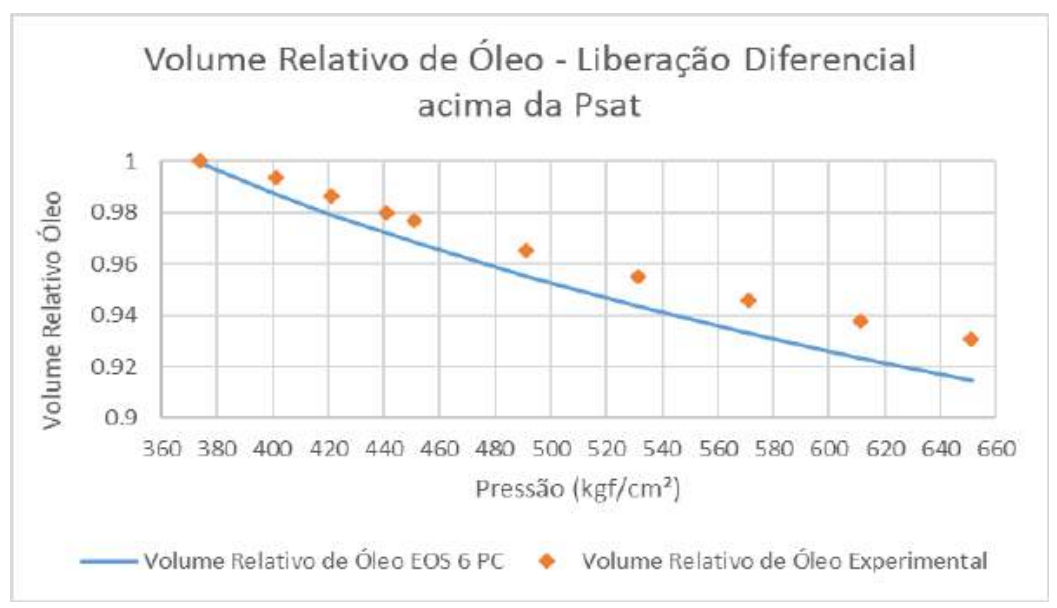

Figura A.64: Volume relativo de óleo da liberação diferencial acima da pressão de saturação.

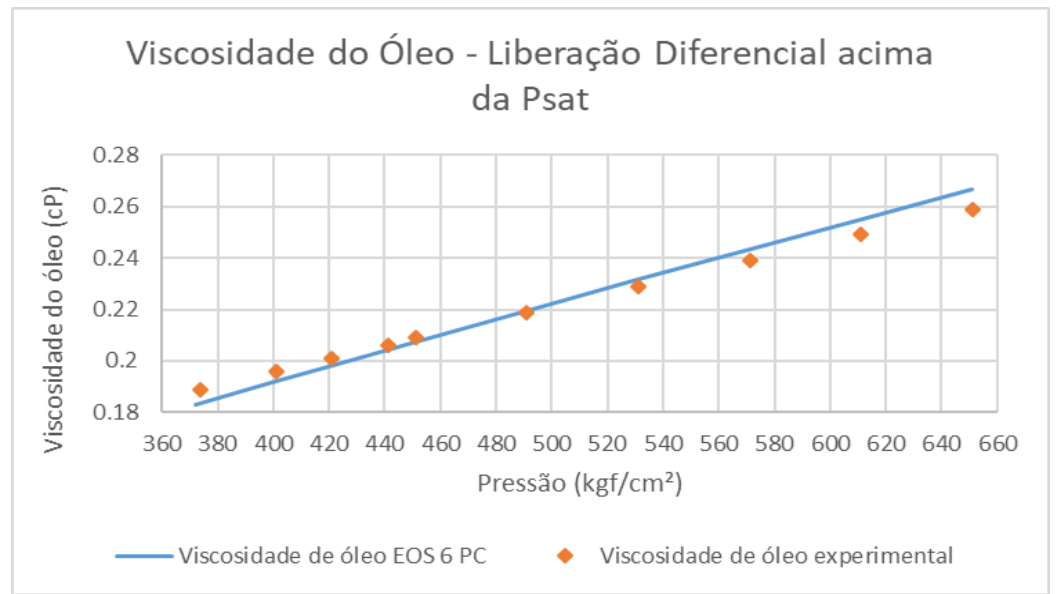

Figura A.65: Viscosidade do óleo da liberação diferencial acima da pressão de saturação.

\section{A.4.1}

\section{Ensaio de liberação diferencial}

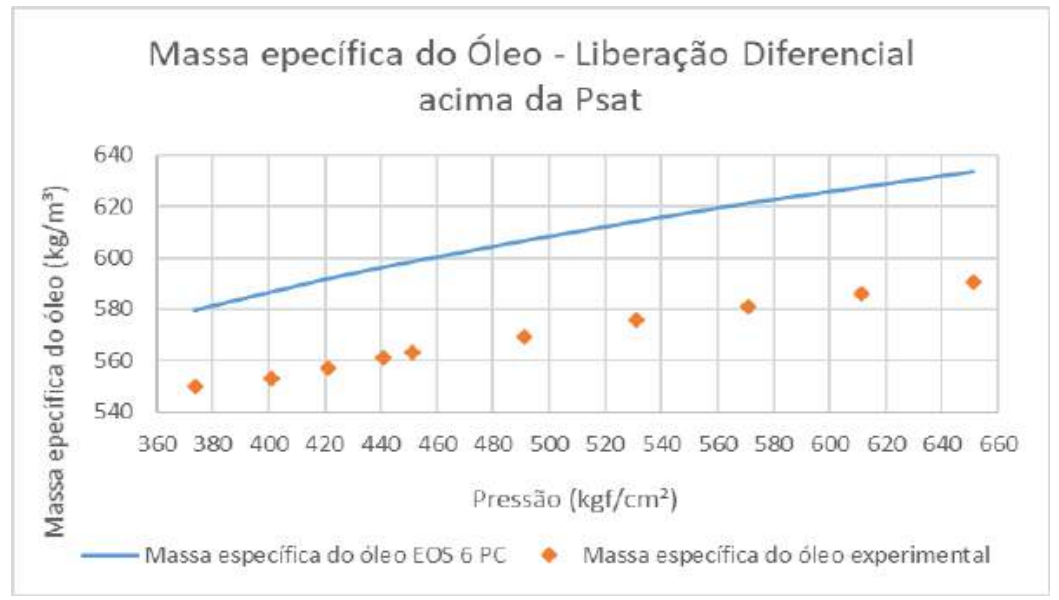

Figura A.66: Massa específica do óleo da liberação diferencial acima da pressão de saturação. 


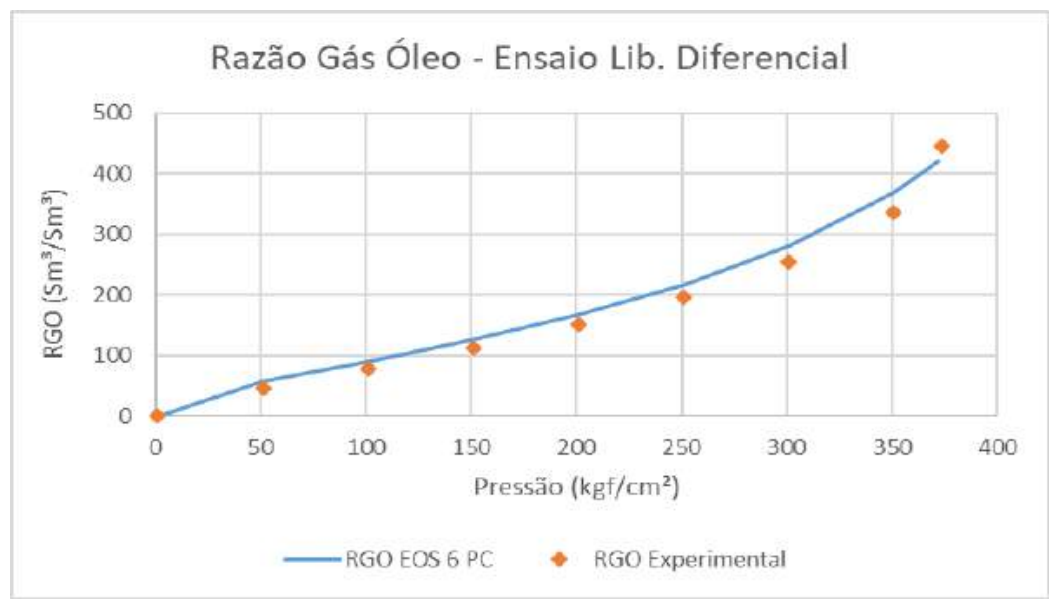

Figura A.67: RGO da liberação diferencial abaixo da pressão de saturação.

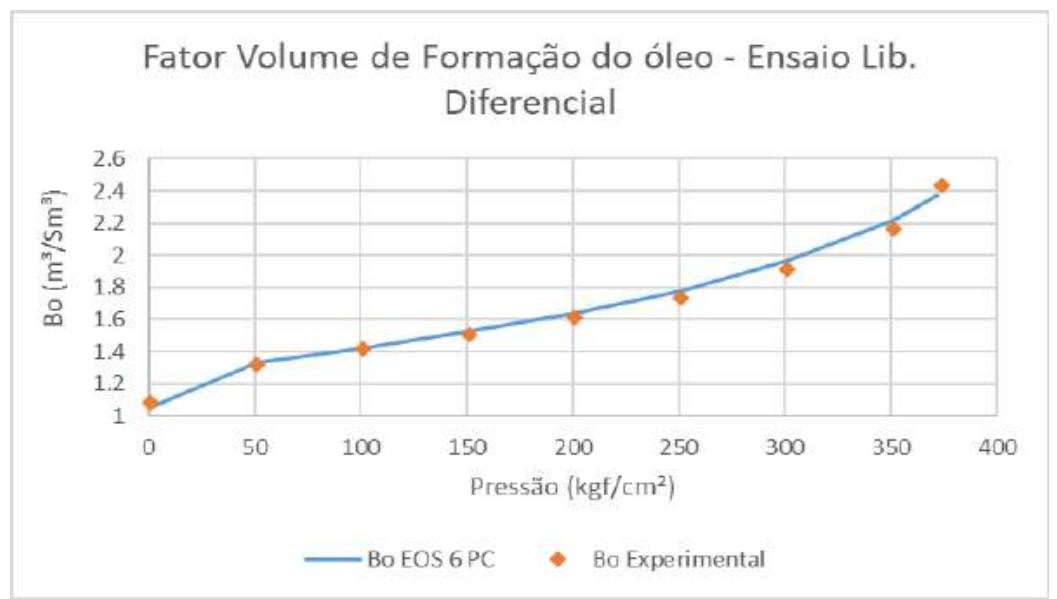

Figura A.68: $B_{o}$ da liberação diferencial abaixo da pressão de saturação.

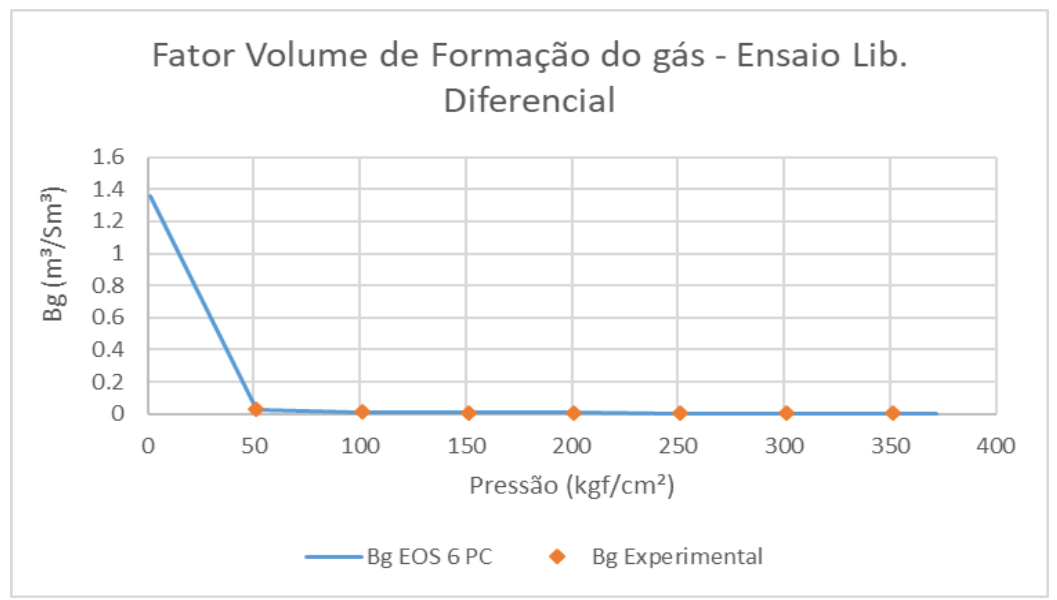

Figura A.69: $B_{g}$ da liberação diferencial abaixo da pressão de saturação. 


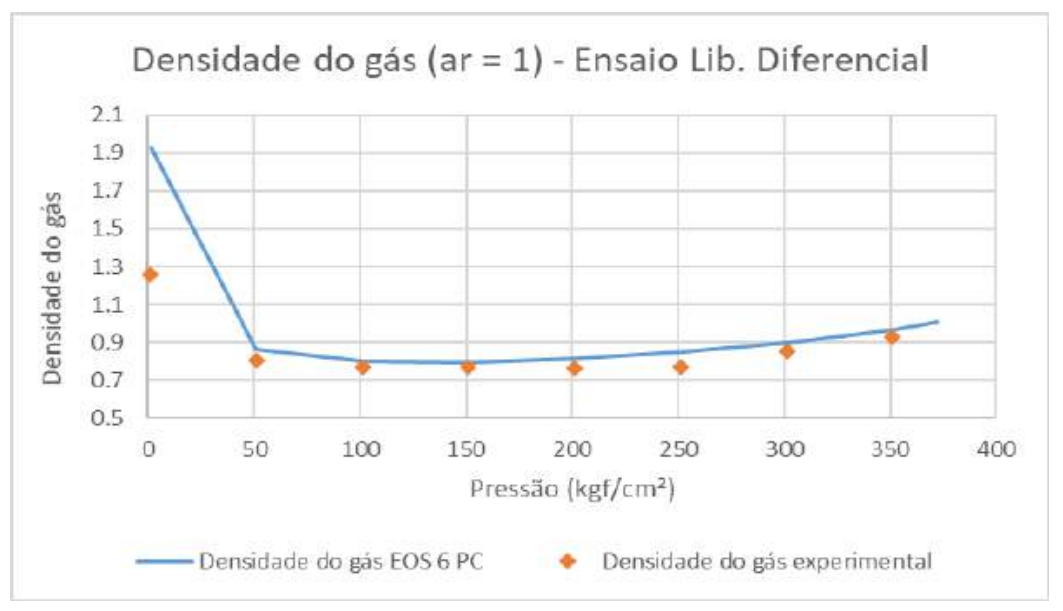

Figura A.70: Densidade do gás abaixo da pressão de saturação.

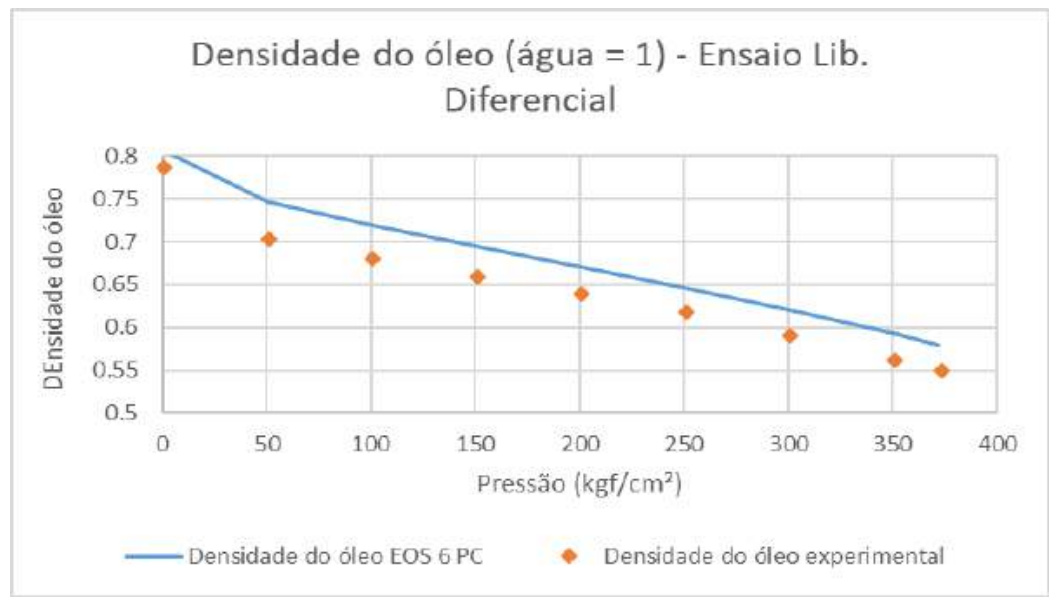

Figura A.71: Densidade do óleo abaixo da pressão de saturação.

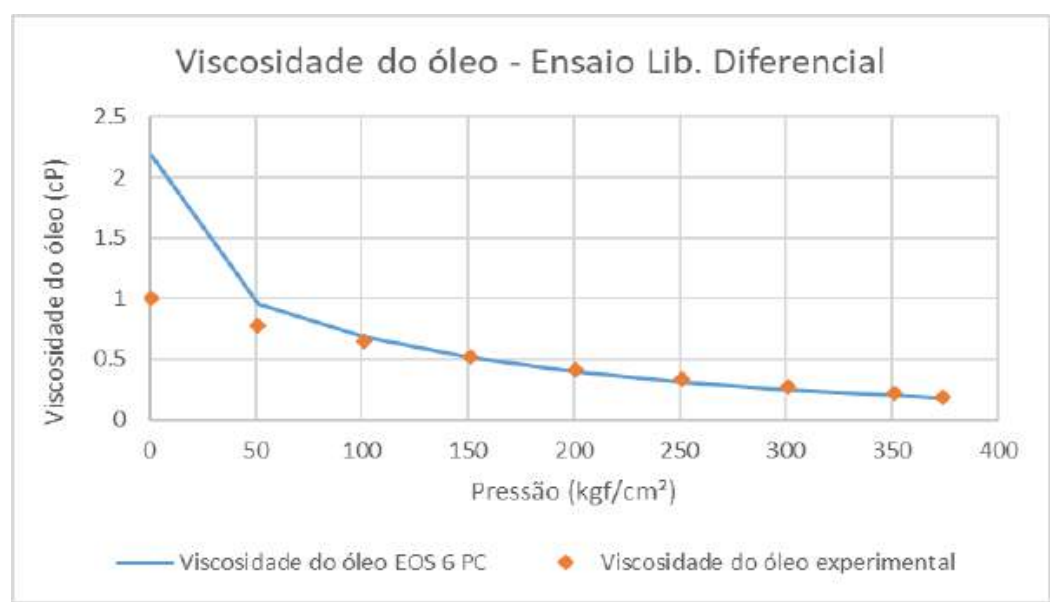

Figura A.72: Viscosidade do óleo abaixo da pressão de saturação. 


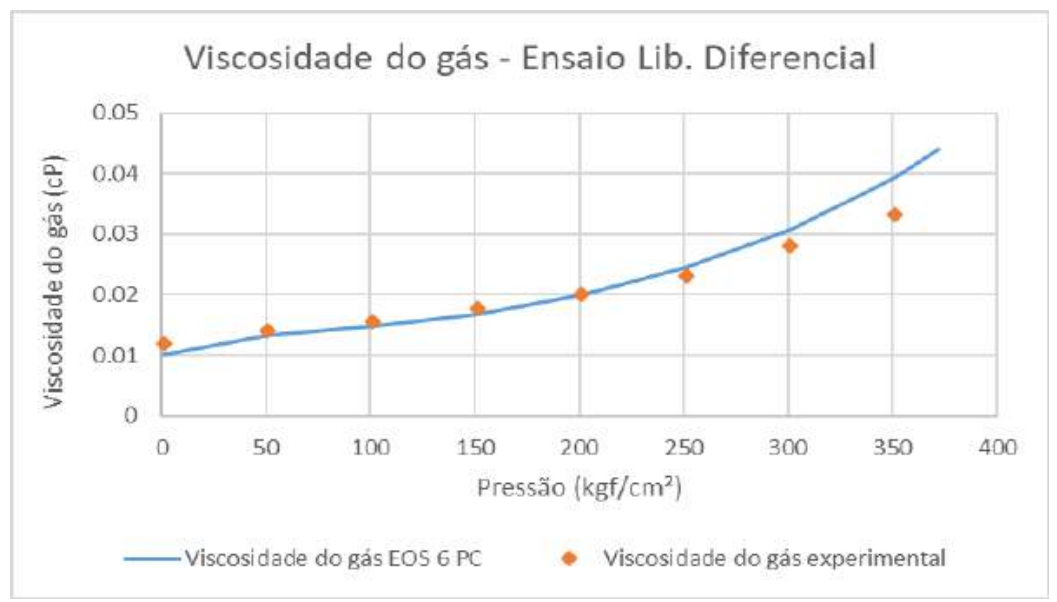

Figura A.73: Viscosidade do gás abaixo da pressão de saturação.

\section{A.4.2}

Ensaios de expansão a composição constante $\mathrm{T}=122^{\circ} \mathrm{C}, 75^{\circ} \mathrm{C}$ e $30^{\circ} \mathrm{C}$

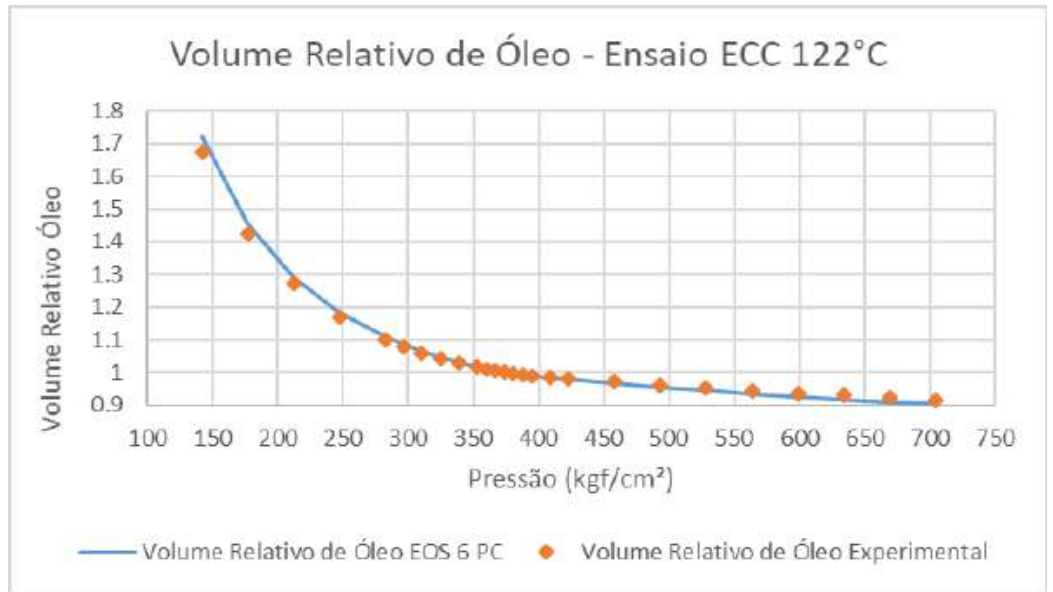

Figura A.74: Volume relativo de óleo, ECC a $122{ }^{\circ} \mathrm{C}$. 


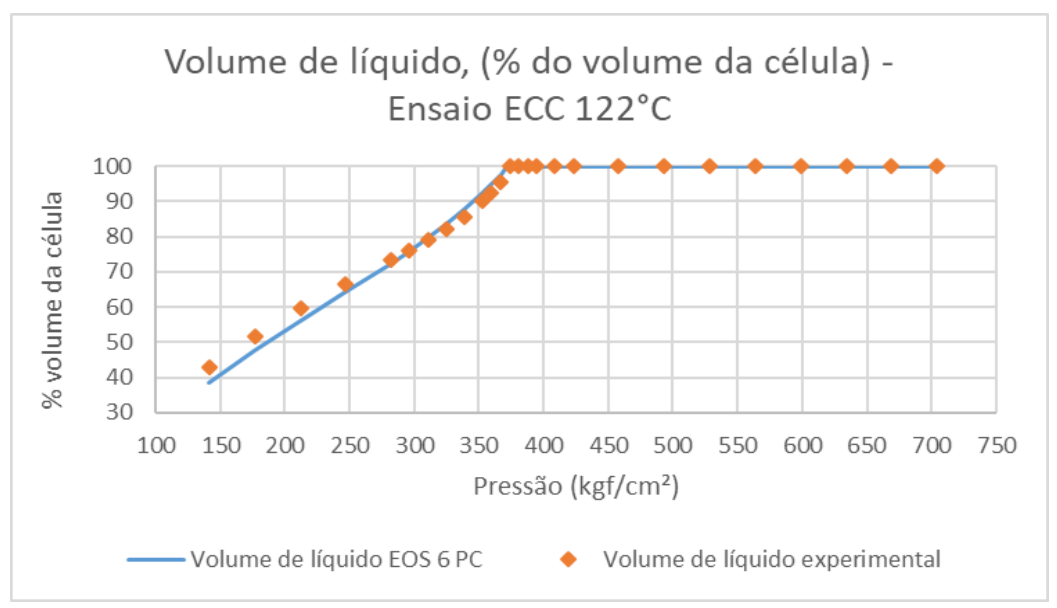

Figura A.75: Volume de líquido, $\%$ do volume da célula, ECC a $122{ }^{\circ} \mathrm{C}$.

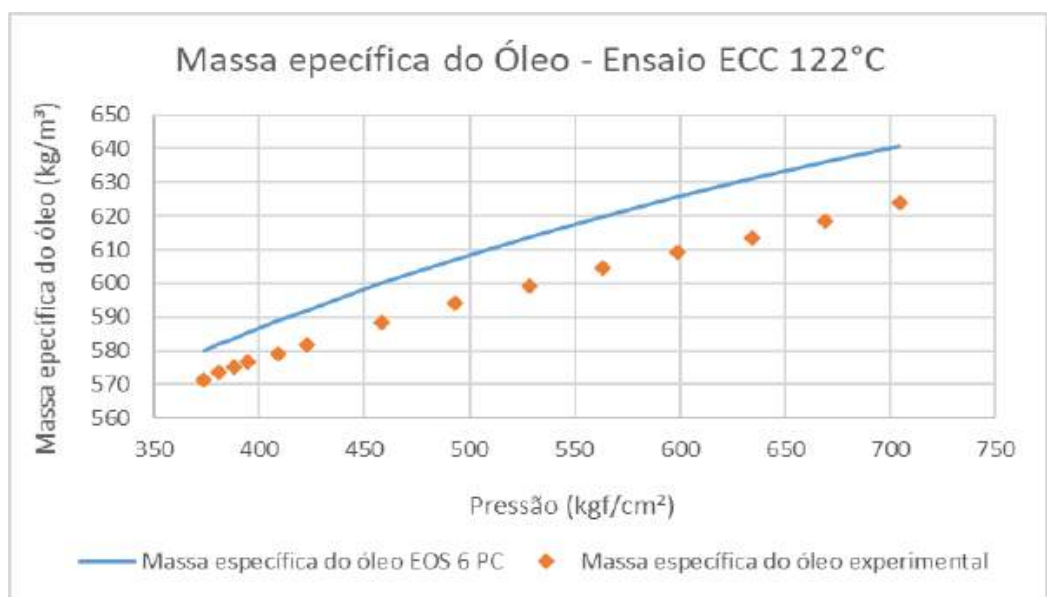

Figura A.76: Massa específica de óleo, ECC a $122{ }^{\circ} \mathrm{C}$.

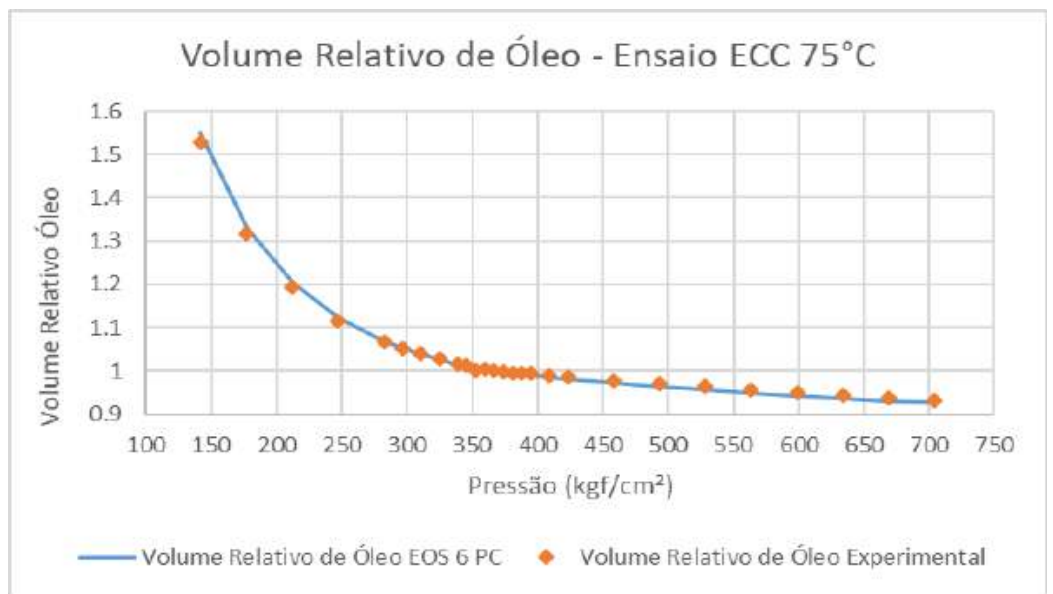

Figura A.77: Volume relativo de óleo, ECC a $75{ }^{\circ} \mathrm{C}$. 


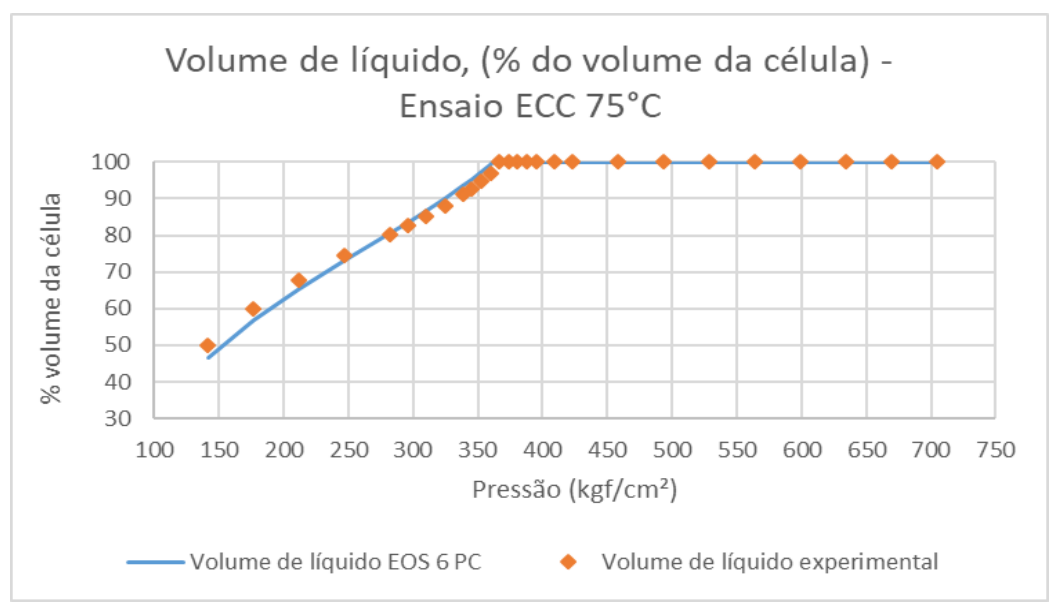

Figura A.78: Volume de líquido, $\%$ do volume da célula, ECC a $75{ }^{\circ} \mathrm{C}$.

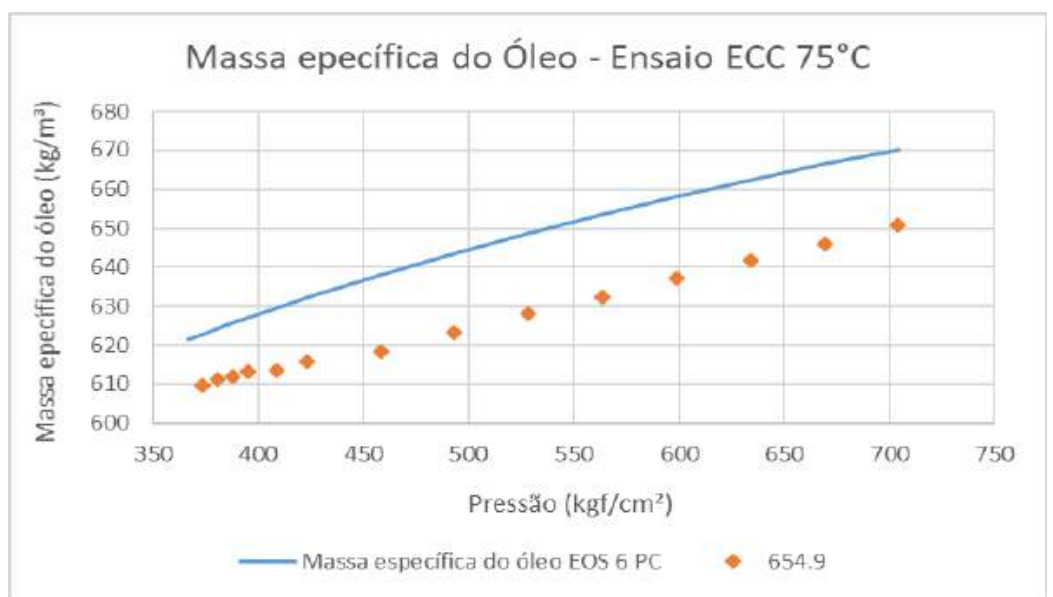

Figura A.79: Massa específica de óleo, ECC a $75^{\circ} \mathrm{C}$.

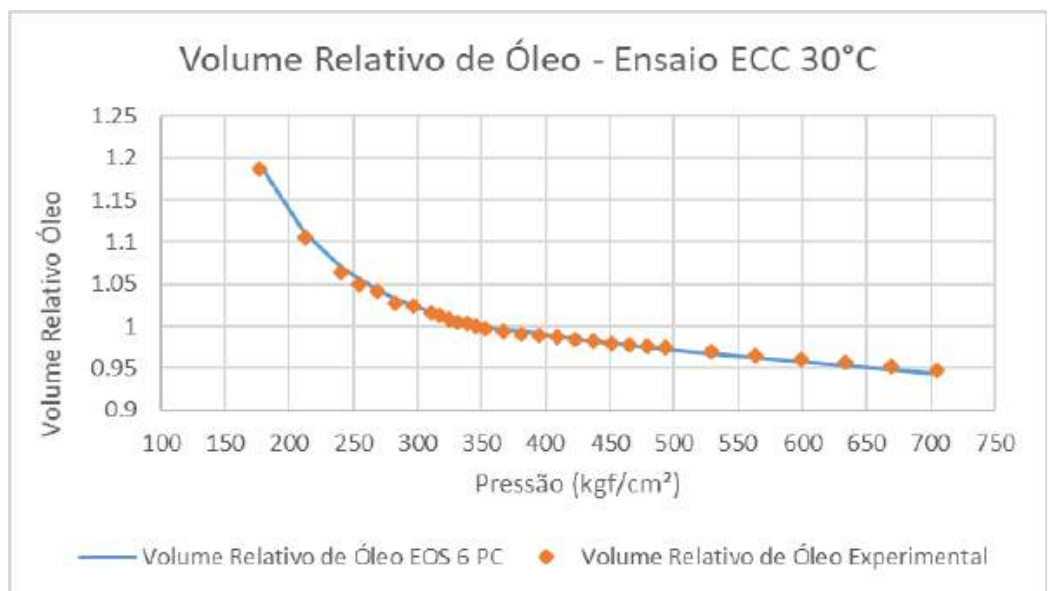

Figura A.80: Volume relativo de óleo, ECC a $30{ }^{\circ} \mathrm{C}$. 


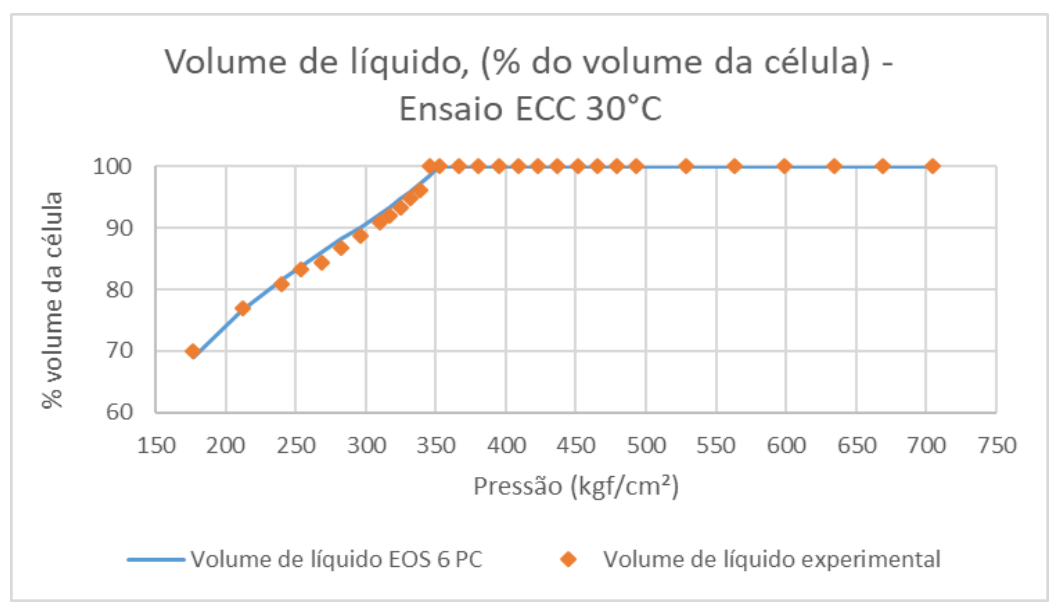

Figura A.81: Volume de líquido, $\%$ do volume da célula, ECC a $30{ }^{\circ} \mathrm{C}$.

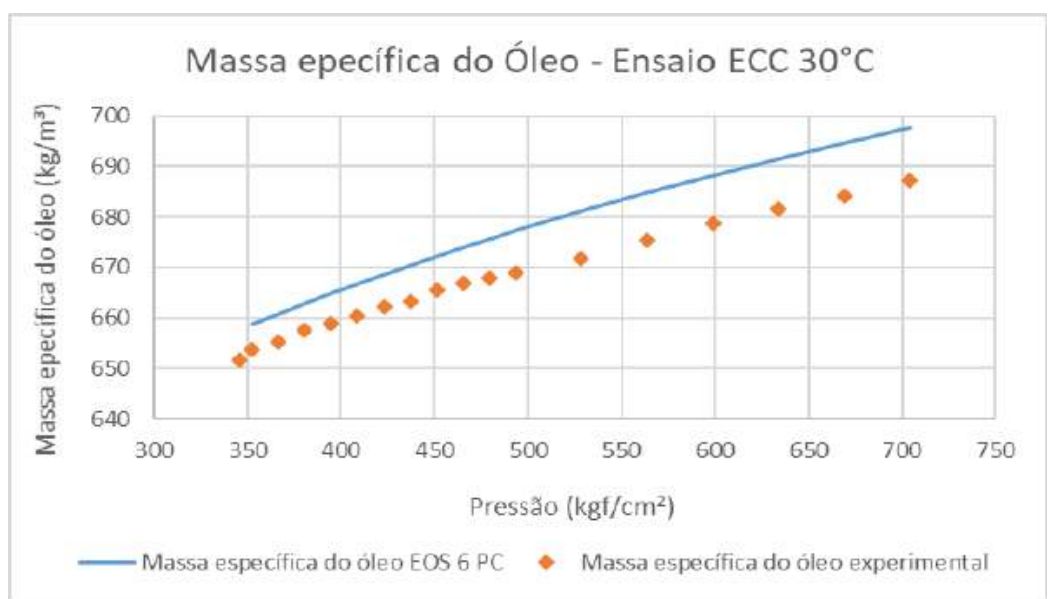

Figura A.82: Massa específica de óleo, ECC a $30{ }^{\circ} \mathrm{C}$. 


\section{A.4.3}

\section{Ensaio de expansão a volume constante}

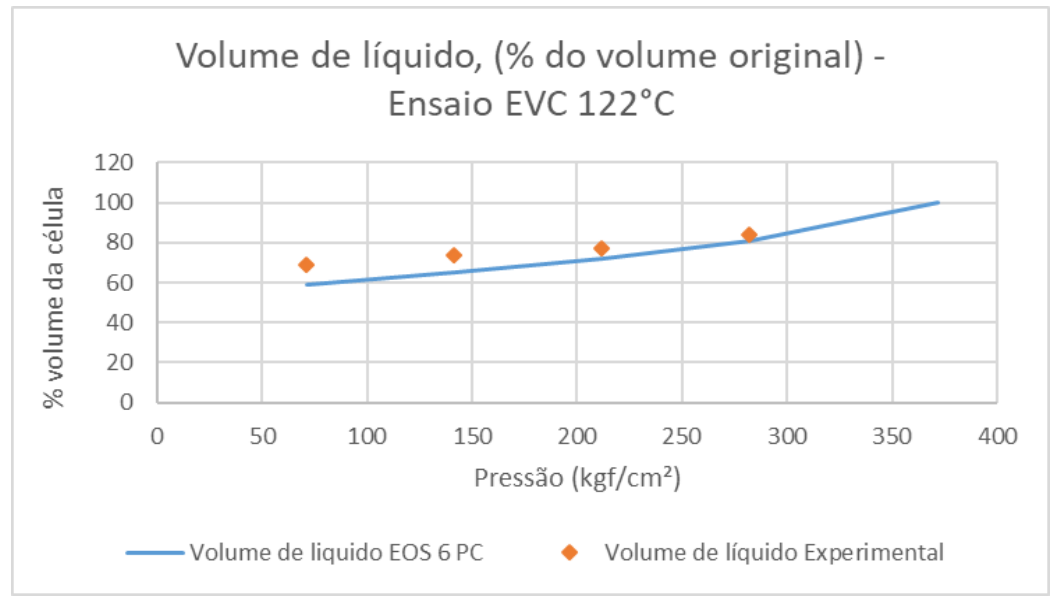

Figura A.83: Volume de líquido, $\%$ do volume original, EVC a $122{ }^{\circ} \mathrm{C}$.

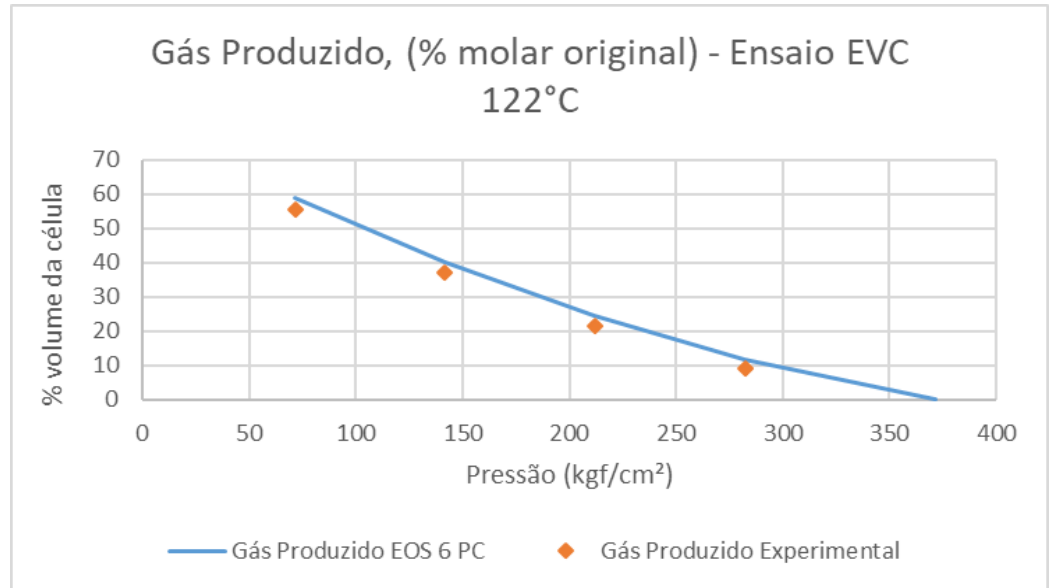

Figura A.84: Gás produzido, \% molar original, EVC a $122{ }^{\circ} \mathrm{C}$.

\section{A.5}

Regressão da EOS com 5 PC 


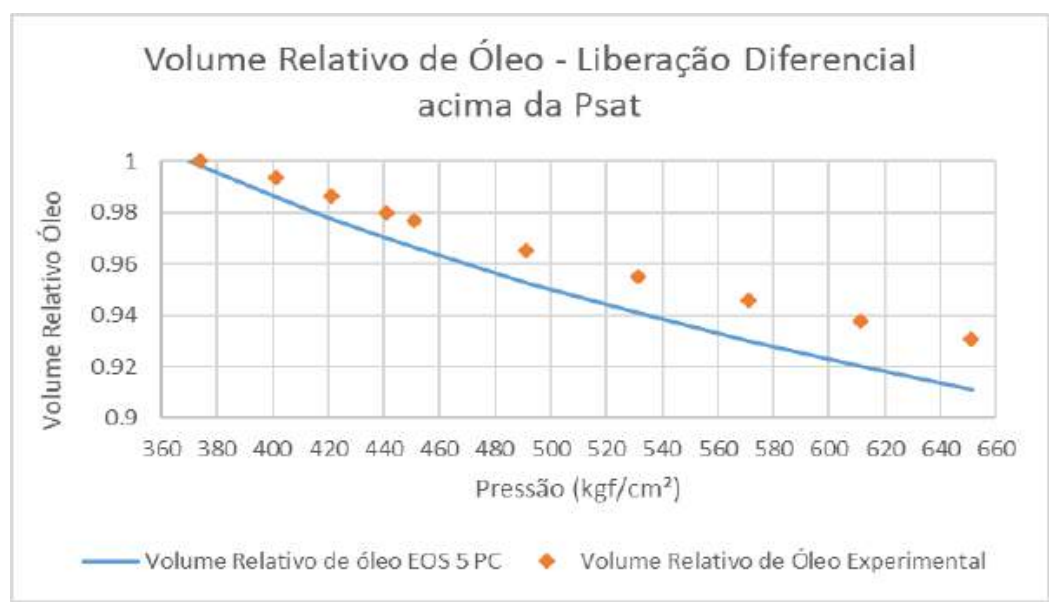

Figura A.85: Volume relativo de óleo da liberação diferencial acima da pressão de saturação.

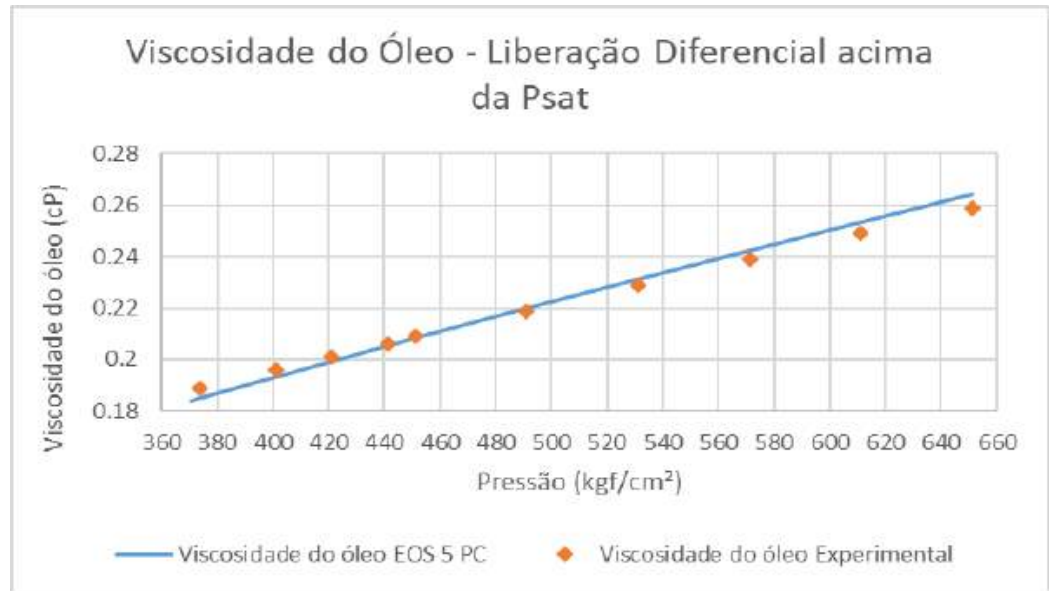

Figura A.86: Viscosidade do óleo da liberação diferencial acima da pressão de saturação.

\section{A.5.1}

\section{Ensaio de liberação diferencial}

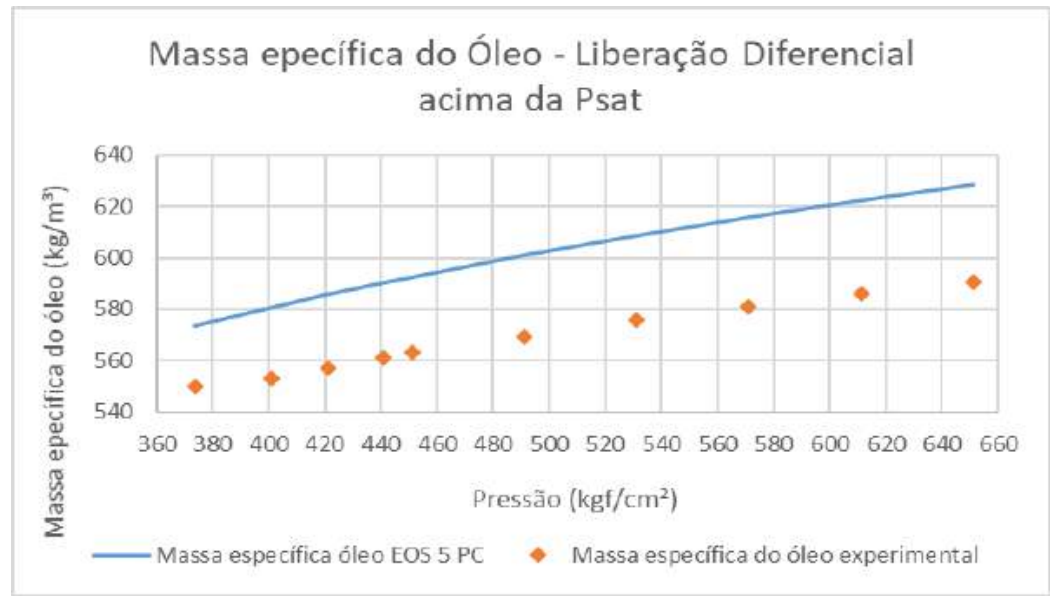

Figura A.87: Massa específica do óleo da liberação diferencial acima da pressão de saturação. 


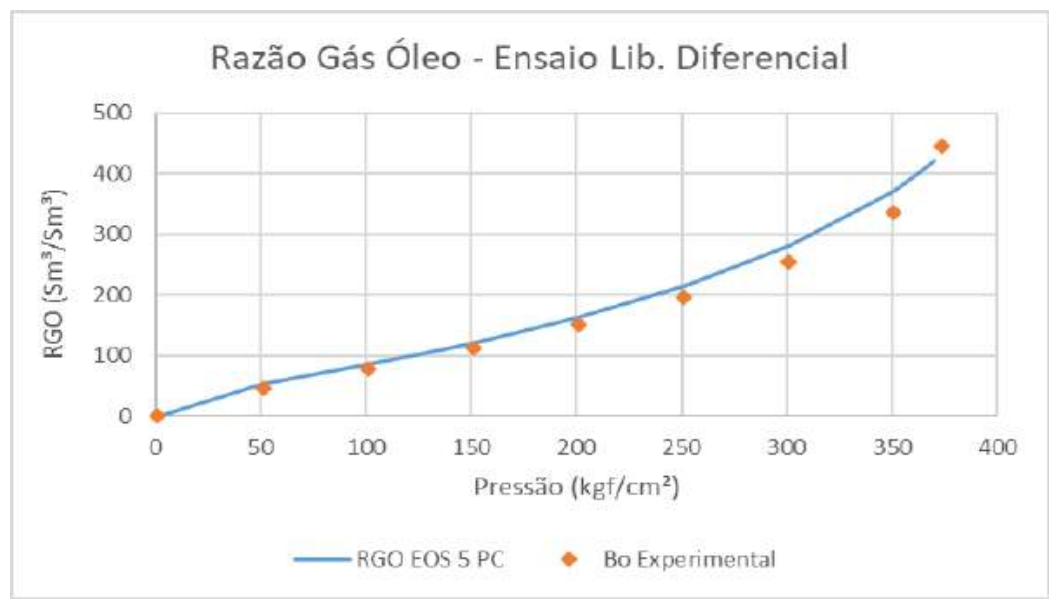

Figura A.88: RGO da liberação diferencial abaixo da pressão de saturação.

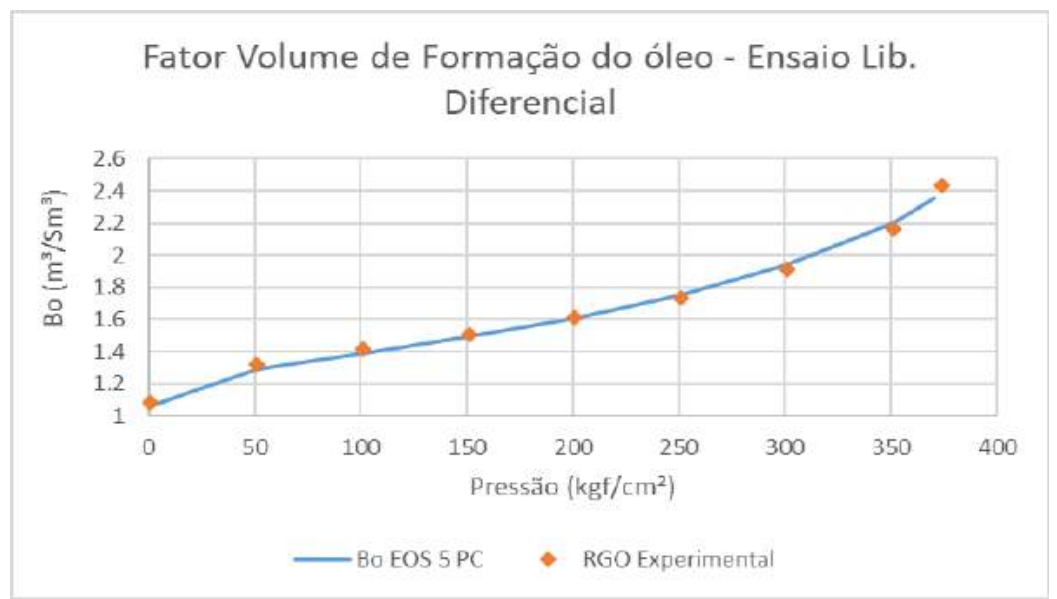

Figura A.89: $B_{o}$ da liberação diferencial abaixo da pressão de saturação.

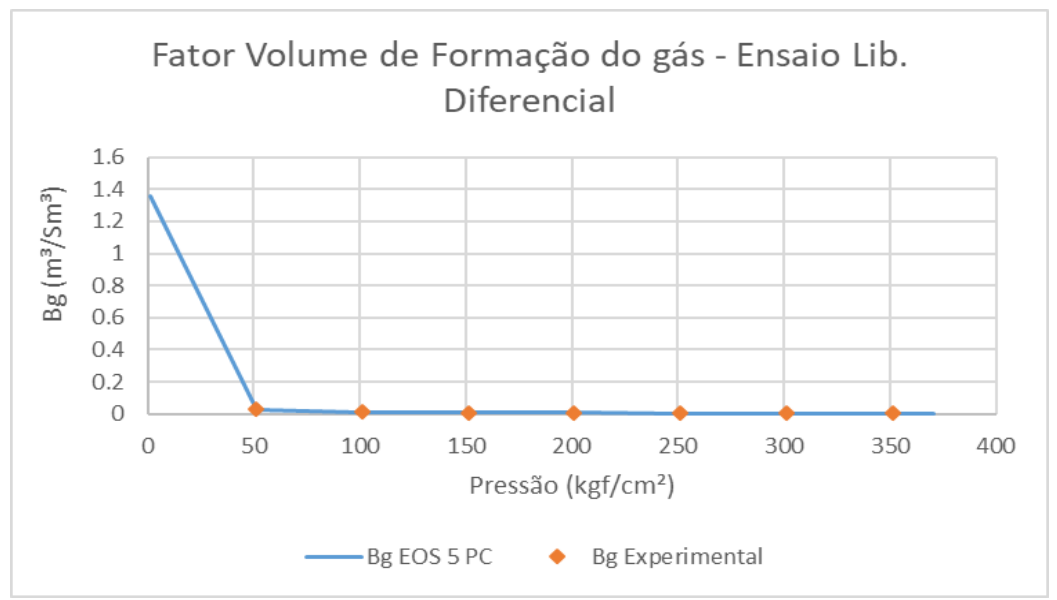

Figura A.90: $B_{g}$ da liberação diferencial abaixo da pressão de saturação. 


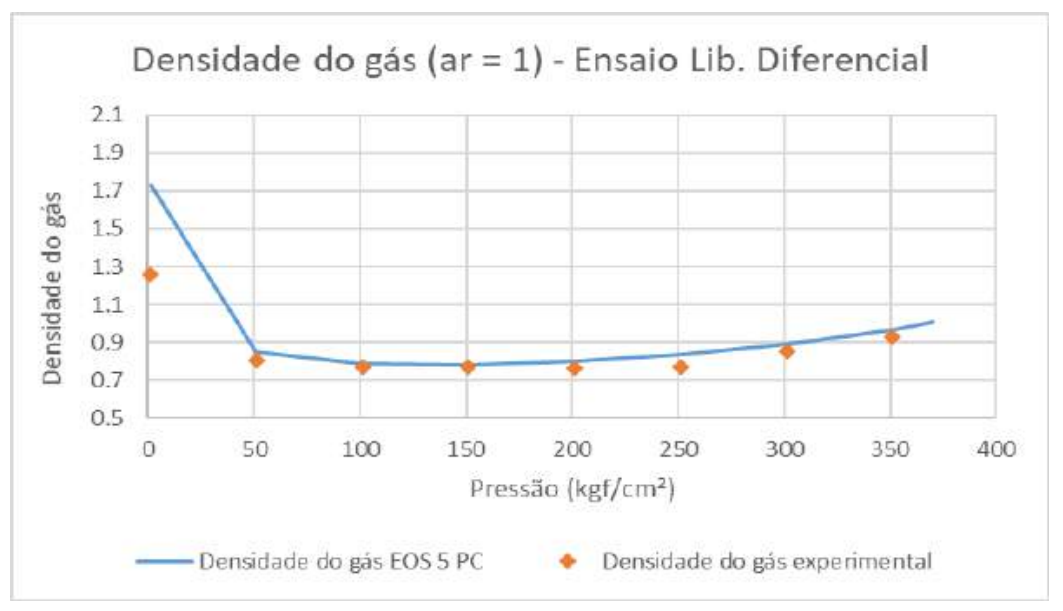

Figura A.91: Densidade do gás abaixo da pressão de saturação.

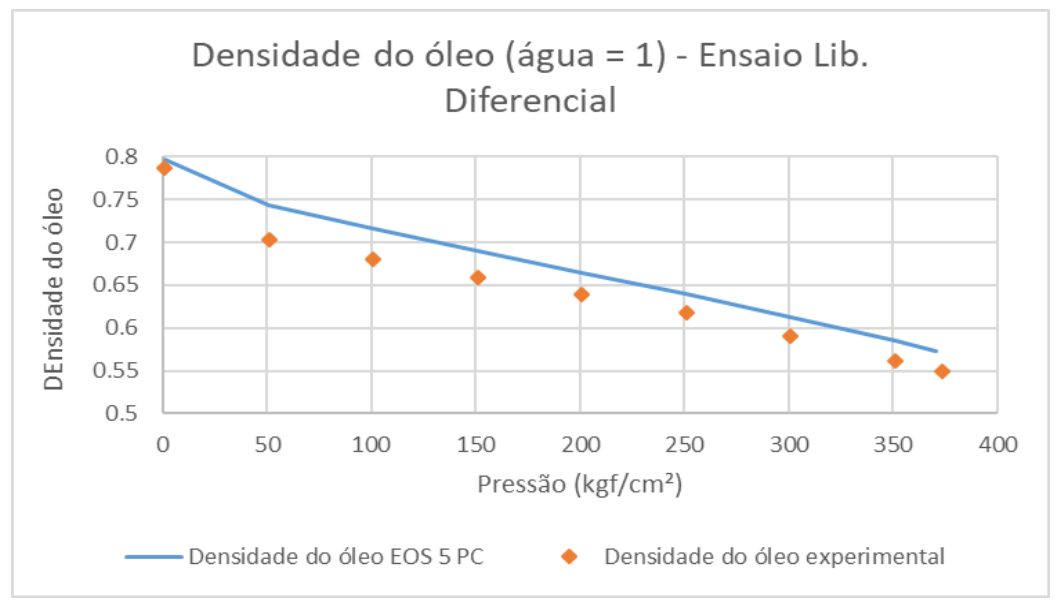

Figura A.92: Densidade do óleo abaixo da pressão de saturação.

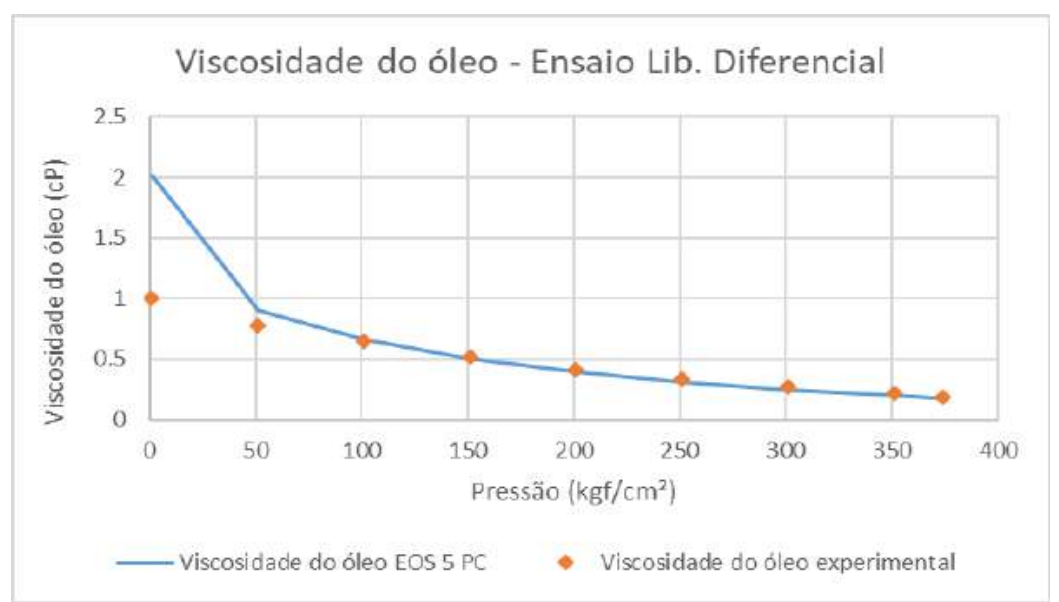

Figura A.93: Viscosidade do óleo abaixo da pressão de saturação. 


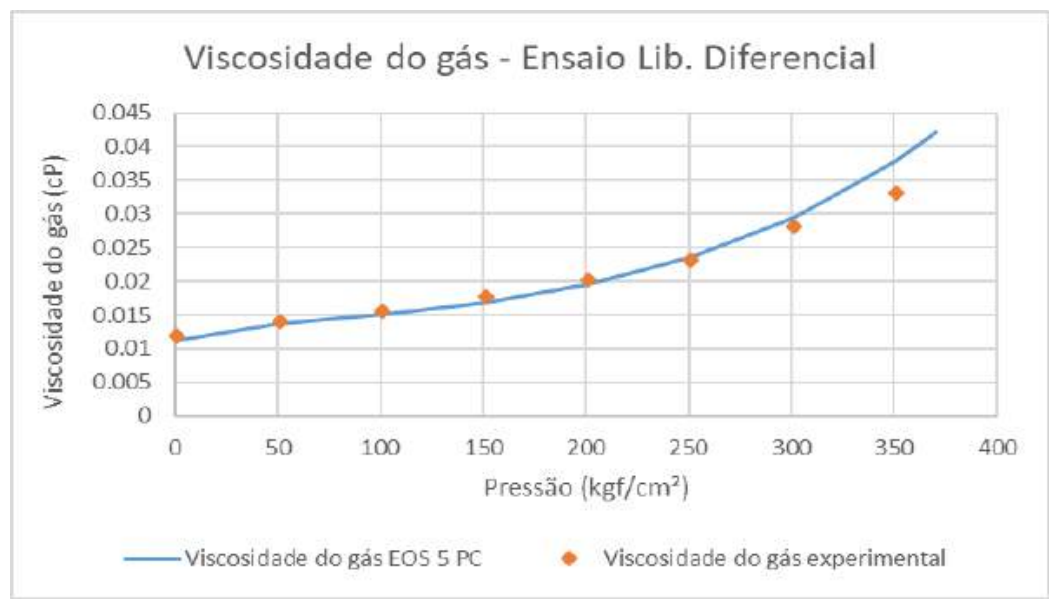

Figura A.94: Viscosidade do gás abaixo da pressão de saturação.

\section{A.5.2}

Ensaios de expansão a composição constante $\mathrm{T}=122^{\circ} \mathrm{C}, 75^{\circ} \mathrm{C}$ e $30^{\circ} \mathrm{C}$

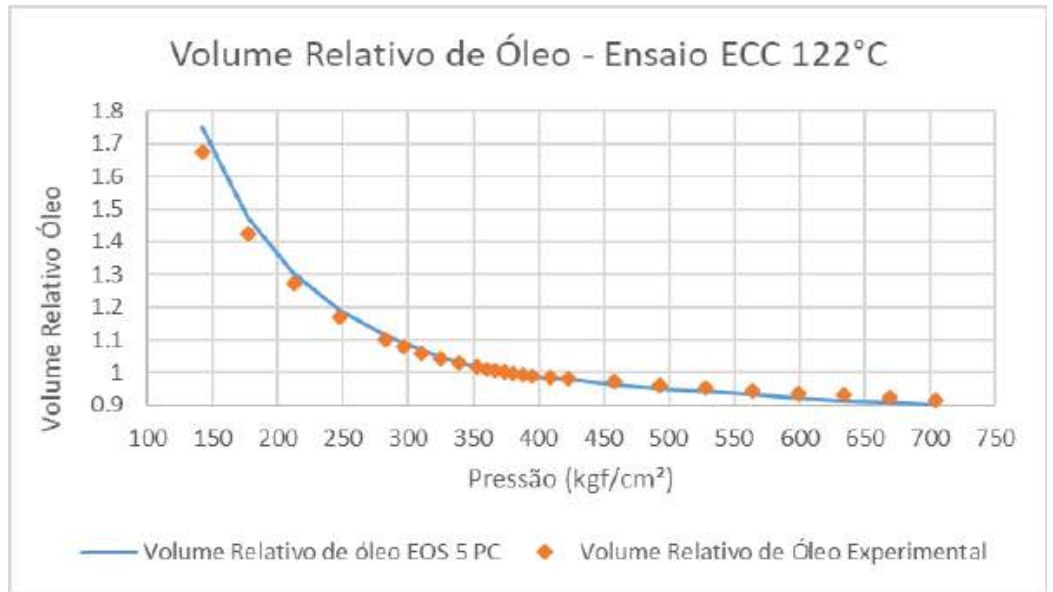

Figura A.95: Volume relativo de óleo, ECC a $122{ }^{\circ} \mathrm{C}$. 


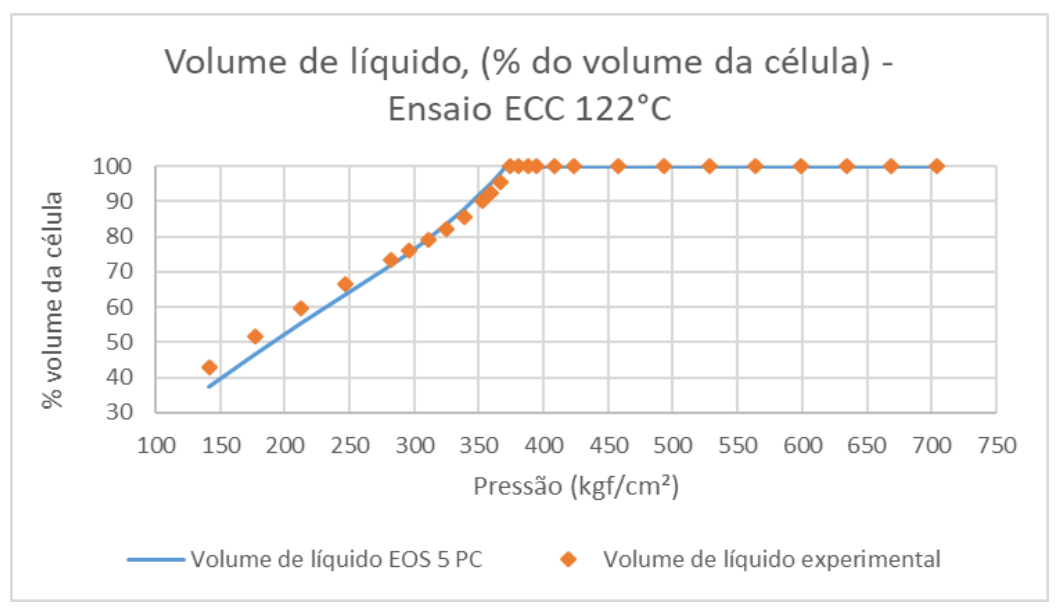

Figura A.96: Volume de líquido, $\%$ do volume da célula, ECC a $122{ }^{\circ} \mathrm{C}$.

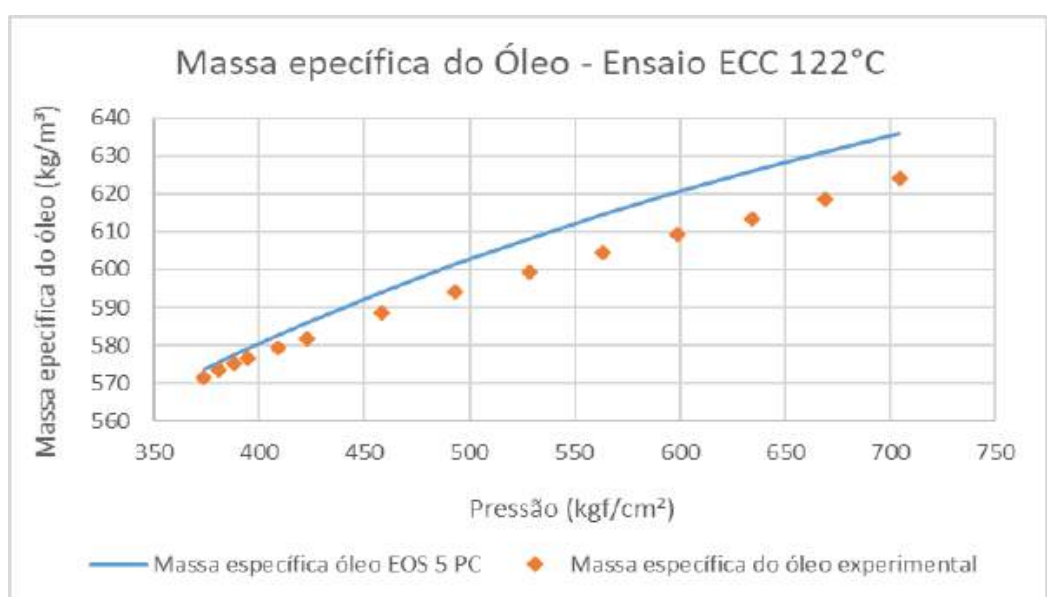

Figura A.97: Massa específica de óleo, ECC a $122{ }^{\circ} \mathrm{C}$.

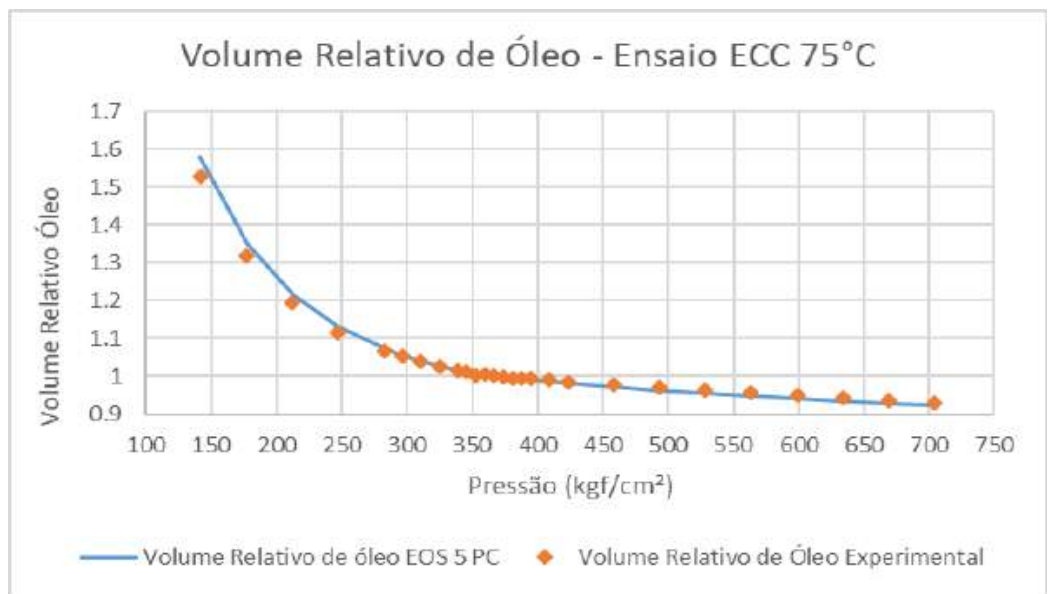

Figura A.98: Volume relativo de óleo, ECC a $75{ }^{\circ} \mathrm{C}$. 


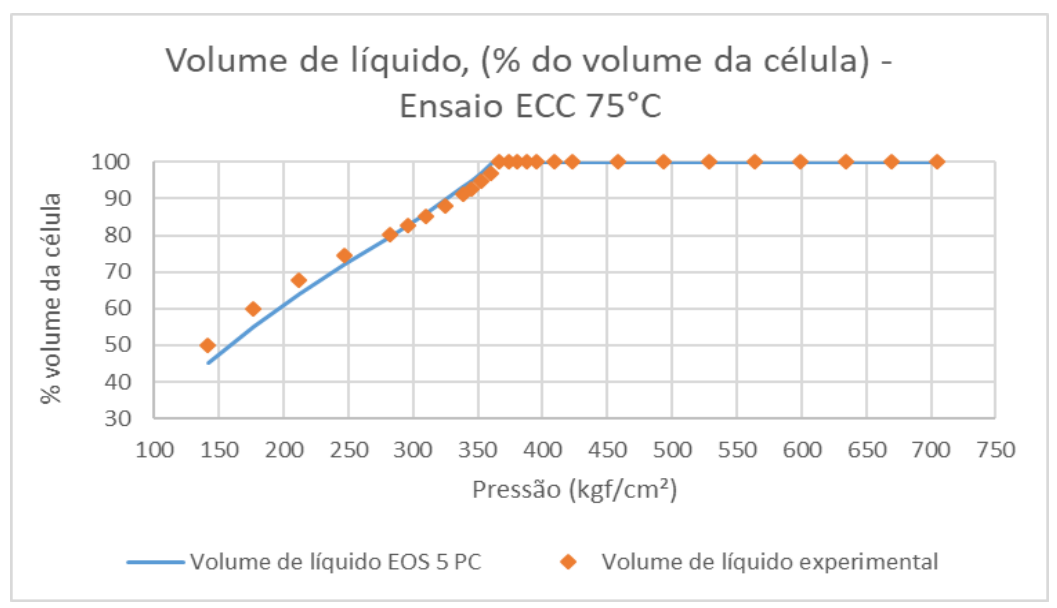

Figura A.99: Volume de líquido, $\%$ do volume da célula, ECC a $75^{\circ} \mathrm{C}$.

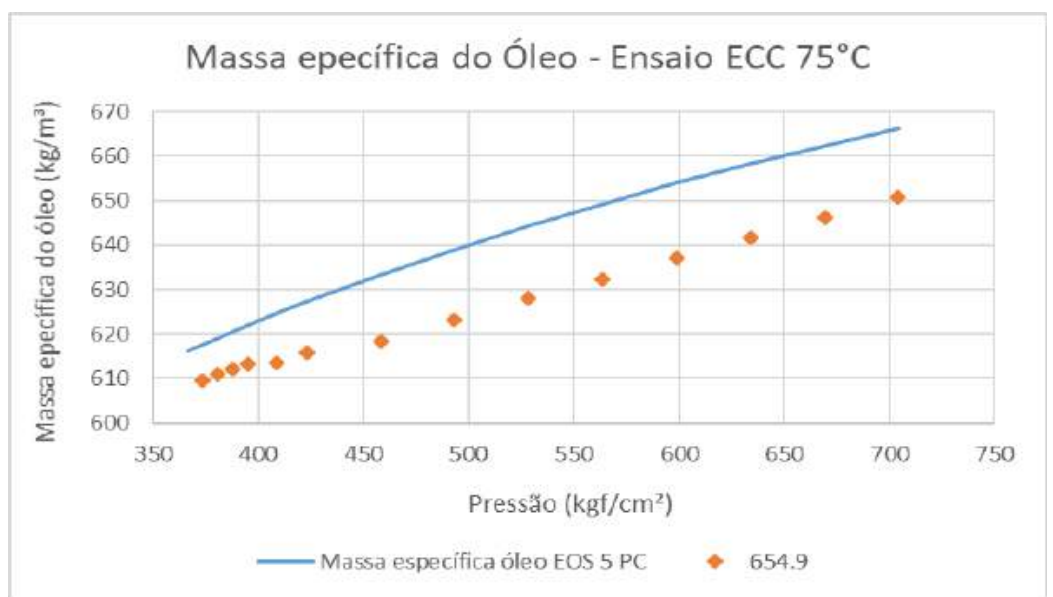

Figura A.100: Massa específica de óleo, ECC a $75{ }^{\circ} \mathrm{C}$.

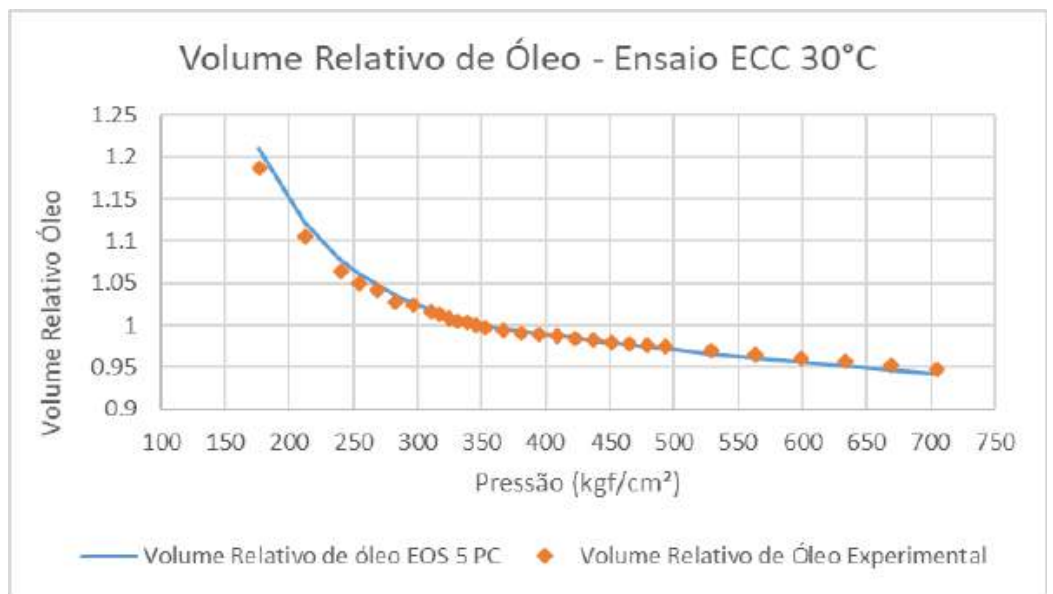

Figura A.101: Volume relativo de óleo, ECC a $30{ }^{\circ} \mathrm{C}$. 


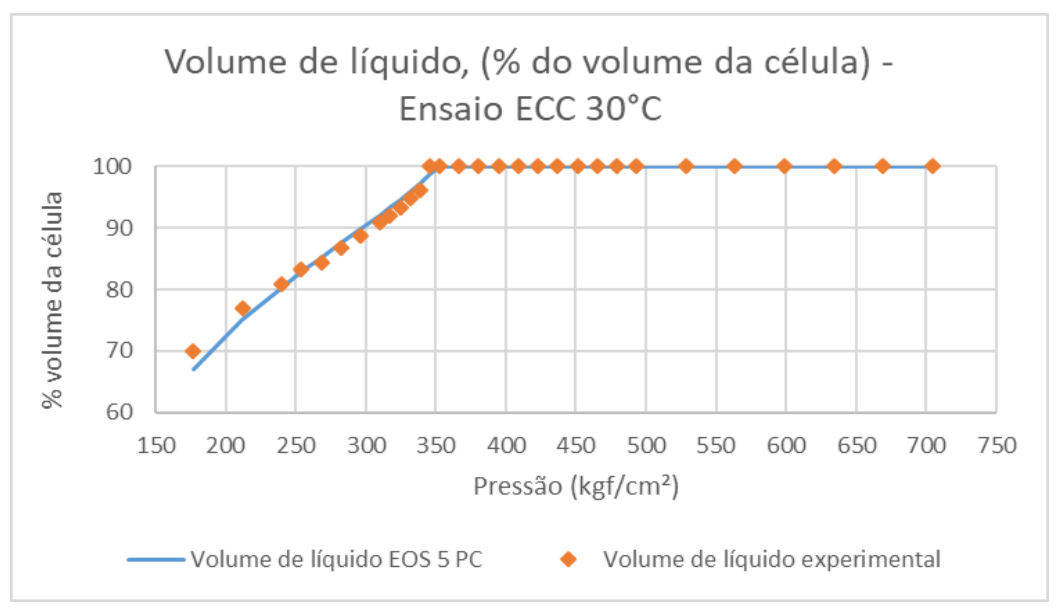

Figura A.102: Volume de líquido, $\%$ do volume da célula, ECC a $30{ }^{\circ} \mathrm{C}$.

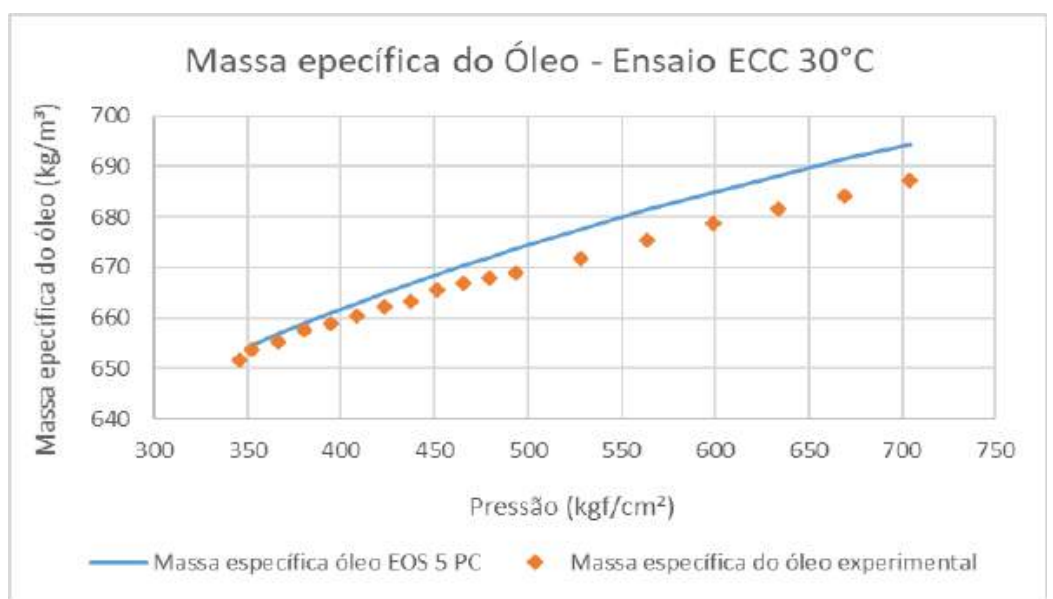

Figura A.103: Massa específica de óleo, ECC a $30{ }^{\circ} \mathrm{C}$. 


\section{A.5.3}

\section{Ensaio de expansão a volume constante}

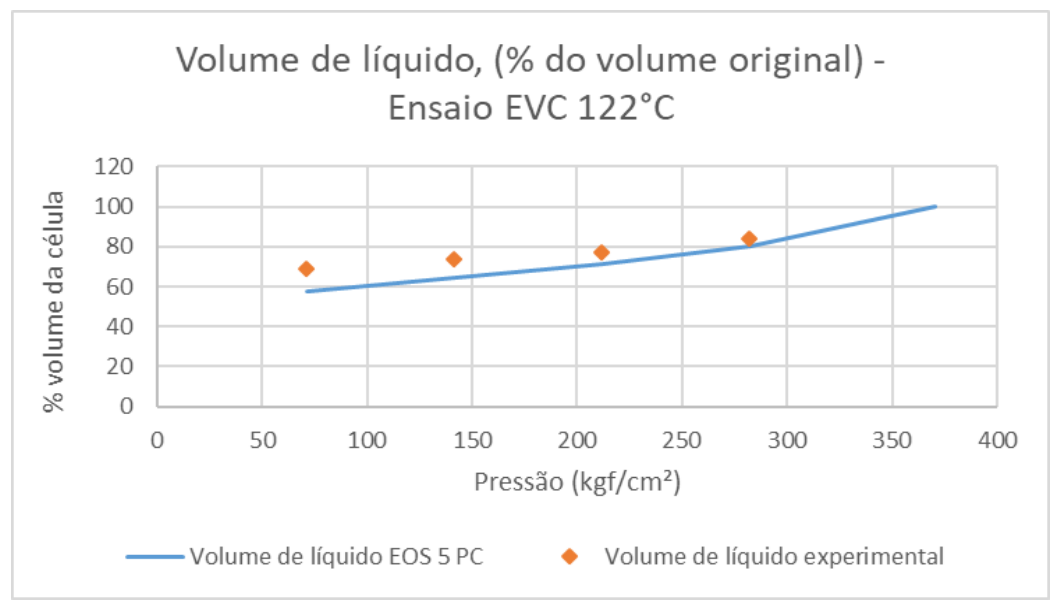

Figura A.104: Volume de líquido, \% do volume original, EVC a $122{ }^{\circ} \mathrm{C}$.

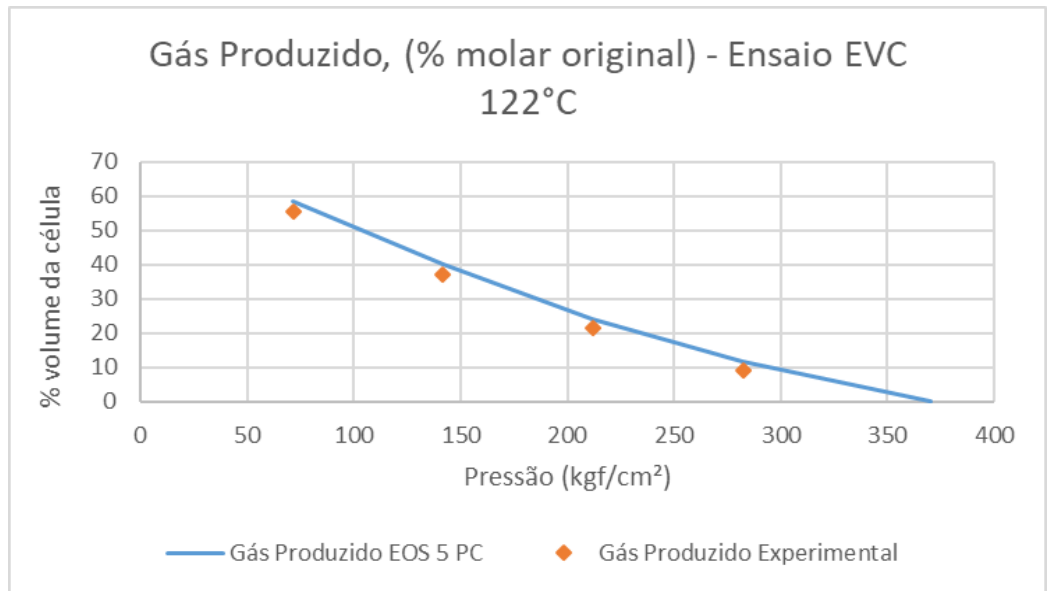

Figura A.105: Gás produzido, \% molar original, EVC a $122{ }^{\circ} \mathrm{C}$.

\section{A.6}

Regressão da EOS com 4 PC 


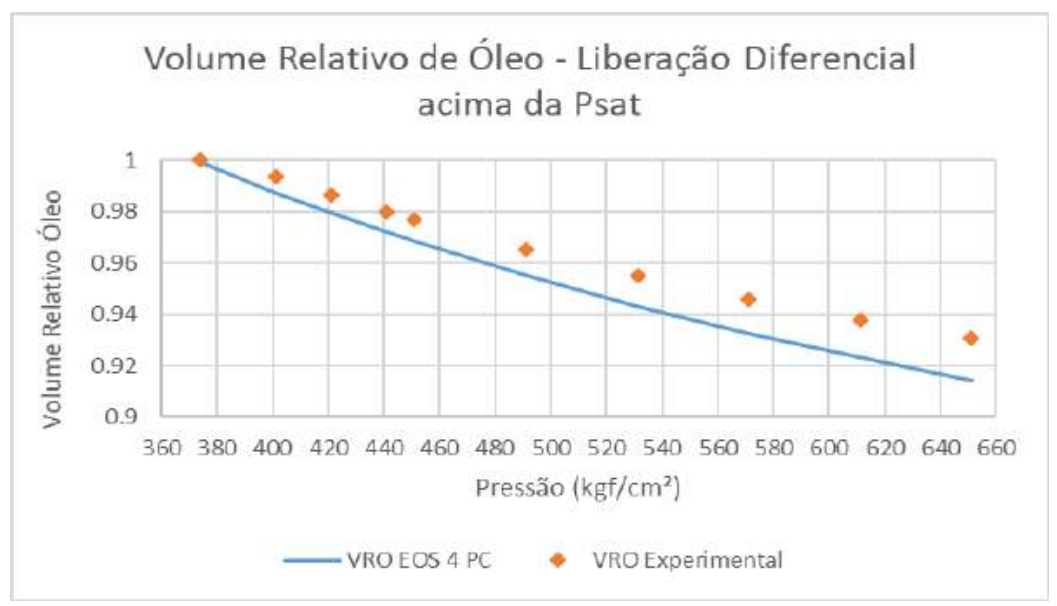

Figura A.106: Volume relativo de óleo da liberação diferencial acima da pressão de saturação.

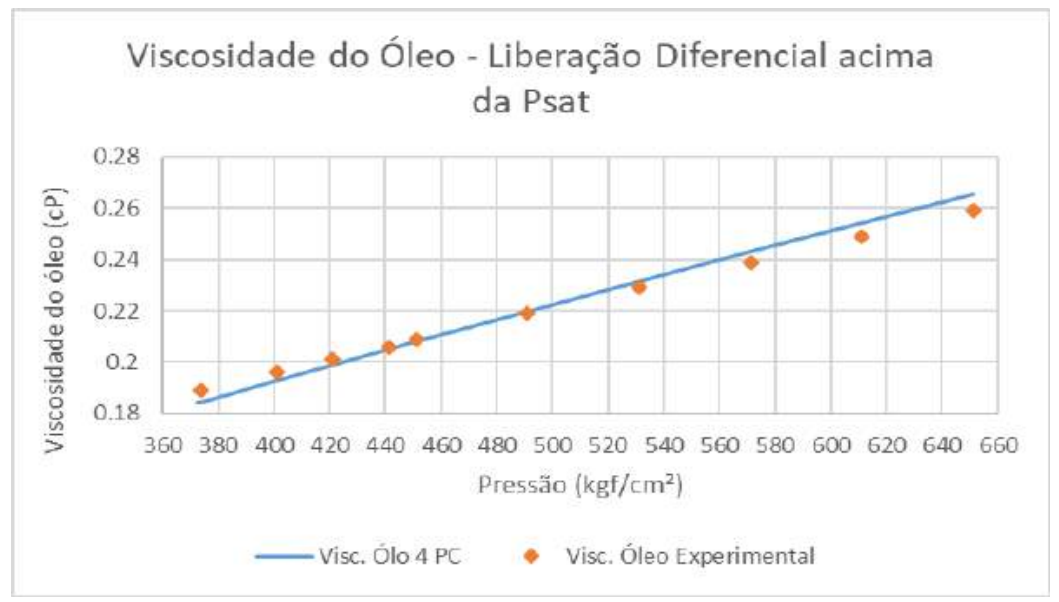

Figura A.107: Viscosidade do óleo da liberação diferencial acima da pressão de saturação.

\section{A.6.1}

\section{Ensaio de liberação diferencial}

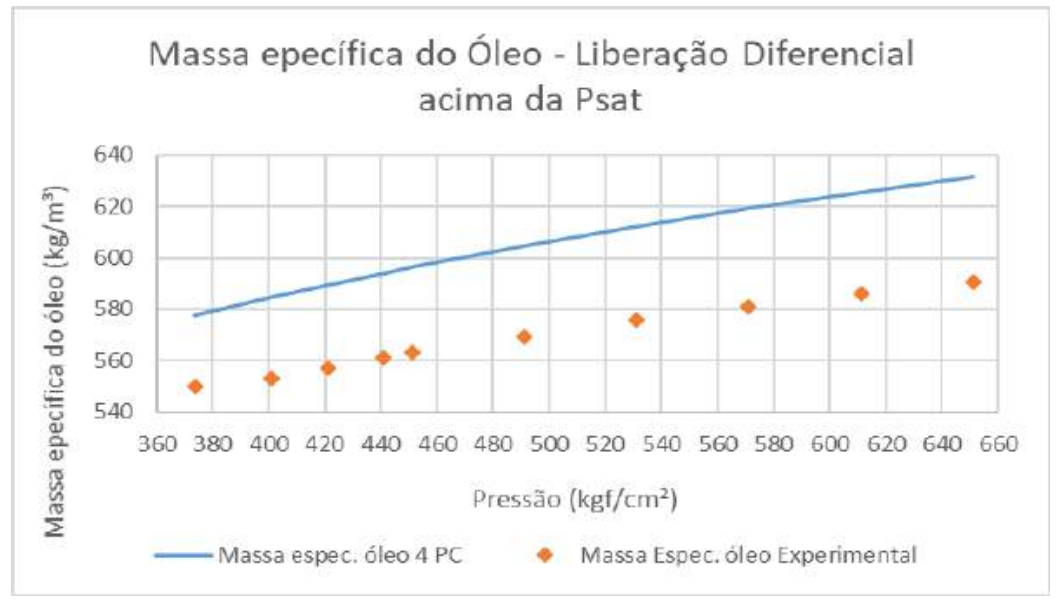

Figura A.108: Massa específica do óleo da liberação diferencial acima da pressão de saturação. 


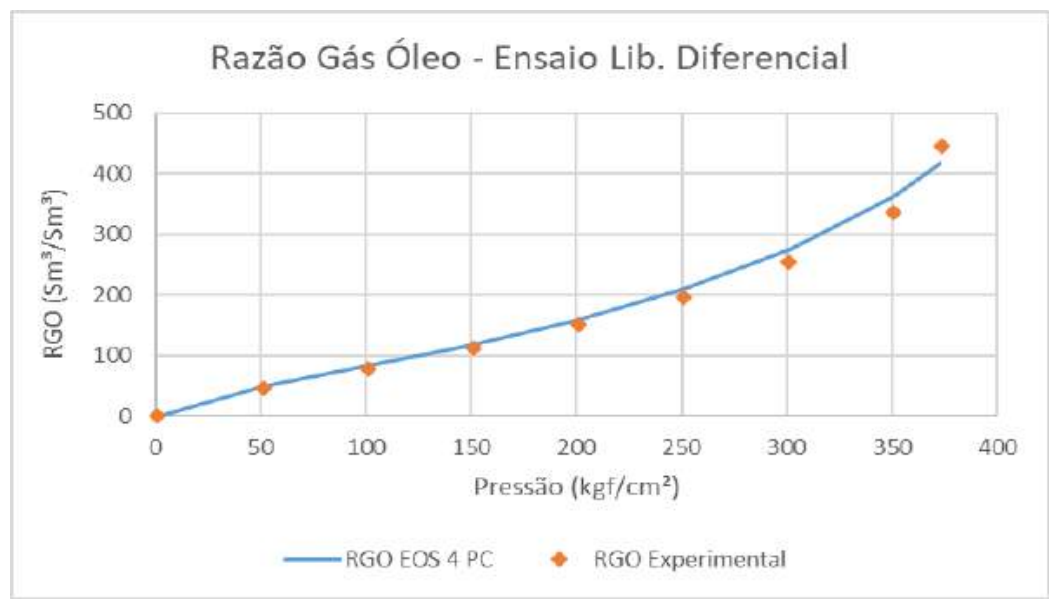

Figura A.109: RGO da liberação diferencial abaixo da pressão de saturação.

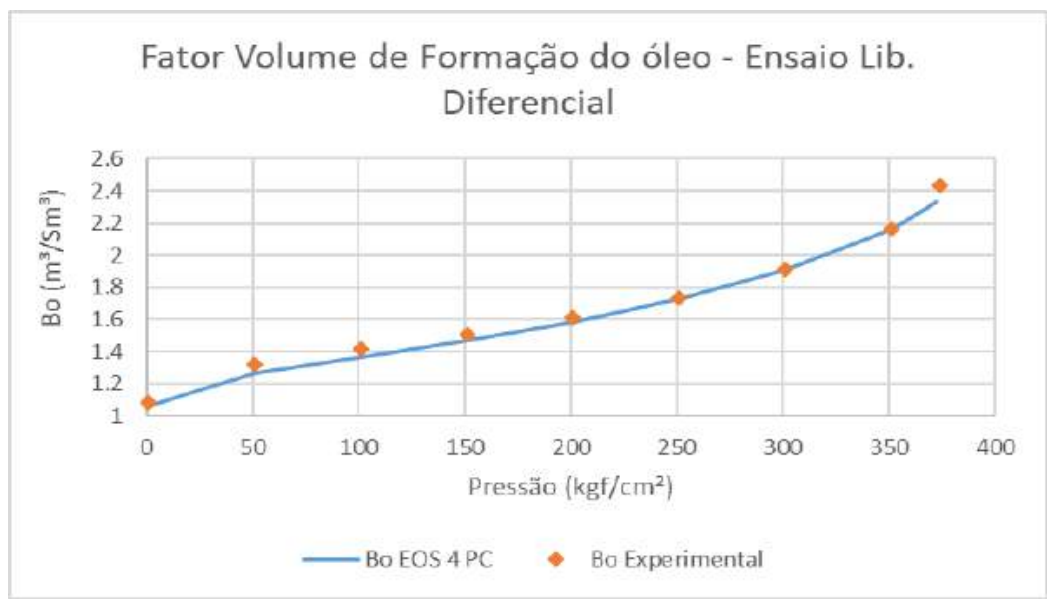

Figura A.110: $B_{o}$ da liberação diferencial abaixo da pressão de saturação.

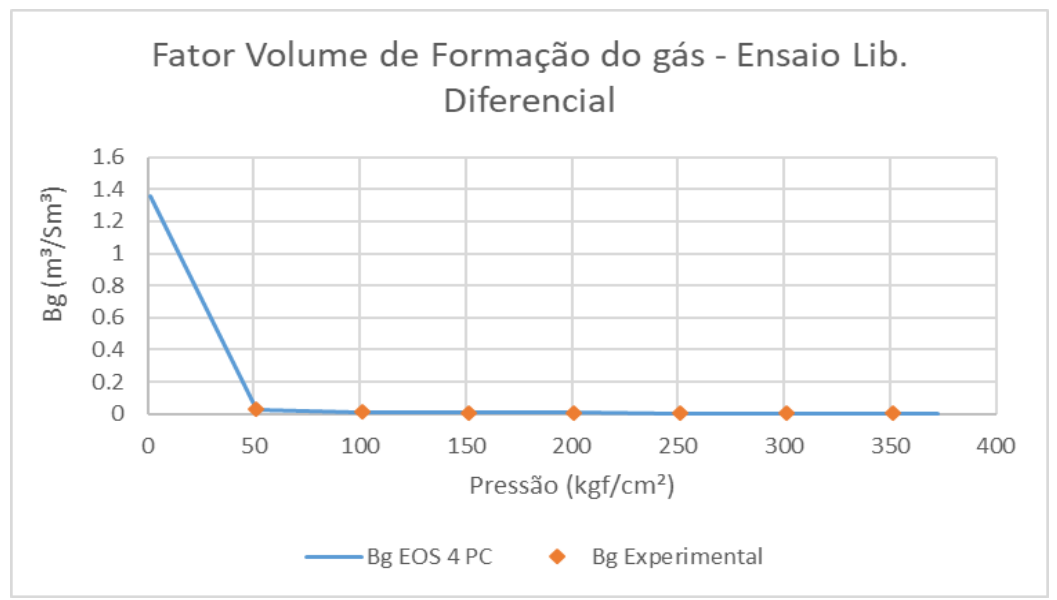

Figura A.111: $B_{g}$ da liberação diferencial abaixo da pressão de saturação. 


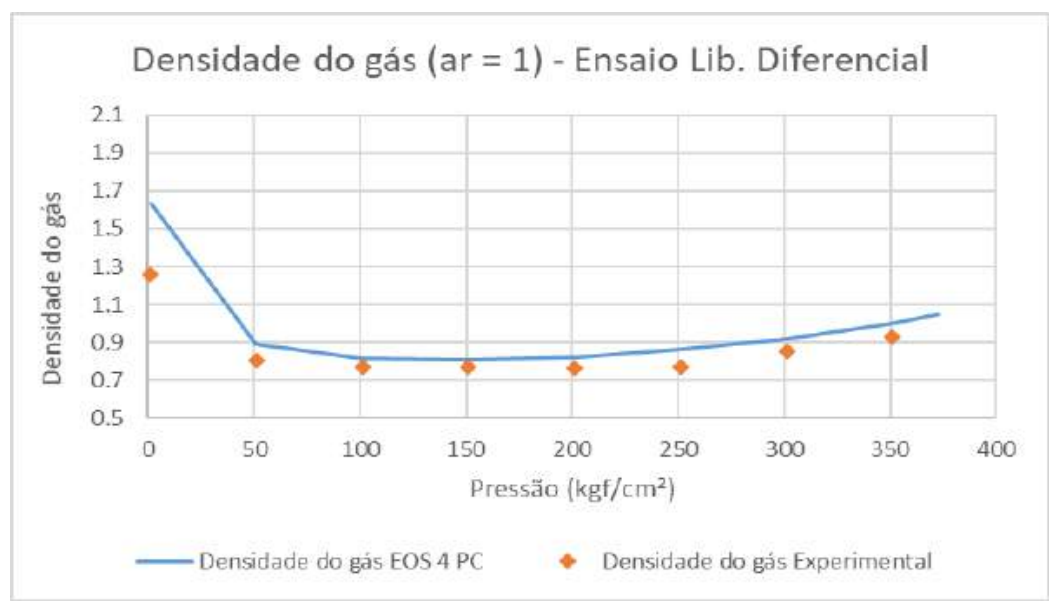

Figura A.112: Densidade do gás abaixo da pressão de saturação.

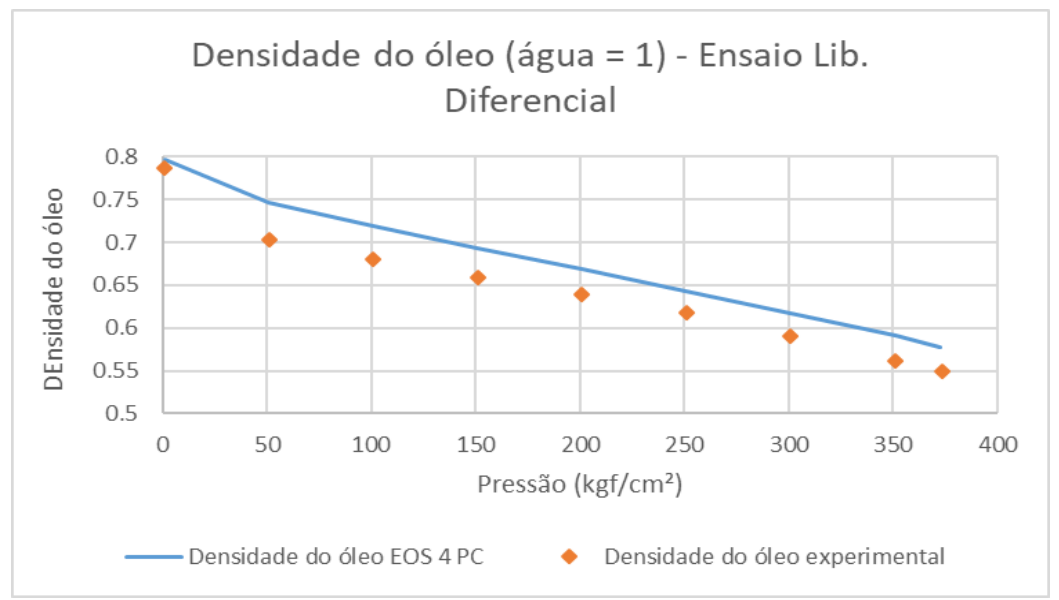

Figura A.113: Densidade do óleo abaixo da pressão de saturação.

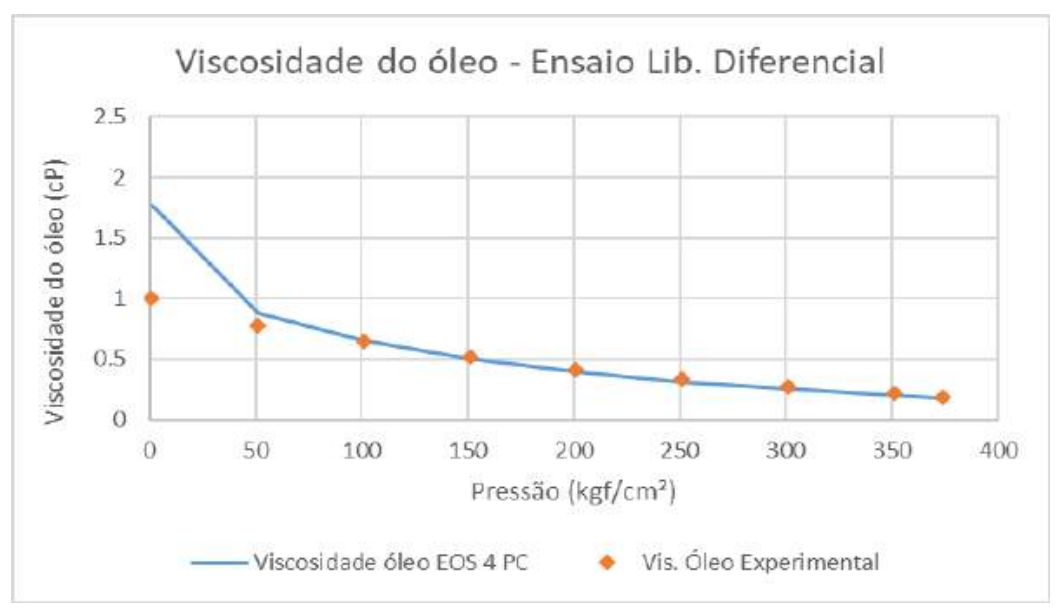

Figura A.114: Viscosidade do óleo abaixo da pressão de saturação. 


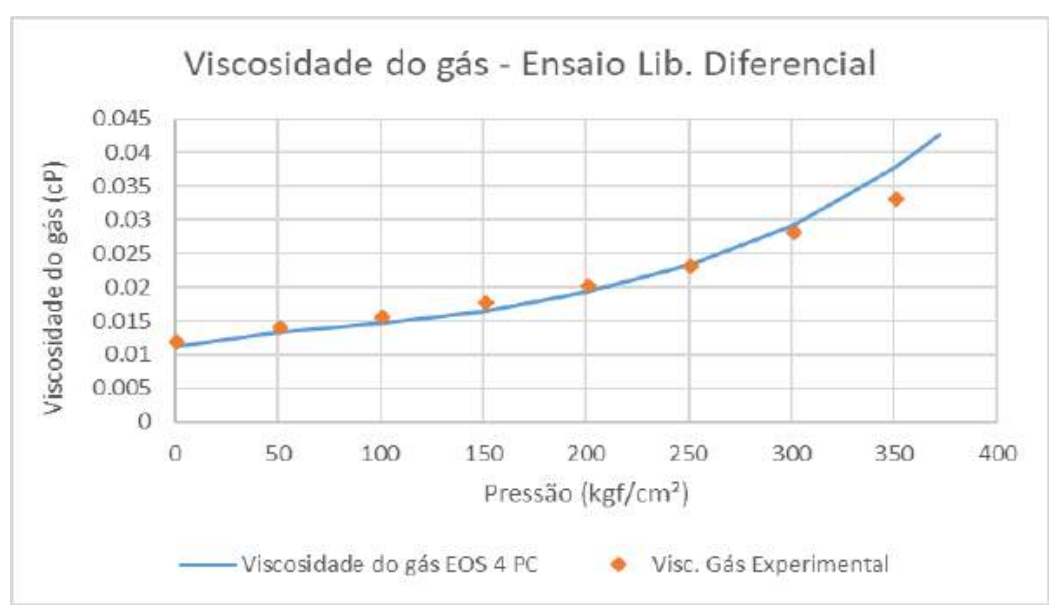

Figura A.115: Viscosidade do gás abaixo da pressão de saturação.

\section{A.6.2}

Ensaios de expansão a composição constante $\mathrm{T}=122^{\circ} \mathrm{C}, 75^{\circ} \mathrm{C}$ e $30^{\circ} \mathrm{C}$

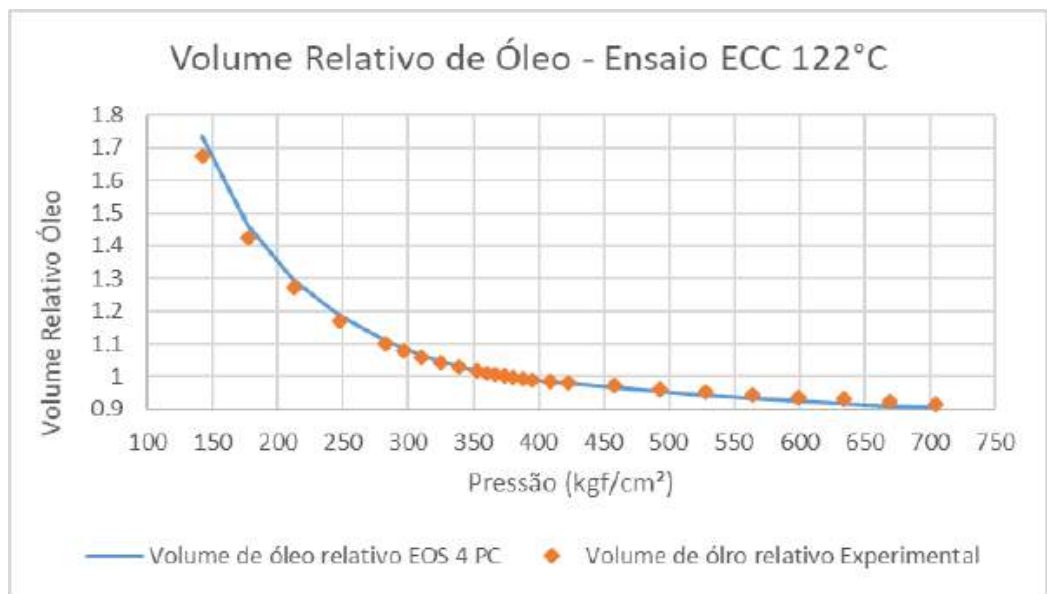

Figura A.116: Volume relativo de óleo, ECC a $122{ }^{\circ} \mathrm{C}$. 


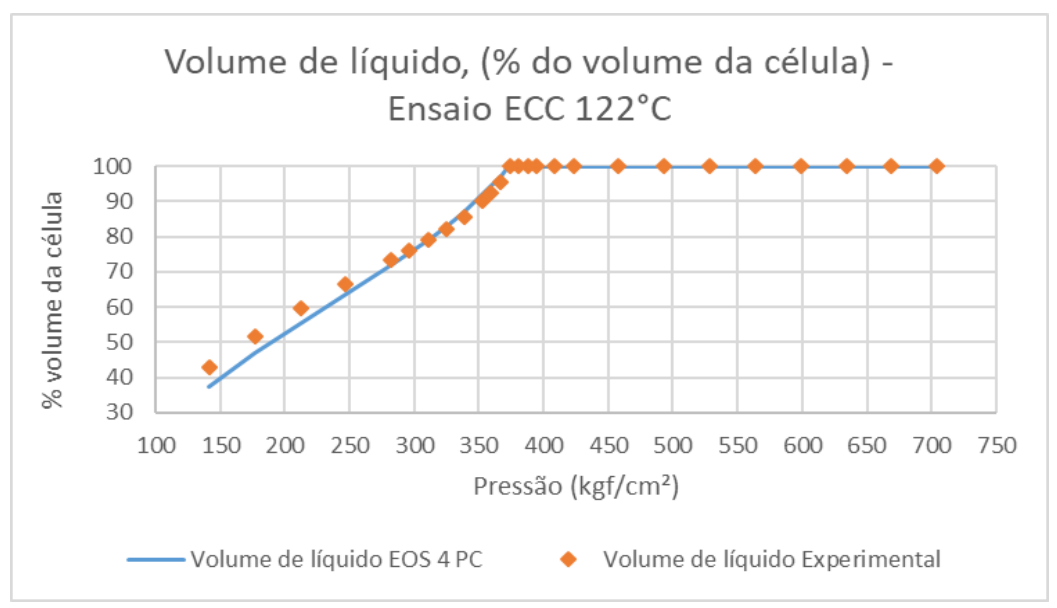

Figura A.117: Volume de líquido, \% do volume da célula, ECC a $122{ }^{\circ} \mathrm{C}$.

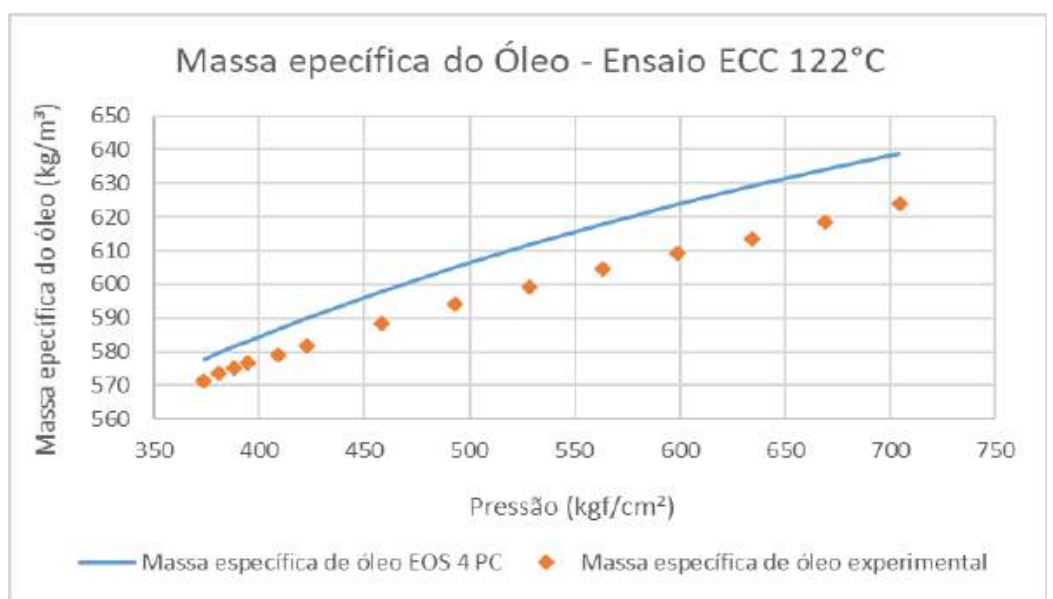

Figura A.118: Massa específica de óleo, ECC a $122{ }^{\circ} \mathrm{C}$.

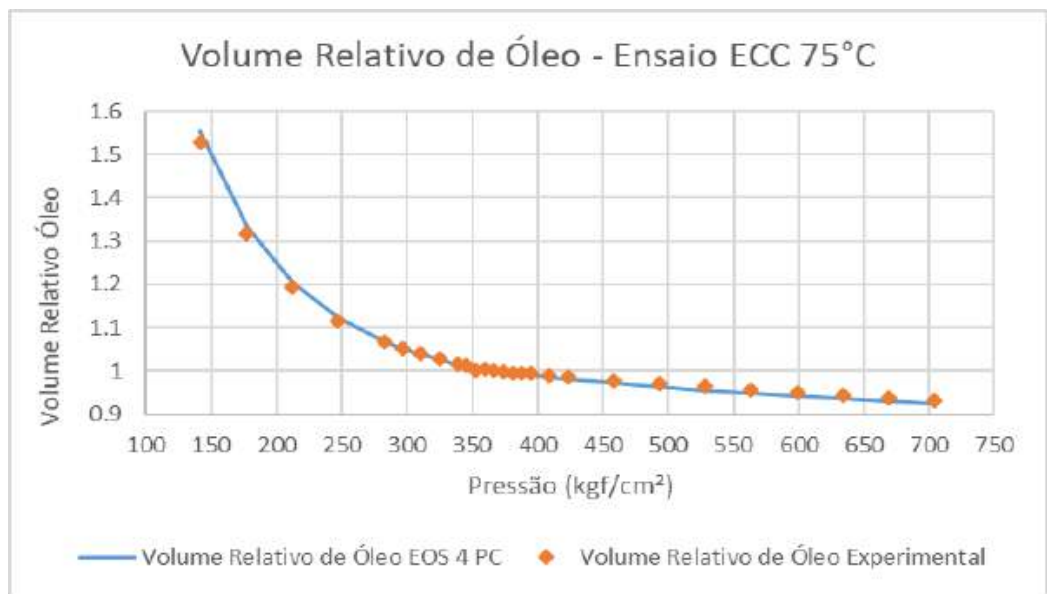

Figura A.119: Volume relativo de óleo, ECC a $75{ }^{\circ} \mathrm{C}$. 


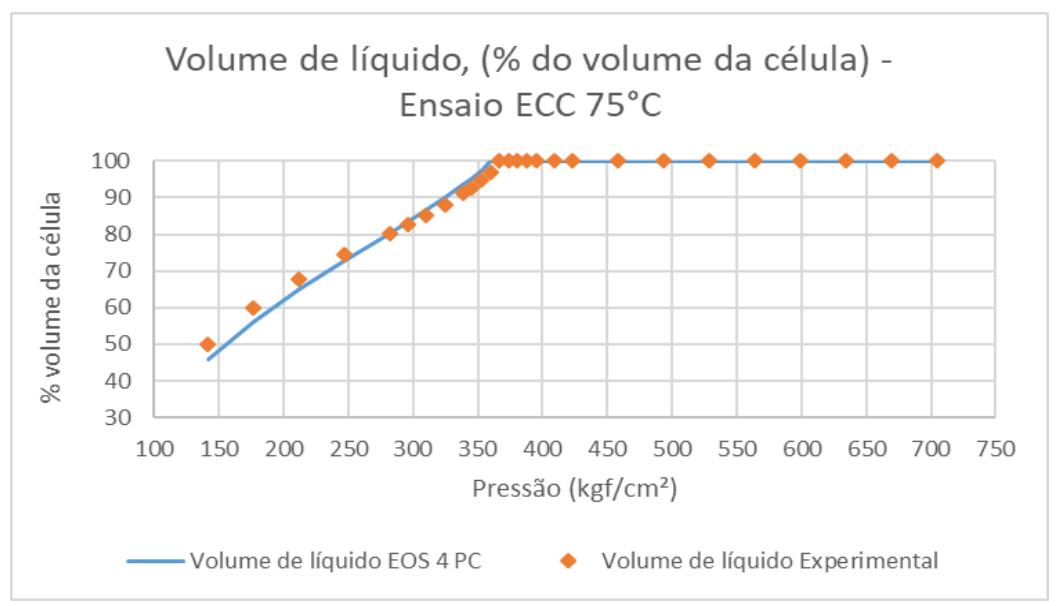

Figura A.120: Volume de líquido, $\%$ do volume da célula, ECC a $75{ }^{\circ} \mathrm{C}$.

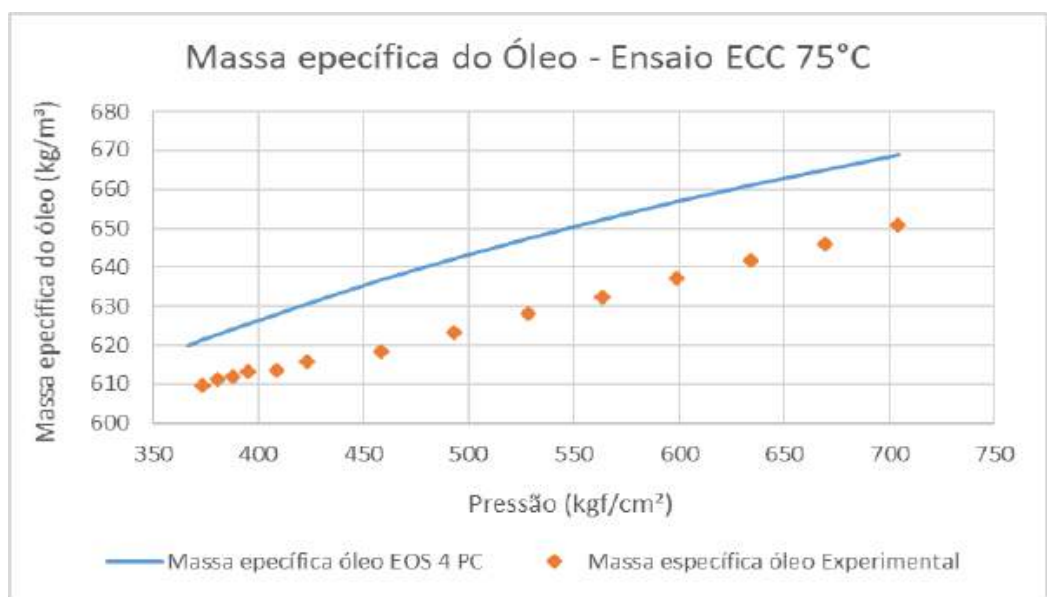

Figura A.121: Massa específica de óleo, ECC a $75{ }^{\circ} \mathrm{C}$.

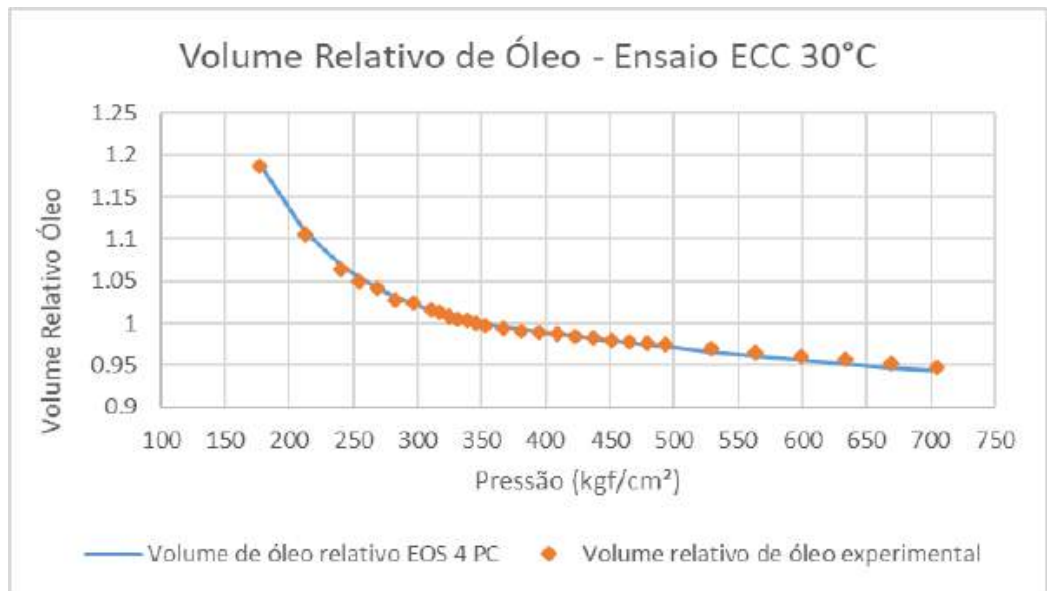

Figura A.122: Volume relativo de óleo, ECC a $30{ }^{\circ} \mathrm{C}$. 


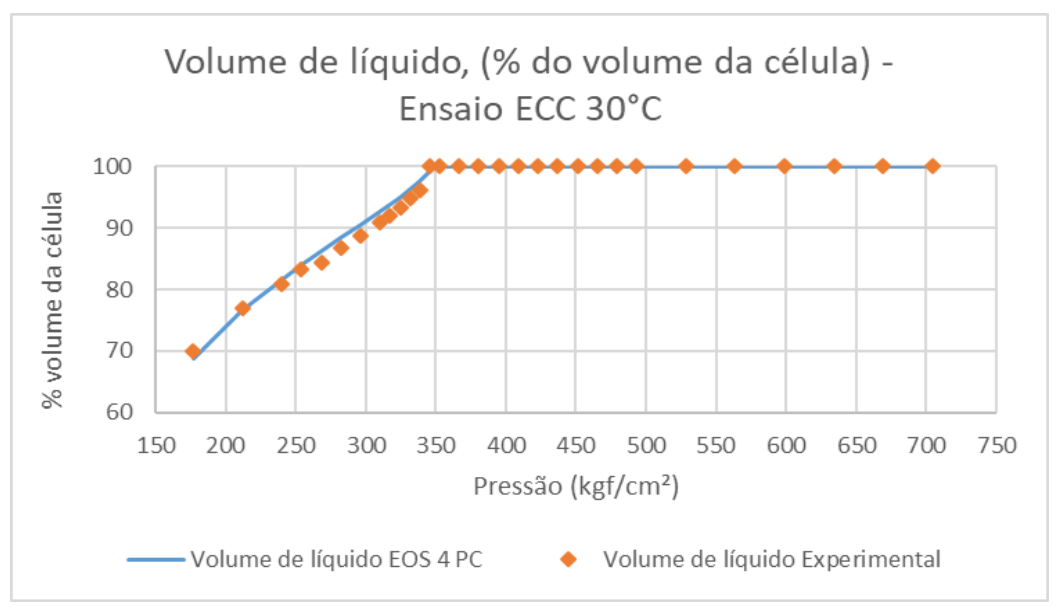

Figura A.123: Volume de líquido, $\%$ do volume da célula, ECC a $30{ }^{\circ} \mathrm{C}$.

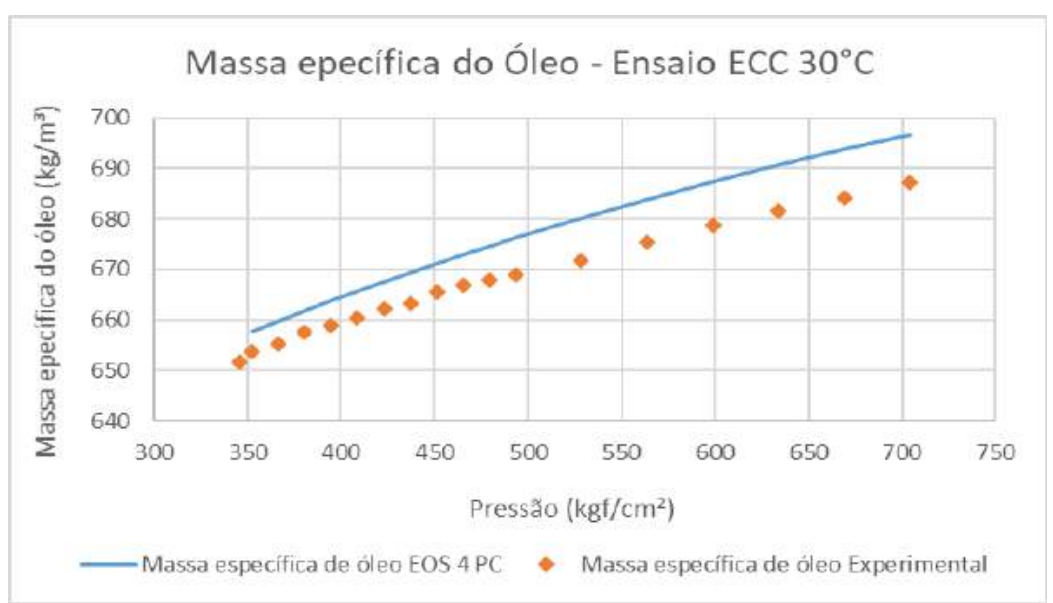

Figura A.124: Massa específica de óleo, ECC a $30{ }^{\circ} \mathrm{C}$. 


\section{A.6.3}

\section{Ensaio de expansão a volume constante}

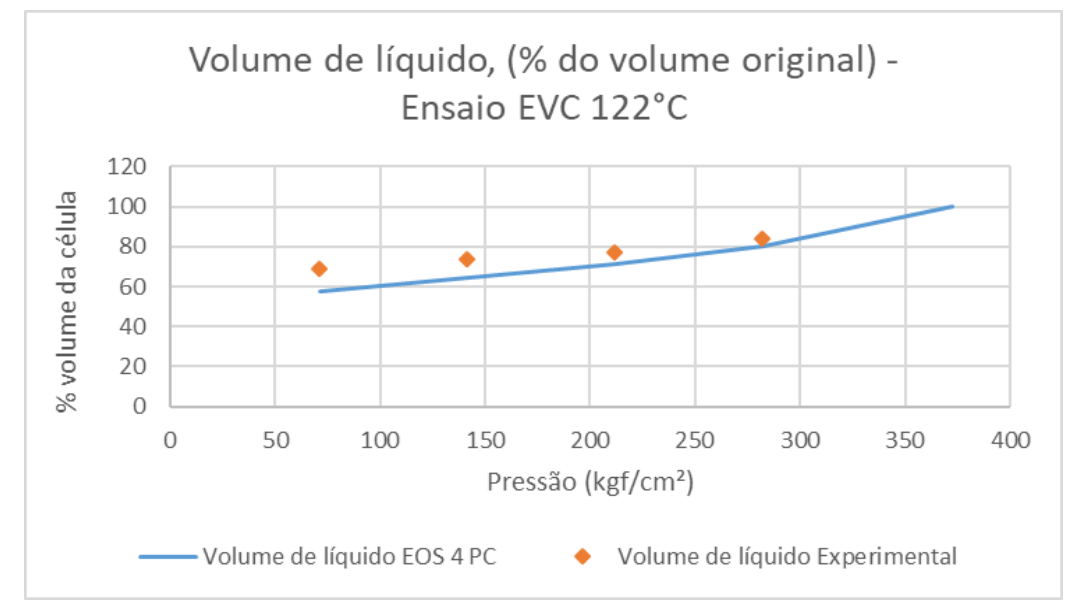

Figura A.125: Volume de líquido, \% do volume original, EVC a $122{ }^{\circ} \mathrm{C}$.

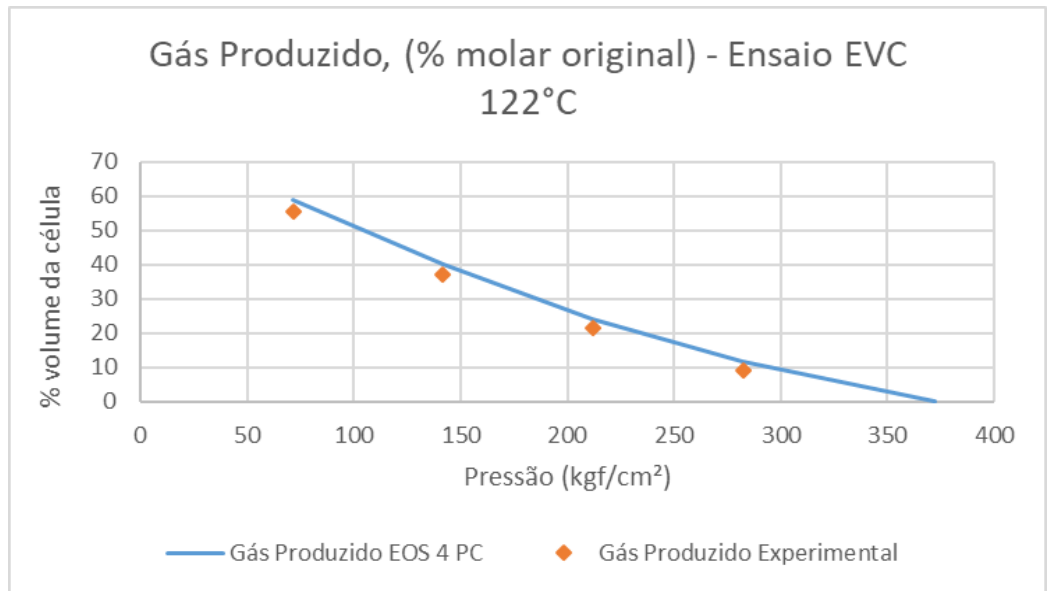

Figura A.126: Gás produzido, \% molar original, EVC a $122{ }^{\circ} \mathrm{C}$. 
B

Resultados - Escoamento no meio poroso

B.1

EOS 24 PC versus EOS 14 PC

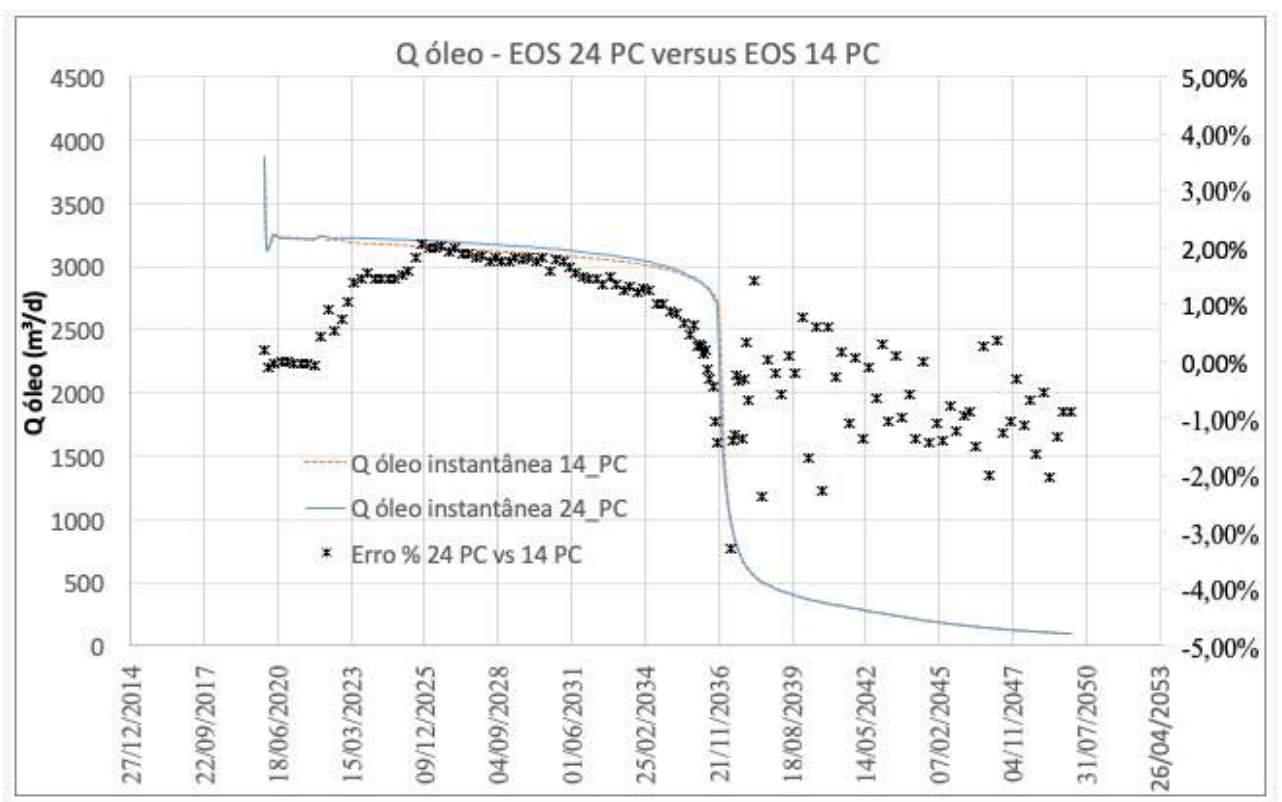

Figura B.1: Vazão de óleo - EOS 24 PC versus EOS 14 PC. 


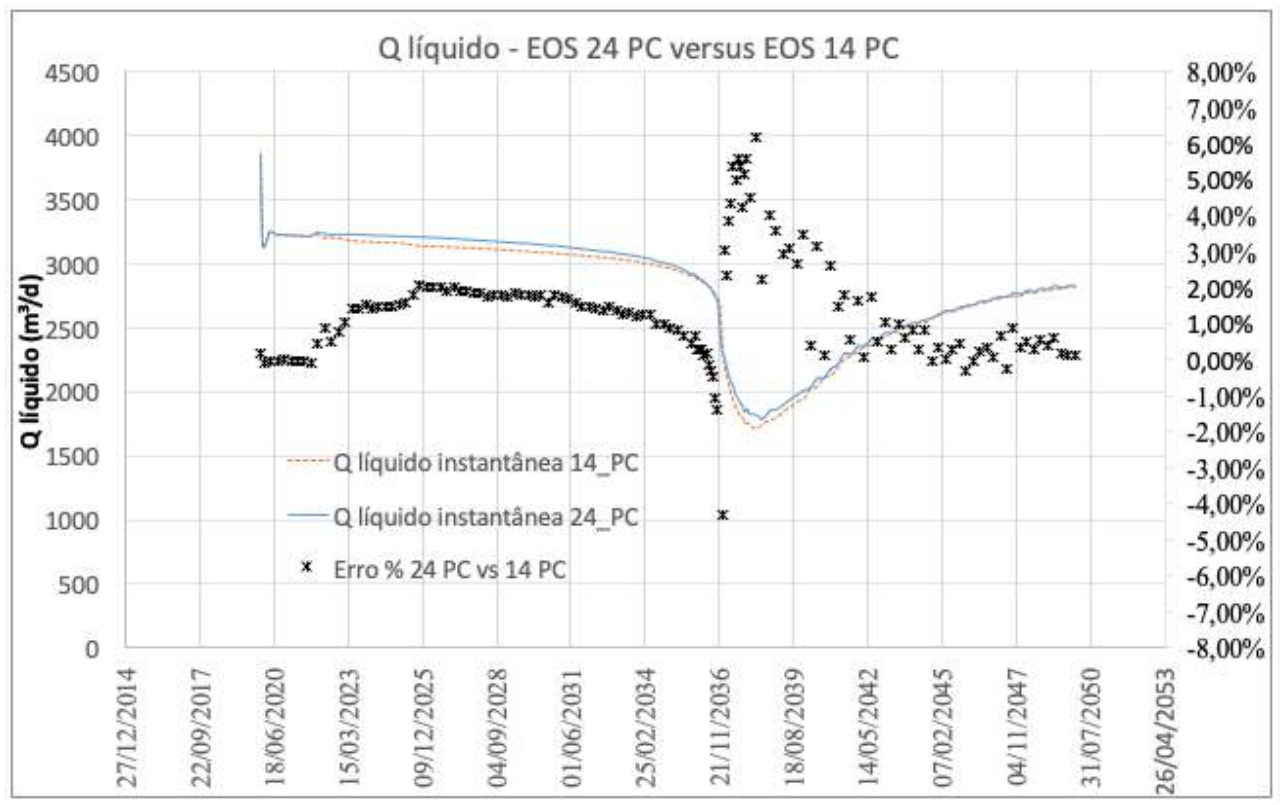

Figura B.2: Vazão de líquido - EOS 24 PC versus EOS 14 PC.

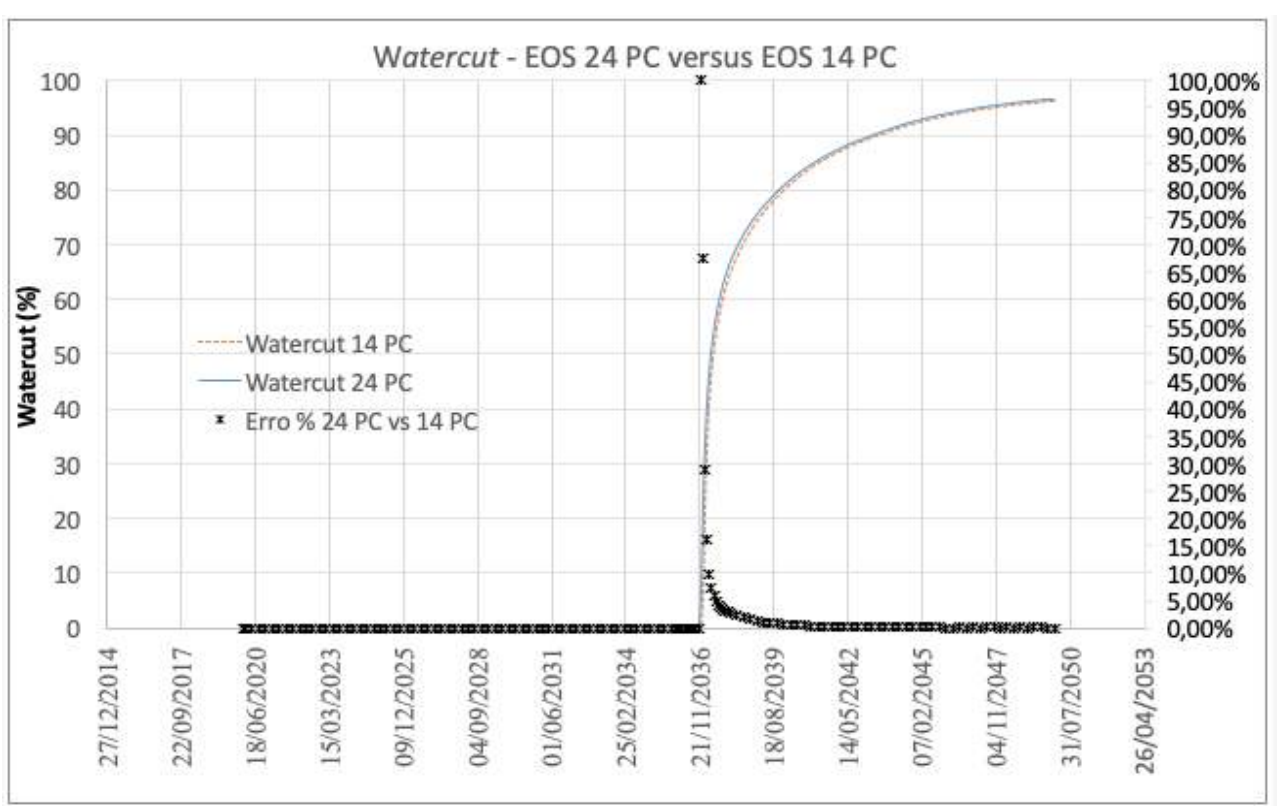

Figura B.3: watercut - EOS 24 PC versus EOS 14 PC. 


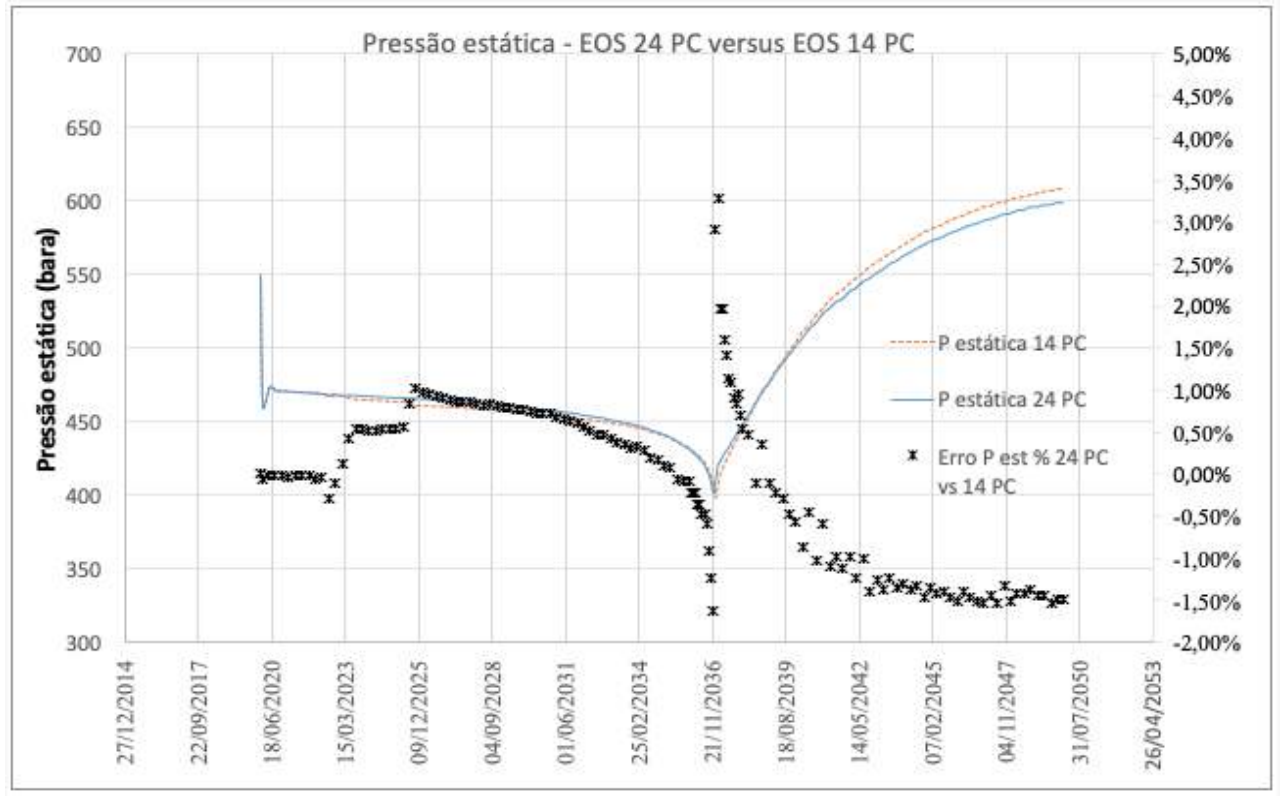

Figura B.4: Pressão estática - EOS 24 PC versus EOS 14 PC.

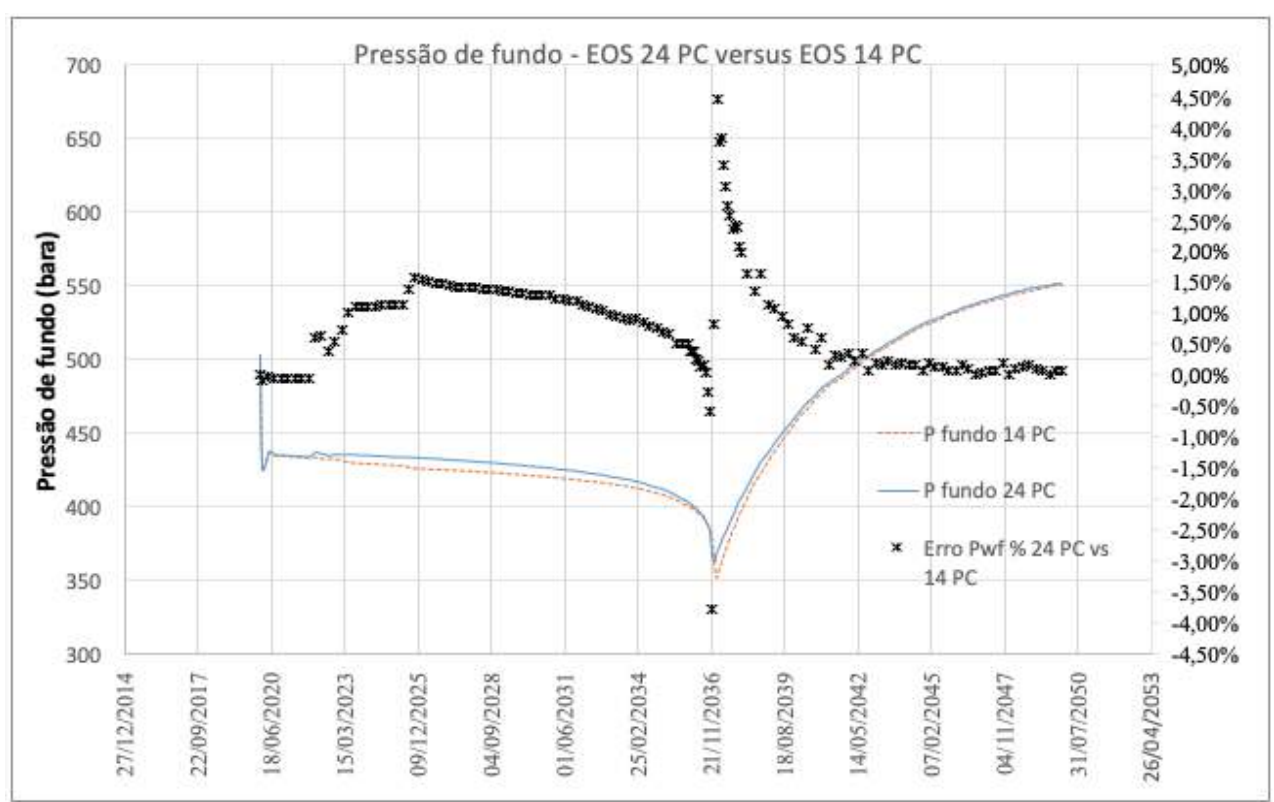

Figura B.5: Pressão de fundo nos canhoneados - EOS 24 PC versus EOS 14 PC. 


\section{B.2}

\section{EOS 24 PC versus EOS 9 PC}

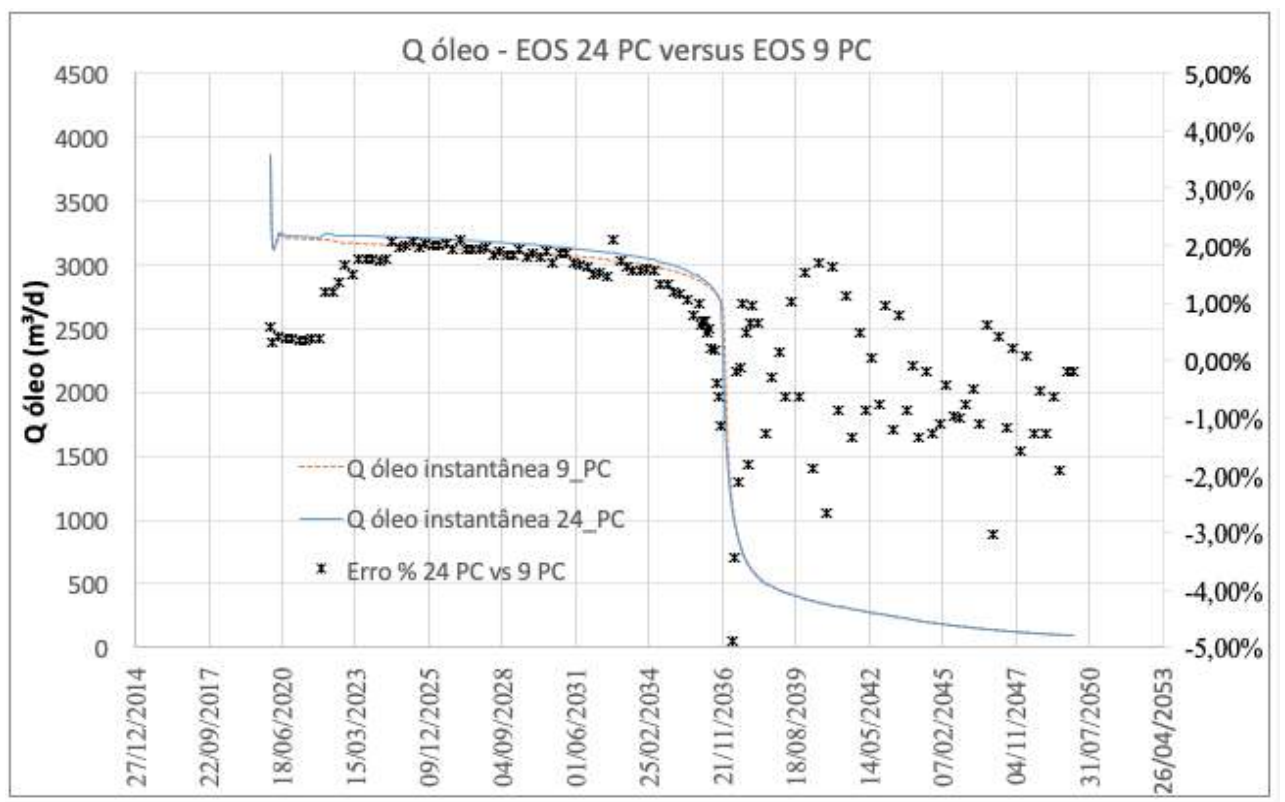

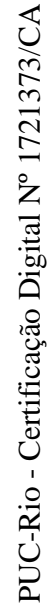

Figura B.6: Vazão de óleo - EOS 24 PC versus EOS 14 PC.

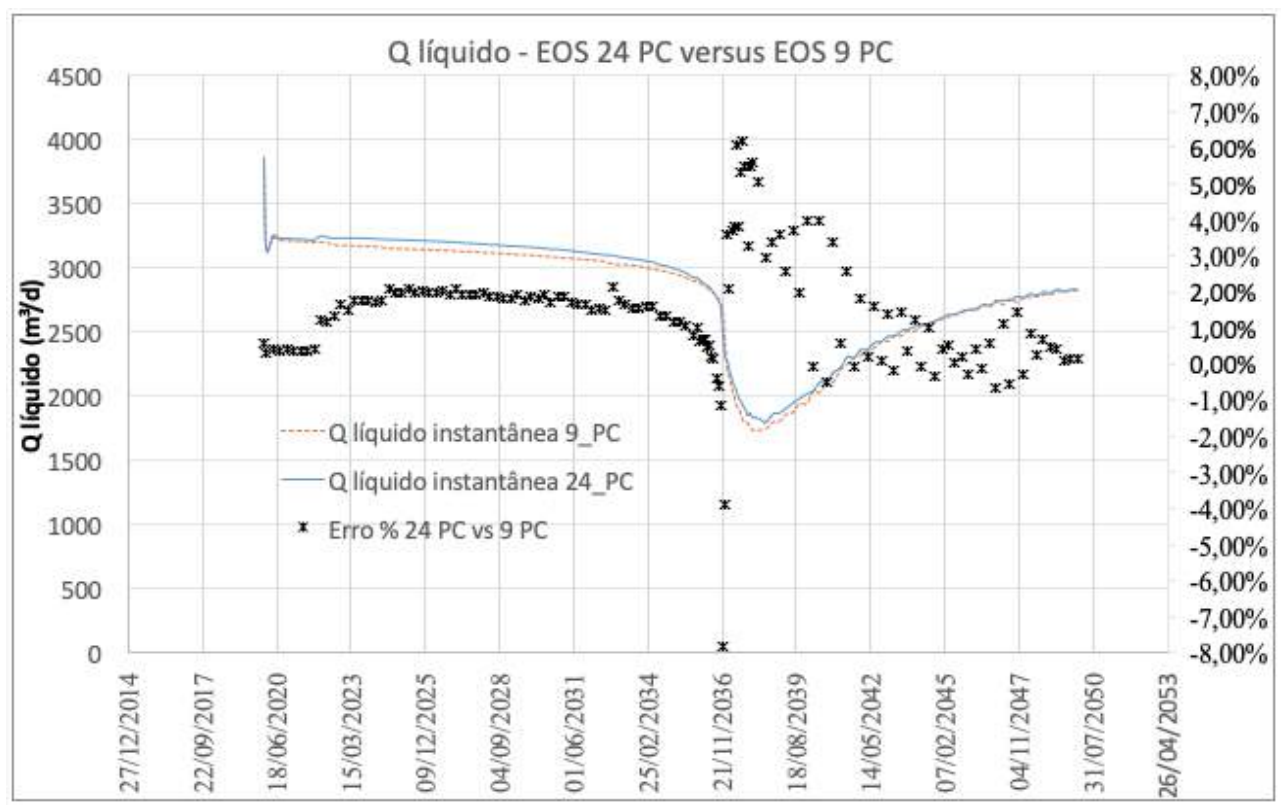

Figura B.7: Vazão de líquido - EOS 24 PC versus EOS 14 PC. 


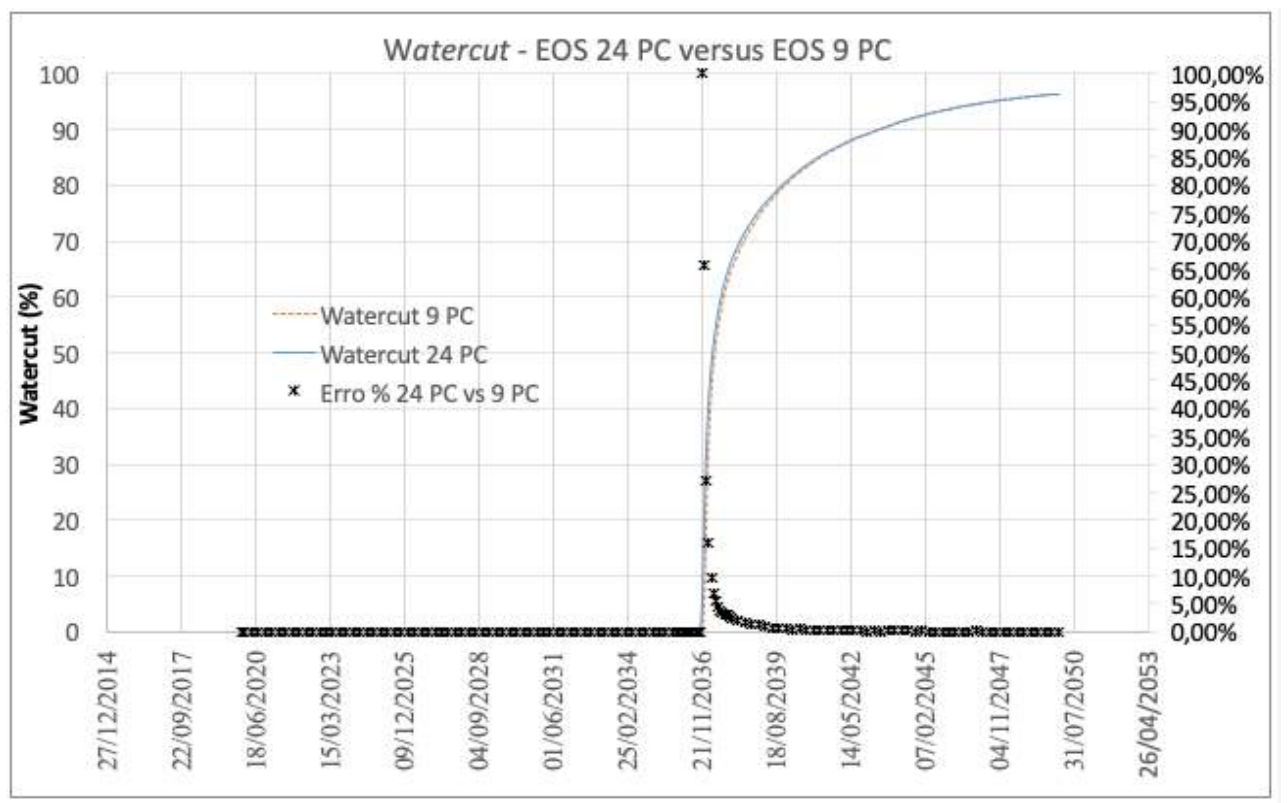

Figura B.8: watercut - EOS 24 PC versus EOS 14 PC.

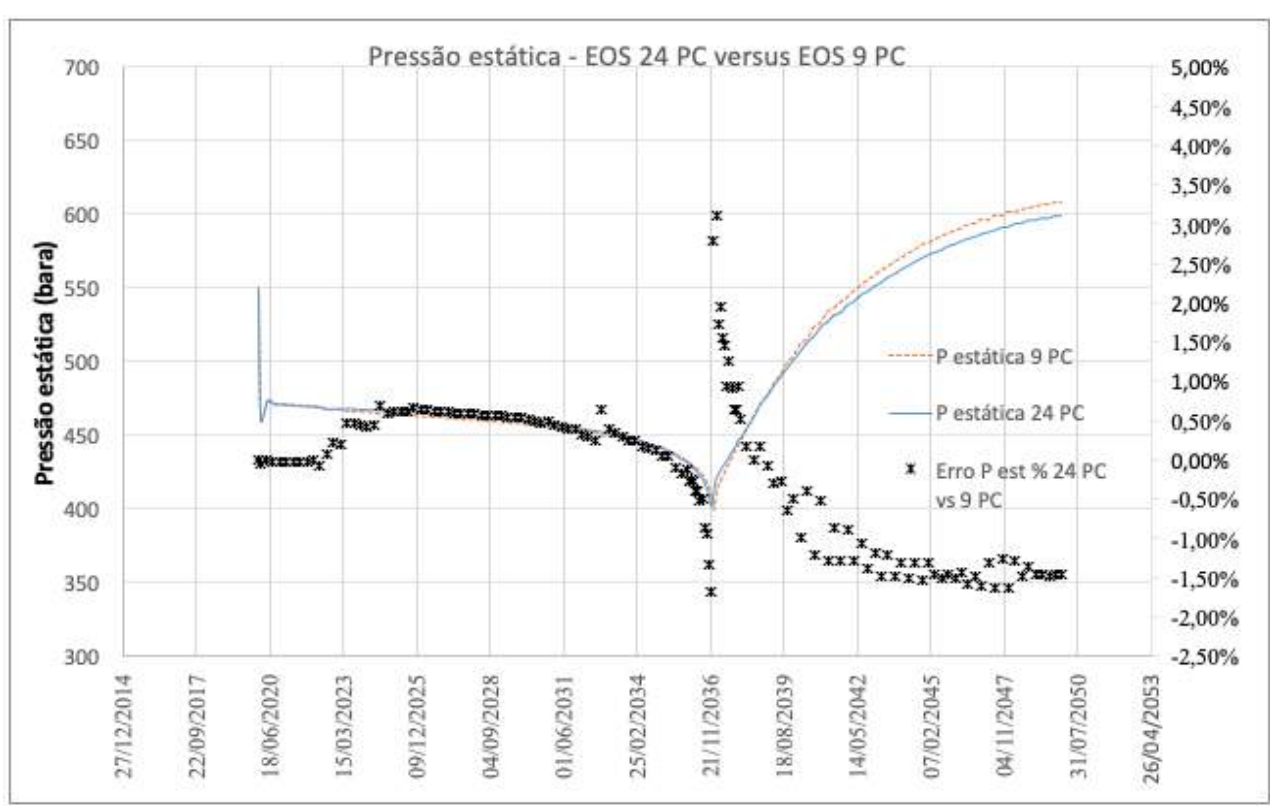

Figura B.9: Pressão estática - EOS 24 PC versus EOS 14 PC. 


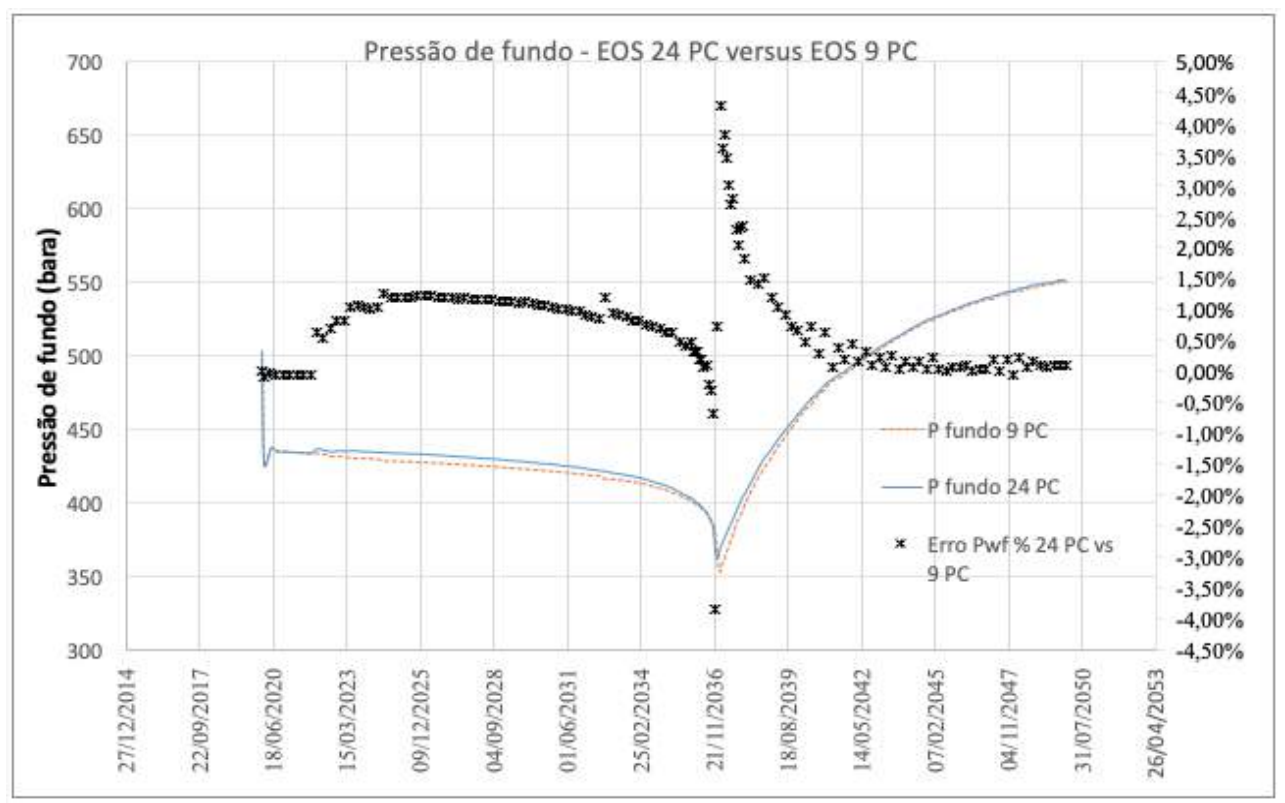

Figura B.10: Pressão de fundo nos canhoneados - EOS 24 PC versus EOS 14 PC.

\section{B.3}

\section{EOS 24 PC versus EOS 7 PC}

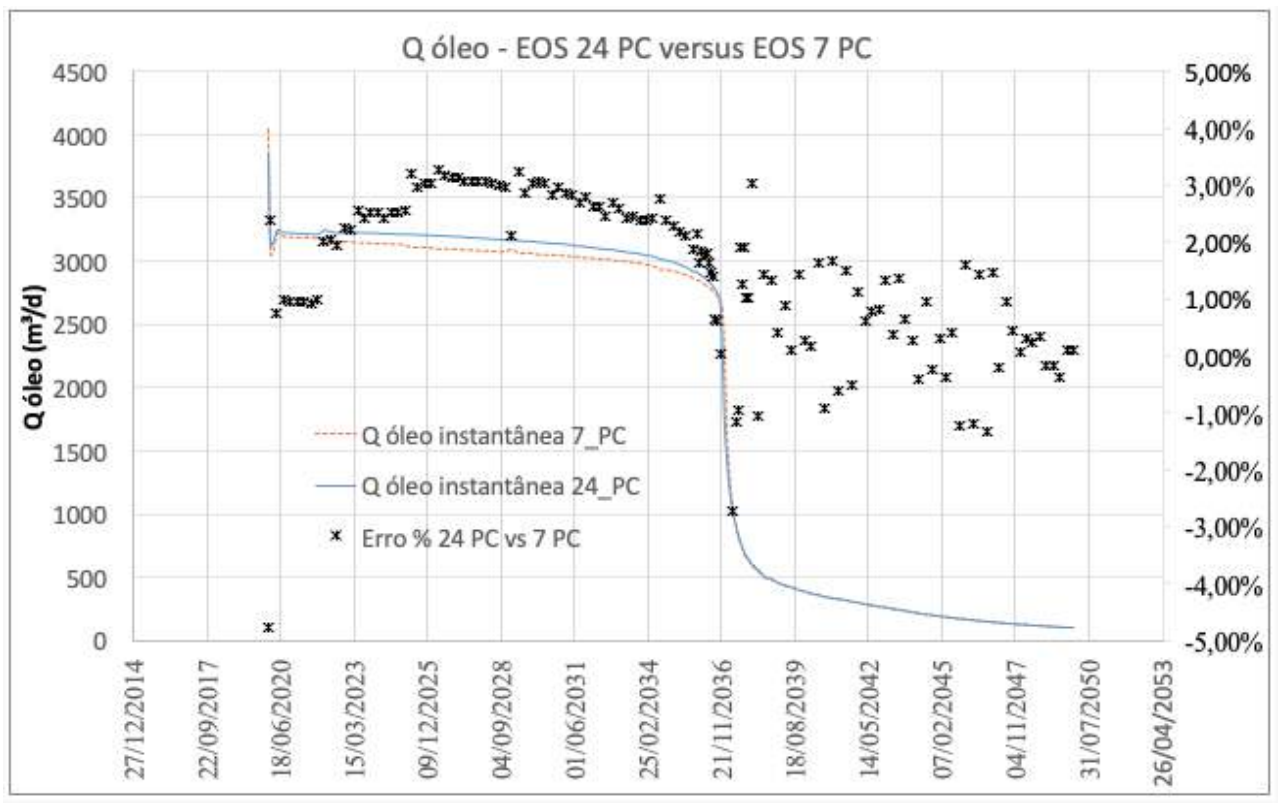

Figura B.11: Vazão de óleo - EOS 24 PC versus EOS 14 PC. 


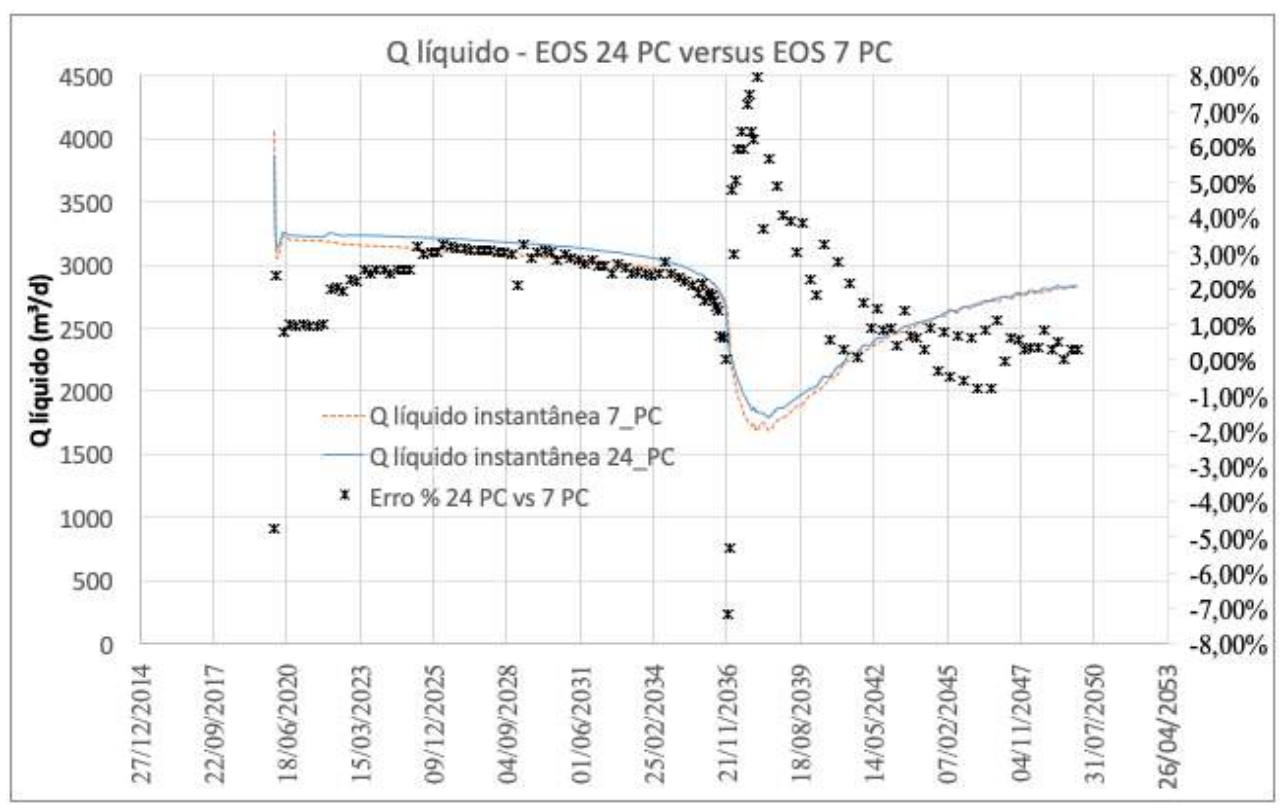

Figura B.12: Vazão de líquido - EOS 24 PC versus EOS 14 PC.

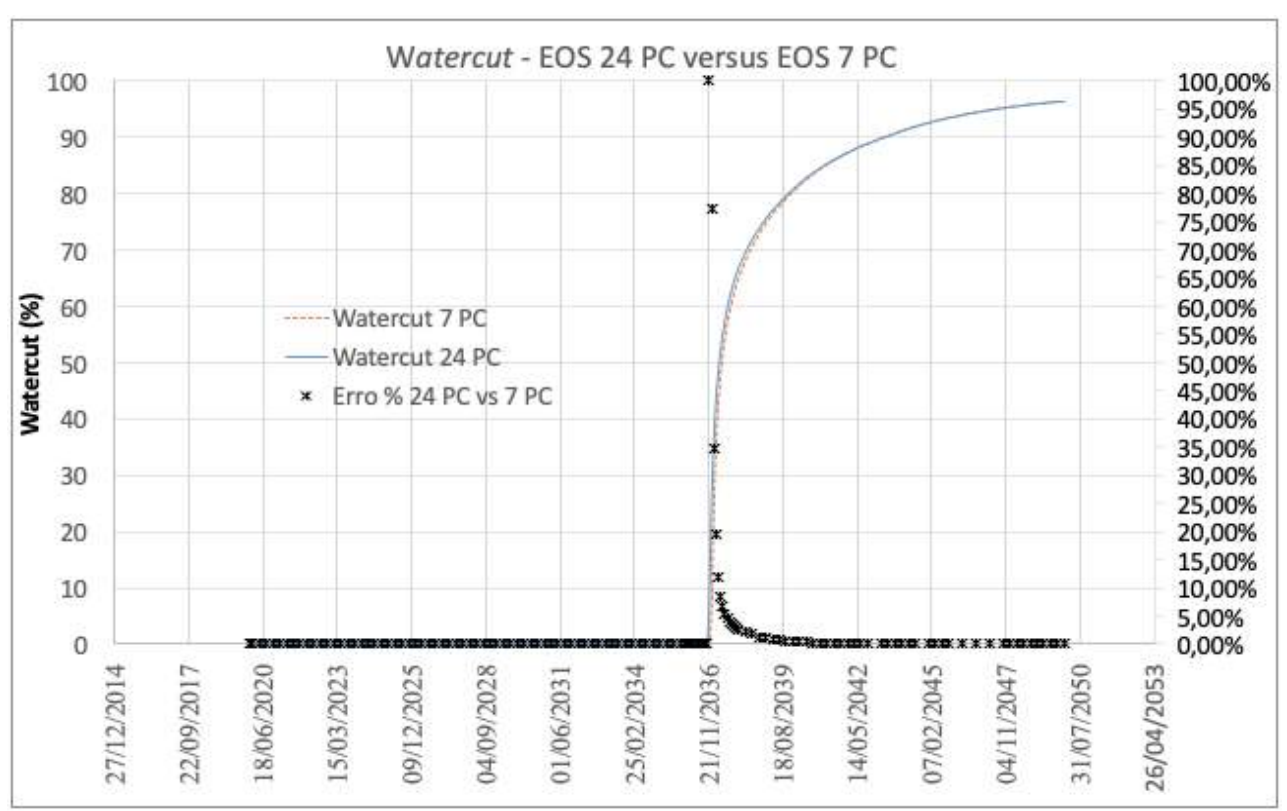

Figura B.13: watercut - EOS 24 PC versus EOS 14 PC. 


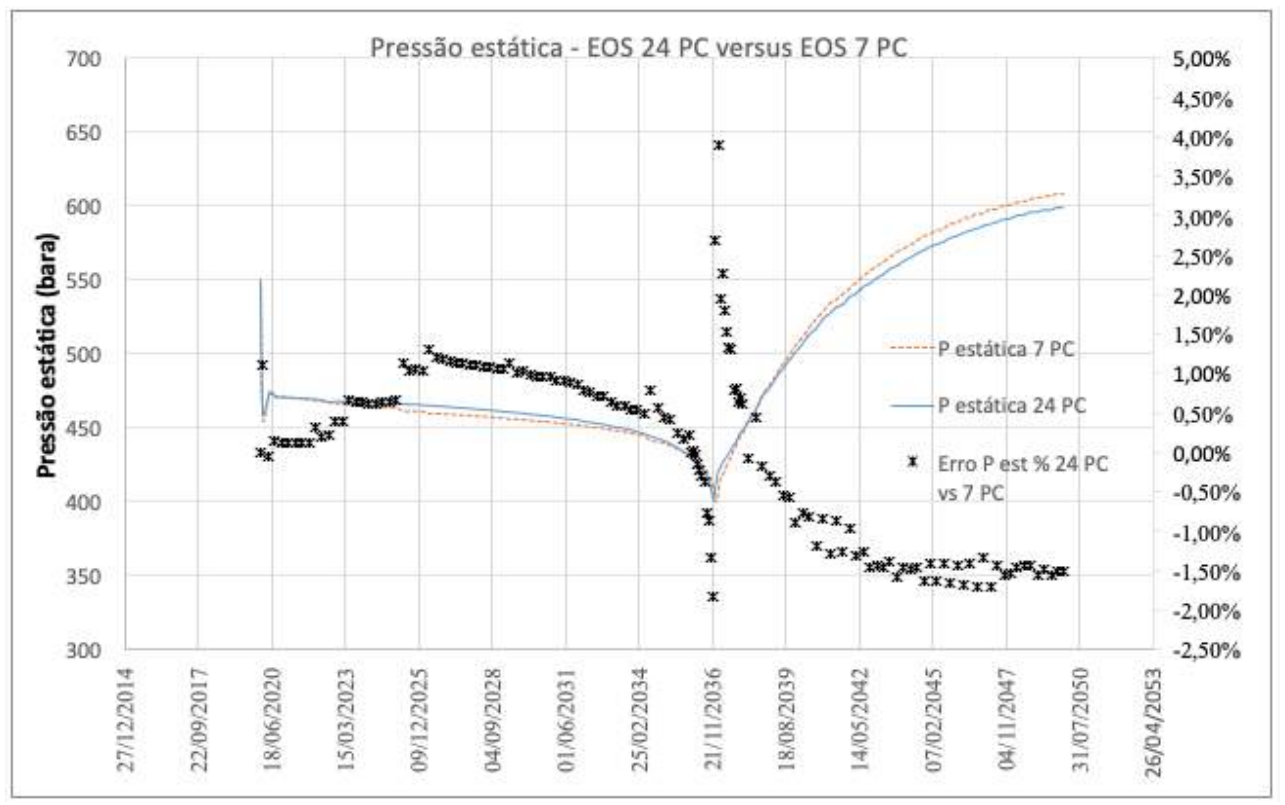

Figura B.14: Pressão estática - EOS 24 PC versus EOS 14 PC.

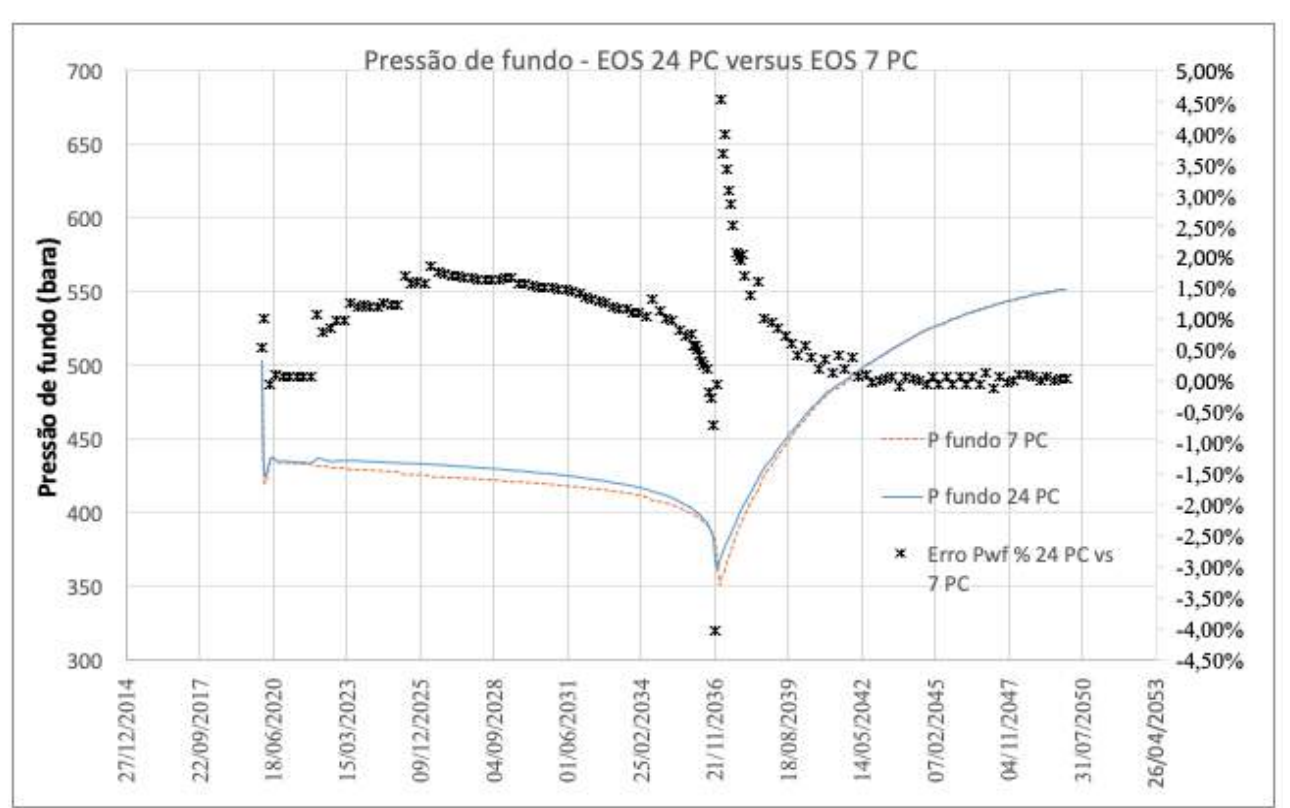

Figura B.15: Pressão de fundo nos canhoneados - EOS 24 PC versus EOS 14 PC. 


\section{B.4}

\section{EOS 24 PC versus EOS 6 PC}

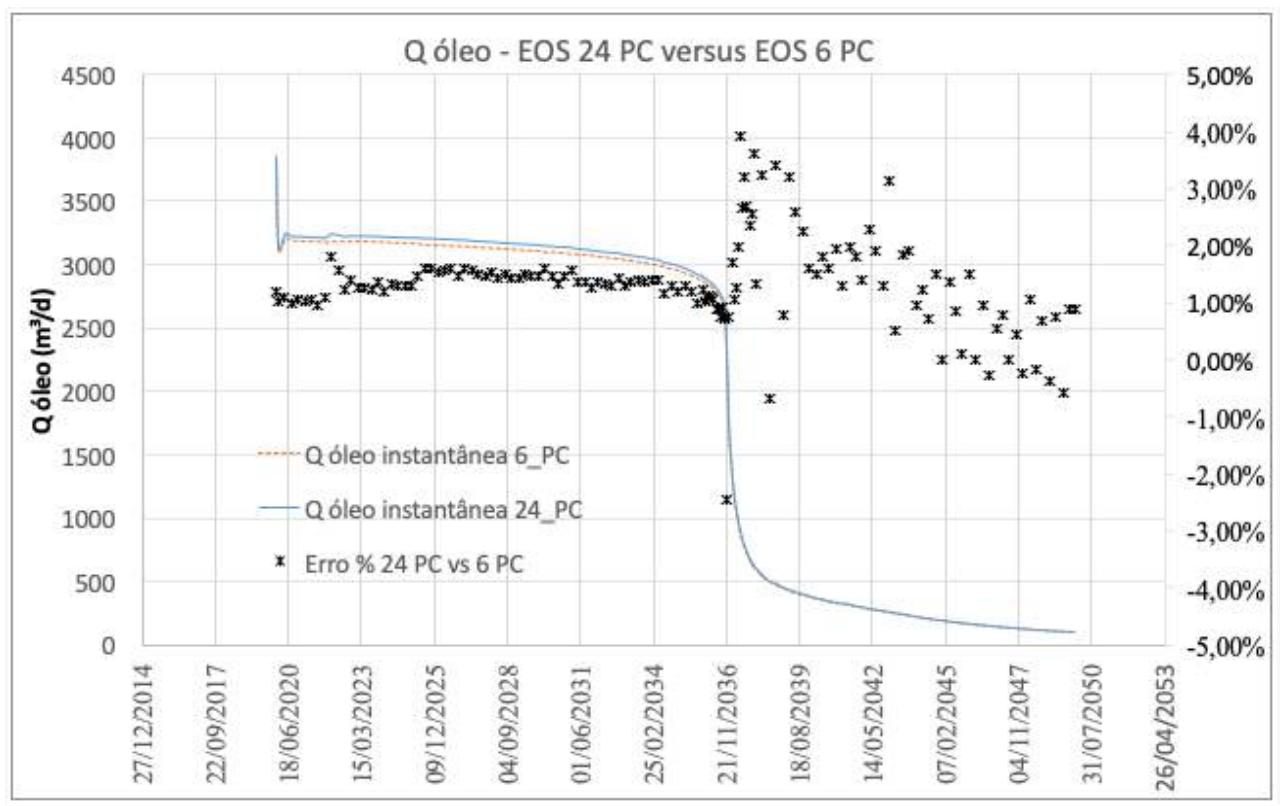

Figura B.16: Vazão de óleo - EOS 24 PC versus EOS 14 PC.

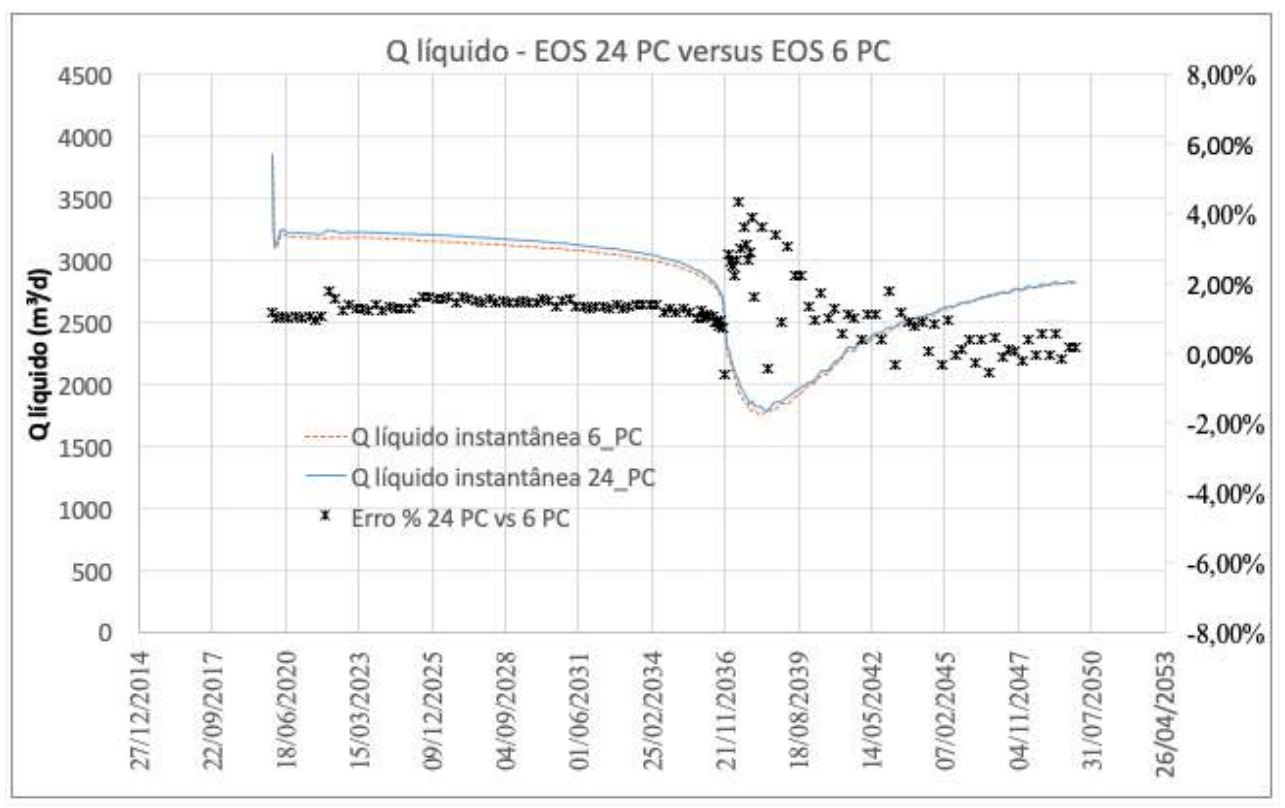

Figura B.17: Vazão de líquido - EOS 24 PC versus EOS 14 PC. 


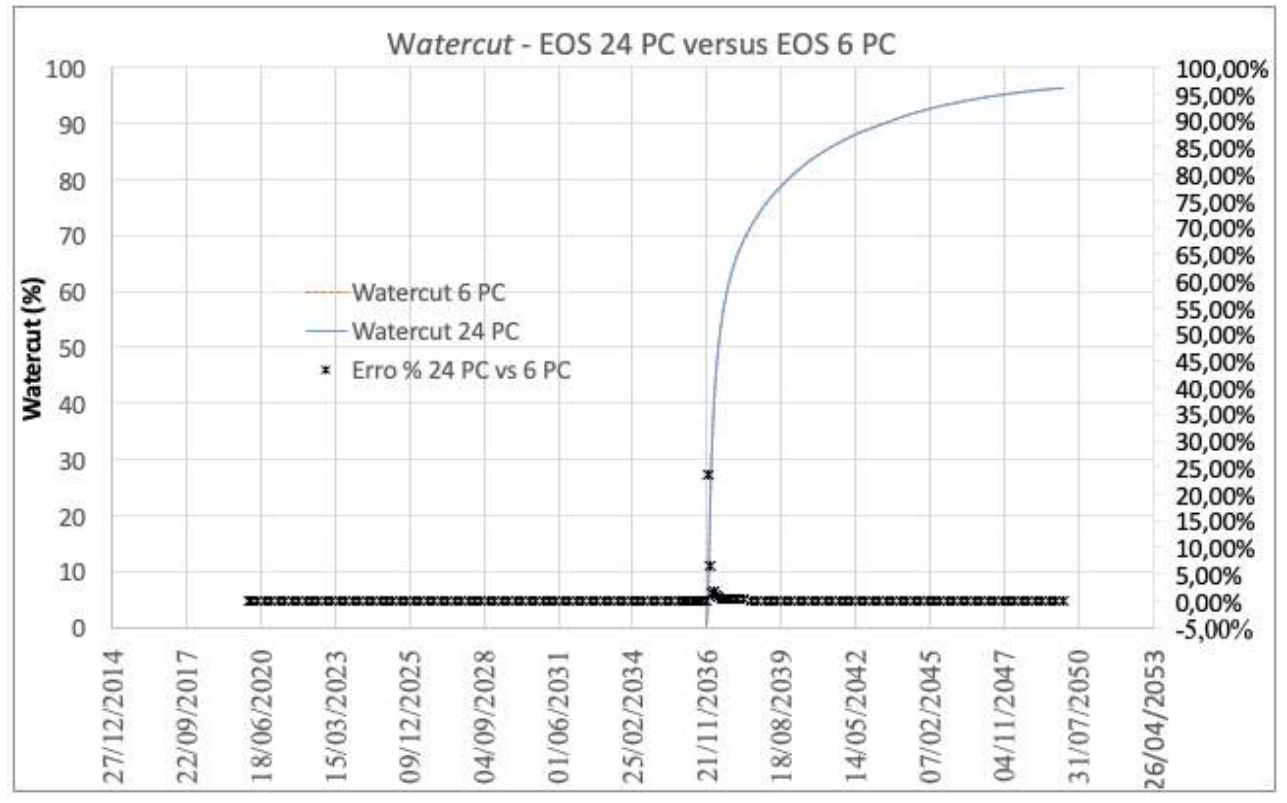

Figura B.18: watercut - EOS 24 PC versus EOS 14 PC.

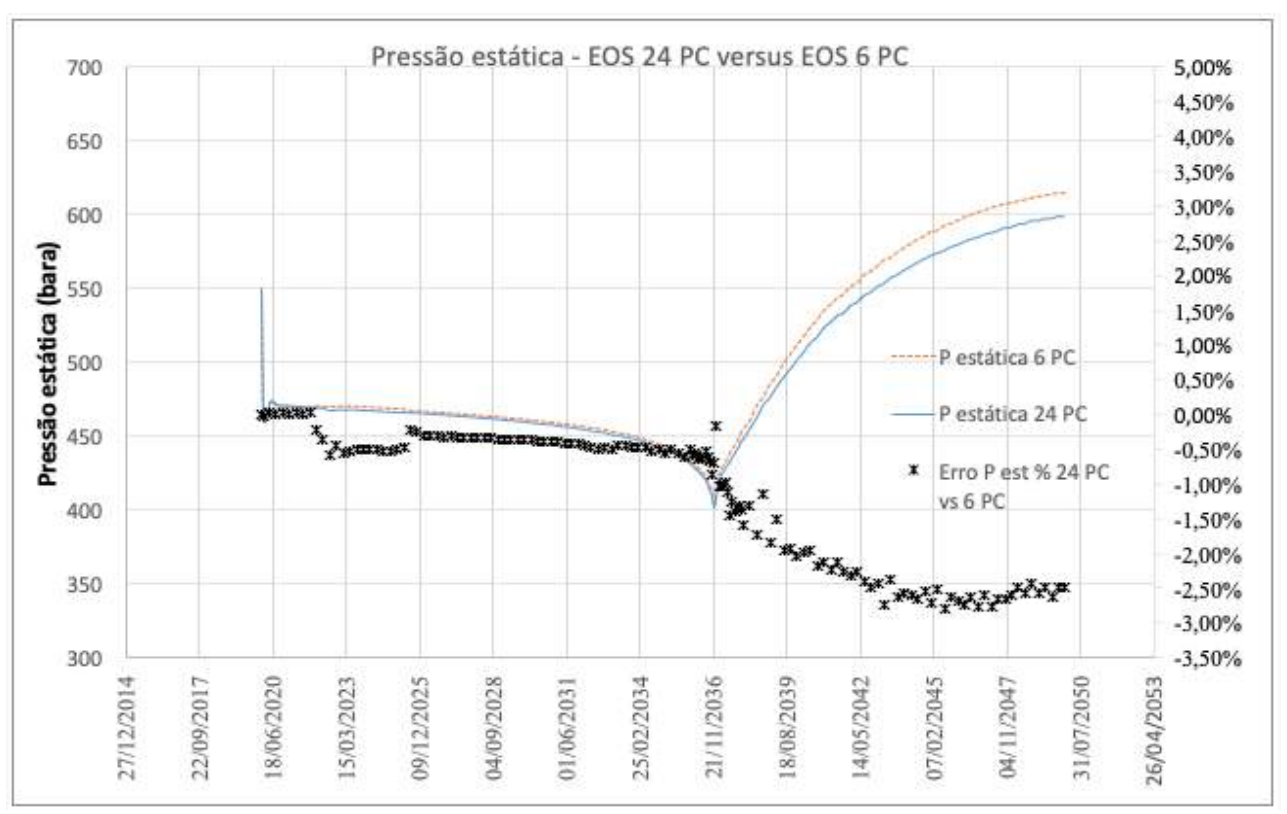

Figura B.19: Pressão estática - EOS 24 PC versus EOS 14 PC. 


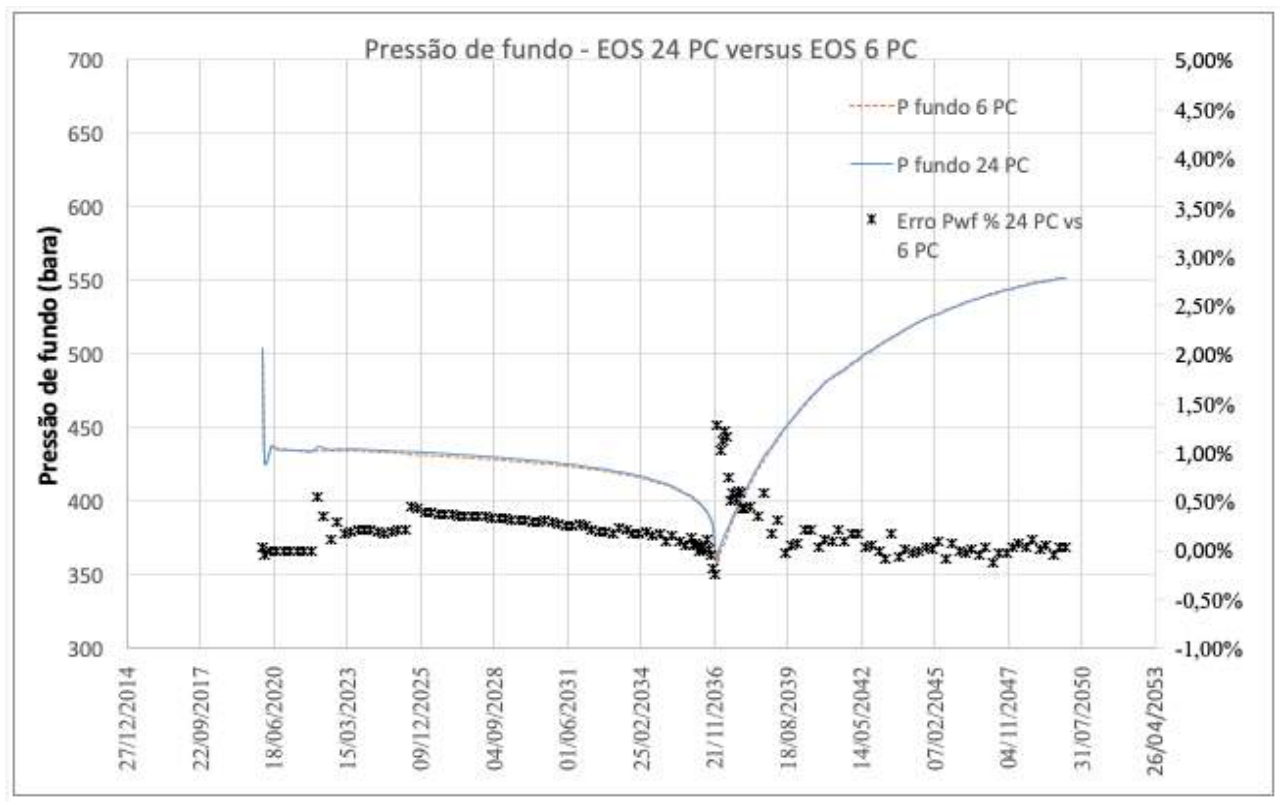

Figura B.20: Pressão de fundo nos canhoneados - EOS 24 PC versus EOS 14 PC.

\section{B.5}

\section{EOS 24 PC versus EOS 5 PC}

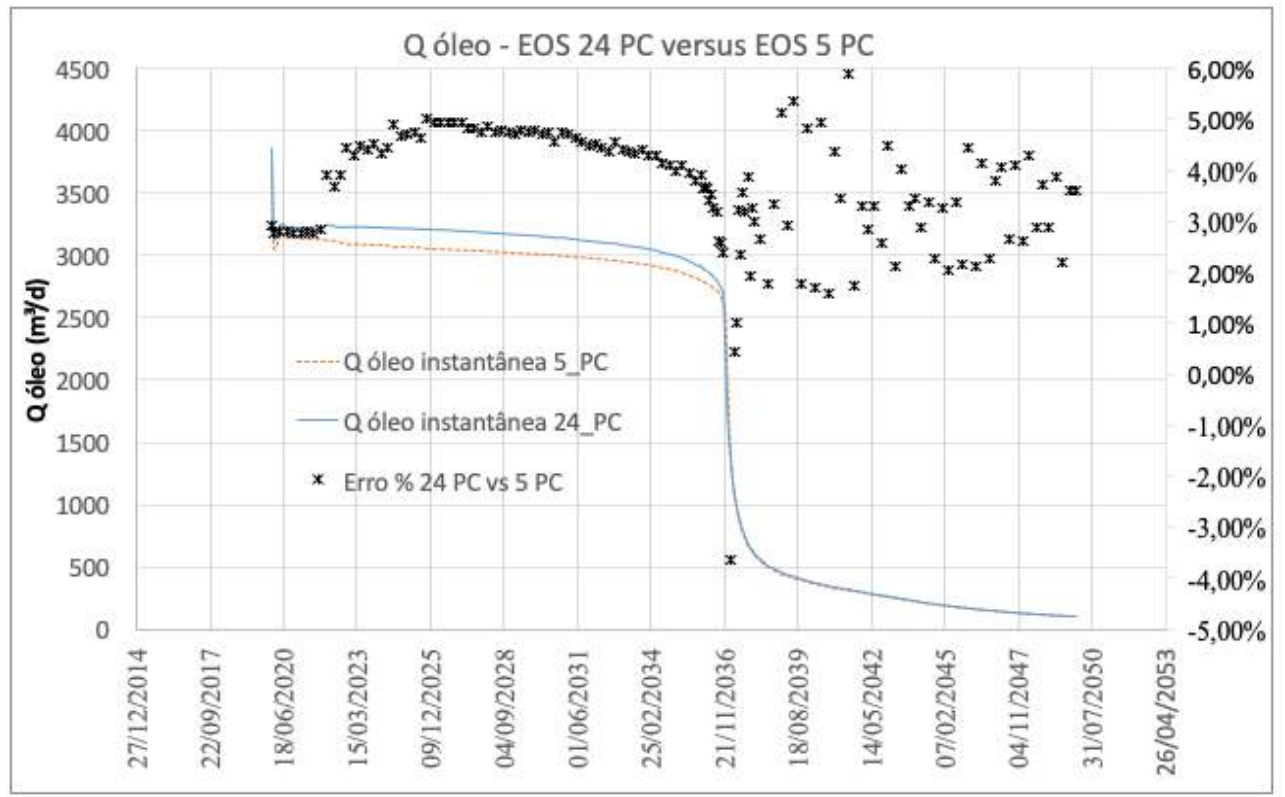

Figura B.21: Vazão de óleo - EOS 24 PC versus EOS 14 PC. 


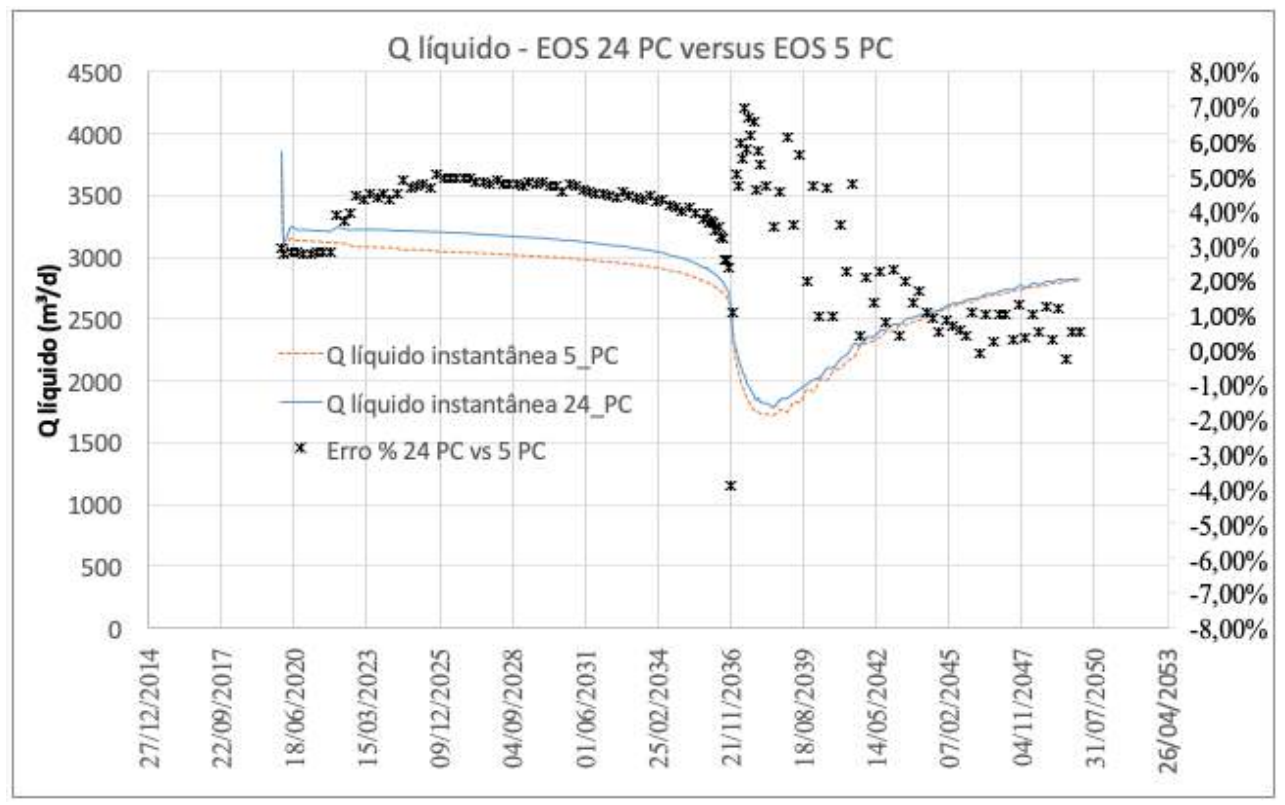

Figura B.22: Vazão de líquido - EOS 24 PC versus EOS 14 PC.

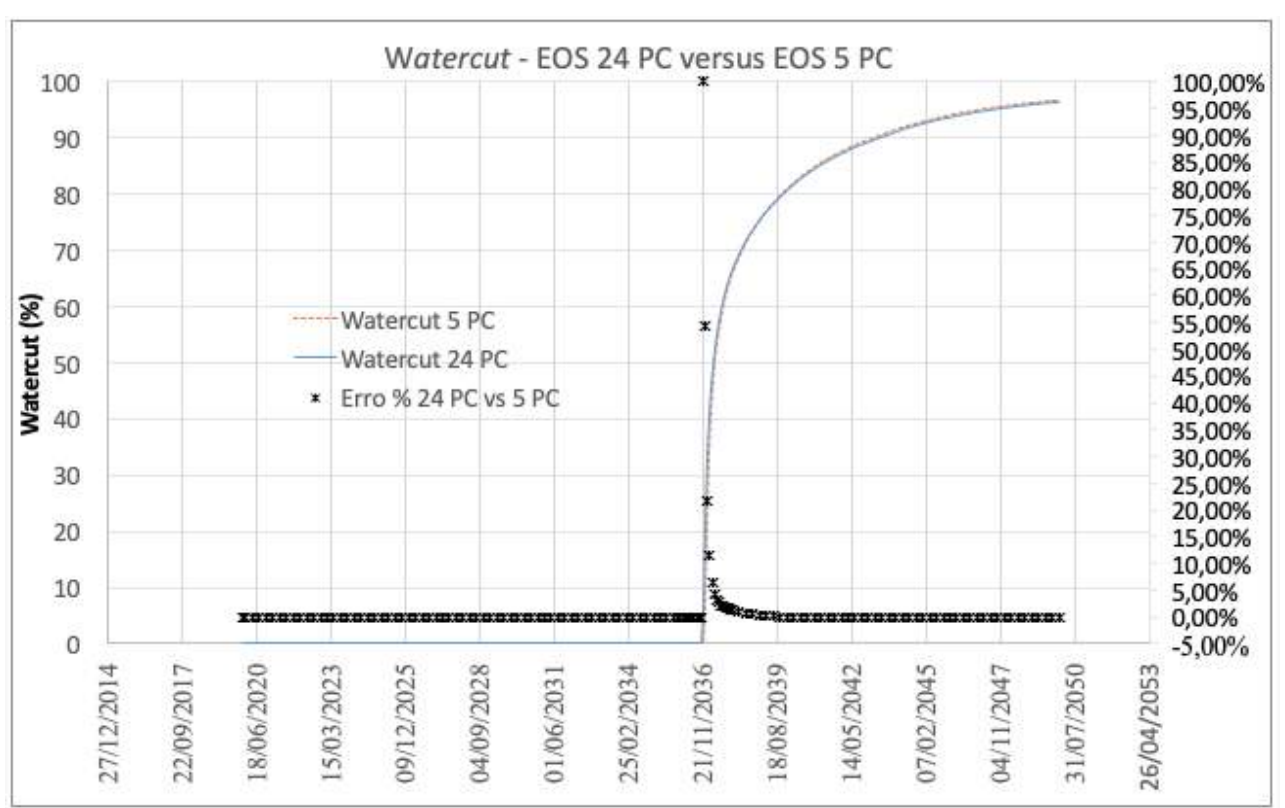

Figura B.23: watercut - EOS 24 PC versus EOS 14 PC. 


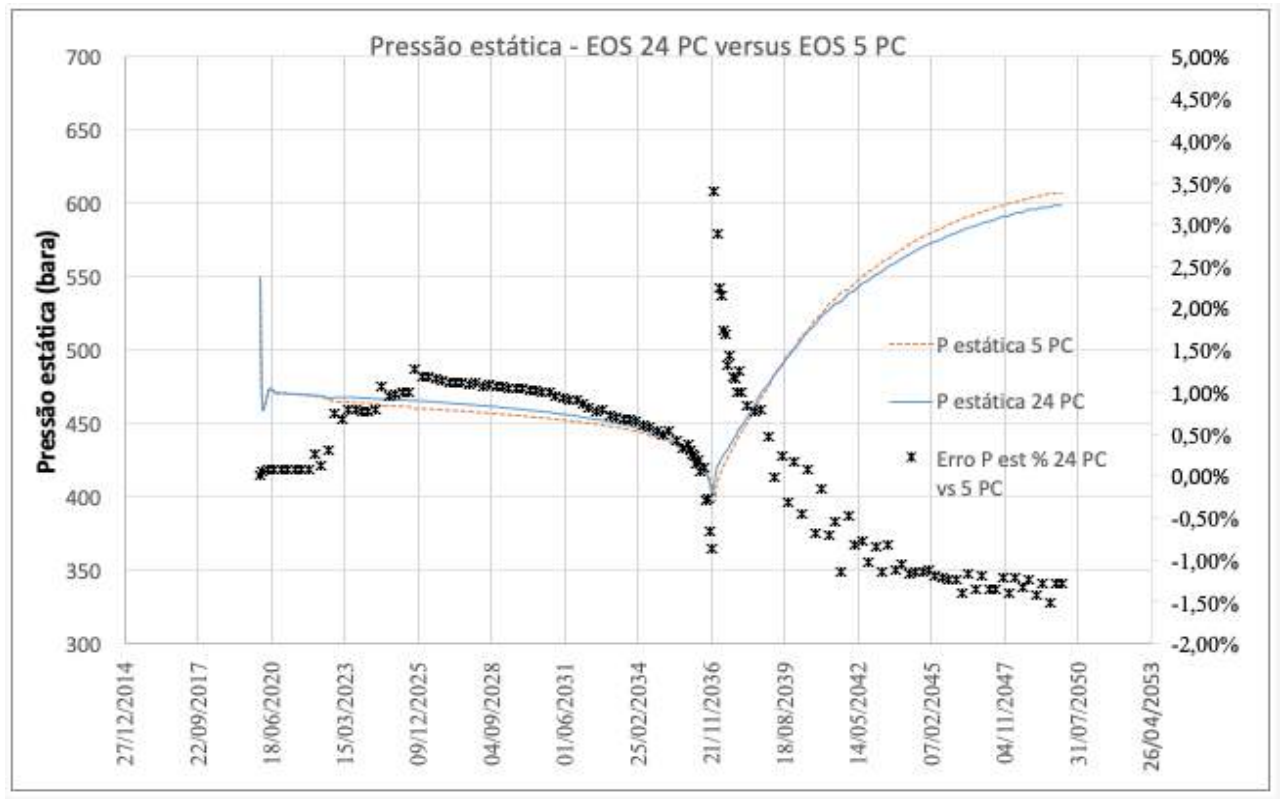

Figura B.24: Pressão estática - EOS 24 PC versus EOS 14 PC.

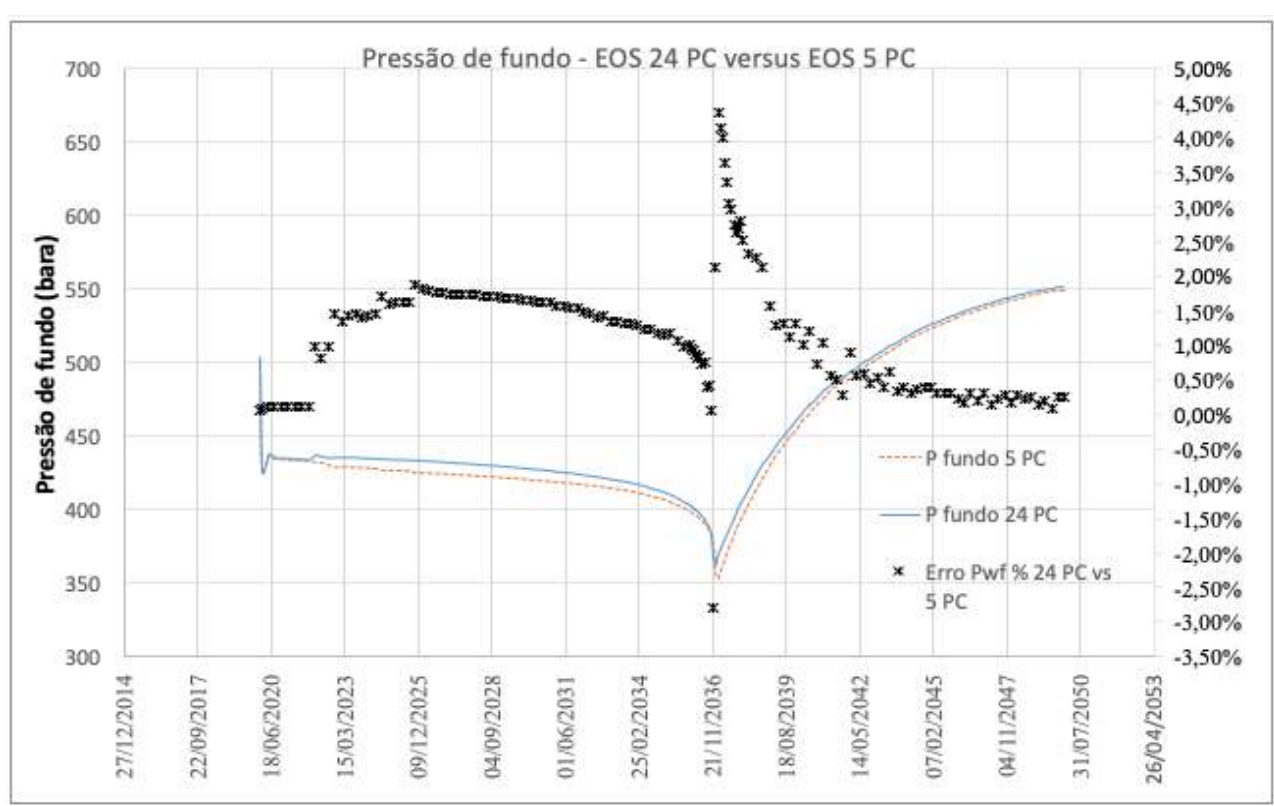

Figura B.25: Pressão de fundo nos canhoneados - EOS 24 PC versus EOS 14 PC. 


\section{B.6}

\section{EOS 24 PC versus EOS 4 PC}

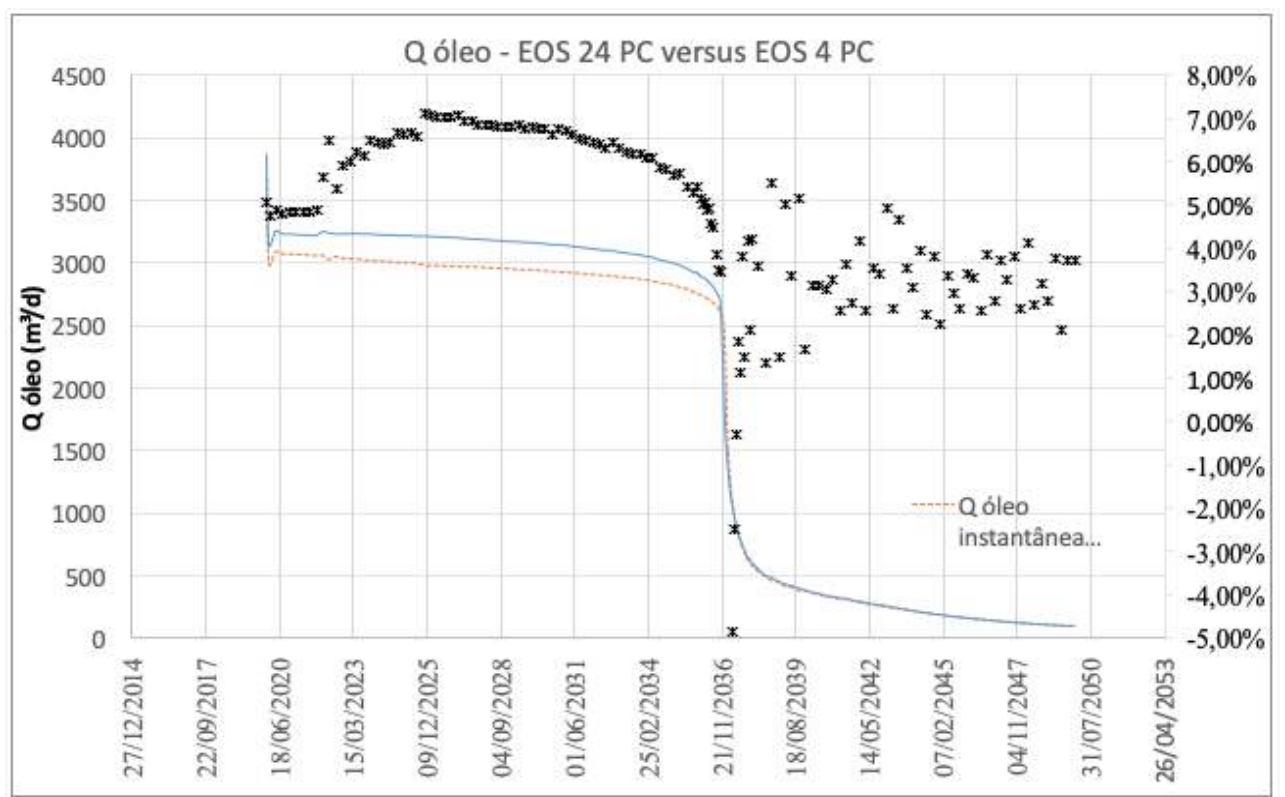

Figura B.26: Vazão de óleo - EOS 24 PC versus EOS 14 PC.

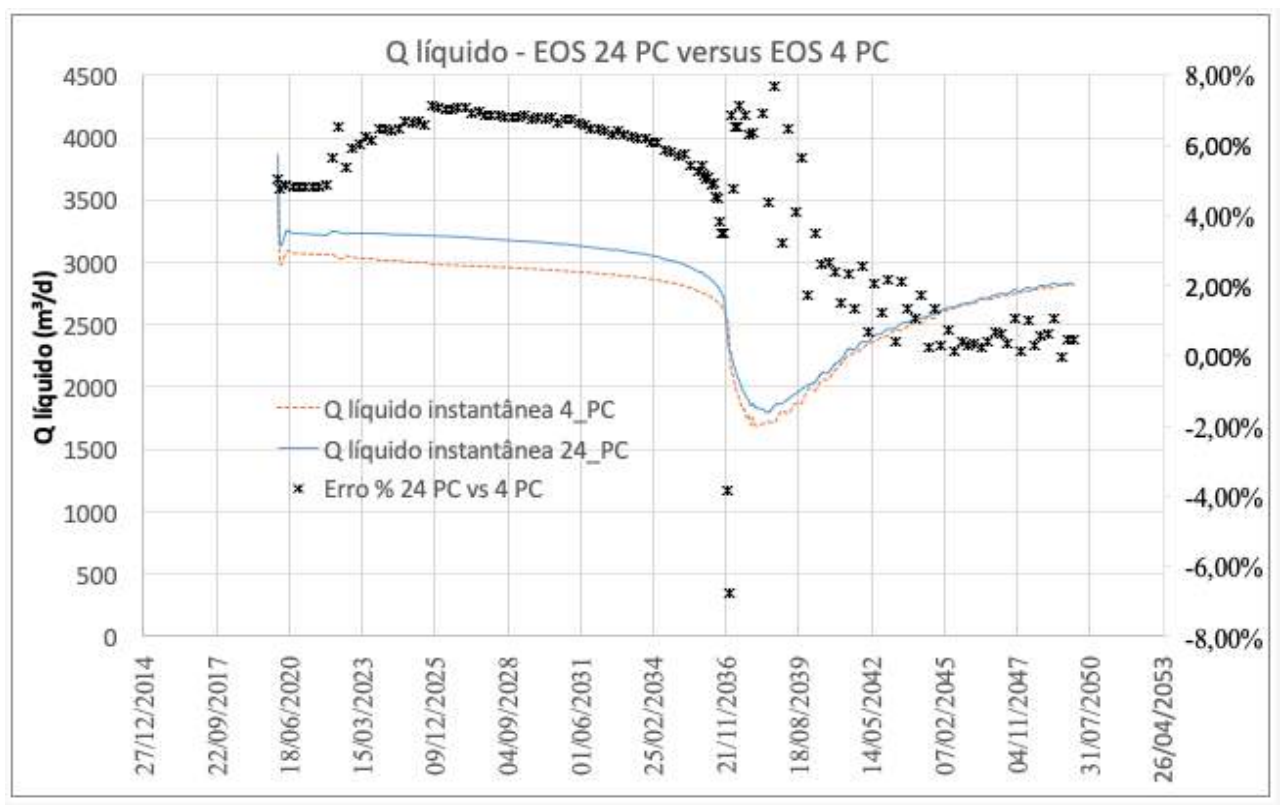

Figura B.27: Vazão de líquido - EOS 24 PC versus EOS 14 PC. 


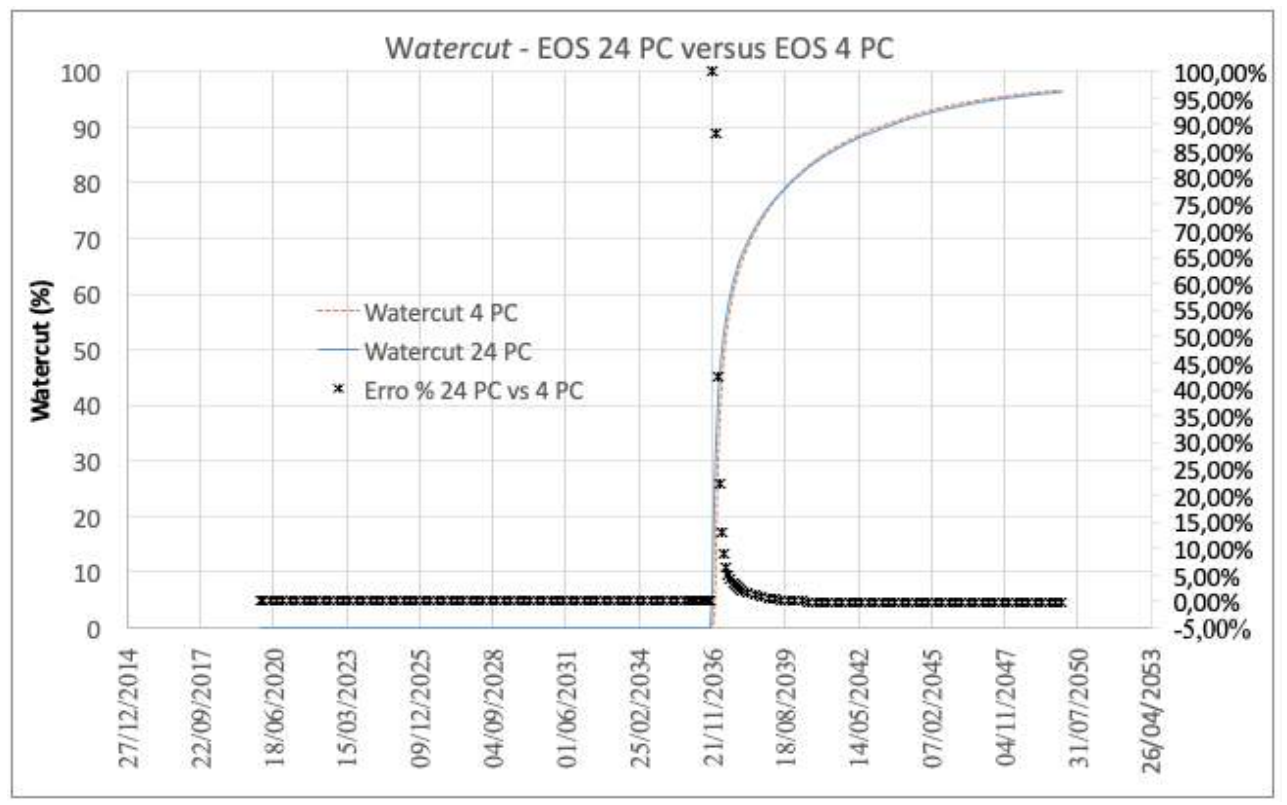

Figura B.28: watercut - EOS 24 PC versus EOS 14 PC.

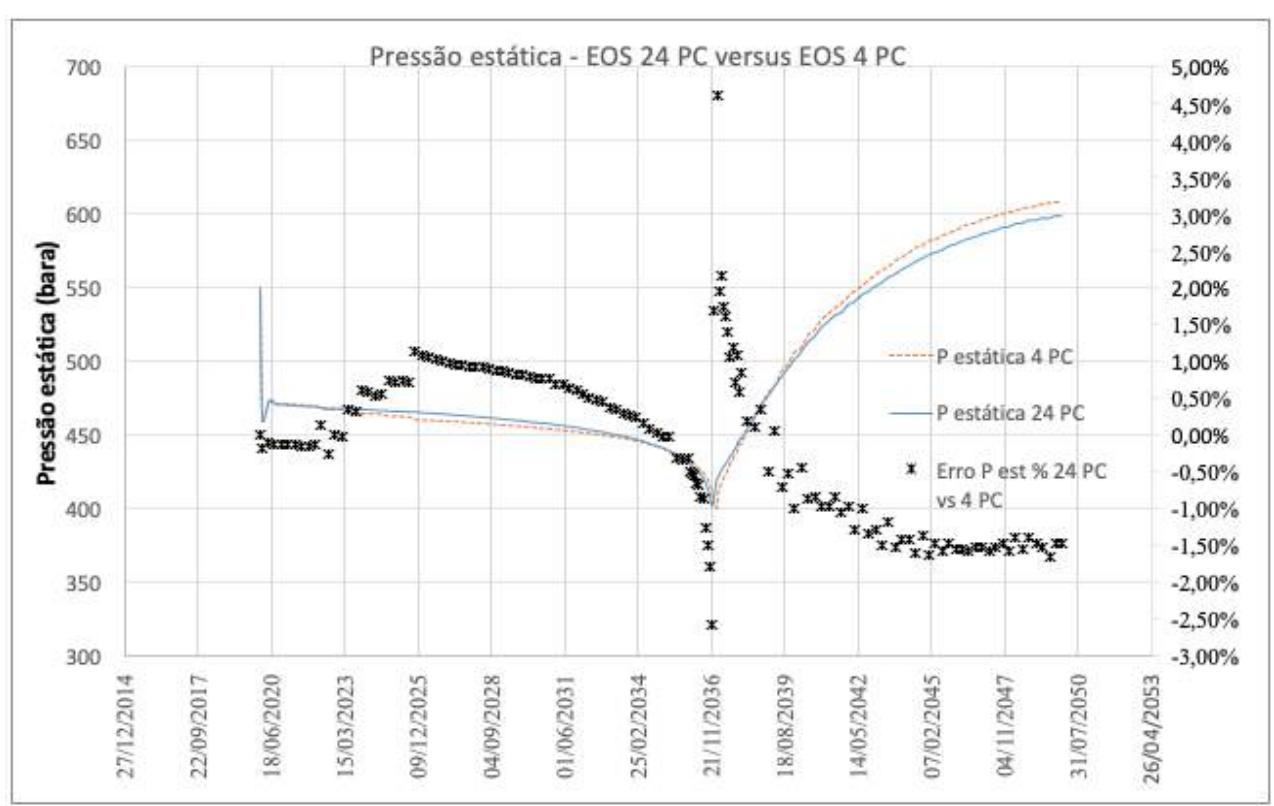

Figura B.29: Pressão estática - EOS 24 PC versus EOS 14 PC. 


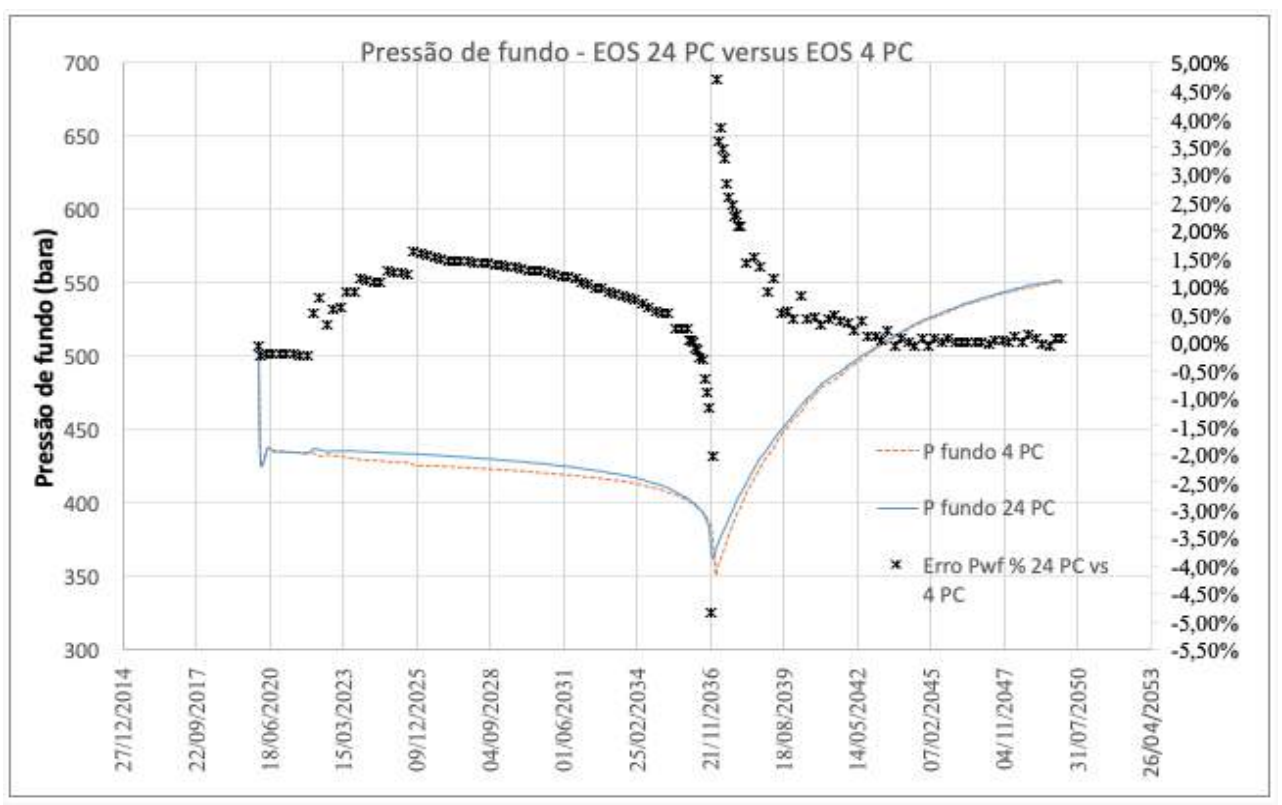

Figura B.30: Pressão de fundo nos canhoneados - EOS 24 PC versus EOS 14 PC. 
C

Resultados - Escoamento nas tubulações

C.1

EOS 24 PC versus EOS 14 PC

\section{C.1.1}

Cenário 1 - Período inicial logo após a abertura do poço

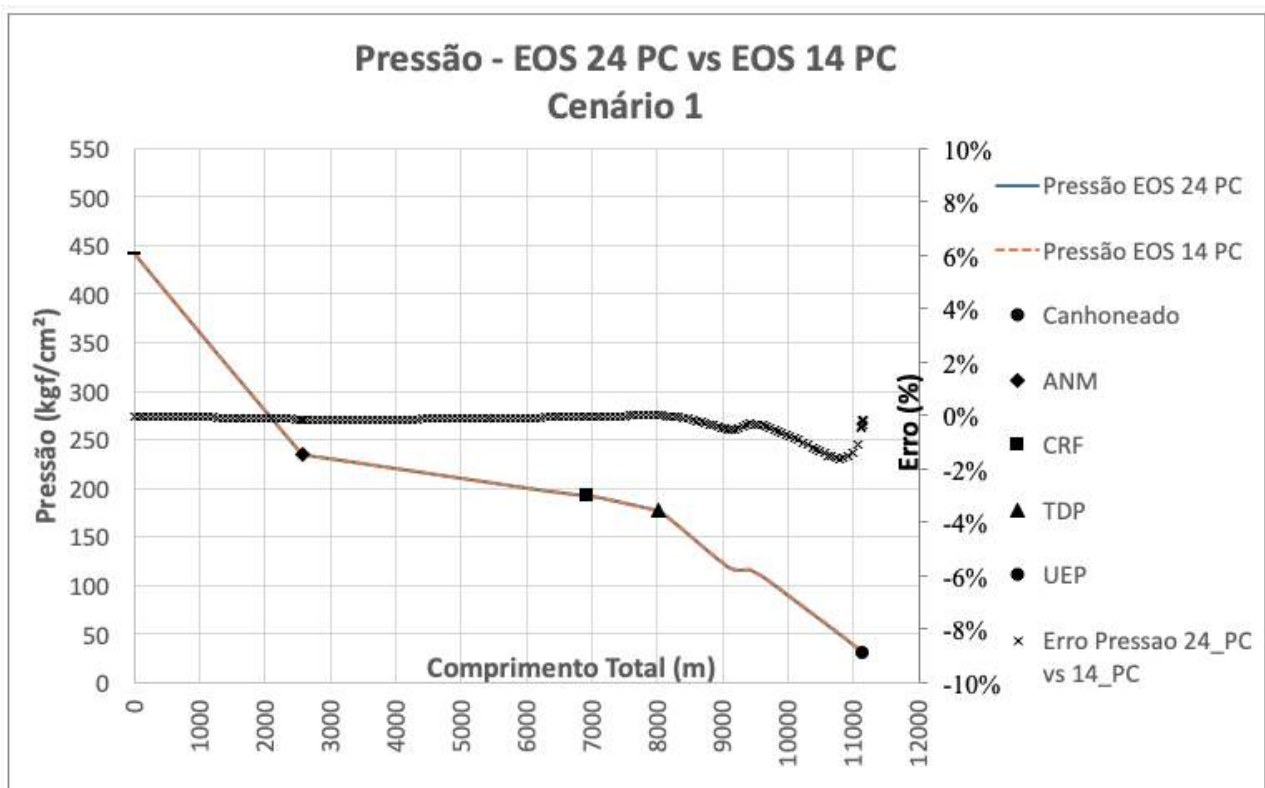

Figura C.1: Perfil de pressão no poço e duto - Cenário 1 - EOS 24 PC versus EOS 14 PC. 


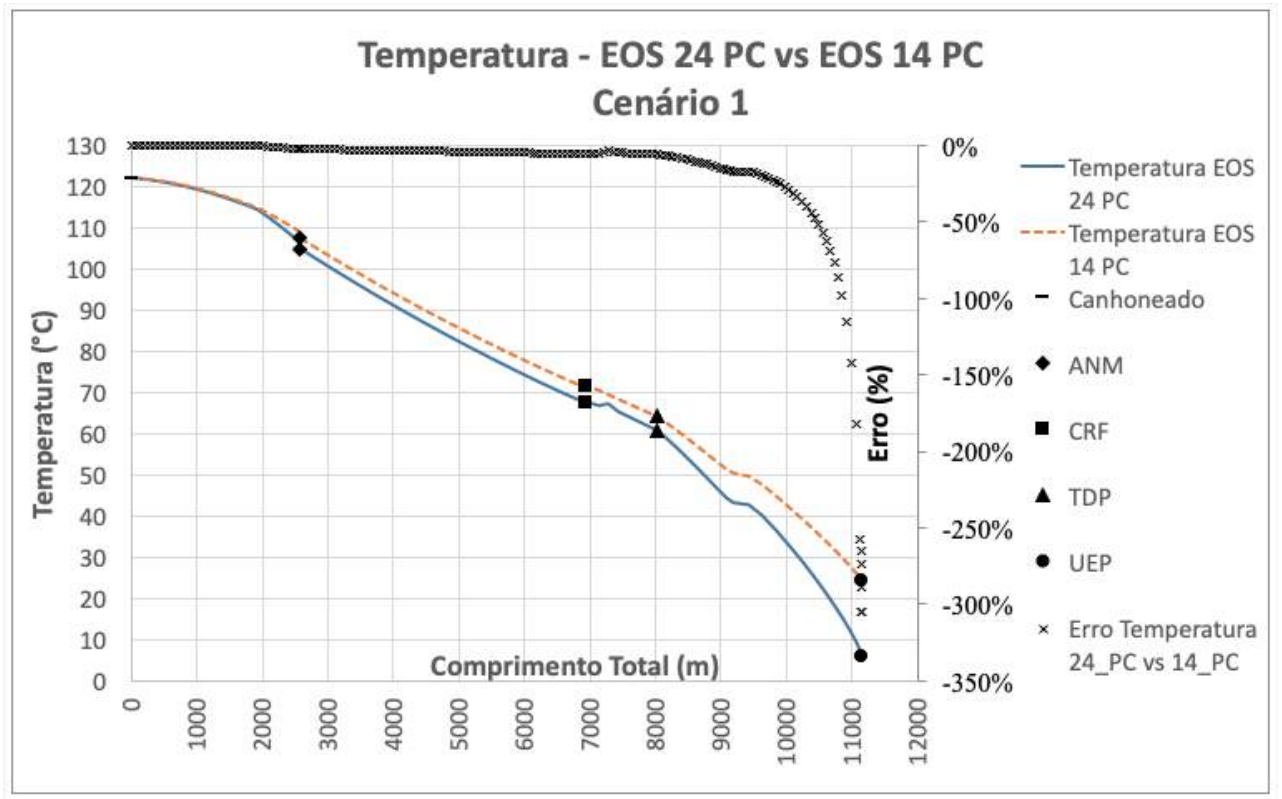

Figura C.2: Perfil de temperatura no poço e duto - Cenário 1 - EOS 24 PC versus EOS $14 \mathrm{PC}$.

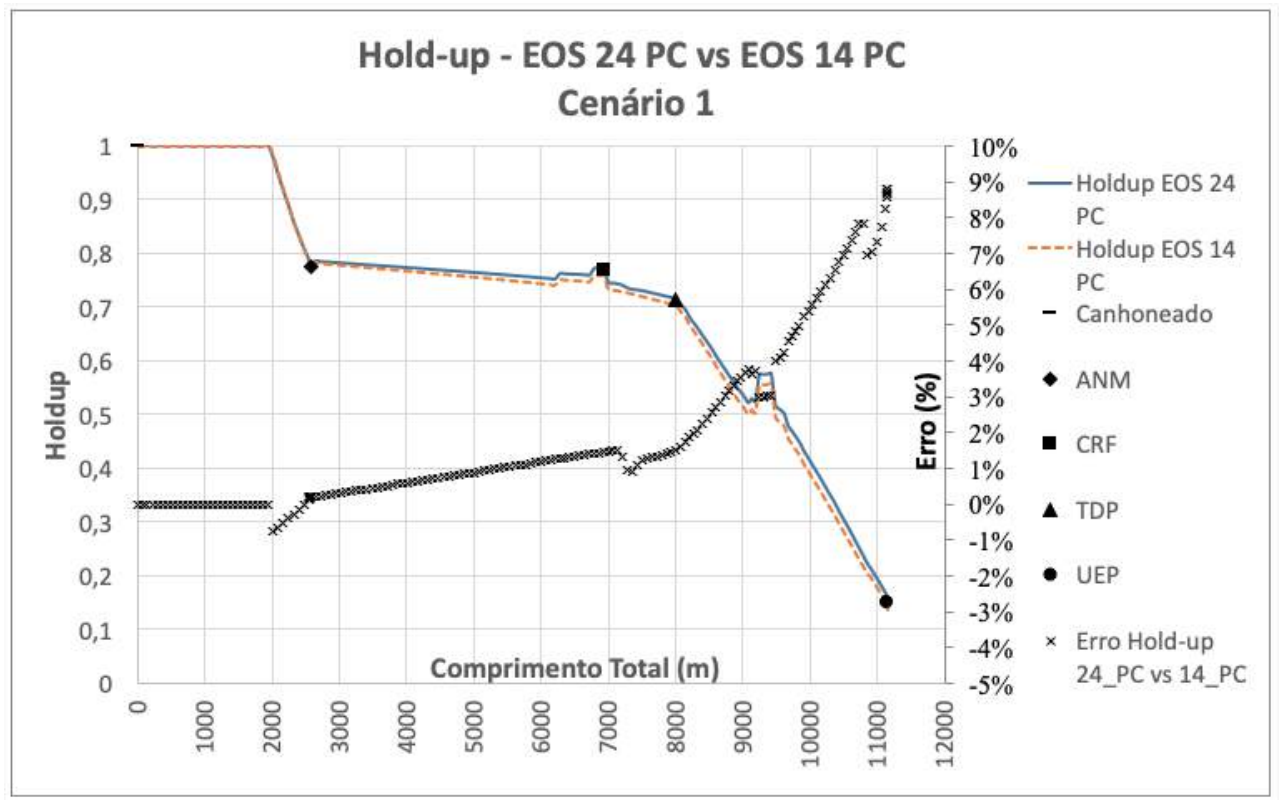

Figura C.3: Holdup no poço e duto - Cenário 1 - EOS 24 PC versus EOS 14 PC. 


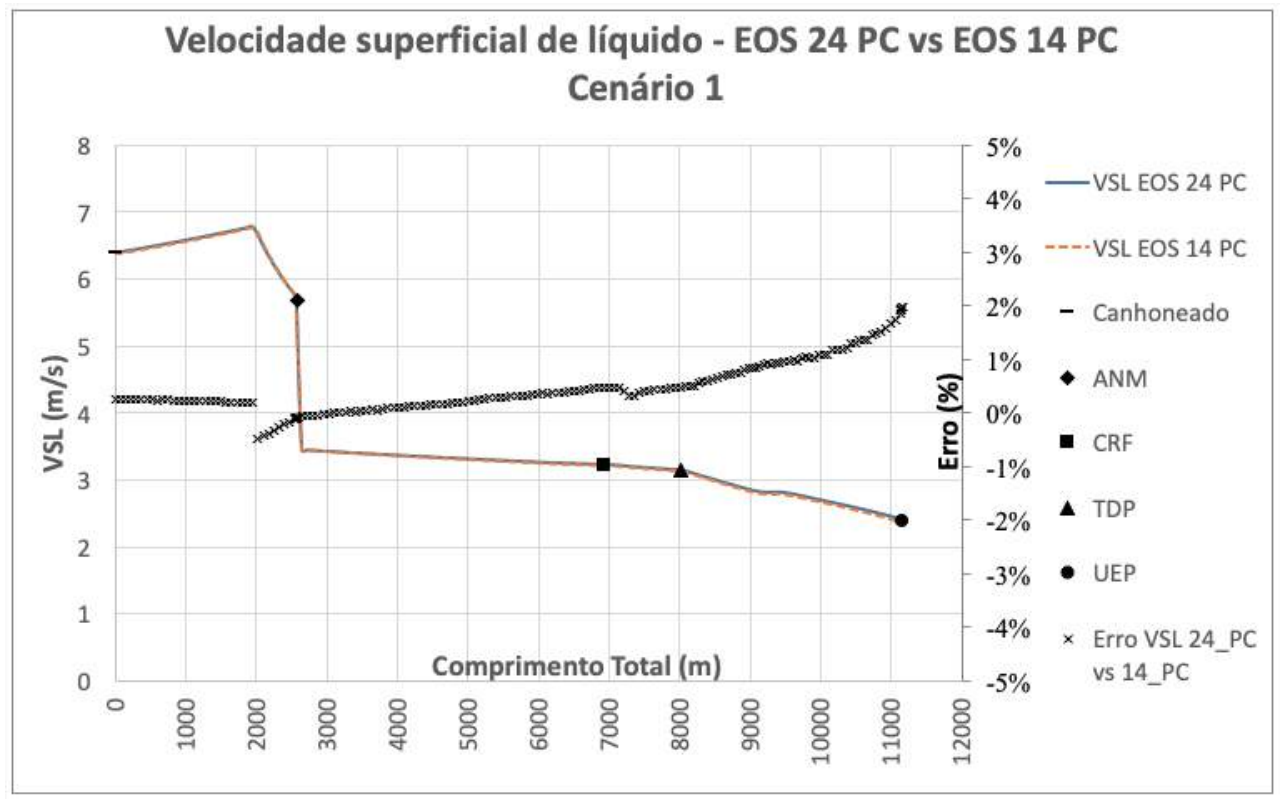

Figura C.4: Velocidade superficial de líquido - Cenário 1 - EOS 24 PC versus EOS 14 PC.

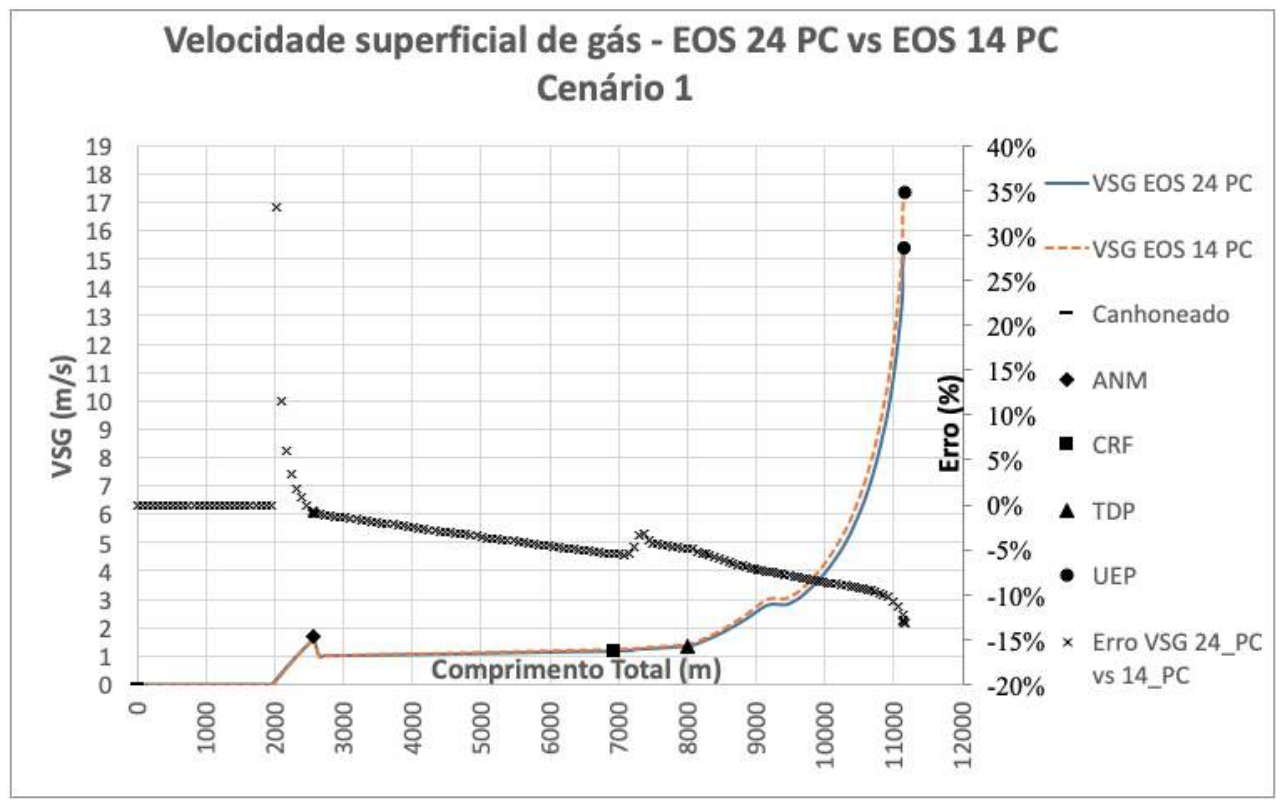

Figura C.5: Velocidade superficial de gás - Cenário 1 - EOS 24 PC versus EOS 14 PC. 


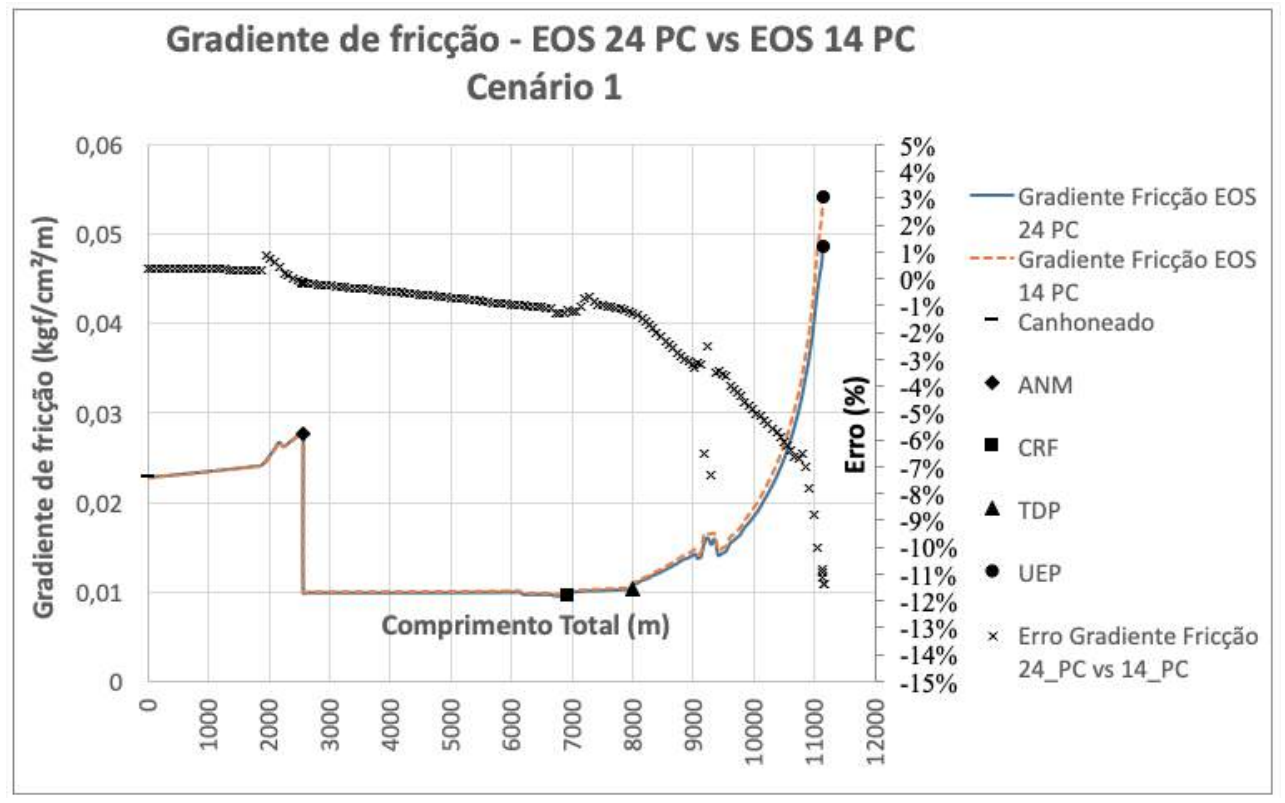

Figura C.6: Gradiente de pressão por fricção - Cenário 1 - EOS 24 PC versus EOS 14 PC.

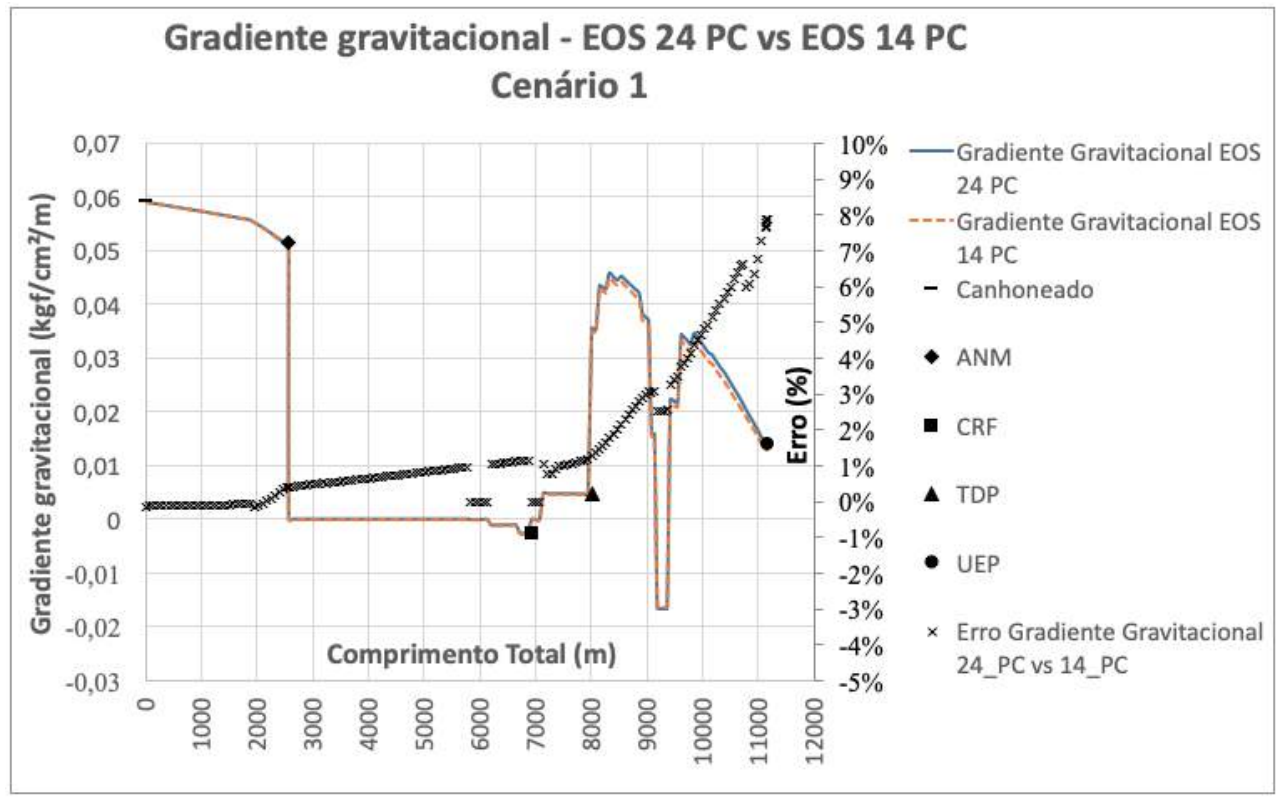

Figura C.7: Gradiente de pressão gravitacional - Cenário 1 - EOS 24 PC versus EOS 14 PC. 


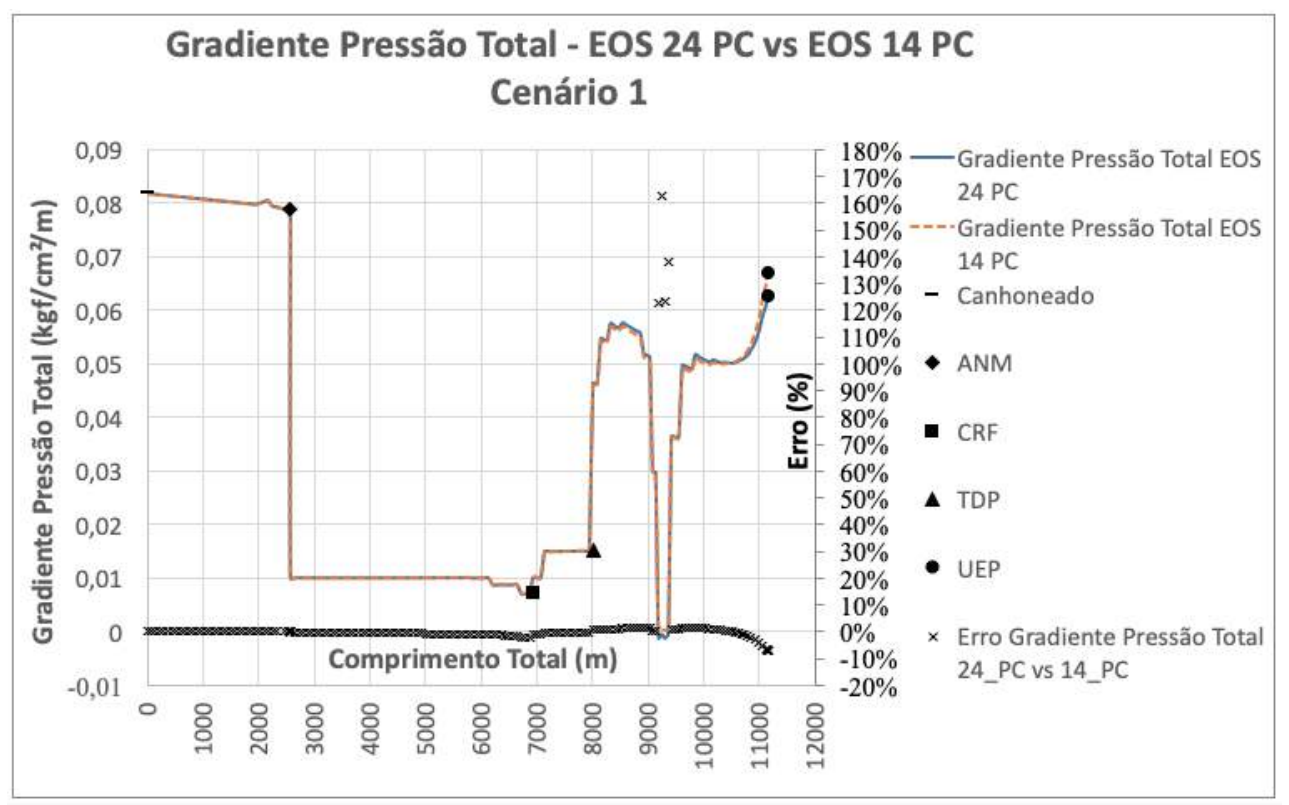

Figura C.8: Gradiente de pressão total - Cenário 1 - EOS 24 PC versus EOS 14 PC.

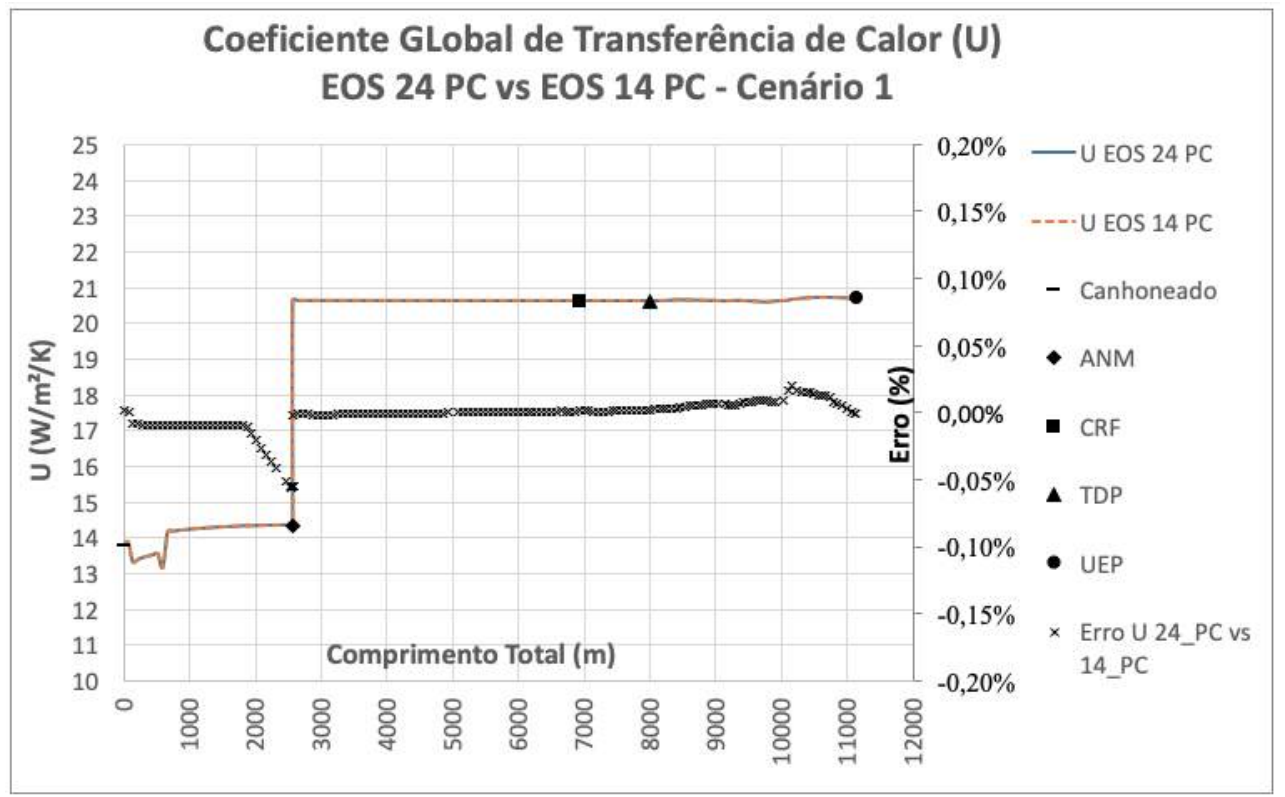

Figura C.9: Coeficiente global de transferência de calor - Cenário 1 - EOS 24 $\mathrm{PC}$ versus EOS $14 \mathrm{PC}$. 


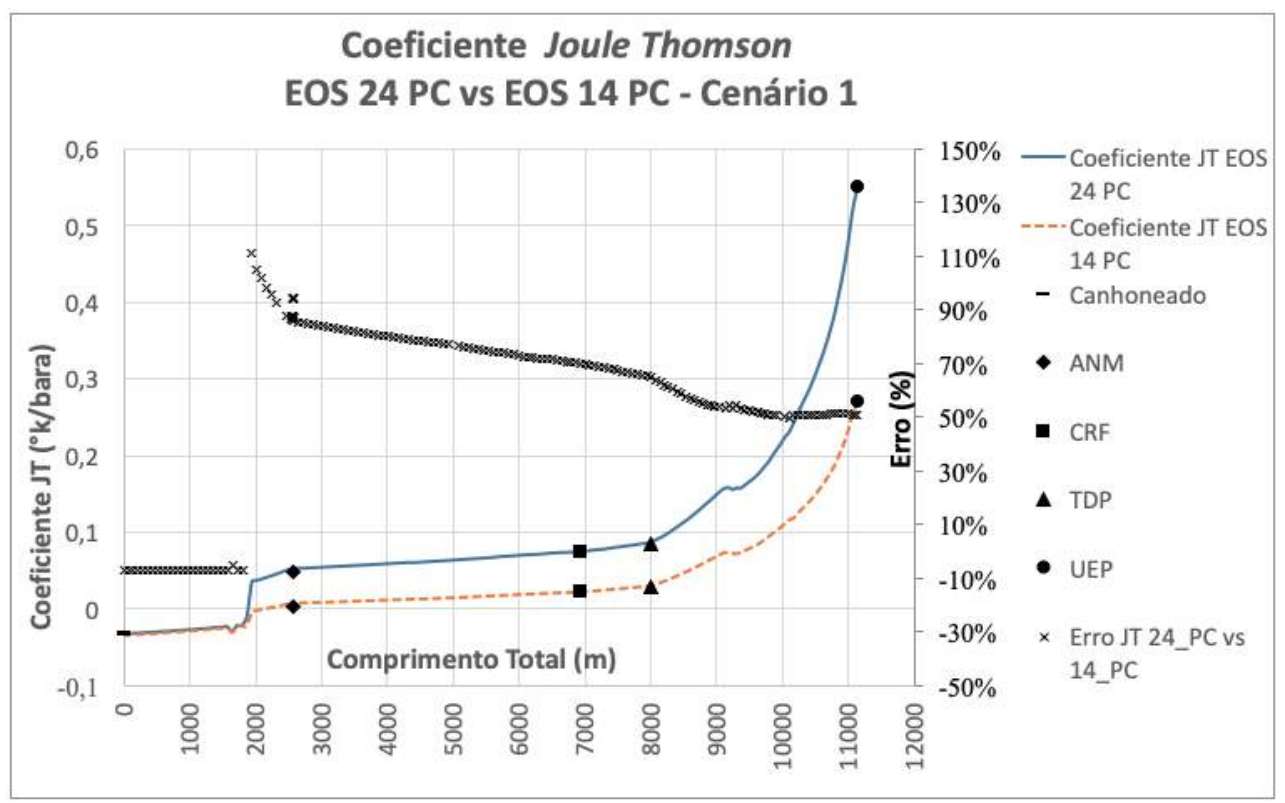

Figura C.10: Coeficiente Joule-Thomson - Cenário 1 - EOS 24 PC versus EOS 14 PC. 


\section{C.1.2}

Cenário 2 - Período inicial antes do breaktrough de água

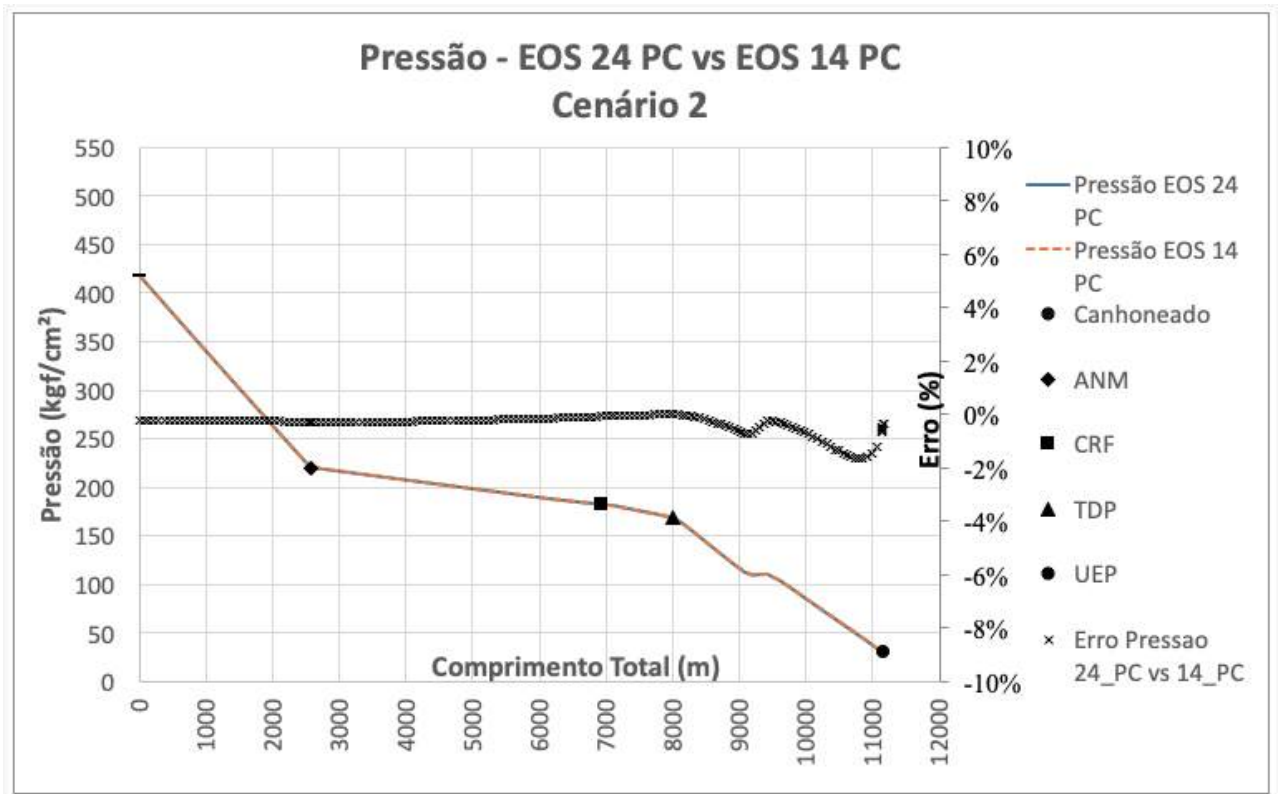

Figura C.11: Perfil de pressão no poço e duto - Cenário 2 - EOS 24 PC versus EOS 14 PC.

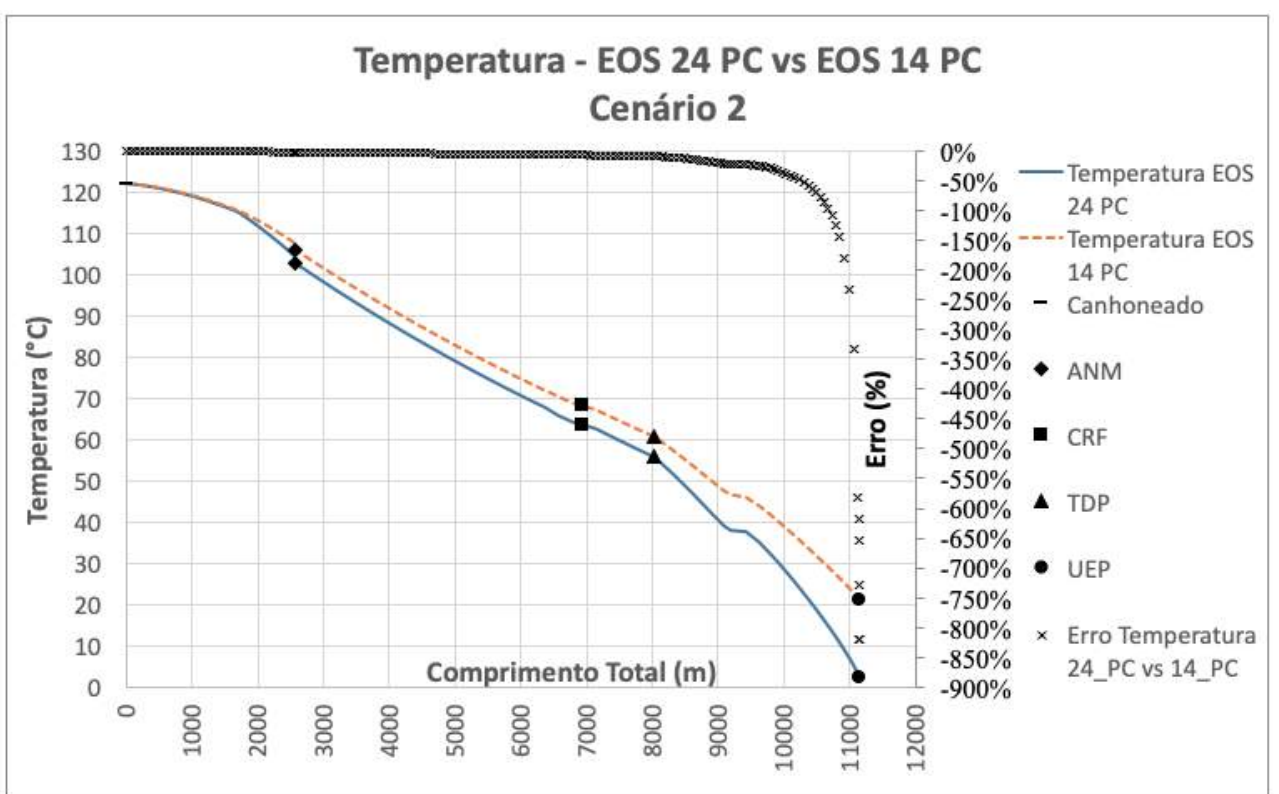

Figura C.12: Perfil de temperatura no poço e duto - Cenário 2 - EOS 24 PC versus EOS 14 PC. 


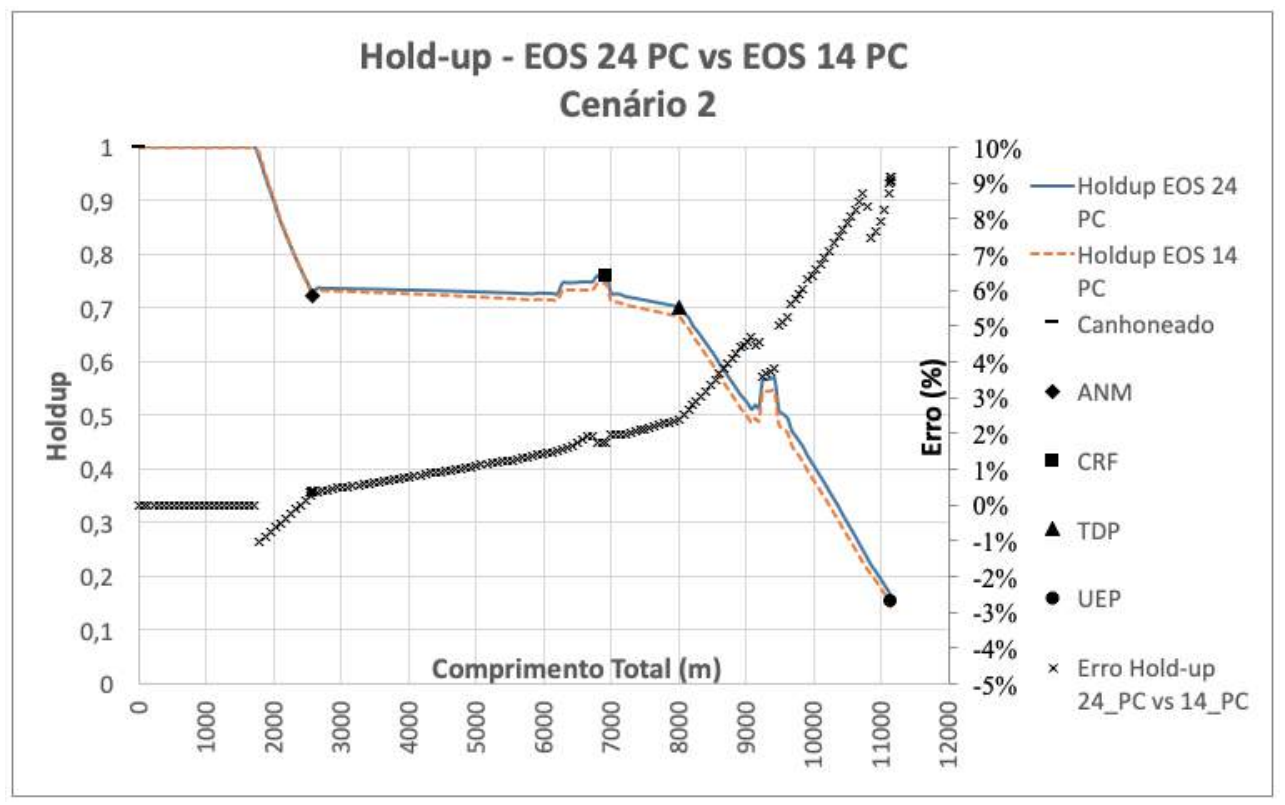

Figura C.13: Holdup no poço e duto - Cenário 2 - EOS 24 PC versus EOS 14 PC.

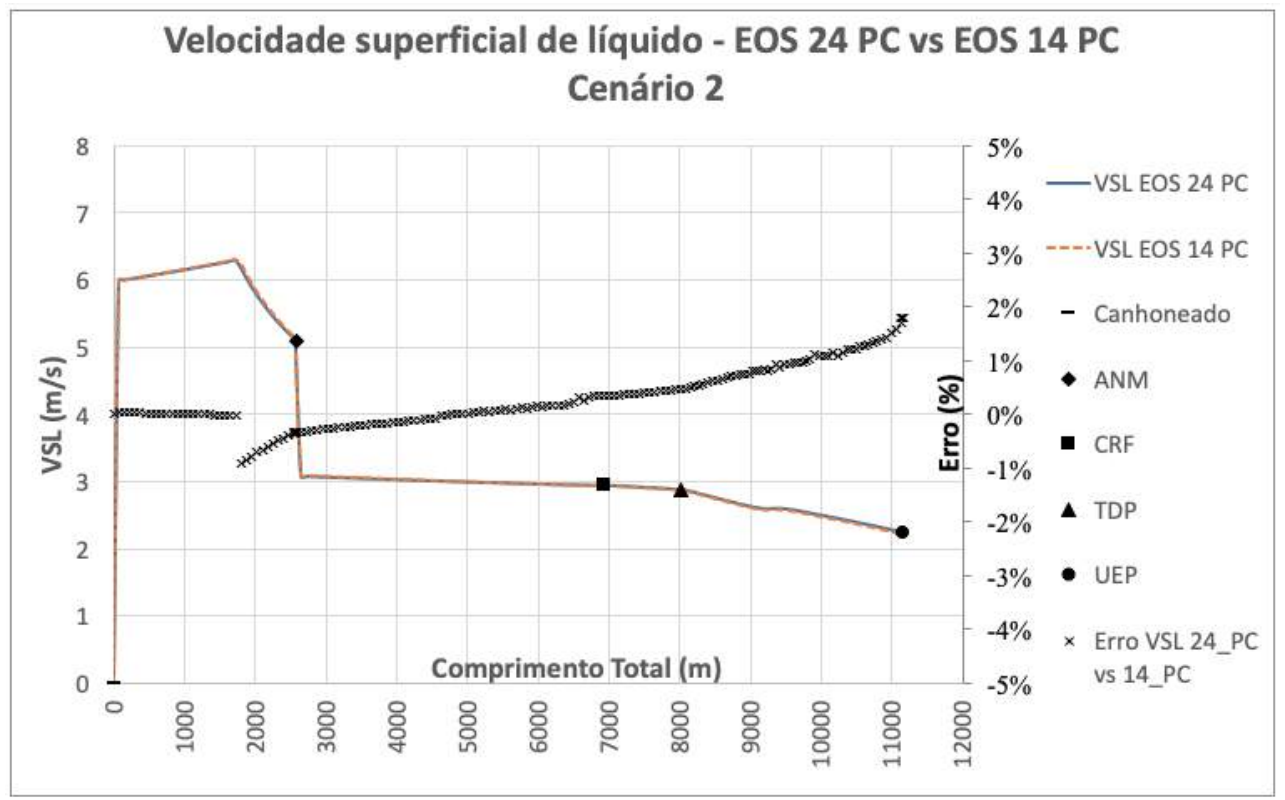

Figura C.14: Velocidade superficial de líquido - Cenário 2 - EOS 24 PC versus EOS 14 PC. 


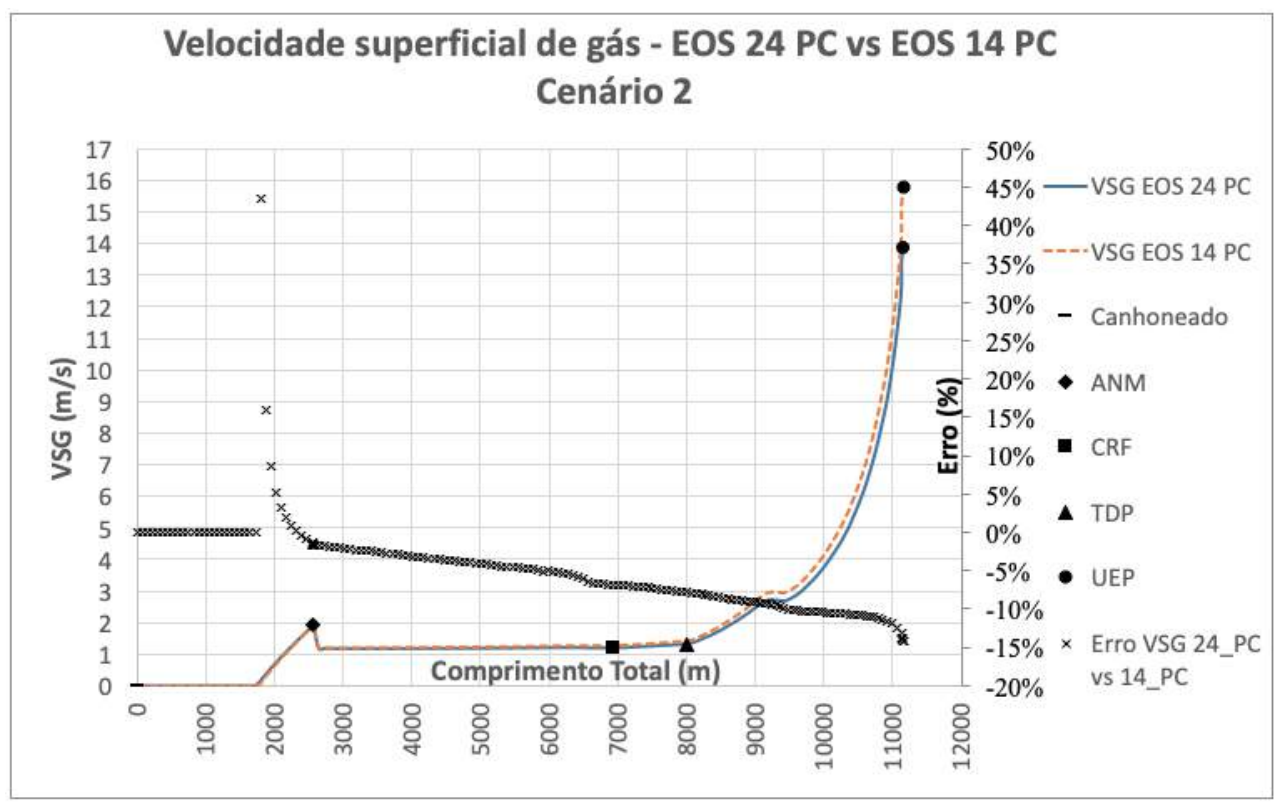

Figura C.15: Velocidade superficial de gás - Cenário 2 - EOS 24 PC versus EOS 14 PC.

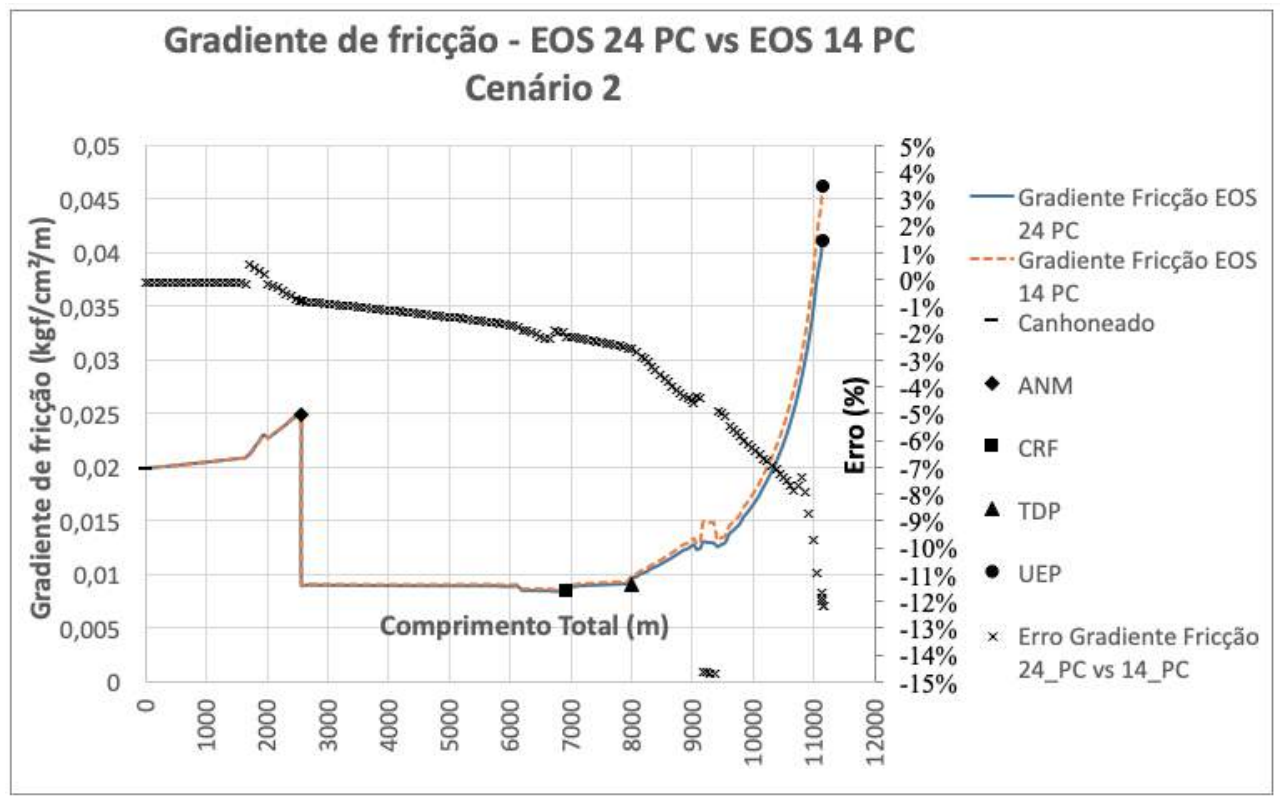

Figura C.16: Gradiente de pressão por fricção - Cenário 2 - EOS 24 PC versus EOS 14 PC. 


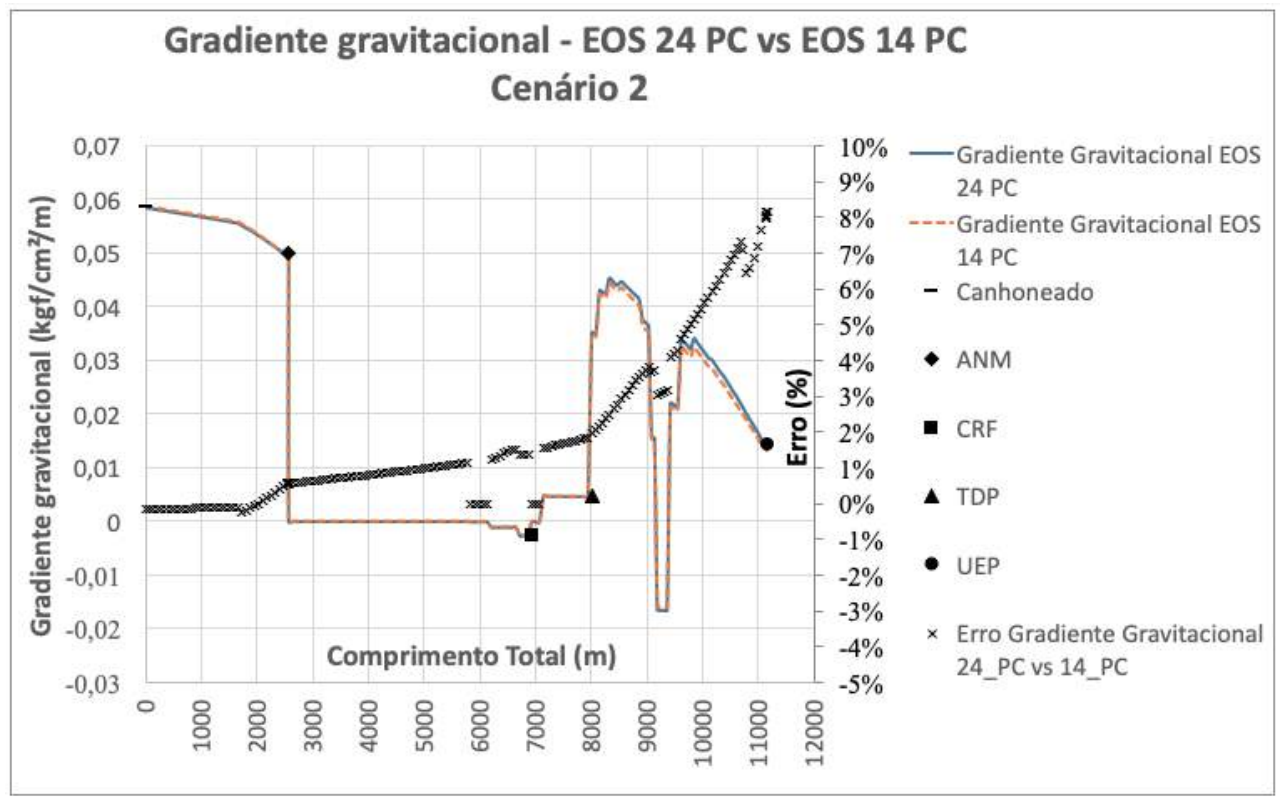

Figura C.17: Gradiente de pressão gravitacional - Cenário 2 - EOS 24 PC versus EOS 14 PC.

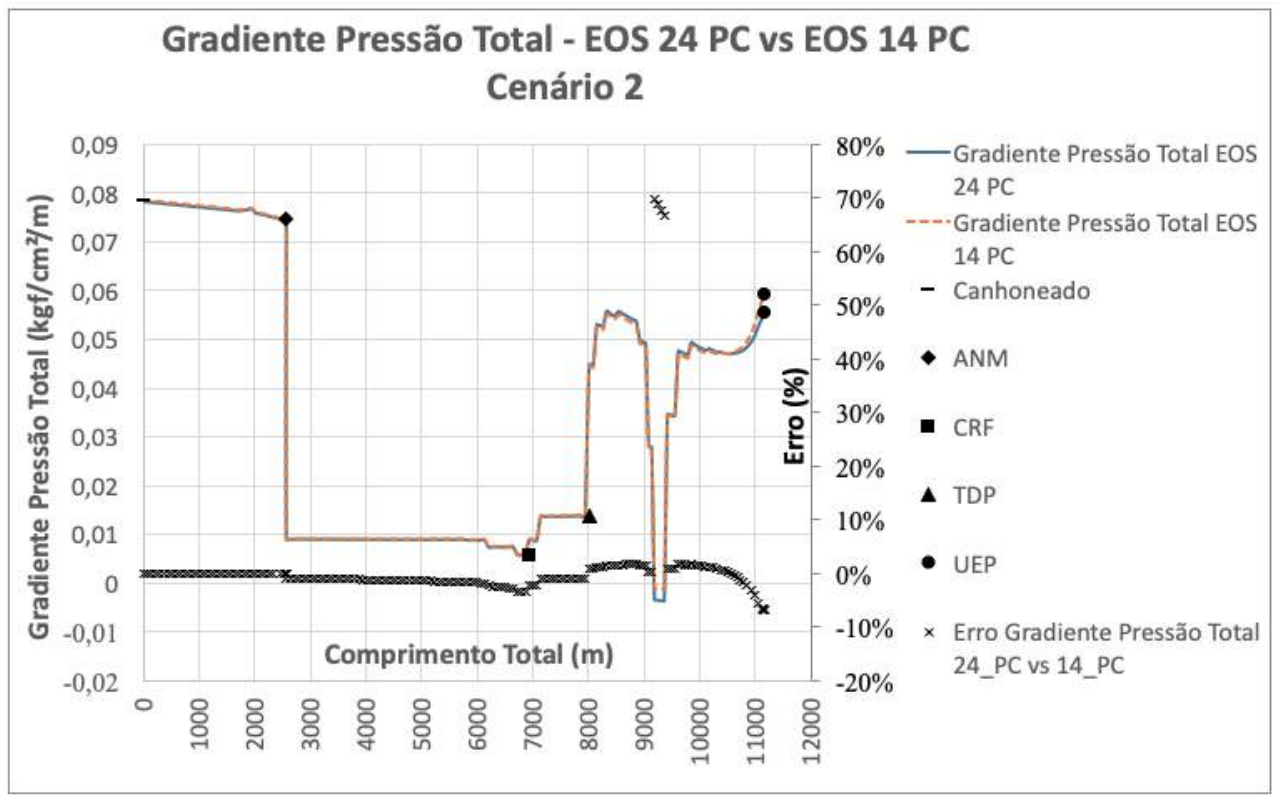

Figura C.18: Gradiente de pressão total - Cenário 2 - EOS 24 PC versus EOS 14 PC. 


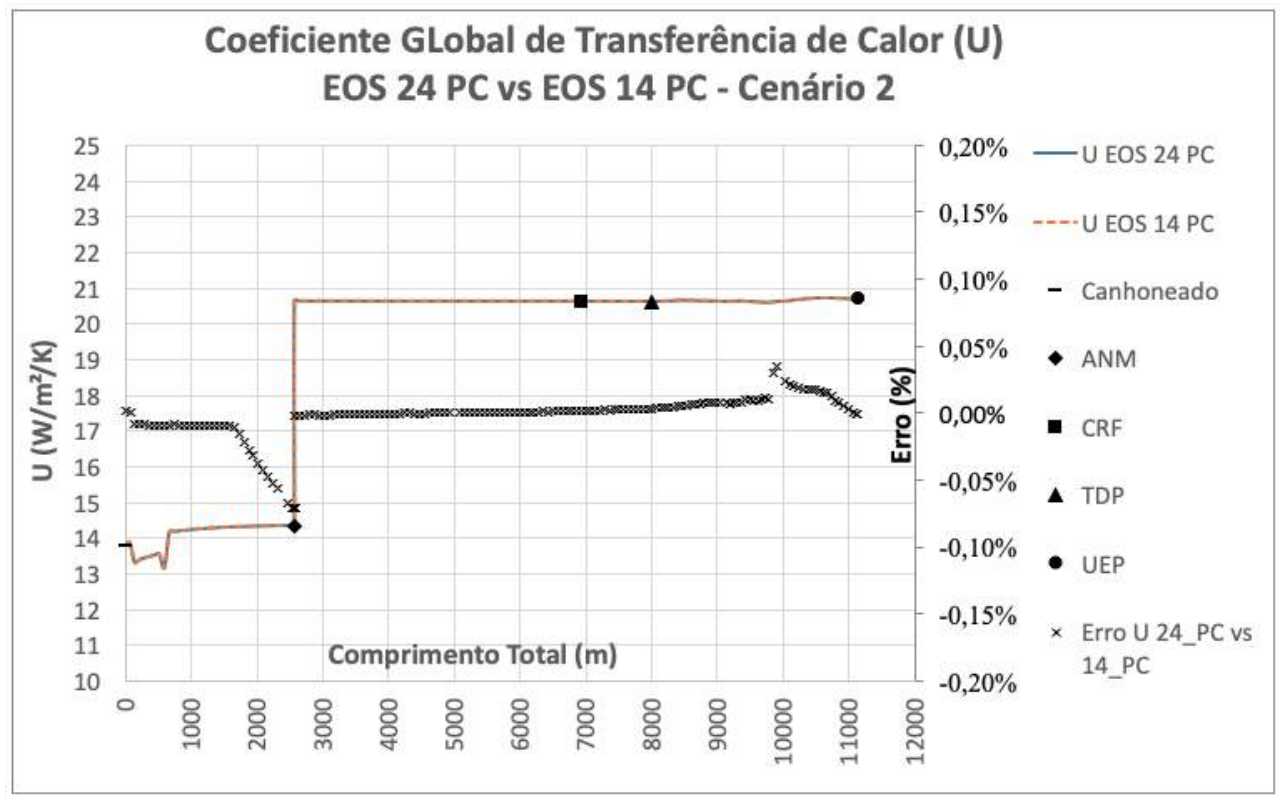

Figura C.19: Coeficiente global de transferência de calor - Cenário 2 - EOS 24 $\mathrm{PC}$ versus EOS $14 \mathrm{PC}$.

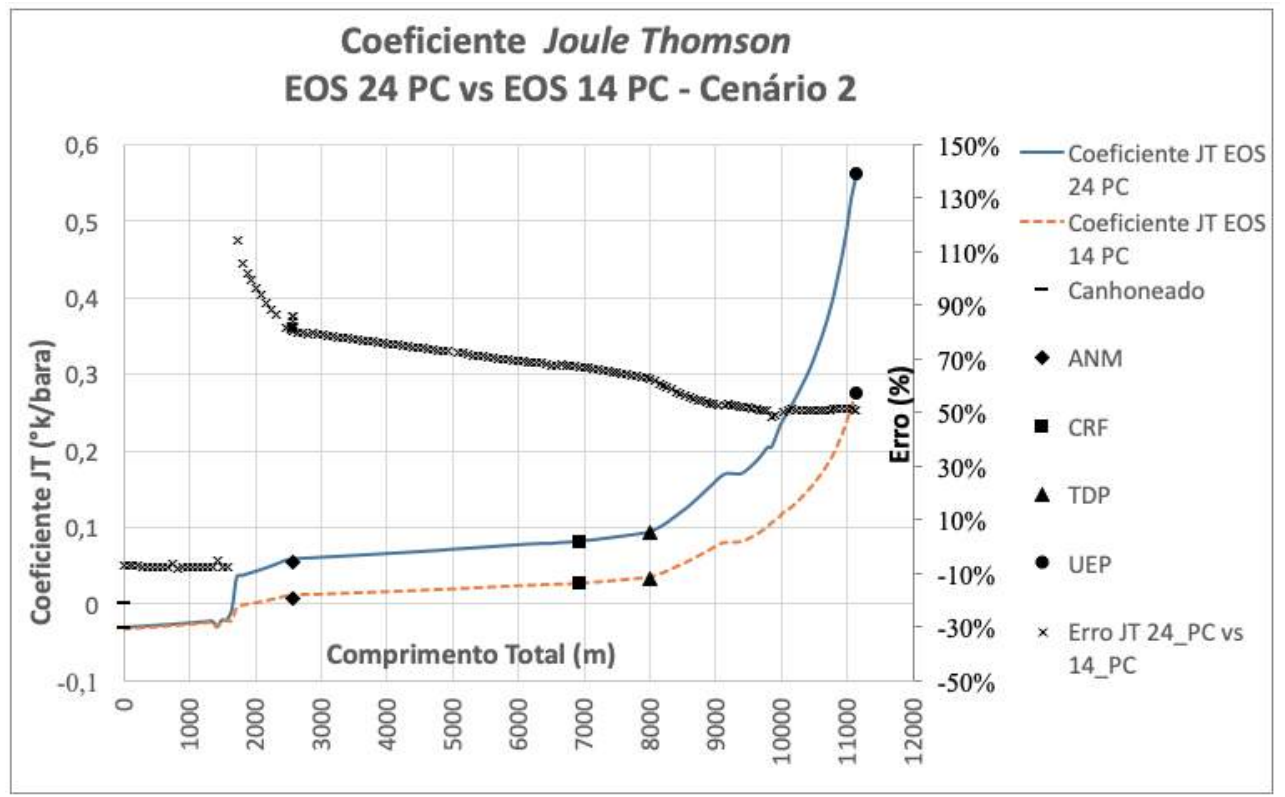

Figura C.20: Coeficiente Joule-Thomson - Cenário 2 - EOS 24 PC versus EOS 14 PC. 


\section{C.1.3}

\section{Cenário 3 - Corte de água intermediário}

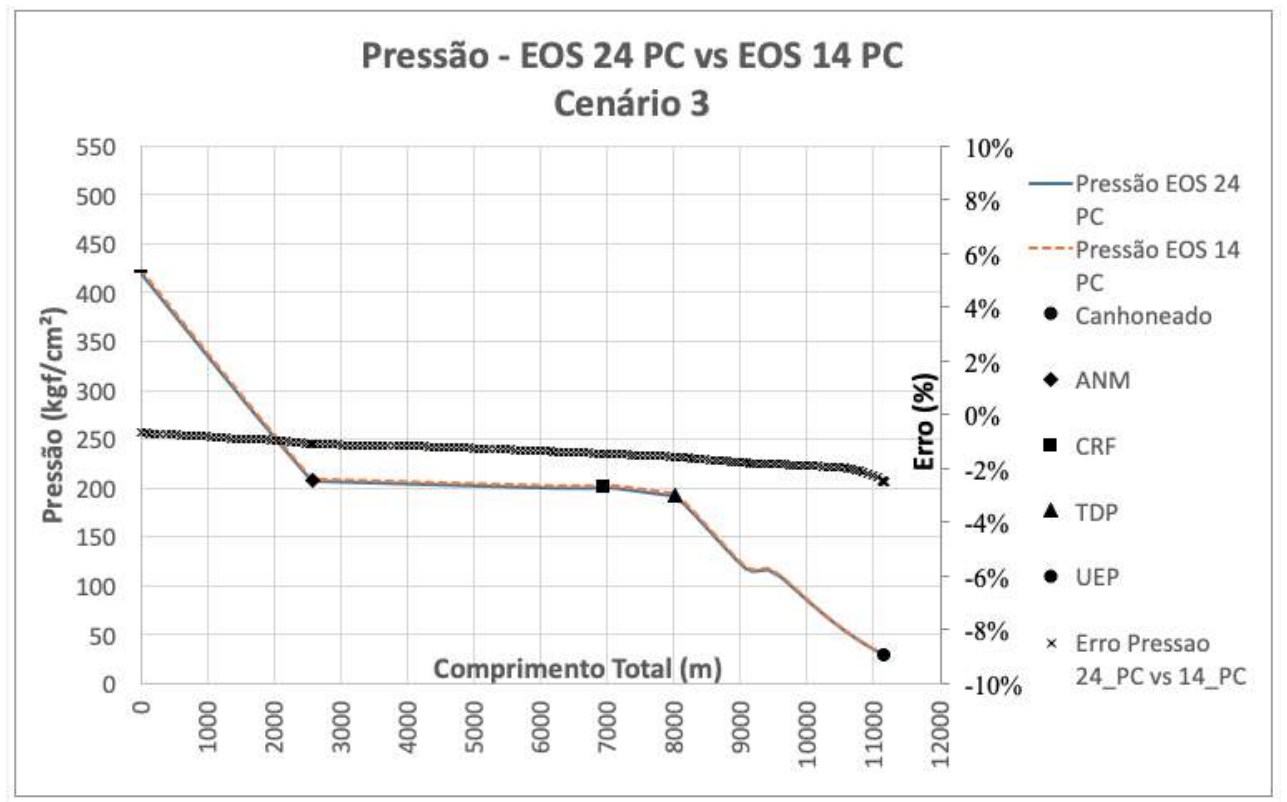

Figura C.21: Perfil de pressão no poço e duto - Cenário 3 - EOS 24 PC versus EOS 14 PC.

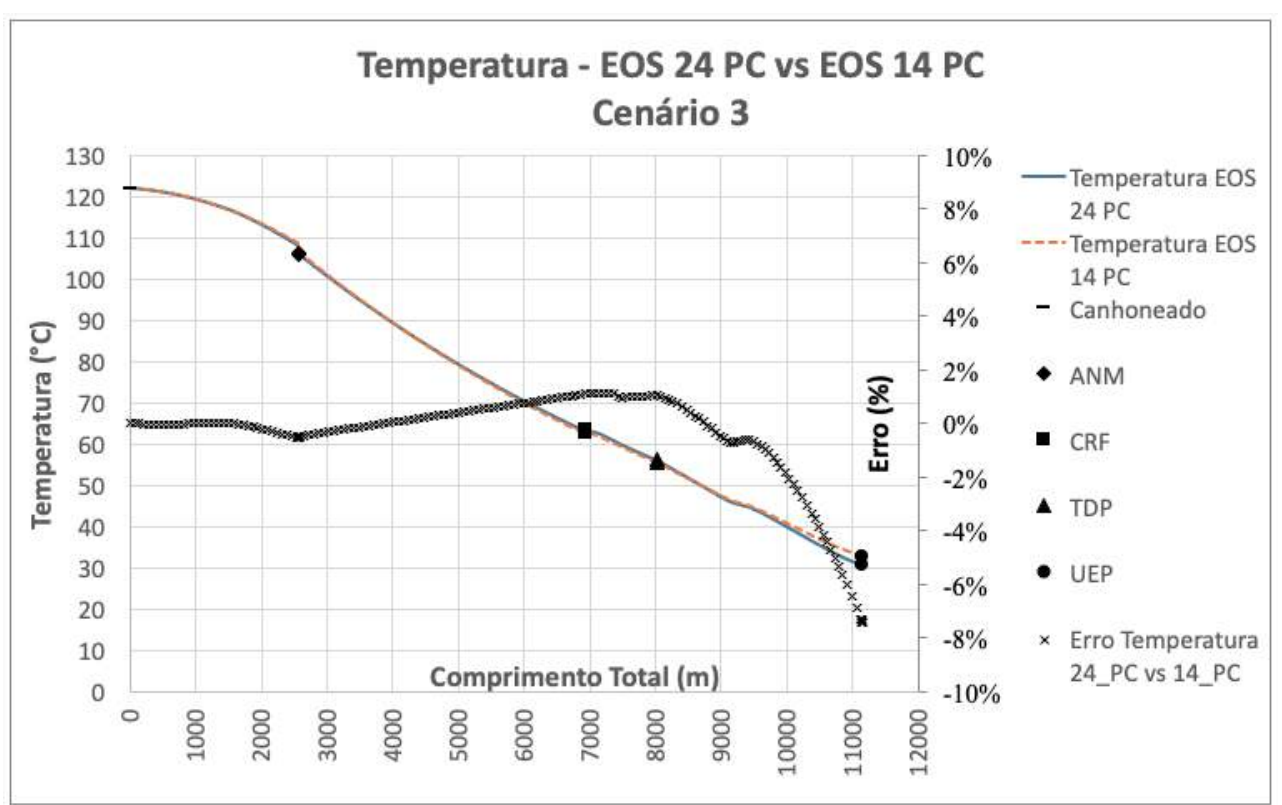

Figura C.22: Perfil de temperatura no poço e duto - Cenário 3 - EOS 24 PC versus EOS $14 \mathrm{PC}$. 


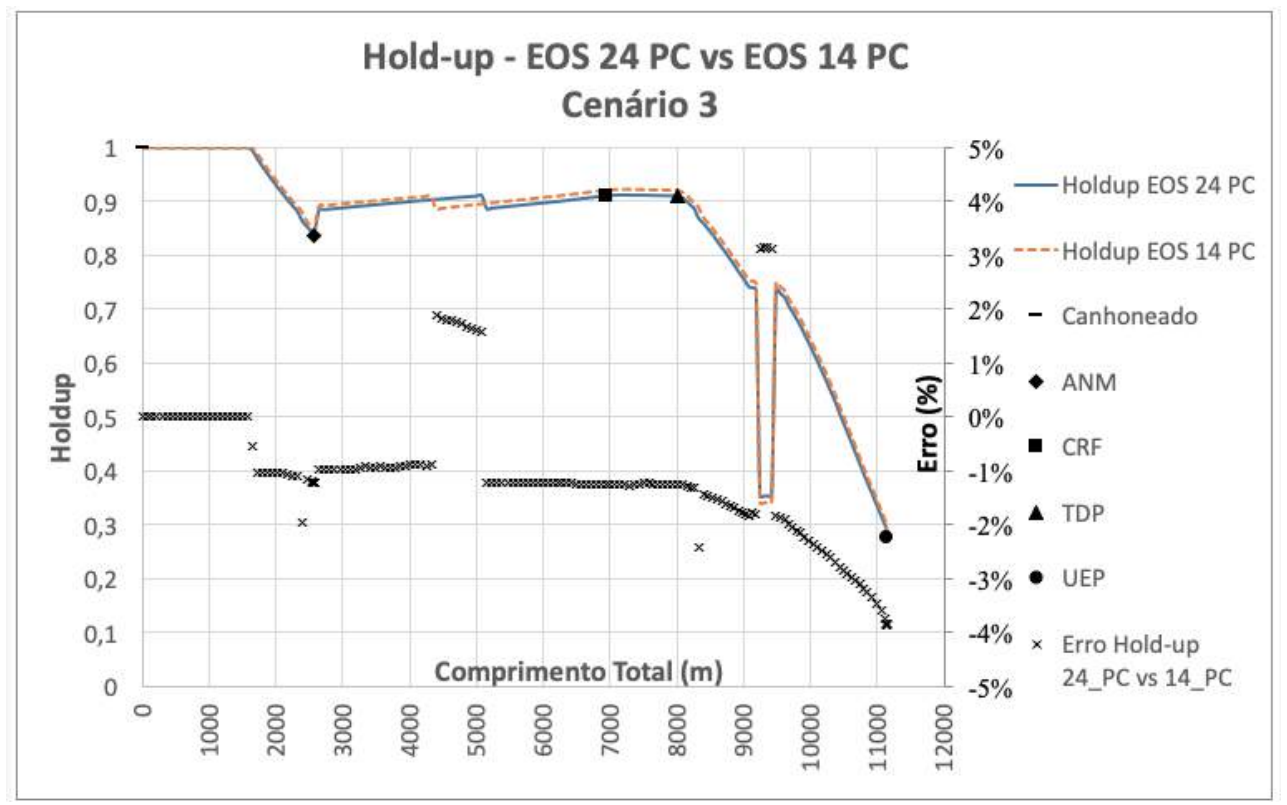

Figura C.23: Holdup no poço e duto - Cenário 3 - EOS 24 PC versus EOS 14 PC.

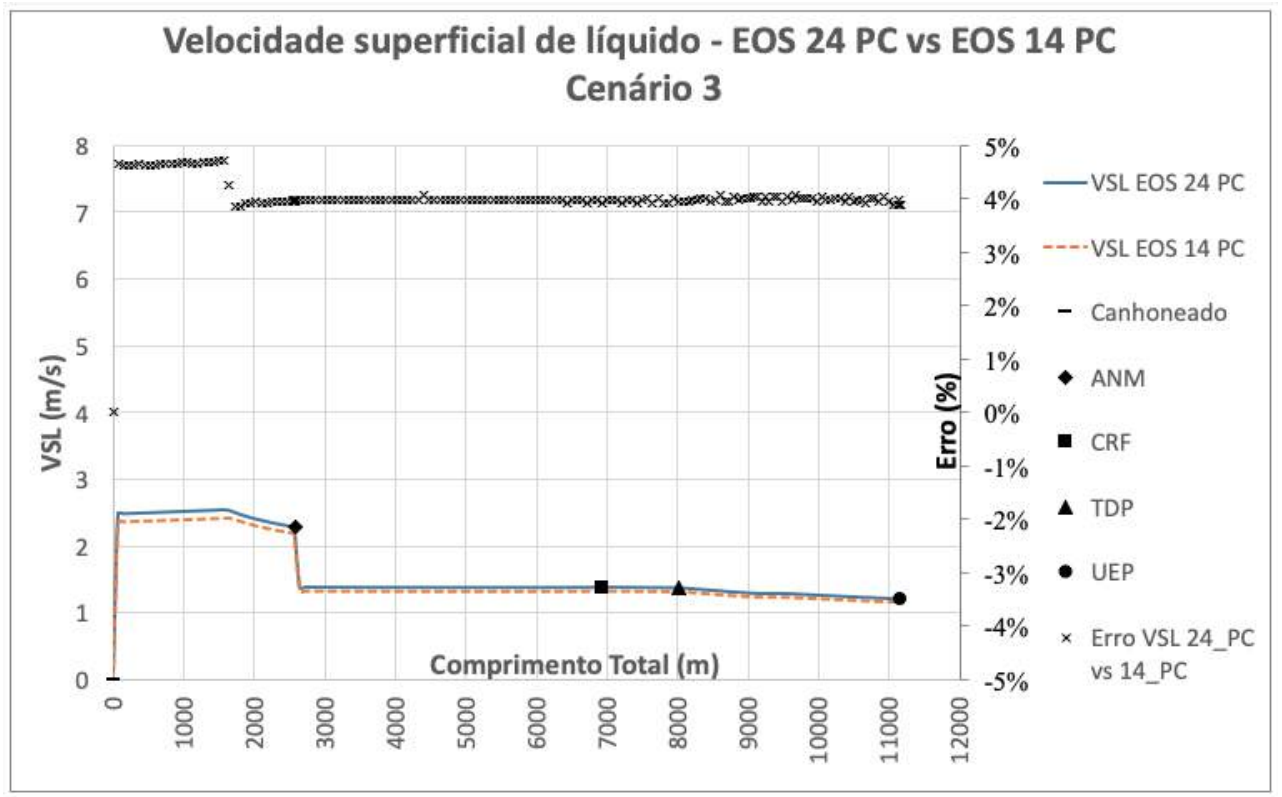

Figura C.24: Velocidade superficial de líquido - Cenário 3 - EOS 24 PC versus EOS 14 PC. 


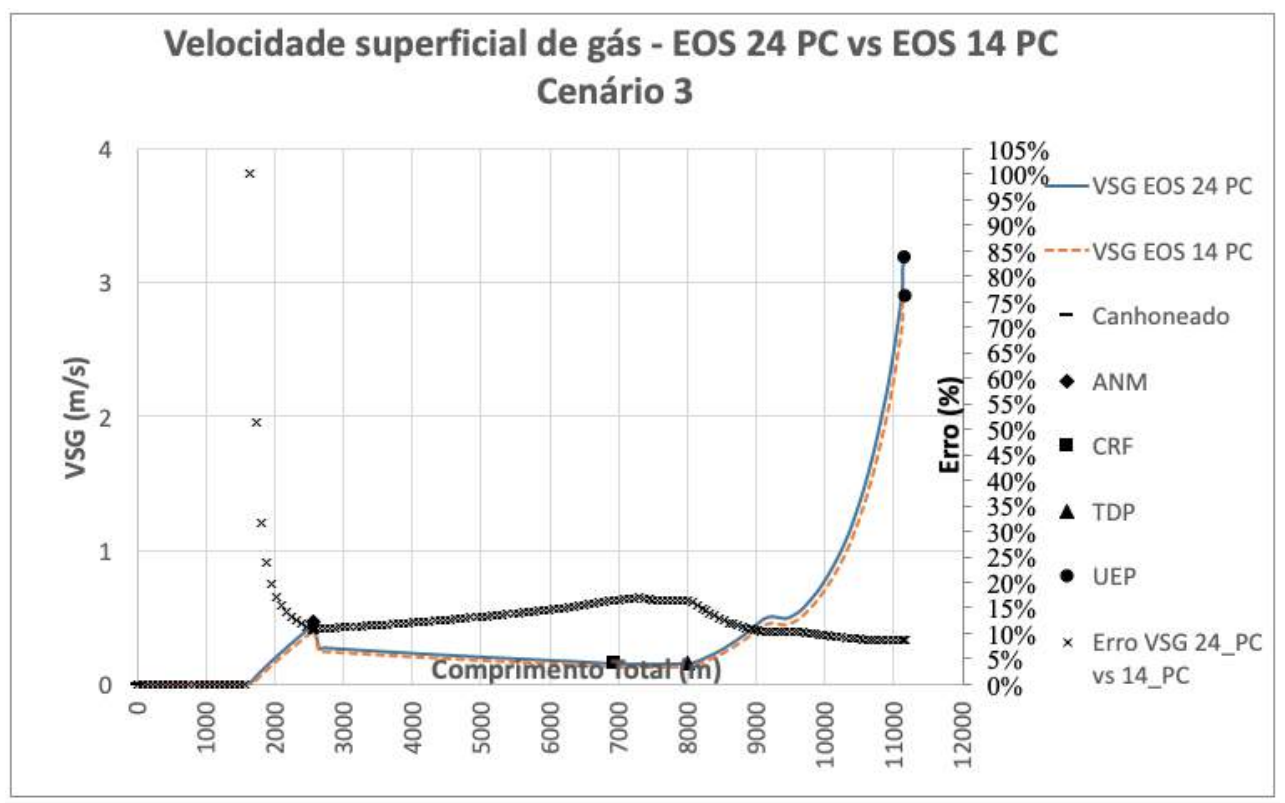

Figura C.25: Velocidade superficial de gás - Cenário 3 - EOS 24 PC versus EOS 14 PC.

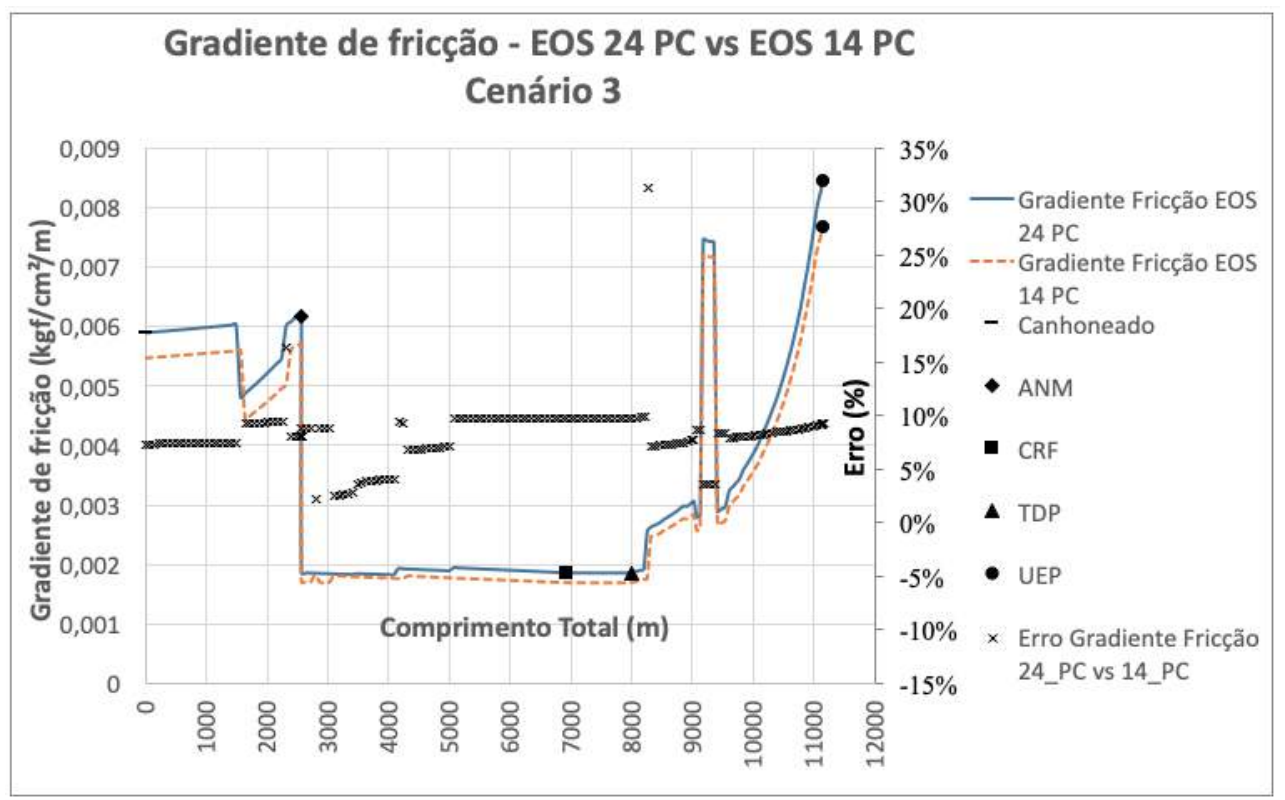

Figura C.26: Gradiente de pressão por fricção - Cenário 3 - EOS 24 PC versus EOS 14 PC. 


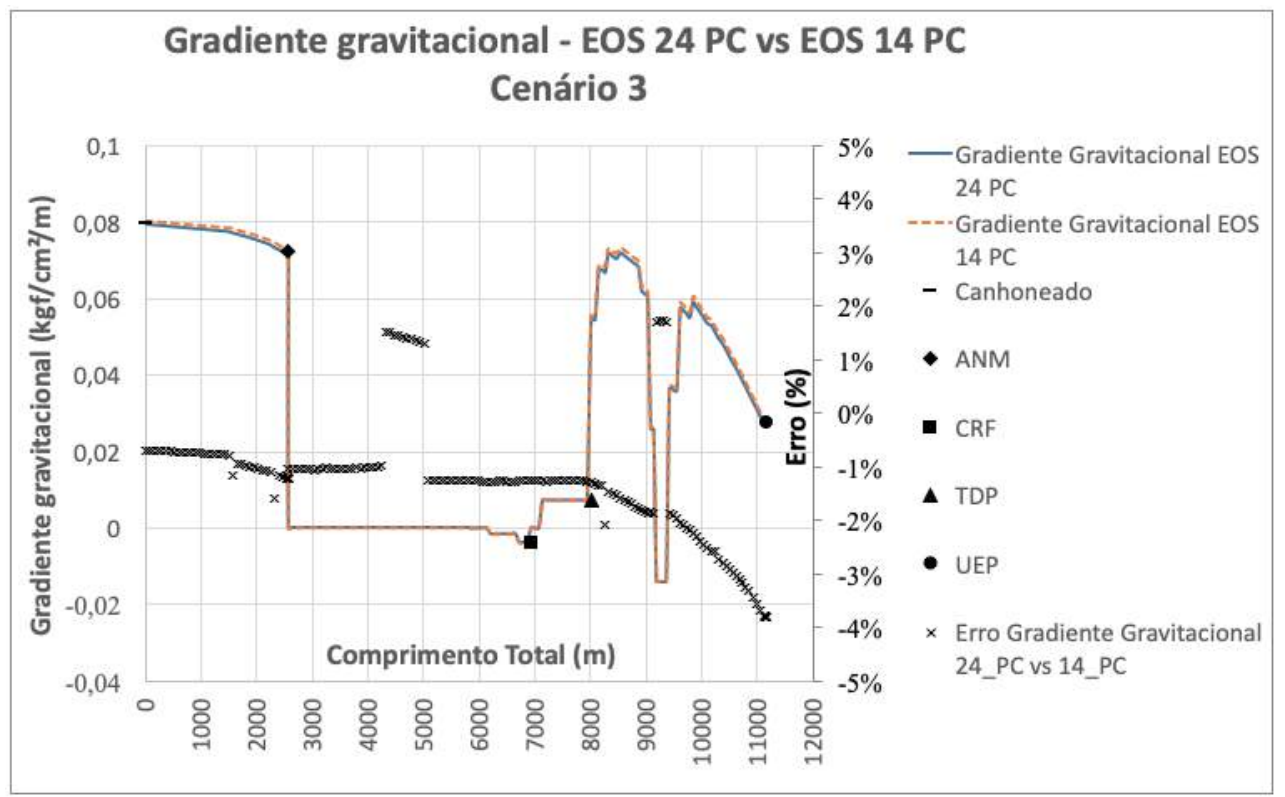

Figura C.27: Gradiente de pressão gravitacional - Cenário 3 - EOS 24 PC versus EOS $14 \mathrm{PC}$.

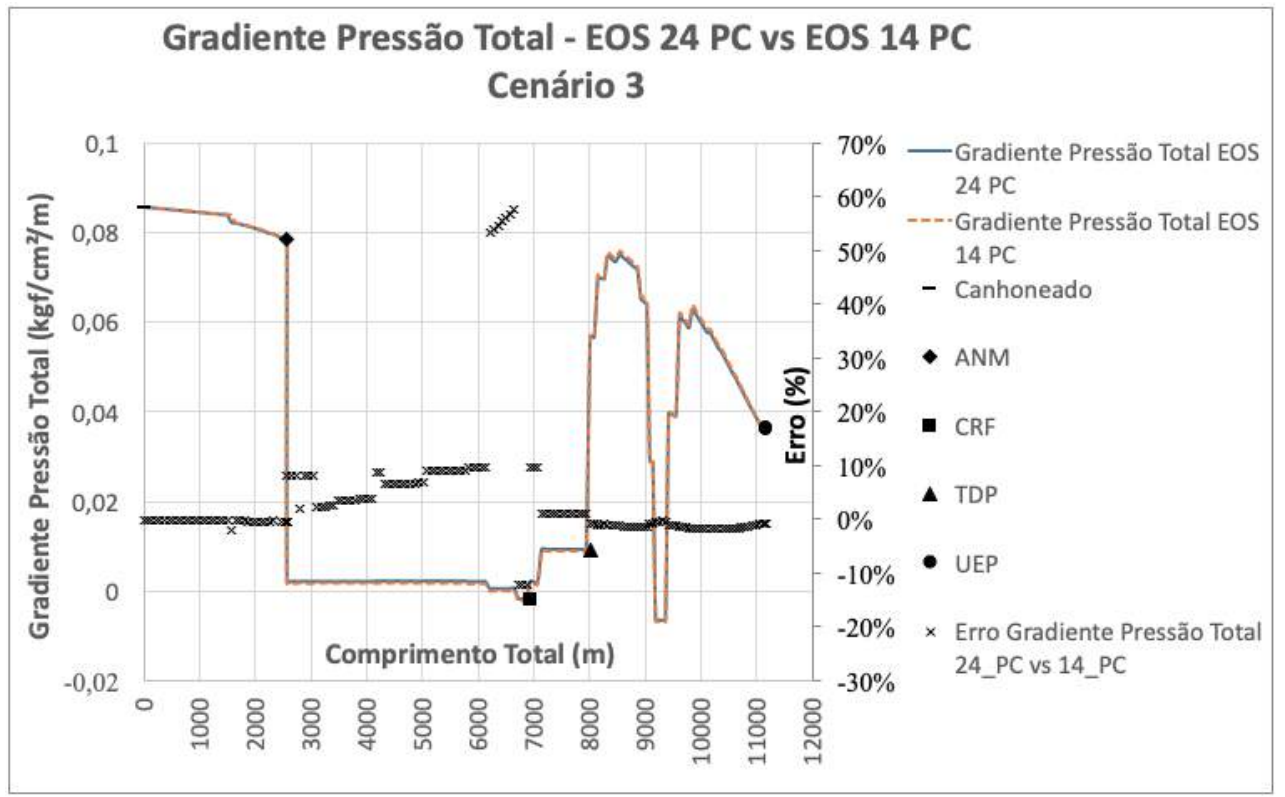

Figura C.28: Gradiente de pressão total - Cenário 3 - EOS 24 PC versus EOS 14 PC. 


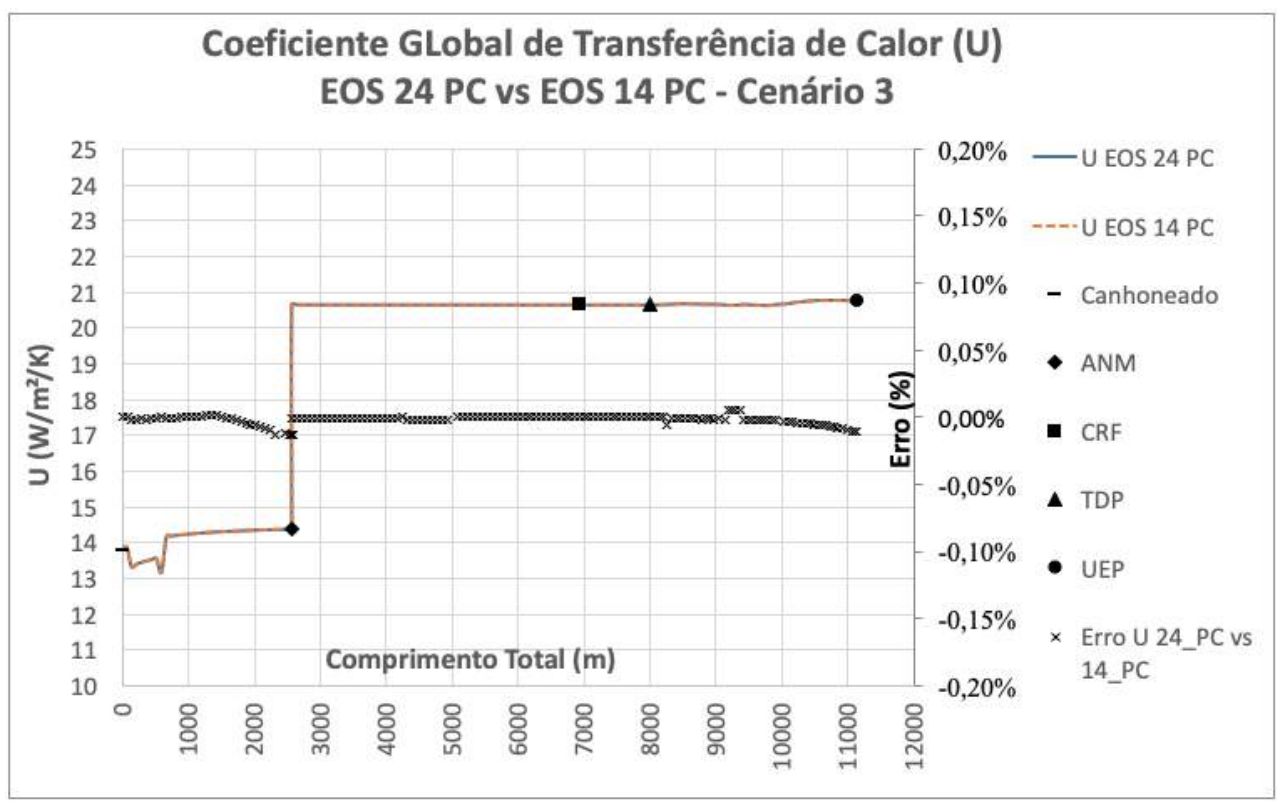

Figura C.29: Coeficiente global de transferência de calor - Cenário 3 - EOS 24 $\mathrm{PC}$ versus EOS $14 \mathrm{PC}$.

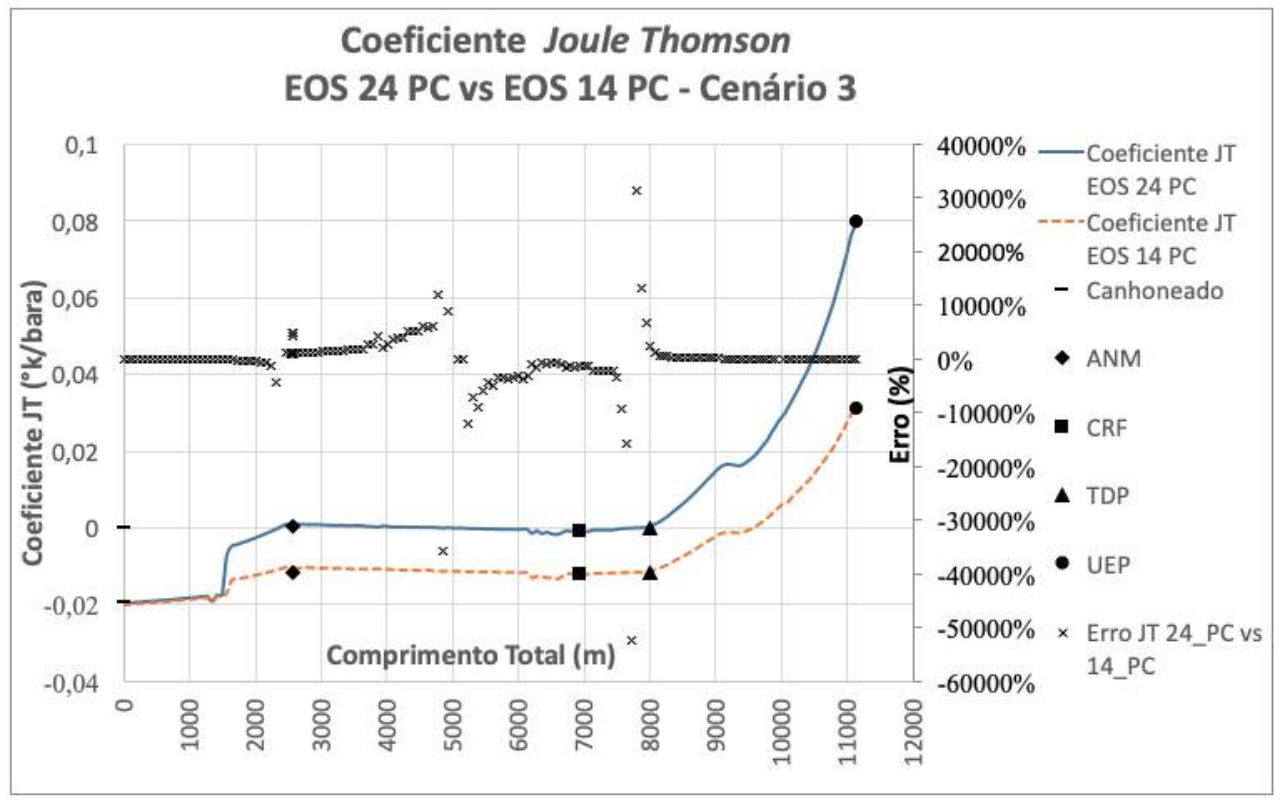

Figura C.30: Coeficiente Joule-Thomson - Cenário 3 - EOS 24 PC versus EOS 14 PC. 


\section{C.2}

\section{EOS 24 PC versus EOS 9 PC}

\section{C.2.1}

Cenário 1 - Período inicial logo após a abertura do poço

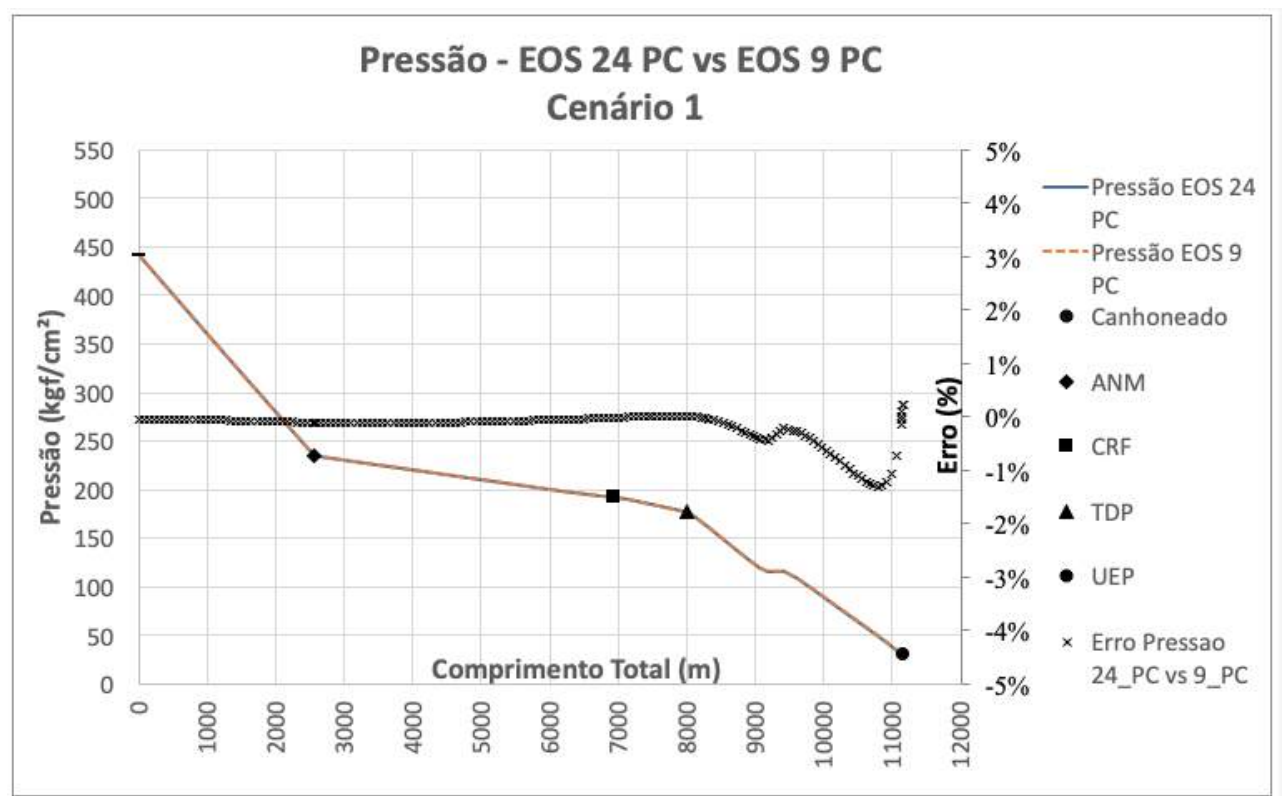

Figura C.31: Perfil de pressão no poço e duto - Cenário 1 - EOS 24 PC versus EOS 9 PC.

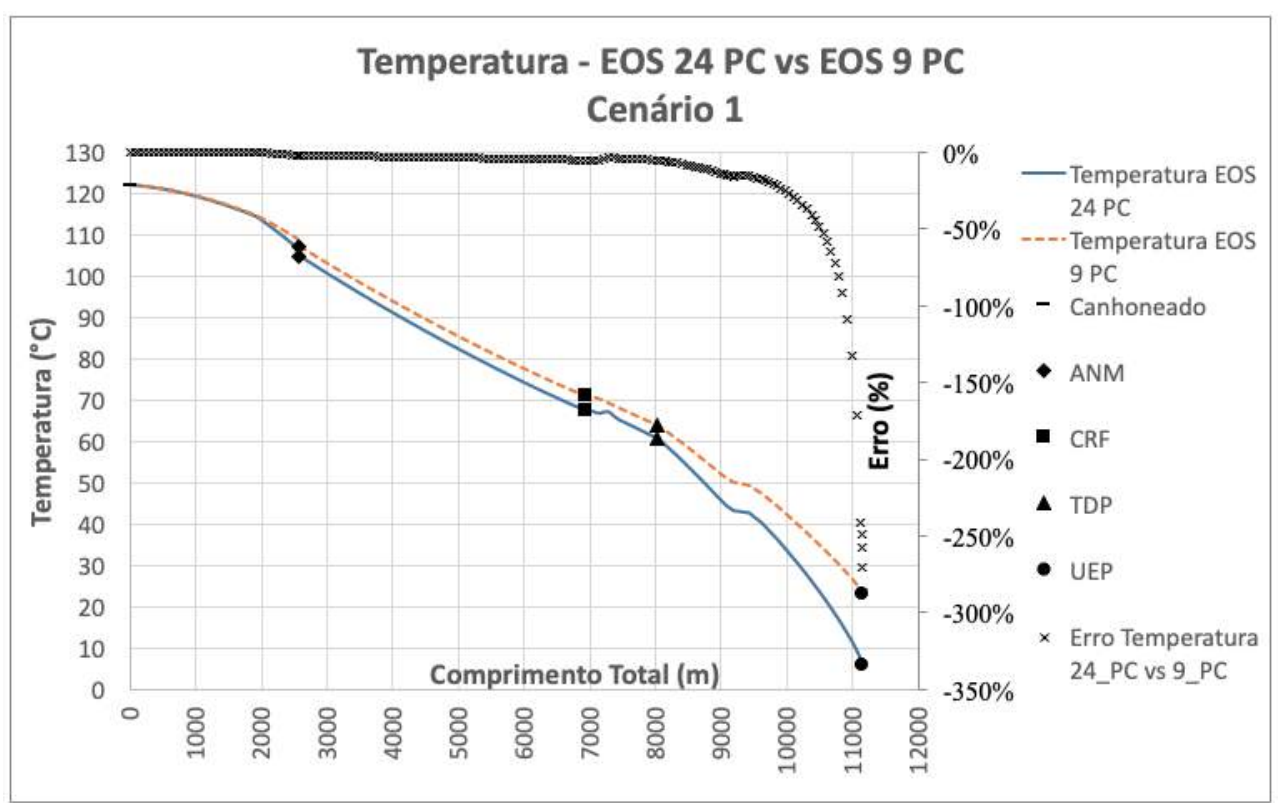

Figura C.32: Perfil de temperatura no poço e duto - Cenário 1 - EOS 24 PC versus EOS 9 PC. 


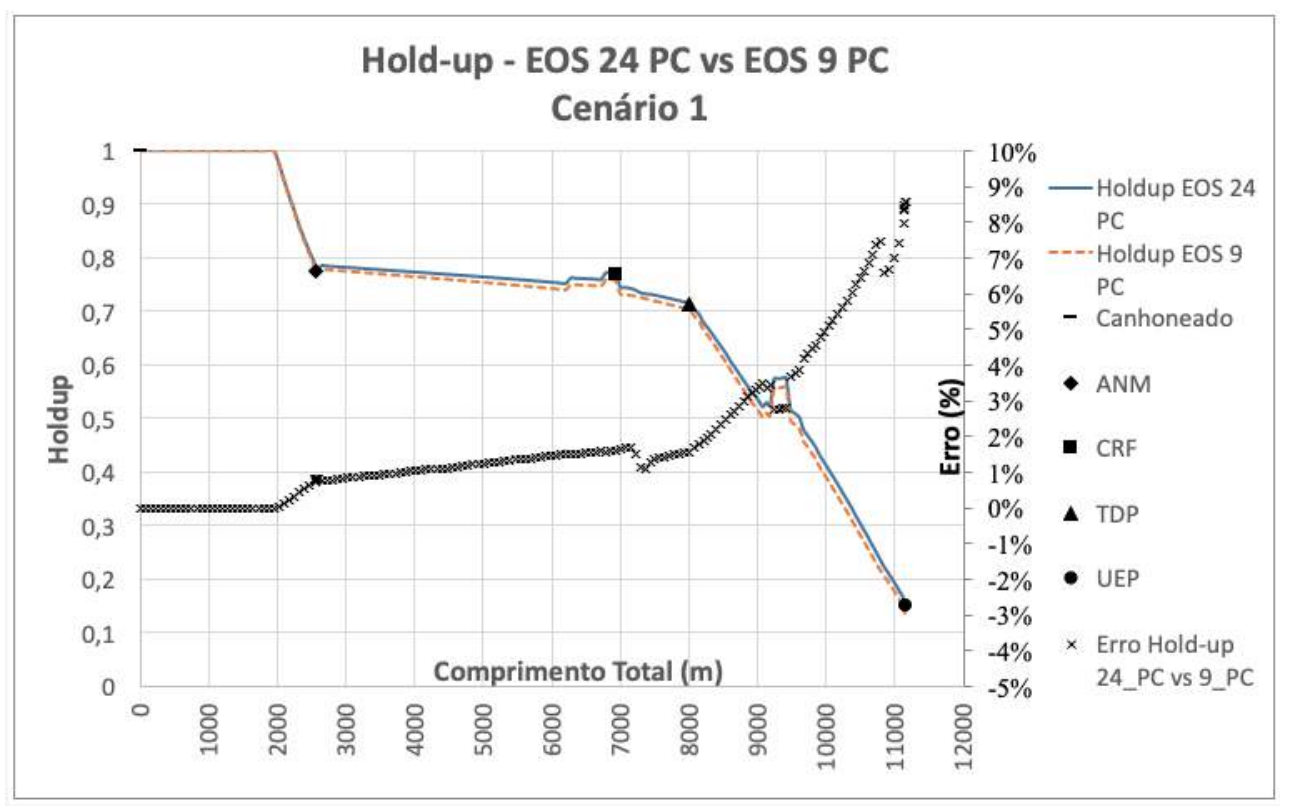

Figura C.33: Holdup no poço e duto - Cenário 1 - EOS 24 PC versus EOS 9 PC.

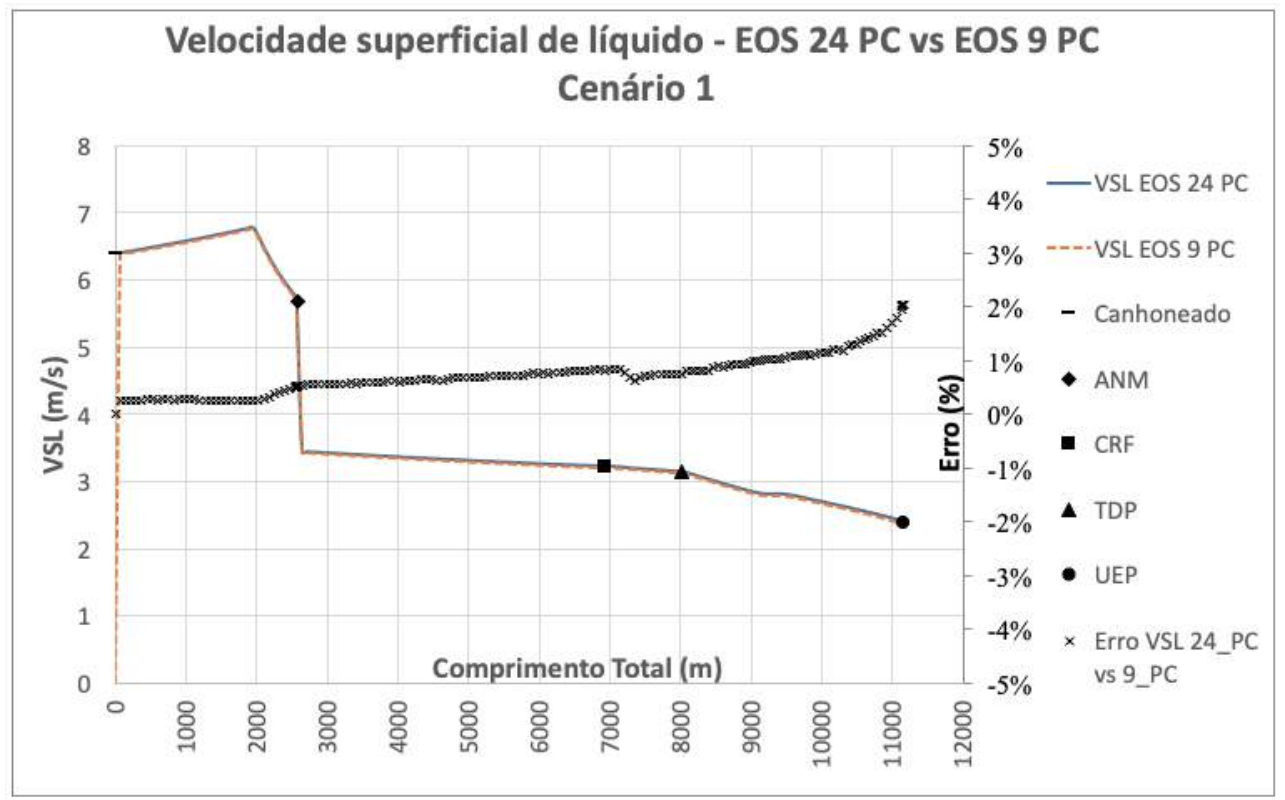

Figura C.34: Velocidade superficial de líquido - Cenário 1 - EOS 24 PC versus EOS 9 PC. 


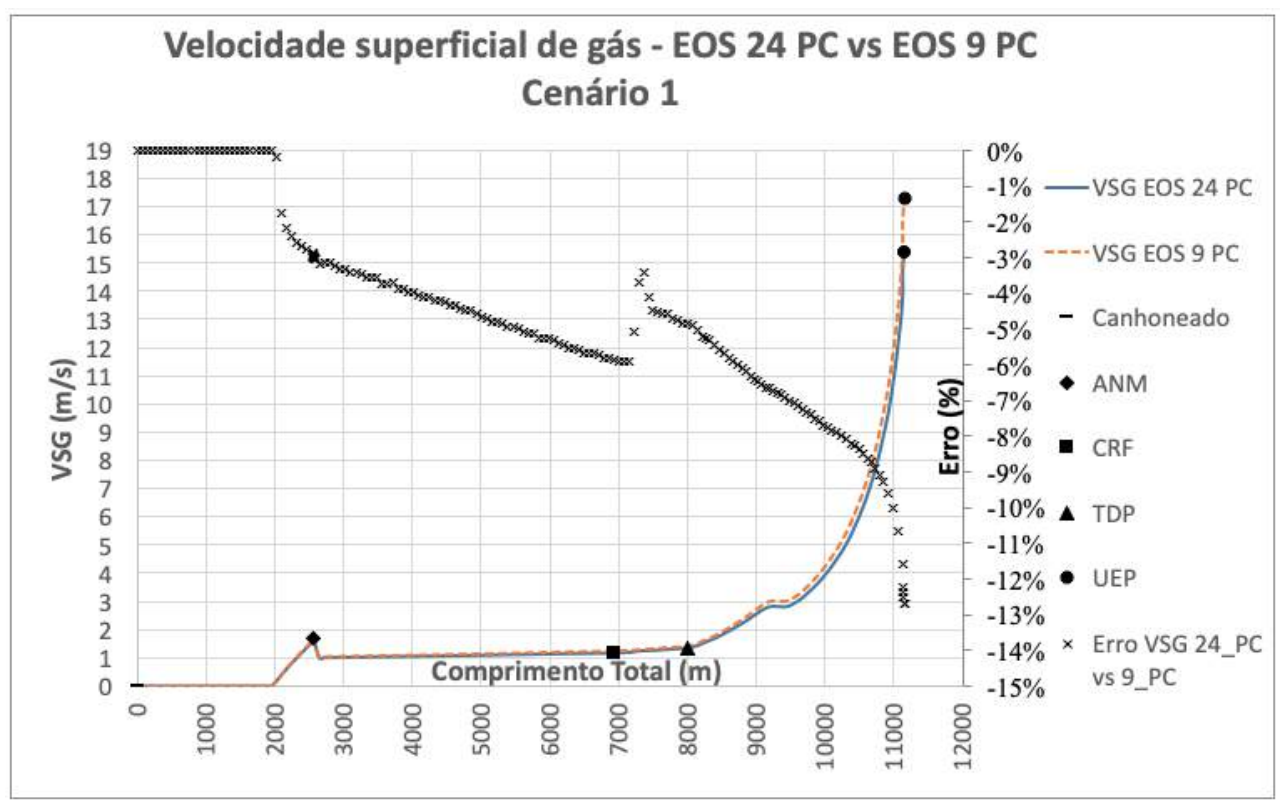

Figura C.35: Velocidade superficial de gás - Cenário 1 - EOS 24 PC versus EOS 9 PC.

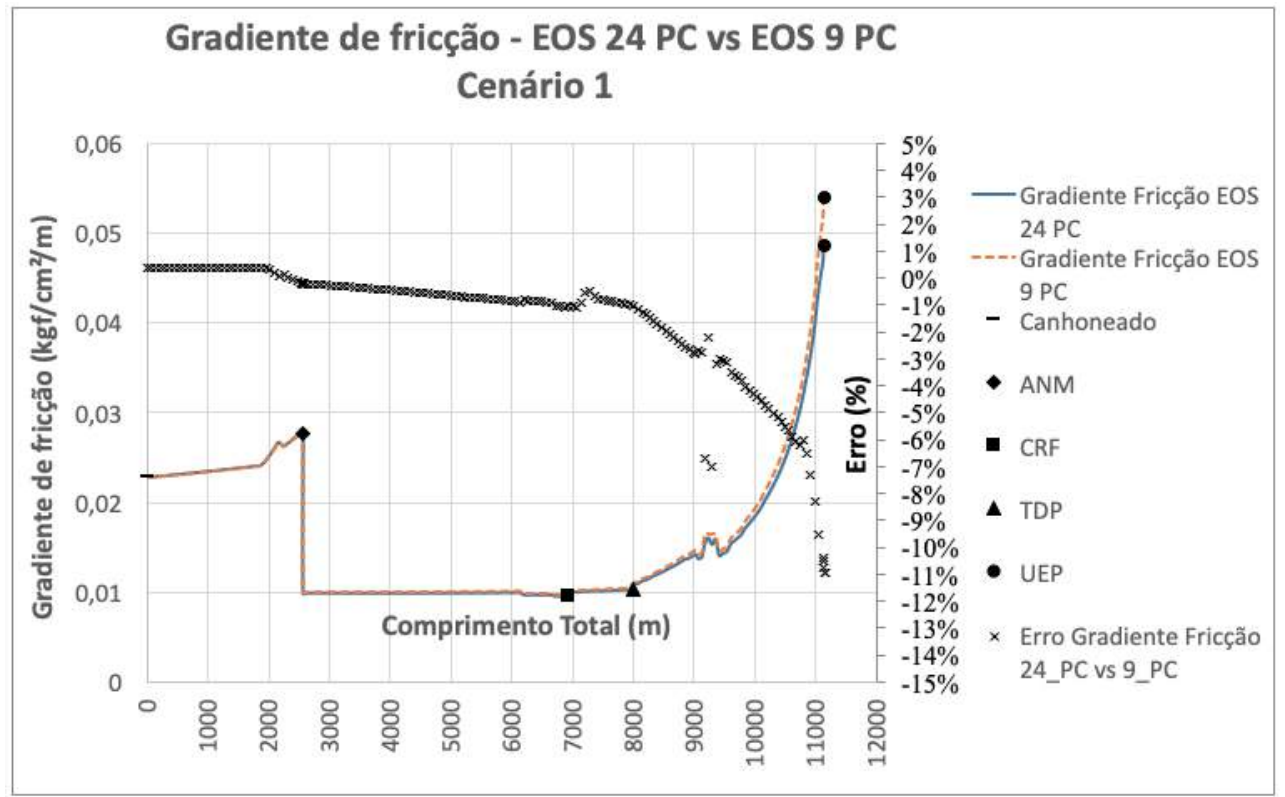

Figura C.36: Gradiente de pressão por fricção - Cenário 1 - EOS 24 PC versus EOS 9 PC. 


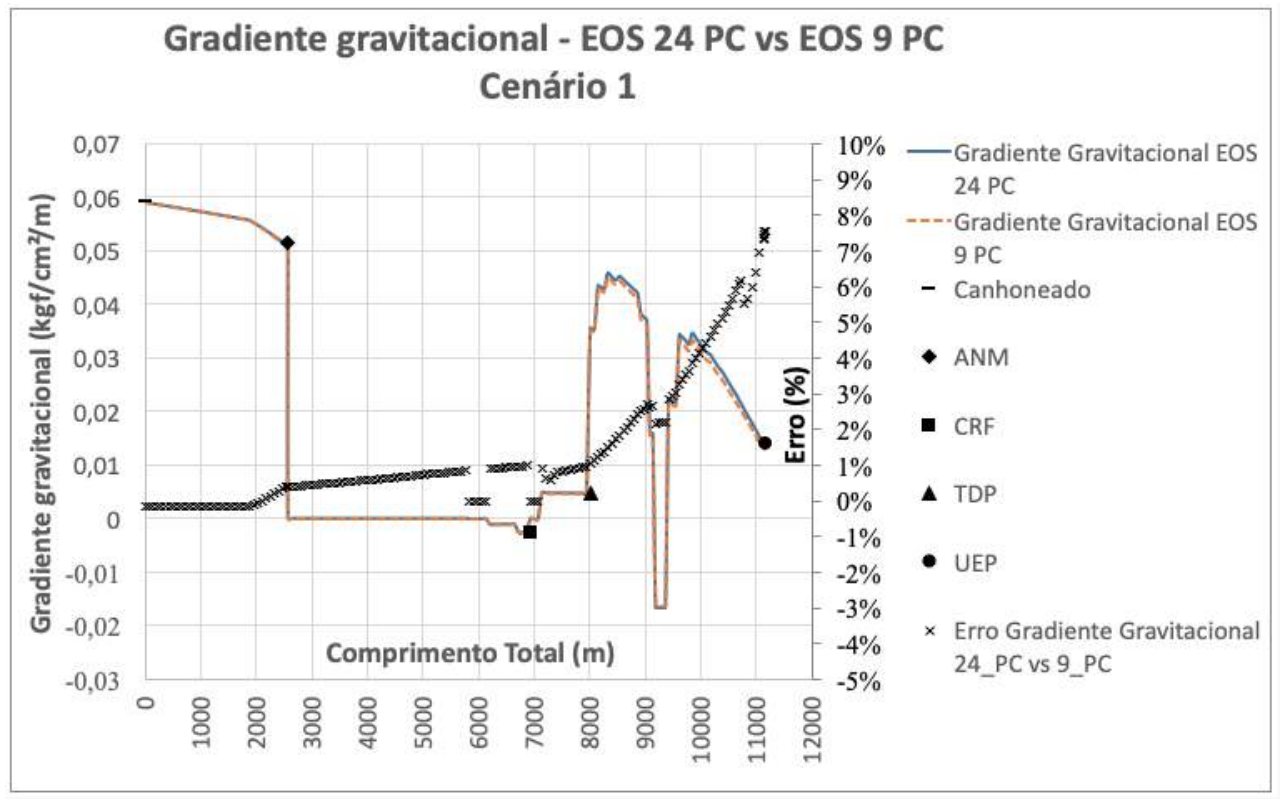

Figura C.37: Gradiente de pressão gravitacional - Cenário 1 - EOS 24 PC versus EOS 9PC.

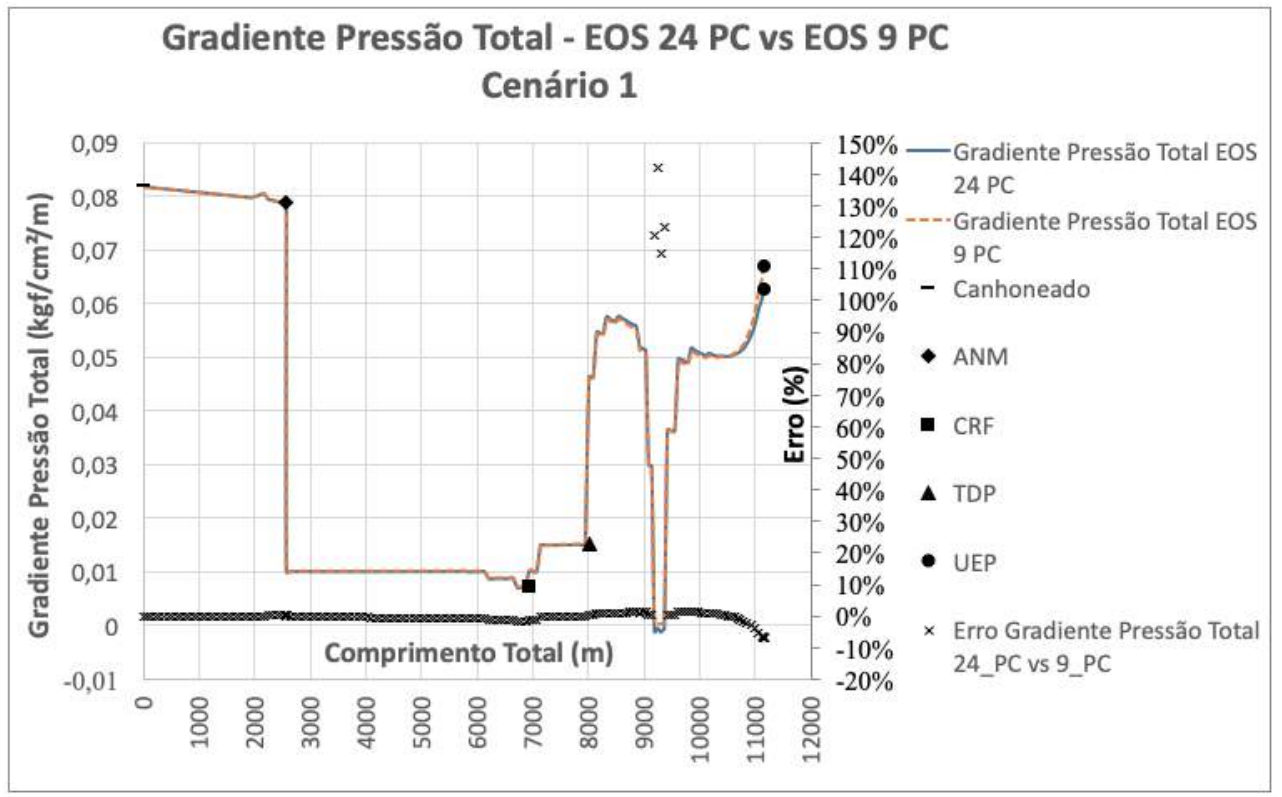

Figura C.38: Gradiente de pressão total - Cenário 1 - EOS 24 PC versus EOS $9 \mathrm{PC}$. 


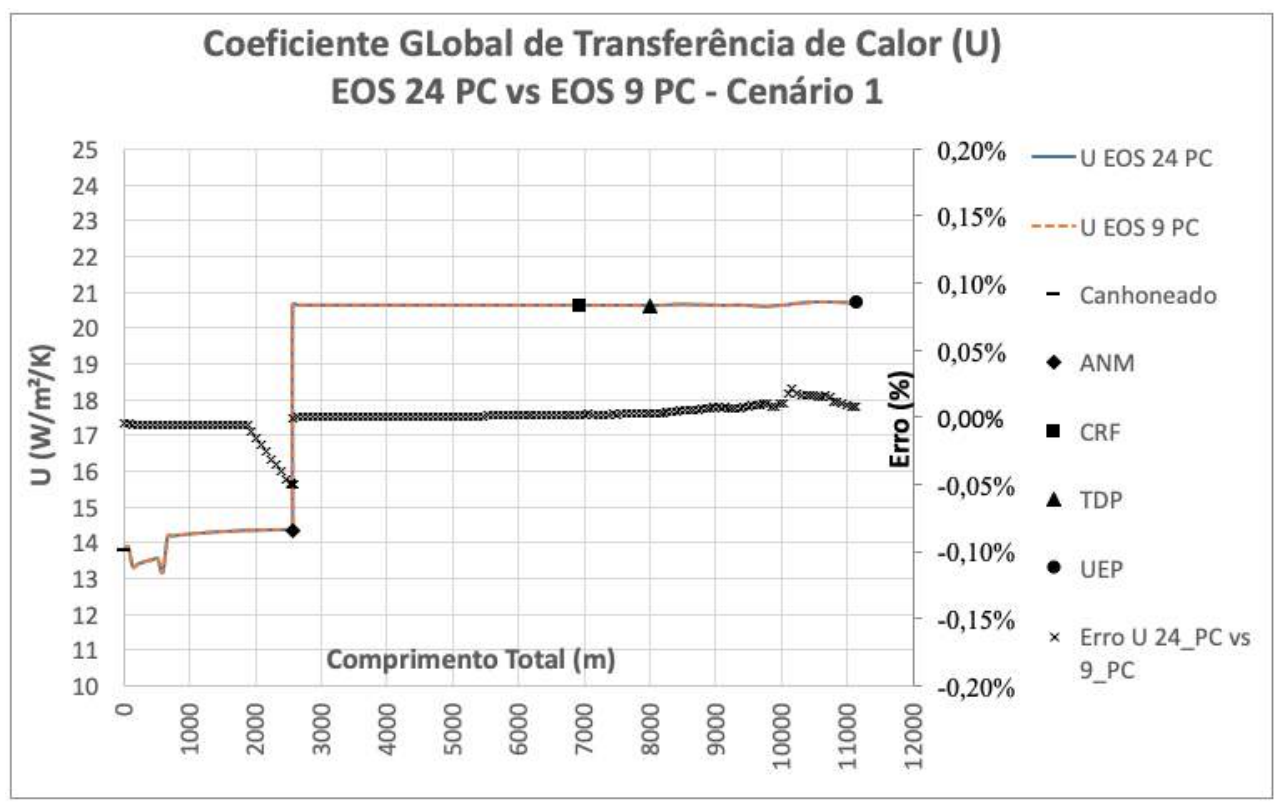

Figura C.39: Coeficiente global de transferência de calor - Cenário 1 - EOS 24 $\mathrm{PC}$ versus EOS 9 PC.

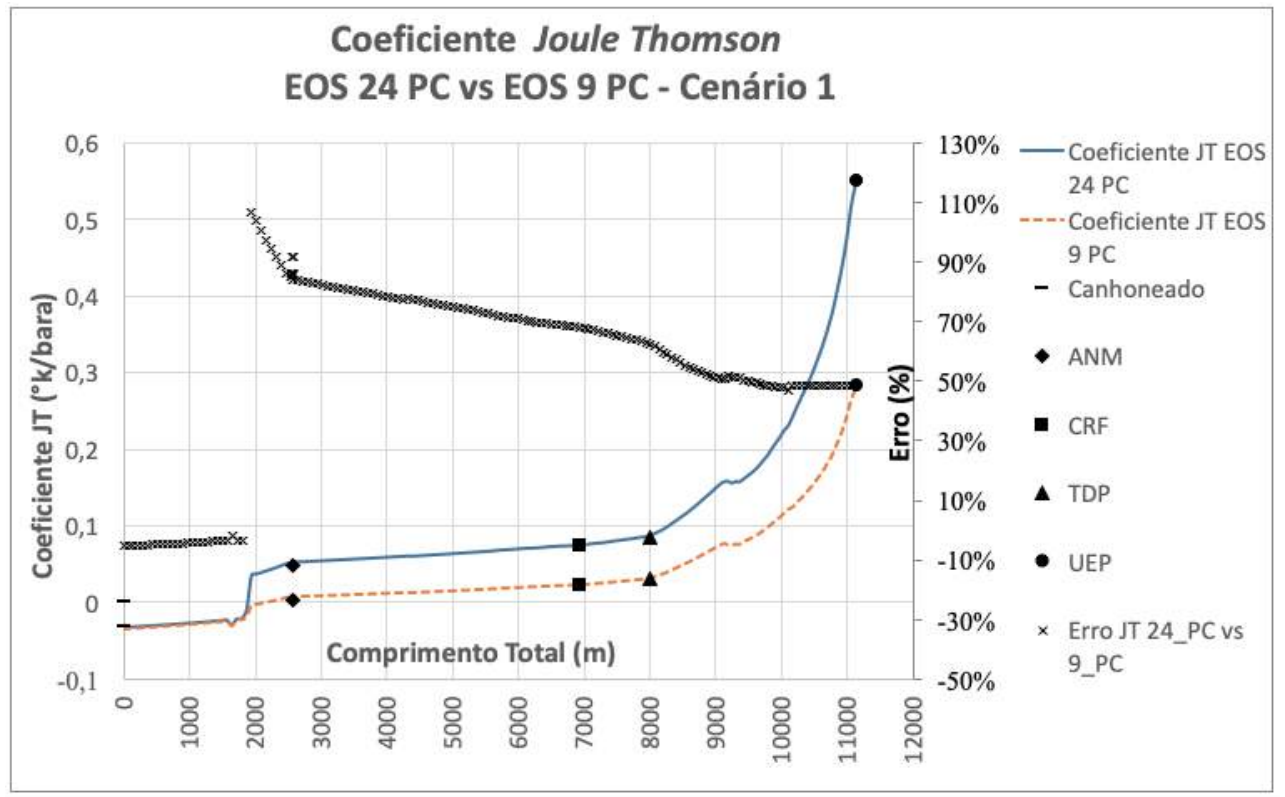

Figura C.40: Coeficiente Joule-Thomson - Cenário 1 - EOS 24 PC versus EOS 9 PC. 


\section{2.2}

\section{Cenário 2 - Período inicial antes do breaktrough de água}

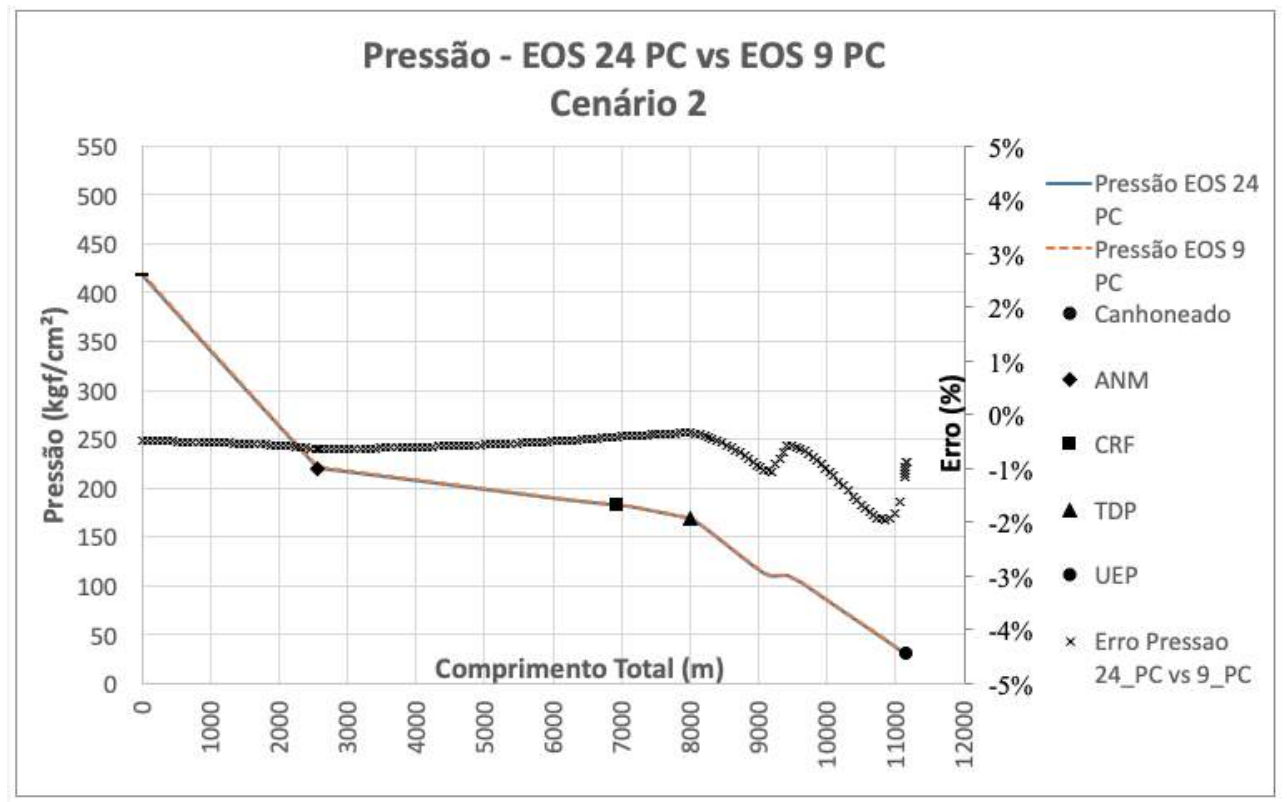

Figura C.41: Perfil de pressão no poço e duto - Cenário 2 - EOS 24 PC versus EOS 9 PC.

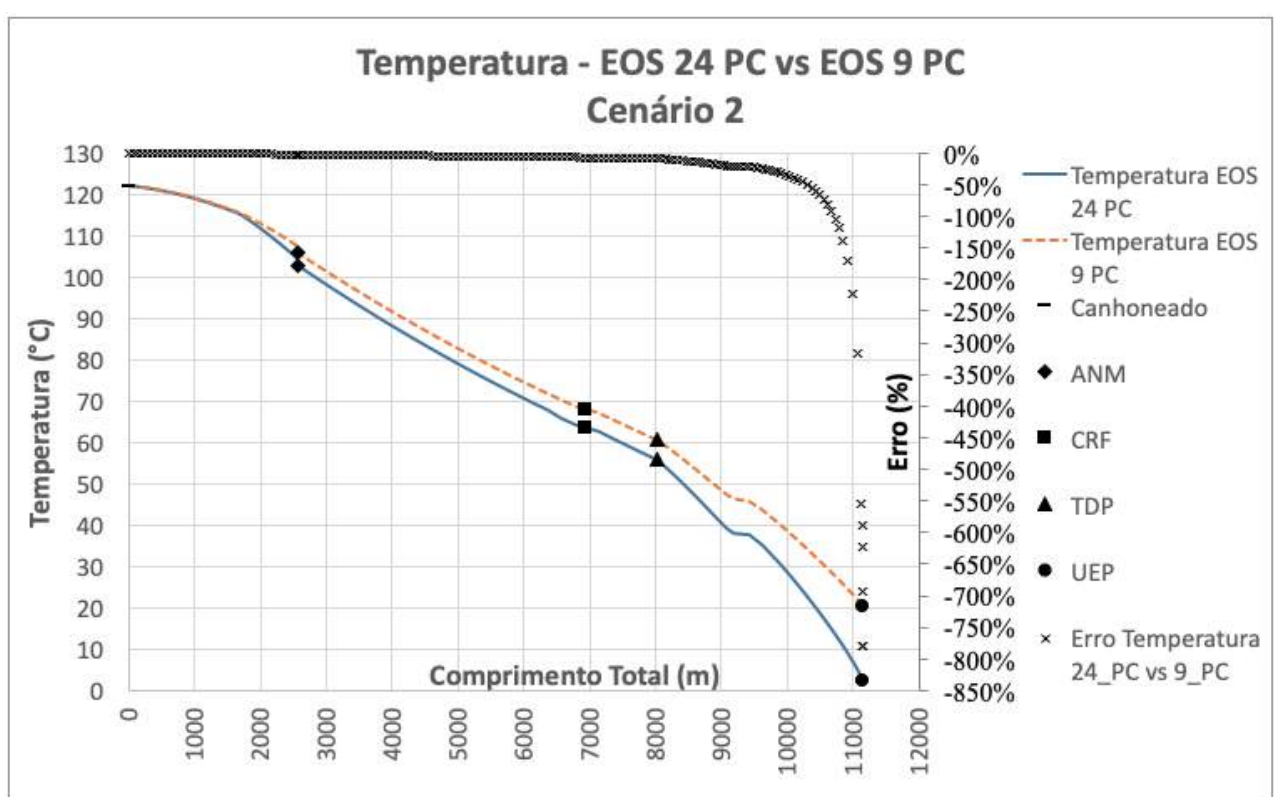

Figura C.42: Perfil de temperatura no poço e duto - Cenário 2 - EOS 24 PC versus EOS 9 PC. 


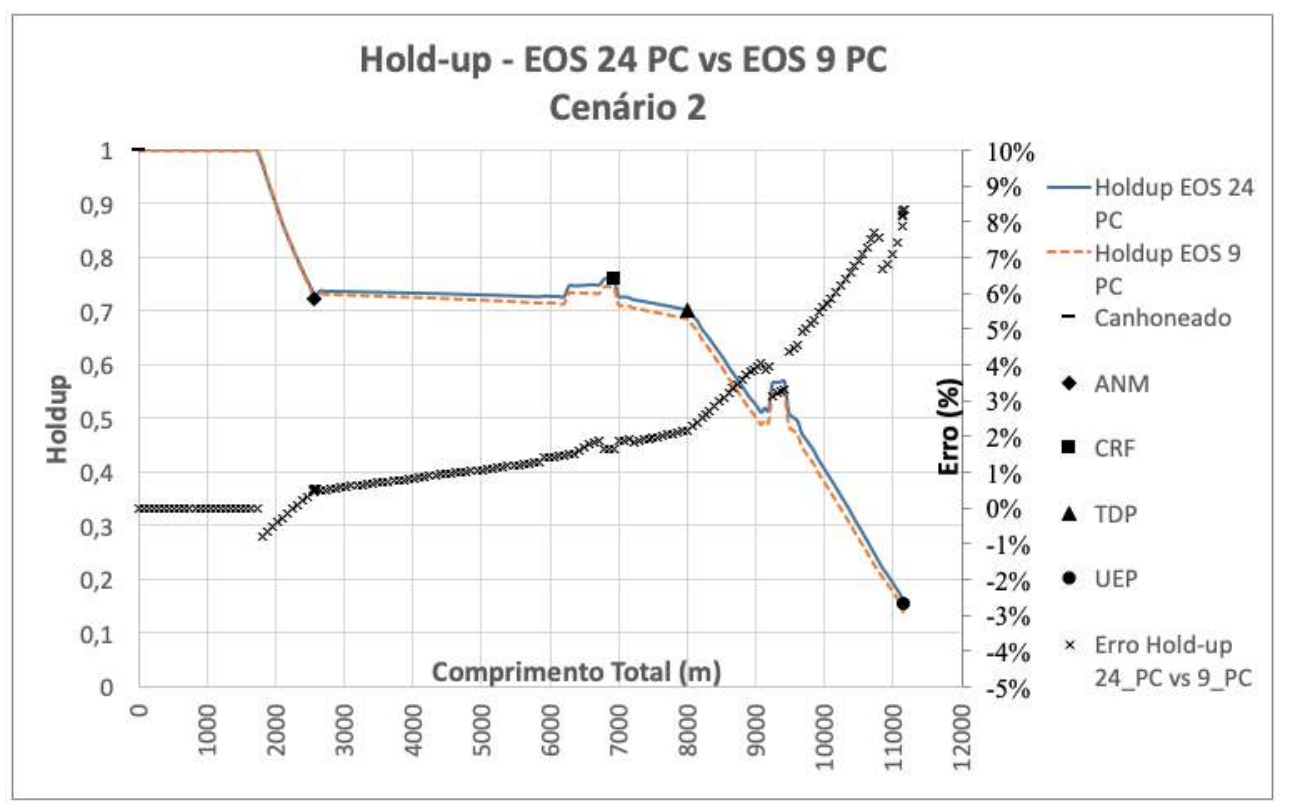

Figura C.43: Holdup no poço e duto - Cenário 2 - EOS 24 PC versus EOS 9 PC.

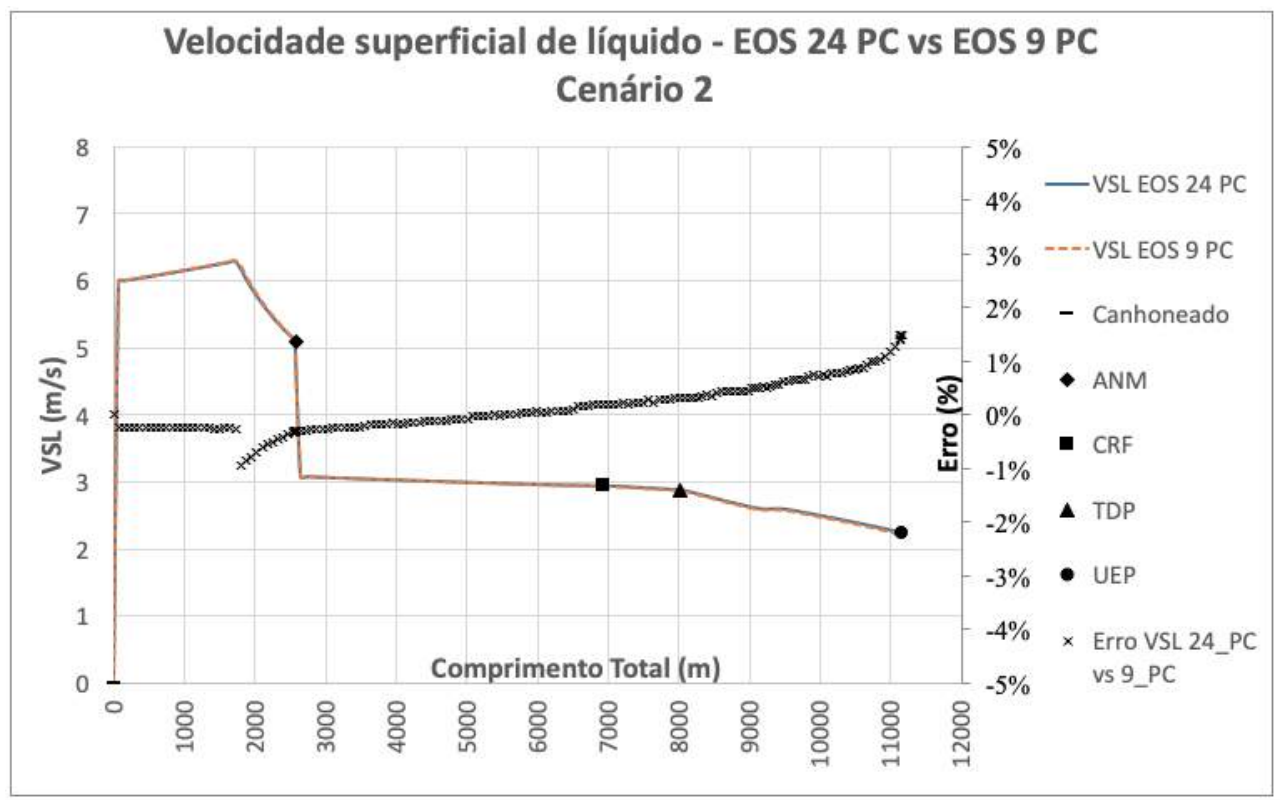

Figura C.44: Velocidade superficial de líquido - Cenário 2 - EOS 24 PC versus EOS 9 PC. 


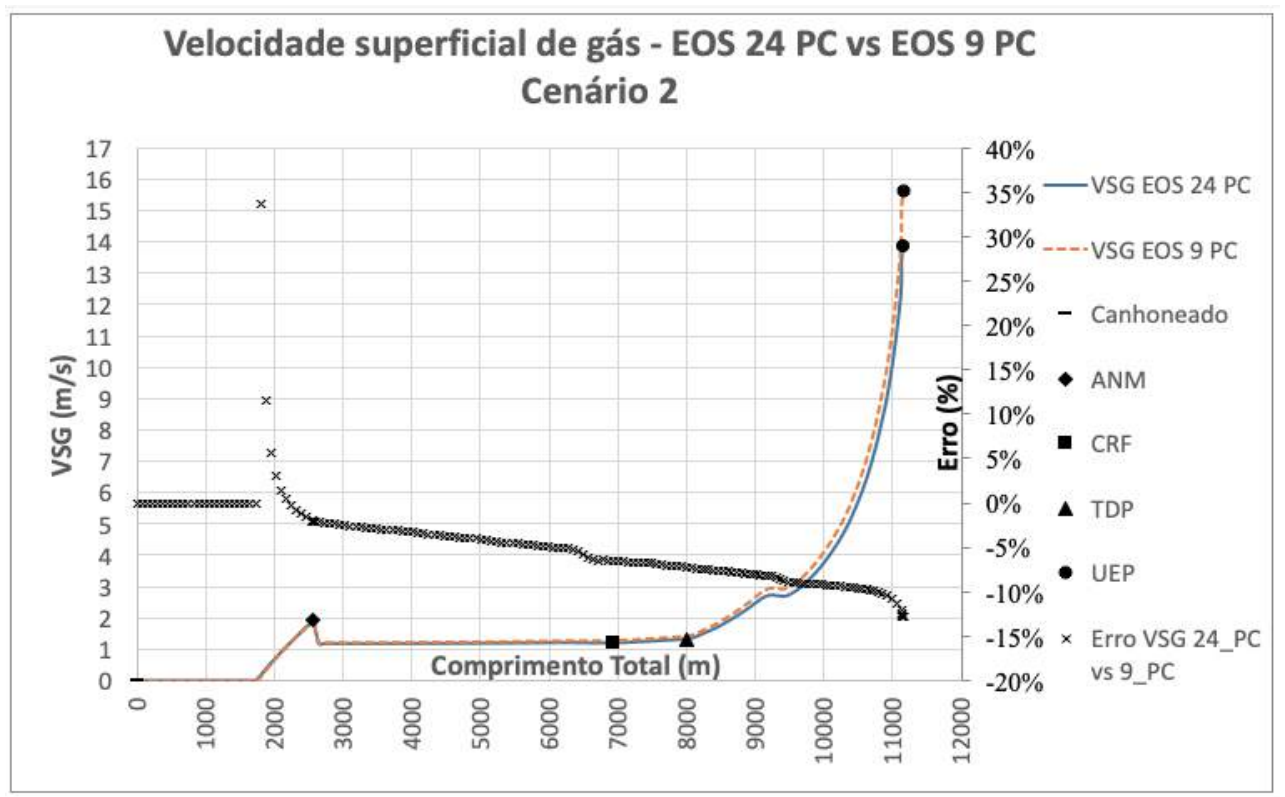

Figura C.45: Velocidade superficial de gás - Cenário 2 - EOS 24 PC versus EOS 9 PC.

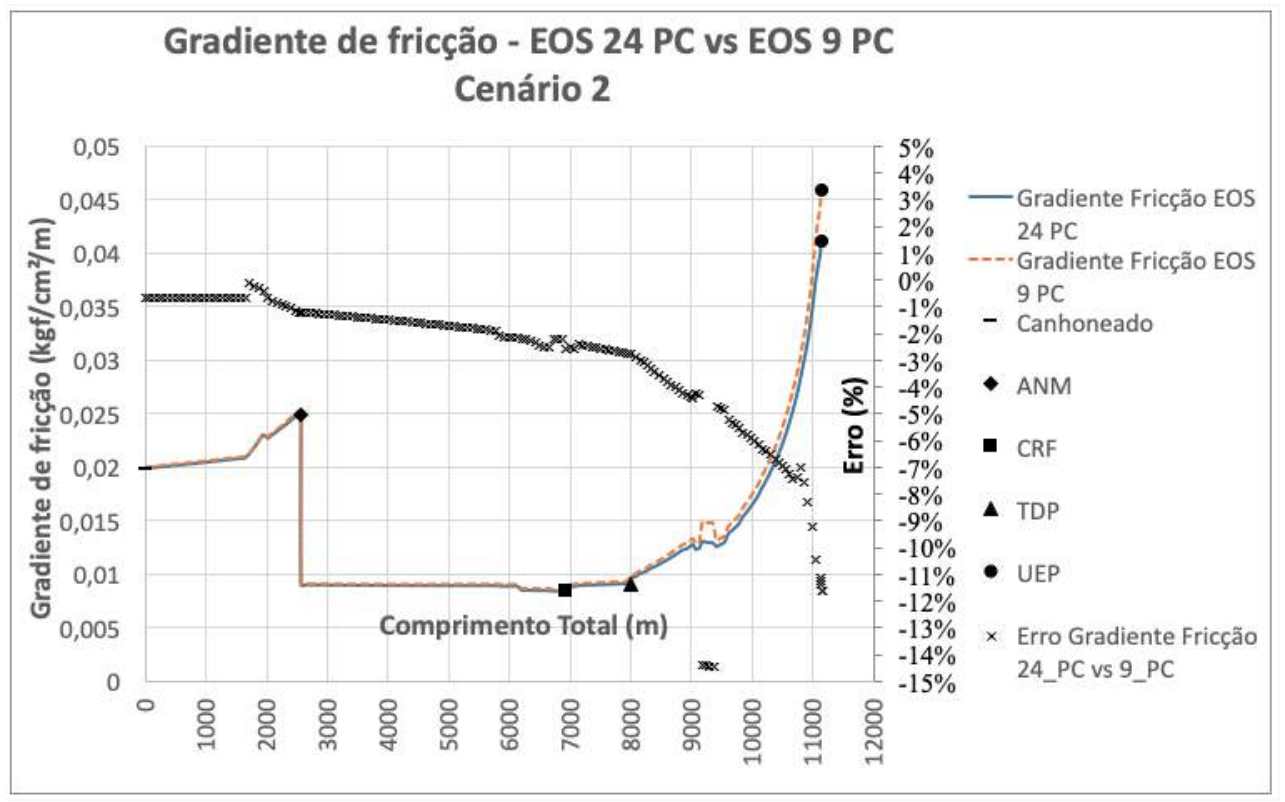

Figura C.46: Gradiente de pressão por fricção - Cenário 2 - EOS 24 PC versus EOS 9 PC. 


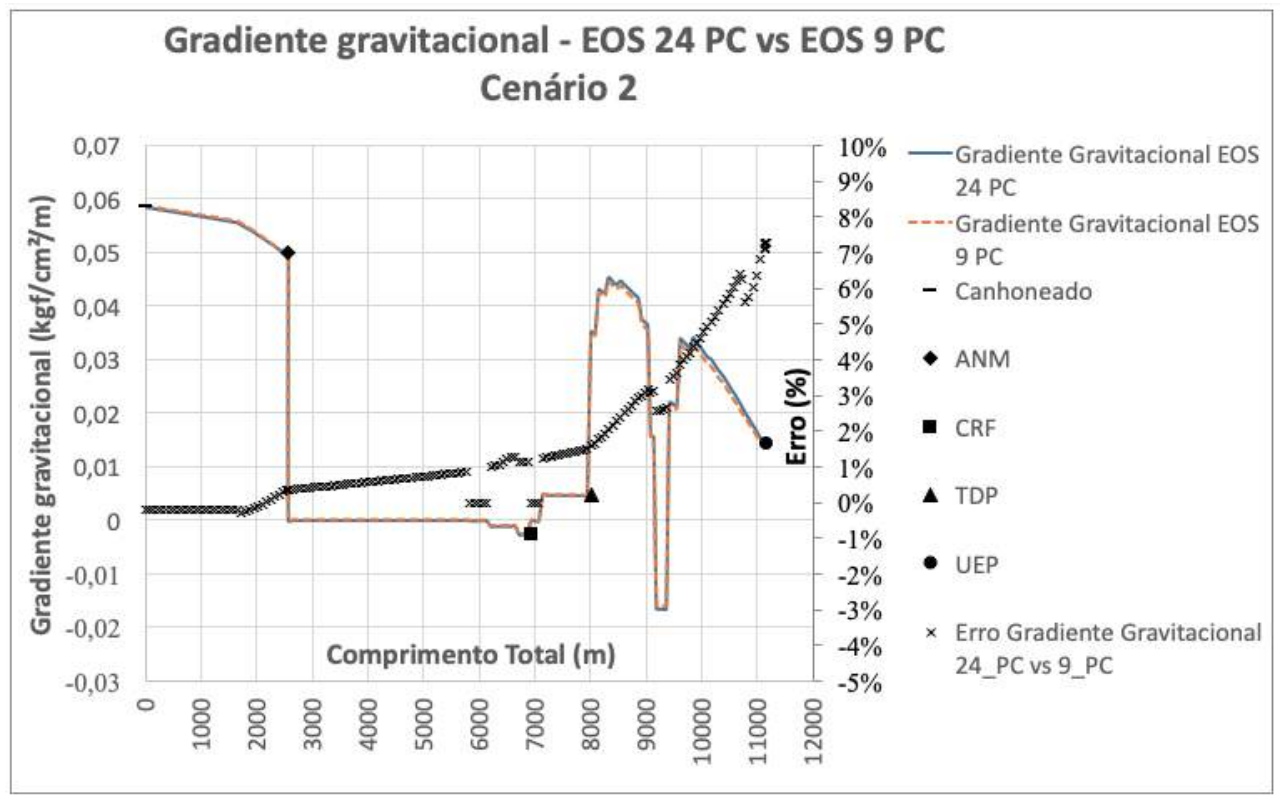

Figura C.47: Gradiente de pressão gravitacional - Cenário 2 - EOS 24 PC versus EOS 9 PC.

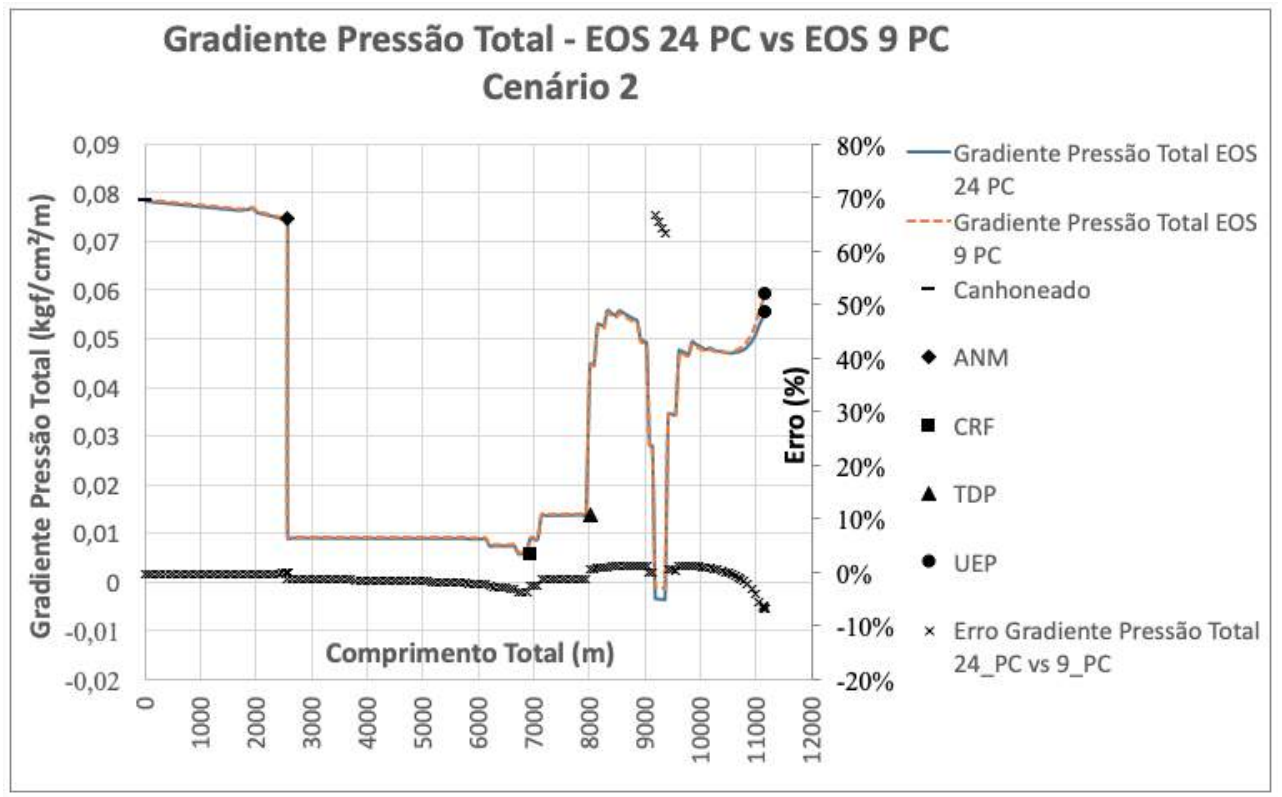

Figura C.48: Gradiente de pressão total - Cenário 2 - EOS 24 PC versus EOS 9 PC. 


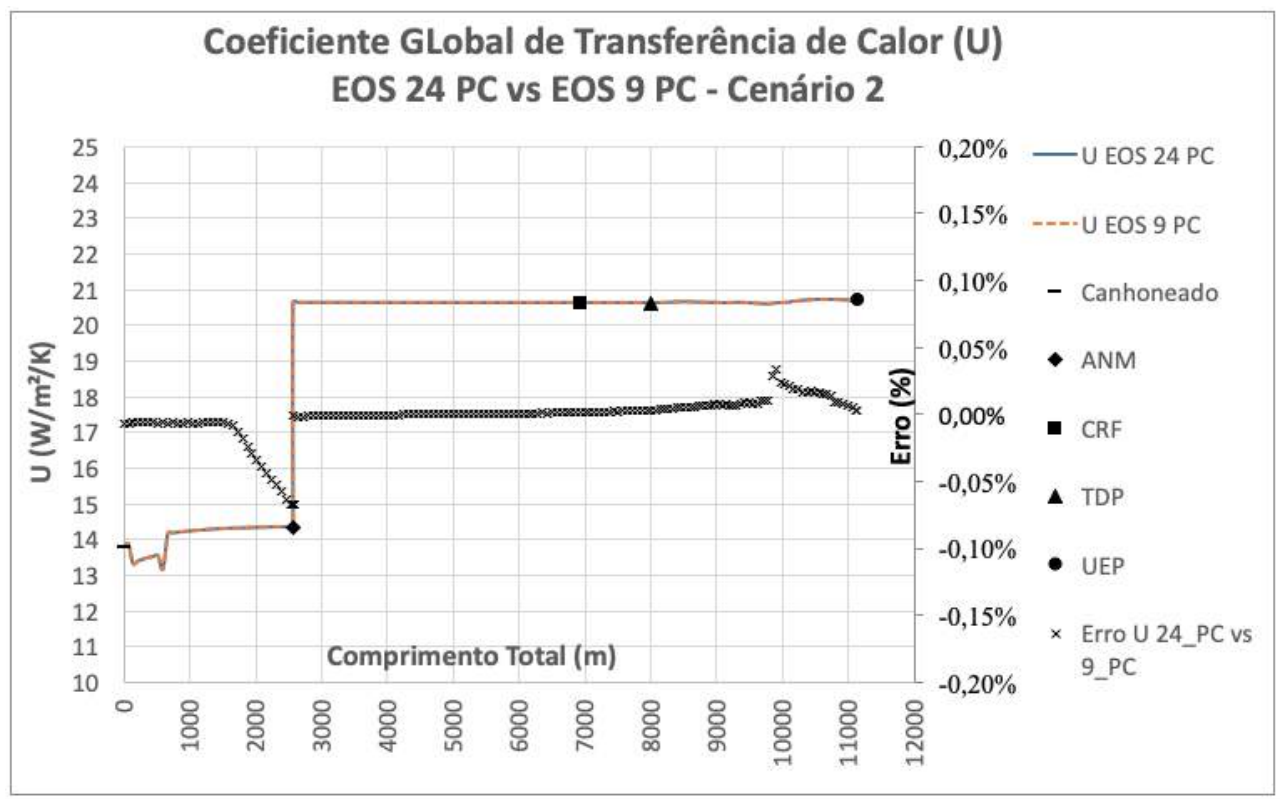

Figura C.49: Coeficiente global de transferência de calor - Cenário 2 - EOS 24 $\mathrm{PC}$ versus EOS 9 PC.

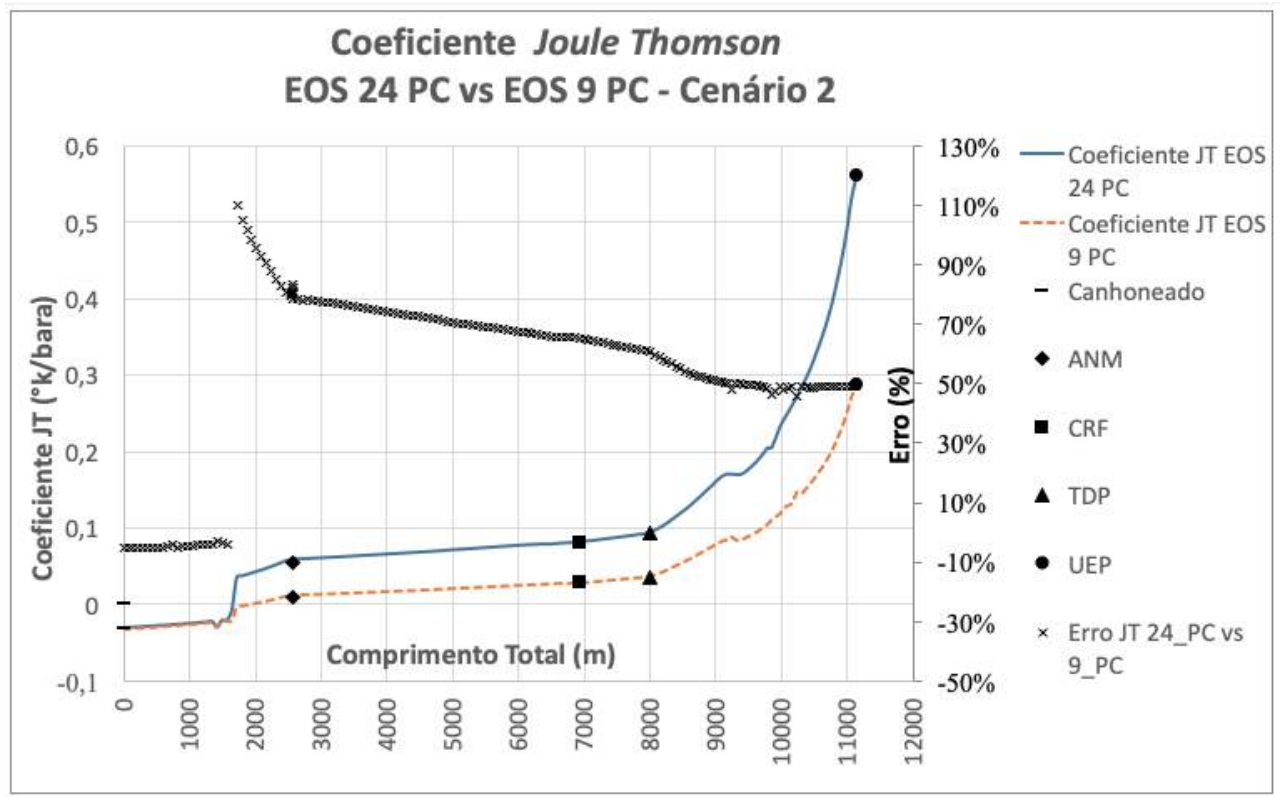

Figura C.50: Coeficiente Joule-Thomson - Cenário 2 - EOS 24 PC versus EOS 9 PC. 


\section{C.2.3}

\section{Cenário 3 - Corte de água intermediário}

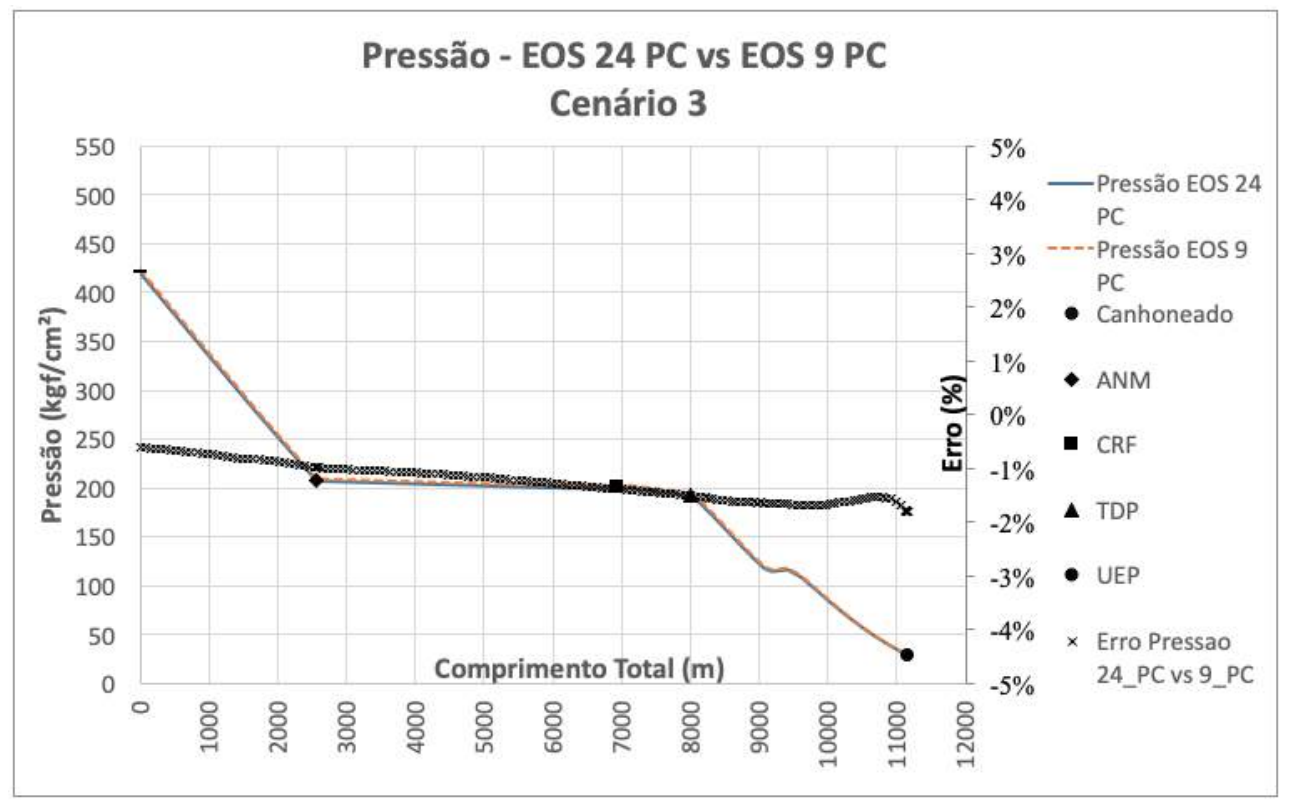

Figura C.51: Perfil de pressão no poço e duto - Cenário 3 - EOS 24 PC versus EOS 9 PC.

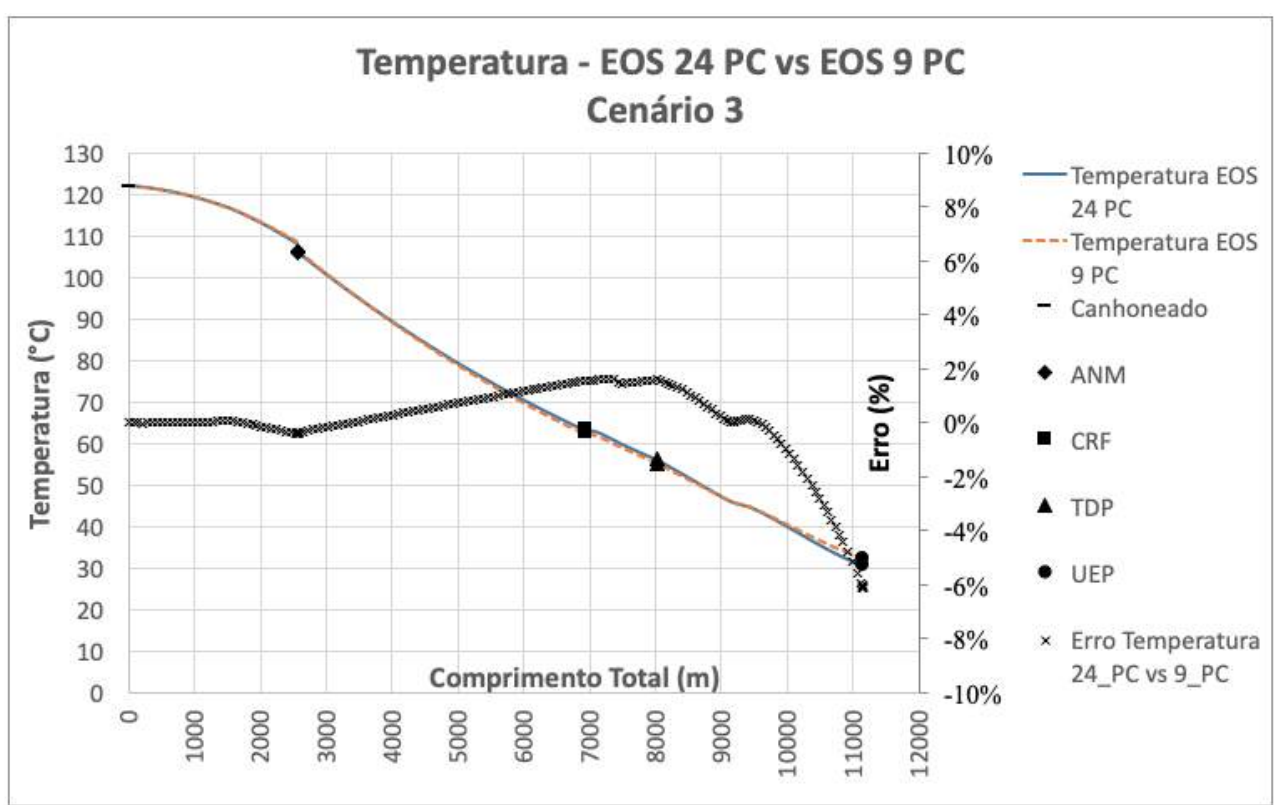

Figura C.52: Perfil de temperatura no poço e duto - Cenário 3 - EOS 24 PC versus EOS 9 PC. 


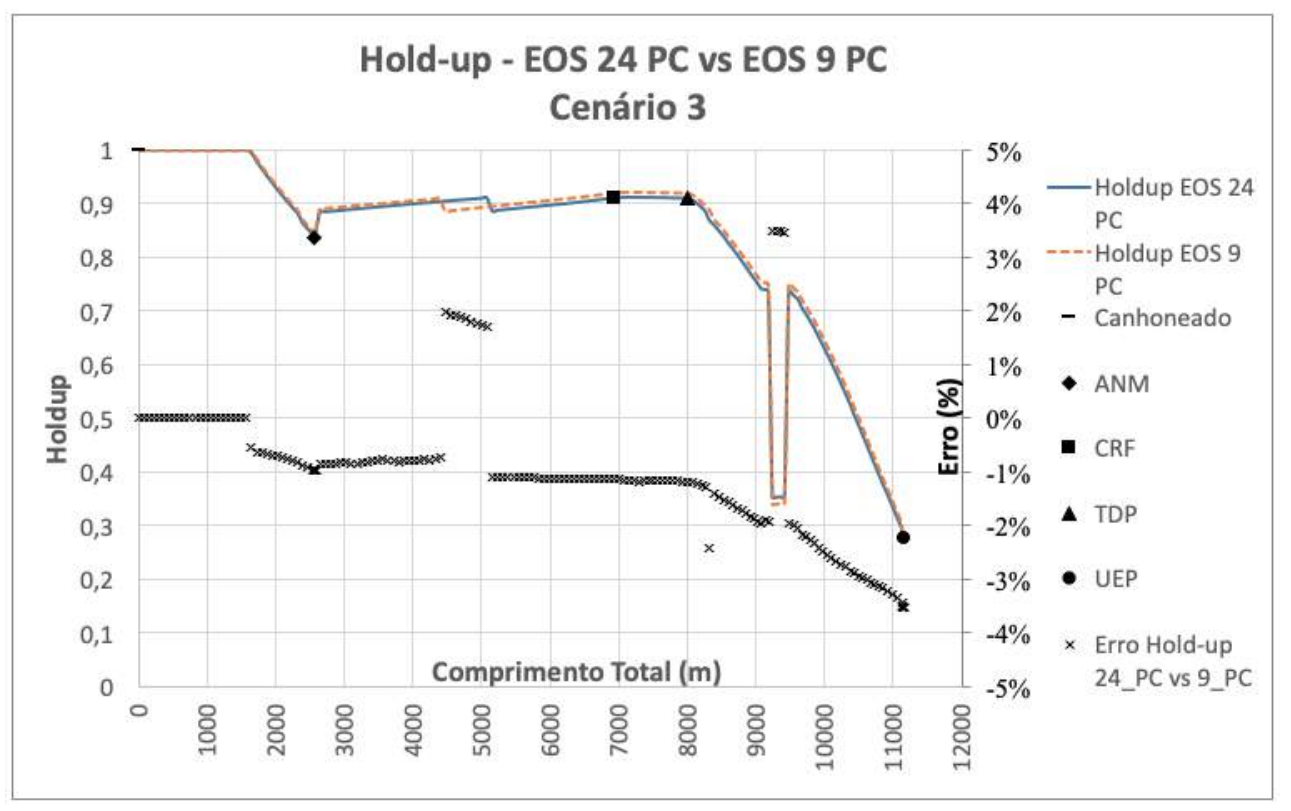

Figura C.53: Holdup no poço e duto - Cenário 3 - EOS 24 PC versus EOS 9 PC.

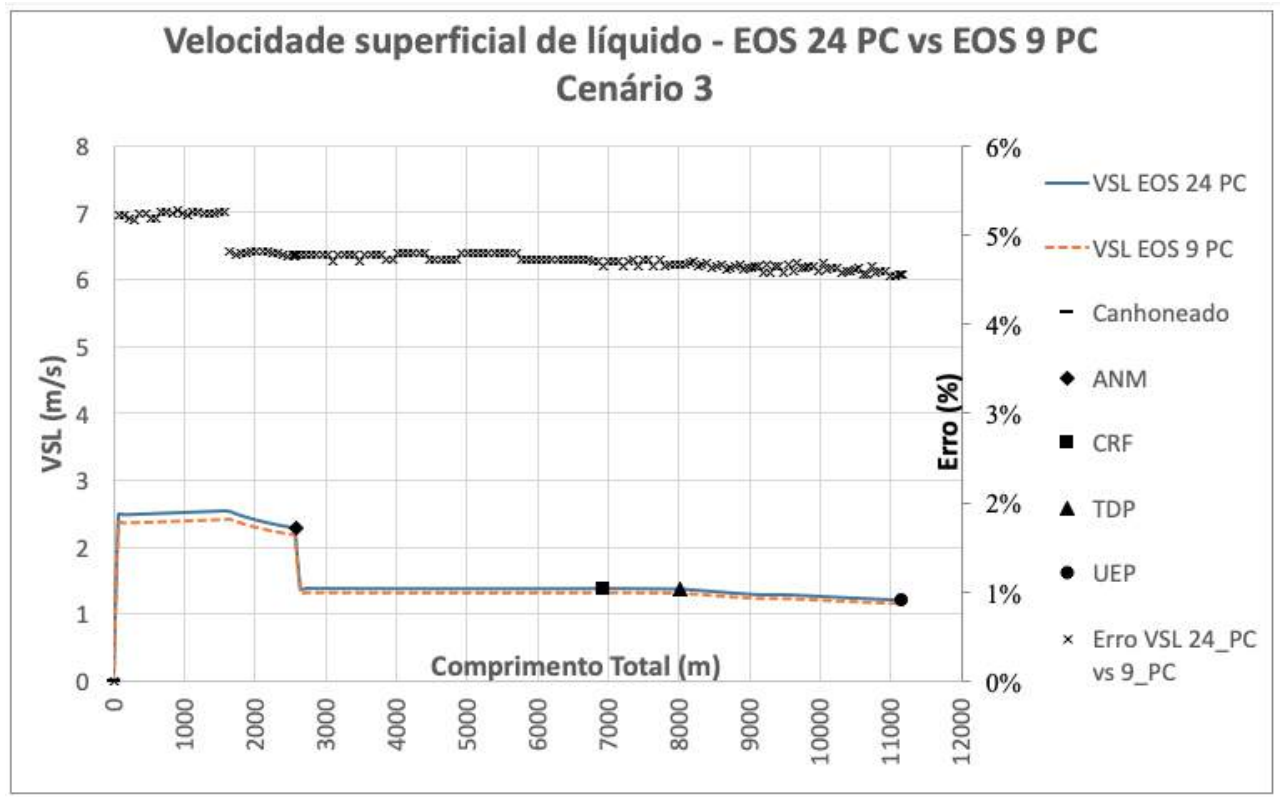

Figura C.54: Velocidade superficial de líquido - Cenário 3 - EOS 24 PC versus EOS 9 PC. 


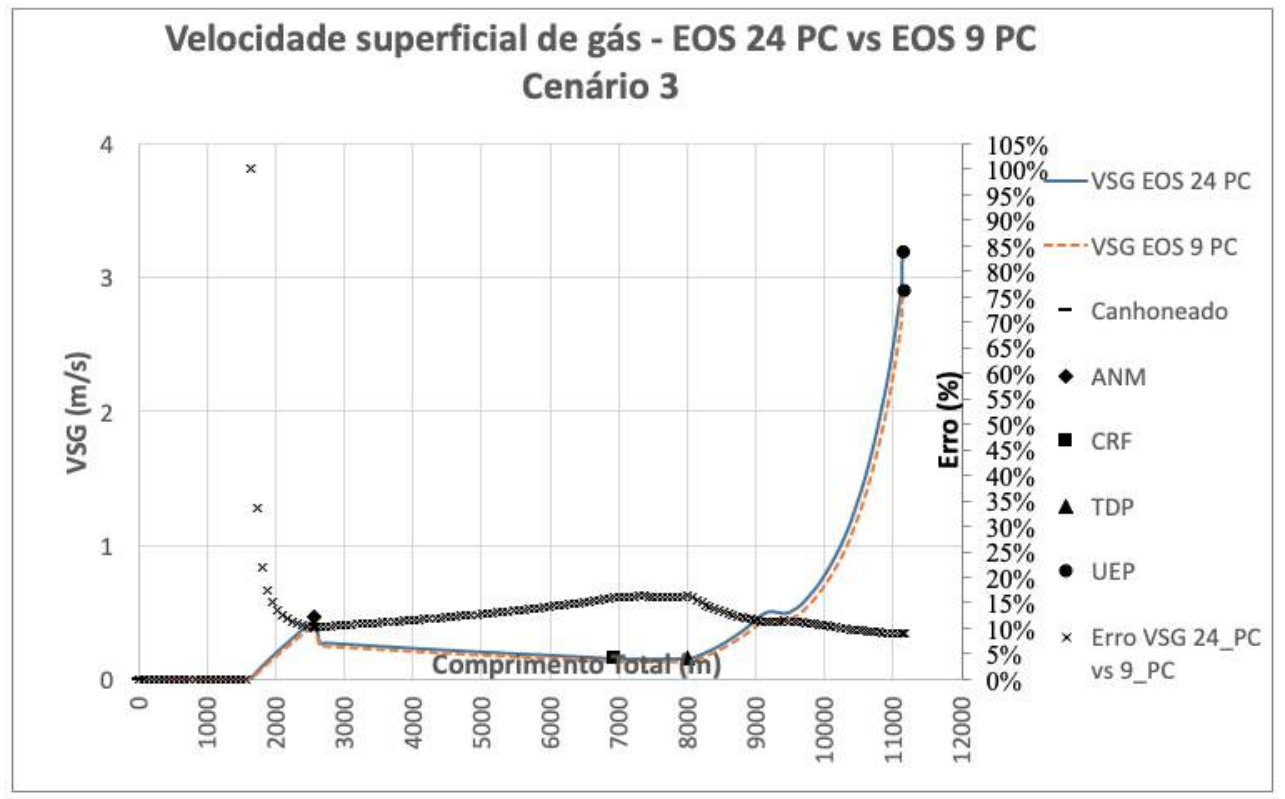

Figura C.55: Velocidade superficial de gás - Cenário 3 - EOS 24 PC versus EOS 9 PC.

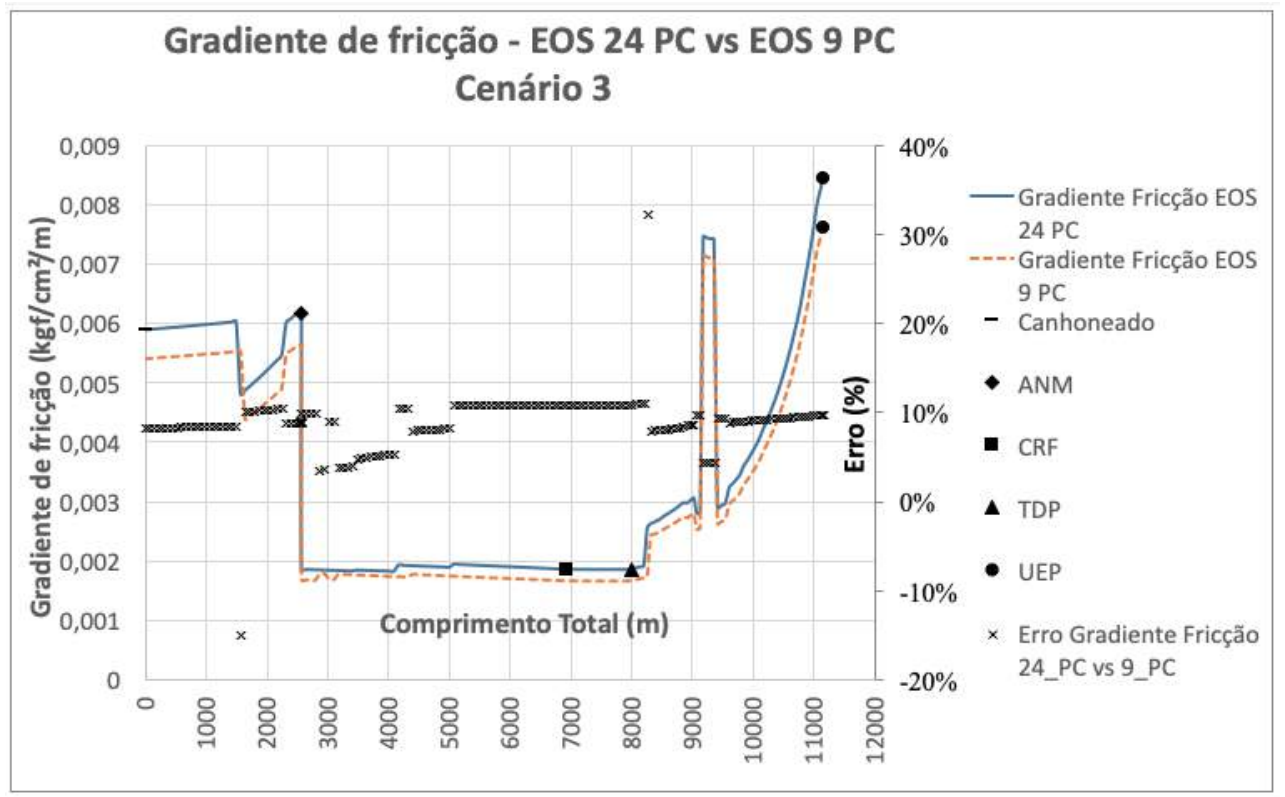

Figura C.56: Gradiente de pressão por fricção - Cenário 3 - EOS 24 PC versus EOS 9 PC. 


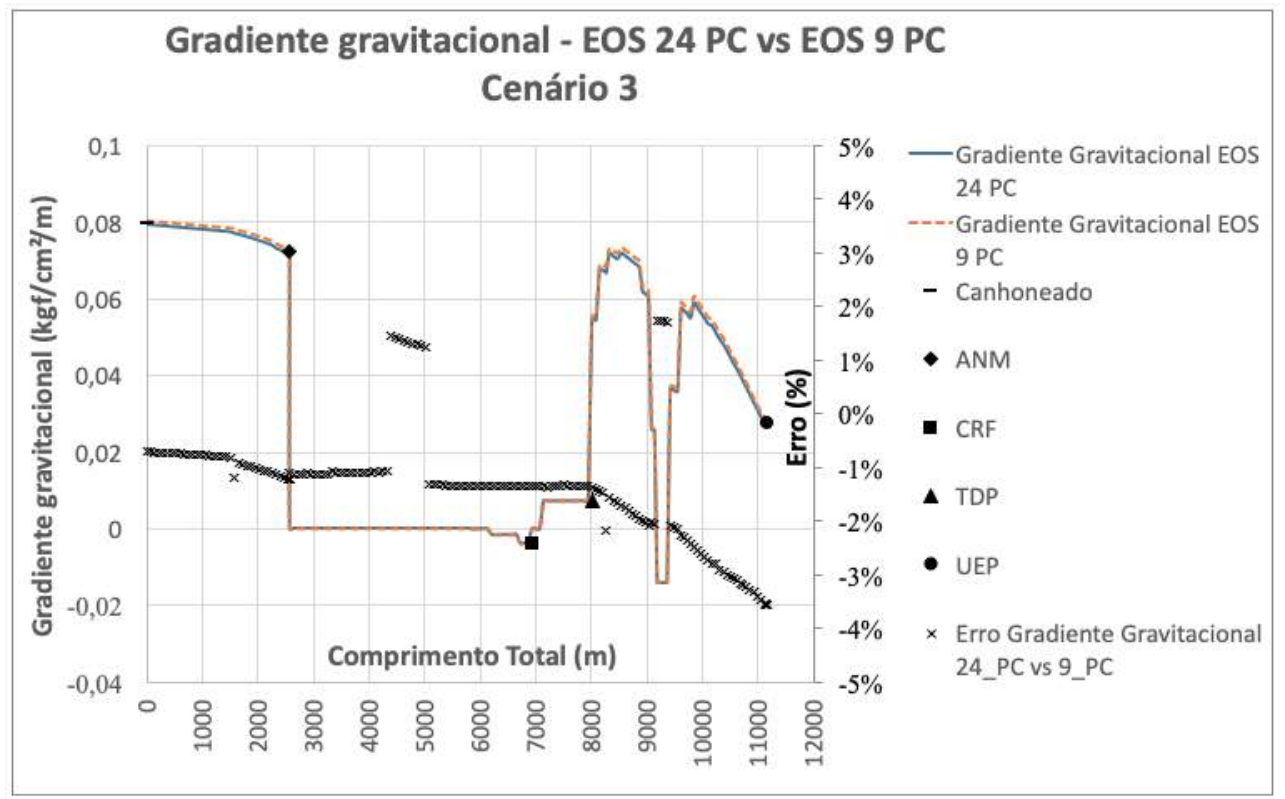

Figura C.57: Gradiente de pressão gravitacional - Cenário 3 - EOS 24 PC versus EOS 9 PC.

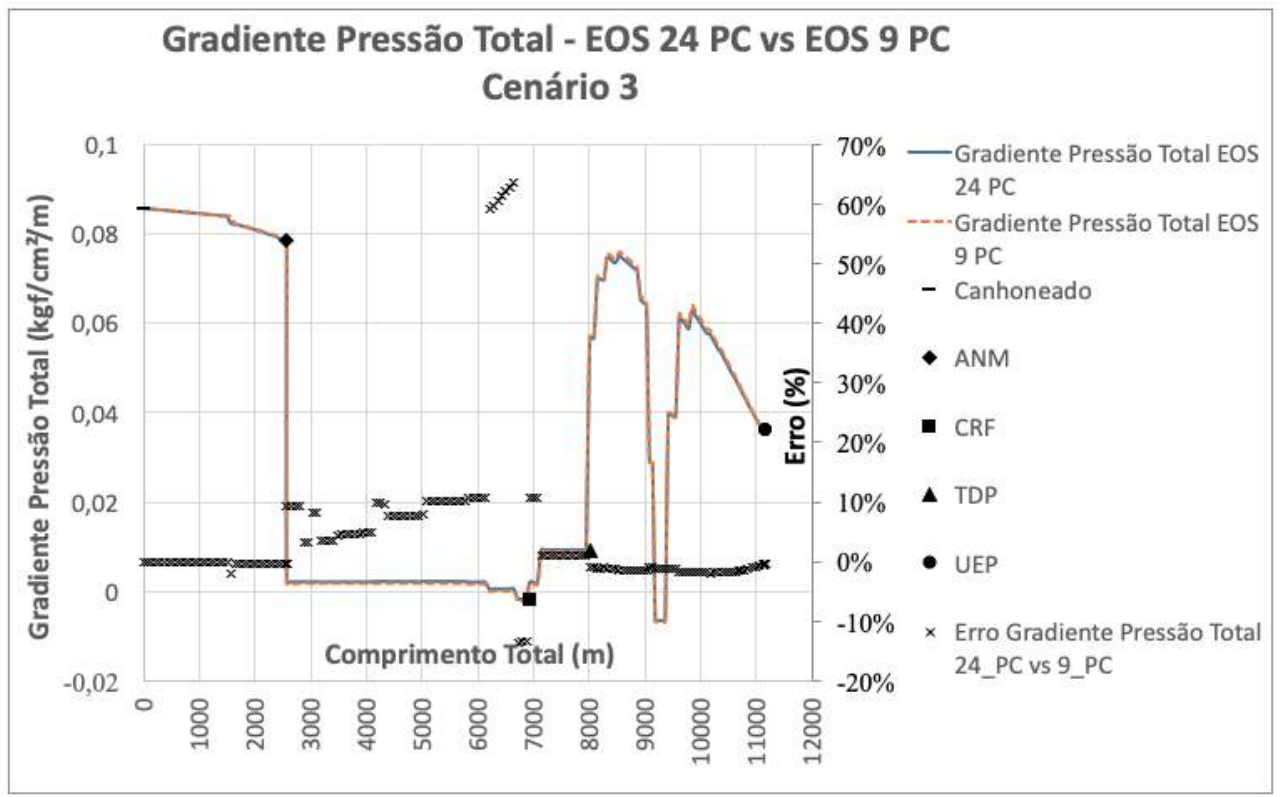

Figura C.58: Gradiente de pressão total - Cenário 3 - EOS 24 PC versus EOS 9 PC. 


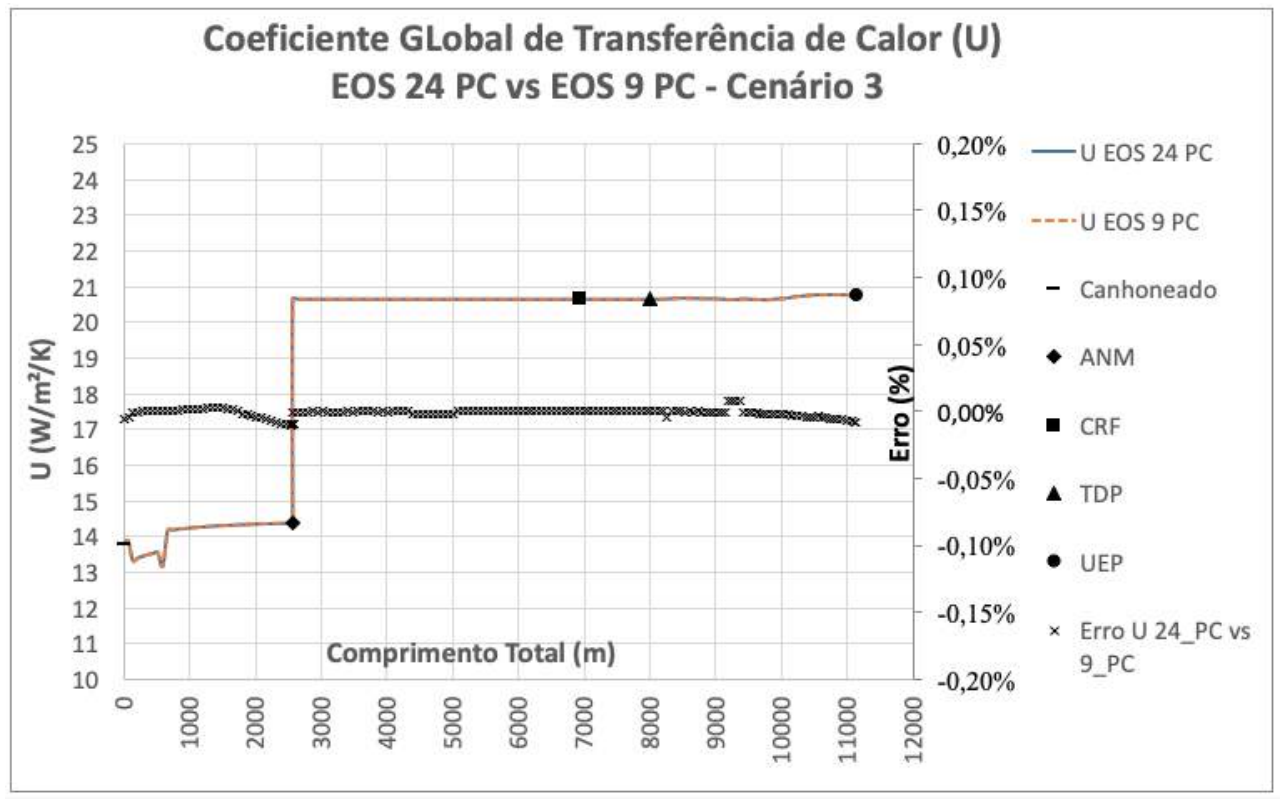

Figura C.59: Coeficiente global de transferência de calor - Cenário 3 - EOS 24 $\mathrm{PC}$ versus EOS 9 PC.

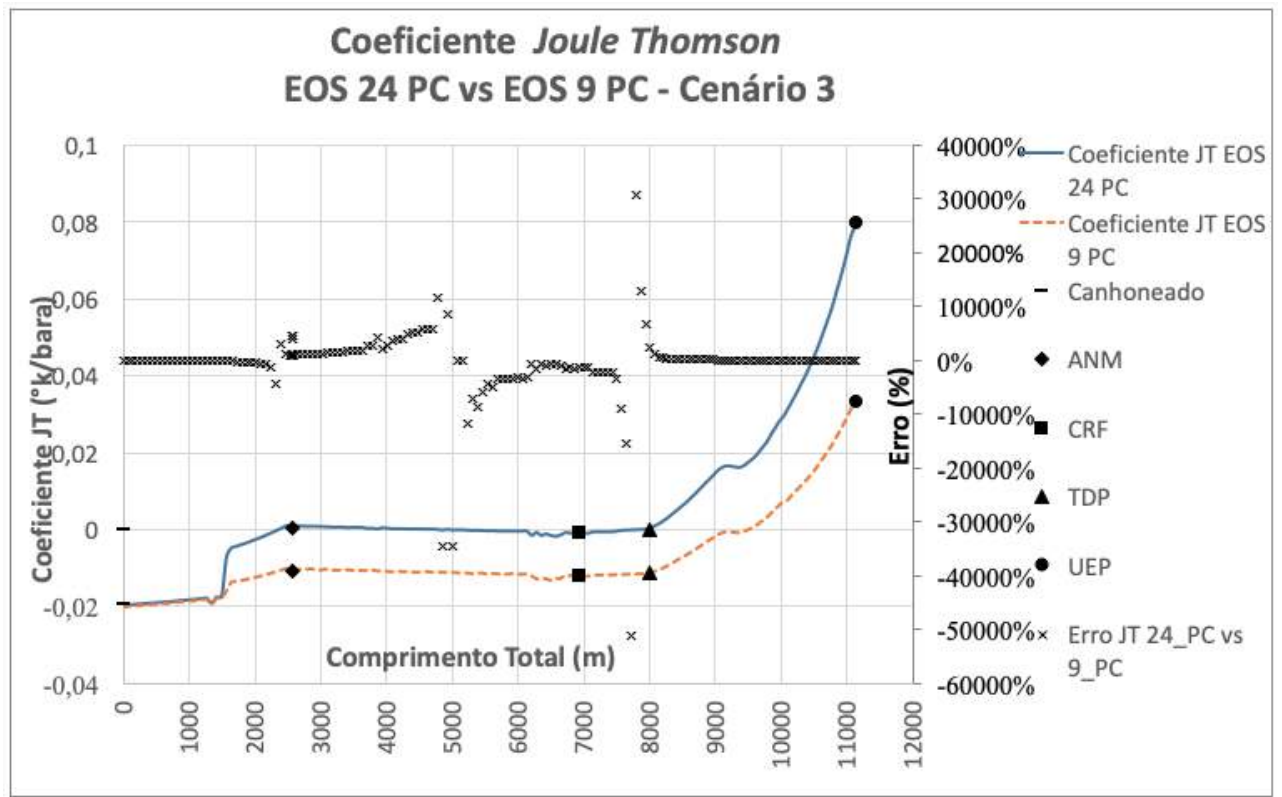

Figura C.60: Coeficiente Joule-Thomson - Cenário 3 - EOS 24 PC versus EOS 9 PC. 


\section{C.3}

\section{EOS 24 PC versus EOS 7 PC}

\section{C.3.1}

Cenário 1 - Período inicial logo após a abertura do poço

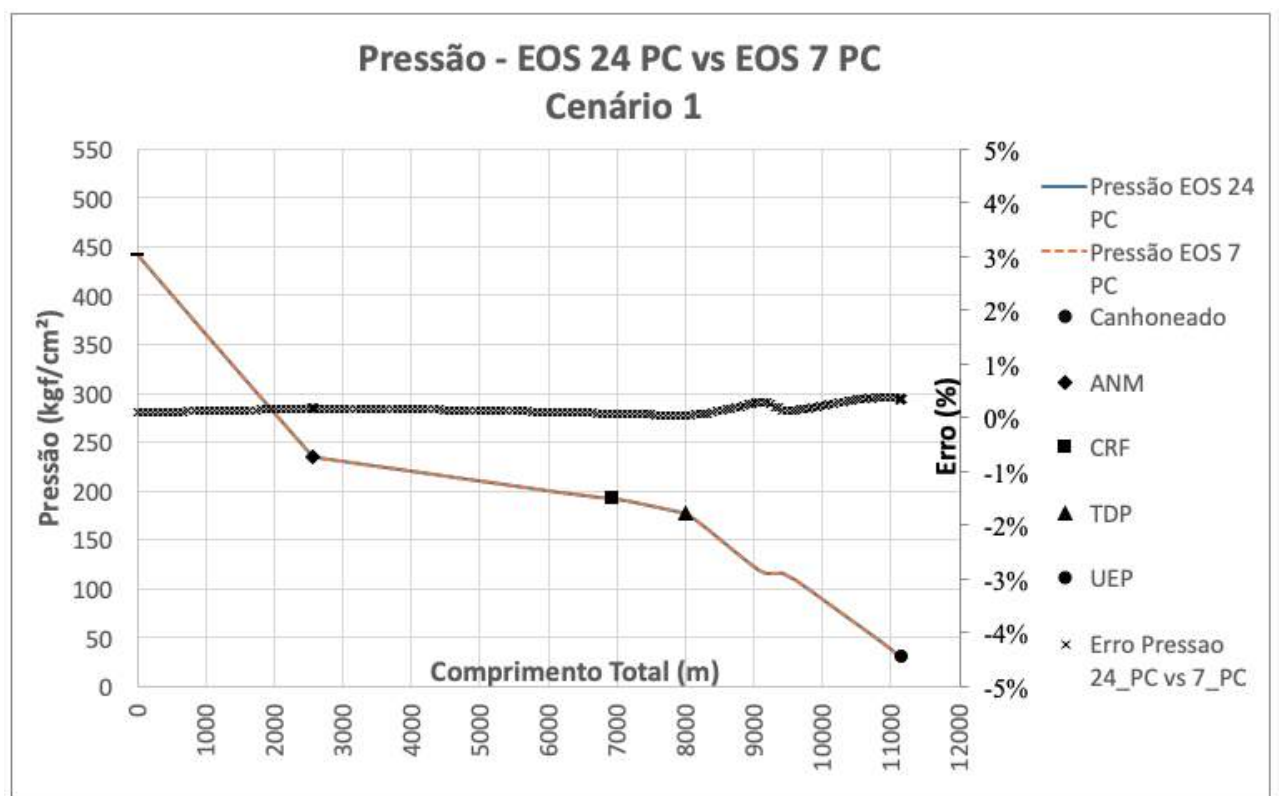

Figura C.61: Perfil de pressão no poço e duto - Cenário 1 - EOS 24 PC versus EOS 7 PC.

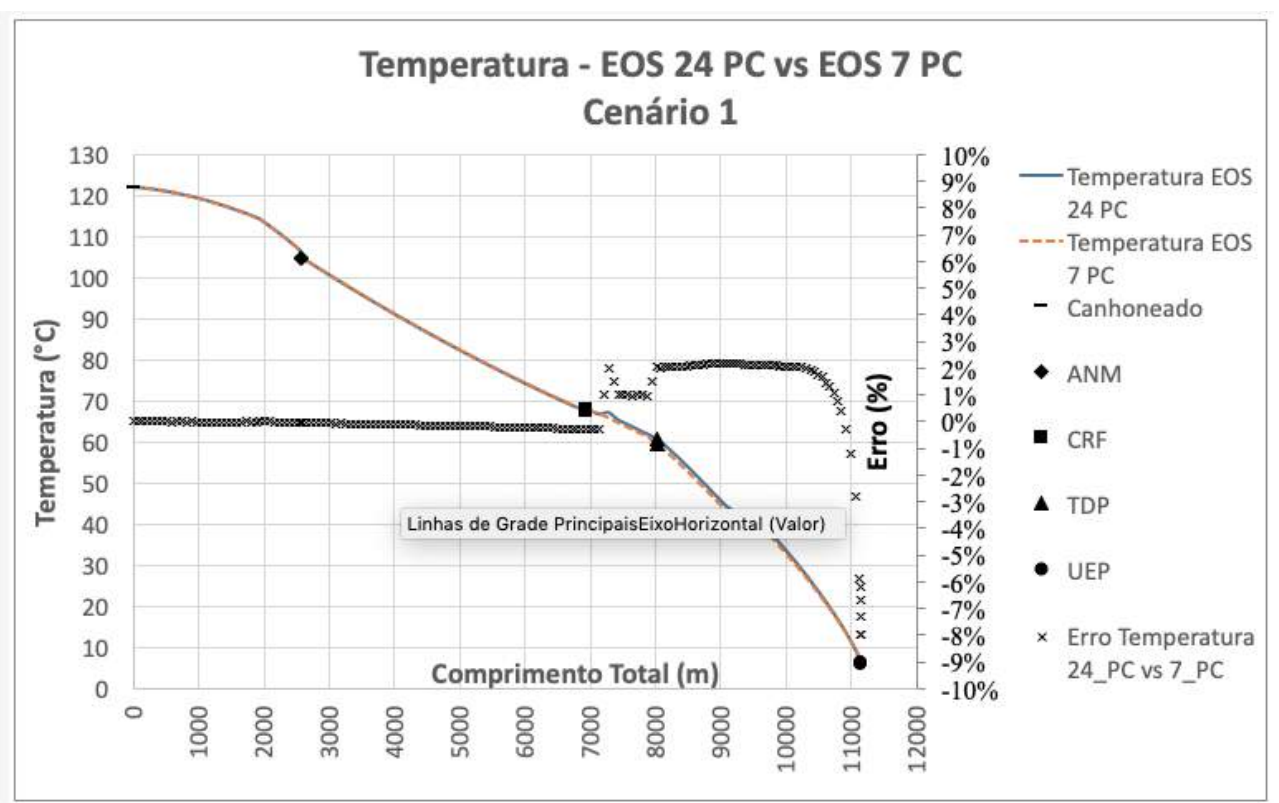

Figura C.62: Perfil de temperatura no poço e duto - Cenário 1 - EOS 24 PC versus EOS 7 PC. 


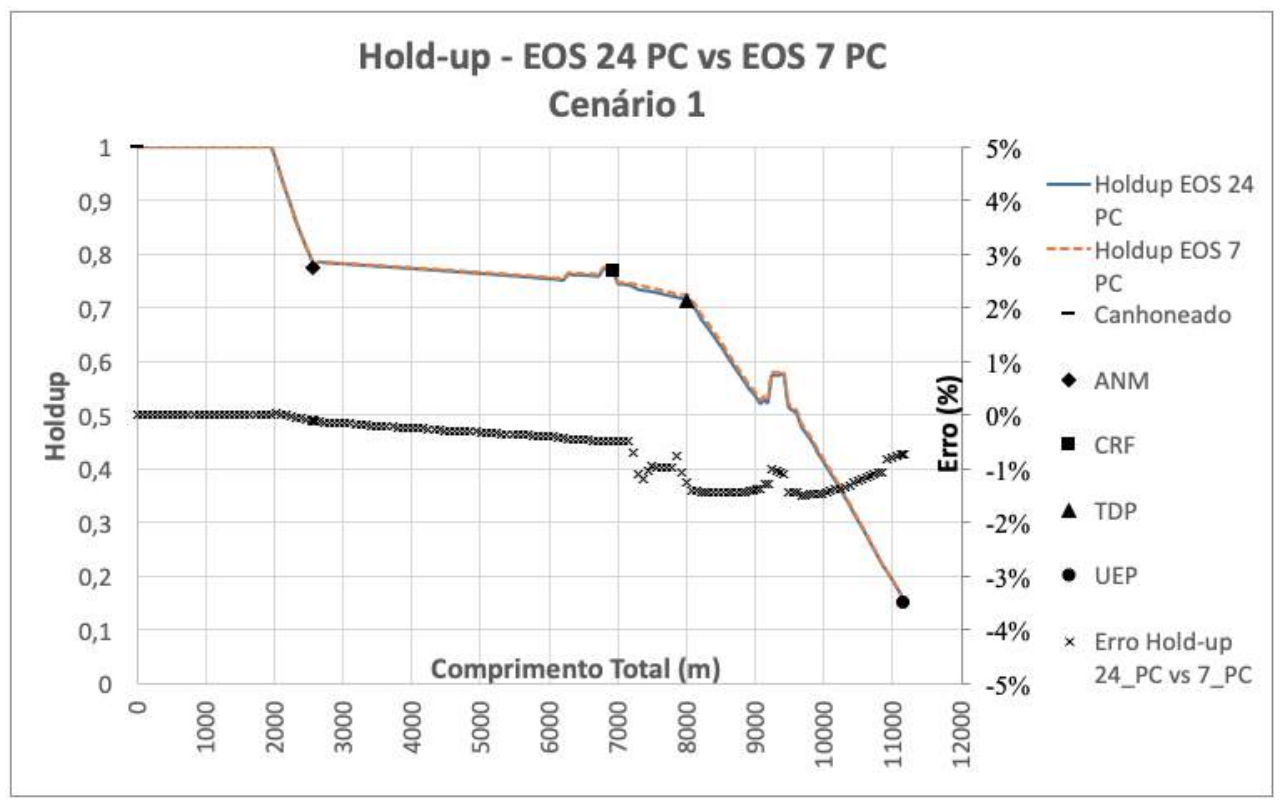

Figura C.63: Holdup no poço e duto - Cenário 1 - EOS 24 PC versus EOS 7 PC.

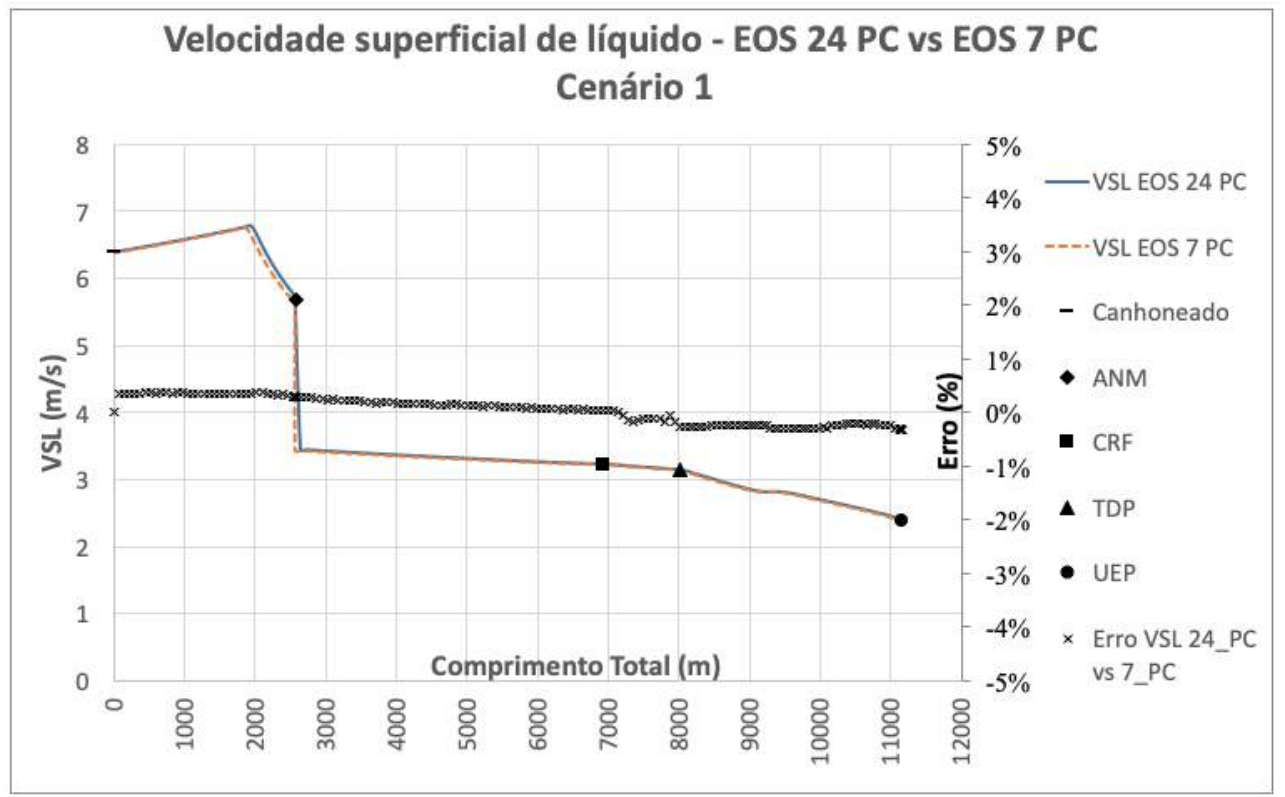

Figura C.64: Velocidade superficial de líquido - Cenário 1 - EOS 24 PC versus EOS 7 PC. 


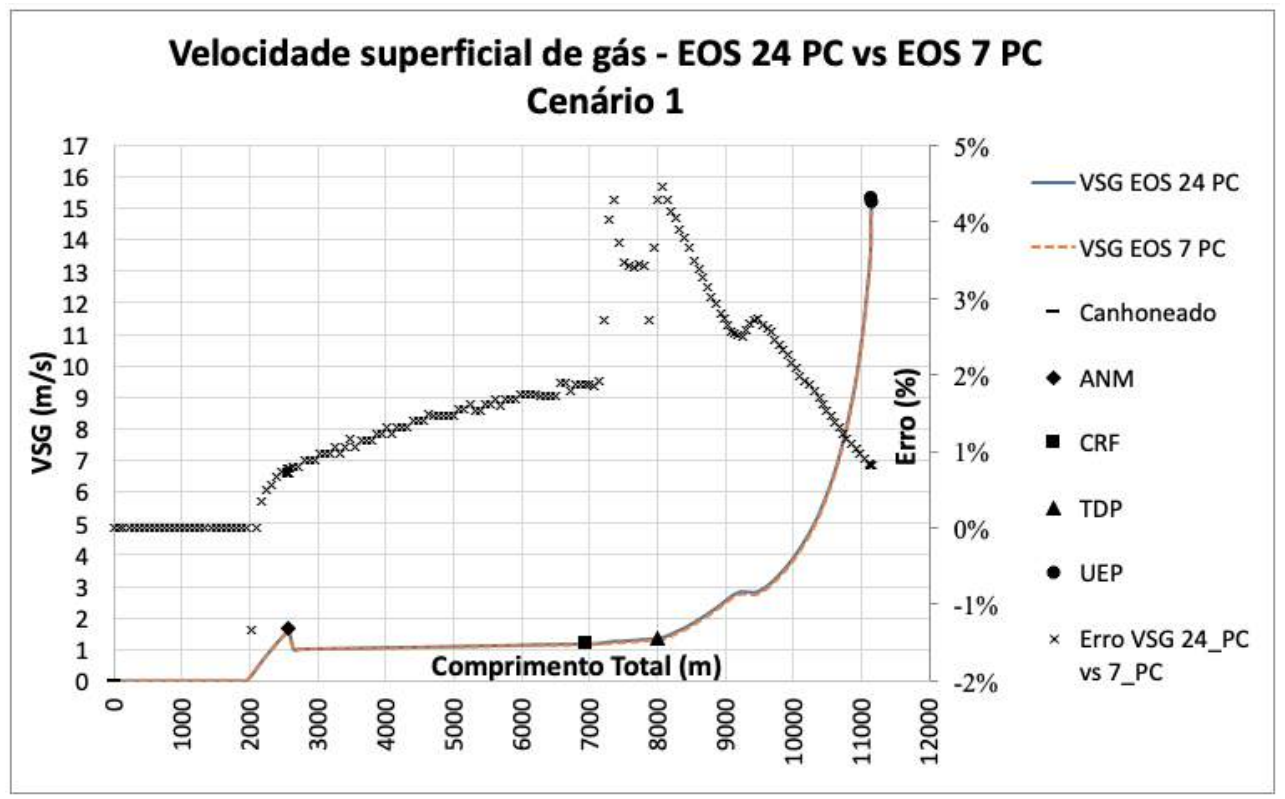

Figura C.65: Velocidade superficial de gás - Cenário 1 - EOS 24 PC versus EOS 7 PC.

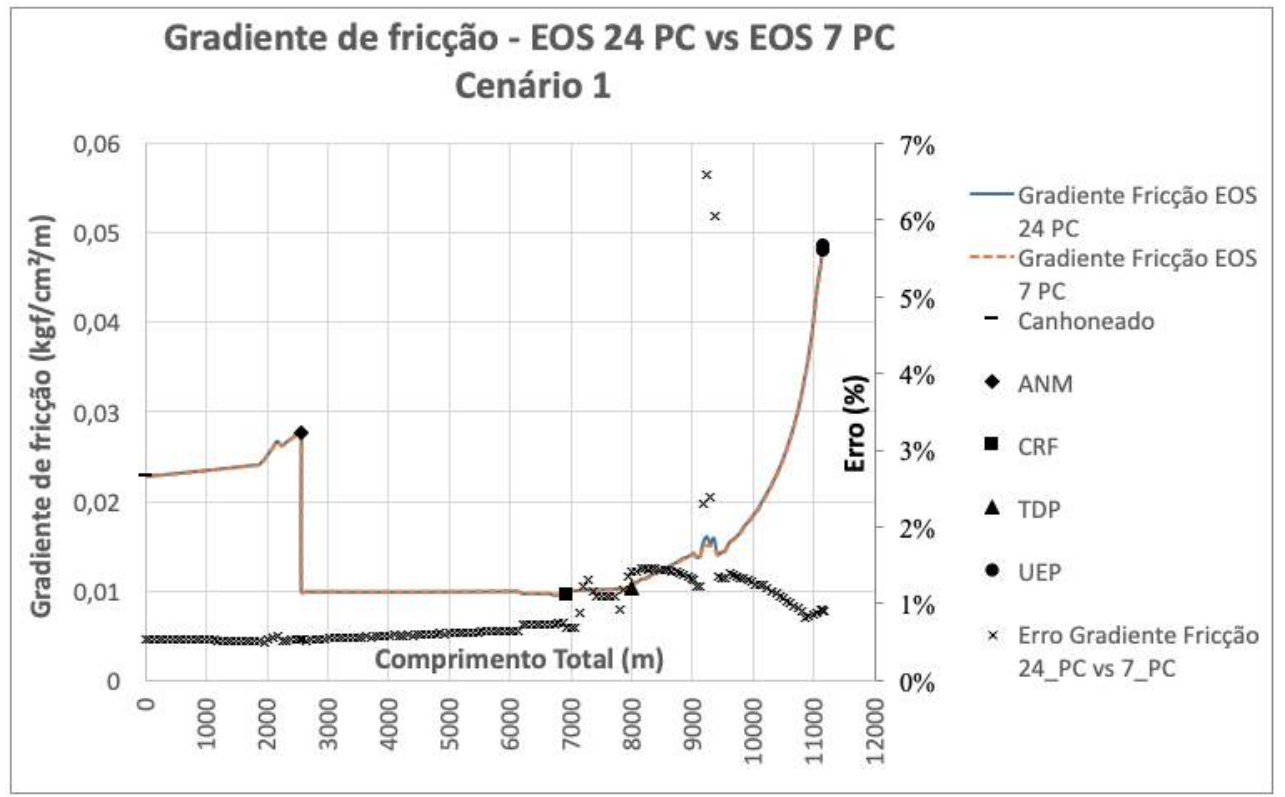

Figura C.66: Gradiente de pressão por fricção - Cenário 1 - EOS 24 PC versus EOS 7 PC. 


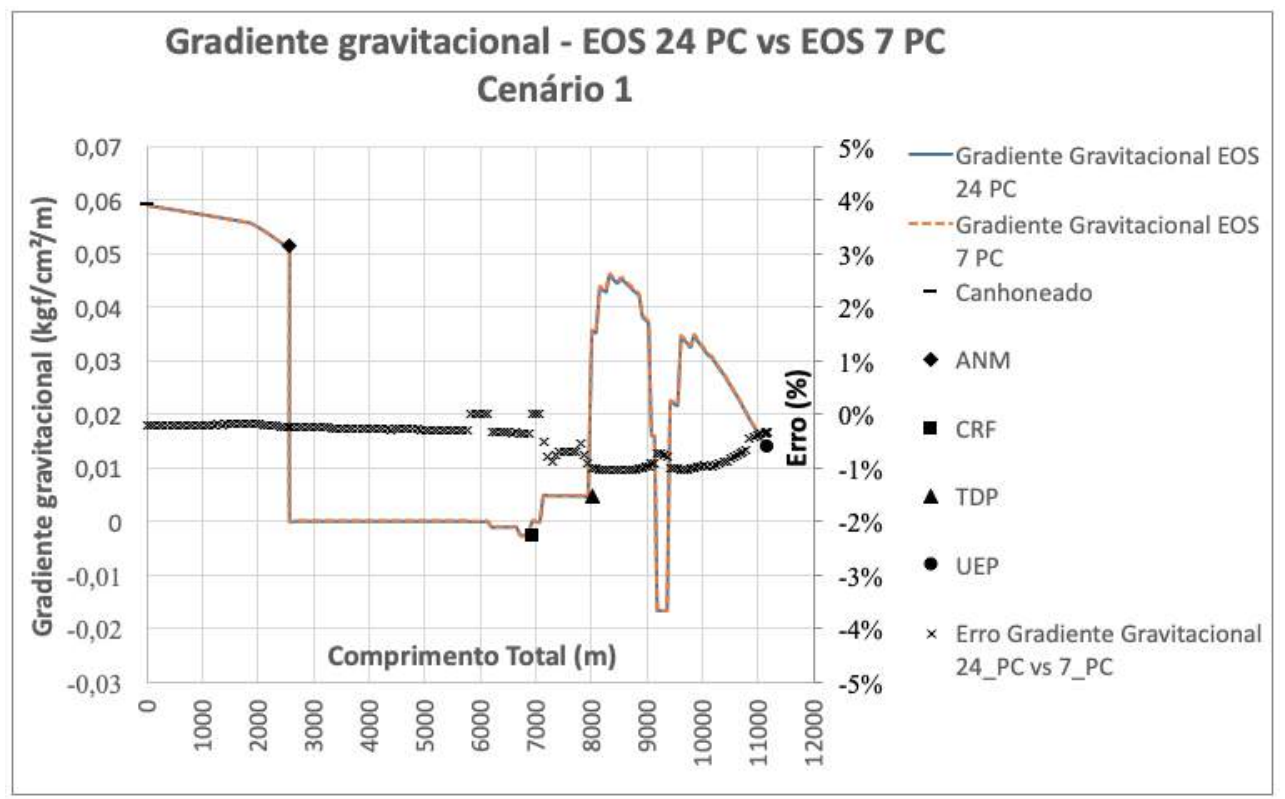

Figura C.67: Gradiente de pressão gravitacional - Cenário 1 - EOS 24 PC versus EOS 7 PC.

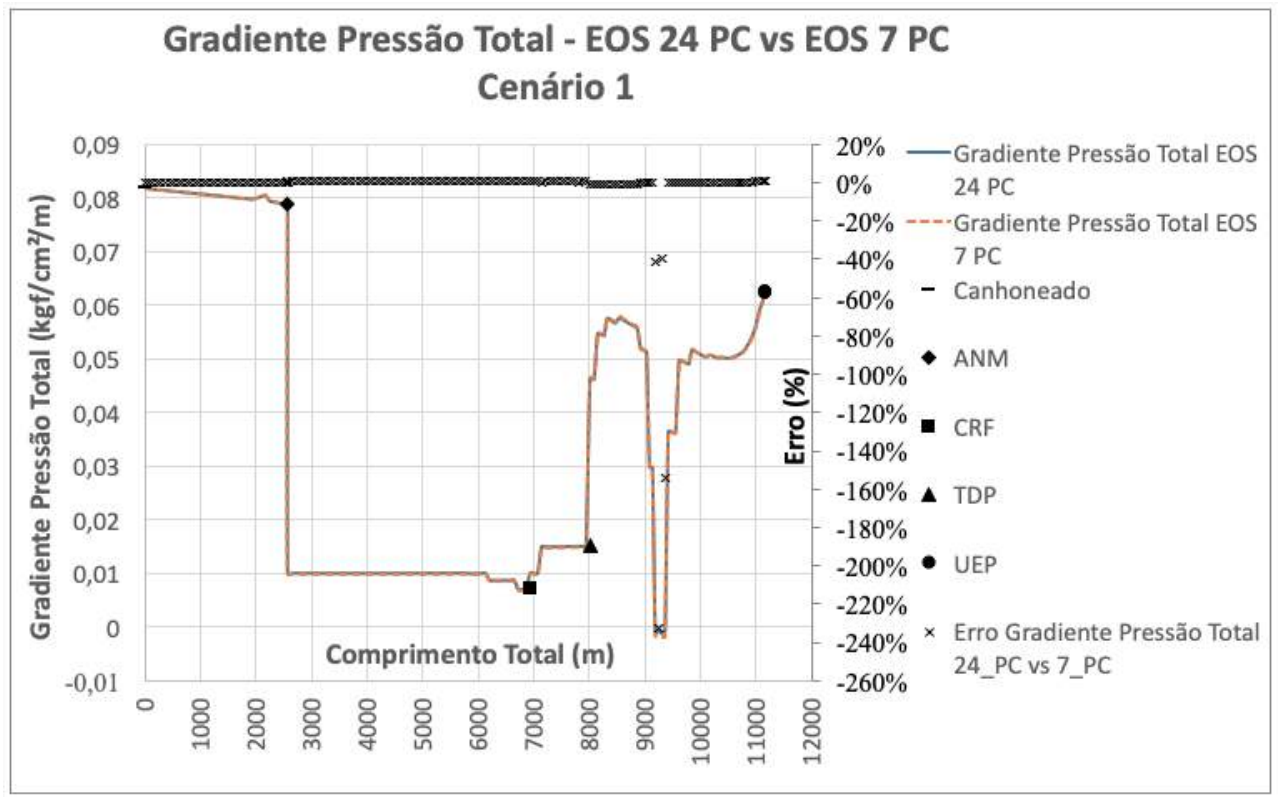

Figura C.68: Gradiente de pressão total - Cenário 1 - EOS 24 PC versus EOS 7 PC. 


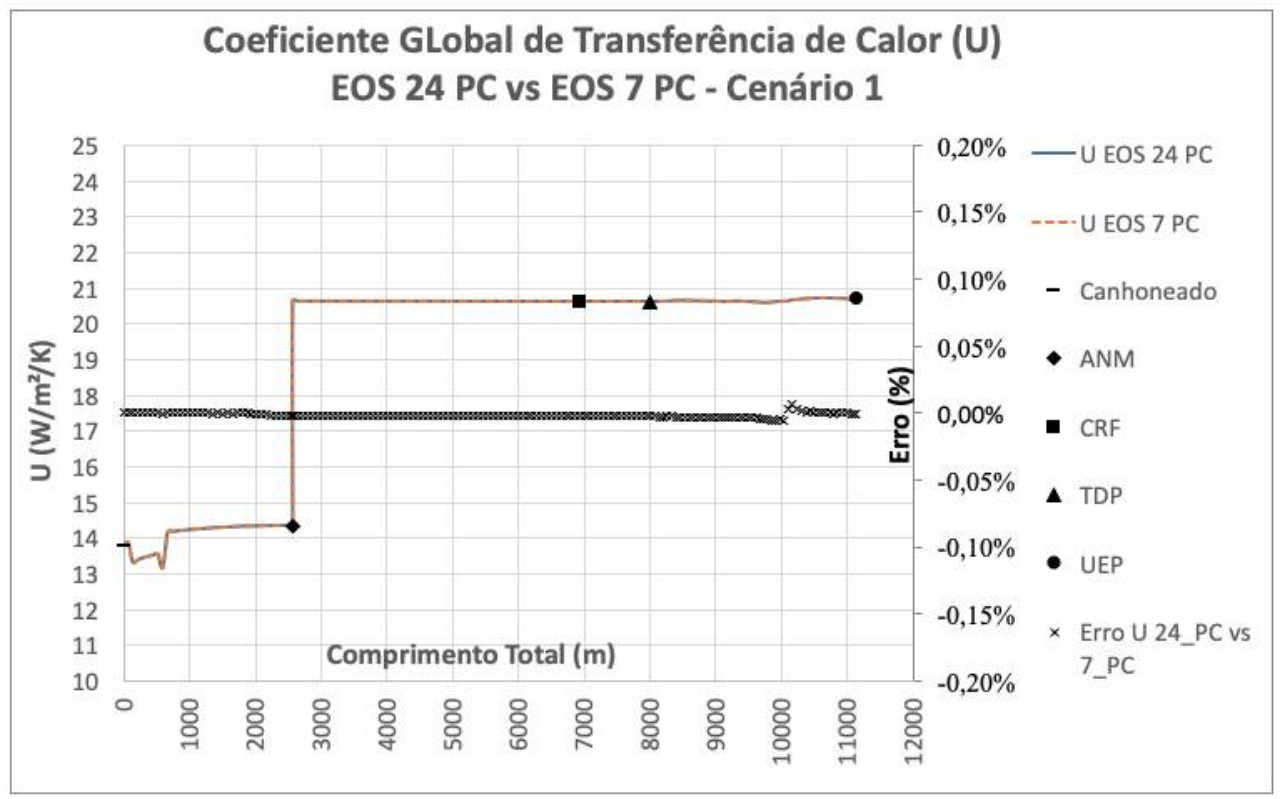

Figura C.69: Coeficiente global de transferência de calor - Cenário 1 - EOS 24 $\mathrm{PC}$ versus EOS 7 PC.

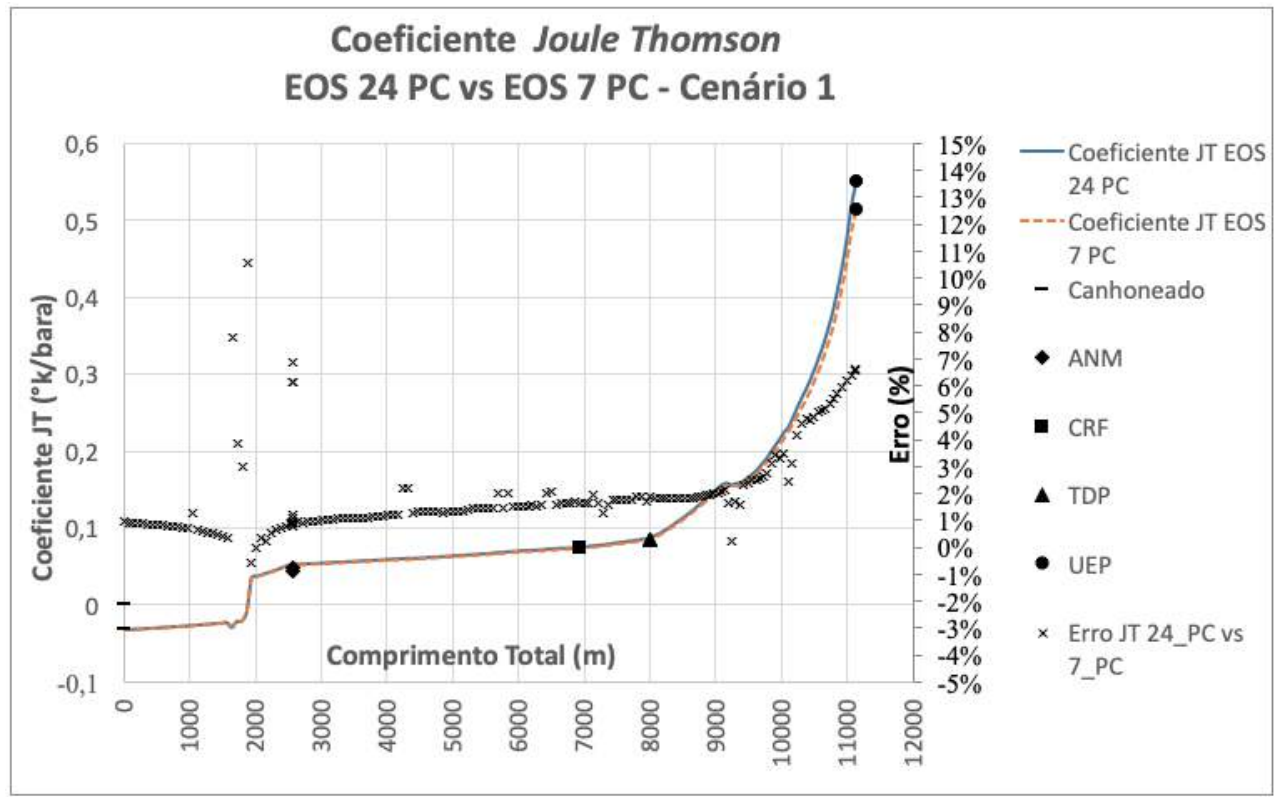

Figura C.70: Coeficiente Joule-Thomson - Cenário 1 - EOS 24 PC versus EOS 7 PC. 


\section{C.3.2}

\section{Cenário 2 - Período inicial antes do breaktrough de água}

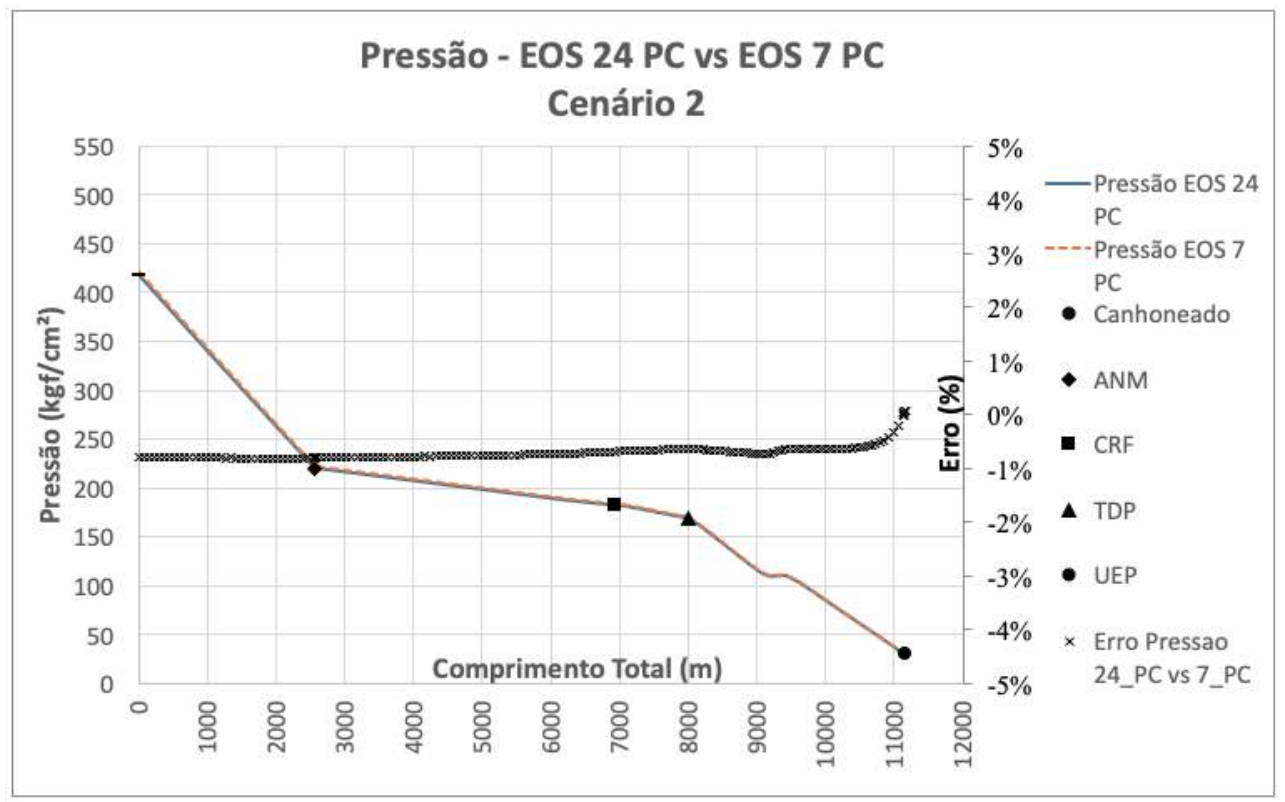

Figura C.71: Perfil de pressão no poço e duto - Cenário 2 - EOS 24 PC versus EOS 7 PC.

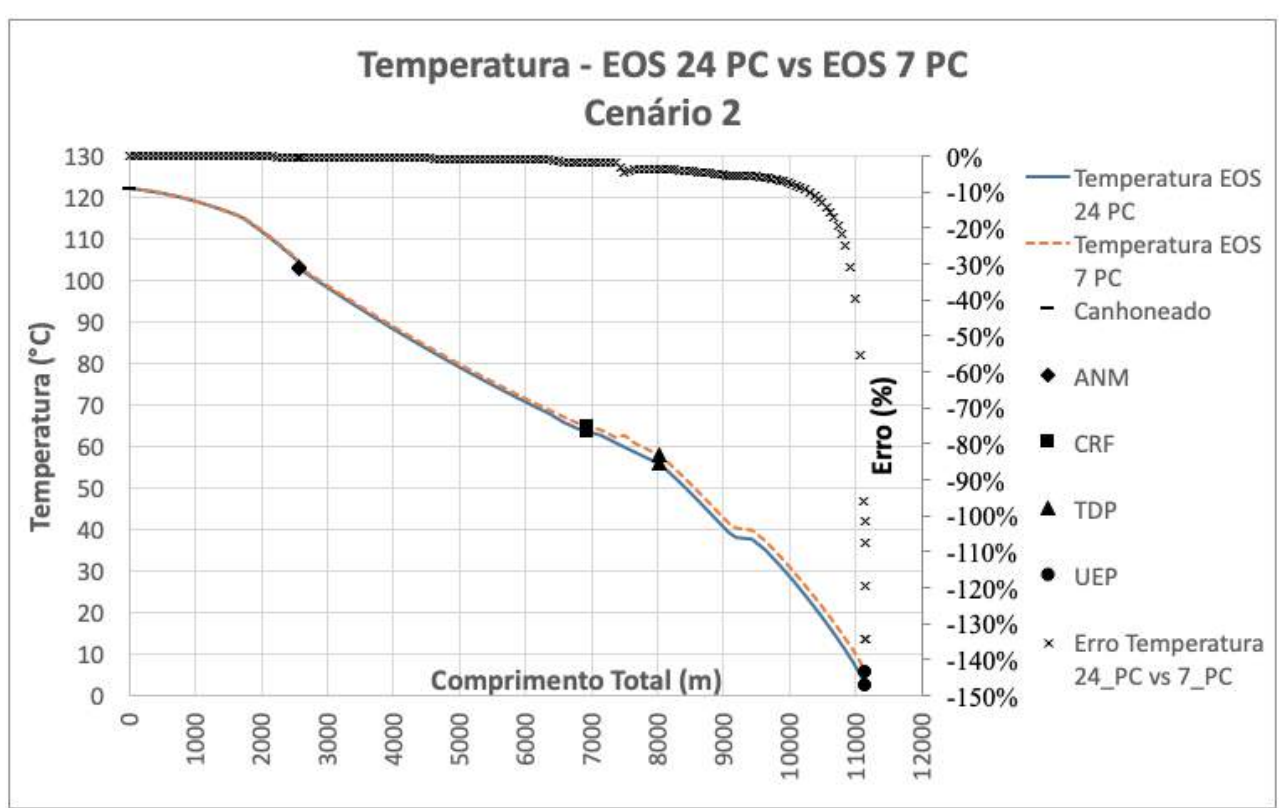

Figura C.72: Perfil de temperatura no poço e duto - Cenário 2 - EOS 24 PC versus EOS 7 PC. 


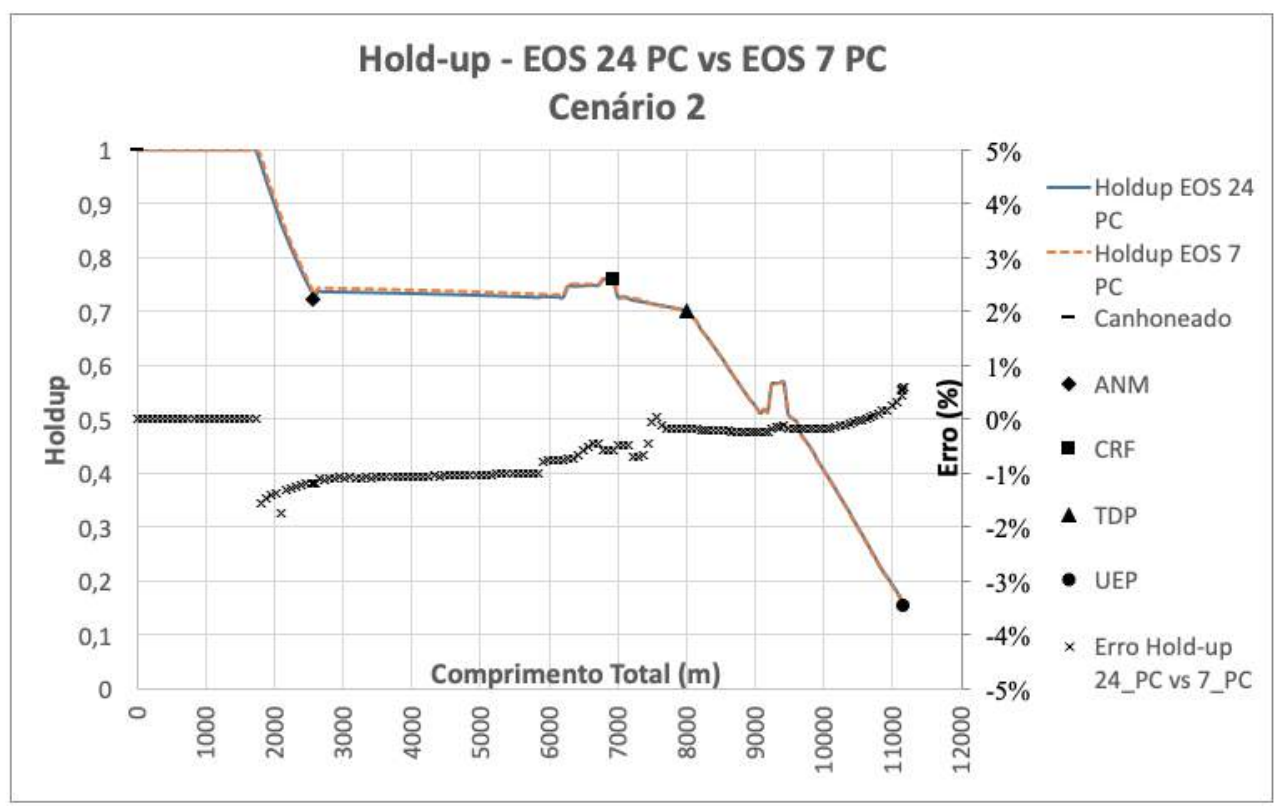

Figura C.73: Holdup no poço e duto - Cenário 2 - EOS 24 PC versus EOS 7 PC.

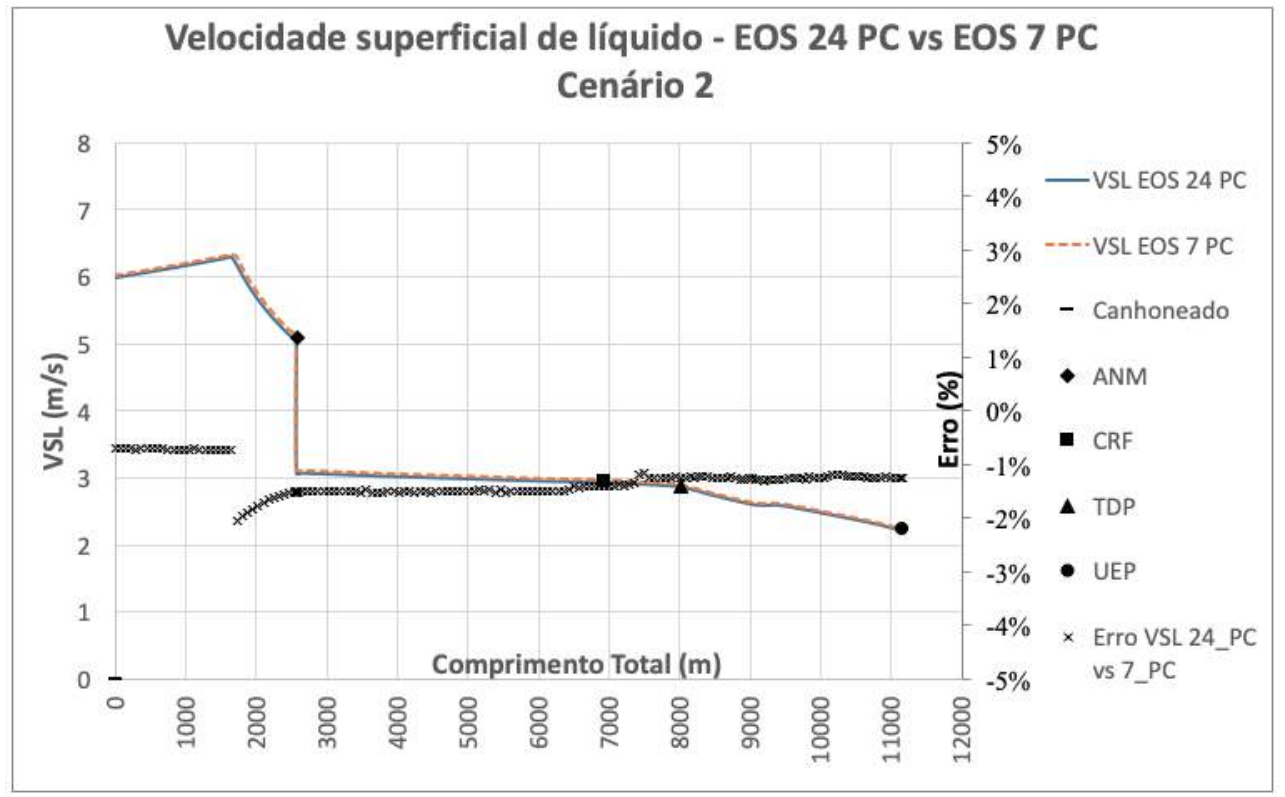

Figura C.74: Velocidade superficial de líquido - Cenário 2 - EOS 24 PC versus EOS 7 PC. 


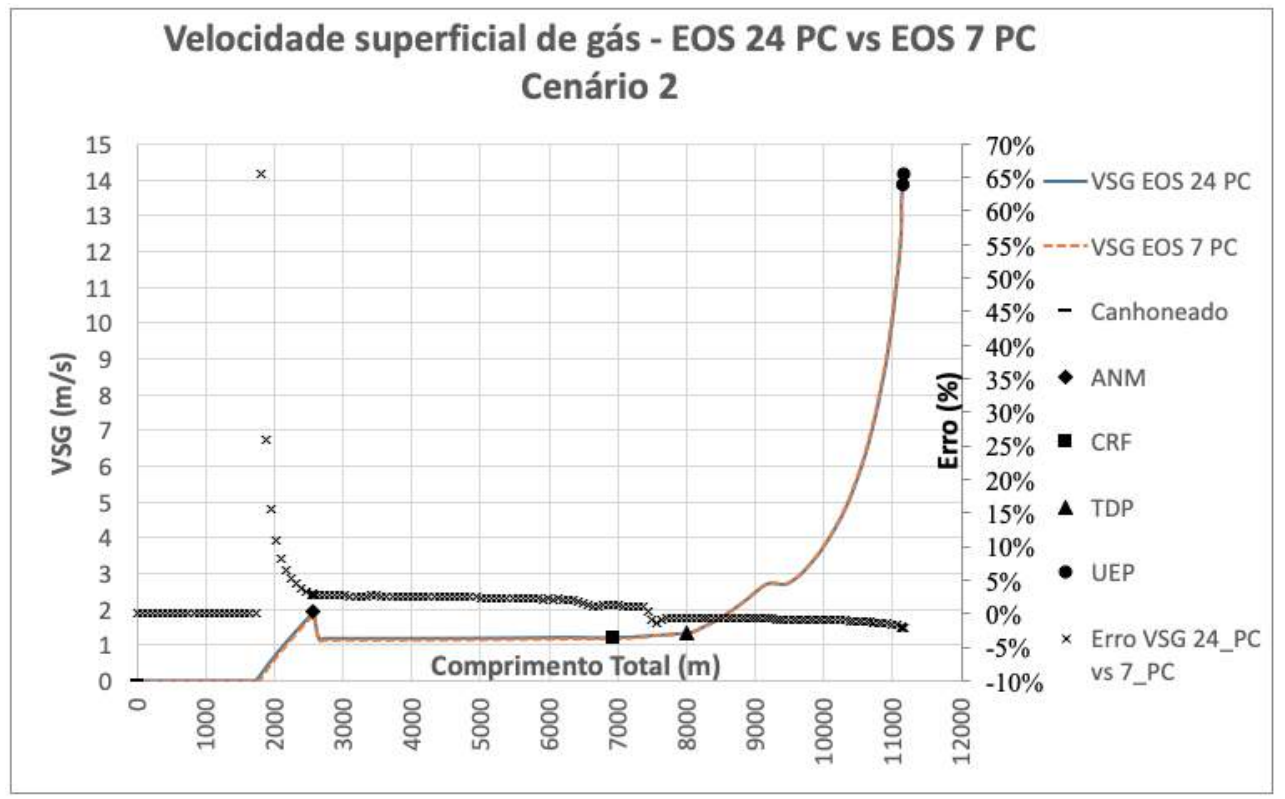

Figura C.75: Velocidade superficial de gás - Cenário 2 - EOS 24 PC versus EOS 7 PC.

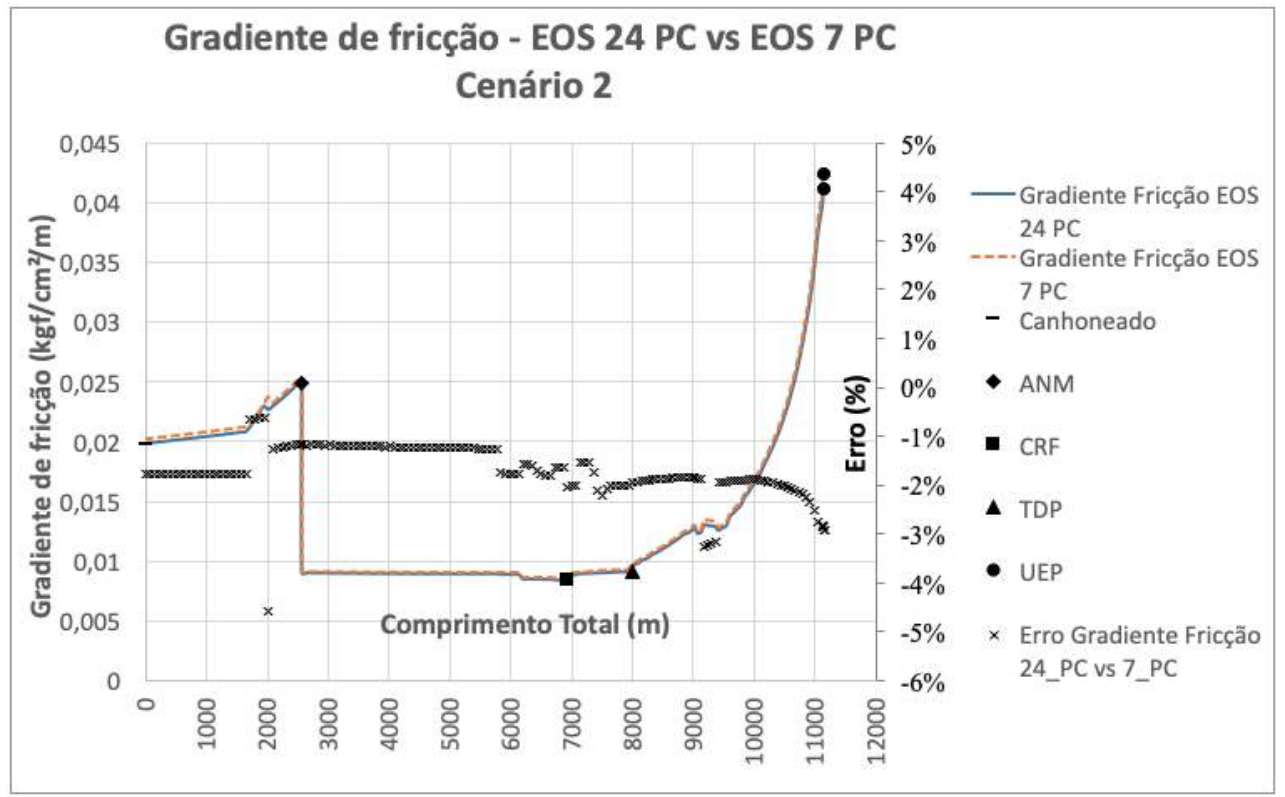

Figura C.76: Gradiente de pressão por fricção - Cenário 2 - EOS 24 PC versus EOS 7 PC. 


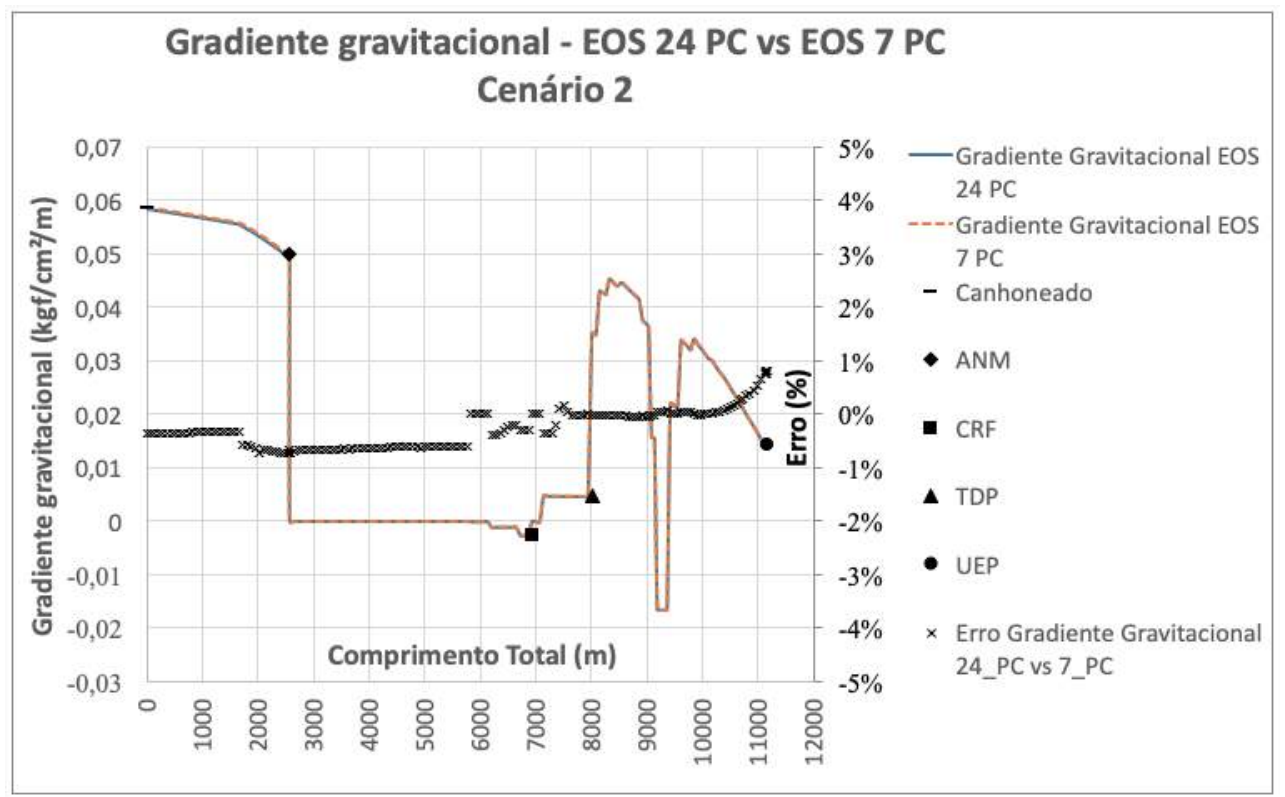

Figura C.77: Gradiente de pressão gravitacional - Cenário 2 - EOS 24 PC versus EOS 7 PC.

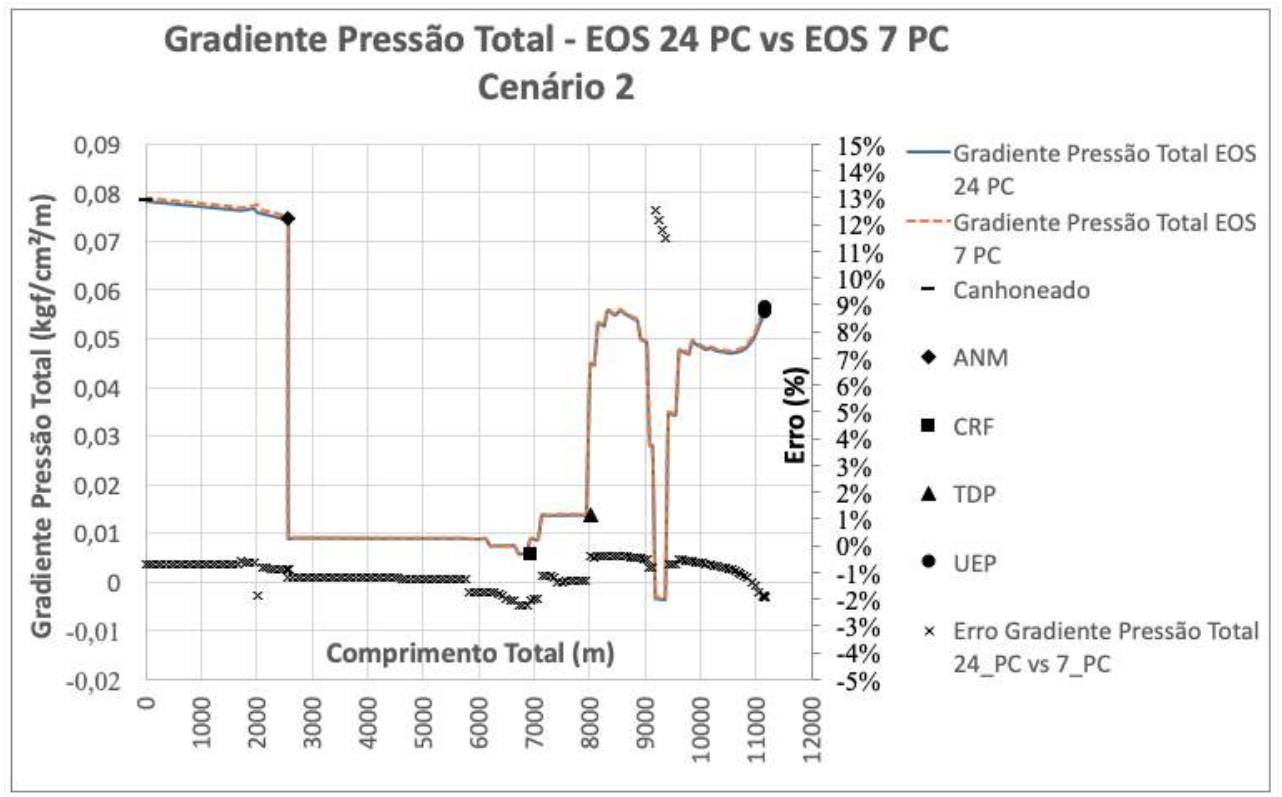

Figura C.78: Gradiente de pressão total - Cenário 2 - EOS 24 PC versus EOS 7 PC. 


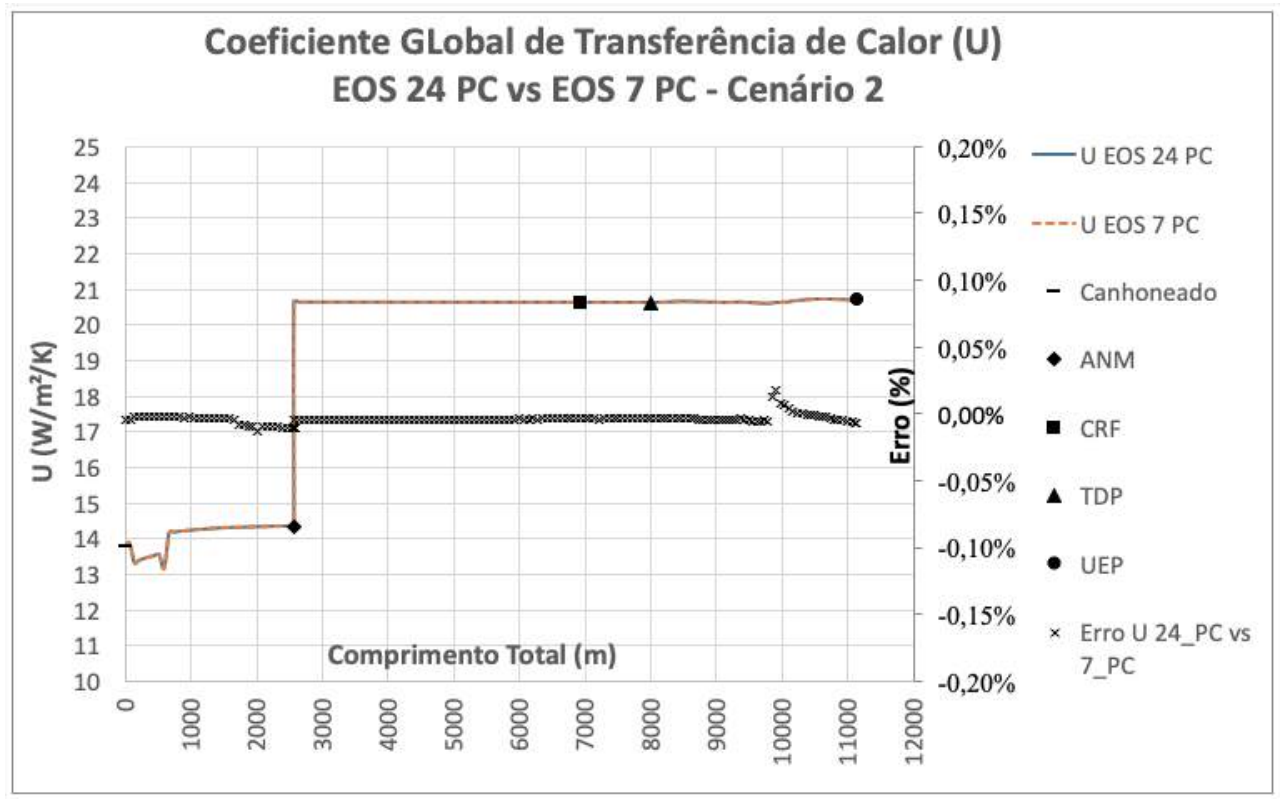

Figura C.79: Coeficiente global de transferência de calor - Cenário 2 - EOS 24 $\mathrm{PC}$ versus EOS $7 \mathrm{PC}$.

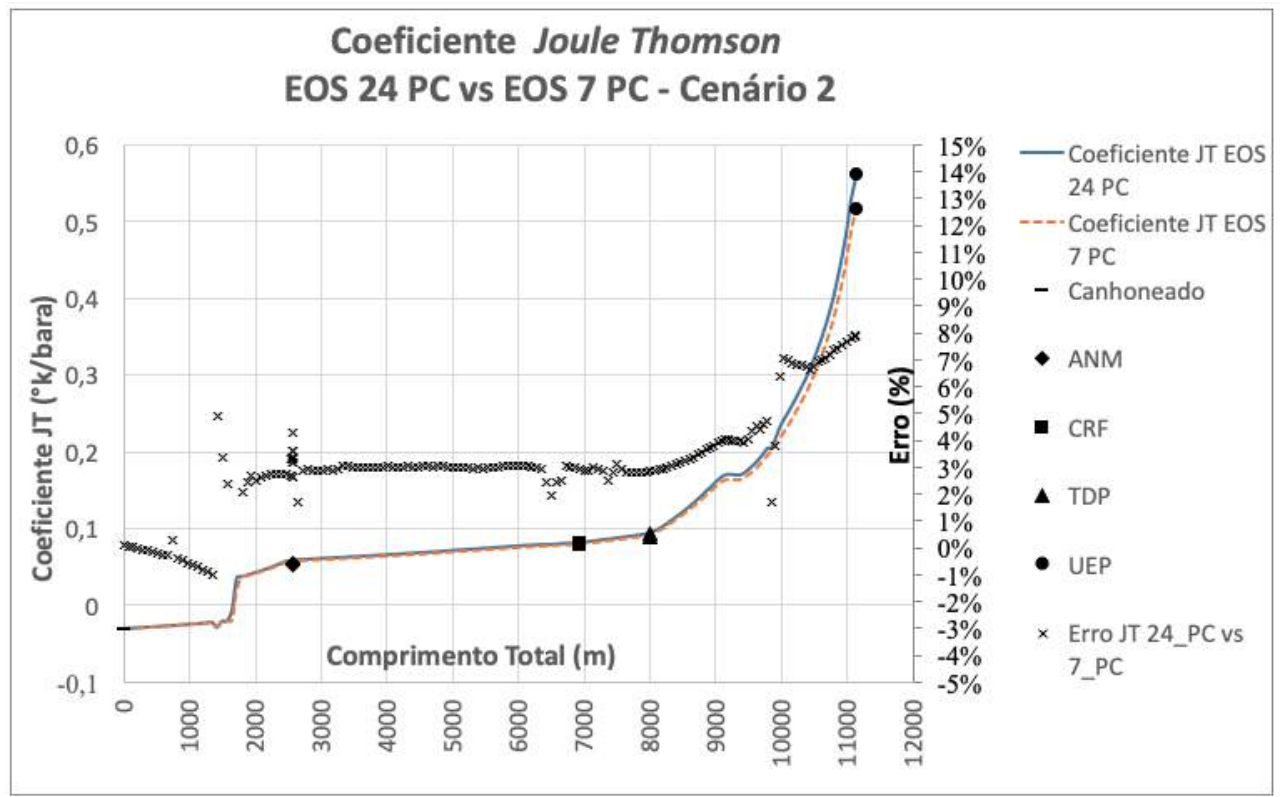

Figura C.80: Coeficiente Joule-Thomson - Cenário 2 - EOS 24 PC versus EOS 7 PC. 


\section{C.3.3}

\section{Cenário 3 - Corte de água intermediário}

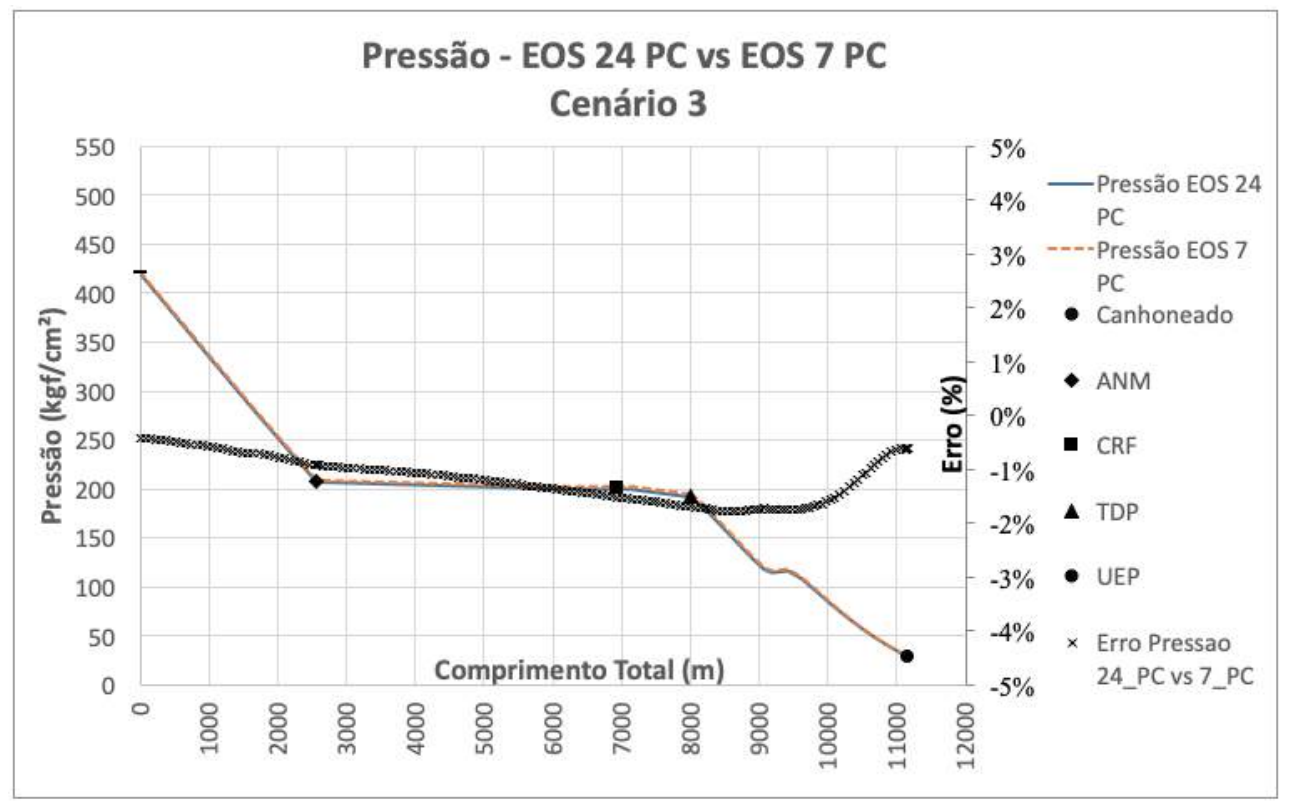

Figura C.81: Perfil de pressão no poço e duto - Cenário 3 - EOS 24 PC versus EOS 7 PC.

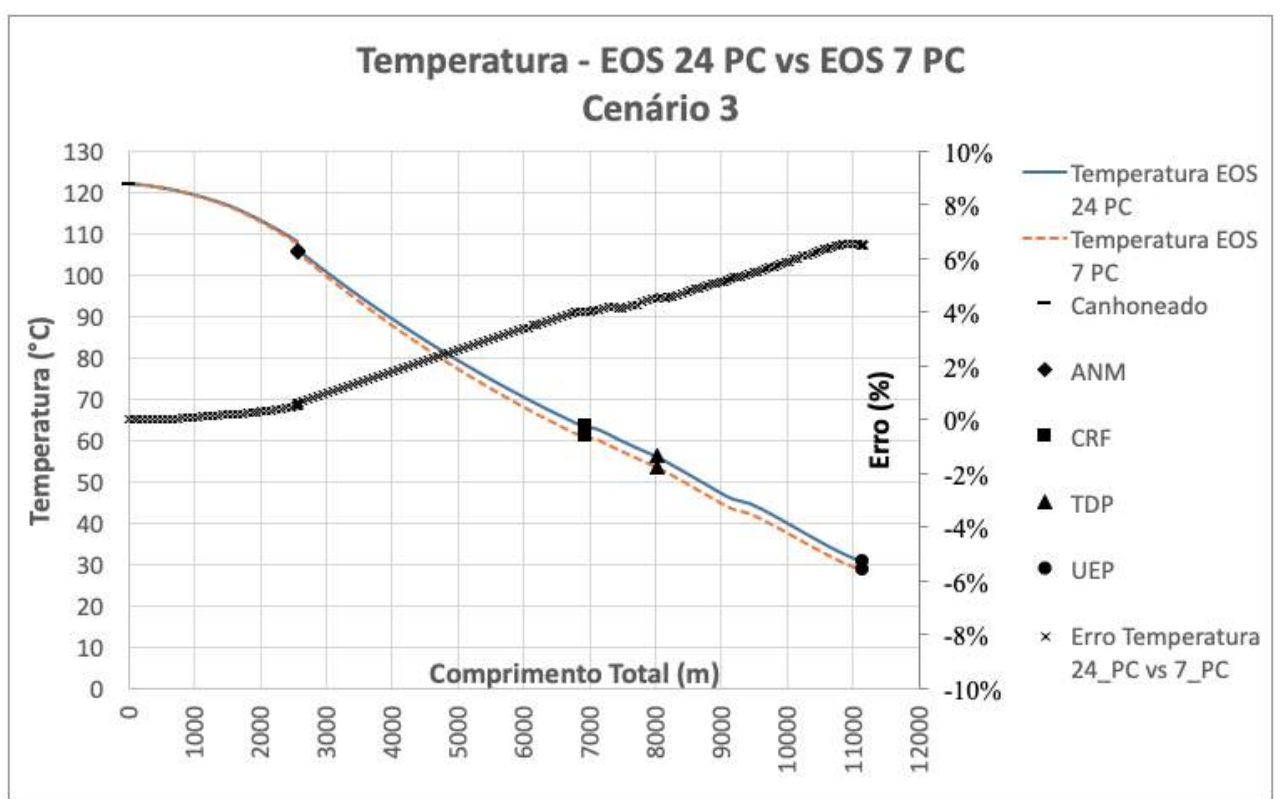

Figura C.82: Perfil de temperatura no poço e duto - Cenário 3 - EOS 24 PC versus EOS 7 PC. 


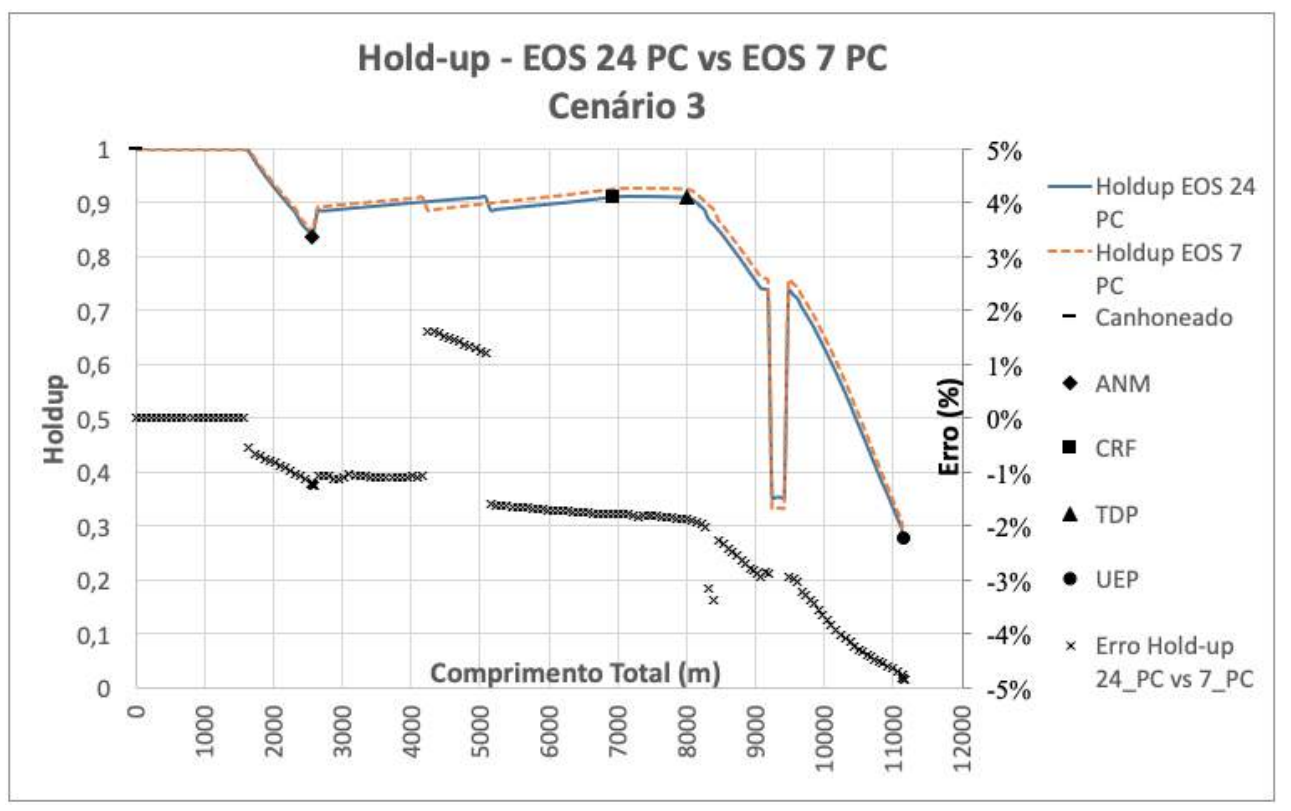

Figura C.83: Holdup no poço e duto - Cenário 3 - EOS 24 PC versus EOS 7 PC.

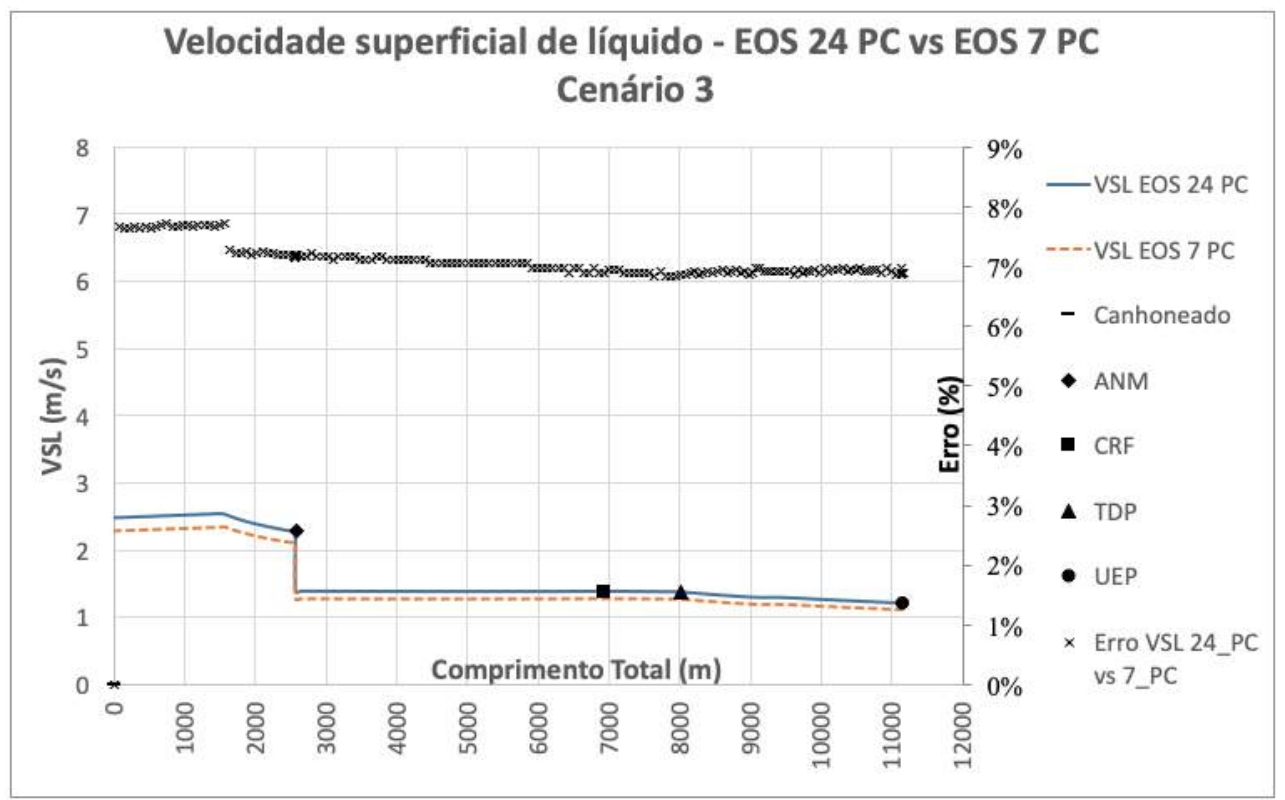

Figura C.84: Velocidade superficial de líquido - Cenário 3 - EOS 24 PC versus EOS 7 PC. 


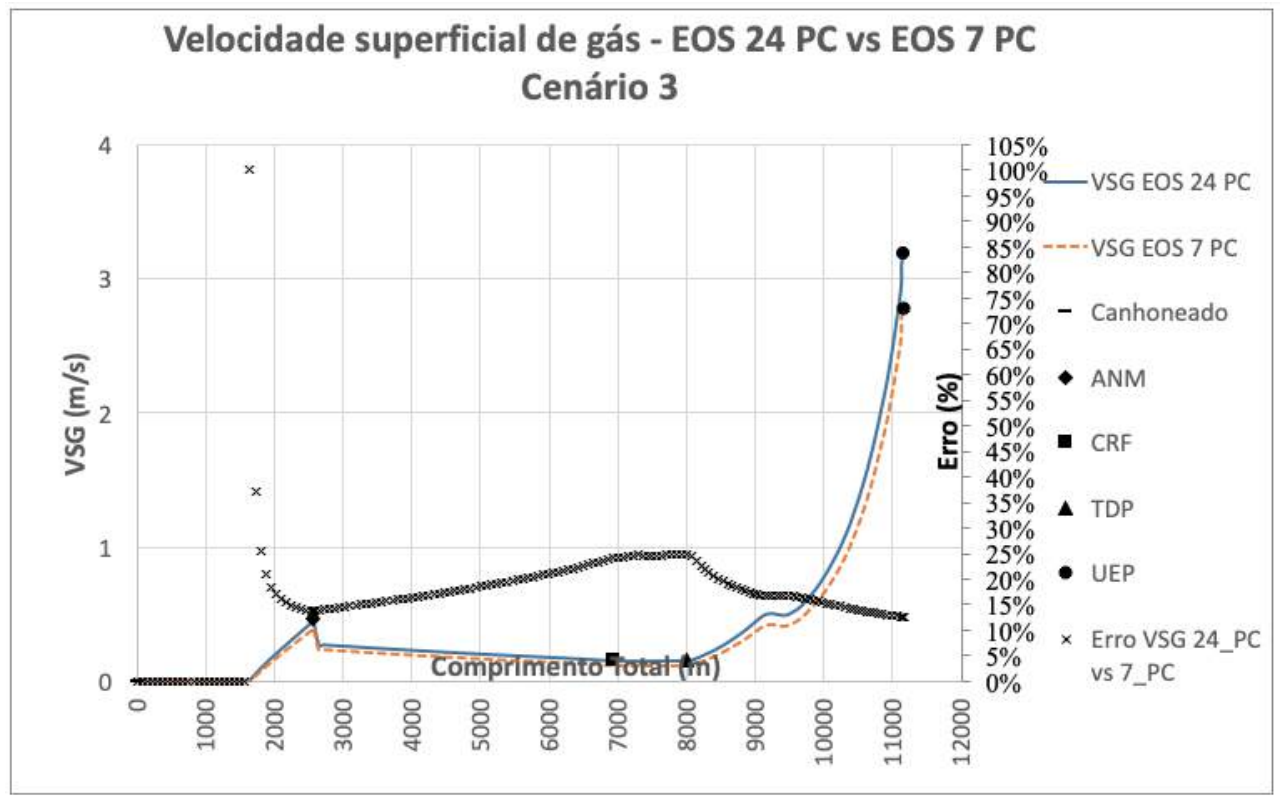

Figura C.85: Velocidade superficial de gás - Cenário 3 - EOS 24 PC versus EOS 7 PC.

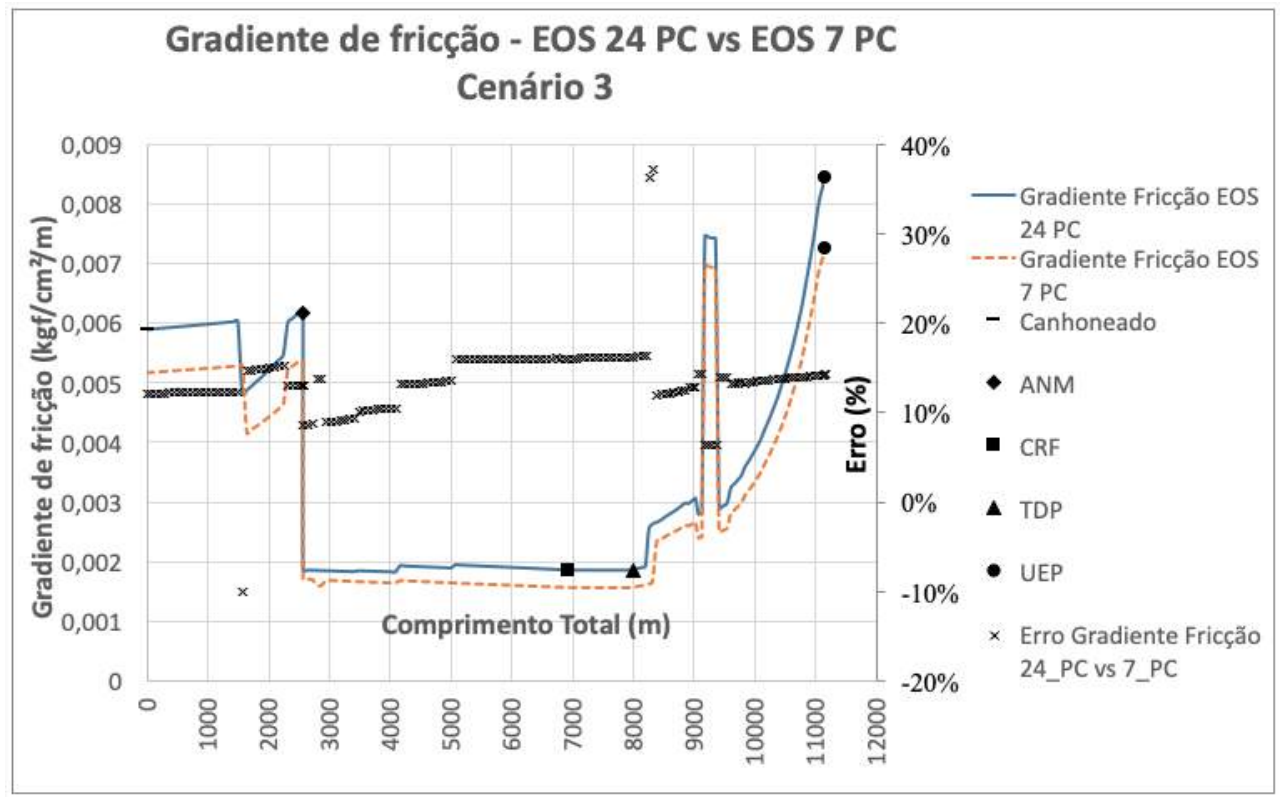

Figura C.86: Gradiente de pressão por fricção - Cenário 3 - EOS 24 PC versus EOS 7 PC. 


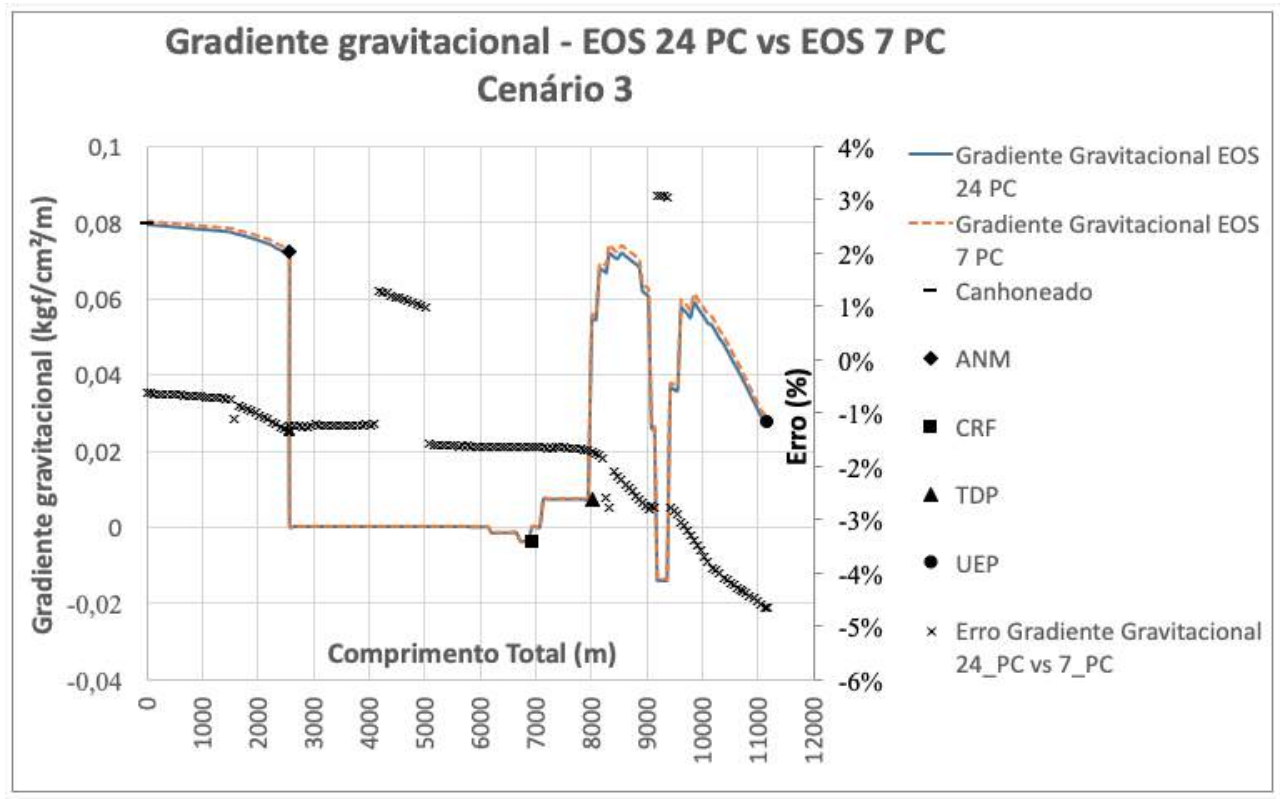

Figura C.87: Gradiente de pressão gravitacional - Cenário 3 - EOS 24 PC versus EOS 7 PC.

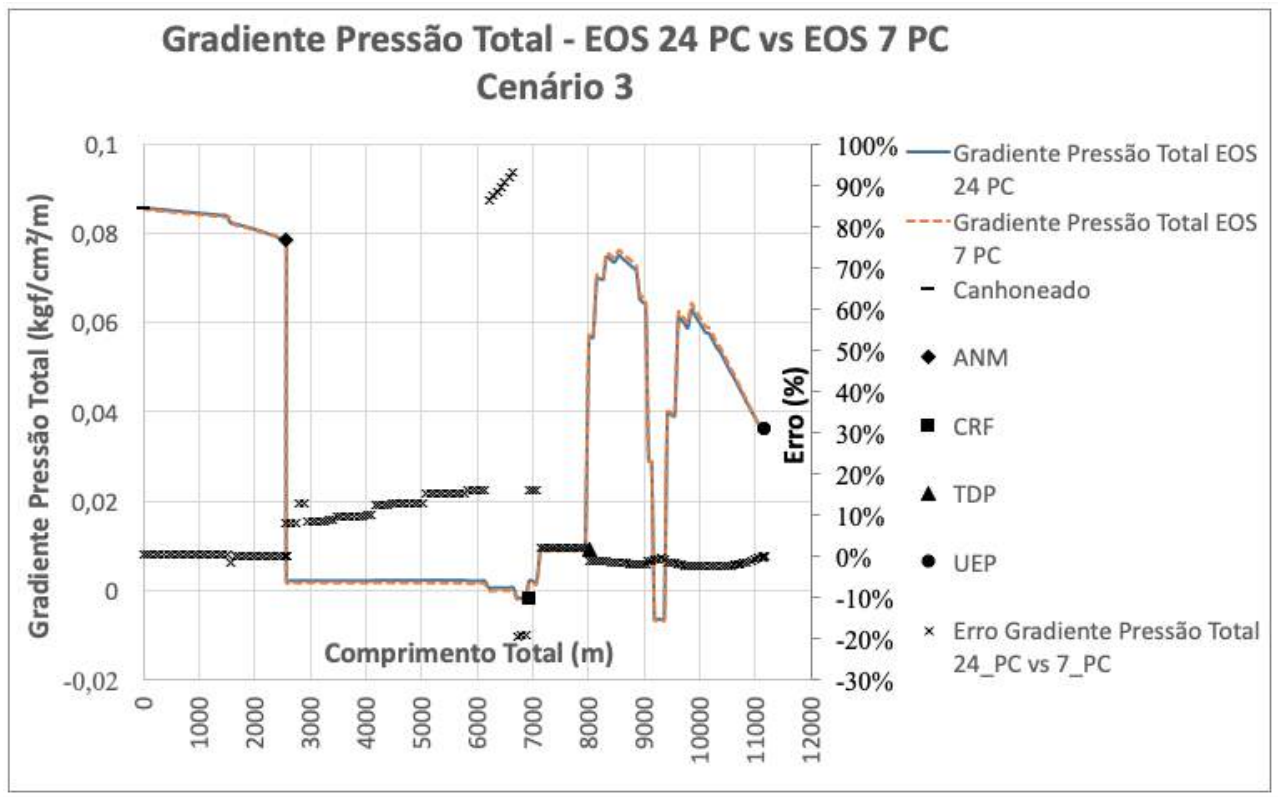

Figura C.88: Gradiente de pressão total - Cenário 3 - EOS 24 PC versus EOS 7 PC. 


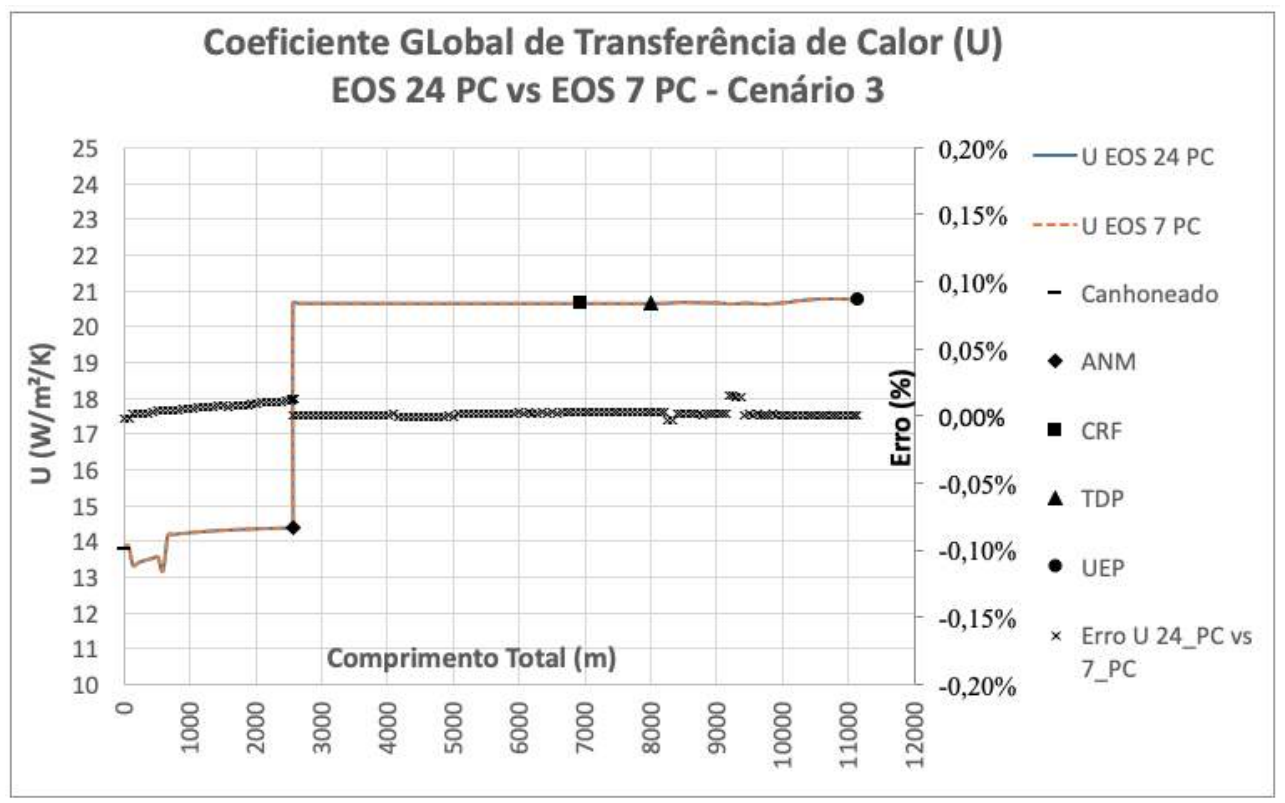

Figura C.89: Coeficiente global de transferência de calor - Cenário 3 - EOS 24 $\mathrm{PC}$ versus EOS $7 \mathrm{PC}$.

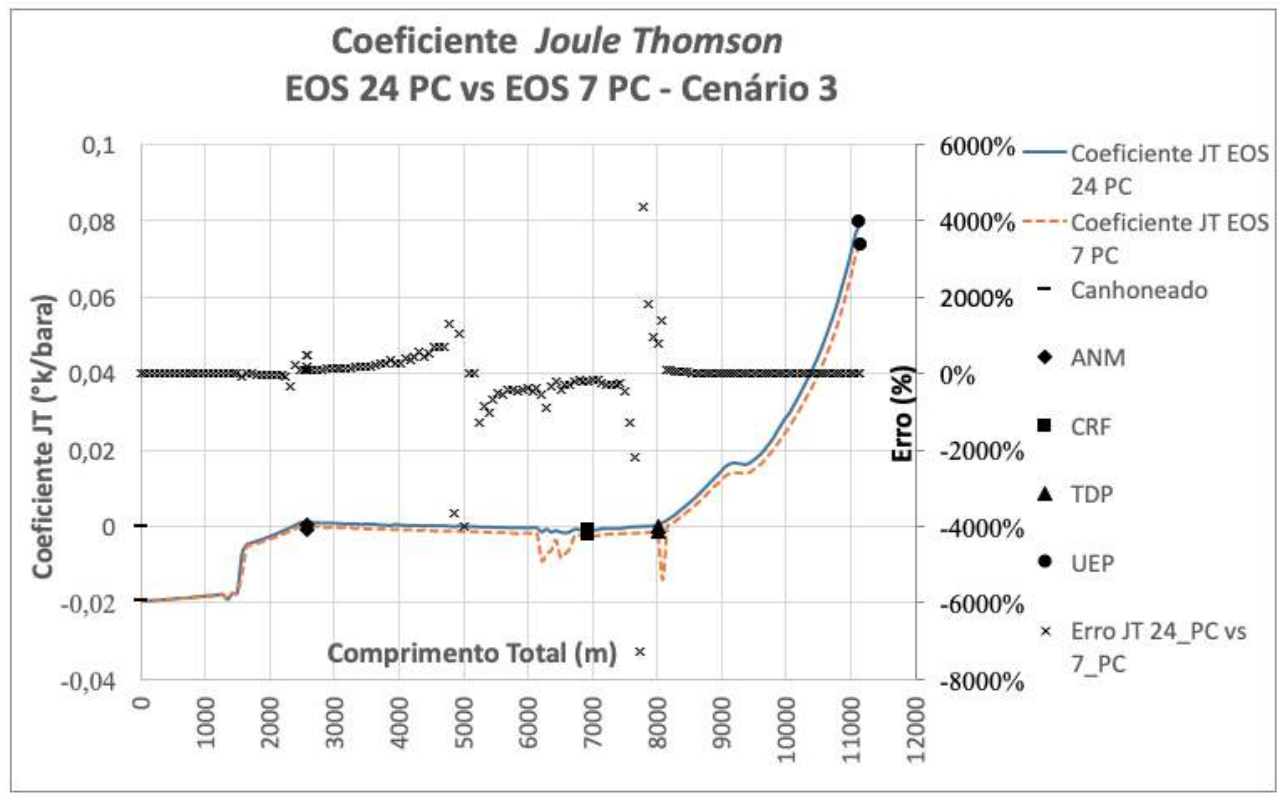

Figura C.90: Coeficiente Joule-Thomson - Cenário 3 - EOS 24 PC versus EOS 7 PC. 


\section{C.4}

\section{EOS 24 PC versus EOS 6 PC}

\section{C.4.1}

Cenário 1 - Período inicial logo após a abertura do poço

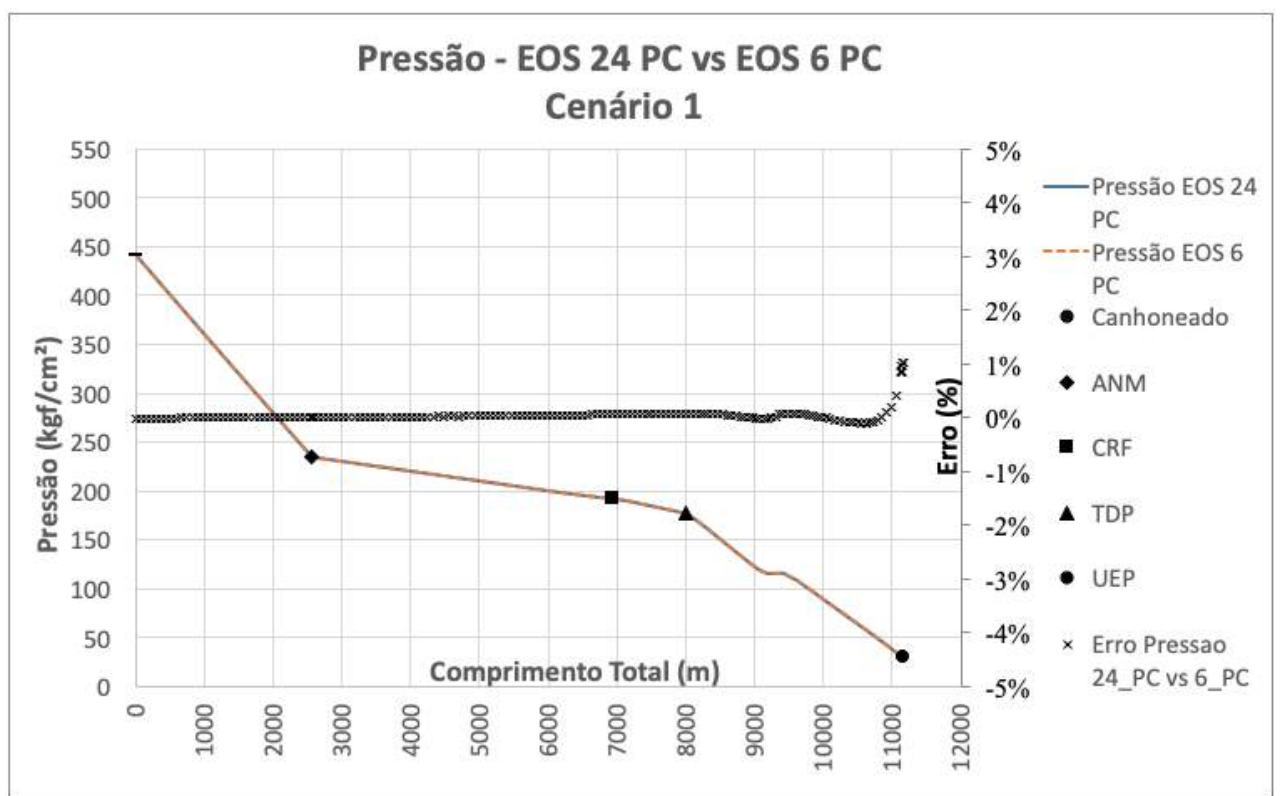

Figura C.91: Perfil de pressão no poço e duto - Cenário 1 - EOS 24 PC versus EOS 6 PC.

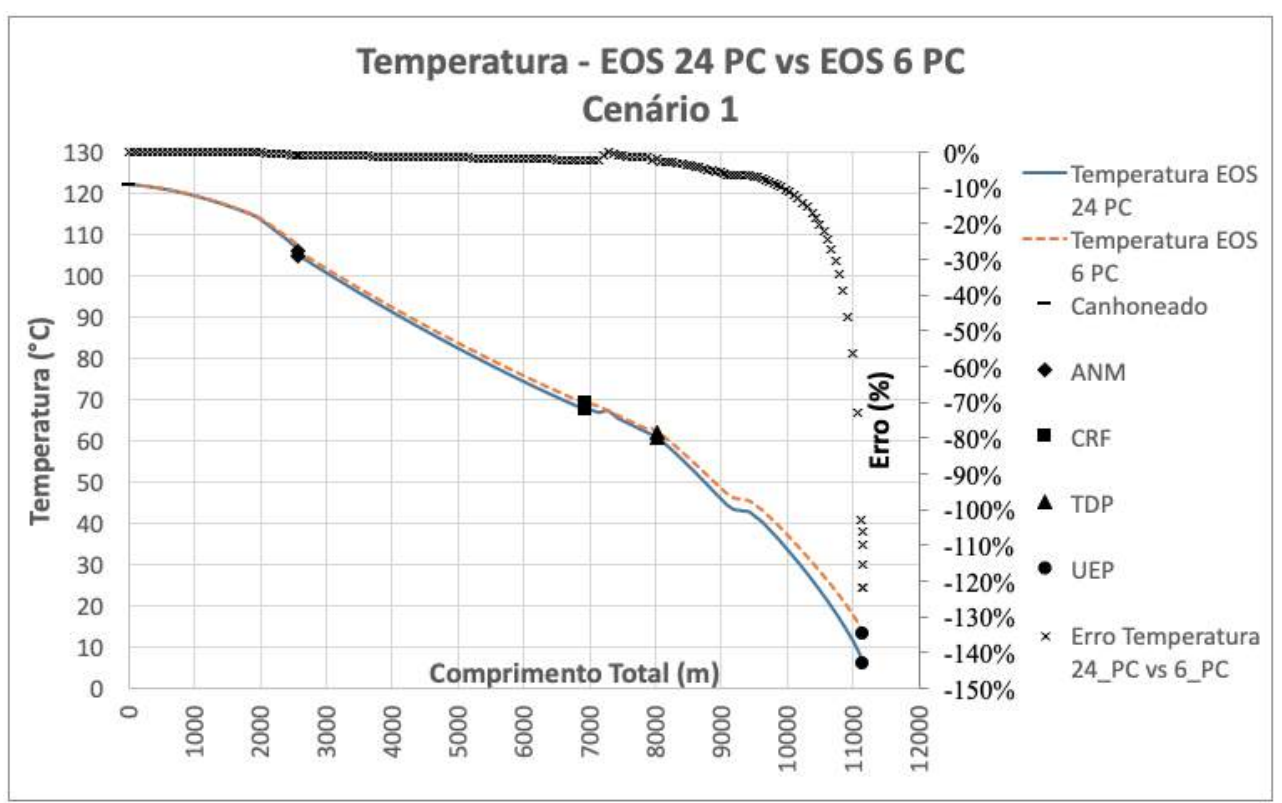

Figura C.92: Perfil de temperatura no poço e duto - Cenário 1 - EOS 24 PC versus EOS 6 PC. 


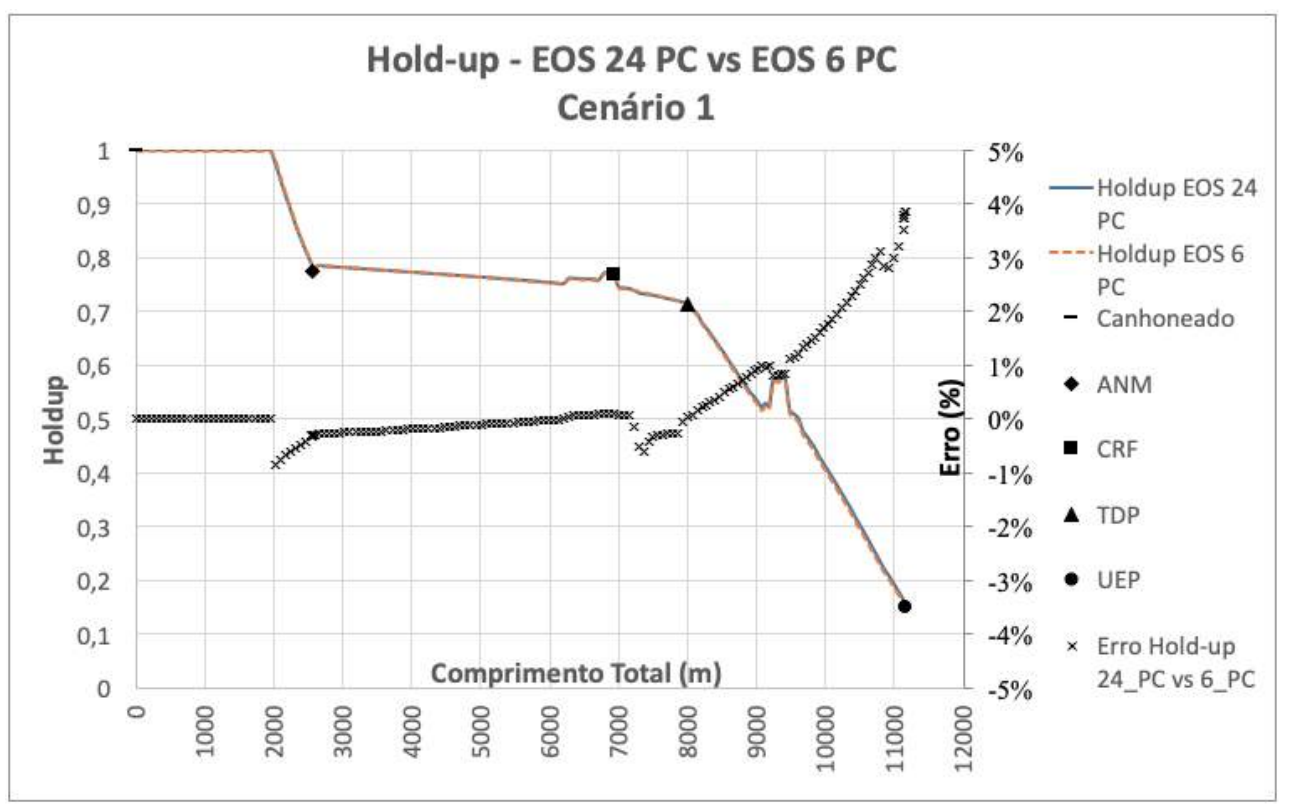

Figura C.93: Holdup no poço e duto - Cenário 1 - EOS 24 PC versus EOS 6 PC.

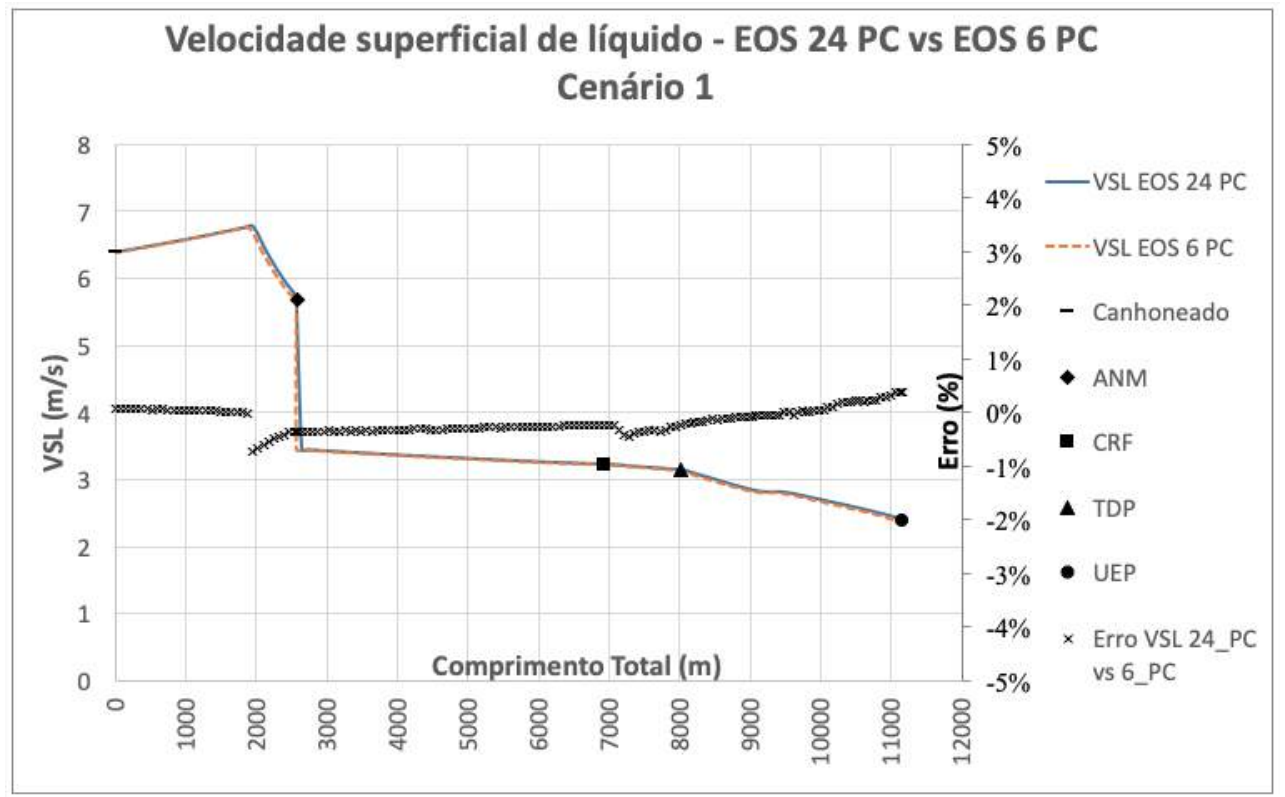

Figura C.94: Velocidade superficial de líquido - Cenário 1 - EOS 24 PC versus EOS 6 PC. 


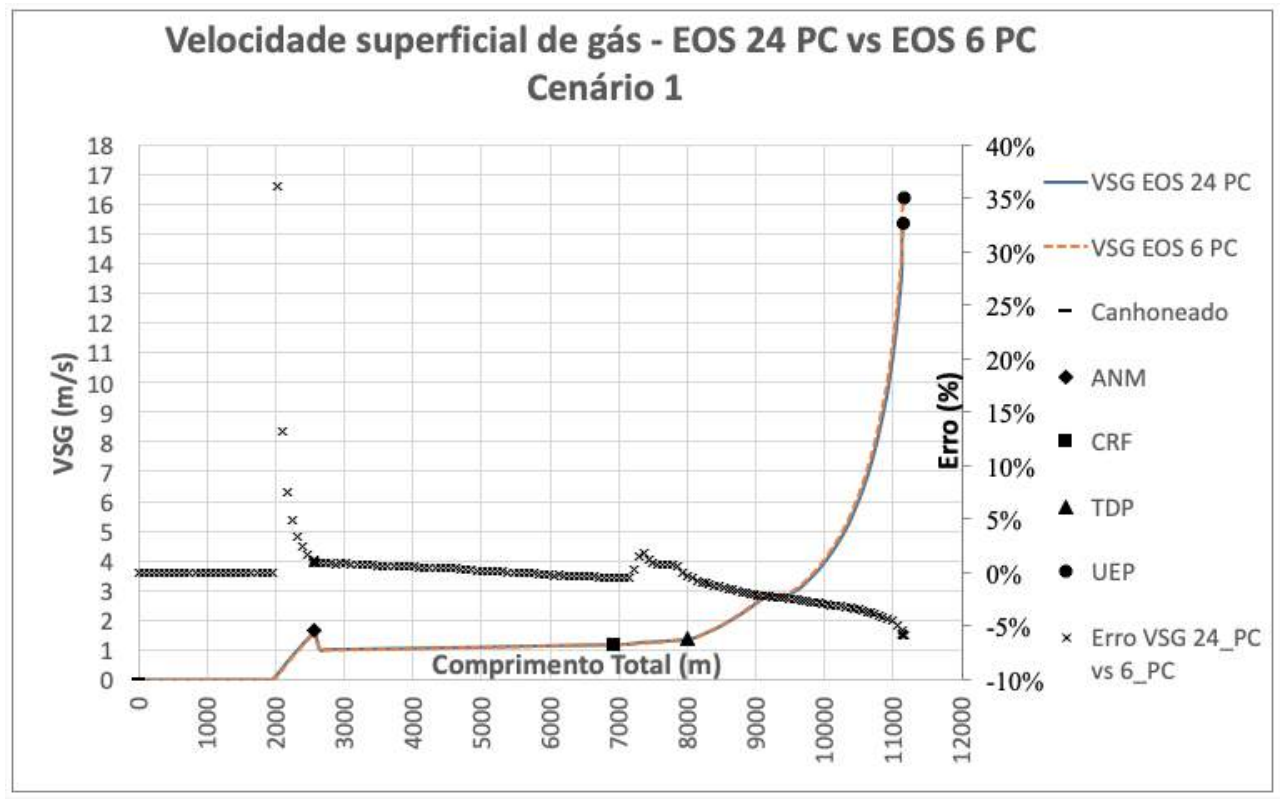

Figura C.95: Velocidade superficial de gás - Cenário 1 - EOS 24 PC versus EOS 6 PC.

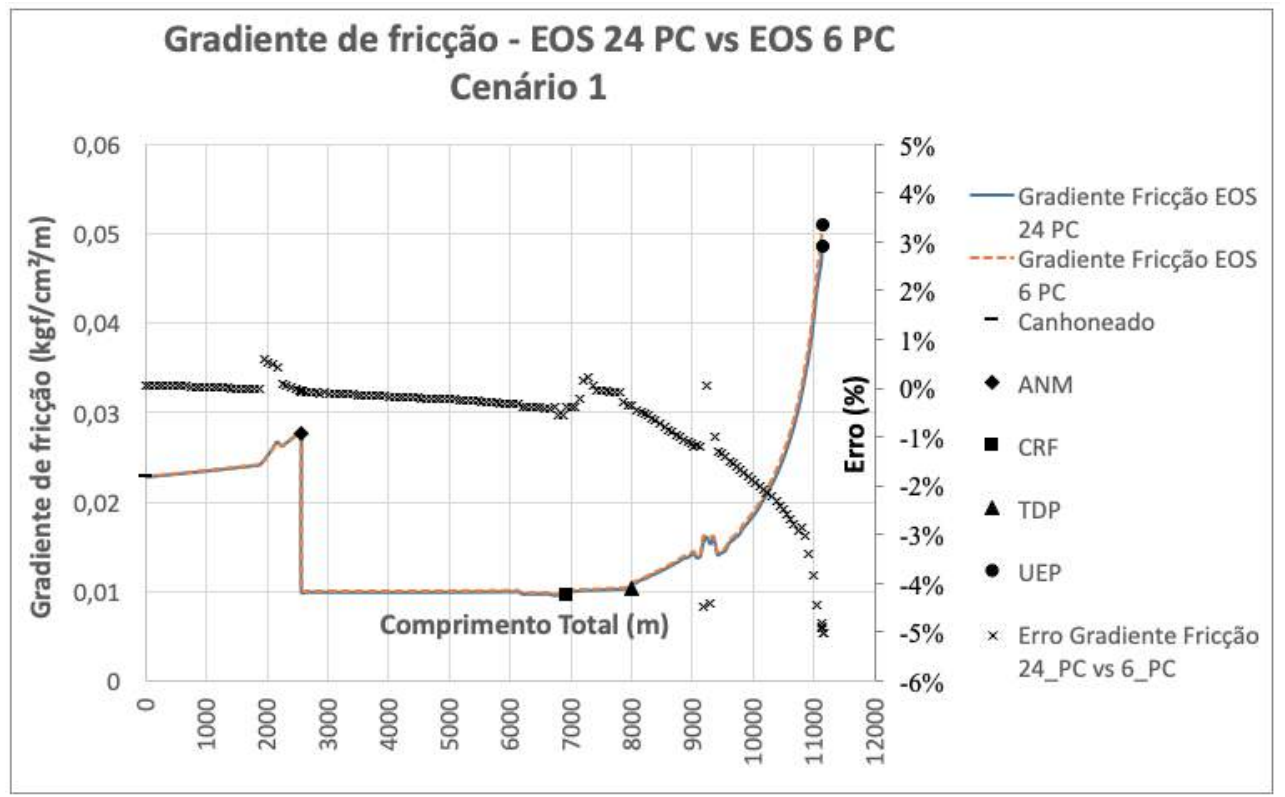

Figura C.96: Gradiente de pressão por fricção - Cenário 1 - EOS 24 PC versus EOS 6 PC. 


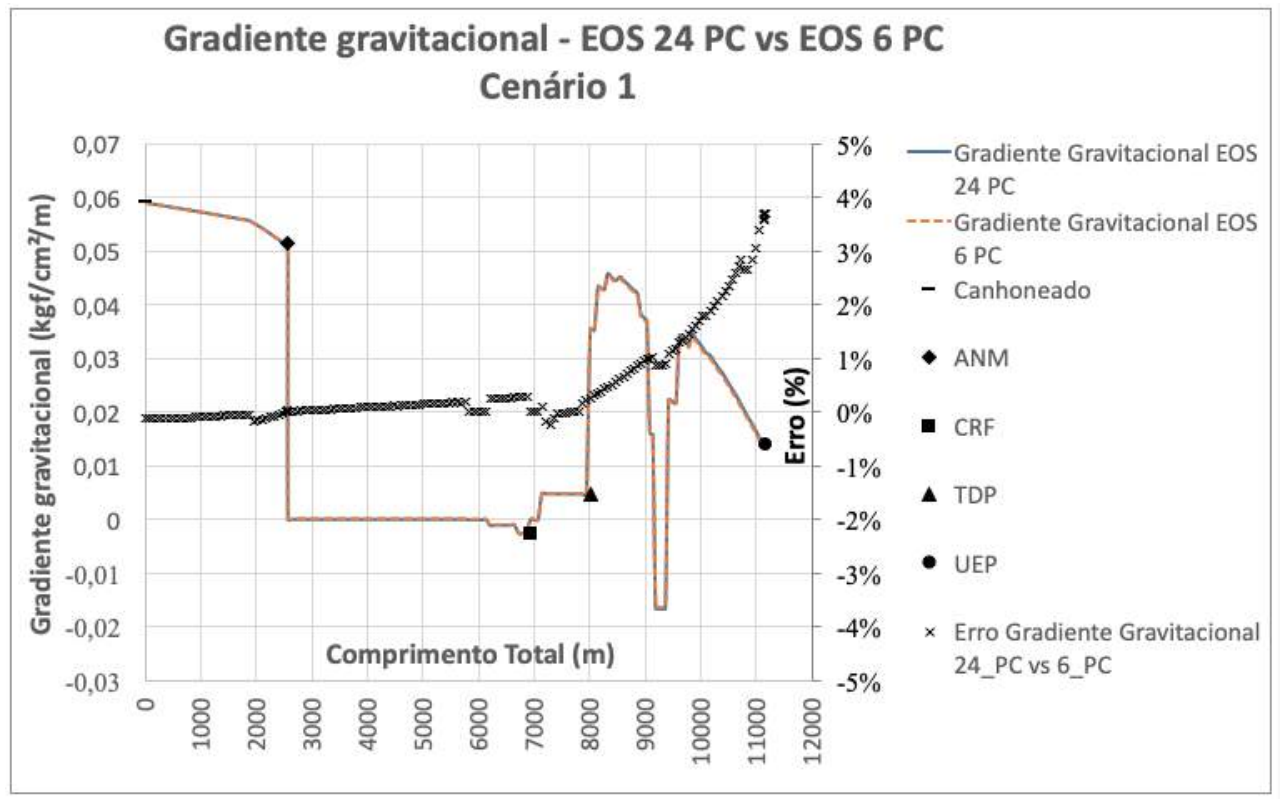

Figura C.97: Gradiente de pressão gravitacional - Cenário 1 - EOS 24 PC versus EOS 6 PC.

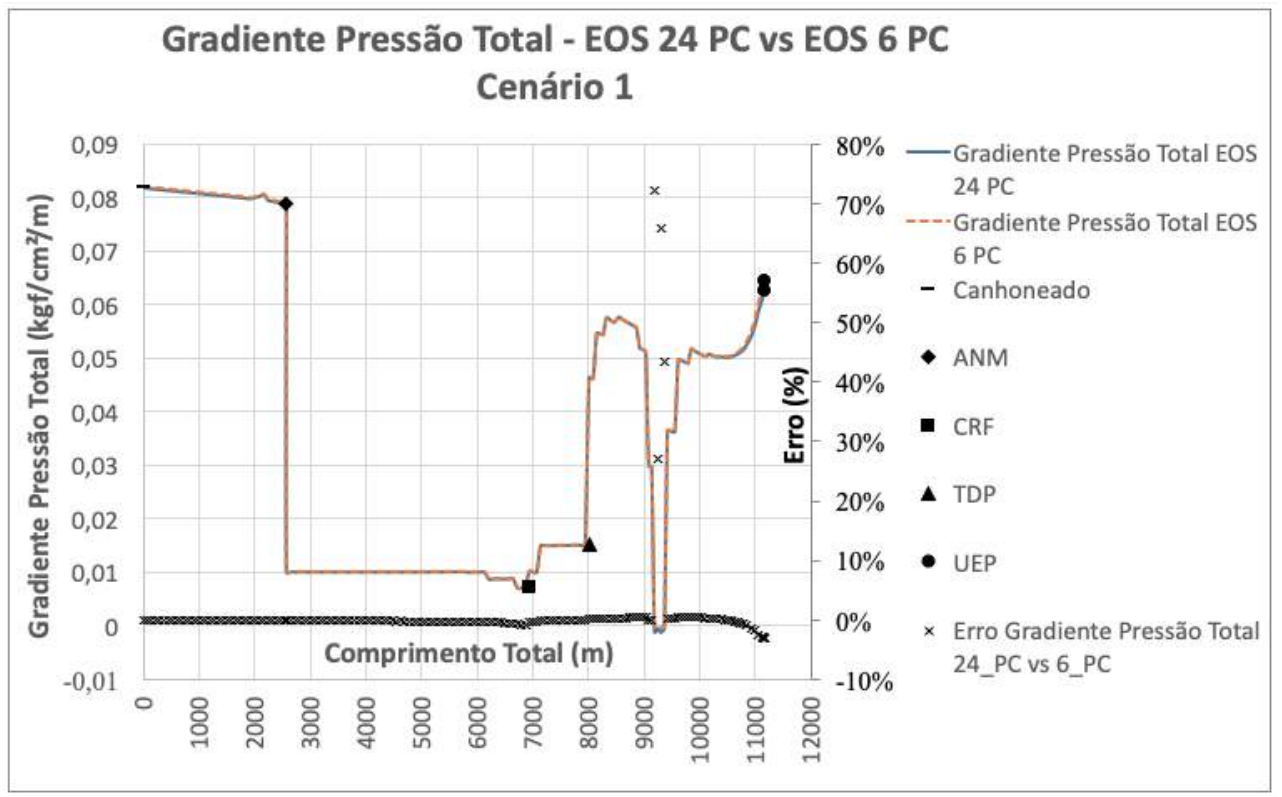

Figura C.98: Gradiente de pressão total - Cenário 1 - EOS 24 PC versus EOS 6 PC. 


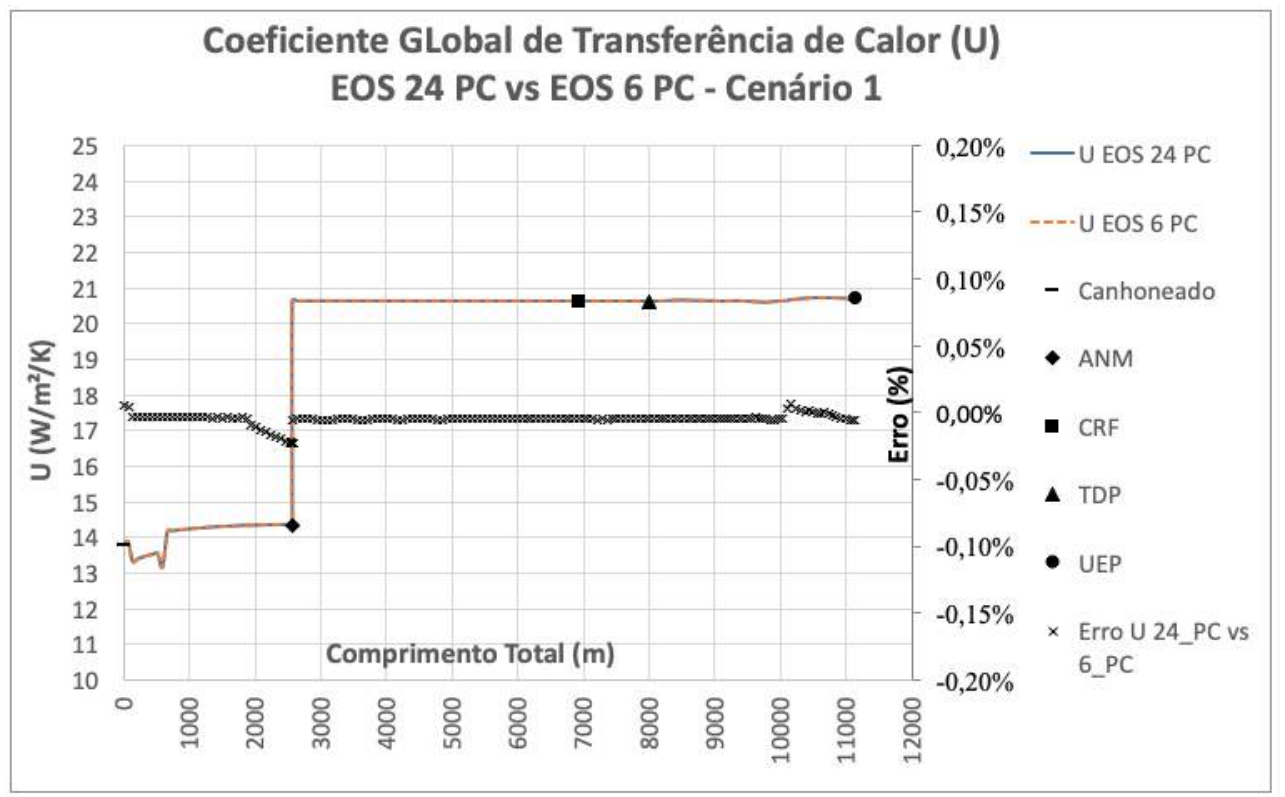

Figura C.99: Coeficiente global de transferência de calor - Cenário 1 - EOS 24 $\mathrm{PC}$ versus EOS $6 \mathrm{PC}$.

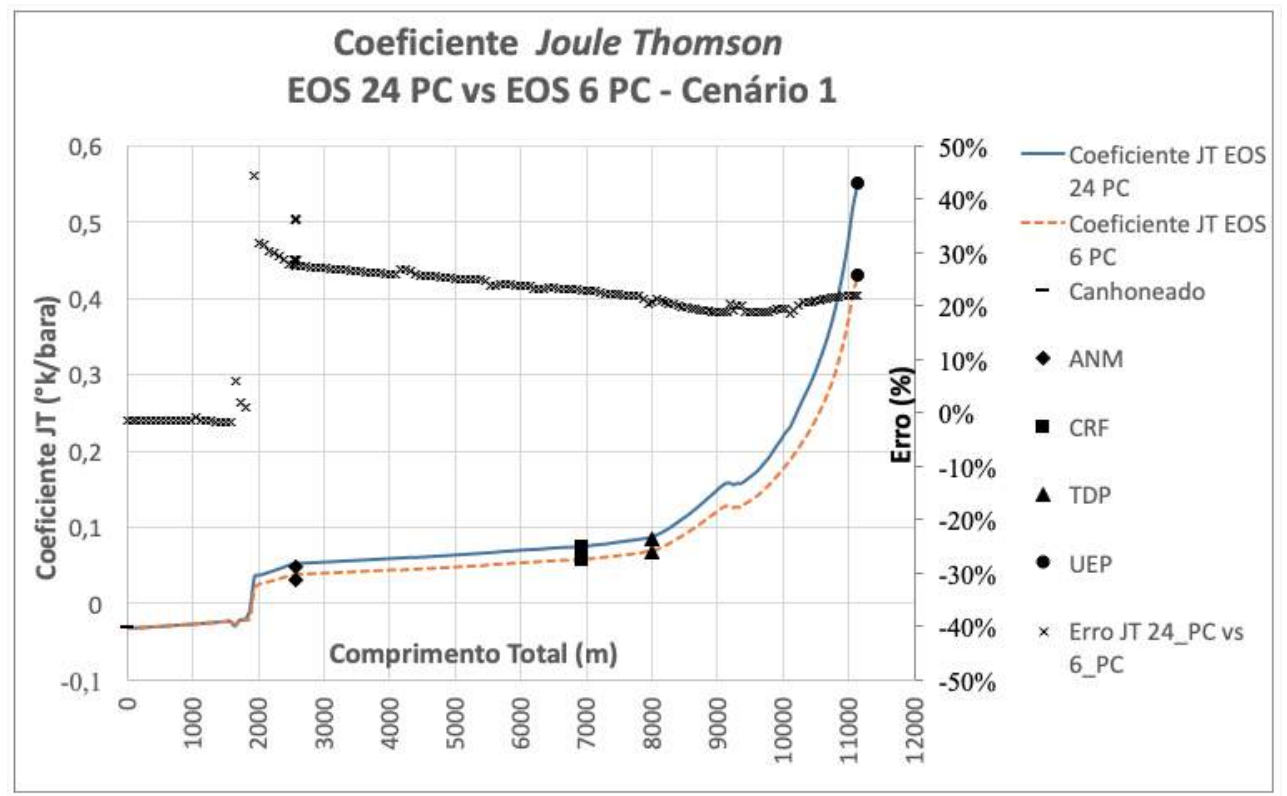

Figura C.100: Coeficiente Joule-Thomson - Cenário 1 - EOS 24 PC versus EOS 6 PC. 


\section{4.2}

\section{Cenário 2 - Período inicial antes do breaktrough de água}

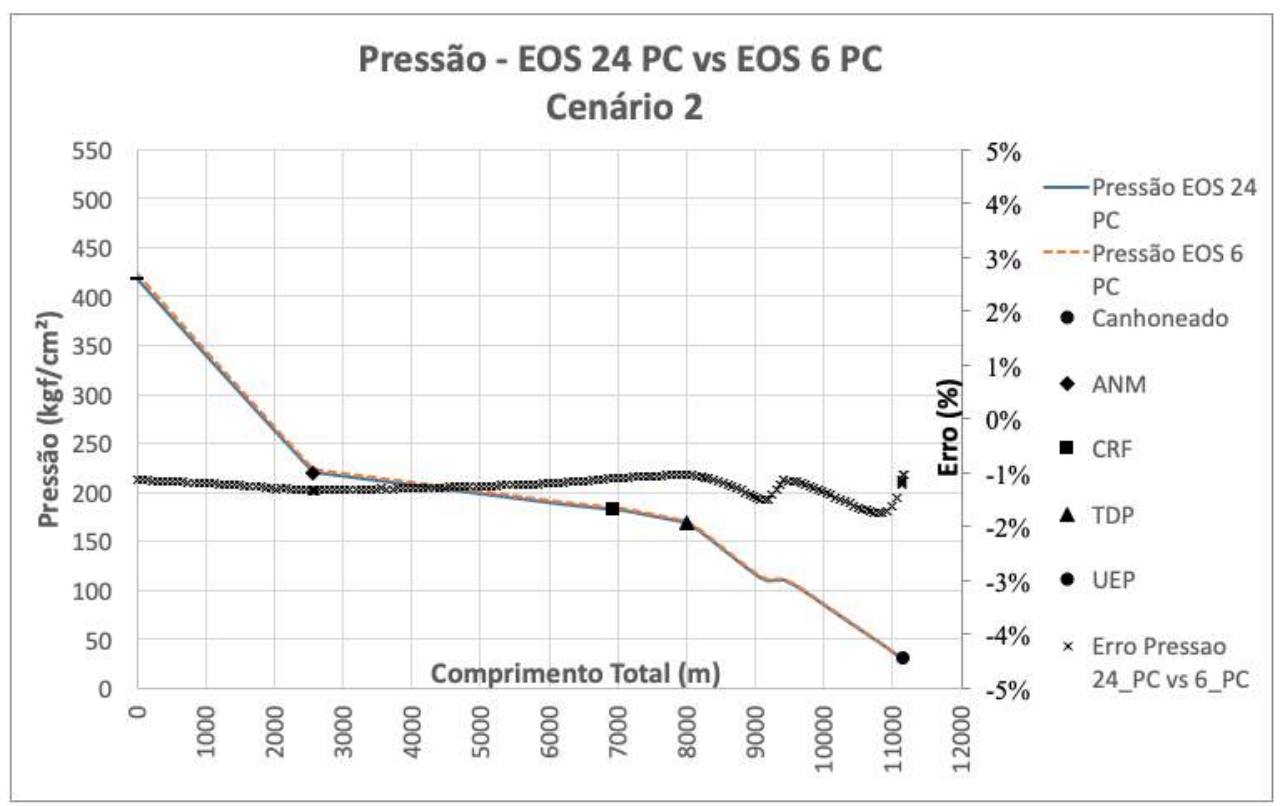

Figura C.101: Perfil de pressão no poço e duto - Cenário 2 - EOS 24 PC versus EOS 6 PC.

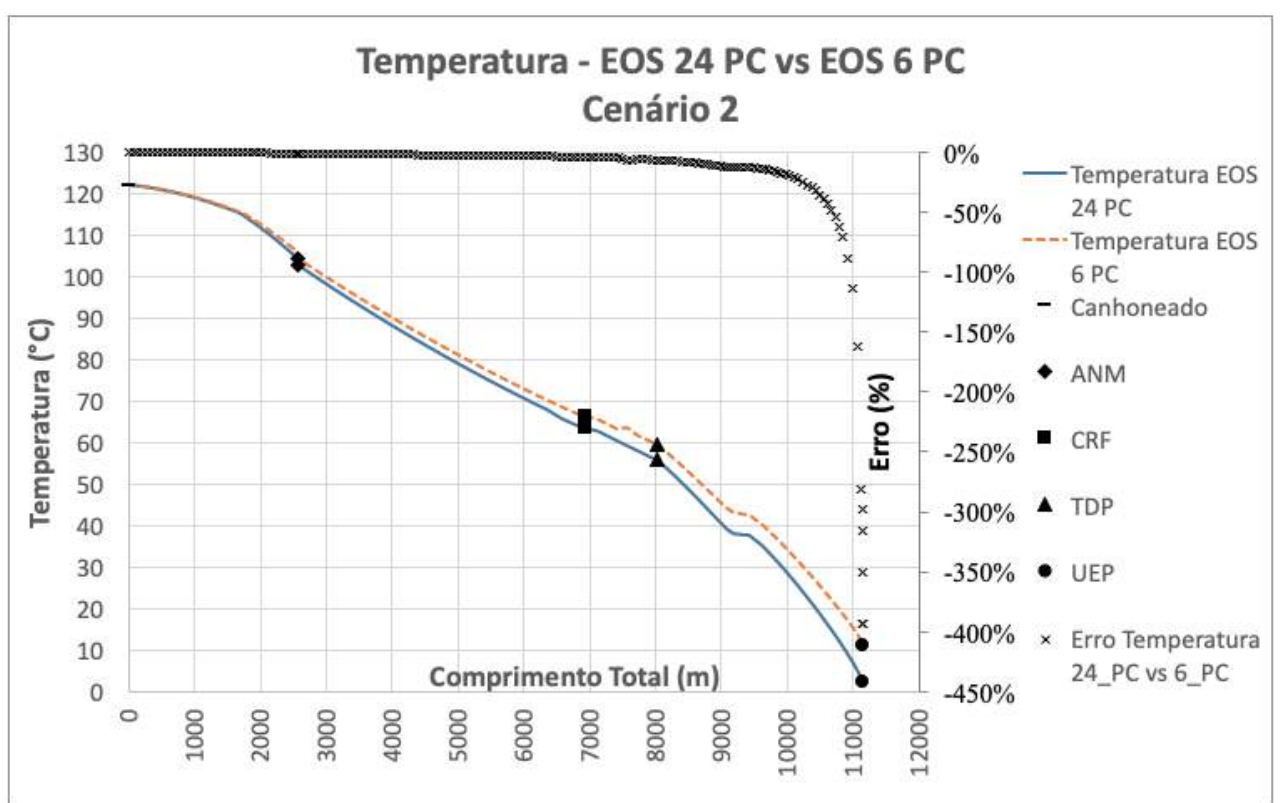

Figura C.102: Perfil de temperatura no poço e duto - Cenário 2 - EOS 24 PC versus EOS 6 PC. 


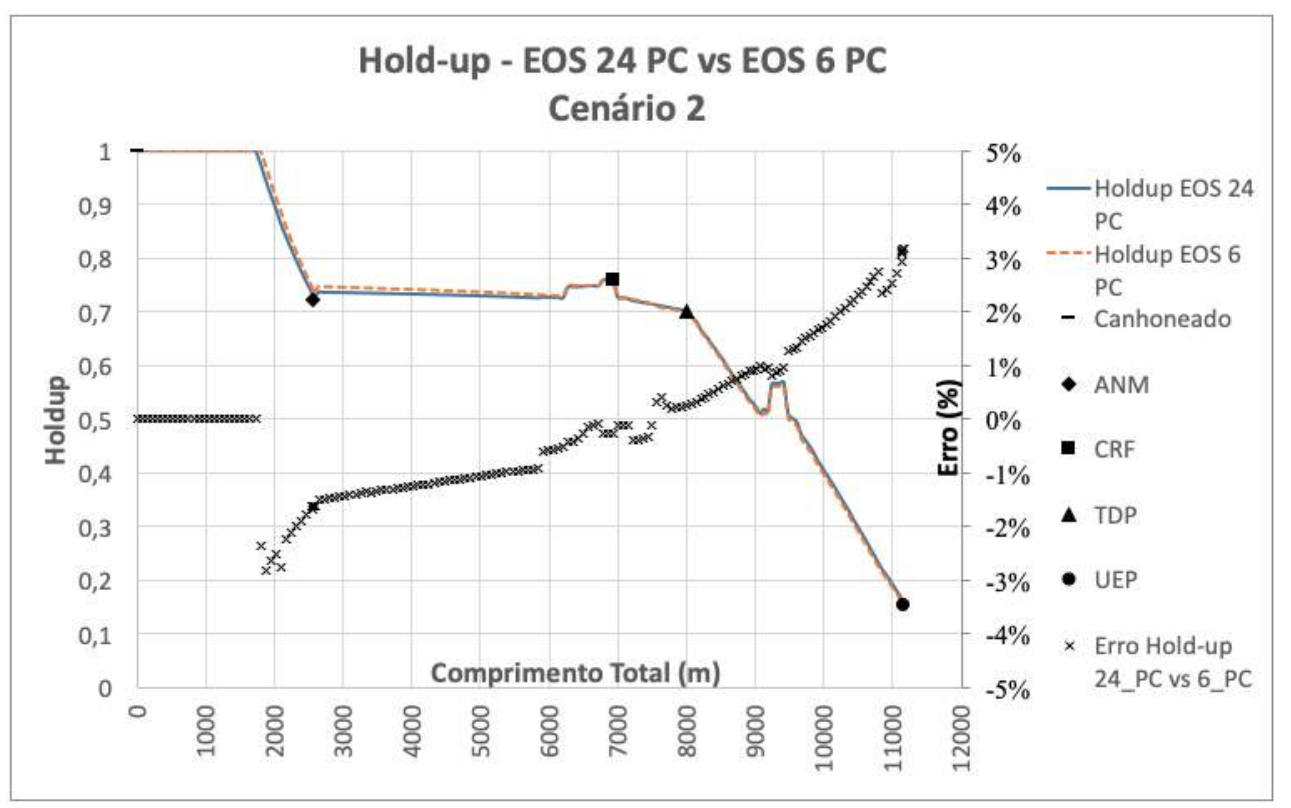

Figura C.103: Holdup no poço e duto - Cenário 2 - EOS 24 PC versus EOS 6 PC.

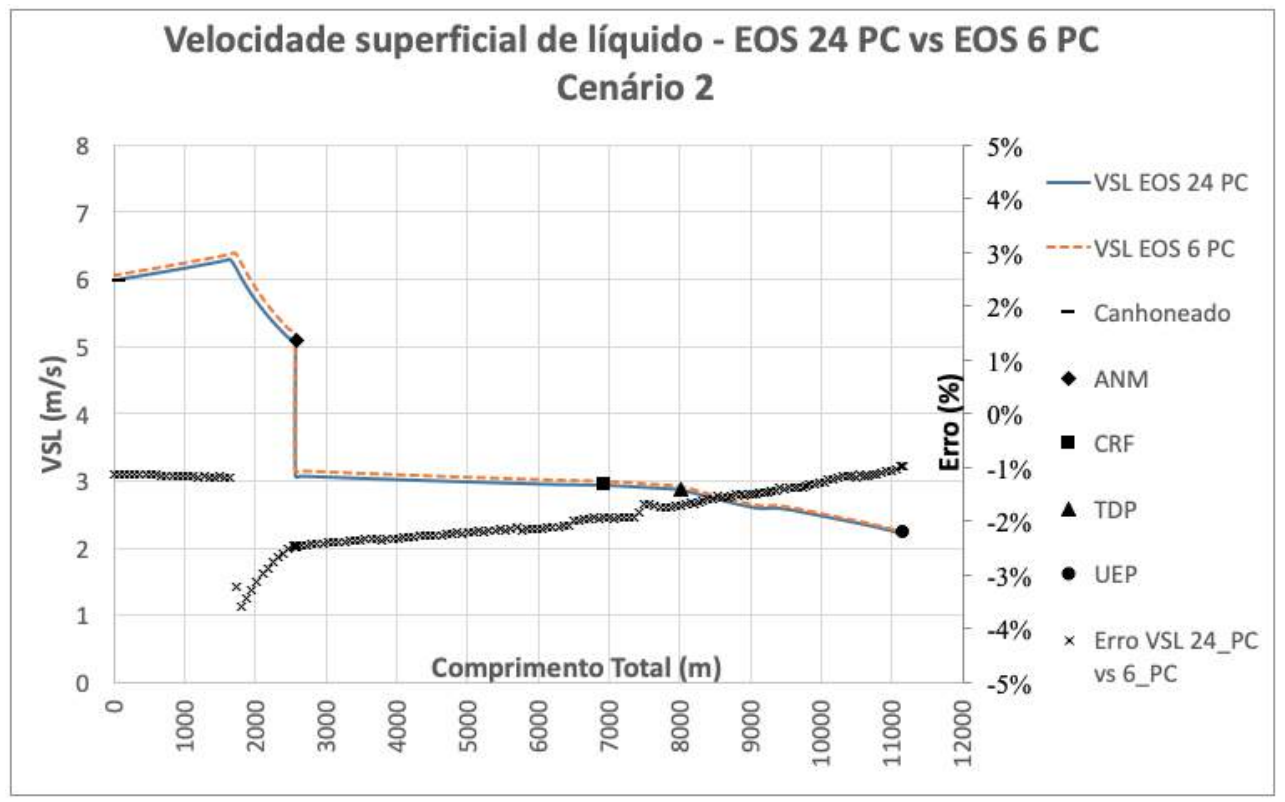

Figura C.104: Velocidade superficial de líquido - Cenário 2 - EOS 24 PC versus EOS 6 PC. 


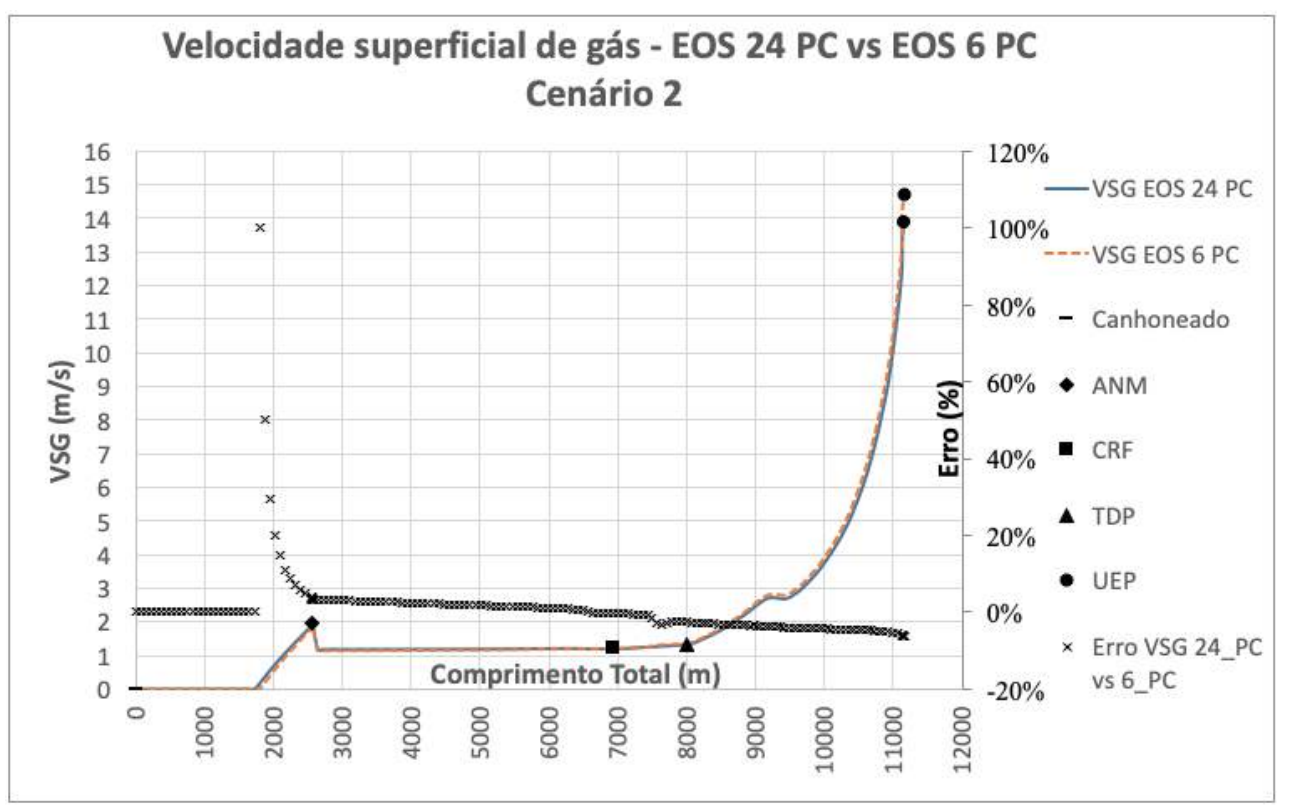

Figura C.105: Velocidade superficial de gás - Cenário 2 - EOS 24 PC versus EOS 6 PC.

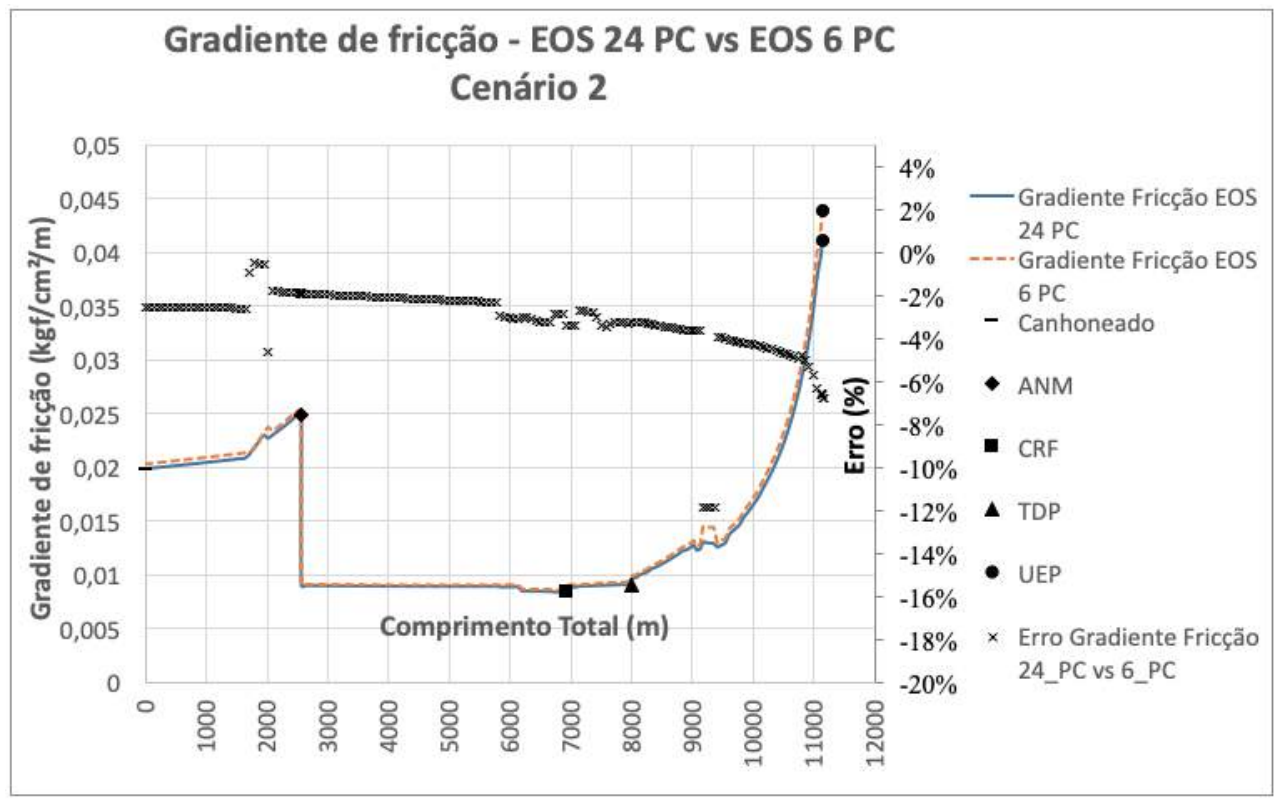

Figura C.106: Gradiente de pressão por fricção - Cenário 2 - EOS 24 PC versus EOS 6 PC. 


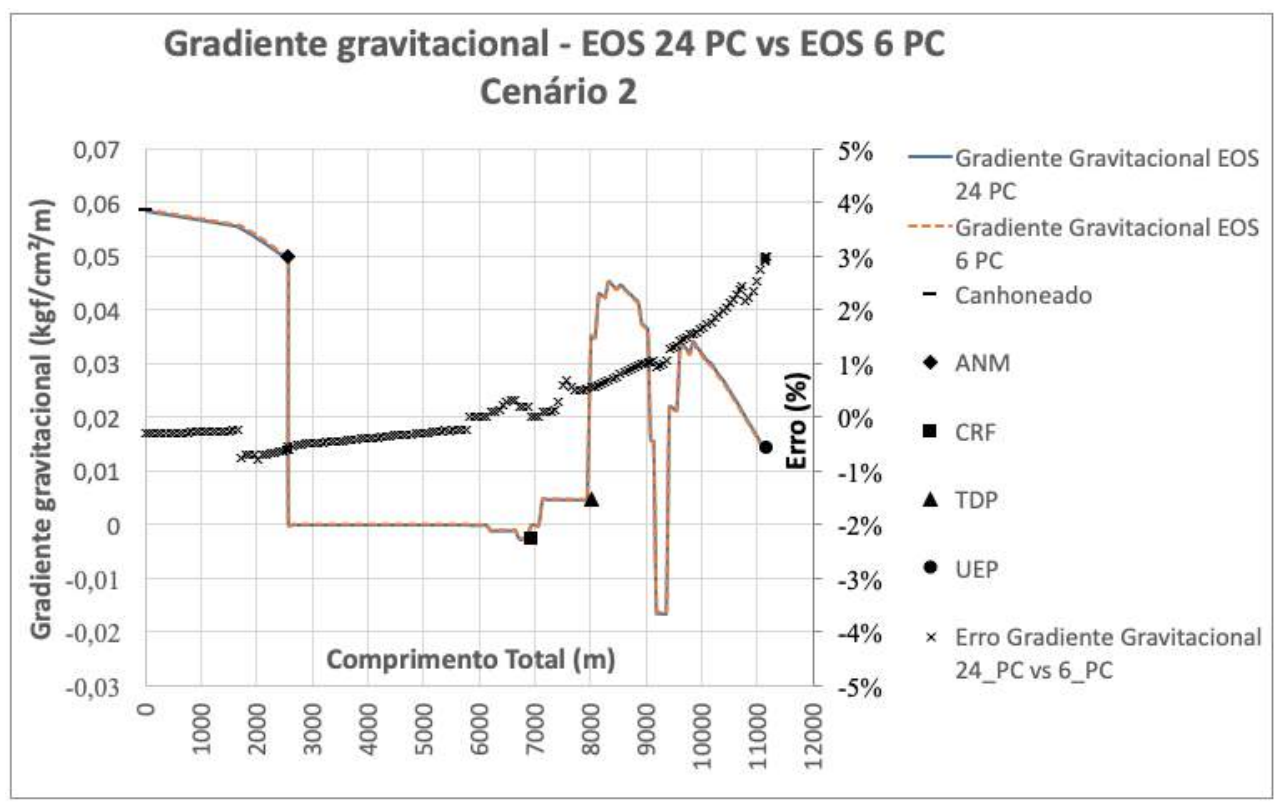

Figura C.107: Gradiente de pressão gravitacional - Cenário 2 - EOS 24 PC versus EOS 6 PC.

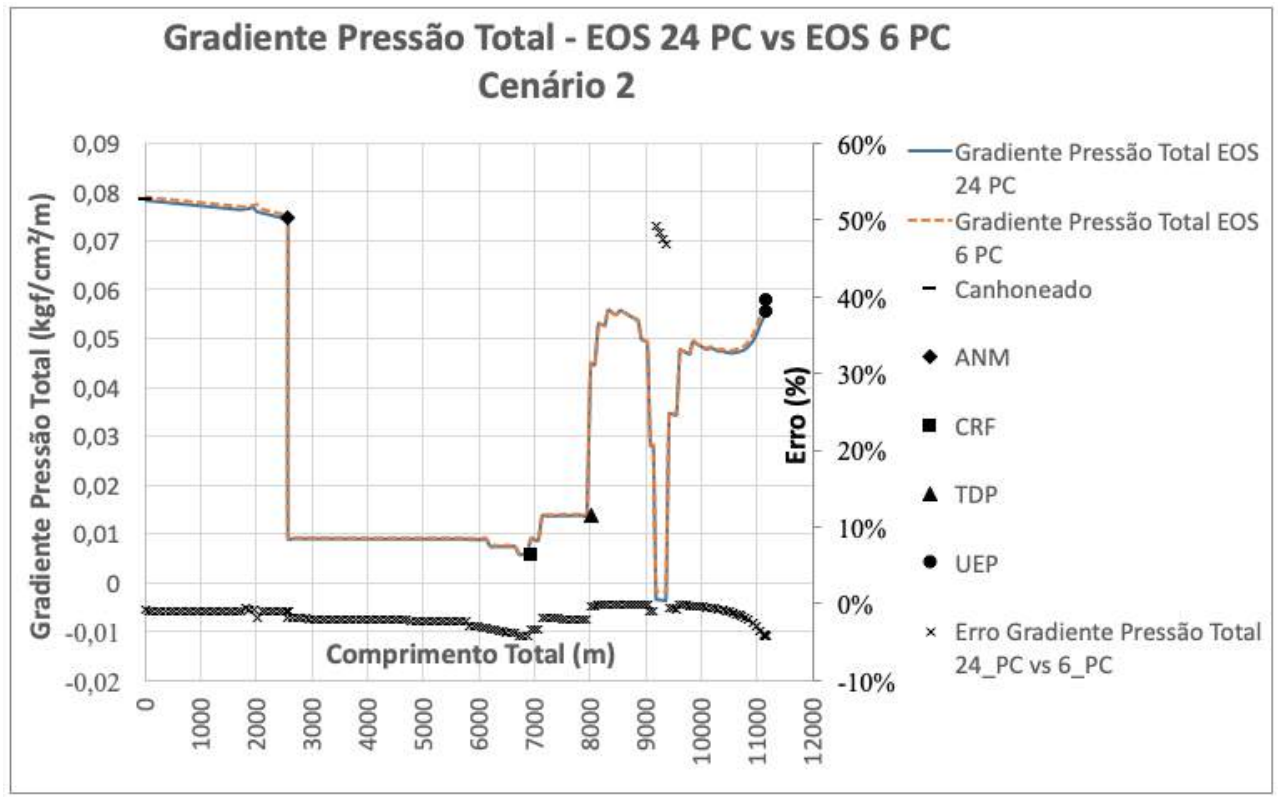

Figura C.108: Gradiente de pressão total - Cenário 2 - EOS 24 PC versus EOS 6 PC. 


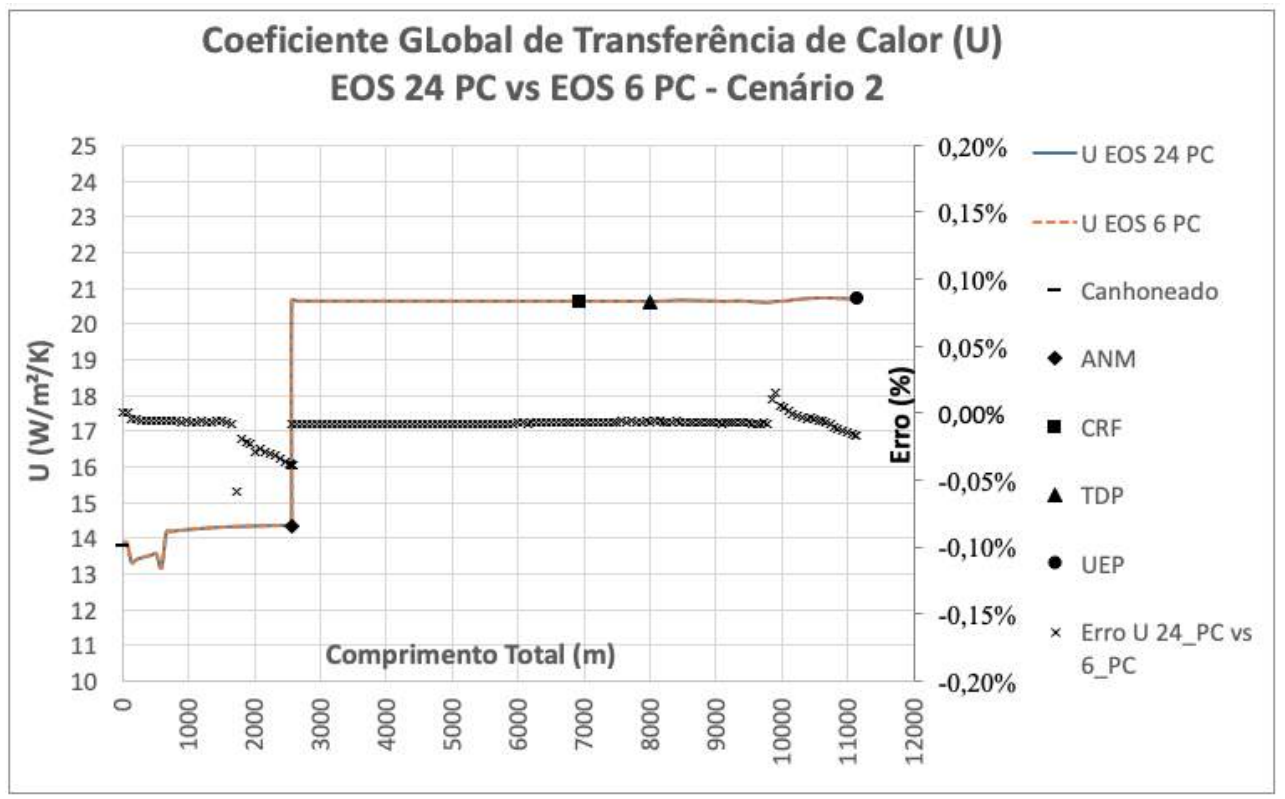

Figura C.109: Coeficiente global de transferência de calor - Cenário 2 - EOS $24 \mathrm{PC}$ versus EOS 6 PC.

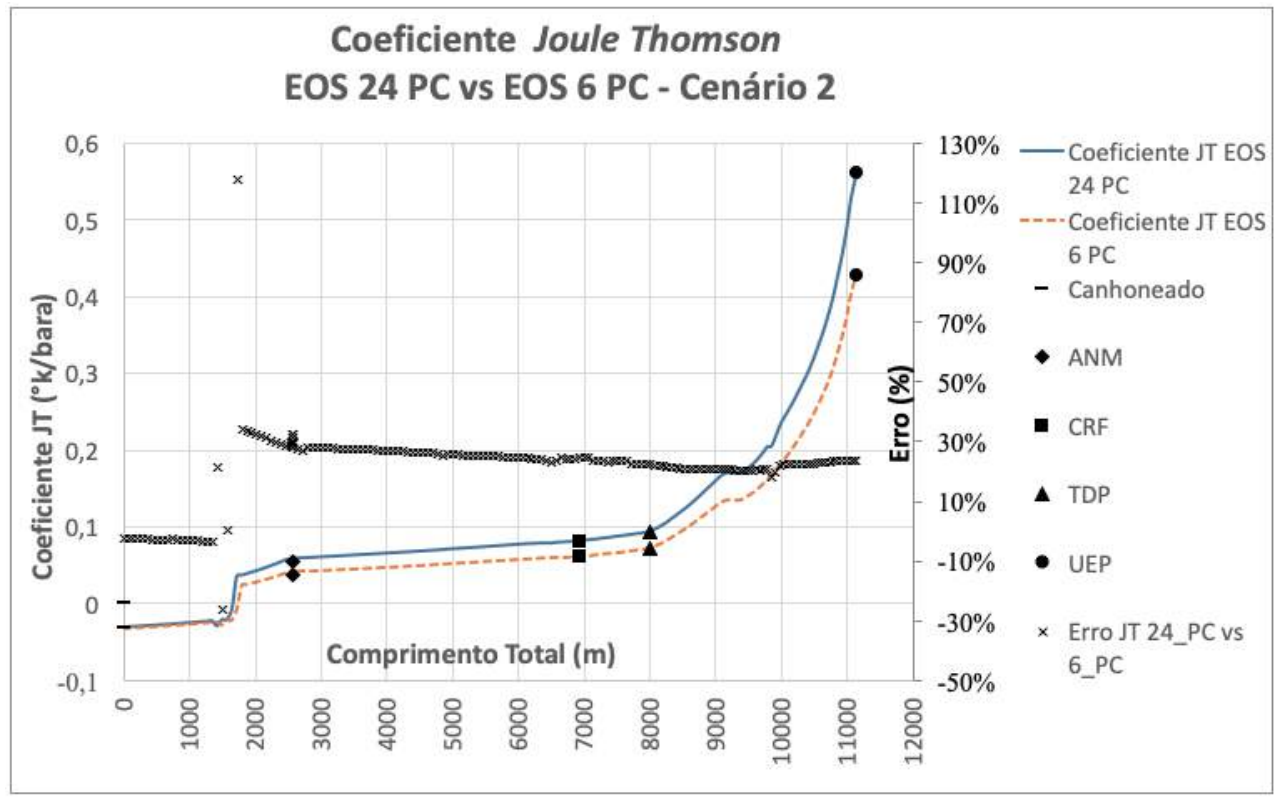

Figura C.110: Coeficiente Joule-Thomson - Cenário 2 - EOS 24 PC versus EOS 6 PC. 


\section{C.4.3}

\section{Cenário 3 - Corte de água intermediário}

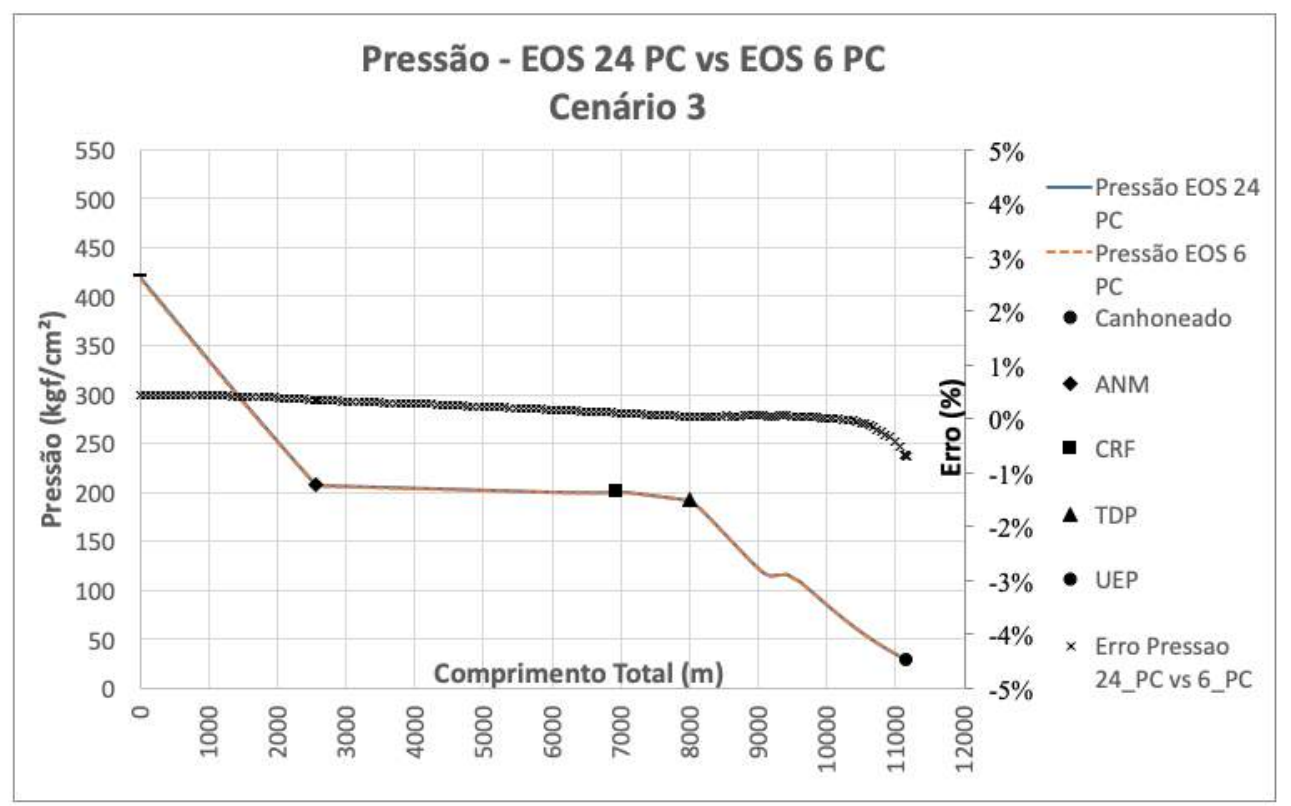

Figura C.111: Perfil de pressão no poço e duto - Cenário 3 - EOS 24 PC versus EOS 6 PC.

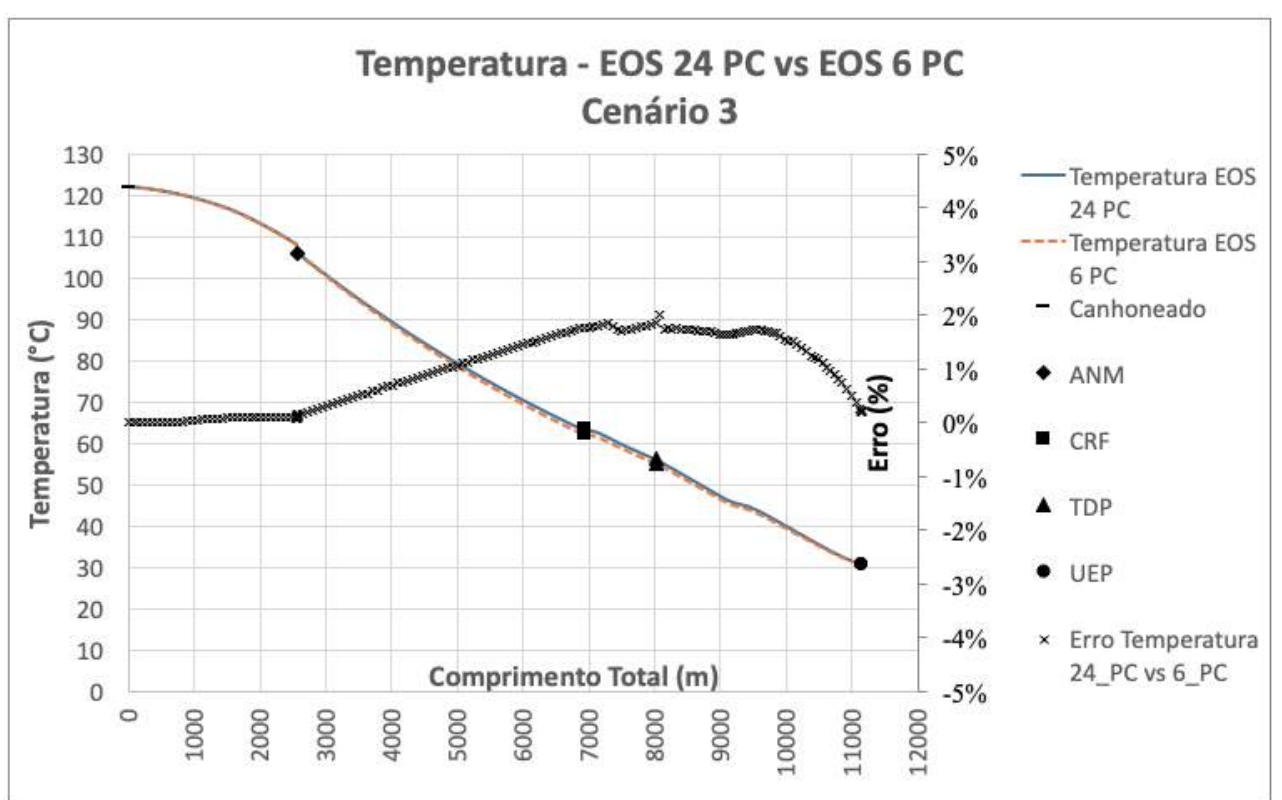

Figura C.112: Perfil de temperatura no poço e duto - Cenário 3 - EOS 24 PC versus EOS 6 PC. 


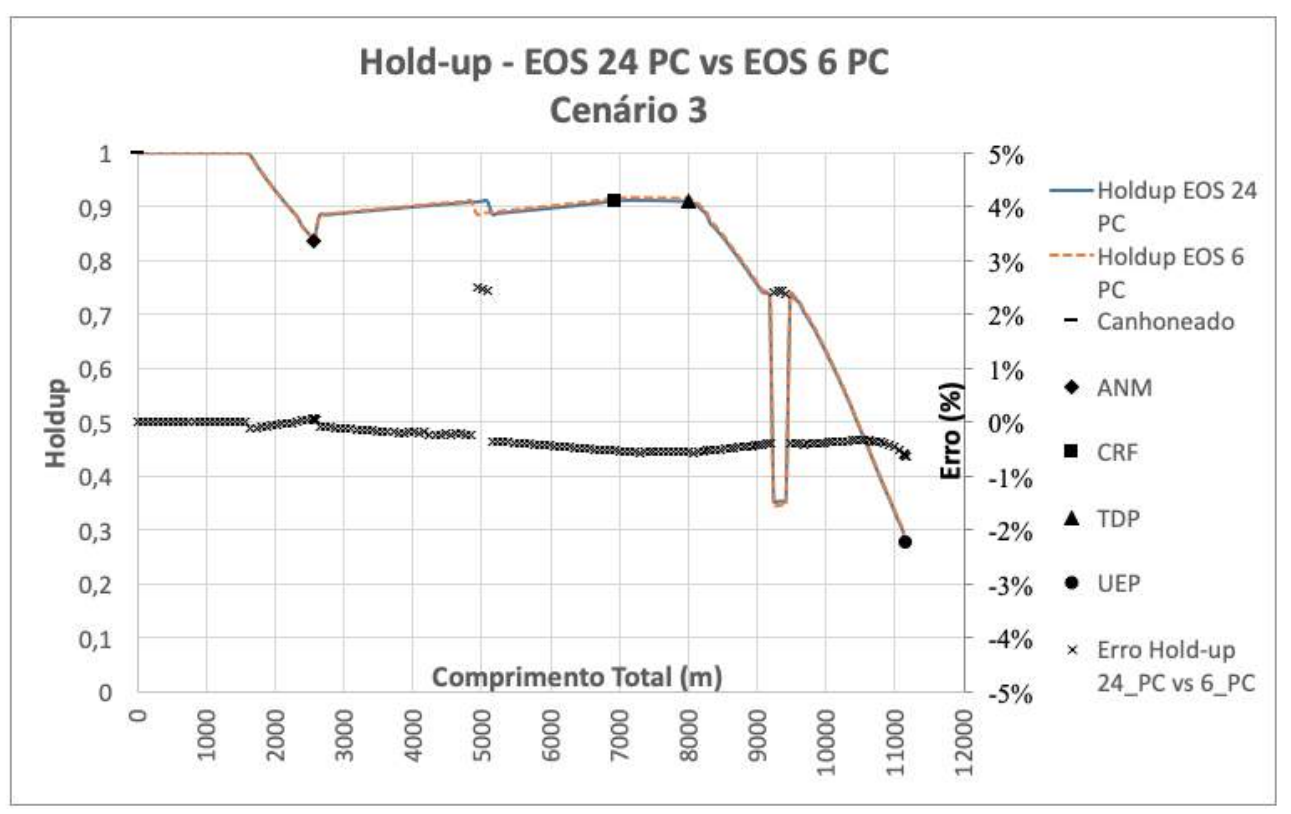

Figura C.113: Holdup no poço e duto - Cenário 3 - EOS 24 PC versus EOS 6 PC.

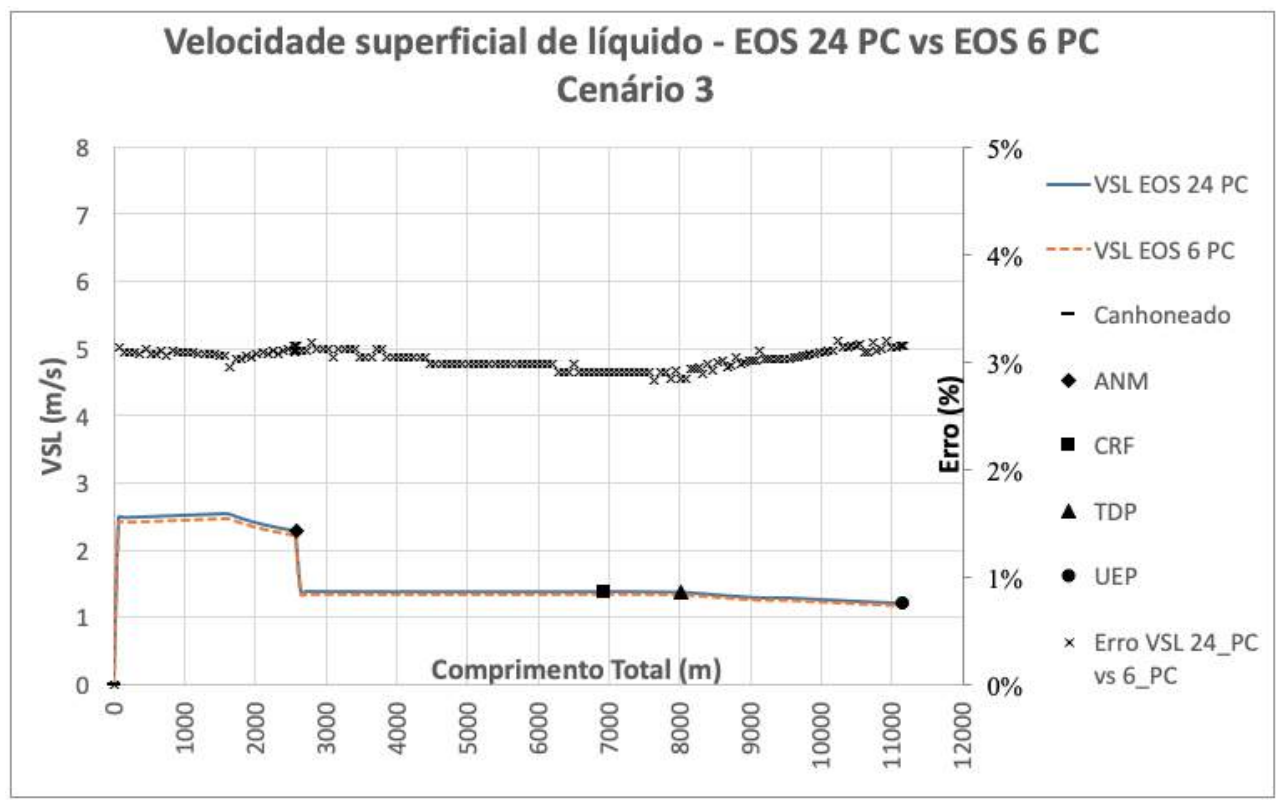

Figura C.114: Velocidade superficial de líquido - Cenário 3 - EOS 24 PC versus EOS 6 PC. 


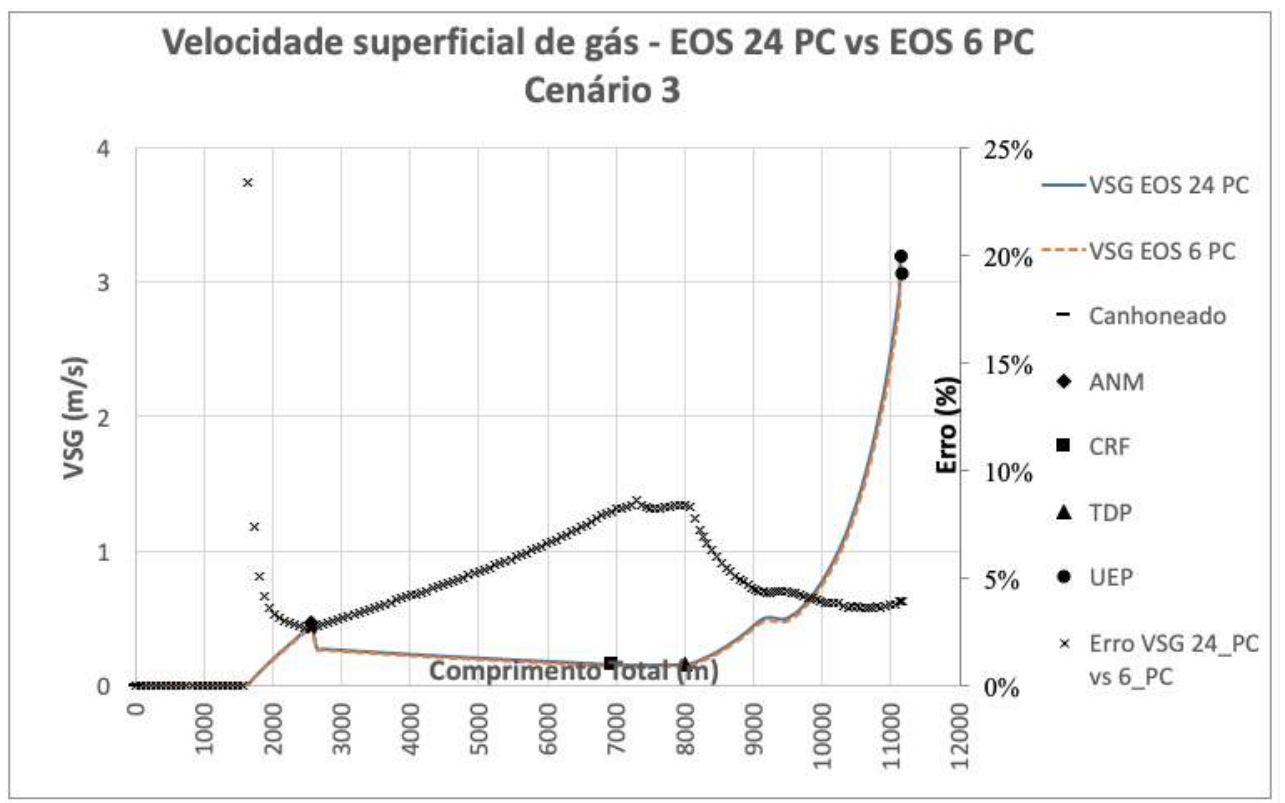

Figura C.115: Velocidade superficial de gás - Cenário 3 - EOS 24 PC versus EOS 6 PC.

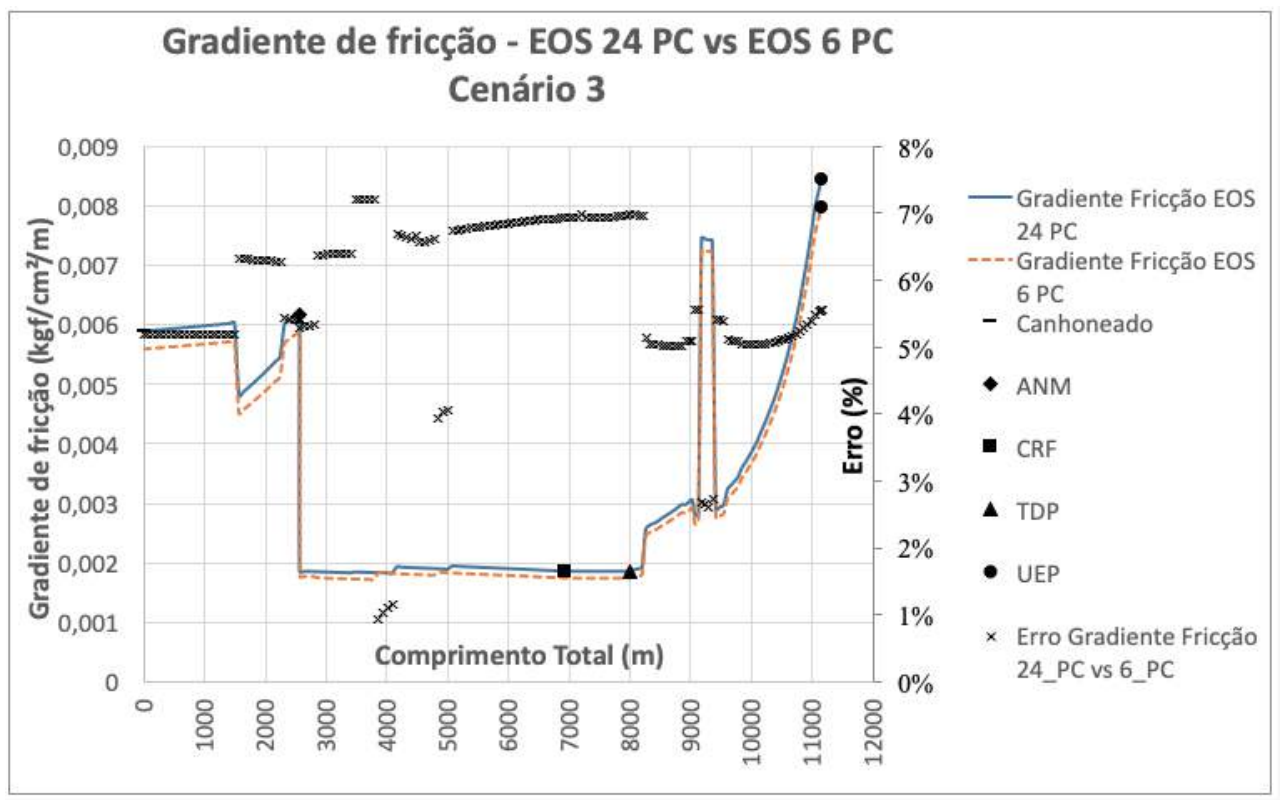

Figura C.116: Gradiente de pressão por fricção - Cenário 3 - EOS 24 PC versus EOS 6 PC. 


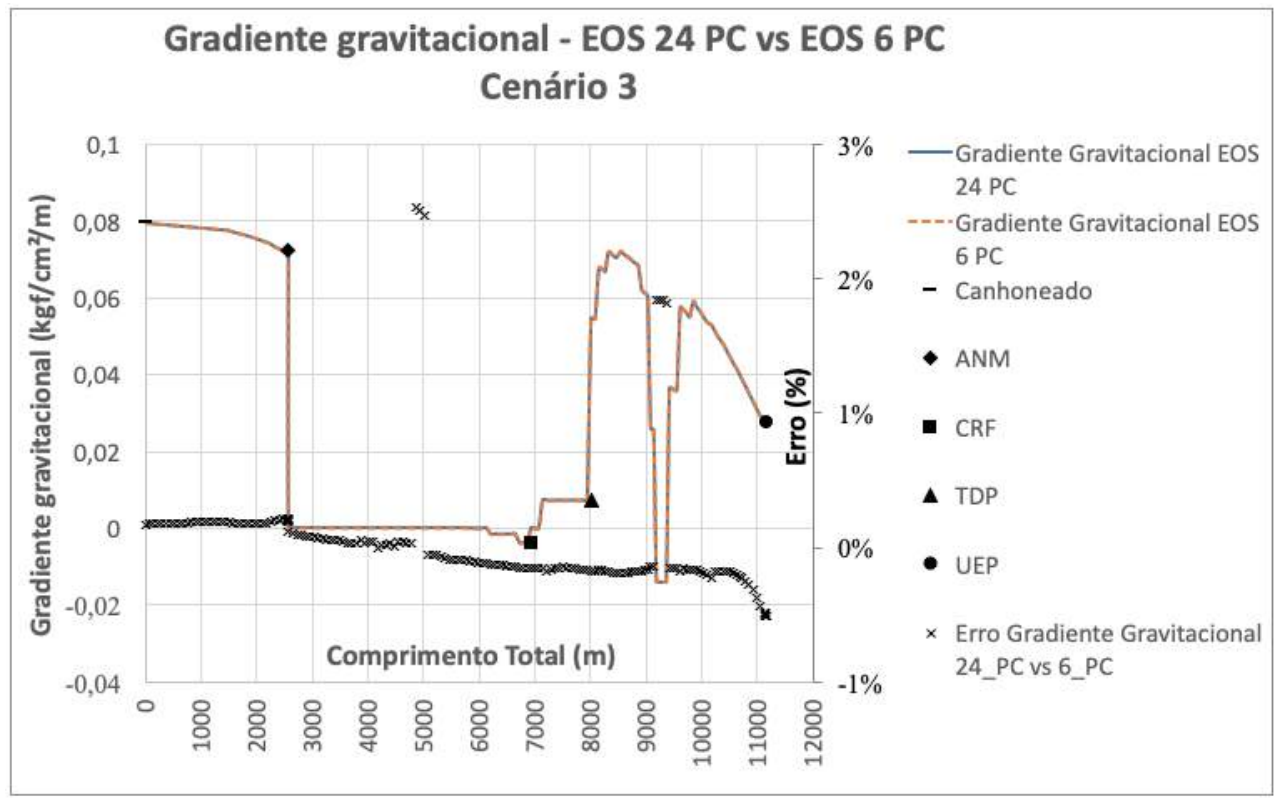

Figura C.117: Gradiente de pressão gravitacional - Cenário 3 - EOS 24 PC versus EOS $6 \mathrm{PC}$.

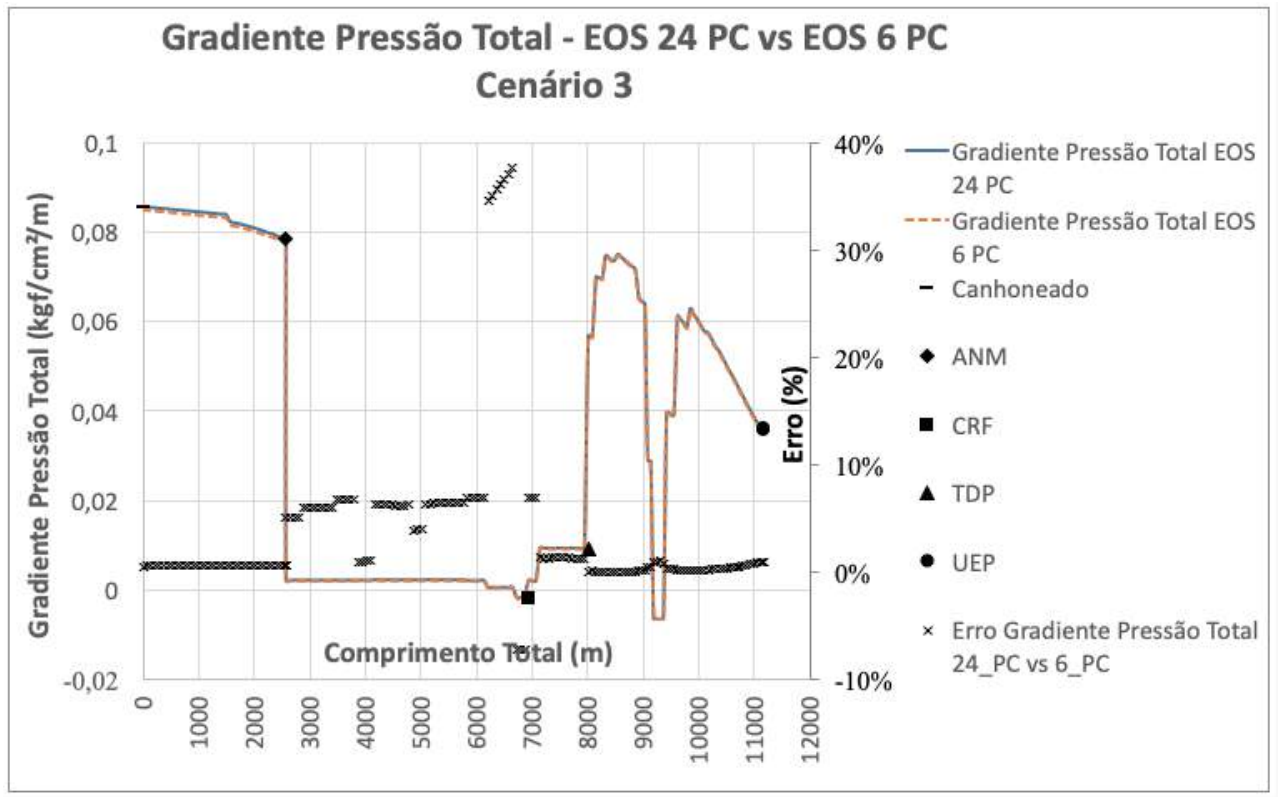

Figura C.118: Gradiente de pressão total - Cenário 3 - EOS 24 PC versus EOS 6 PC. 


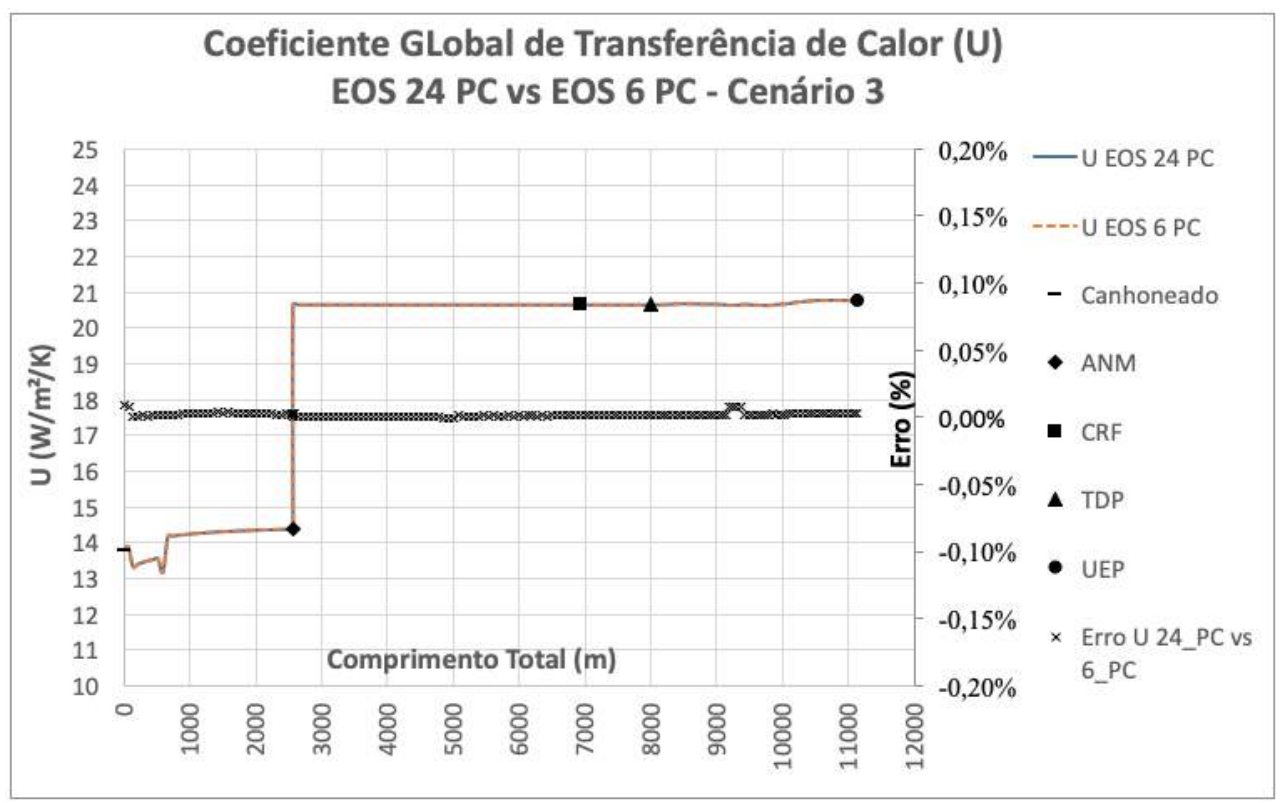

Figura C.119: Coeficiente global de transferência de calor - Cenário 3 - EOS $24 \mathrm{PC}$ versus EOS 6 PC.

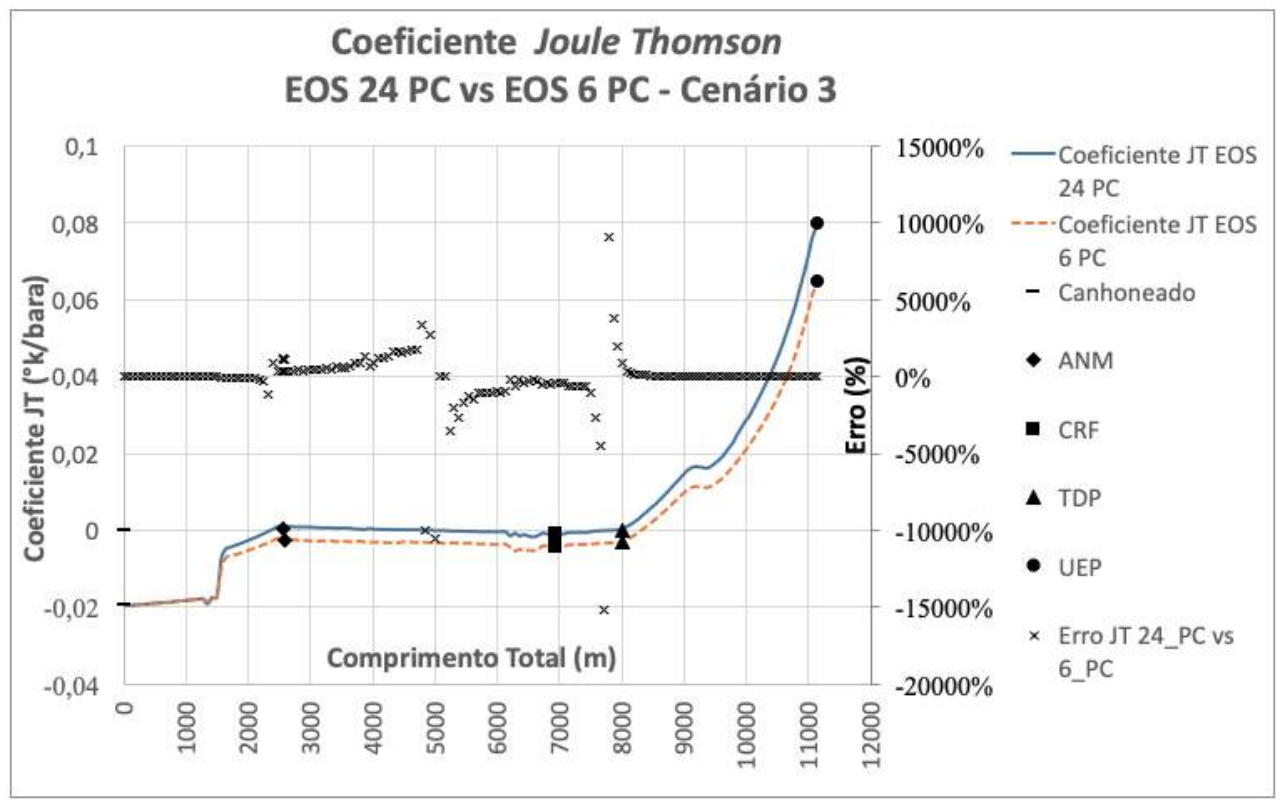

Figura C.120: Coeficiente Joule-Thomson - Cenário 3 - EOS 24 PC versus EOS 6 PC. 


\section{C.5}

\section{EOS 24 PC versus EOS 5 PC}

\section{C.5.1}

Cenário 1 - Período inicial logo após a abertura do poço

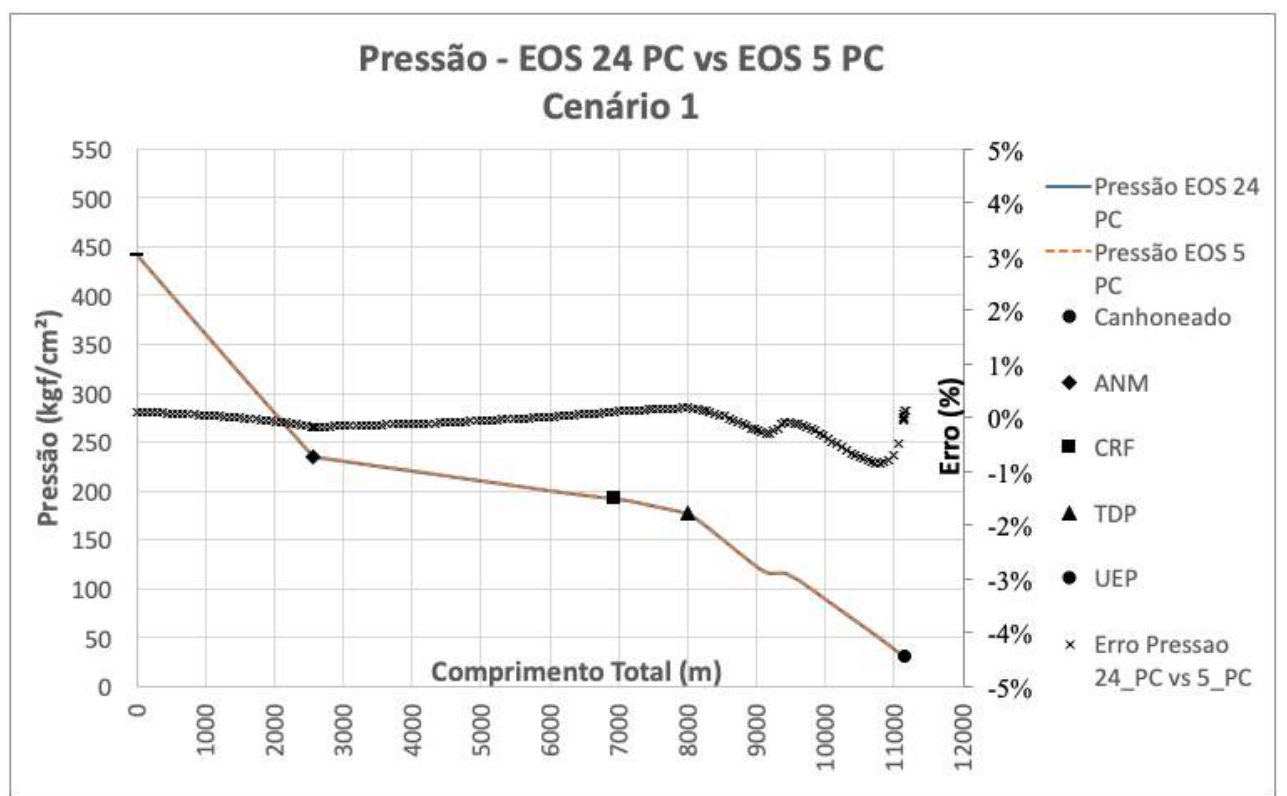

Figura C.121: Perfil de pressão no poço e duto - Cenário 1 - EOS 24 PC versus EOS 5 PC.

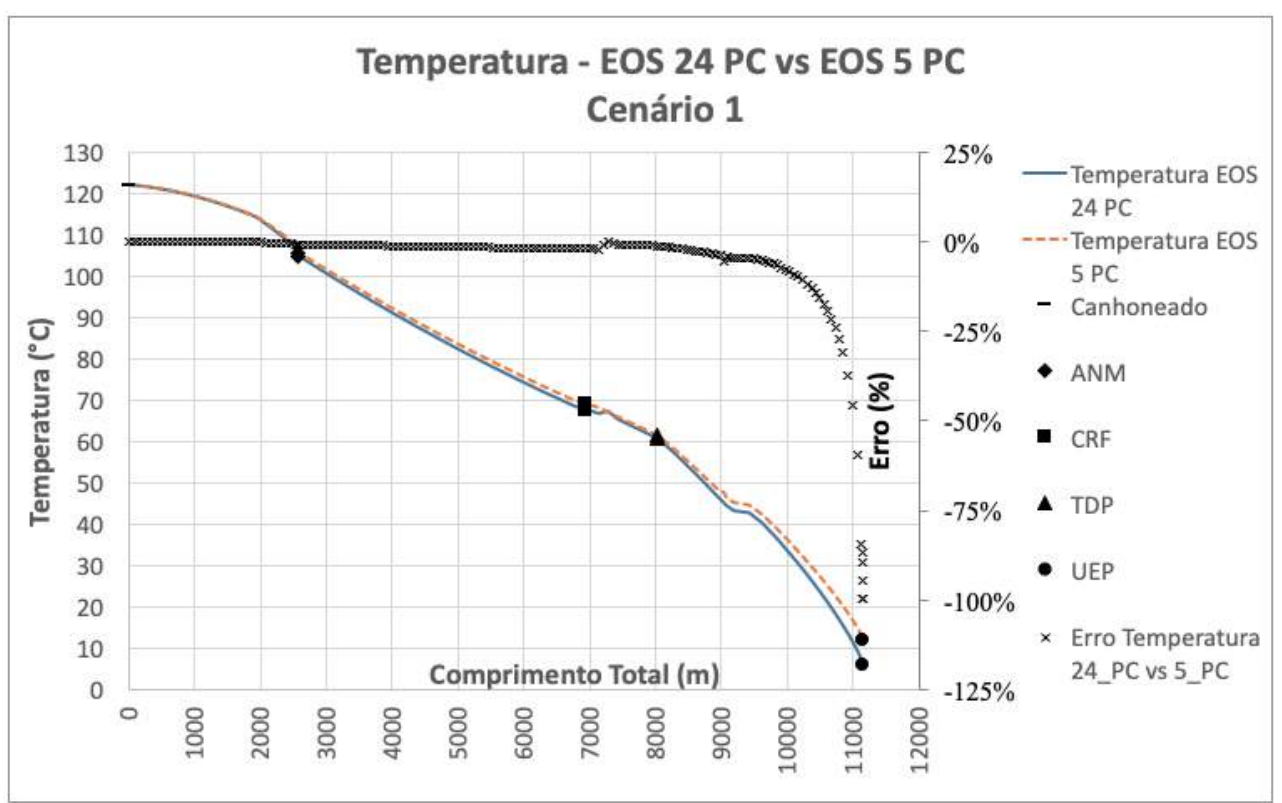

Figura C.122: Perfil de temperatura no poço e duto - Cenário 1 - EOS 24 PC versus EOS 5 PC. 


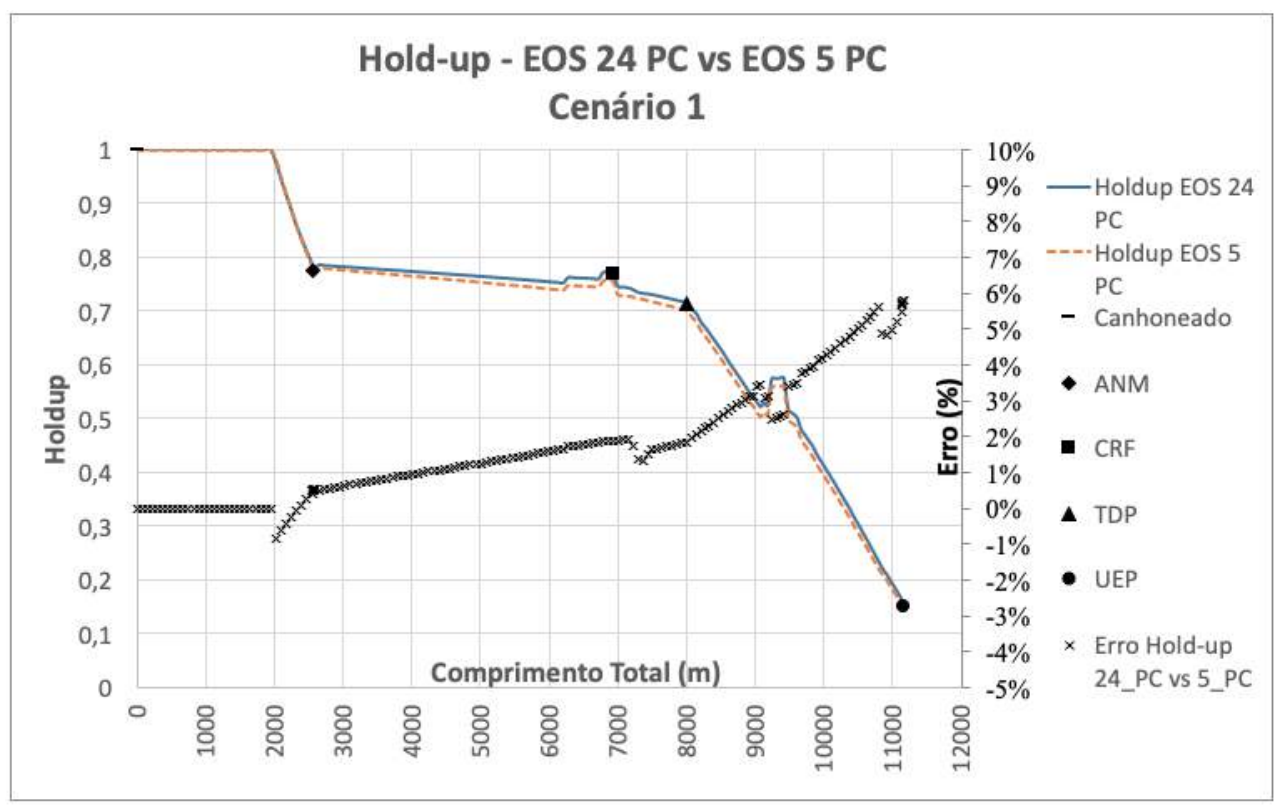

Figura C.123: Holdup no poço e duto - Cenário 1 - EOS 24 PC versus EOS 5 PC.

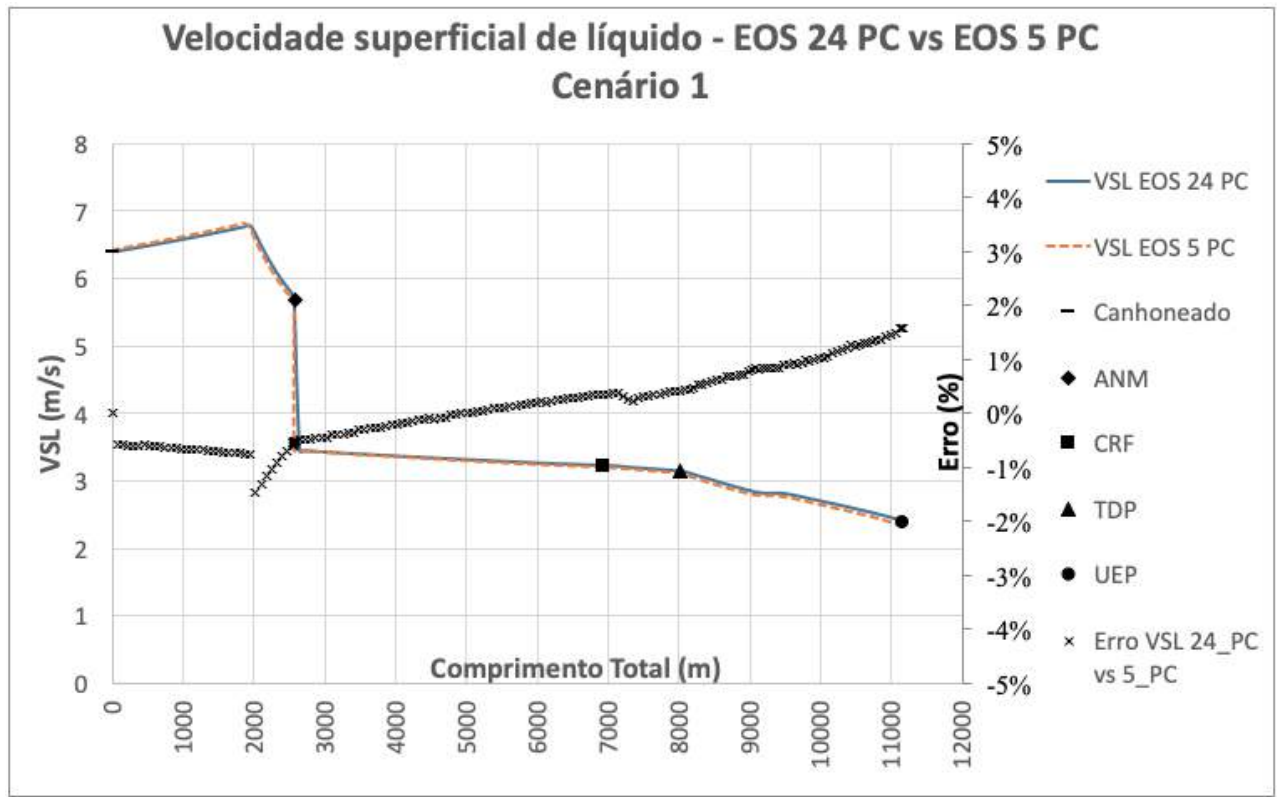

Figura C.124: Velocidade superficial de líquido - Cenário 1 - EOS 24 PC versus EOS 5 PC. 


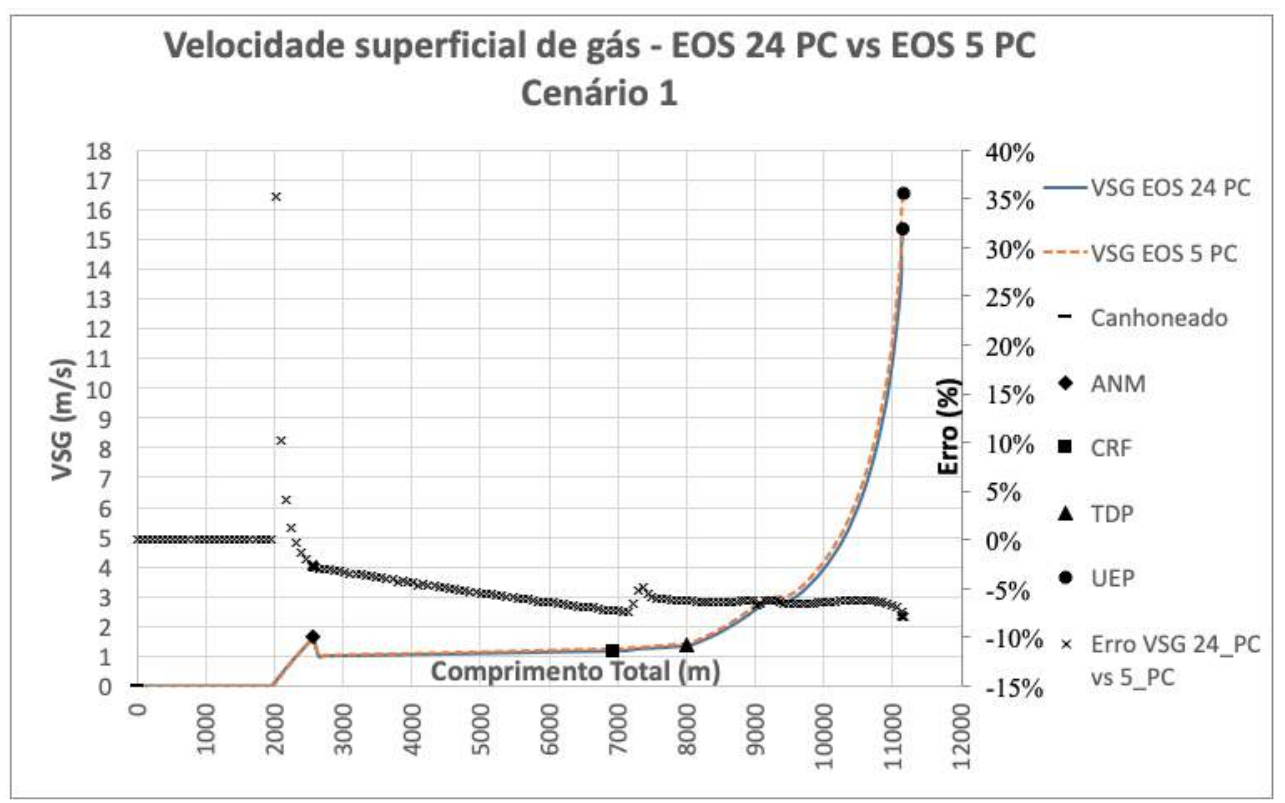

Figura C.125: Velocidade superficial de gás - Cenário 1 - EOS 24 PC versus EOS 5 PC.

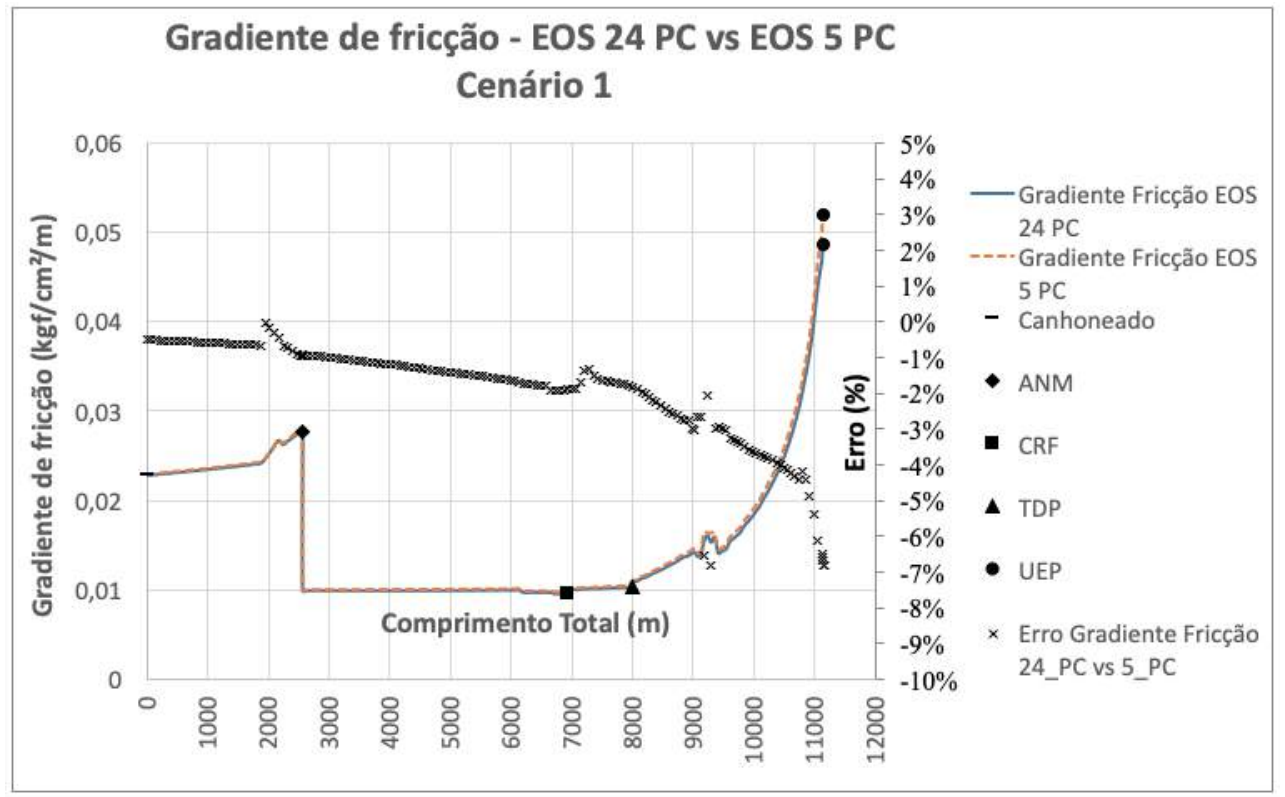

Figura C.126: Gradiente de pressão por fricção - Cenário 1 - EOS 24 PC versus EOS 5 PC. 


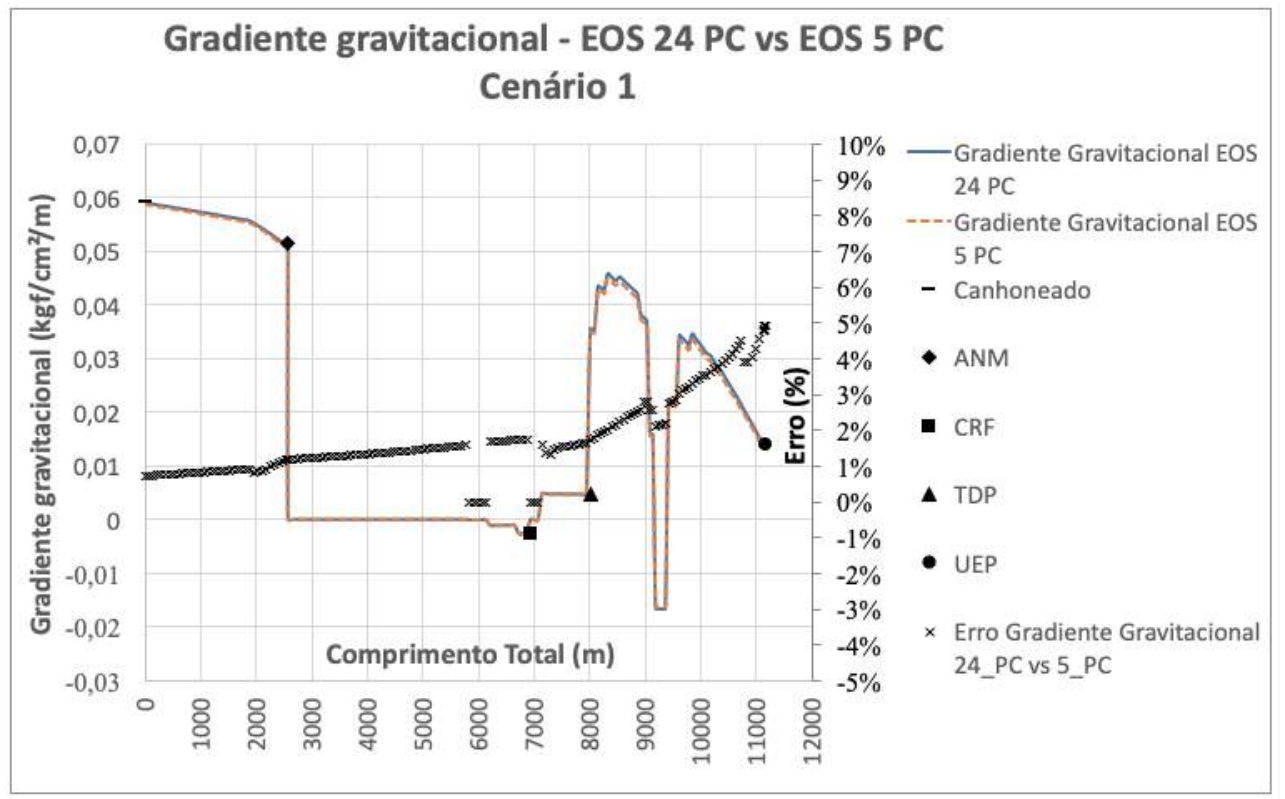

Figura C.127: Gradiente de pressão gravitacional - Cenário 1 - EOS 24 PC versus EOS 5 PC.

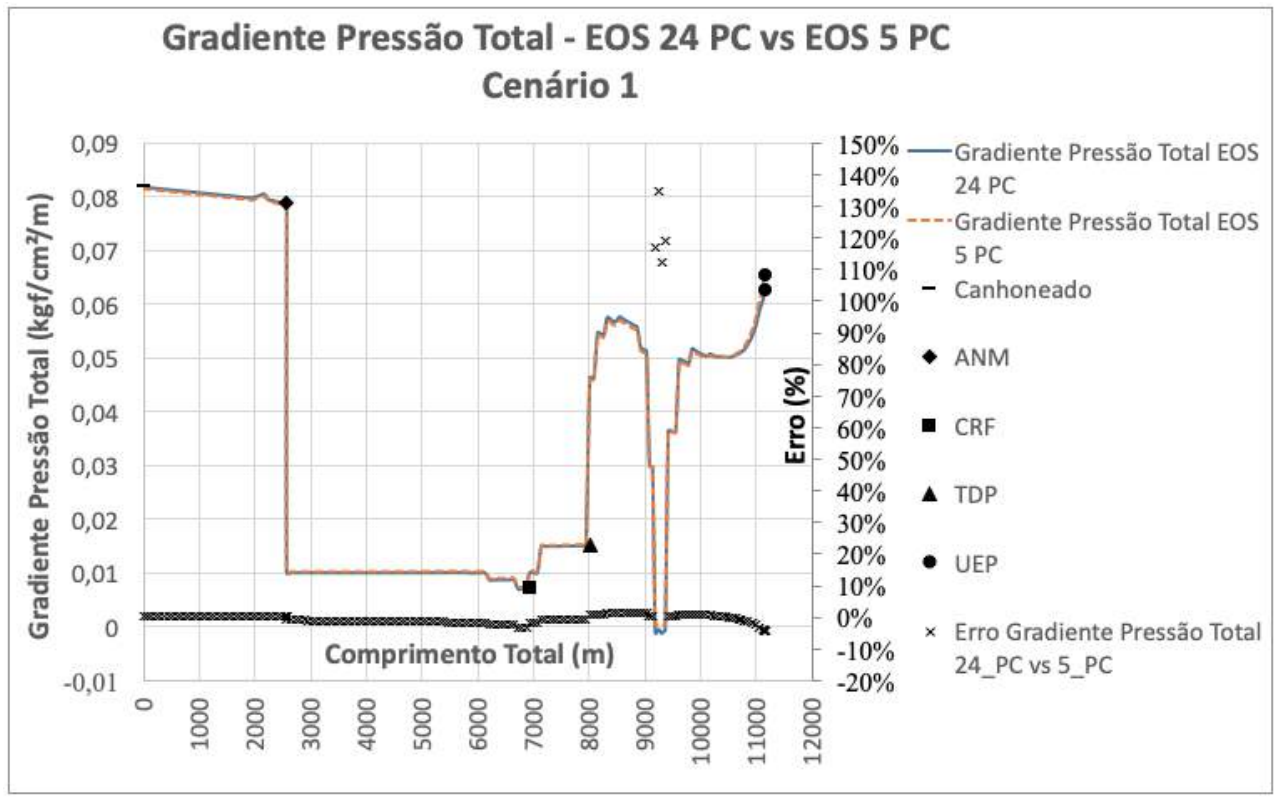

Figura C.128: Gradiente de pressão total - Cenário 1 - EOS 24 PC versus EOS $5 \mathrm{PC}$. 


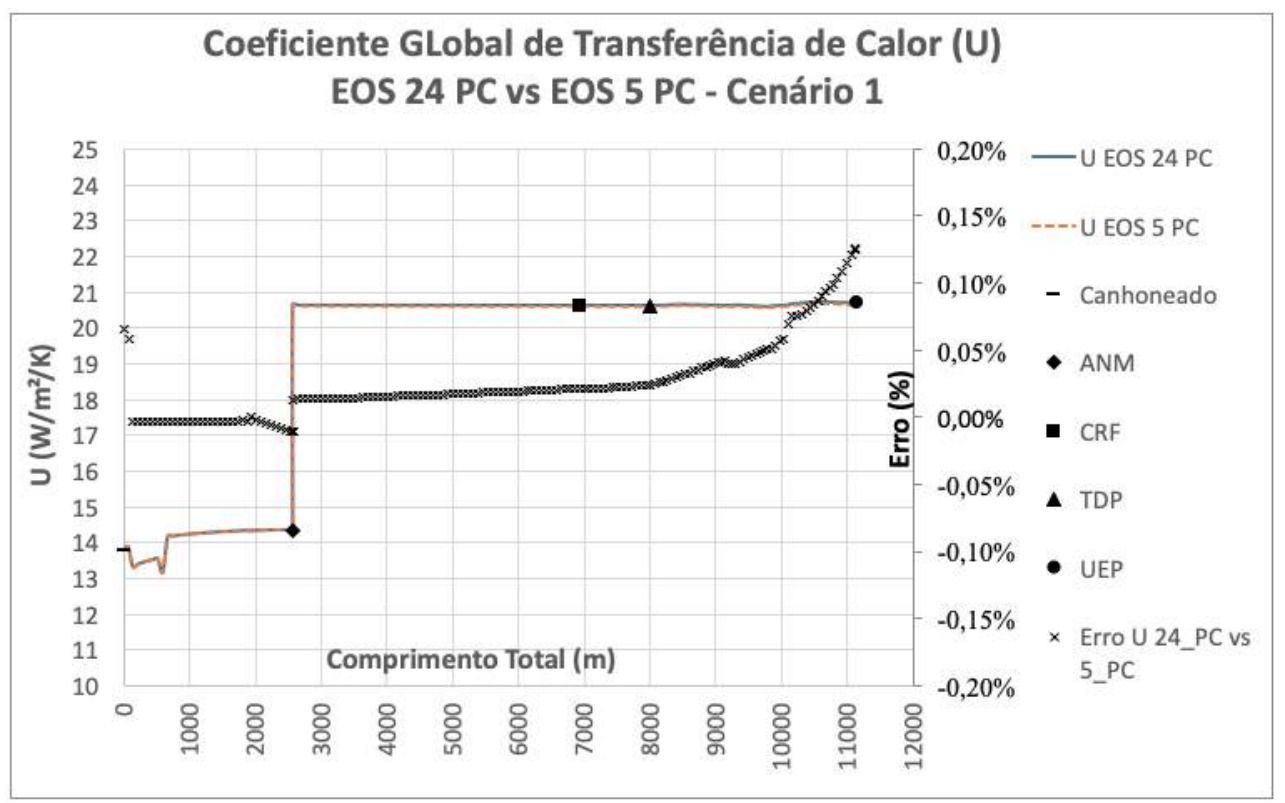

Figura C.129: Coeficiente global de transferência de calor - Cenário 1 - EOS $24 \mathrm{PC}$ versus EOS 5 PC.

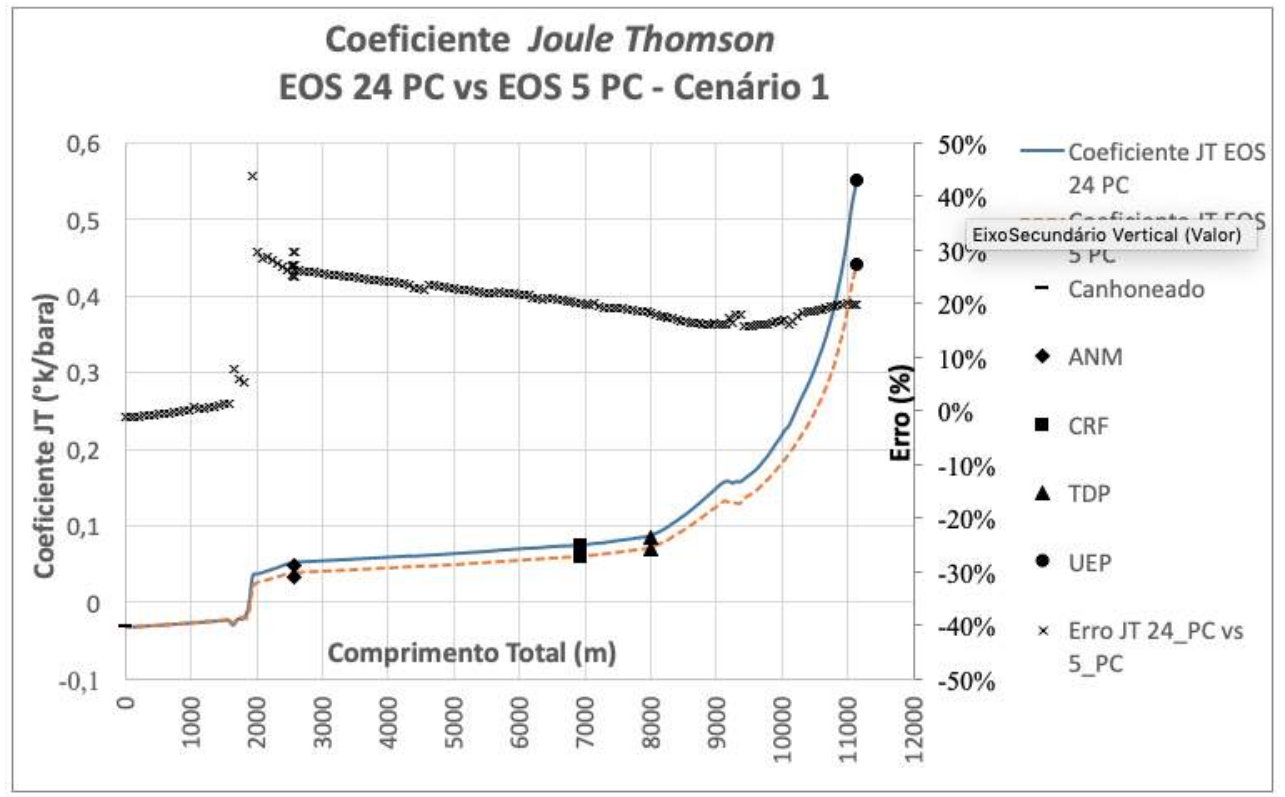

Figura C.130: Coeficiente Joule-Thomson - Cenário 1 - EOS 24 PC versus EOS 5 PC. 


\section{C.5.2}

\section{Cenário 2 - Período inicial antes do breaktrough de água}

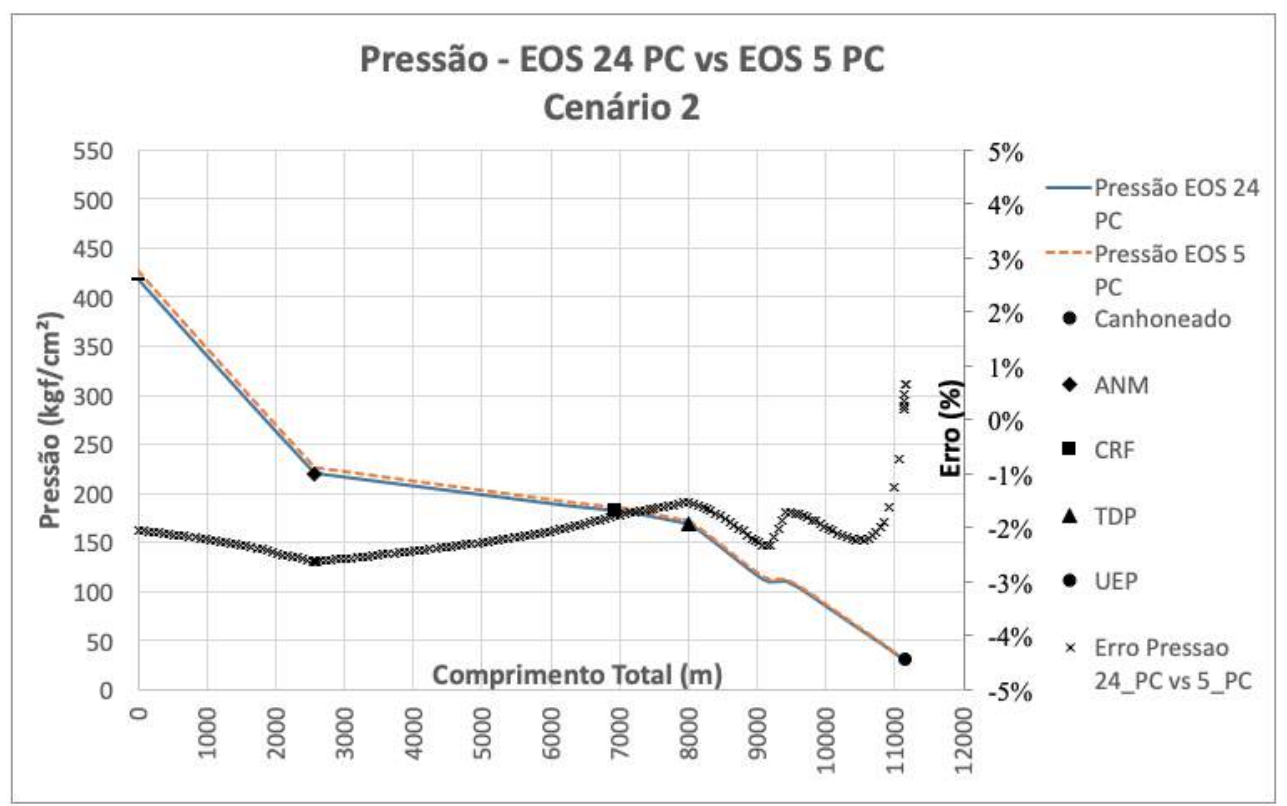

Figura C.131: Perfil de pressão no poço e duto - Cenário 2 - EOS 24 PC versus EOS 5 PC.

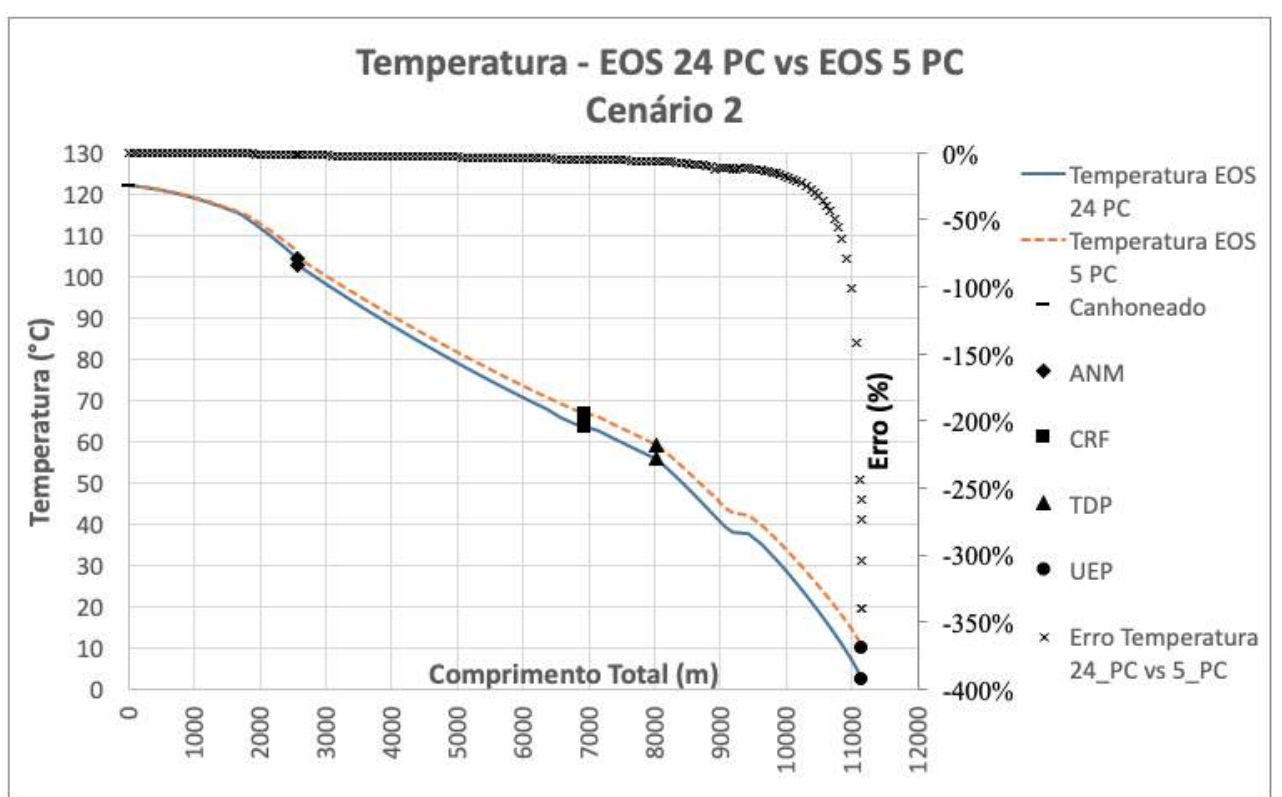

Figura C.132: Perfil de temperatura no poço e duto - Cenário 2 - EOS 24 PC versus EOS 5 PC. 


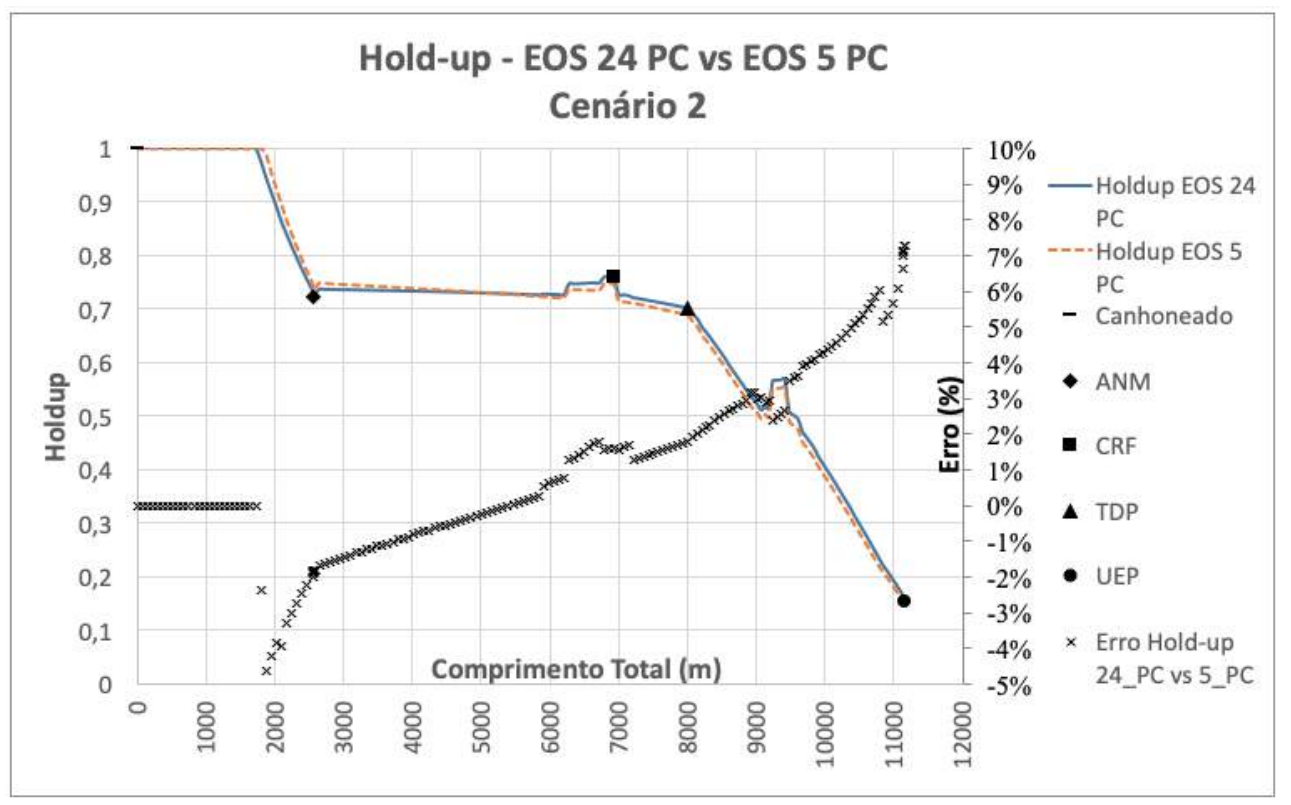

Figura C.133: Holdup no poço e duto - Cenário 2 - EOS 24 PC versus EOS 5 PC.

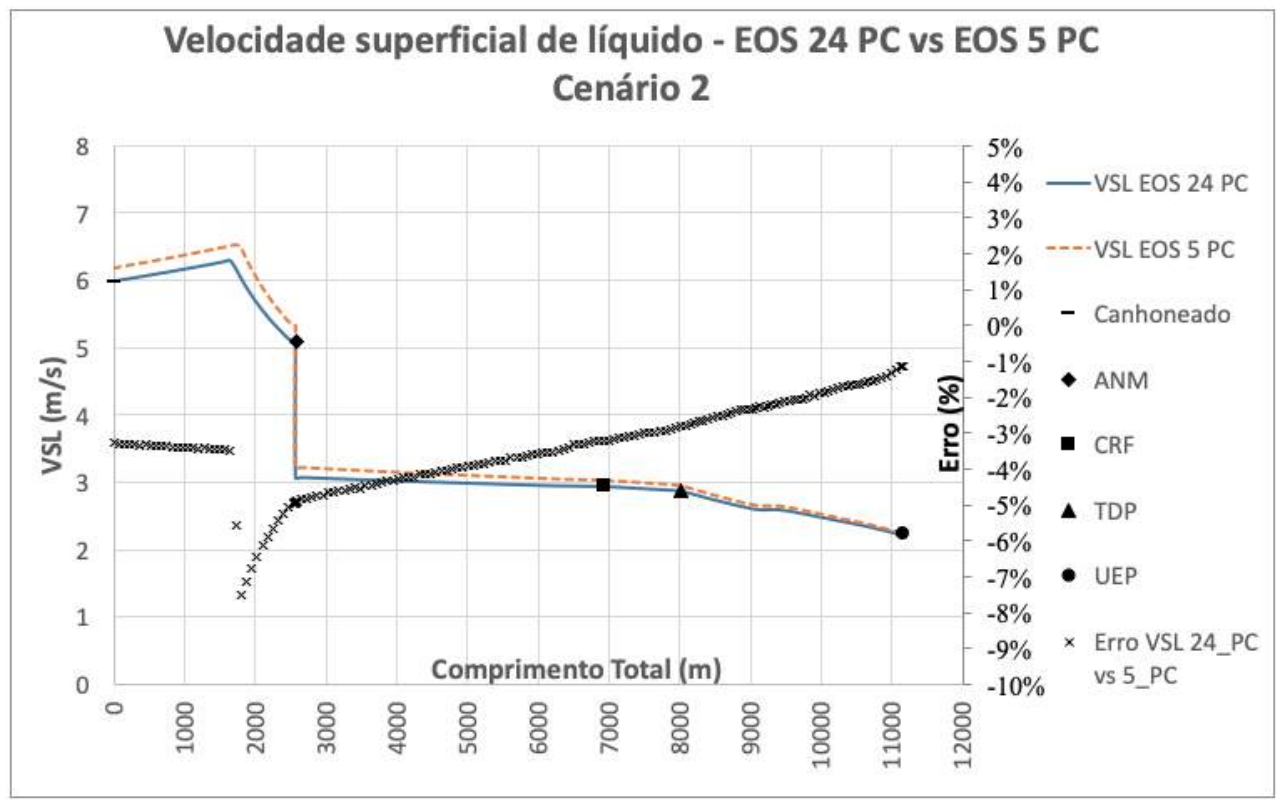

Figura C.134: Velocidade superficial de líquido - Cenário 2 - EOS 24 PC versus EOS 5 PC. 


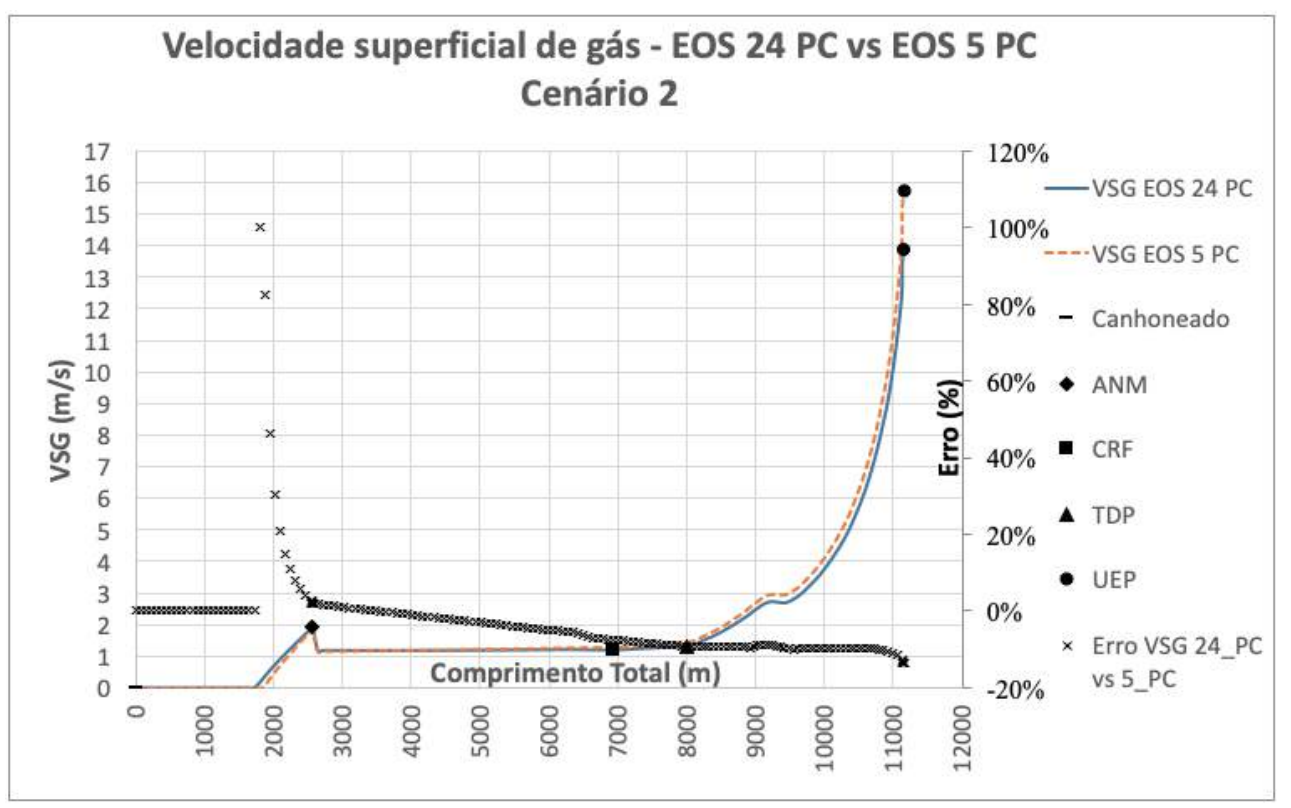

Figura C.135: Velocidade superficial de gás - Cenário 2 - EOS 24 PC versus EOS 5 PC.

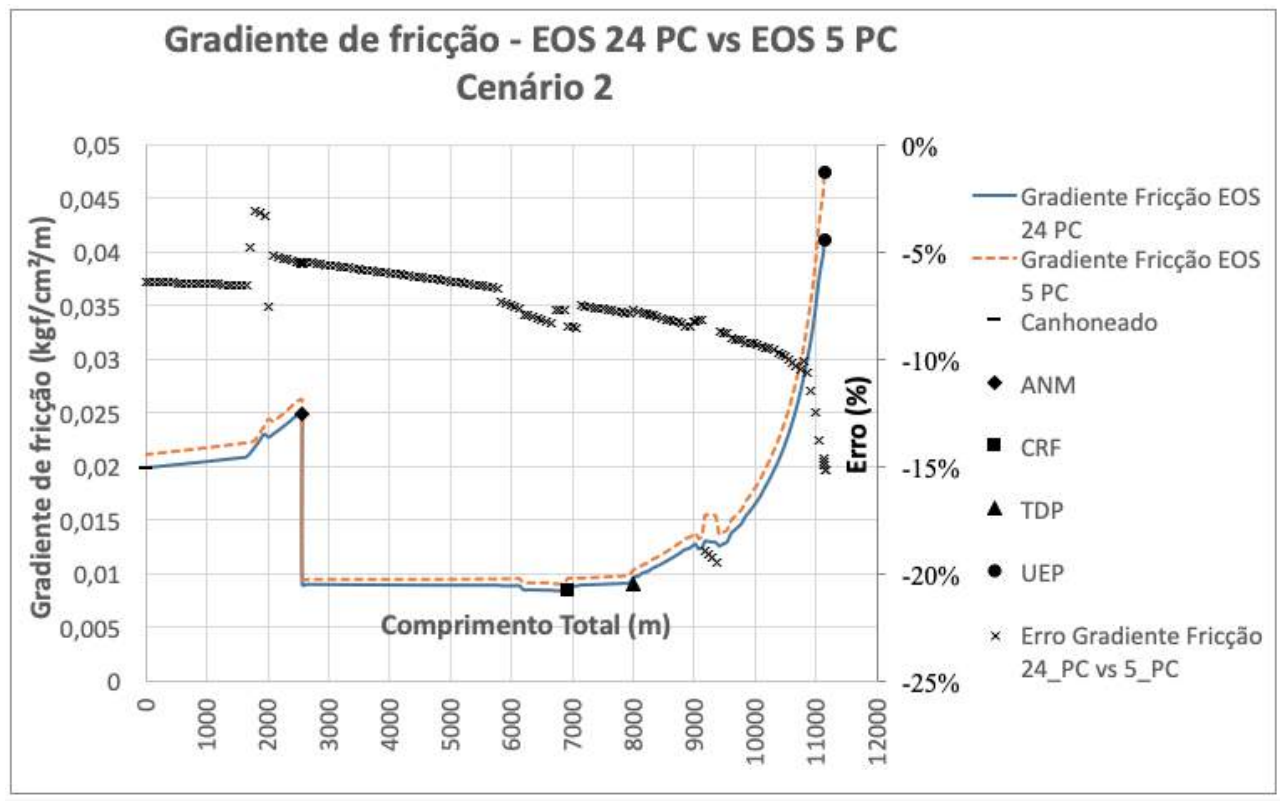

Figura C.136: Gradiente de pressão por fricção - Cenário 2 - EOS 24 PC versus EOS 5 PC. 


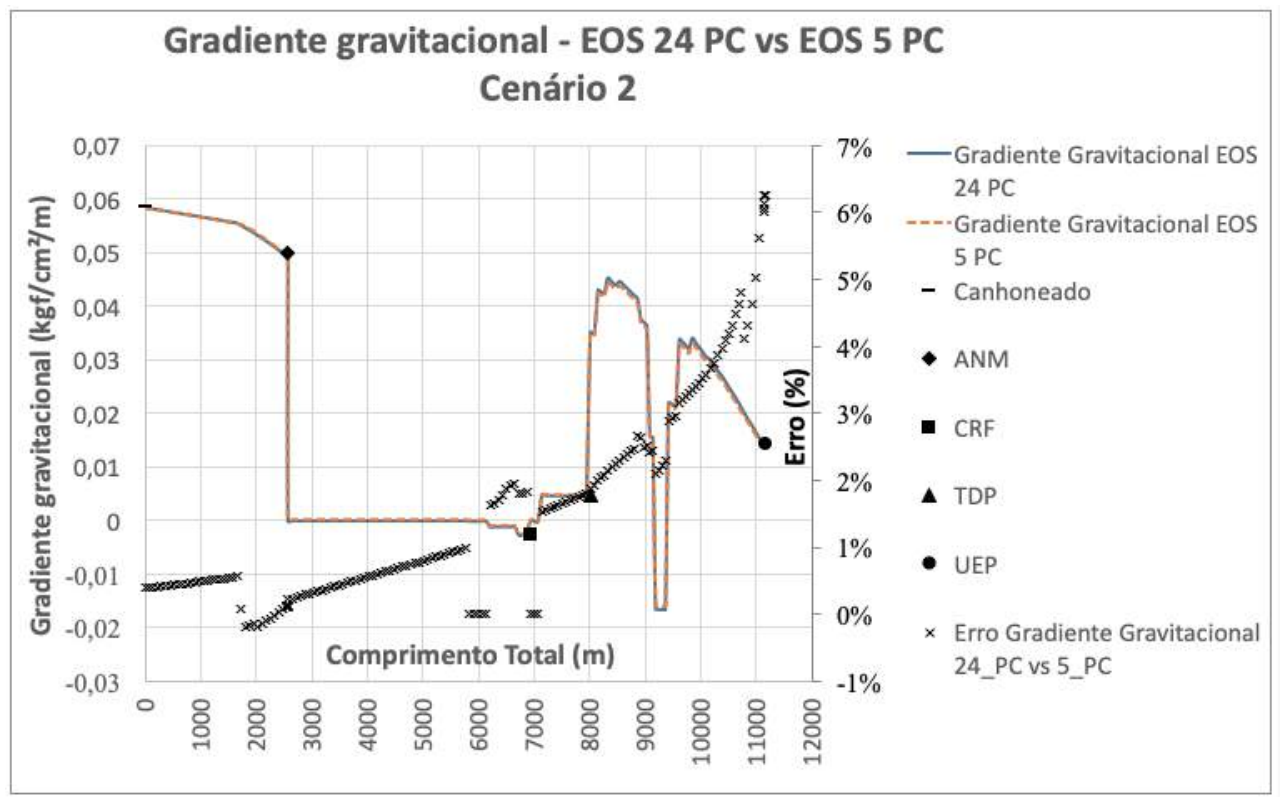

Figura C.137: Gradiente de pressão gravitacional - Cenário 2 - EOS 24 PC versus EOS 5 PC.

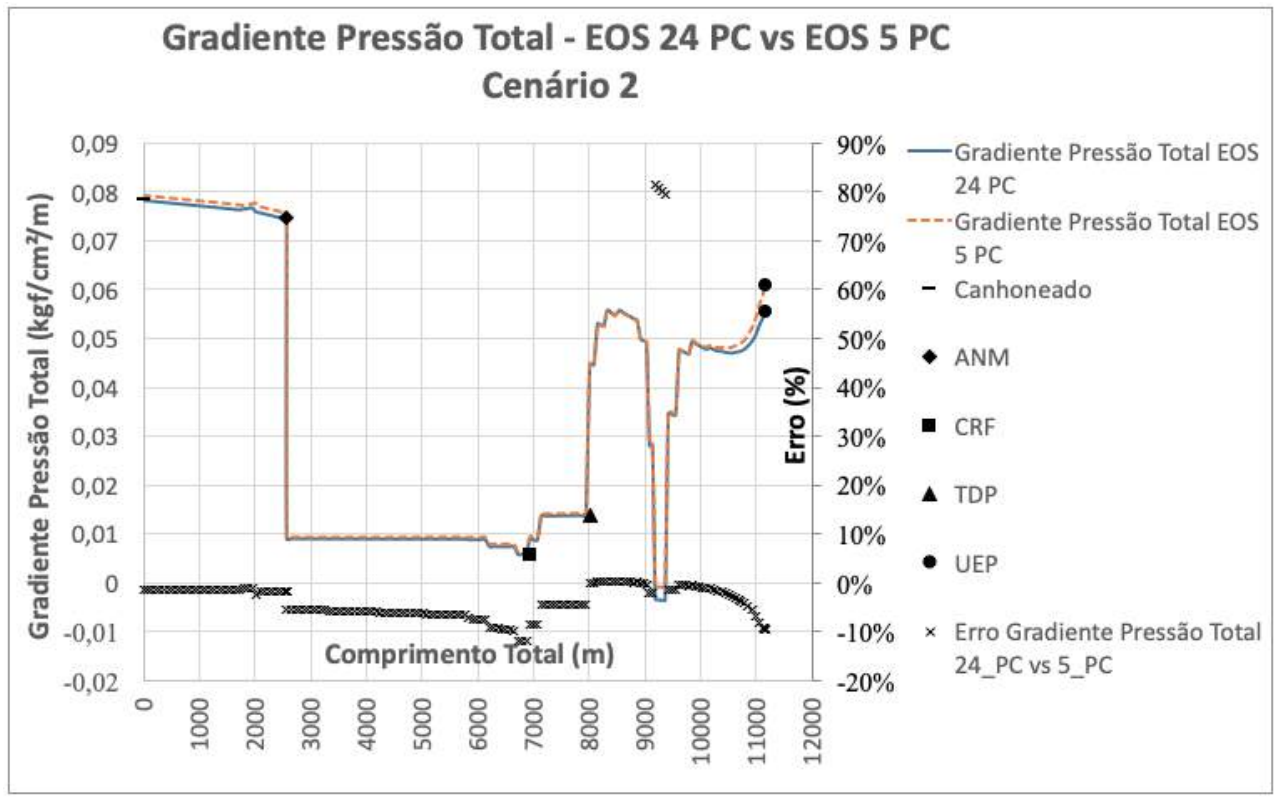

Figura C.138: Gradiente de pressão total - Cenário 2 - EOS 24 PC versus EOS 5 PC. 


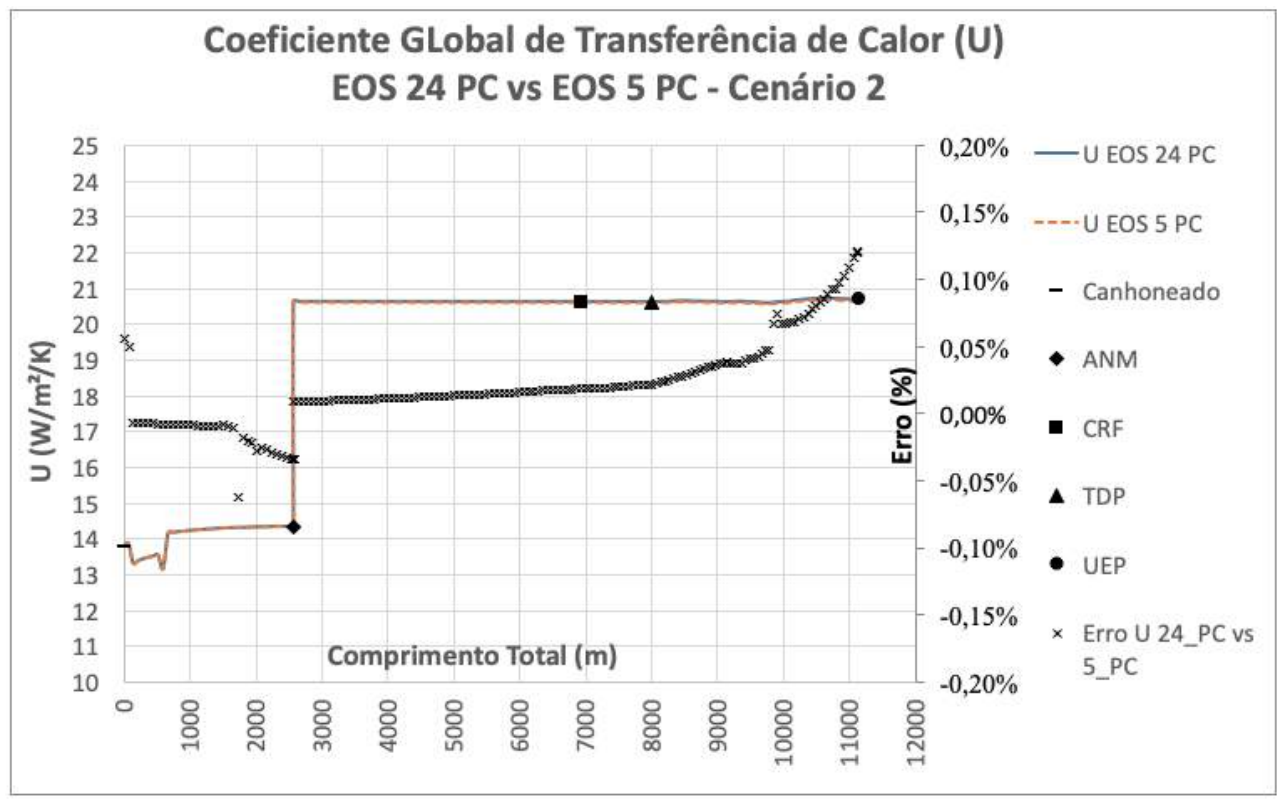

Figura C.139: Coeficiente global de transferência de calor - Cenário 2 - EOS $24 \mathrm{PC}$ versus EOS 5 PC.

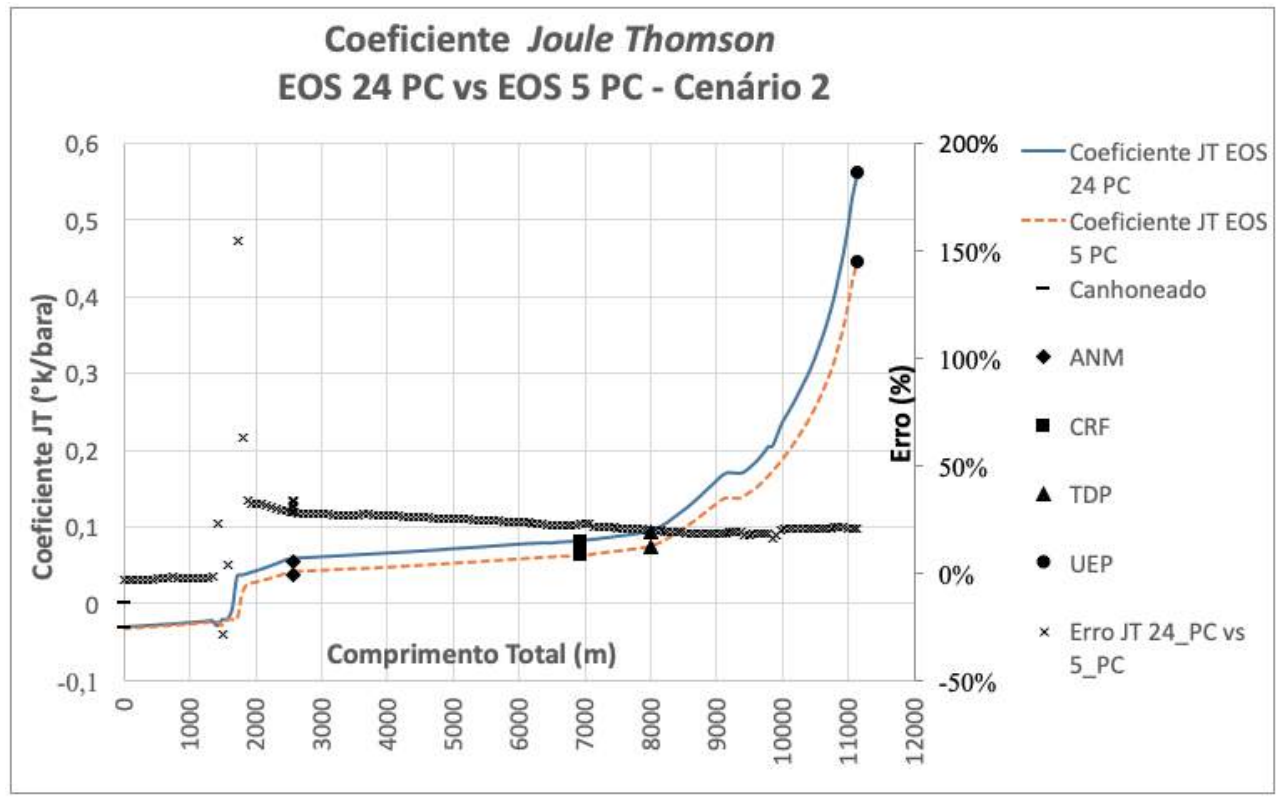

Figura C.140: Coeficiente Joule-Thomson - Cenário 2 - EOS 24 PC versus EOS 5 PC. 


\section{C.5.3}

\section{Cenário 3 - Corte de água intermediário}

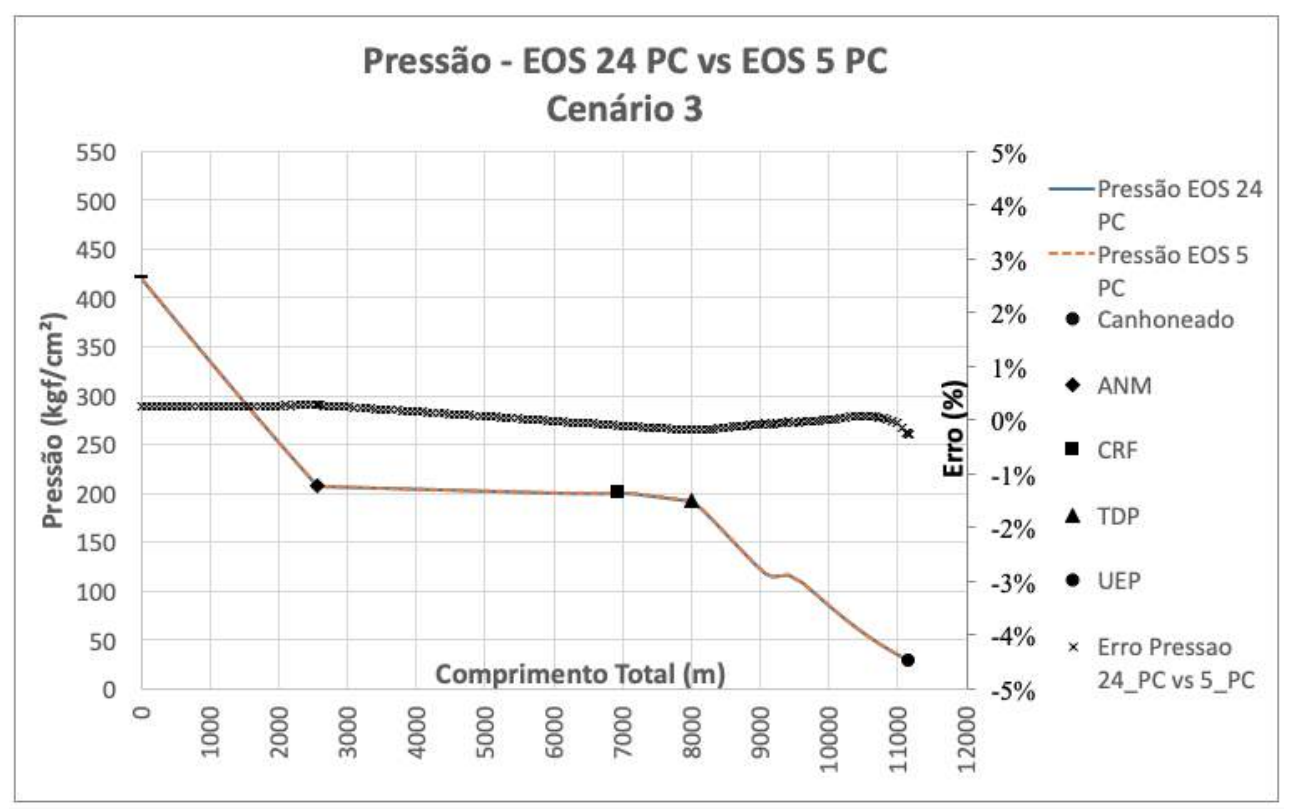

Figura C.141: Perfil de pressão no poço e duto - Cenário 3 - EOS 24 PC versus EOS 5 PC.

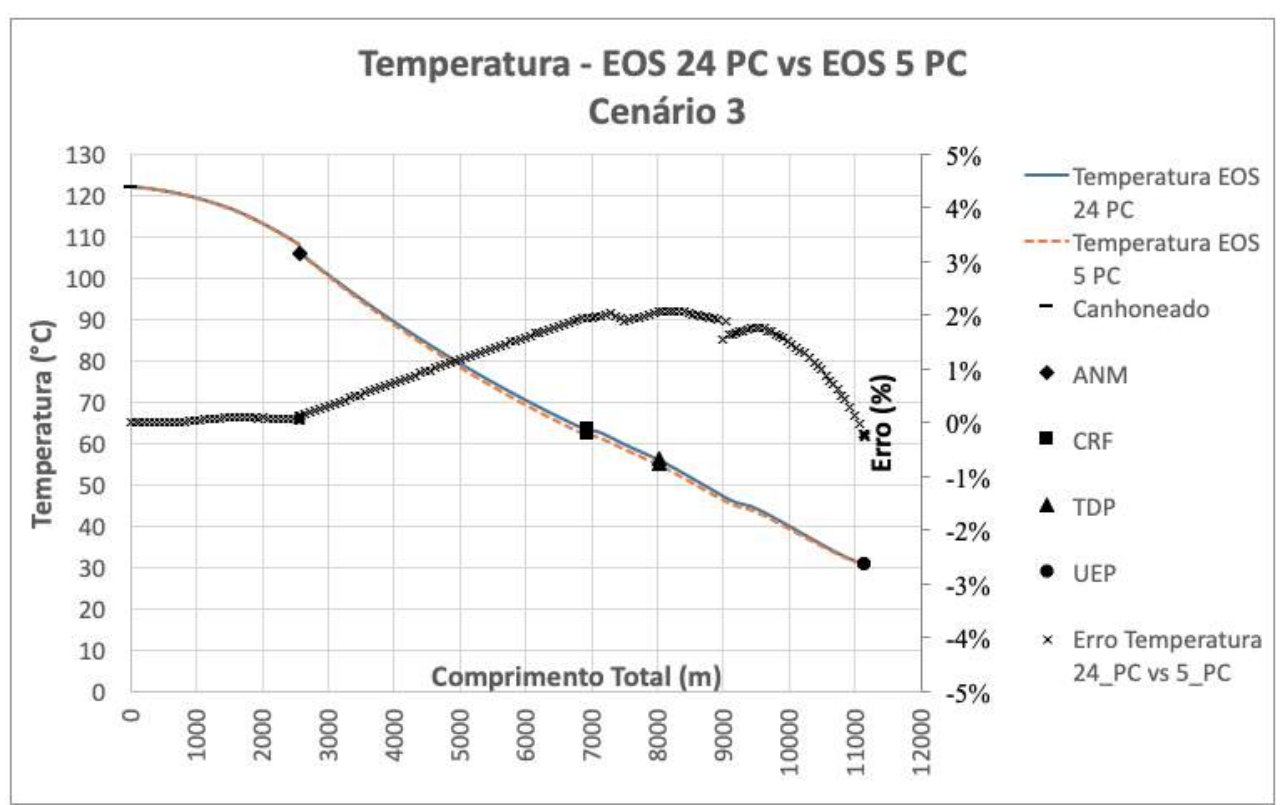

Figura C.142: Perfil de temperatura no poço e duto - Cenário 3 - EOS 24 PC versus EOS 5 PC. 


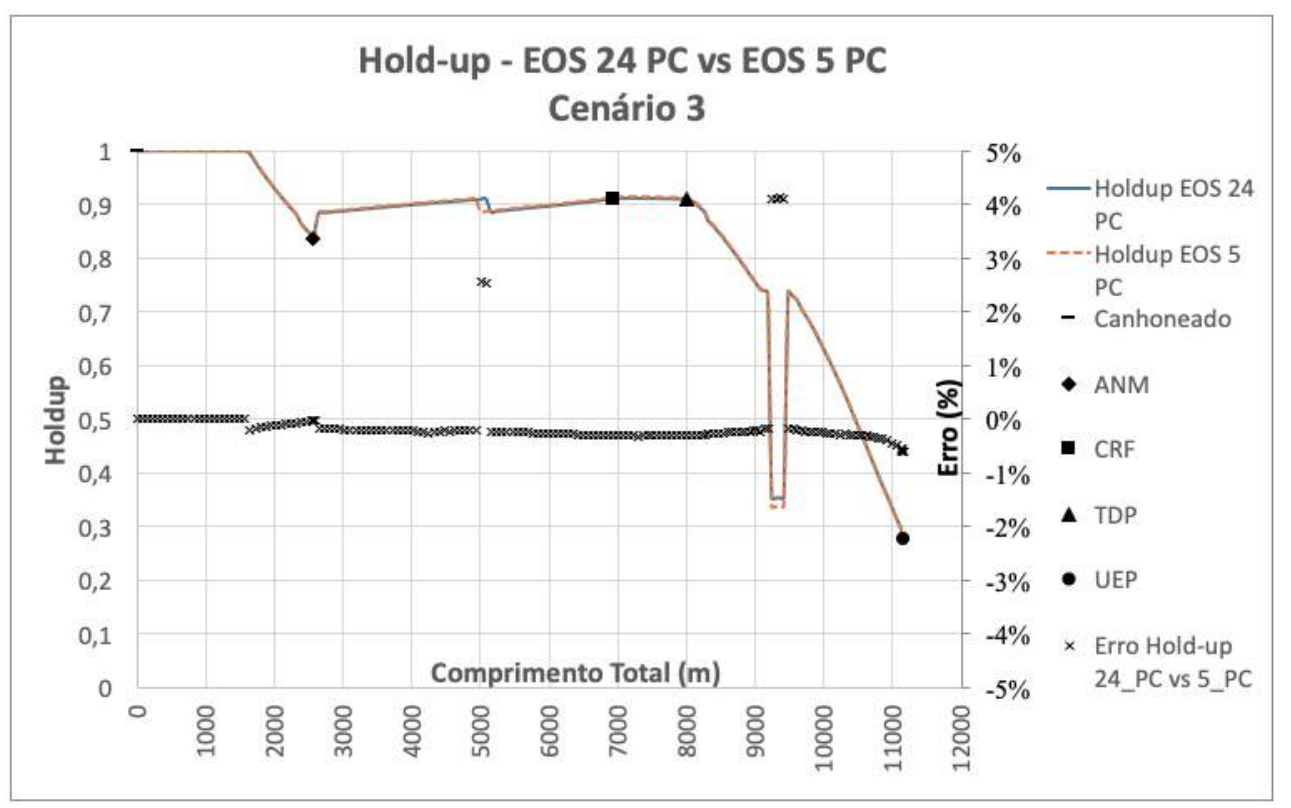

Figura C.143: Holdup no poço e duto - Cenário 3 - EOS 24 PC versus EOS 5 PC.

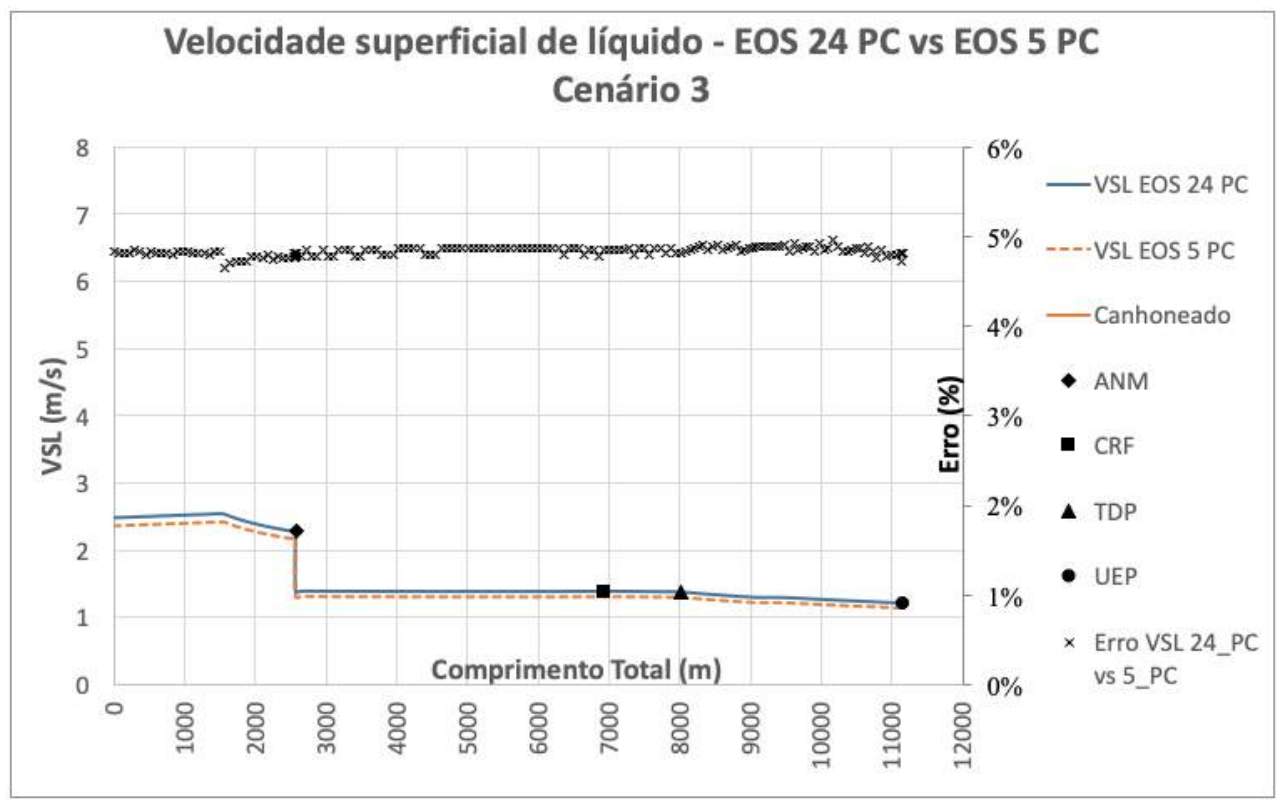

Figura C.144: Velocidade superficial de líquido - Cenário 3 - EOS 24 PC versus EOS 5 PC. 


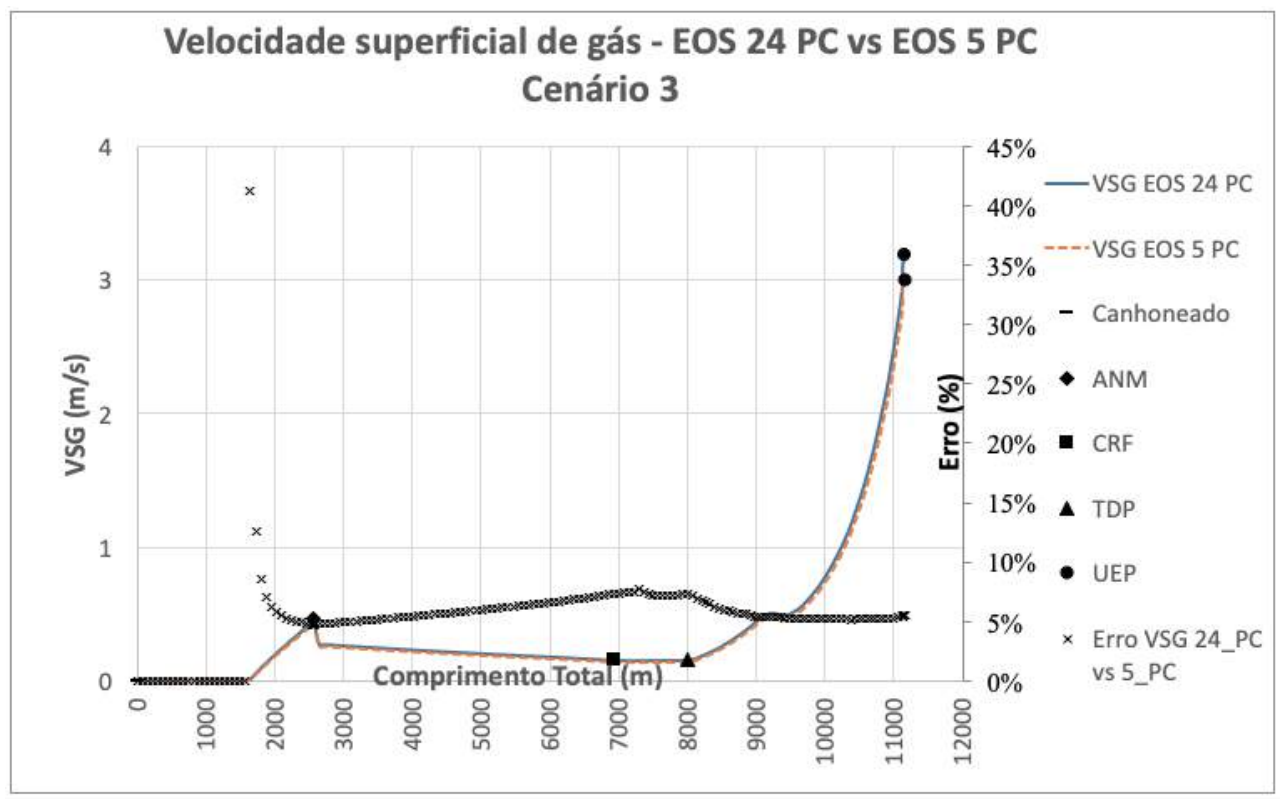

Figura C.145: Velocidade superficial de gás - Cenário 3 - EOS 24 PC versus EOS 5 PC.

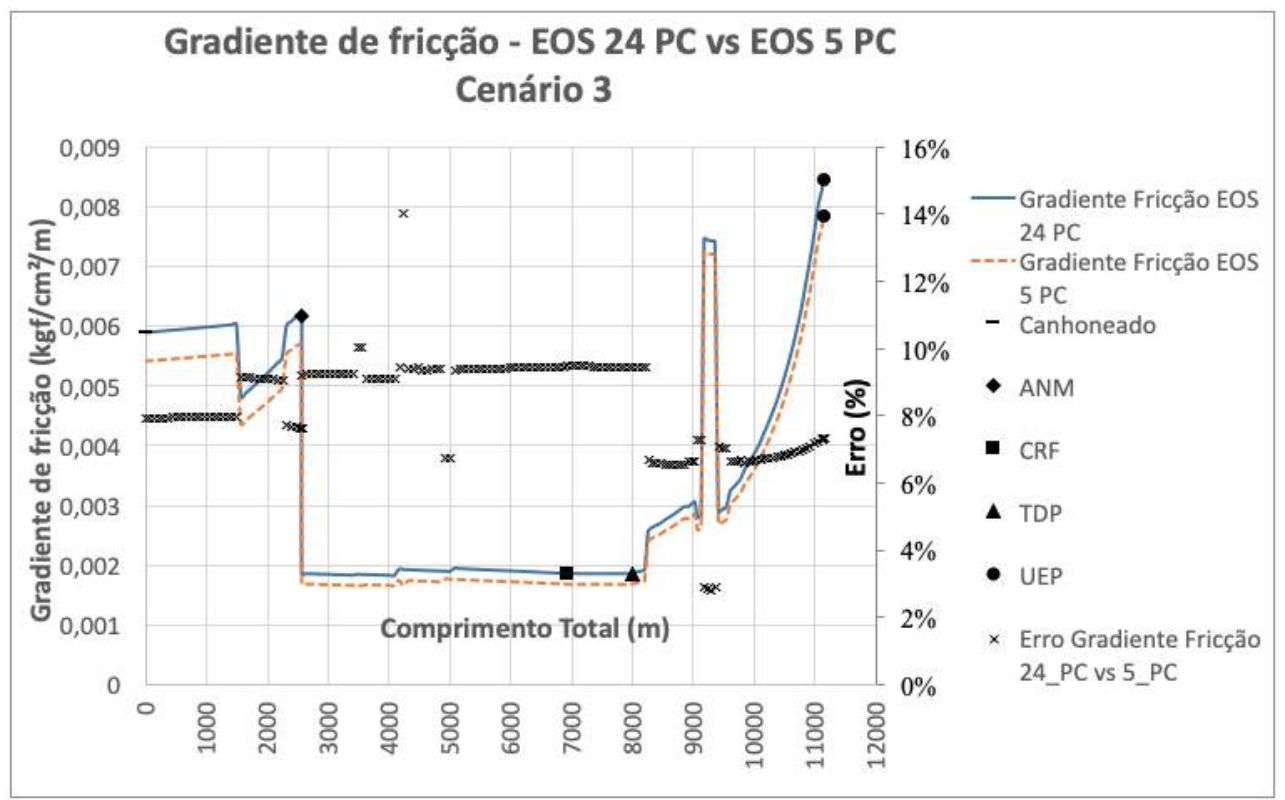

Figura C.146: Gradiente de pressão por fricção - Cenário 3 - EOS 24 PC versus EOS 5 PC. 


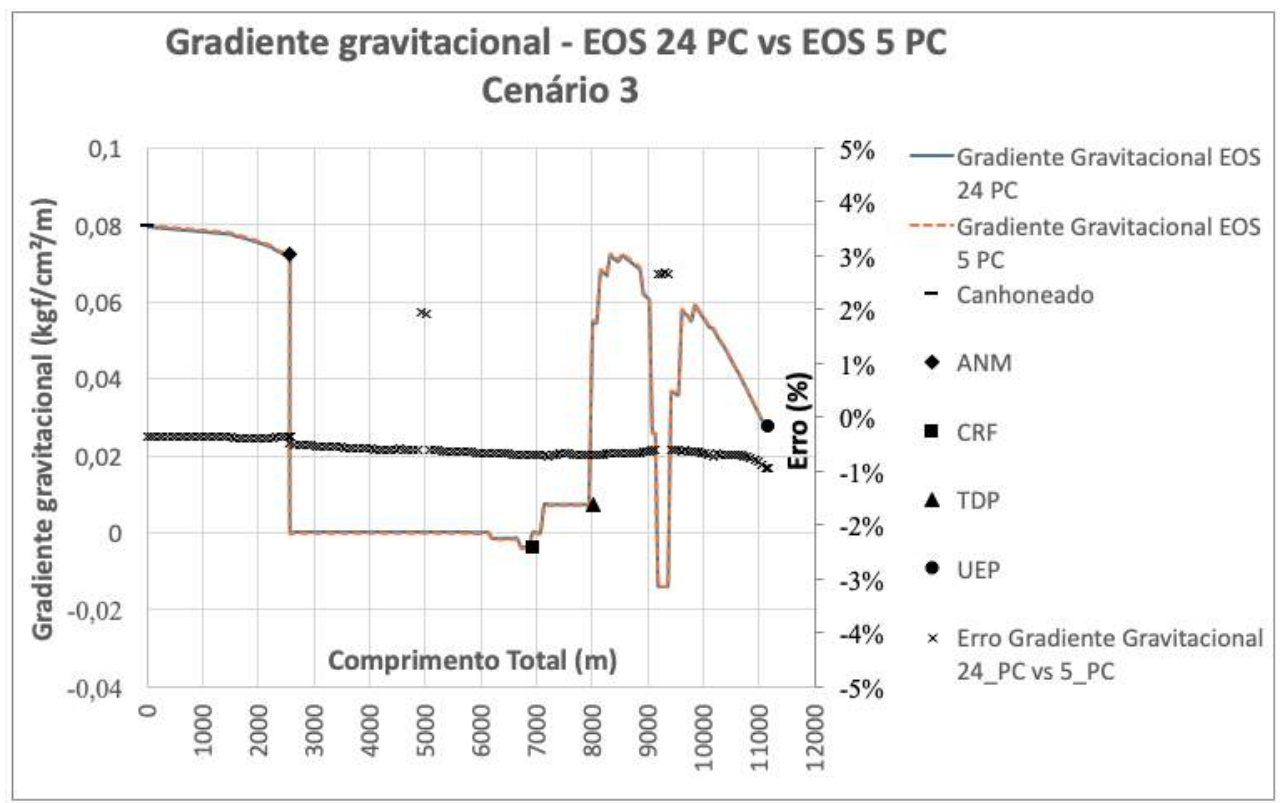

Figura C.147: Gradiente de pressão gravitacional - Cenário 3 - EOS 24 PC versus EOS 5 PC.

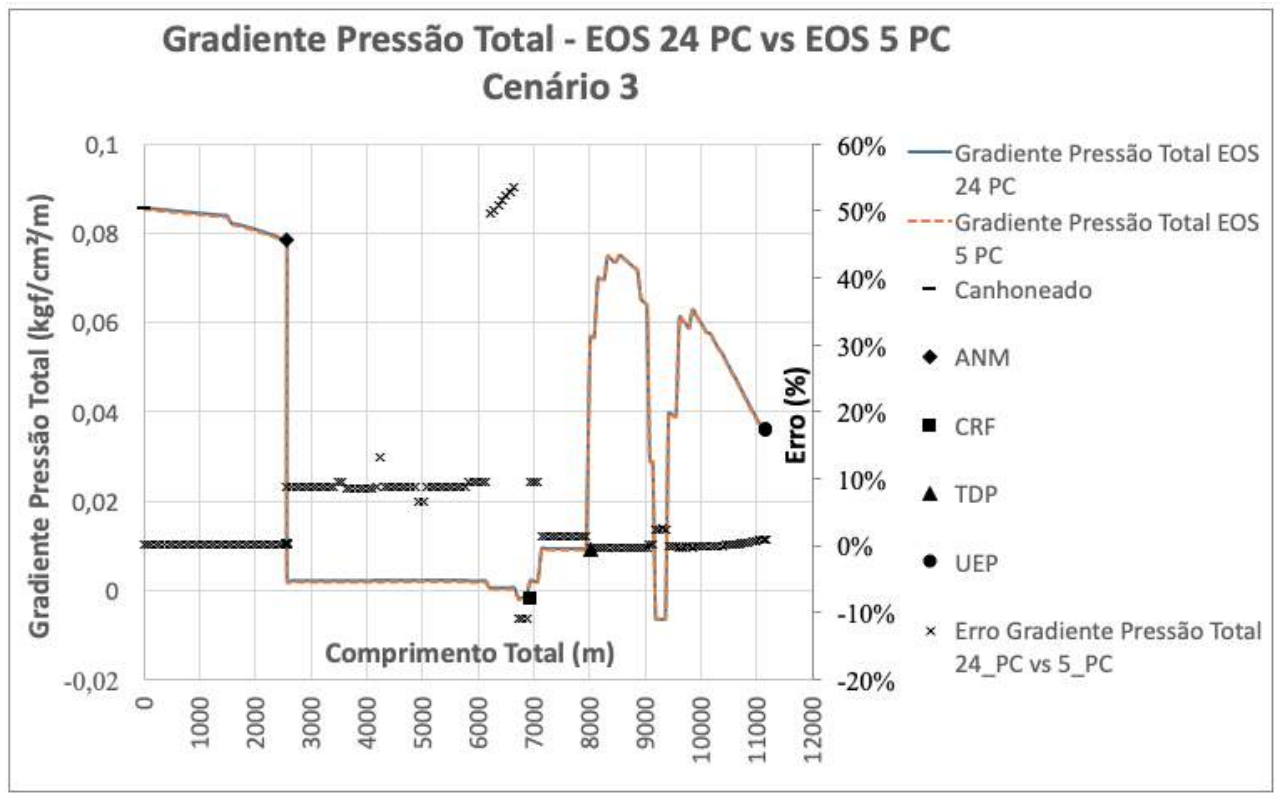

Figura C.148: Gradiente de pressão total - Cenário 3 - EOS 24 PC versus EOS 5 PC. 


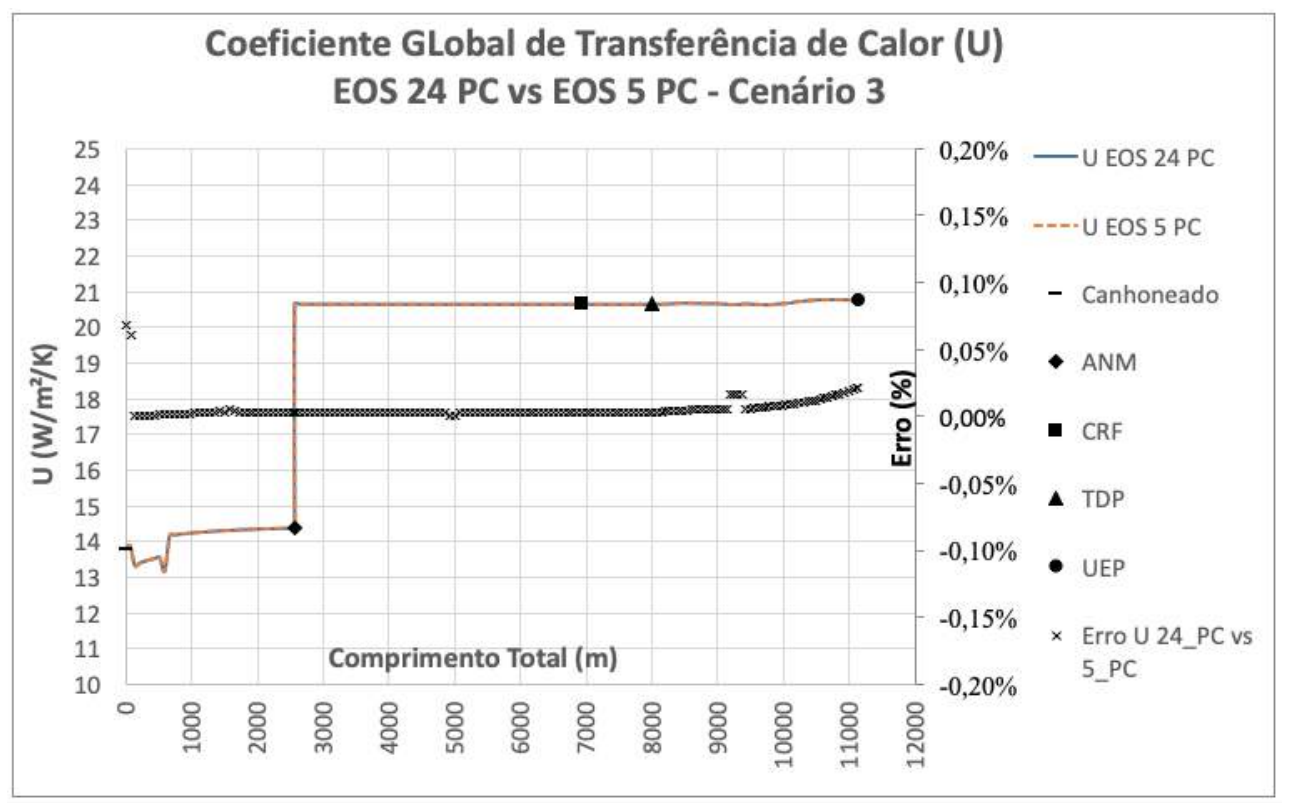

Figura C.149: Coeficiente global de transferência de calor - Cenário 3 - EOS $24 \mathrm{PC}$ versus EOS 5 PC.

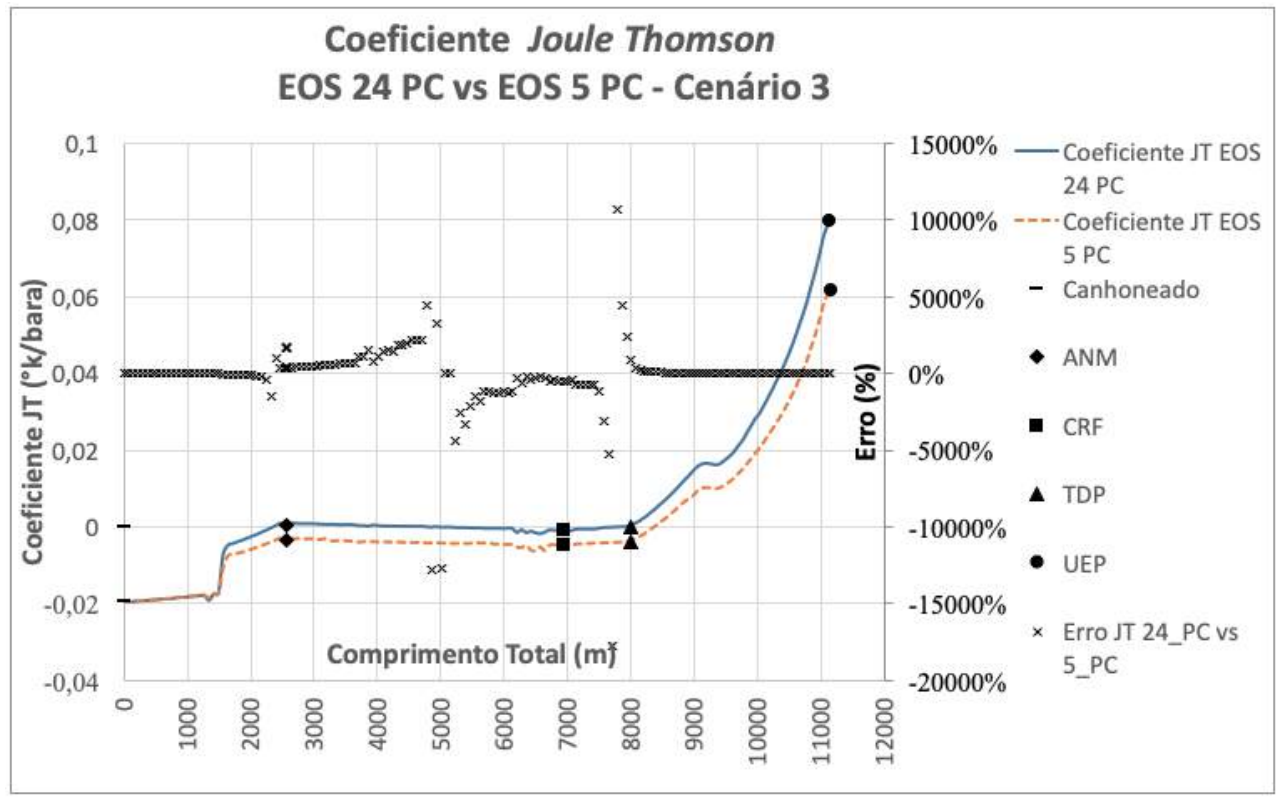

Figura C.150: Coeficiente Joule-Thomson - Cenário 3 - EOS 24 PC versus EOS 5 PC. 


\section{C.6}

\section{EOS 24 PC versus EOS 4 PC}

\section{C.6.1}

Cenário 1 - Período inicial logo após a abertura do poço

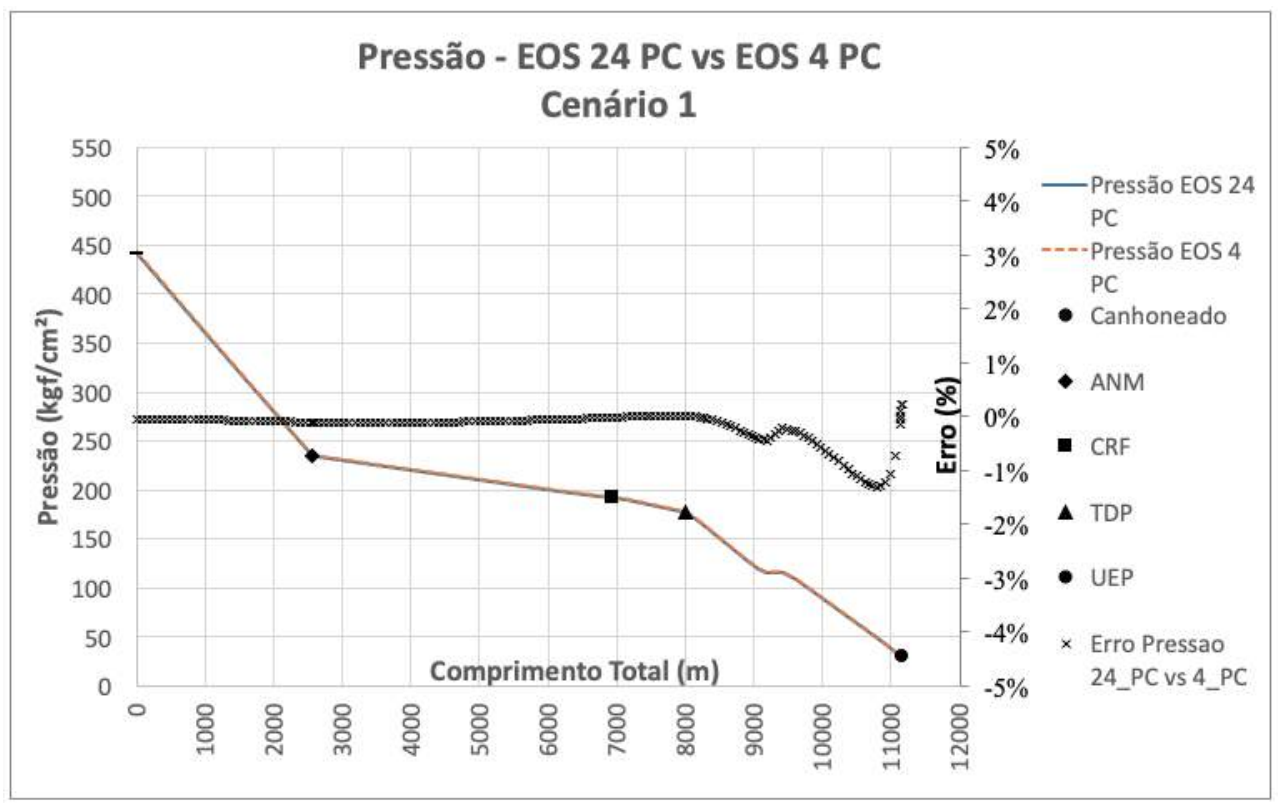

Figura C.151: Perfil de pressão no poço e duto - Cenário 1 - EOS 24 PC versus EOS 4 PC.

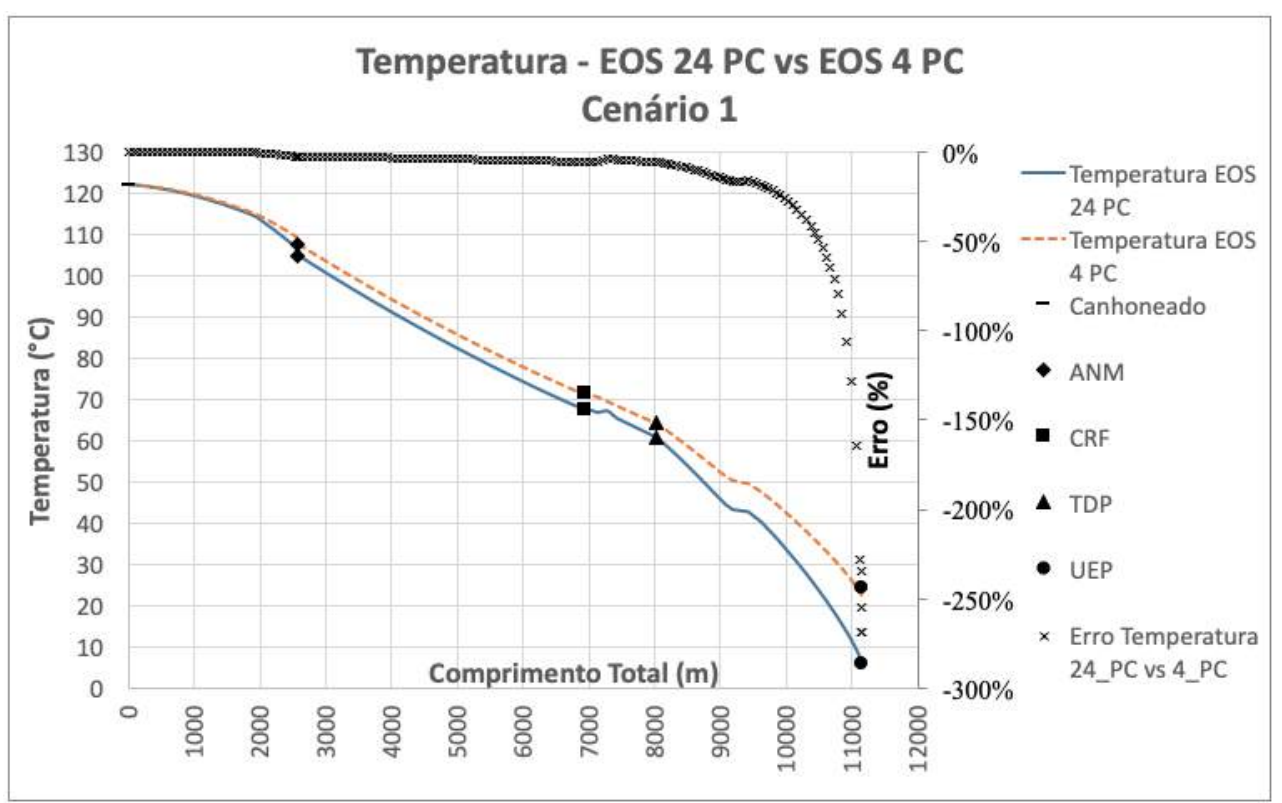

Figura C.152: Perfil de temperatura no poço e duto - Cenário 1 - EOS 24 PC versus EOS 4 PC. 


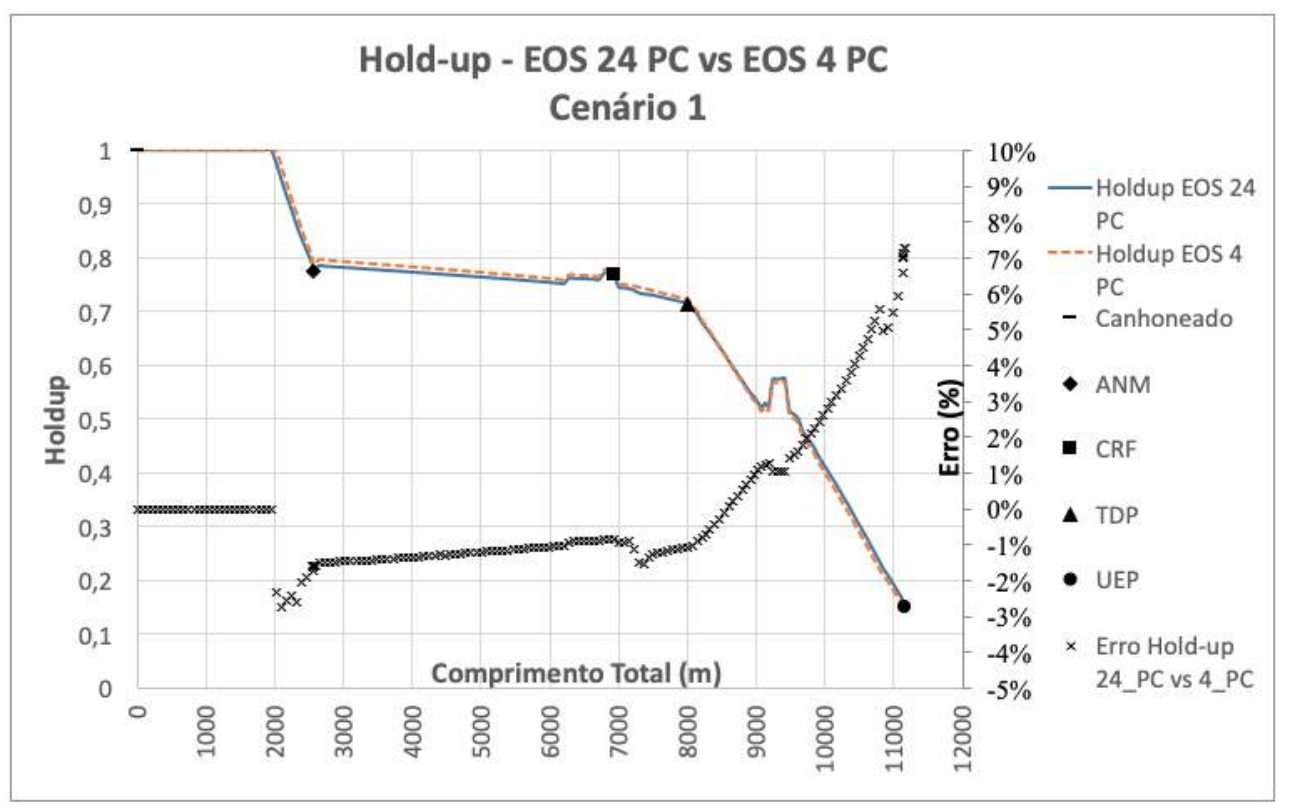

Figura C.153: Holdup no poço e duto - Cenário 1 - EOS 24 PC versus EOS 4 PC.

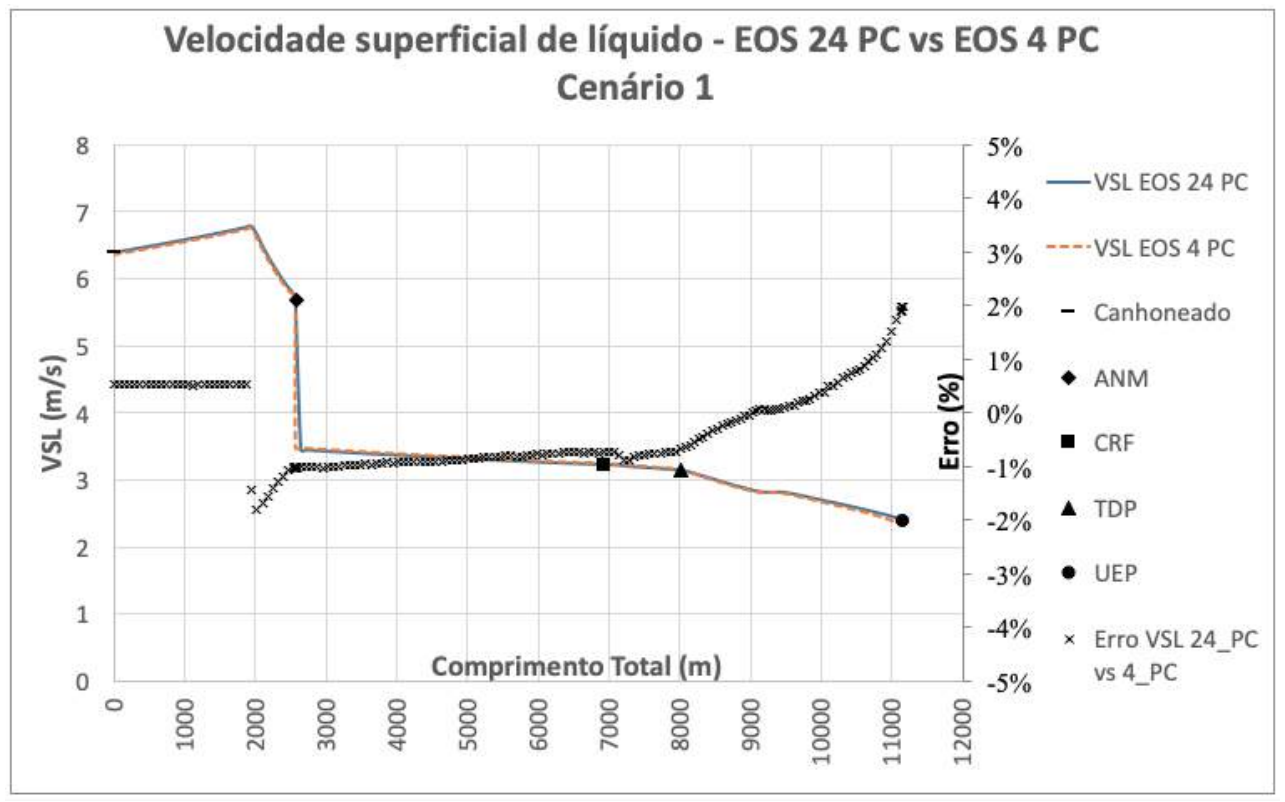

Figura C.154: Velocidade superficial de líquido - Cenário 1 - EOS 24 PC versus EOS 4 PC. 


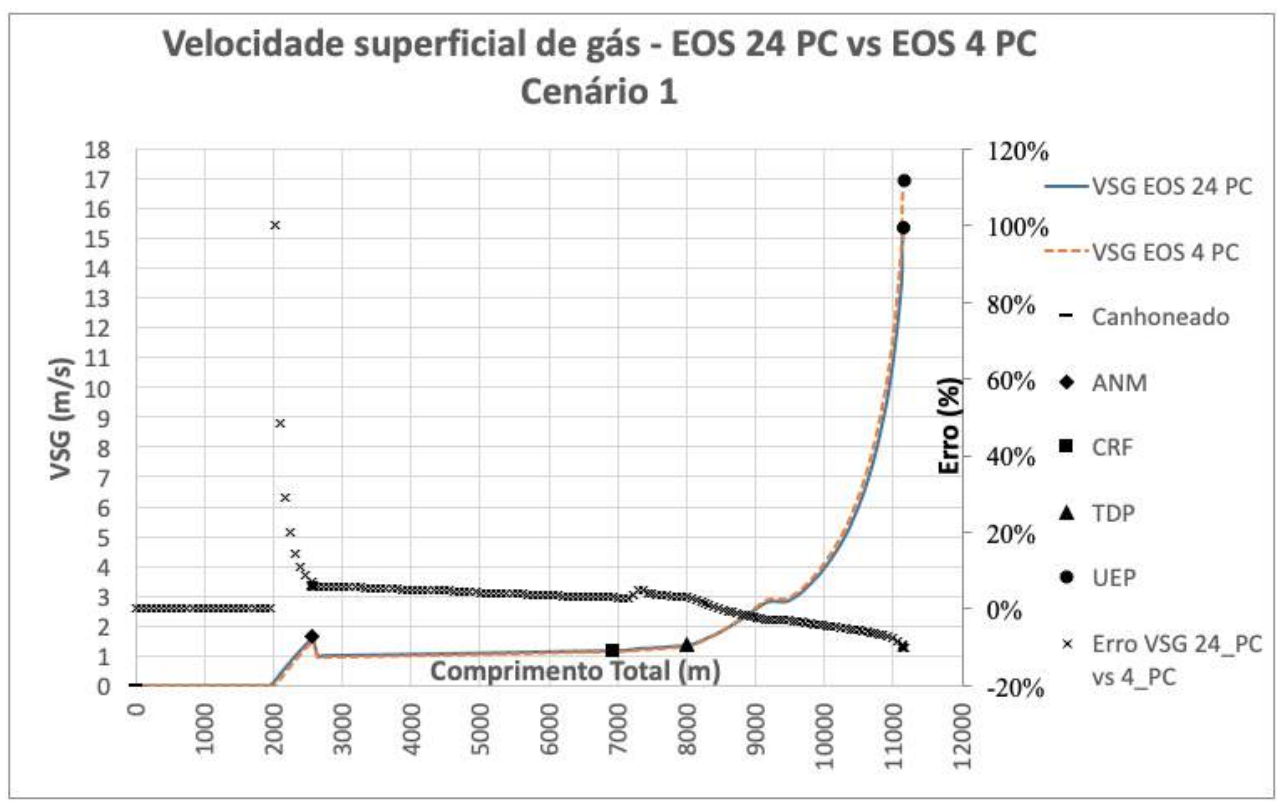

Figura C.155: Velocidade superficial de gás - Cenário 1 - EOS 24 PC versus EOS 4 PC.

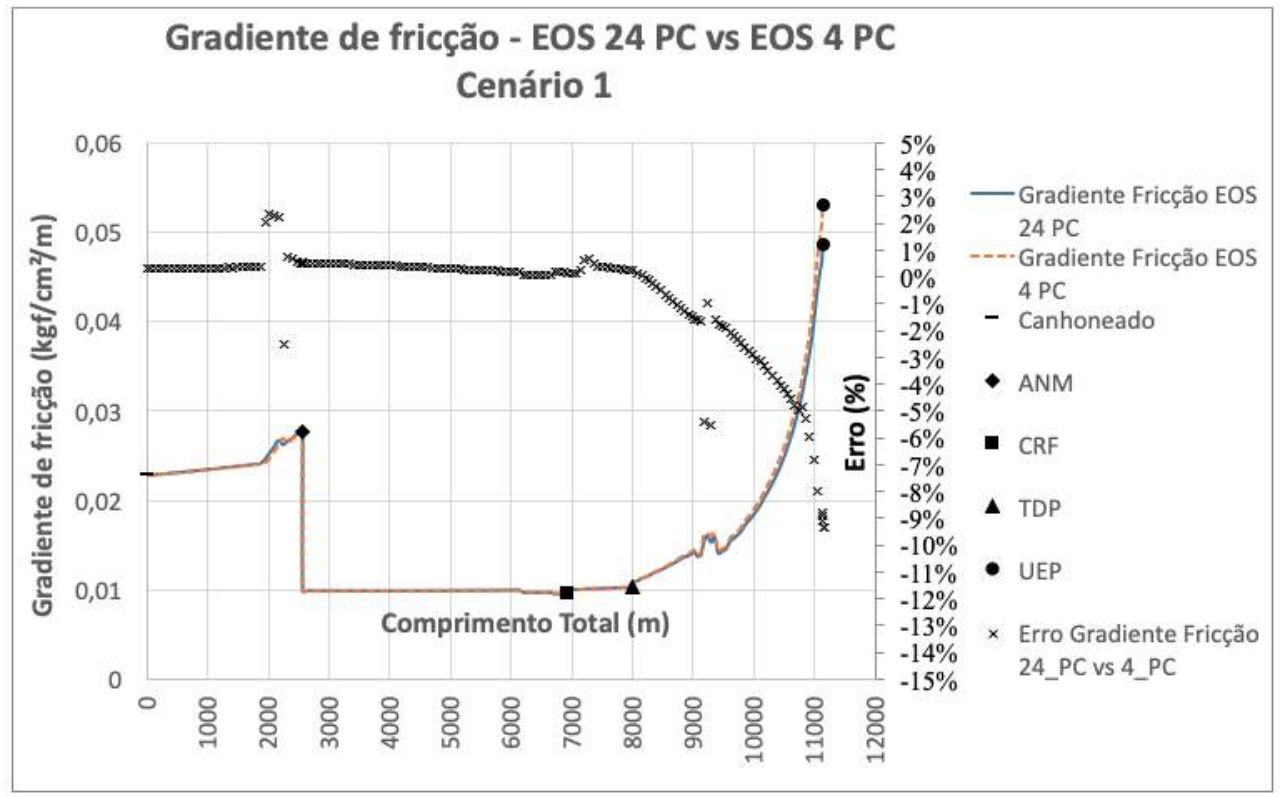

Figura C.156: Gradiente de pressão por fricção - Cenário 1 - EOS 24 PC versus EOS 4 PC. 


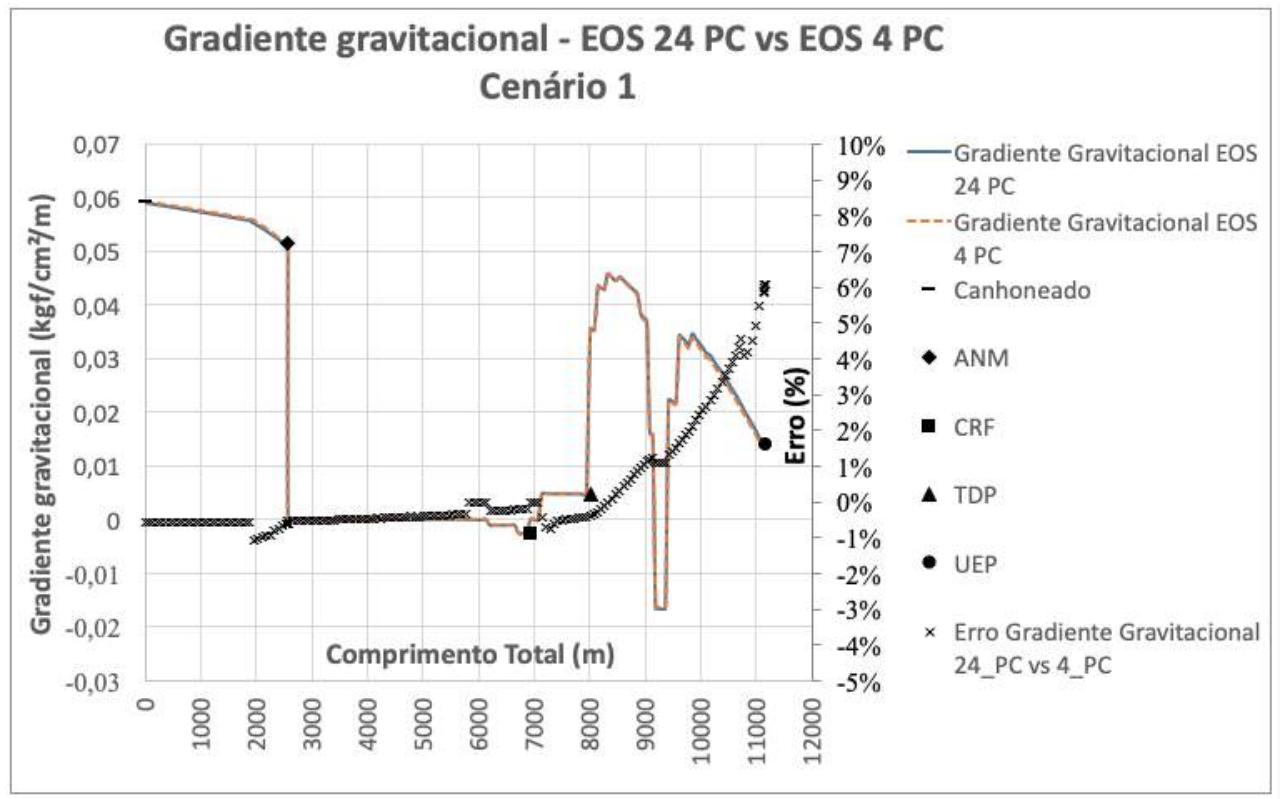

Figura C.157: Gradiente de pressão gravitacional - Cenário 1 - EOS 24 PC versus EOS 4 PC.

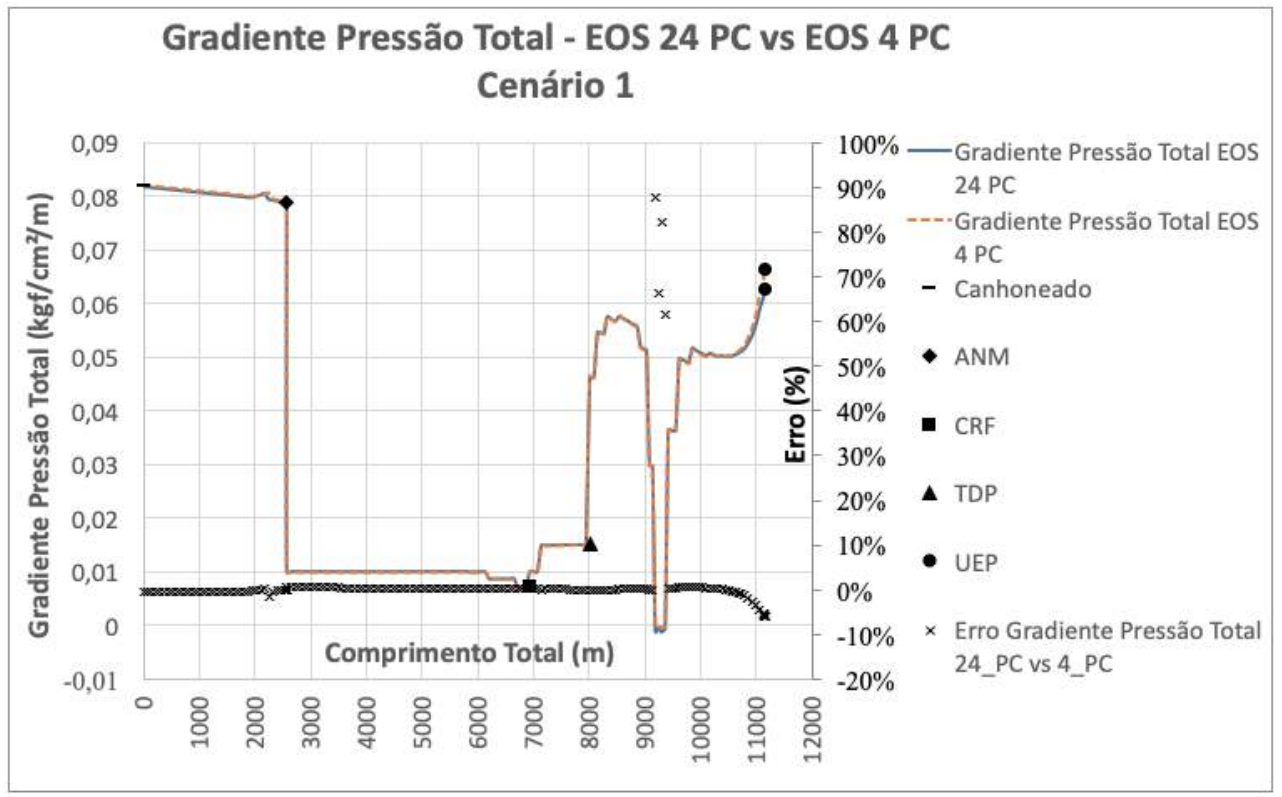

Figura C.158: Gradiente de pressão total - Cenário 1 - EOS 24 PC versus EOS 4 PC. 


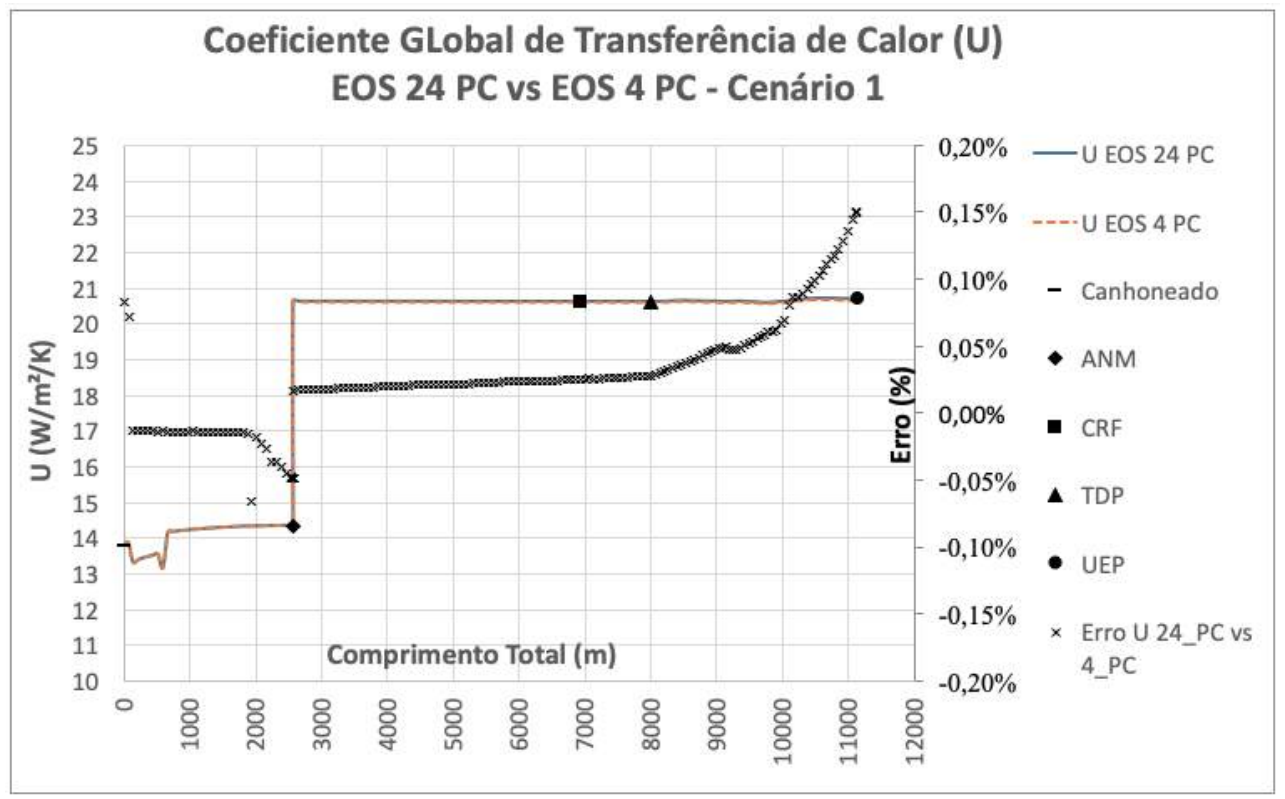

Figura C.159: Coeficiente global de transferência de calor - Cenário 1 - EOS $24 \mathrm{PC}$ versus EOS 4 PC.

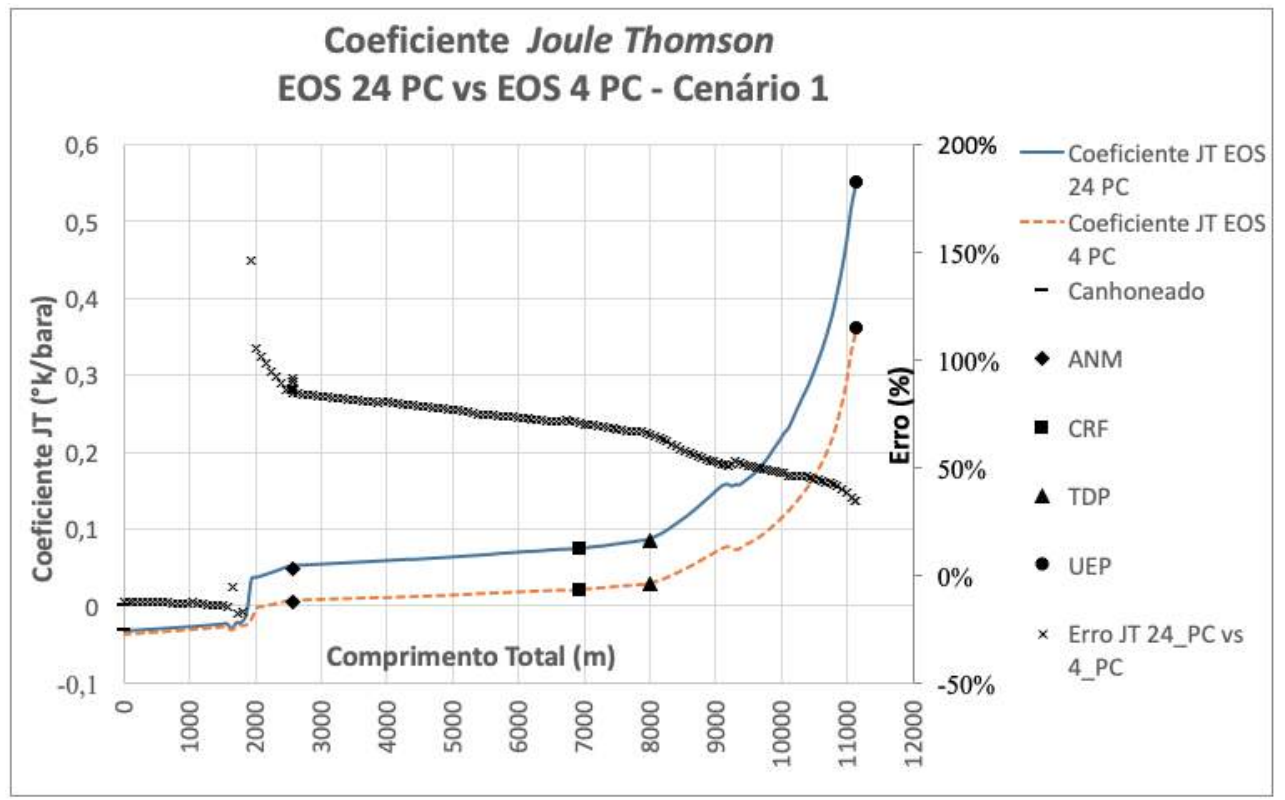

Figura C.160: Coeficiente Joule-Thomson - Cenário 1 - EOS 24 PC versus EOS 4 PC. 


\section{C.6.2}

\section{Cenário 2 - Período inicial antes do breaktrough de água}

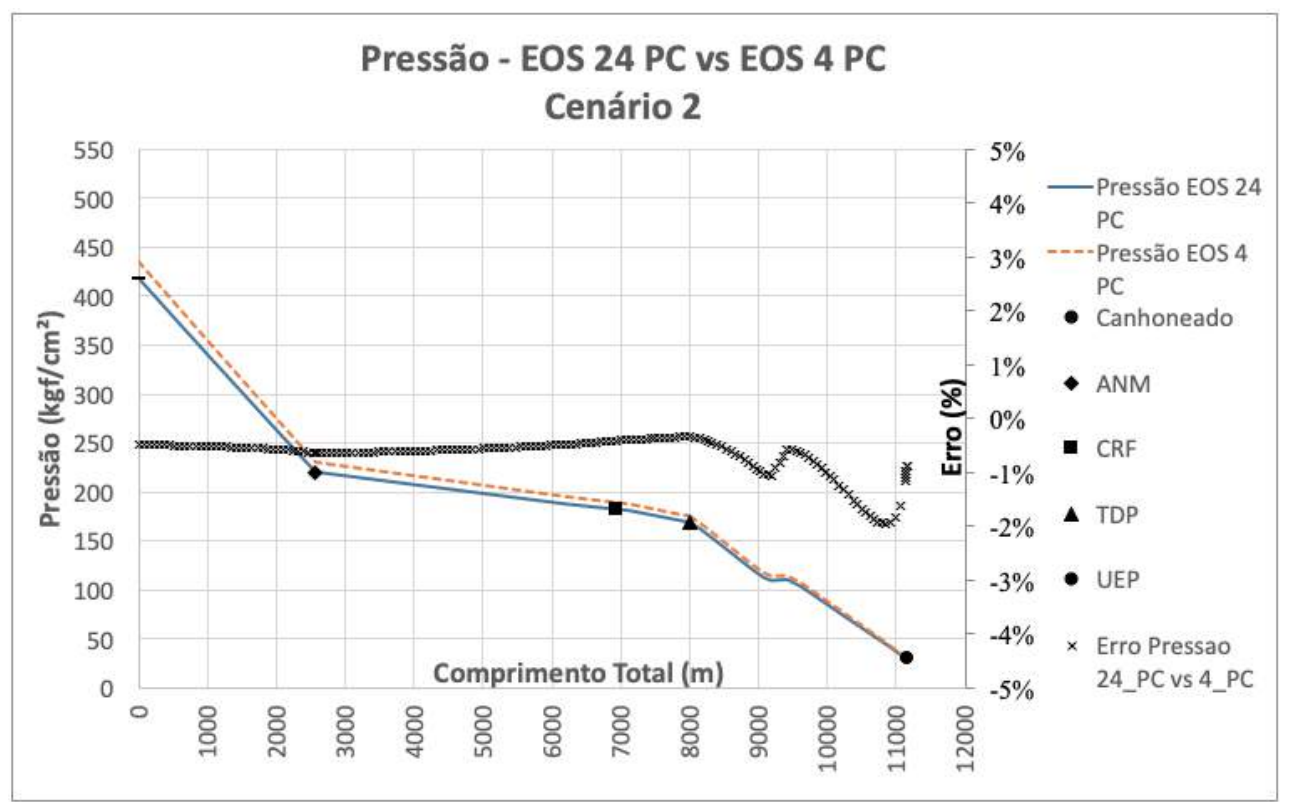

Figura C.161: Perfil de pressão no poço e duto - Cenário 2 - EOS 24 PC versus EOS 4 PC.

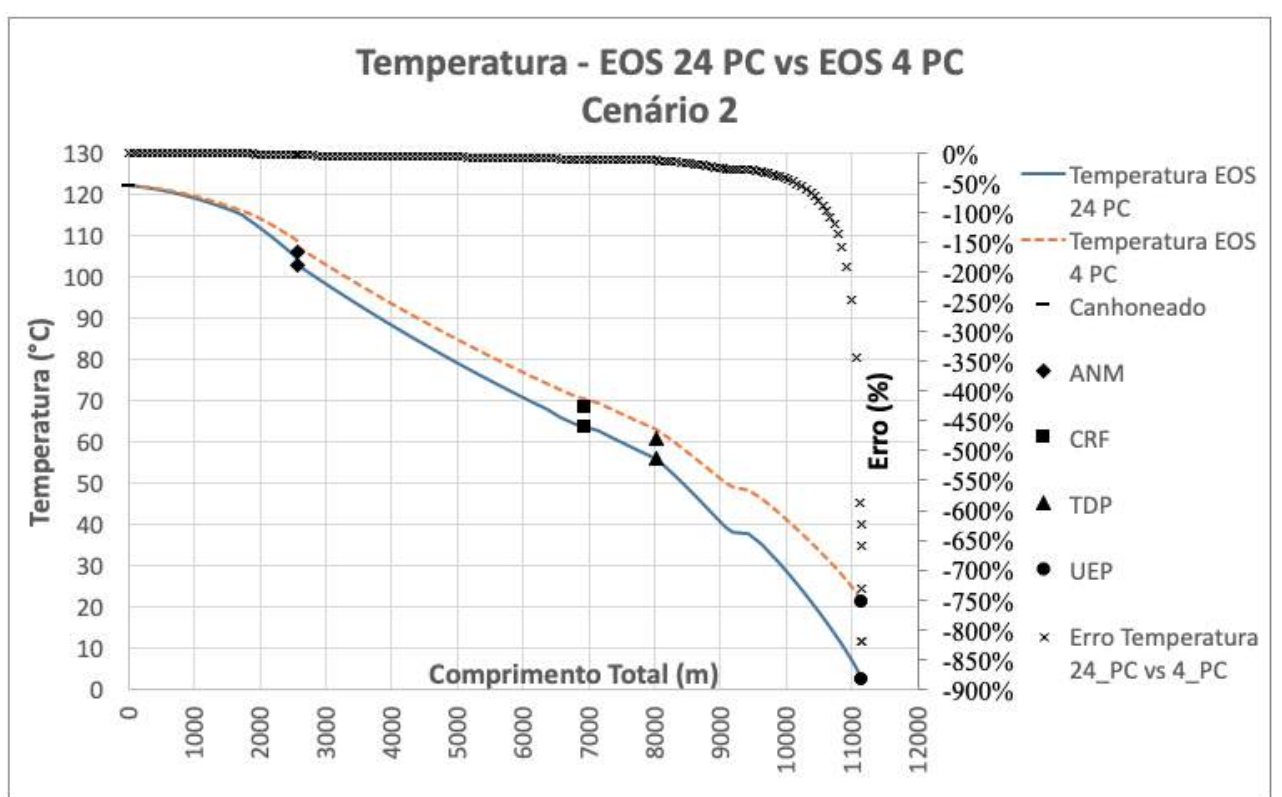

Figura C.162: Perfil de temperatura no poço e duto - Cenário 2 - EOS 24 PC versus EOS 4 PC. 


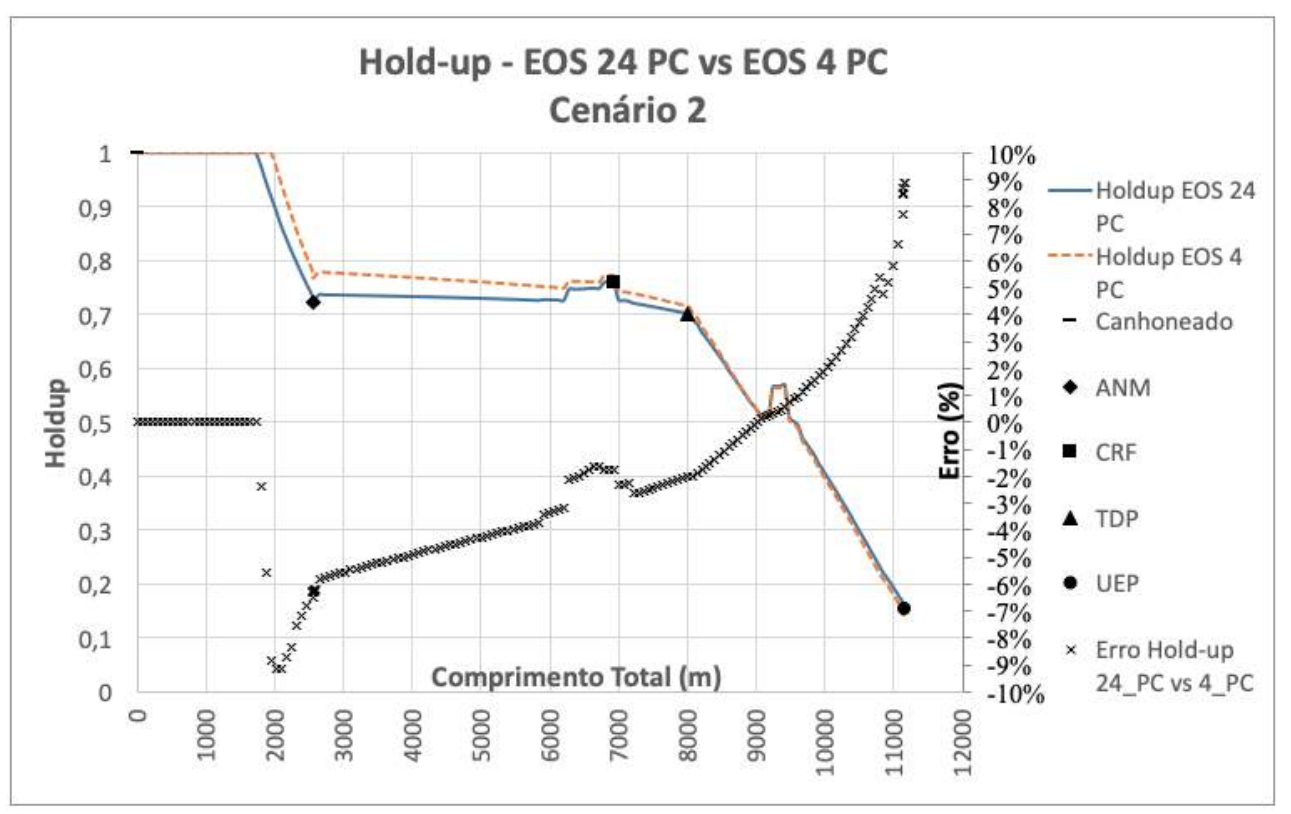

Figura C.163: Holdup no poço e duto - Cenário 2 - EOS 24 PC versus EOS 4 PC.

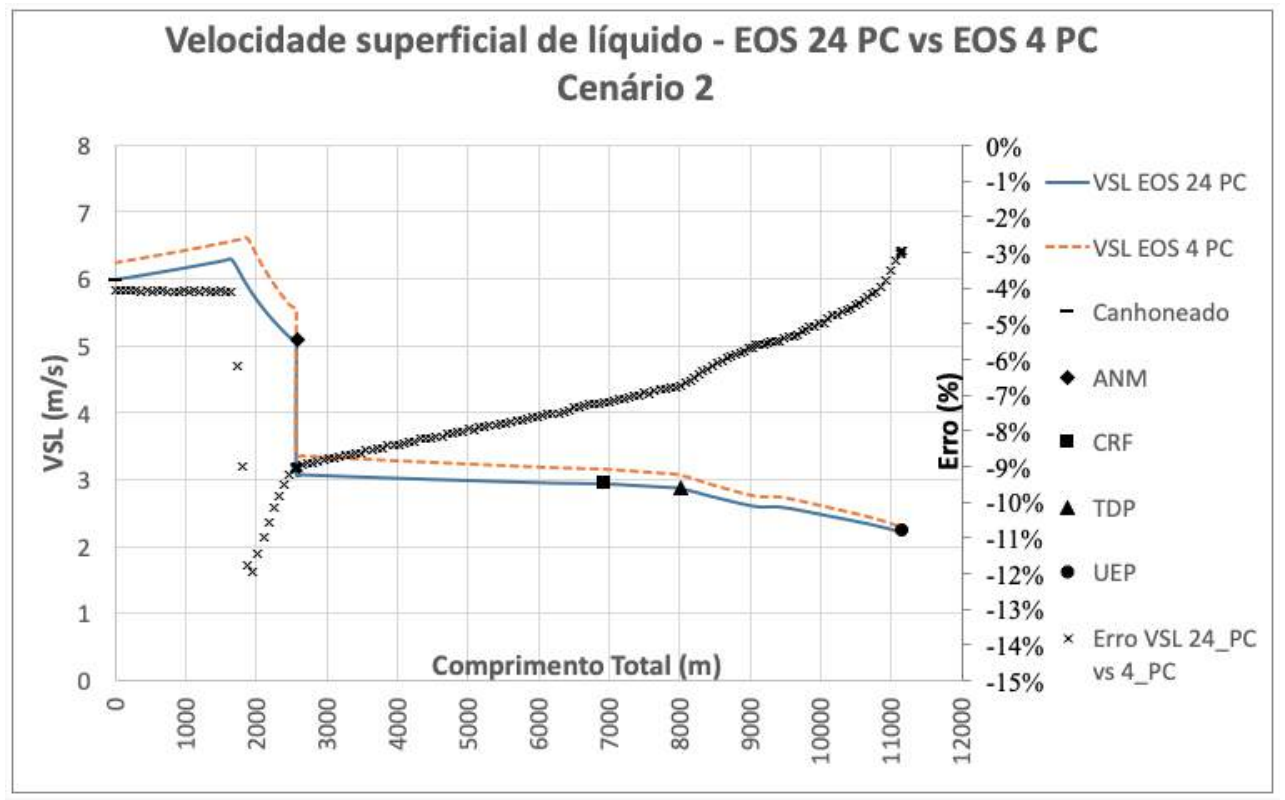

Figura C.164: Velocidade superficial de líquido - Cenário 2 - EOS 24 PC versus EOS 4 PC. 


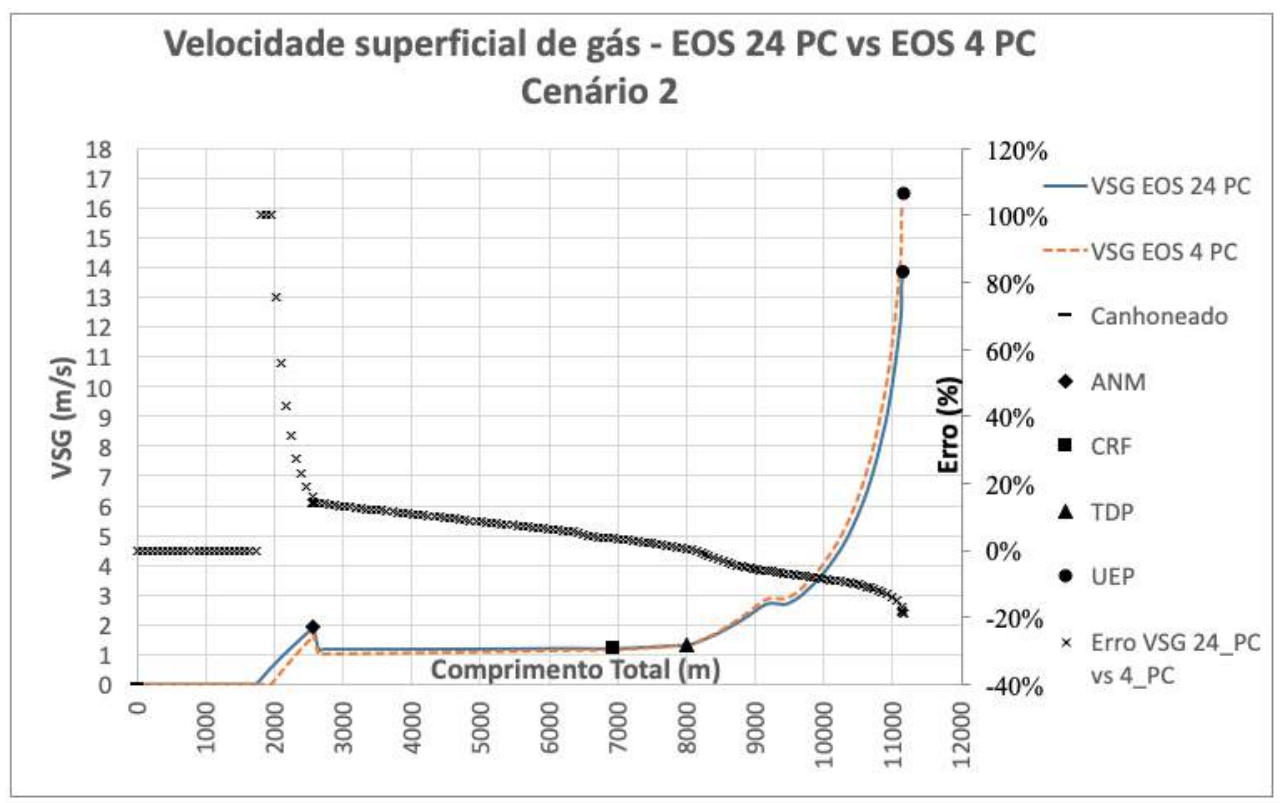

Figura C.165: Velocidade superficial de gás - Cenário 2 - EOS 24 PC versus EOS 4 PC.

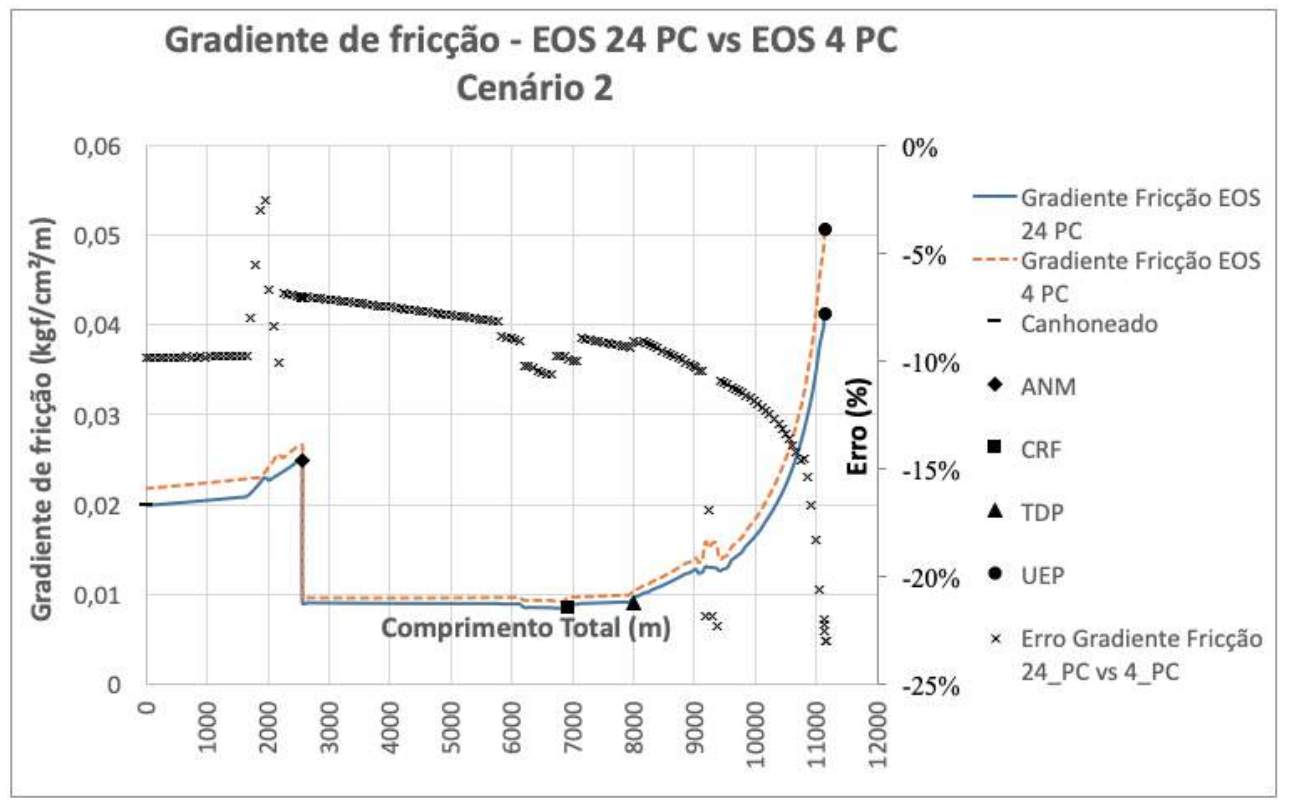

Figura C.166: Gradiente de pressão por fricção - Cenário 2 - EOS 24 PC versus EOS 4 PC. 


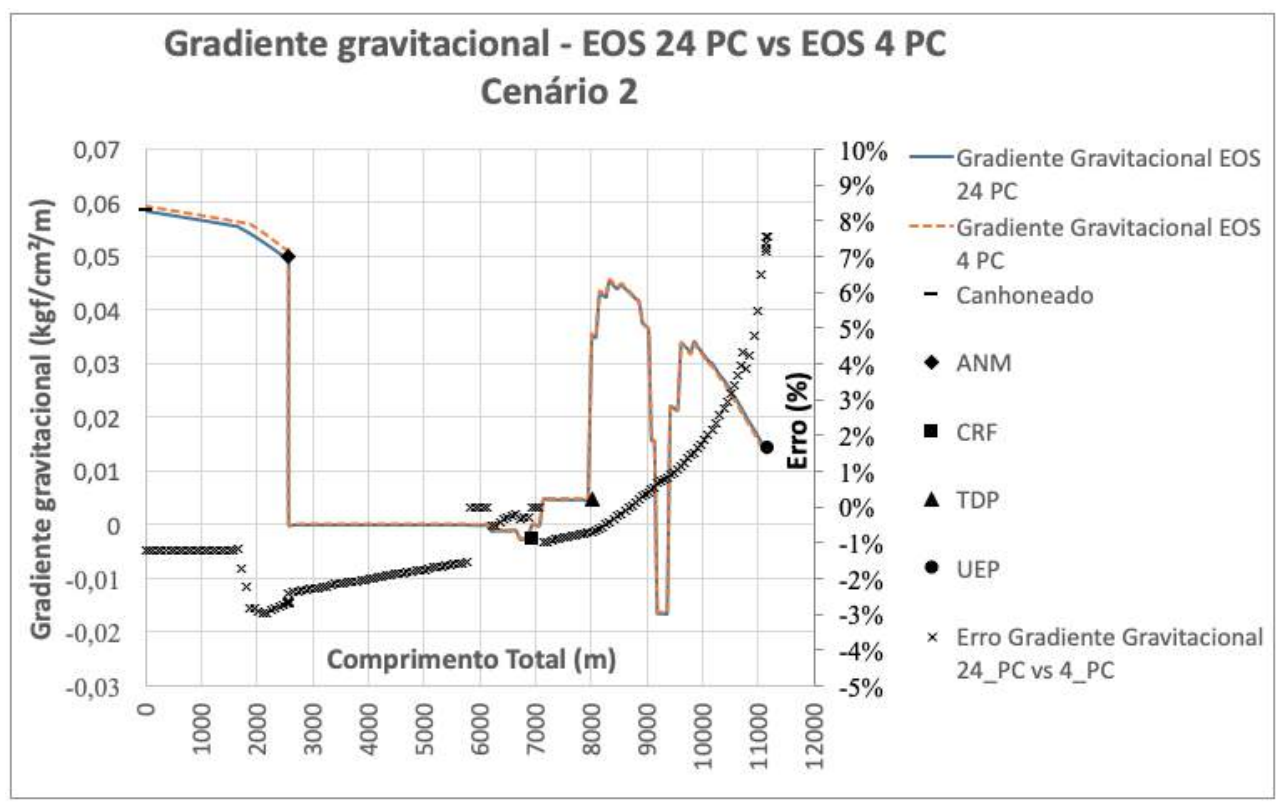

Figura C.167: Gradiente de pressão gravitacional - Cenário 2 - EOS 24 PC versus EOS 4 PC.

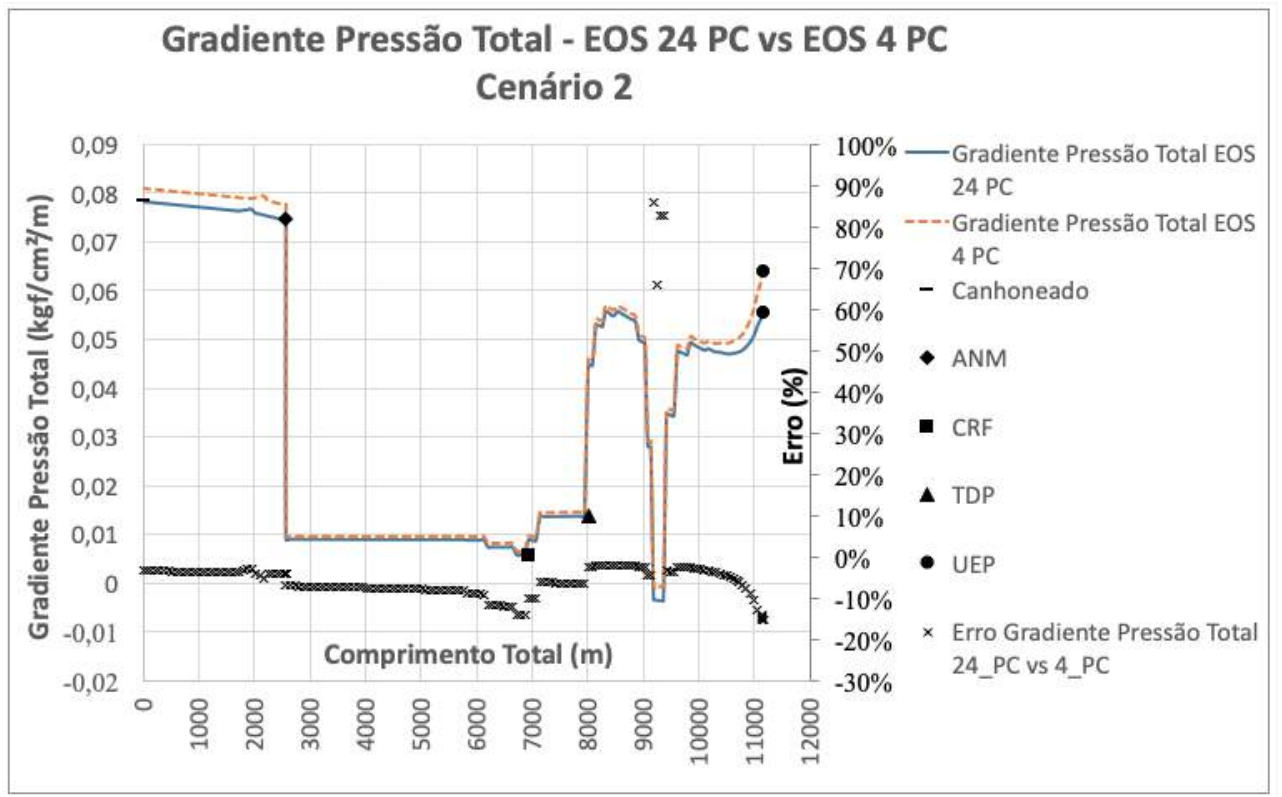

Figura C.168: Gradiente de pressão total - Cenário 2 - EOS 24 PC versus EOS 4 PC. 


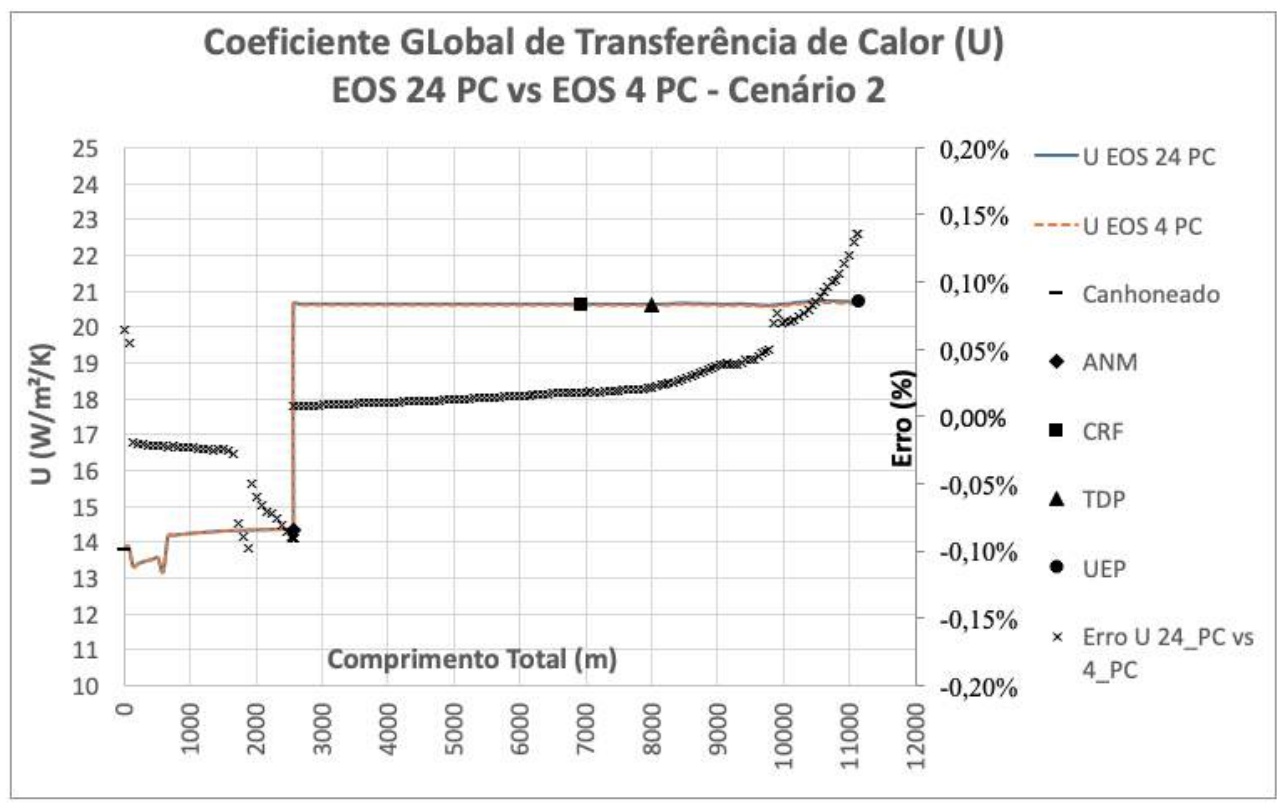

Figura C.169: Coeficiente global de transferência de calor - Cenário 2 - EOS $24 \mathrm{PC}$ versus EOS 4 PC.

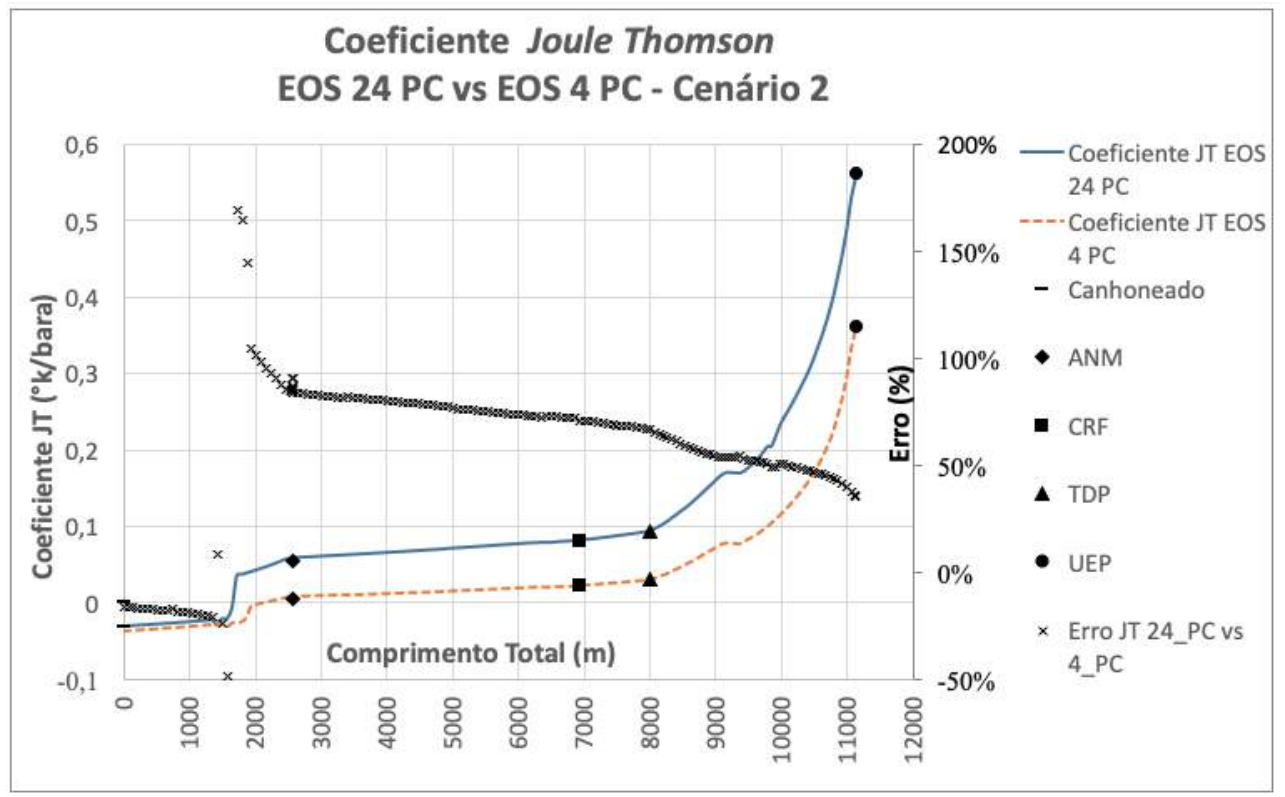

Figura C.170: Coeficiente Joule-Thomson - Cenário 2 - EOS 24 PC versus EOS 4 PC. 


\section{C.6.3}

\section{Cenário 3 - Corte de água intermediário}

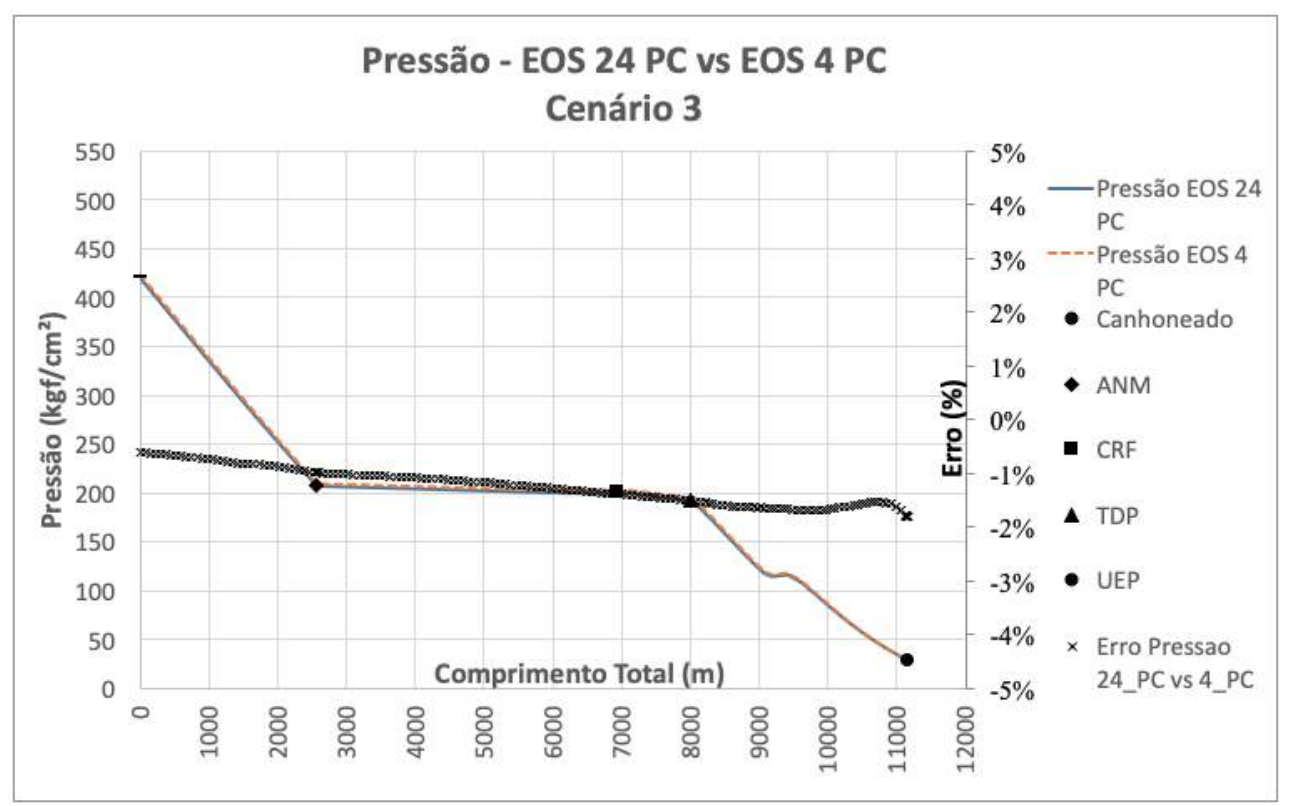

Figura C.171: Perfil de pressão no poço e duto - Cenário 3 - EOS 24 PC versus EOS 4 PC.

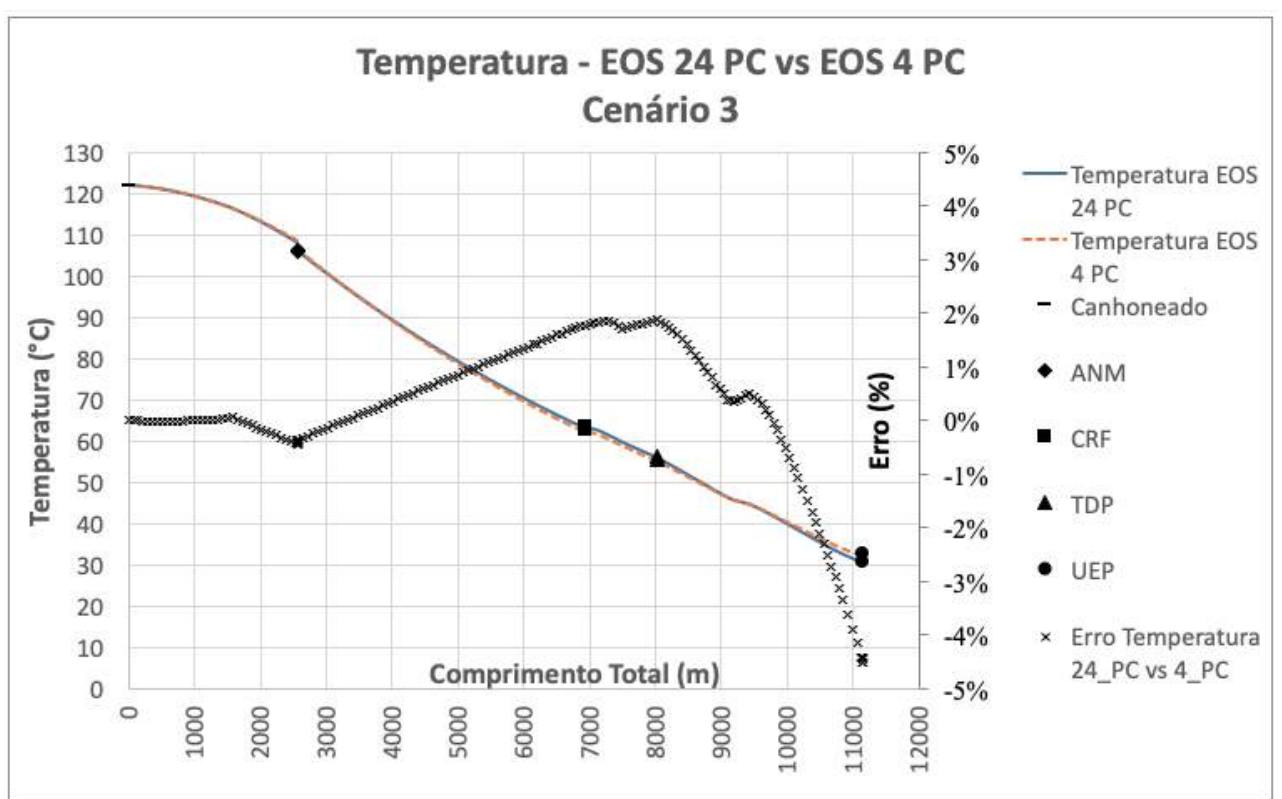

Figura C.172: Perfil de temperatura no poço e duto - Cenário 3 - EOS 24 PC versus EOS 4 PC. 


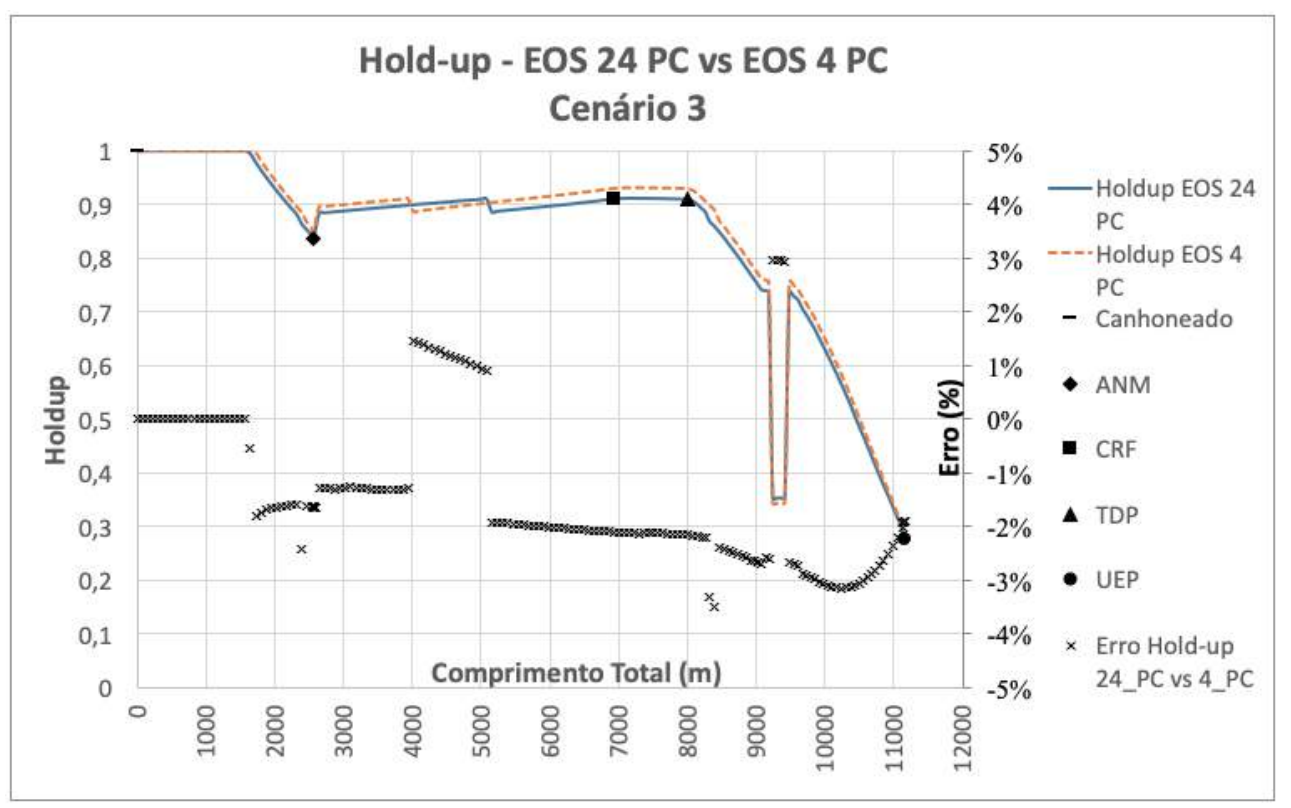

Figura C.173: Holdup no poço e duto - Cenário 3 - EOS 24 PC versus EOS 4 PC.

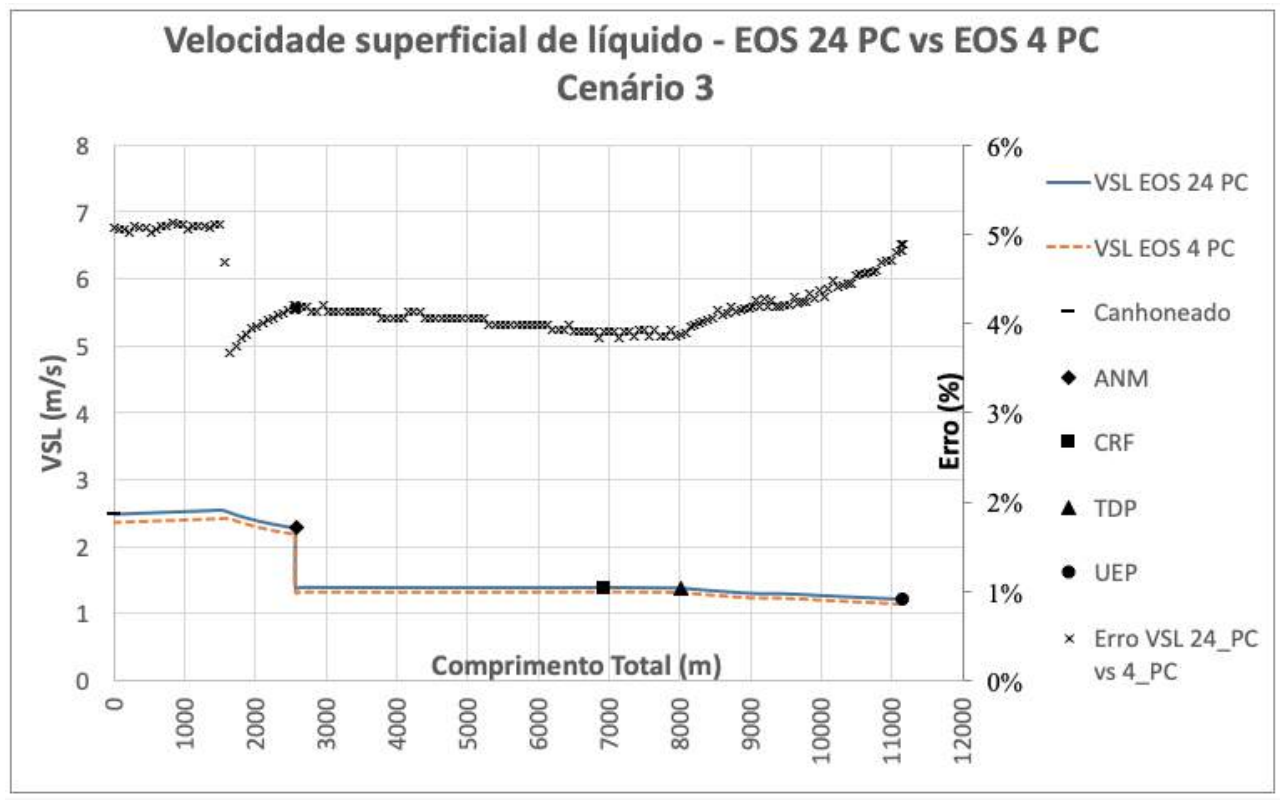

Figura C.174: Velocidade superficial de líquido - Cenário 3 - EOS 24 PC versus EOS 4 PC. 


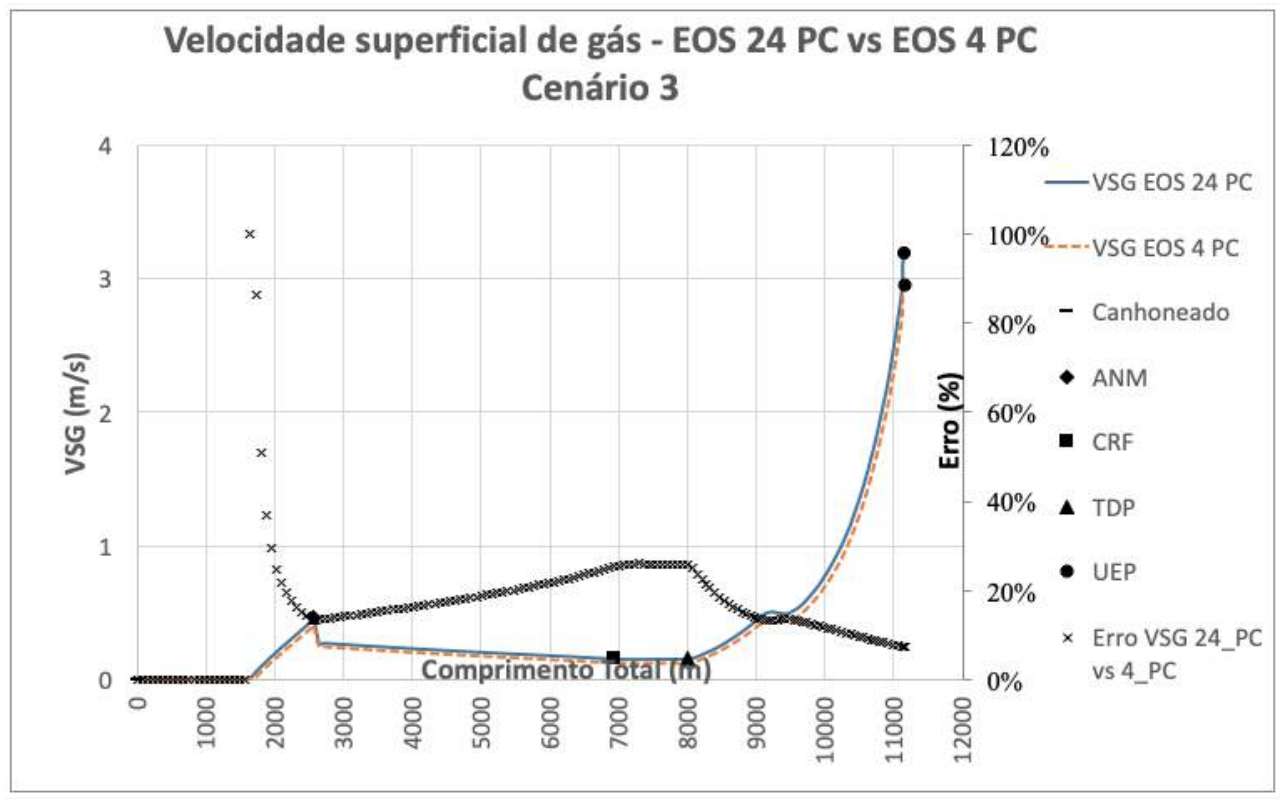

Figura C.175: Velocidade superficial de gás - Cenário 3 - EOS 24 PC versus EOS 4 PC.

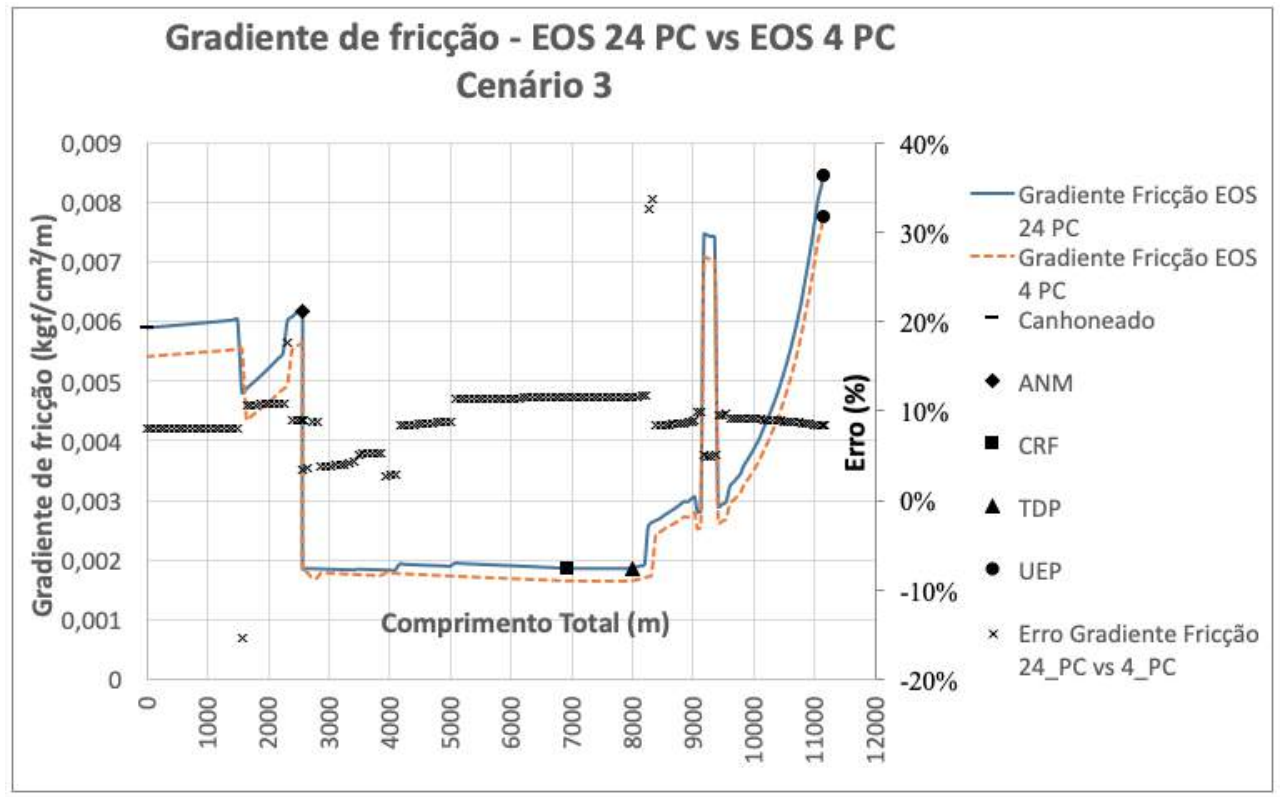

Figura C.176: Gradiente de pressão por fricção - Cenário 3 - EOS 24 PC versus EOS 4 PC. 


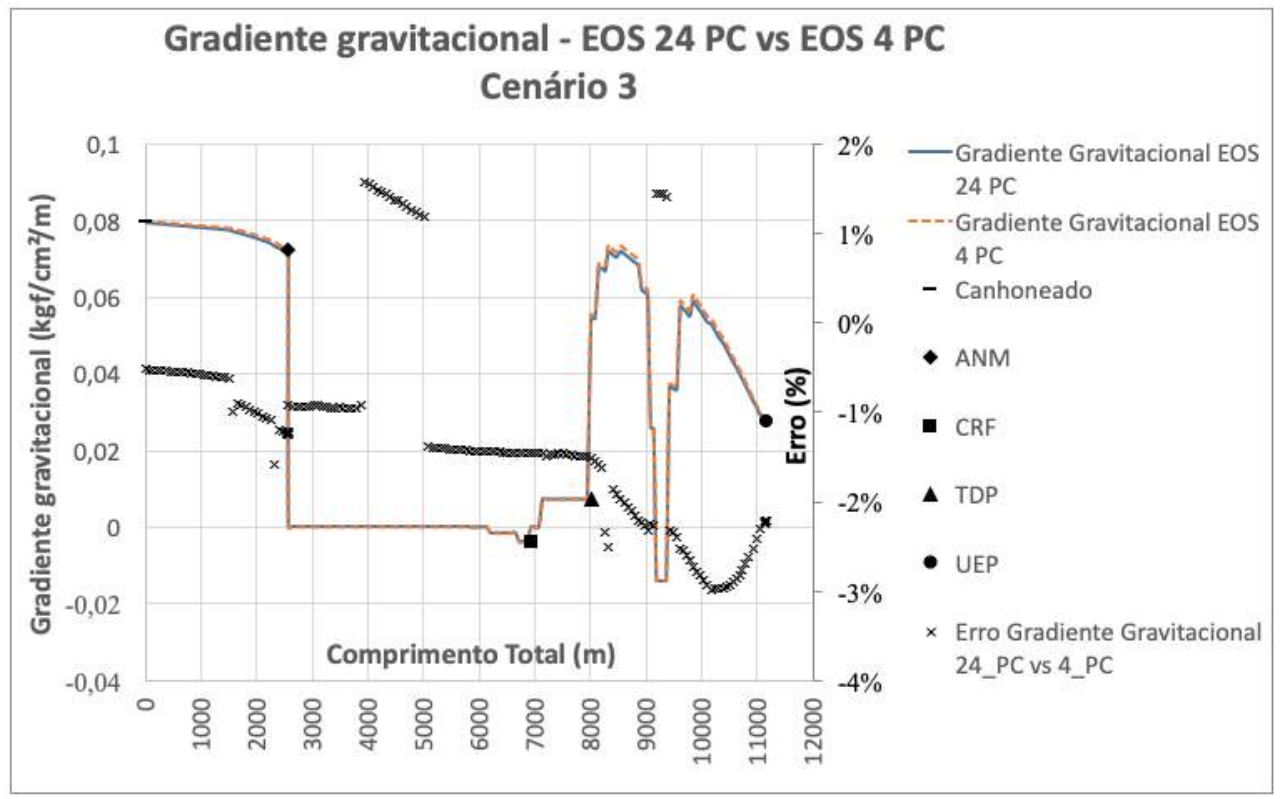

Figura C.177: Gradiente de pressão gravitacional - Cenário 3 - EOS 24 PC versus EOS $4 \mathrm{PC}$.

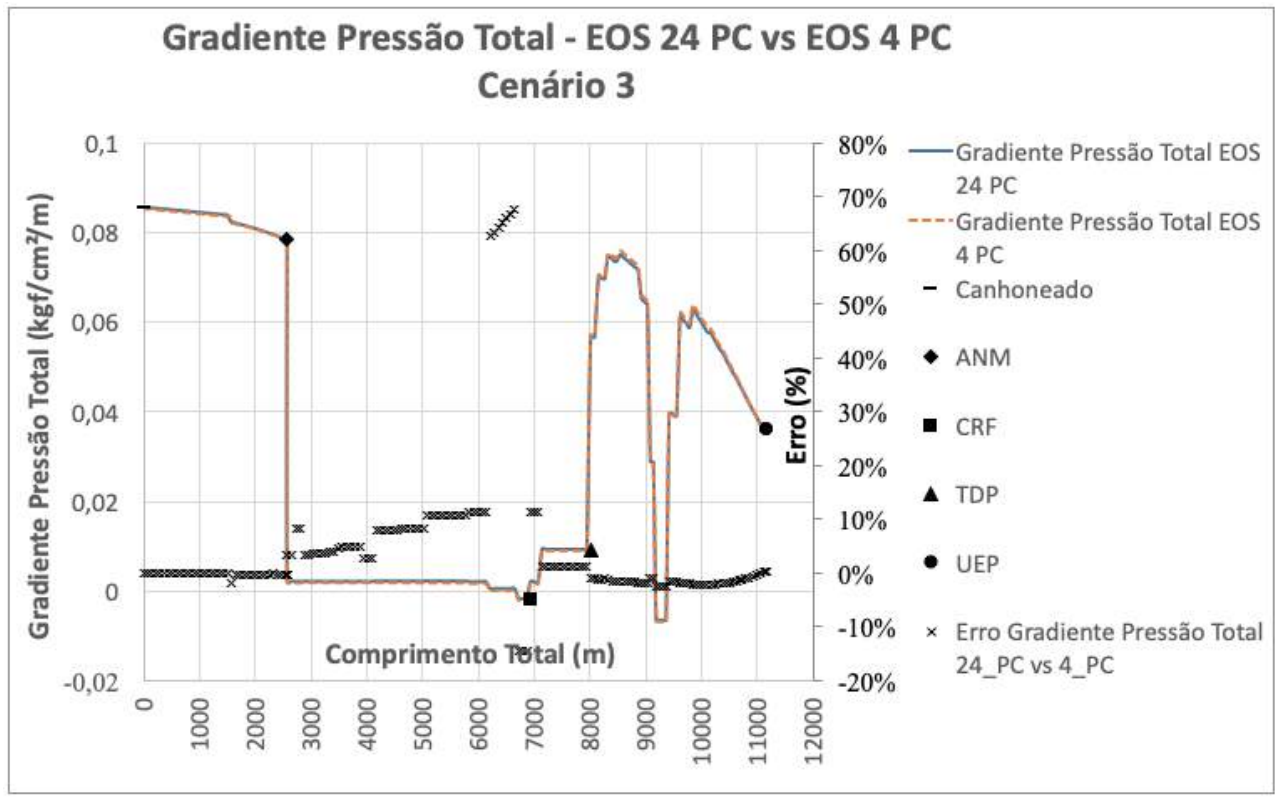

Figura C.178: Gradiente de pressão total - Cenário 3 - EOS 24 PC versus EOS 4 PC. 


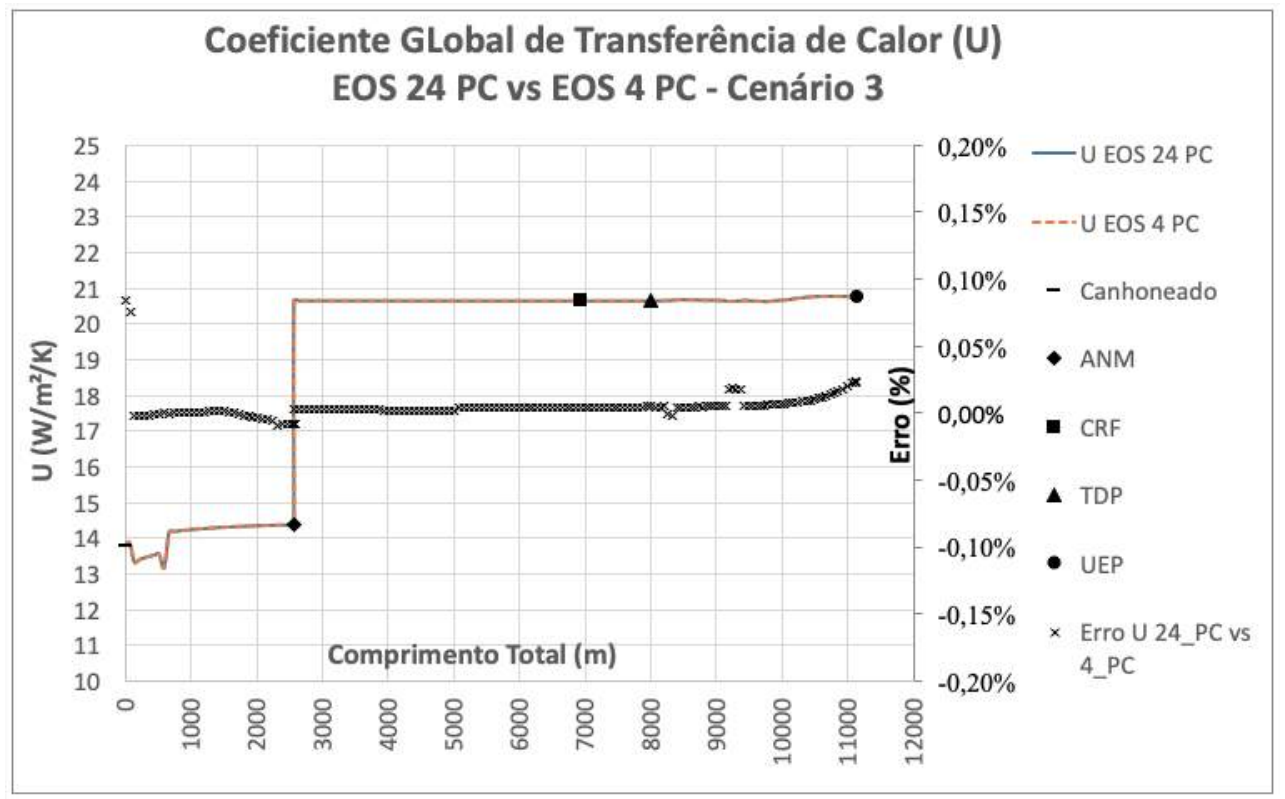

Figura C.179: Coeficiente global de transferência de calor - Cenário 3 - EOS $24 \mathrm{PC}$ versus EOS 4 PC.

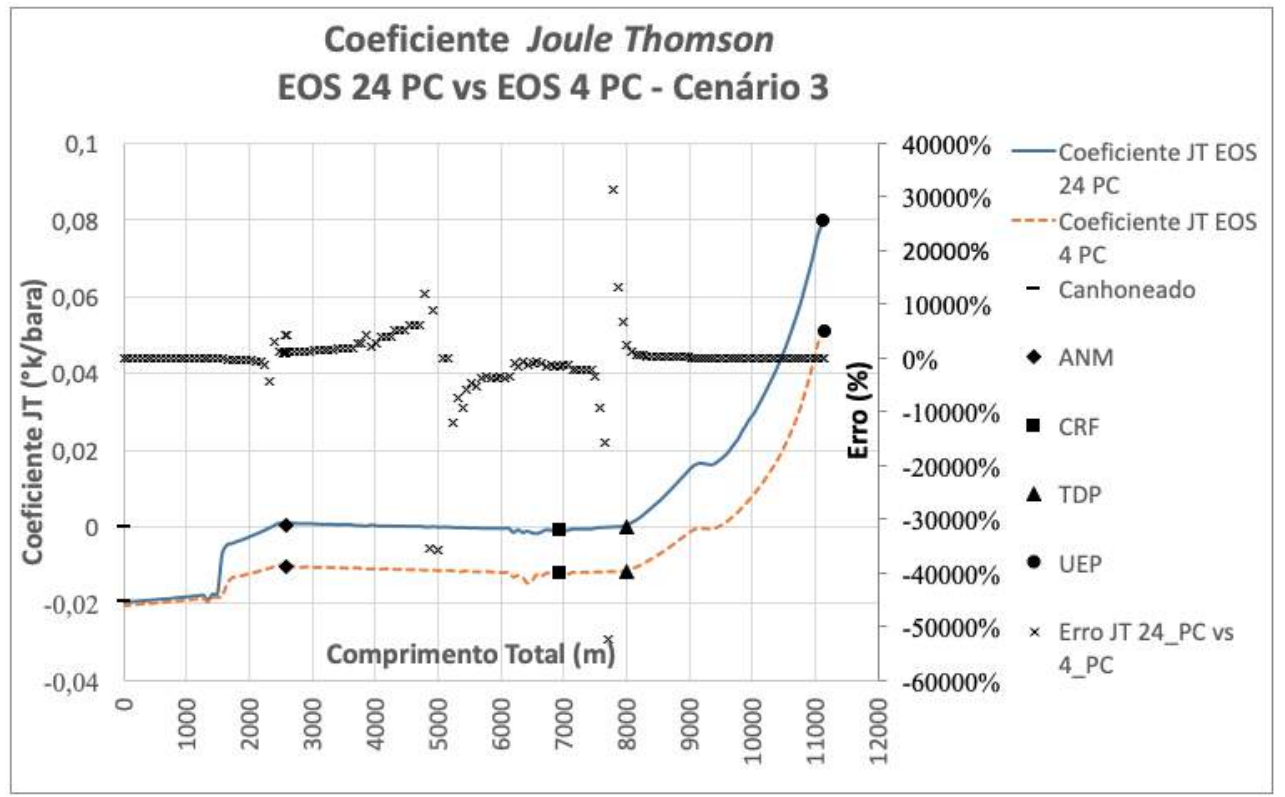

Figura C.180: Coeficiente Joule-Thomson - Cenário 3 - EOS 24 PC versus EOS 4 PC. 